Fabio Andrade Machado

\title{
Análise da variação longitudinal do esqueleto axial em Serpentes (Squamata) empregando ferramentas de morfometria geométrica.
}

Dissertação apresentada ao Instituto de Biociências da Universidade de São Paulo, para a obtenção de Título de Mestre em Ciências, na Área de Zoologia.

Orientador: Hussam Zaher

São Paulo 


\section{Ficha Catalográfica}

Machado, Fabio A.
"Análise da variação longitudinal do
esqueleto axial em Serpentes (Squamata)
empregando ferramentas de morfometria
geométrica".
111 páginas + 3 Apêndices
Dissertação (Mestrado) - Instituto de
Biociências da Universidade de São Paulo.
Departamento de Zoologia.
1. Vértebra 2. Mormofetria
geométrica 3. Distância de Procrustes 4.
Classificação 5. Registro Fóssil
I. Universidade de São Paulo.
Instituto de Biociências. Departamento de
Zoologia.

\section{Comissão Julgadora:}


Aos meus avós. 
From this distant vantage point, the Earth might not seem of particular interest. But for us, it's different. Consider again that dot. That's here, that's home, that's us. On it everyone you love, everyone you know, everyone you ever heard of, every human being who ever was, lived out their lives. The aggregate of our joy and suffering, thousands of confident religions, ideologies, and economic doctrines, every hunter and forager, every hero and coward, every creator and destroyer of civilization, every king and peasant, every young couple in love, every mother and father, hopeful child, inventor and explorer, every teacher of morals, every corrupt politician, every "superstar," every "supreme leader," every saint and sinner in the history of our species lived there - on a mote of dust suspended in a sunbeam.

Carl Sagan. 1994. 


\section{Agradecimentos}

Primeiramente ao Hussam, por me acolher em seu laboratório, pelo incentivo e confiança depositada no desenvolvimento desta dissertação. Por transmitir a importância de manter os pés nos chão e de ensinar, com seus trabalhos e com sua pessoa, a defender apaixonadamente o que consideramos correto, sem perder a objetividade. Acima de tudo, pela amizade e compreensão.

À Erika, por sugerir minha associação com o Hussam, pela orientação tanto oficial quanto extra-oficial, pelas oportunidades profissionais e acadêmicas. Pelo diálogo aberto, pela troca de idéias e risadas. Principalmente, pelo incentivo e companheirismo.

A todos os membros do laboratório de Herpetologia do MZUSP, por aceitarem este estranho no ninho, e por estarem sempre dispostos a discutir, ensinar e a aprender. À Carol por ceder seu tempo me ensinando as normas da coleção herpetologia, me ajudando a navegar entre potes, etiquetas e álcool. Ao Maurício Forlani, por ser um ótimo companheiro e colega, tanto em campo quanto no laboratório, e por demonstrar em sua postura um exemplo de comprometimento, dedicação e profissionalismo. Ao Felipe Grazziotin e ao Ricardo Arturo Guerra Fuentes (Gringo), pelas discussões acaloradas e estimulantes e por demonstrarem que o respeito e compreensão podem superar até mesmo as opiniões mais discordantes.

A todos os membros do laboratório de Paleontologia, por manterem as portas sempre abertas, permitindo manter acesa minha infantil paixão pelos dinossauros. Ao Ricardo Domingues (Wolves), por sempre mostrar uma nova forma de pensar, trazendo um oxigênio para um ambiente dominado por Zoólogos. Ao Alberto Carvalho pelas parcerias, e por sempre aparentar estar de bom humor, a despeito das 
circunstâncias. Principalmente, ao Paulo Nascimento (Pirula), por ser um companheiro de trabalho, de idéias, de bar, de risadas e de imaginação fértil. Acima de tudo por ser um bom amigo.

A todos os colegas dos demais laboratórios, e à comunidade de alunos do MZUSP, por estarem sempre dispostos a se reunirem, mesmo frente à opiniões conflitantes. Ao Fabio Nascimento, por sempre estar aberto a discutir um pouco mais sobre carnívoros. À Grazielle Giacomo, pela amizade e parcerias que, apesar de poucas, têm tudo para ser o começo de muitas outras. Ao Rodrigo Cesar Marques (Portuga), por muitas coisas, mas essencialmente pela confiança e amizade, e por ser uma das pessoas mais estimulantes que conheço. A todos aqueles outros que foram amigos e companheiros - nomeá-los aqui tomaria mais espaço do que tenho.

A todos os funcionários do MZUSP, pelo profissionalismo e comprometimento que foram tão necessários para a conclusão deste trabalho. A toda a equipe da biblioteca, sempre muito disposta e eficiente. À equipe da limpeza, essencial para a manutenção da organização de nosso espaço físico. À equipe da segurança, pelo trabalho incansável, tão essencial para o museu. A todos os estagiários e funcionários que trabalham na curadoria do MZUSP, pela constante batalha para a melhoria de nossos acervos.

Aos meus professores, tanto em sala de aula quanto fora dela. Ao Hussam, por despertar meu interesse em sistemática e taxonomia, algo que nunca imaginei possível. Ao José Guilherme Berlink (Zé Gui), pelas aulas estimulantes, e pela oportunidade de ampliar meus horizontes sobre metabolismo e alometria. Ao Paulo Inácio Prado, por abrir um novo caminho, não apenas no aprendizado de $\mathrm{R}$, mas principalmente por me 
introduzir ao mundo da verossimilhança.

A todos os membros da disciplina BIE5782, pelo trabalho estimulante, pela oportunidade e pelo aprendizado conjunto. Ao Paulo Inácio, por ter me convidado inicialmente para fazer parte da monitoria e por sempre abordar os assuntos de maneira elegante e explicativa. Ao Alexandre Adalardo (Alê), pela seriedade e comprometimento com o ensino, sempre mantendo uma via dupla de aprendizado e ensino, e pelas piadas sutis e precisas. Ao Guilherme Garcia (Pato), por sempre estar disposto a uma troca de informações sobre linhas de comando, teorias e mamíferos. Ao Gustavo Ferreira (Ari), pelo humor ácido e por mostrar que plantas podem ser legais e, quiçá, úteis. À Barbara Henning (Babi), pela momentânea, porém importante companhia. À Tatiana Kawamoto (Tati), pelo companheirismo e ajuda incondicionais, sem nunca perder a oportunidade de rir um pouco das minhas confusões e exageros.

Aos membros do antigo Laboratório de Morfometria, que fará tanta falta. À Erika, pelo incentivo, por me ensinar morfometria geométrica e sempre estimular minha sede de entender melhor os métodos. Ao Guilherme Garcia, por ter aprendido junto comigo e por ter me ensinado um pouco mais. Ao Thiago Zahn (Wally), por sempre abordar aspectos inesperados dos problemas encontrados, e por dividir seus interesses quiméricos comigo.

Aos meus colegas do antigo Laboratório de Artrópodes, que apesar de terem me abrigado durante minha graduação, só agora nossas colaborações e amizades realmente se revelaram. Ao Hilton Japyassú, por ter sido um grande orientador e amigo, por ter sempre me incentivado a procurar teorias novas, mesmo que isso eventualmente tenha me afastado da etologia. À Tati Kawamoto, pelo companheirismo, amizade, ajuda 
suporte, compreensão, críticas, oportunidades, incentivos e por tudo mais - é no mínimo justo dizer que sem sua presença minha dissertação nunca teria sido concluída.

Por último, aos meus familiares, pelo suporte em todos os níveis. Aos meus avós, pelo amor, compreensão e preocupação. A todos meus primos pelo companheirismo, pelos momentos vividos junto, e por todas as situações inusitadas que me meteram durante esses anos, seja pular ao som de um trio elétrico ou comparecer a um casamento no Paraguai. À minha mãe, pelo incentivo incondicional, compreensão e os eventuais puxões de volta para a realidade. Ao meu pai, pelo constante suporte, amor e companheirismo. Ao meu irmão, por sempre estar presente, mesmo que distante. Finalmente, ao meu pai, minha mãe e meu irmão, pelo suporte nos momentos difíceis e pela companhia nos momentos alegres, pelas diferenças que nos unem, pelo amor e pelo respeito. 


\section{Índice}

RESUMO 1

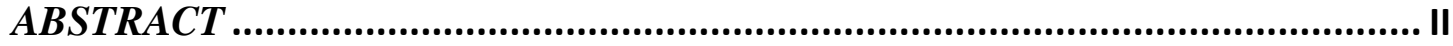

1. INTRODUÇÃ

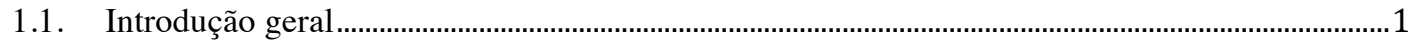

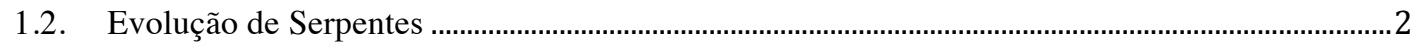

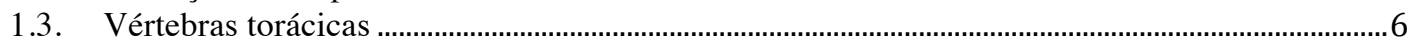

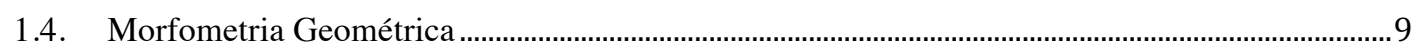

1.5. Morfometria de vértebras e ecomorfologia vertebral.................................................................... 14

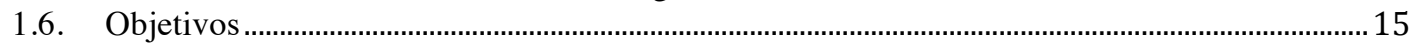

2. MATERIAIS E MÉTODOS................................................................. 18

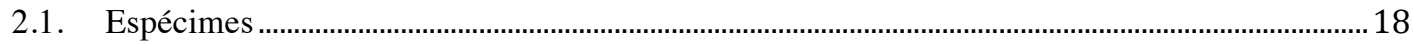

2.2. Aquisição de Imagens e Digitalização ....................................................................................... 18

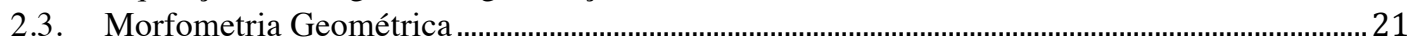

2.4. Análise de dissociação .................................................................................................................... 22

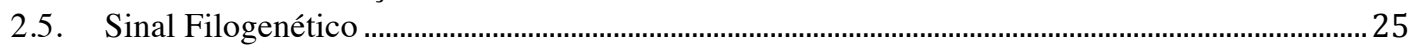

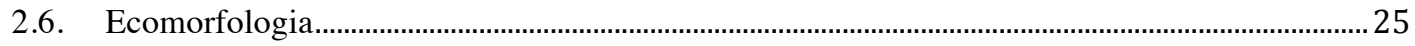

2.7. Análise de Discriminação e Classificação.............................................................................................. 27

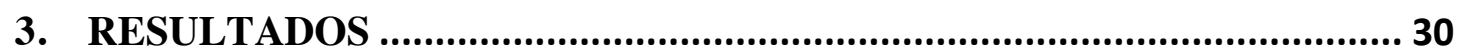

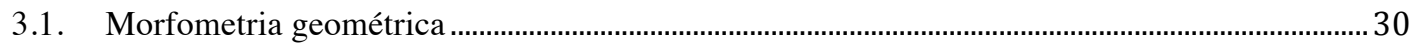

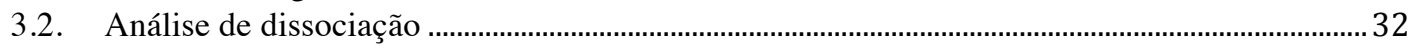

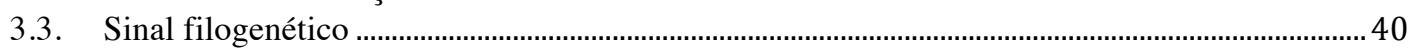

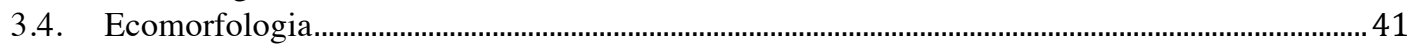

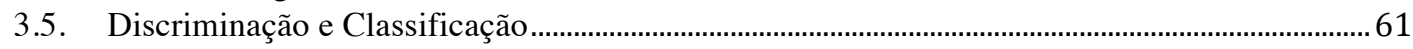

4. DISCUSSÃ 0 .............................................................................. 73

4.1. O esqueleto axial de Serpentes como complexo morfo-funcional integrado............................. 73

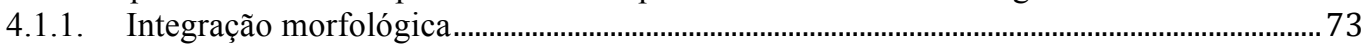

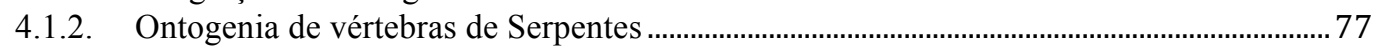

4.2. Fatores determinantes da forma vertebral: Filogenia e Ecologia.................................................... 81

4.2.1. Ecomorfologia vertebral................................................................................................... 81

4.2.2 Relação entre evolução do veneno e forma vertebral na evolução de Colubroides ........... 83

4.3. Classificação de elementos vertebrais dissociados.......................................................................... 87

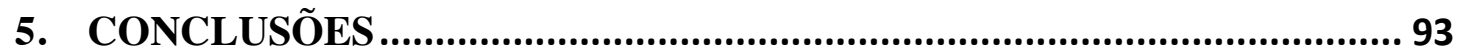

5.1. Sumário dos resultados encontrados........................................................................................ 93

5.2. A utilidade da morfometria geométrica para o registro fóssil em Serpentes. ........................... 94

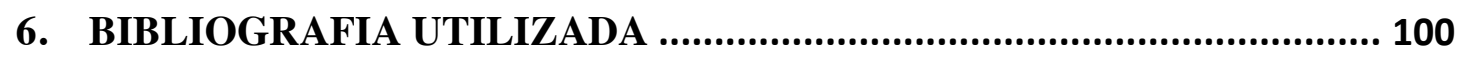

7. APÊNDICE I - FILOGENIA E INDIVÍDUOS ANALISADOS .................. A-1

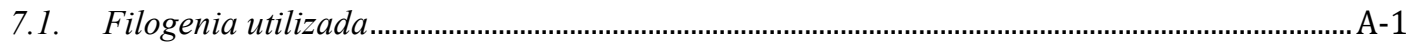

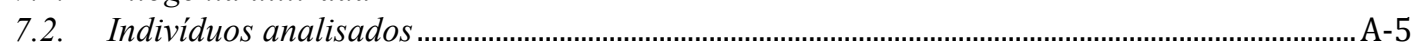


8. APÊNDICE II - SUMÁRIOS DA VARIAÇÃO DO ESQUELETO AXIAL

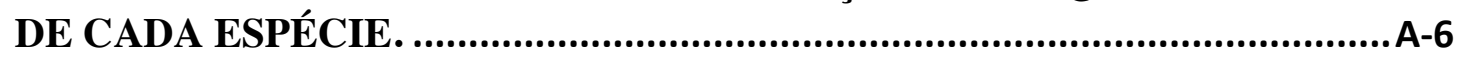

9. APÊNDICE III - SUMÁRIOS DA VARIAÇÃO TAXONÔMICA DAS DIFERENTES POSIÇÕES VERTEBRAIS. ............................................... A-149 


\section{Resumo}

As cobras são um grupo de vertebrados extremamente bem sucedido. Apesar da aparente simplicidade, elas conseguiram ocupar uma grande diversidade de habitats. $\mathrm{O}$ esqueleto axial das serpentes apresenta relação com vários aspectos da vida que puderam ter tido influência direta em seu sucesso evolutivo. Além disso, a forma dos elementos vertebrais possui valor taxonômico, fato que desperta particular interesse, visto que a maior parte do registro fóssil deste grupo é constituído por elementos vertebrais desarticulados. A morfometria geométrica utiliza informações sobre a posição de pontos em duas ou três dimensões, localizados sobre estruturas anatômicas para análise estatística da variação da forma. Esse conjunto de técnicas tem se mostrado eficaz em avaliar variações da forma que não seriam diagnosticadas por métodos tradicionais. $\mathrm{O}$ presente trabalho buscou avaliar as vértebras do esqueleto pré-cloacal de Serpentes no contexto da morfometria geométrica, considerando as influências ecológicas e filogenéticas sob estas estruturas, e investigando ainda a utilidade taxonômica da forma vertebral. Os resultados apresentados aqui sugerem a existência de uma padronização do esqueleto axial de serpentes que é conservada ao longo da história evolutiva desse grupo. Análises ecomorfológicas demonstram que a forma vertebral é fortemente influenciada por hábitos de vida como fossorialidade e constrição. A despeito da ausência de sinal filogenético, as análises de classificação de elementos vertebrais dissociados demonstram que a forma vertebral pode ser utilizada para a diagnose de vértebras isoladas. Esses resultados reforçam a necessidade de realização de análises de variação longitudinal para a identificação correta de material fóssil referente a este grupo. 


\begin{abstract}
Snakes are an extremely successful group of vertebrates. Despite their apparent morphological simplicity, they managed to occupy a great diversity of habitats. The axial skeleton of snakes has relationships with various aspects of their life history that could have had direct influence in the evolutionary success of these animals. Furthermore, the shape of the vertebrae is recognized as being of taxonomic value, a fact that elicits a special interest, since the majority of the fossil record of this group is composed of disarticulated vertebral elements. Geometric morphometrics methods use information about the position of landmarks in two or three dimensions, placed over anatomical structures for statistical analyses of shape variation. This group of techniques has been shown to identify shape variations that would not be diagnosed through traditional methods. The present work sought to evaluate the vertebrae of the pre-cloacal skeleton of Serpentes in the context of geometric morphometrics, evaluating the influences of ecology and phylogeny over the shape of these structures, and also investigating the taxonomic usefulness of vertebral shape. Results presented here suggest the existence of a patterning of the axial skeleton that is conserved throughout the evolutionary history of the group. An ecomorphological analysis demonstrates that the vertebral shape is highly influenced by life-history traits such as fossoriality and constriction. Despite the absence of phylogenetic signal, analyzes of classification of dissociated vertebral elements show that the vertebral shape can be used to diagnose isolated vertebrae. These results reiterate the necessity of performing studies of longitudinal variation in order to correctly identify fossil material associated with this group.
\end{abstract}




\section{Introdução}

\subsection{Introdução geral}

As Serpentes sempre fascinaram os seres humanos, como atesta a riqueza de elementos simbólicos nas diversas culturas humanas relacionados às cobras ou animais serpentiformes (HOWEY, 2005; WERNESS, 2006). Este fascínio pode ir muito além de uma simples peculiaridade cultural, uma vez que a coevolução com esses animais pode ter sido um fator importante na determinação de muitas das capacidades cognitivas de nossa linhagem, estimulando o crescimento do volume cerebral através de interações de predador-presa (ISBELL, 2006).

Seja por medo, fascínio ou história evolutiva, todos nós conseguimos facilmente reconhecer um indivíduo desse grupo pela ausência de membros e por apresentarem um corpo alongado. De fato, Linnaeus em sua primeira proposta de classificação taxonômica agrupou todos os animais apodes no mesmo gênero Anguis, já evidenciando a importância conferida a estas características, mesmo que intuitivamente, como diagnósticas de grupos naturais. Um corpo serpentiforme não é, entretanto, um bom diagnóstico para o grupo, uma vez que muitos outros clados de tetrápodes viventes e fósseis apresentam padrões similares de alongamento e perda de membros (WIENS \& SLIGLUFF, 2001).

Serpentes apresentam uma combinação exclusiva de caracteres, incluindo o alongamento do corpo, aumento da cinese craniana e presença de glândulas de veneno (RIEPPEL, 1988), que as tornam um grupo extremamente bem sucedido. São reconhecidas atualmente aproximadamente 3070 espécies de serpentes (UETZ, 2009), constituindo assim o segundo grupo mais diverso de diapsidas viventes, depois apenas das aves. São indubitavelmente membros do clado Squamata e, apesar do 
estabelecimento de Serpentes como um grupo natural ter longa data (WAGLER, 1830), suas relações filogenéticas dentro de Squamata ainda não estão estabelecidas e continuam sendo fonte de debate e objeto de estudo até hoje (e.x: LEE, 1998; SAINT et al., 1998; VIDAL \& HEDGeS 2004a, 2005; TOWNSEND et al., 2004; LEE, 2005; FRY et al., 2006; CONRAD, 2008; LeE, 2009; VIDAL \& HedGes, 2009).

As propostas de relações de parentesco dentro de Serpentes são igualmente controversas, com hipóteses sendo colocadas e disputadas em uma taxa igualmente elevada (POUGH et al., 1998; ZAHER \& RIEPPEL, 2002; LeE \& SCANLON, 2002; APESTEguía \& ZAhER, 2006; VidAL \& DAVID, 2004; WIENS et al., 2008; LEE et al., 2007). O estabelecimento das relações de parentesco tanto dentro quanto fora do grupo é de suma importância, não apenas para o delineamento de taxonomias filogeneticamente sustentadas, mas principalmente como possível via para se propor e testar hipóteses sobre a origem do grupo.

\subsection{Evolução de Serpentes}

Apesar deste cenário filogenético conturbado, um consenso parece emergir das diversas propostas (e.g. FRY et al., 2006; APESTEGUíA \& ZAHER, 2006; LeE et al., 2007; LEE et al., 2009): Serpentes, junto com Iguania, Anguioidea e Varanoidea, constituem o clado Toxicofera (Figura 1.1) que contêm todas as espécies de répteis com glândulas secretoras especializadas (FRY et al., 2006, 2009). 
A
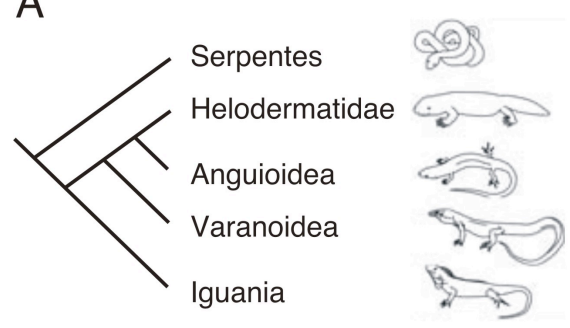

C

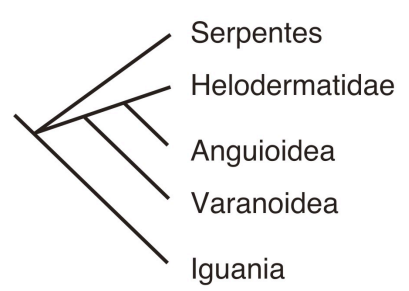

B

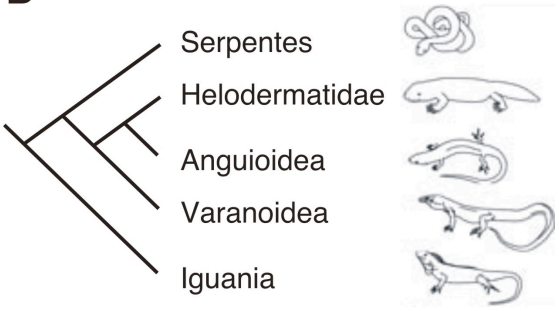

Figura 1.1. Hipóteses das relações filogenéticas entre os grupos que constituem o clado Toxicofera. A- VIDAL \& Hedges (2004a, 2005) e Fry et al. (2006); B- LEE et al., 2009; C- VIDAL \& HEDGES (2009). Modificado de FRY et al. (2006).

Dentro de Serpentes há uma dicotomia basal bem definida entre Scolecophidia e Alethinophidia (McDowell, 1987; RAGE. 1987; CADLE, 1988; RIEPPEL 1988; PoUgh et al., 1998). Scolecophidia são animais pequenos (contendo, inclusive, as menores serpentes do mundo; HEDGES, 2008), fossoriais e que apresentam um crânio compacto (Greene, 1997, Pough et al., 1998). Alimentam-se principalmente de artrópodes e outros invertebrados que podem ser encontrados no meio fossorial ou junto ao solo (Pough et al., 1998). Alethinophidia apresenta arranjo taxonômico mais complexo e, apesar de análises recentes corroborarem o monofiletismo de diversos grupos (e. g. BURBRINK, 2005; VidAL et al., 2006; ZAHER et al., 2009; HedGES et al., 2009), um consenso sobre as suas relações filogenéticas mais inclusivas permanece distante (Figura 1.2). Os alethinofídios podem ser divididos grosseiramente em Anilioidea - animais que compartilham com Scolecophidia algumas características cranianas microstomatas presumidamente plesiomórfica - e macrostomata - animais que podem liberar a sínfise mandibular e engolir presas muito mais largas (TCHERnov et al., 2000; SCALON \& LEE, 2000; LEE \& SCALON, 2002; APESTEGUÍA \& ZAHER, 2006). 


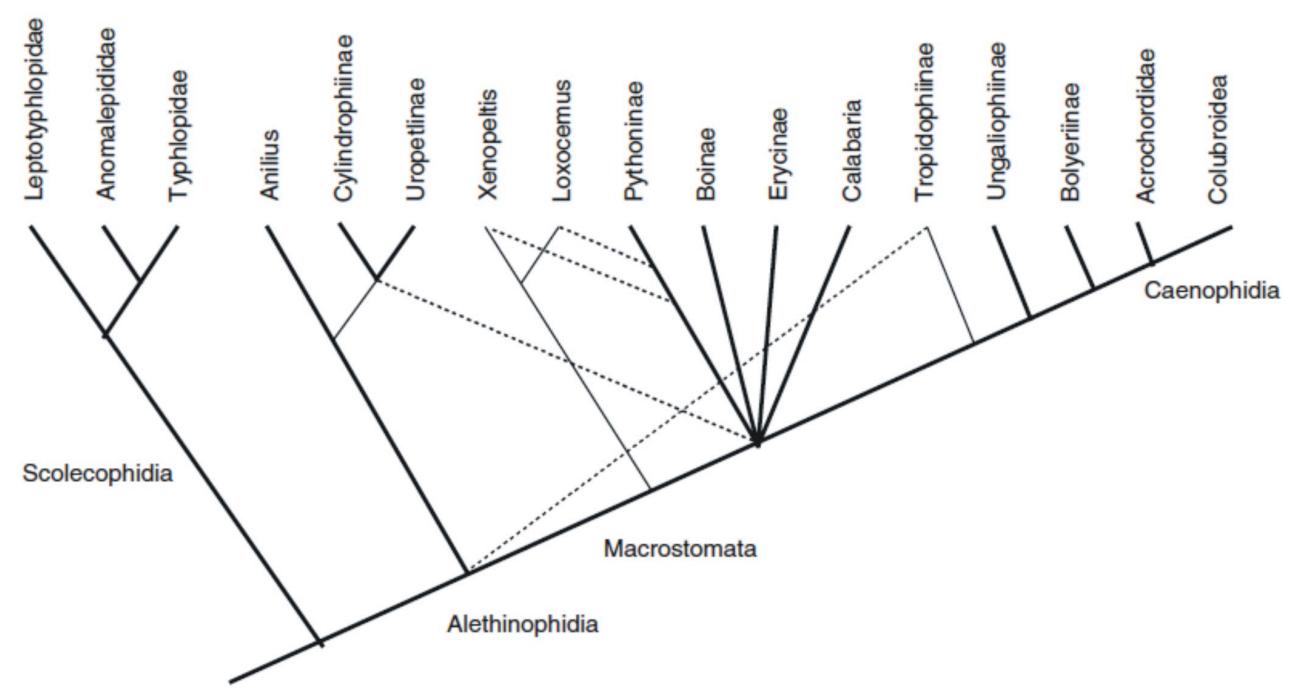

Figura 1.2. Representação de diversas hipóteses filogenéticas aceitas a respeito das relações de parentesco em Serpentes. Linhas em negrito indicam relações sustentadas por estudos morfológicos e moleculares (ou sustentadas por um e não fortemente contrariada pela outra). Linhas finas e tracejadas indicam relações sustentadas apenas por análises morfológicas e moleculares, respectivamente. Modificado de Lee et al. (2007).

Análises recentes mostram, entretanto, que os Anilioidea não constituem um grupo natural: apesar de Aniliidae (i.e. Anilius) permanecer em uma posição basal em Alethinophidia, os "Anilioidea" asiáticos (Uropeltidae sensu McDowelL, 1975) não apresentam uma posição definida (VIDAL \& Hedges, 2002, 2004; 2009; VIDAl \& DAVID, 2004; VidAl et al., 2007). Macrostomados, um grupo originalmente considerado monofilético (SCAlON \& LeE, 2000; LeE \& Scalon 2002; Apesteguía \& ZaHer, 2006, LEE et al., 2007) tem sido progressivamente desconstruído, principalmente pela inclusão dos Uropeltidae em posições mais derivadas (GRAZZIOTIN et al., 2007; WiENS et al., 2008, VIDAL et al. 2009) e da associação de Tropidophiidae (um grupo macrostomado presumidamente associado à Caenophidia) com Aniliidae (VIDAL \& HEDGES, 2002, 2004; Vidal \& DaVID, 2004; NoONAN \& ChIPPINDALE, 2006; VidAL et al., 2007, 2009; WIENS et al., 2008).

Emergem como grupos bem resolvidos o clado formado por Pythonidae, Xenopeltidae e Loxocemidae (VIDAL \& Hedges, 2002, 2004; VIDAL \& 
DAVID, 2004; GRAZZIOTIN et al., 2007; VIDAL et al., 2007, 2009; WIENS, 2008) e o clado das boas (Boidae), incluindo Calabarinae, Boinae e Erycinae (VIDAL \& HedGES, 2002, 2004; LAWSON et al., 2004, 2005; GrAZZIOTIN et al. 2007; VIDAL et al., 2007; LEE et al., 2007; WiENS, 2008), com Bolyeriidae associado aos Caenophidia (APESTEguía \& ZAHER, 2006; LeE et al., 2007, VIDAL et al., 2007). O clado Caenophidia formado por Acrochordus+Colubroides (sensu ZAHER et al., 2009) tem se revelado incrivelmente consistente, tanto em análises morfológicas (SCAlON \& LeE, 2000; LeE \& SCAlon, 2002; Apesteguía \& Zaher, 2006), moleculares (VIDAL \& HEDGES, 2002; LAWSON et al., 2004, 2005; VIDAL et al., 2007; WIENs et al., 2008) quanto nas análises combinadas (GRAZZIOTIN et al., 2007; LEE et al., 2007).

É em Caenophidia que se encontra a maior diversidade de Serpentes, incluindo todos os grupos classicamente reconhecidos como venenosos [FRY et al. (2009), mas ver VIDAL (2002) para observações a respeito do uso do termo "venenoso"]. Em Caenophidia temos Acrochordus como grupo irmão de todos os Colubroides (SCALON \& LEE, 2000; LEE \& Scalon, 2002; Vidal \& Hedges, 2002; APESTEGuía \& Zaher, 2006; VIDAL et al., 2007; GRAZZIOTIN et al., 2007; LEE et al., 2007; WIENS et al., 2008), seguidos por Xenodermatidae, Pareatidae, Viperidae e Homolapsidae como grupos irmãos de clados progressivamente menos inclusivos, terminando em uma grande dicotomia entre Elapoidea (incluindo Psammophiidae, Elapidae, Atractaspididae e Lamprophiidae) e Colubroidea (incluindo Colubridae, Calamariidae, Pseudoxenodontidae, Natricidae e Dipsadidae) (ZAHER et al., 2009).

Em Serpentes, a identificação correta do registro fóssil adquire um significado especial, transferindo o enfoque da identificação taxonômica e estudo de paleocomunidades para a análise filogenética, com a 
finalidade de jogar luz na origem e relações do grupo. A interpretação taxonômica deste registro fóssil é uma tarefa desafiadora. Características osteológicas únicas, como a grande cinese craniana e aumento da estreptostilia, fazem do crânio desses animais uma estrutura frágil e de difícil fossilização (JOHNSON, 1954). De fato, a maior parte do registro fóssil associado ao grupo provém de elementos pós-cranianos, mais especificamente, de elementos vertebrais (RAGE, 1987) que, além de numerosos (até 400 elementos em cada indivíduo; RoMER, 1956), apresentam grande homogeneidade ao longo do organismo (CARROLL, 1988; COATES \& RUTA, 2000).

\subsection{Vértebras torácicas}

A morfologia das vértebras torácicas em Serpentes é modificada em relação ao padrão de Squamata (Figura 1.3). O centro vertebral é procélico, apresentando um cótilo anterior bem desenvolvido e um côndilo posterior arredondado. A face ventral pode conter uma crista longitudinal achatada chamada quilha hemal, ou pode apresentar um processo ventralmente bem desenvolvido em forma de lâmina ou espinho, a hipapófise. O centro vertebral é coberto por um arco neural atravessado longitudinalmente por um canal neural. $\mathrm{O}$ arco é composto por duas placas ósseas verticais, os pedicelos, que são fusionados, sem traços de suturas, nas regiões laterais do centro. Eles se ligam às placas ósseas dorsais e à lâmina do arco neural, que pode ser achatada ou recurvada, normalmente flexionando-se dorsalmente na região mesial. Sobre essa estrutura normalmente se forma o espinho neural, que costuma ser uma lâmina lateralmente achatada. Porém, esta pode apresentar a forma de um espinho ou mesmo estar completamente ausente. 
A

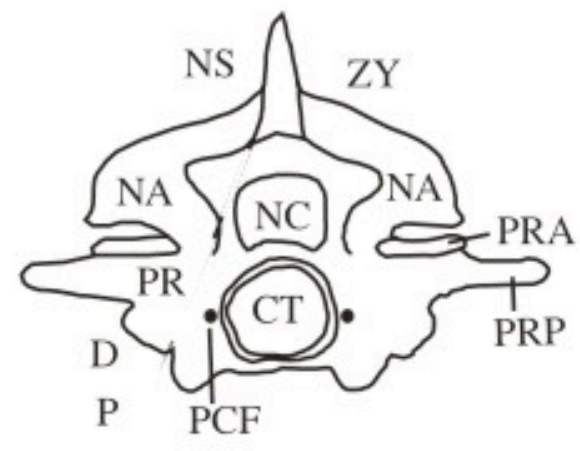

C

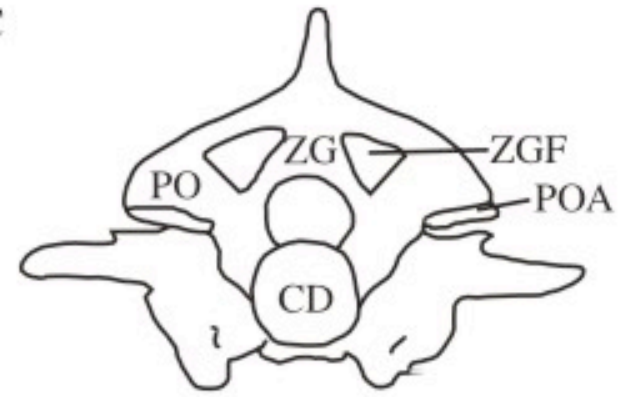

B

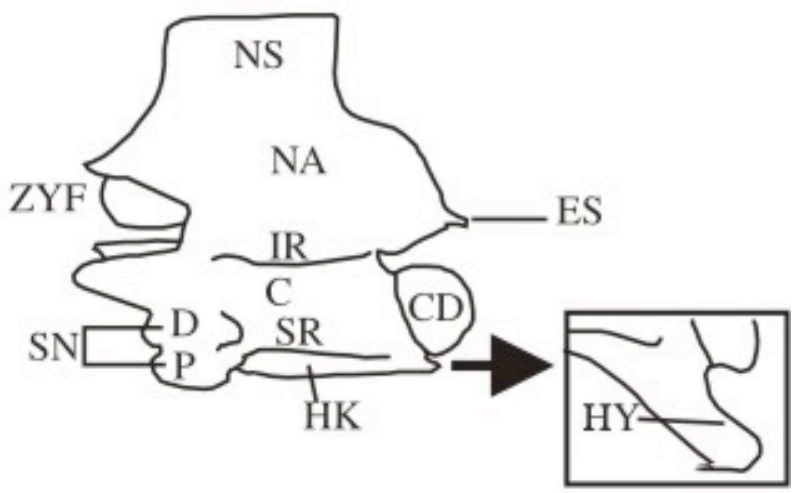

$\mathrm{D}$

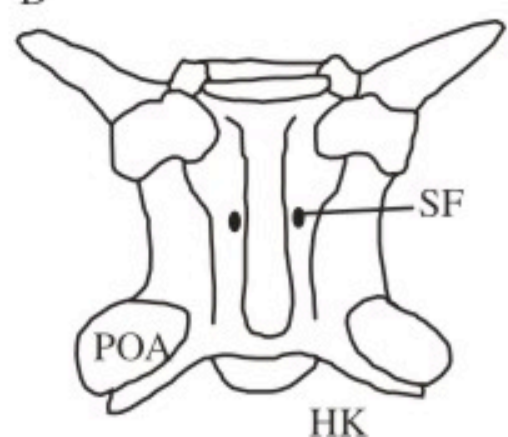

Figura 1.3. Anatomia das vértebras torácicas de Serpentes. A: Vista anterior. B: Vista lateral C: Vista posterior. D: Vista ventral. Abreviações: C, centro; CD, côndilo; CT, cotilo; D, diapófise; ES, espinho epizygapofiseal; HE, hemapofise; HK, quilha hemal; HY, hypapofise; IR borda interzigapofiseal; NA, arco neural; NC, canal neural; NS, espinho neural; P, parapófise; PCF, forâmen paracotilar; PO, postzigapofise; POA, faceta articular pós-zigapofiseal; PR, pré-zigapofise; PRA, faceta articular prezigapofiseal; PRP, processo acessório prezigapofiseal; SF, forâmen subcentral; SN, sinapofise; SR, borda subcentral; ZG, zigantrum; ZGF, faceta articular zigantral; ZY, zigosfeno; ZYF, faceta articular zigosfenal.

A região dorsal anterior do arco neural é adornada por uma estrutura articular chamada zigósfeno que apresenta superfícies articulares achatadas e ventro-lateralmente orientadas. A porção posterior dorsal do arco é modificada em um zigantrum, que possui facetas dorsomedialmente direcionadas que se articulam com o zigósfeno de outra vértebra. O aparato zigósfeno-zigantrum não é exclusivo a este grupo, estando presentes também em Iguanidae, Varanidae e Teiidae. Entretanto, a grande separação entre a superfície articular do zigósfeno e das zigapófises presente nas serpentes é normalmente vista como uma modificação significativa e confere uma conformação vertebral única a 
este grupo.

Os lados póstero-laterais do arco neural são lateralmente estendidos, terminando em superfícies articulares ventralmente direcionadas chamadas de pós-zigapófises. Elas articulam com as facetas prézigapofiseais da vértebra imediatamente anterior. Essas superfícies são achatadas e dorsalmente orientadas e variam em angulatura nos diferentes táxons. Essas superfícies se apóiam em projeções do centro vertebral, logo abaixo do cótilo. Em alguns grupos essa projeção se estende além da superfície articular, formando um processo acessório pré-zigapofiseal em forma de espinho. As superfícies articulares sinapofiseais localizam-se na região anterior da vértebra, e emergem como projeções ventrolateralmente orientadas que sustentam as costelas dos animais, podendo estar presente como um único processo arredondado, ou subdivido em para e diapófises em diversos grupos.

Por ser o principal elemento do esqueleto axial em Serpentes, a coluna vertebral assume grande parte das funções de locomoção e modo de vida destes animais, sendo similar aos membros de outros tetrápodes do ponto de vista das forças mecânicas (PrANGE \& ChristMAn, 1975). Ontogeneticamente, a forma vertebral pode ser influenciada por interações musculares tanto em períodos pré-natais, por influencia de fatores genéticos, quanto pós-natais, por influencia do uso e exercício (GANS, 1974).

A avaliação da forma vertebral em Serpentes enfrenta diversos problemas, uma vez que se trata de uma estrutura serialmente homóloga, tornando difícil o estabelecimento de regras de comparação entre diferentes táxons e até mesmo entre diferentes indivíduos. Uma boa avaliação entre diferentes grupos necessita da identificação correta das 
reais fontes de variação no esqueleto axial, sejam elas, individual, filogenética ou relativa à posição do elemento vertebral no animal. Para tal, a análise da forma vertebral necessita levar em conta a posição relativa dos processos e articulações, descontando qualquer tipo de variação introduzida por diferenças de tamanho ou posição dos elementos (GASC, 1976).

A morfometria geométrica é um conjunto de técnicas que permite a decomposição da forma em variáveis independentes de tamanho, e avalia a diferença entre a posição relativa de estruturas anatômicas nos diferentes indivíduos (BooKsteIN, 1991). Desta forma, constitui a ferramenta ideal para a análise da forma vertebral, sendo especialmente útil na avaliação do esqueleto axial em Serpentes.

\subsection{Morfometria Geométrica}

Morfometria é a área que estuda a variação e mudança da forma e tamanho dos organismos. Segundo, Kendall (1977) "forma" pode ser definida como "toda a informação geométrica que resta quando efeitos de posição, escala e rotação são removidos de um objeto". As primeiras tentativas de se formalizar a mensuração da forma em zoologia tiveram incentivo inicial da taxonomia e consistia principalmente no estudo de medidas classicamente estabelecidas de altura, largura e tamanho de estruturas, com a finalidade de se obter descritores taxonômicos das espécies (Lestrel, 2000). Essas medidas eram, quase que em sua maioria, táxon - específicas, impedindo a comparação até mesmo de grupos proximamente aparentados. Além disso, esse tipo de medida costuma apresentar um alto grau de colinearidade e dependência, pois comumente amostra repetidamente as mesmas dimensões, e baseia-se em poucos marcos anatômicos (ZELDITCH et al., 2004). Apesar de grandes 
avanços metodológicos que aumentaram enormemente o poder destas análises (e.g. STRAUSS \& BoOKSTEIn, 1982; Bookstein et al., 1985), este conjunto de métodos carece de embasamento em Teoria Estatística da Forma (sensu KENDALl et al., 1999).

Para solucionar esses problemas, a morfometria geométrica (sensu BoOKSTEIN 1991) concentra-se na análise de coordenadas espaciais de pontos, ou "landmarks". Os landmarks são pontos de interesse que apresentam relações de correspondência entre as formas a serem comparadas (DRYDEN \& MARDIA, 1998). Essa correspondência pode ter base biológica ou matemática. No caso de estruturas biológicas, os landmarks podem ser divididos, segundo BoOKSTEIN (1991) em:

1. Landmarks do tipo I - Pontos de encontro de 3 estruturas, como suturas de ossos.

2. Landmarks do tipo II - Pontos extremos (maior concavidade ou convexidade) de uma estrutura.

3. Landmarks do tipo III (ou semi-landmarks) - Pontos construídos a partir de relações topológicas, normalmente em bordas de estruturas, ou pontos igualmente espaçados ao longo de uma estrutura ou superfície.

Landmarks do tipo I e II normalmente exprimem correspondências biológicas, mais explicitamente, relações de homologia operacional (Smith, 1990), enquanto landmarks do tipo III apresentam correspondências matemáticas, como a amostragem de curvas e contornos. Apesar disso, há consenso de que em análises de estruturas biológicas todos os landmarks devem exprimir algum grau de correspondência biológica baseada em homologia (Polly, 2008), o que levou à formulação de sínteses teóricas e metodológicas para a utilização da informação de landmarks de todos os tipos em uma mesma análise (BOOKSTEIN, 1997; MACLEOD, 1999). 
As coordenadas de configurações de landmarks, entretanto, são afetadas tanto por posição e orientação, quanto pelo tamanho (ou escala), sendo então necessária a remoção destes efeitos através de uma Análise Generalizada de Procrustes (“Generalized Procrustes Analysis” ou GPA; ROHLF \& SLICE 1990): A posição é removida através da centralização de todas as coordenadas na origem, subtraindo de cada landmark as coordenadas do centróide (média das coordenadas dos landmarks). Para se escalar a configuração, divide-se a configuração de landmarks por uma medida de tamanho. Em morfometria geométrica, o tamanho CS (“Centroid Size”, Bookstein 1991) do objeto $\eta$ é:

$$
C S\left(\eta_{m n}\right)=\sqrt{\sum_{i=1}^{m} \sum_{j=1}^{n}\left(x_{i j}-\bar{x}_{j}\right)^{2}}
$$

sendo $m$ o número de marcos anatômicos, $n$ o número de dimensões e $x$ o valor da coordenada. O CS é uma medida de tamanho geométrica equivalente à soma das distâncias euclidianas de cada landmark ao centróide da configuração.

Para se remover o efeito da rotação, minimiza-se a distância de Procrustes entre as configurações $\eta$ e $\eta$,

$$
d_{\text {procrustes }}\left(\eta_{n m}, \eta_{m n}^{\prime}\right)=\sqrt{\sum_{i=1}^{n} \sum_{j=1}^{m}\left(x_{i j}-\dot{x}_{i j}\right)^{2}}
$$

multiplicando a configuração $\eta$ pela matriz de rotação $\boldsymbol{H}$,

$$
H=V S U^{T},
$$

sendo $\boldsymbol{V}$ e $\boldsymbol{U}$ matrizes ortonormais $n \times n$ obtidas pela decomposição de 
valor singular

$$
\eta^{T} \eta^{\prime}=U \Sigma V^{T}
$$

e $\mathbf{S}$, uma matriz identidade com os elementos da diagonal de $\Sigma$ (Gower, 1970).

Para duas dimensões $\boldsymbol{H}$ tem a forma

$$
H=\left[\begin{array}{cc}
\cos \theta & -\operatorname{sen} \theta \\
\operatorname{sen} \theta & \cos \theta
\end{array}\right]
$$

sendo o ângulo $\theta$ a solução que minimiza $d_{\text {procrustes }}$ por quadrados mínimos.

Para múltiplas configurações, o processo é realizado iterativamente, calculando-se a forma média das configurações e superpondo todos os indivíduos a ela até que a soma de quadrados não mude mais significativamente (ROHLF \& SLICE, 1990). Mantendo o $C S=1$ para todas as configurações, a distância minimizada é a distância parcial de Procrustes, colocando as formas no espaço da pré-forma (SLICE, 2001).

Devido ao caráter não-euclidiano dos espaços morfométricos (ROHLF, 2000), a aplicação de métodos clássicos em morfometria torna-se nãoconvencional ou mesmo inaplicável. Para superar isso, as configurações de landmarks são projetadas ortogonalmente, a partir do espaço da préforma para um espaço tangente ao primeiro, no ponto referente à forma média, segundo sendo $\mathbf{X}$ uma matriz de Configurações

$$
\mathbf{X}^{\prime}=\mathbf{X}\left(\mathbf{I}_{k p}-\mathbf{X}_{c}^{t}\left(\mathbf{X}_{c} \mathbf{X}_{c}^{t}\right)^{-1} \mathbf{X}_{c}\right)
$$

Equação 6.

superpostas no formato $n \times k^{*} p$, Ikp uma matriz identidade e Xc a forma 
média. Isto garante a melhor aproximação da métrica de Procrustes do espaço de Kendall (SLICE, 2001), minimizando qualquer tipo de viés amostral (MARCus et al., 2000) ou metodológico (ROHLF, 2000). As diferenças entre cada coordenada das configurações de landmarks e as da forma média são chamadas de "resíduos de Procrustes", que são as variáveis que melhor descrevem a forma livre dos efeitos de posição, rotação e tamanho (Figura 3.4).
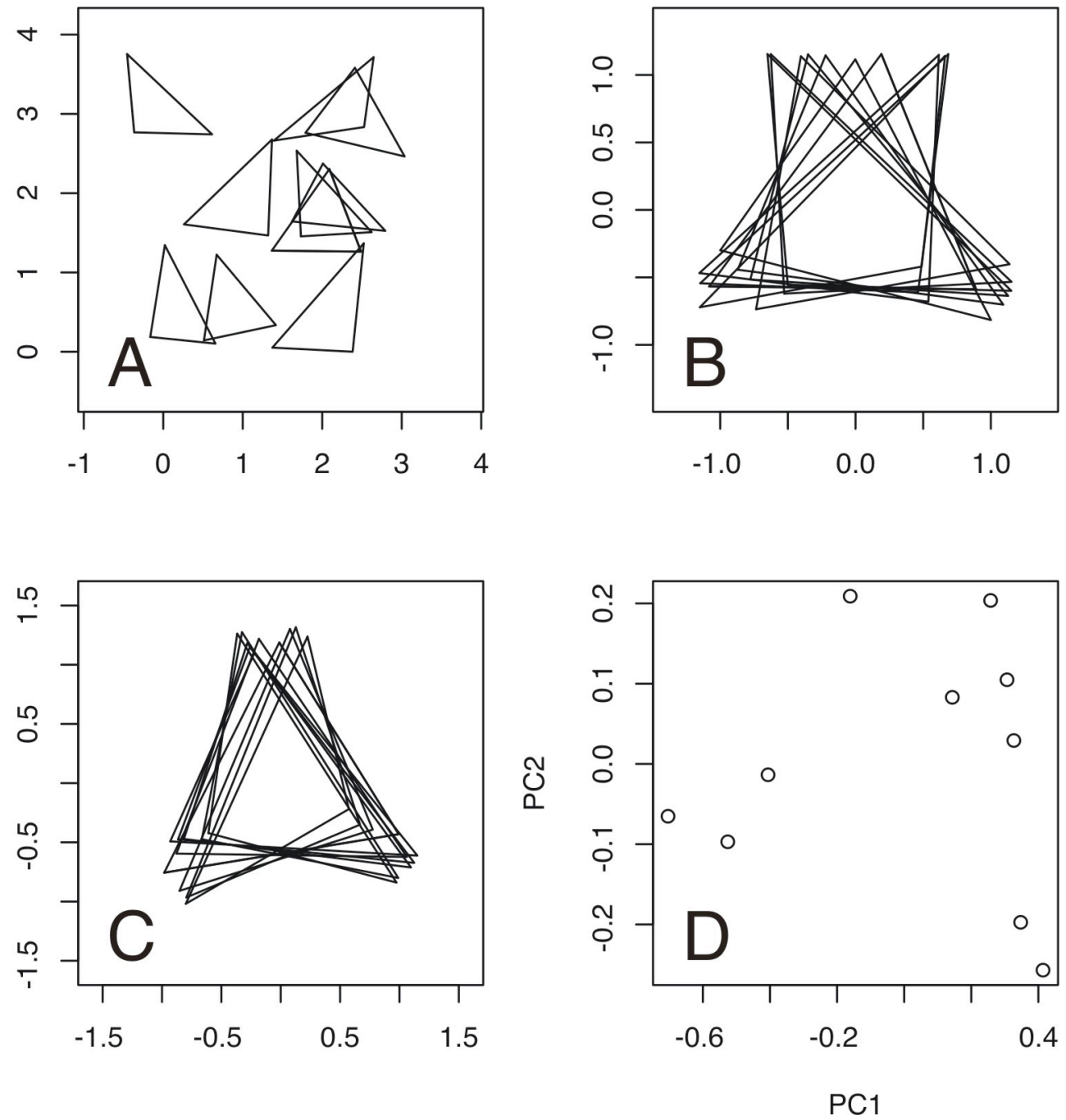

Figura 3.4. Exemplificação dos passos de uma Superposição Generalizada de Procrustes. A- Formas (triângulos) no espaço original; B- Formas superpostas [coordenadas do centróide de cada configuração $=(0,0)$ ] e escalonadas $(\mathrm{CS}=1)$; BFormas rotacionadas (por quadrados mínimos) para minimizar a distancia de Procrustes entre cada forma e a configuração media; D- Análise de componentes principais sobre os resíduos de Procrustes. Os componentes principais representam variáveis da forma independentes de rotação, posição e tamanho. 
Os dados obtidos desta maneira são utilizados para investigar a correlação entre forma e processos biológicos, como filogenia e ecologia (BOOKSTEIN, 1991).

\subsection{Morfometria de vértebras e ecomorfologia vertebral}

É através da morfologia que os animais exercem funções com performances diferenciais que expressam aptidão (ARNOLD, 1983; KINGSOLVER \& HuEY 2003). Entretanto, a relação forma-função não é de maneira alguma trivial, com uma única estrutura exercendo e influenciando funções distintas (GARLAND \& HUEY, 1987). O estudo da forma, e suas influências ontogenéticas, adaptativas e filogenéticas, tenta esclarecer esta questão fundamental da morfologia comparada, para a qual não existe uma resposta unificada.

A estrutura do esqueleto axial em Serpentes é tida como um importante componente para a locomoção (SAVITZKY, 1980; ARNOLD \& BENNETT, 1988; Moon, 1999; Shine, 2000), suporte do corpo (Prange \& ChristMAn, 1976), forrageamento (SAVITZKY, 1980; Moon, 1999), reprodução (SHINE, 2000) e provavelmente para a realização de diversas outras funções biológicas. Sabe-se ainda que alguns hábitos de vida são especialmente influentes na morfologia de Serpentes, afetando diversos conjuntos de caracteres, incluindo a forma vertebral. Exemplos desse processo são o hábito de vida fossorial (SAVITZKY, 1983) e a capacidade de constrição (SAVITZKY, 1980). Nesses casos, o hábito de vida parece influenciar diretamente a morfologia vertebral, alterando superfícies de inserções musculares e as relações biomecânicas (GASC, 1976). Além disso, esses hábitos de vida parecem apresentar algum padrão filogenético, uma vez que existem grandes clados de animais que apresentam exclusivamente um desses dois hábitos, como é o caso de 
Boidae e Pythonidae (constrição) e Scolecophidea, Aniliidae, e Uropeltidae (fossorialidade).

Apesar disso, avaliações quantitativas da forma vertebral e suas relações com a ecologia do grupo são escassas, e realizadas principalmente com a utilização de medidas lineares (e.g. JoHnson, 1954, 1955; GASC, 1976). Esta abordagem clássica, entretanto, sofre com a perda de informações a respeito das posições relativas das estruturas dentro do objeto de estudo. Para vértebras, este é um problema especialmente relevante, uma vez que a posição das estruturas pode ter significado funcional (GASC, 1976; Moon, 1999). Nesse contexto a utilização da morfometria geométrica é especialmente promissora.

\subsection{Objetivos}

Poucos estudos analíticos foram realizados com o objetivo de quantificar a forma vertebral e sua relevância para a construção de cenários evolutivos para Serpentes. O presente trabalho tem como objetivo geral avaliar a forma vertebral de Serpentes no contexto da morfometria geométrica, investigando sua relação com fatores ecológicos e filogenéticos em uma escala taxonômica ampla, contribuindo ainda com questões relacionadas à história evolutiva dos grandes grupos de Serpentes. Dentro desse contexto três objetivos mais específicos podem ser identificados:

1) Observar e descrever a variação longitudinal do esqueleto axial em Serpentes, em um contexto de morfometria geométrica, avaliando a integração morfológica evolutiva presente ao longo do corpo dos animais.

Justificativa: O esqueleto axial de Serpentes é visto como muito homogêneo em relação à forma vertebral (CARROLL, 1988; COATES 
$\&$ RUTA, 2000). Com o tempo, notou-se que tal homogeneidade era apenas relativa aos outros grupos de Squamata, e mais descrições da variação longitudinal gradual das vértebras apareceram na literatura. Sendo assim, é possível que esses padrões descritos sejam evidência da presença de sub-regiões internas ao esqueleto axial de Serpentes. A existência de tais sub-regiões seria especialmente relevante para questões não apenas sistemáticas (definição de caracteres independentes) e paleotaxonomicas (identificação do registro fóssil), mas principalmente para a formulação de hipóteses sobre a ontogênese e funcionamento do esqueleto destes animais, oferecendo subsídios para interpretações a respeito da história evolutiva do grupo (ex: SAVITZKY, 1980)

2) Investigar as relações forma-função das vértebras em Serpentes, testando especificamente as influências de hábitos fossoriais e constritores na forma vertebral, buscando também identificar a presença de sinal filogenético no esqueleto axial.

Justificativa: JoHNSON (1954, 1955), em trabalhos iniciais, identificou uma forte tendência filogenética governando a forma das vértebras nas Serpentes. Estes trabalhos, entretanto, não avaliam a variação longitudinal em si, impedindo a relação da forma vertebral com variáveis ecológicas mais minuciosas. Além disso, os preceitos estatísticos supostos por Johnson de independência de modo de vida e filogenia dificilmente se mantêm sob uma inspeção mais rigorosas. Sendo assim, a questão das relações forma-função/filogenia continua em aberto (GASC, 1976) e dificilmente uma resposta trivial pode emergir. Um estudo comparativo da forma vertebral em Serpentes permite avaliar e pesar os efeitos de herança compartilhada e adaptações pontuais (eventualmente identificando convergências 
adaptativas), possibilitando um melhor entendimento do cenário evolutivo em Serpentes.

3) Investigar o poder discriminatório da morfometria geométrica aplicada à morfologia de vértebras torácicas em Serpentes e avaliar sua utilidade para a interpretação do registro fóssil.

Justificativa: As relações filogenéticas entre os grandes grupos Serpentes são baseados quase exclusivamente em conjuntos de caracteres provenientes dos complexos morfológicos esqueléticos e musculares cranianos ou de dados moleculares. Tal fato vai de encontro com a natureza do registro fóssil deste grupo, que é constituído basicamente de elementos vertebrais desarticulados (RAGE, 1987). A elaboração de um diagnóstico morfométrico para a classificação sistemática de elementos vertebrais isolados seria de grande utilidade para a interpretação deste registro altamente fragmentado. Por esse motivo, faz-se necessário avaliar o poder de distintas técnicas de classificação, de forma a guiar futuras análises do registro fóssil. 


\section{Materiais e Métodos}

\subsection{Espécimes}

Foram utilizados nas análises esqueletos secos ou diafanizados de exemplares pertencentes a 35 espécies alocadas em 15 famílias distintas de Serpentes, todos depositados ou disponíveis na coleção do Museu de Zoologia da USP (Tabela 2.1). Essa amostra compreende os principais grupos de Serpentes viventes. A lista dos indivíduos avaliados e devidamente identificados encontra-se no Apêndice I.

\subsection{Aquisição de Imagens e Digitalização}

Os esqueletos foram desarticulados e a ordem relativa das vértebras foi mantida. Foram selecionadas 15 vértebras torácicas igualmente espaçadas ao longo do corpo de cada exemplar, sendo a primeira vértebra a imediatamente posterior ao complexo atlas-axis e a última a imediatamente anterior à primeira vértebra cloacal (Figura 2).

Todos os espécimes foram fotografados com uma câmera Nikon Coolpix 995 acoplada a uma lupa Nikon SMZ800 em 4 vistas distintas (Anterior, Lateral, Posterior, Ventral) e digitalizadas utilizando o programa TPSDig2 (F. J. RoHLF, http://life.bio.sunysb.edu/morph). Para amostrar a forma das distintas vistas foram escolhidos os seguintes landmarks e curvas (Figura 2.1): 
Tabela 2.1. Lista de espécies analisadas.

\begin{tabular}{|c|c|c|}
\hline Infra-ordem & Família & Espécie \\
\hline \multirow[t]{4}{*}{ Scolecophidia } & Typhlopidae & Typhlops brongersmianus \\
\hline & & Rhinotyphlops schlegelii \\
\hline & Leptotyphlopidae & Leptotyphlops koppesi \\
\hline & Anomalepididae & Liotyphlops beui \\
\hline \multirow[t]{31}{*}{ Alethinophidia } & Aniliidae & Anilius scytales \\
\hline & Uropeltidae & Cylindrophis ruffus \\
\hline & Xenopeltidae & Xenopeltis unicolor \\
\hline & Loxocemidae & Loxocemus bicolor \\
\hline & Boidae & Boa constrictor \\
\hline & & Candoia carinata \\
\hline & & Epicrates cenchria \\
\hline & & Corallus hortulanus \\
\hline & & Eunectes murinus \\
\hline & & Acrantophis dumerili \\
\hline & & Eryx jaculus \\
\hline & & Calabaria rheinhardtii \\
\hline & & Lichanura trivirgata \\
\hline & & Exiliboa placata \\
\hline & & Ungaliophis continentalis \\
\hline & Pythonidae & Morelia viridis \\
\hline & & Liasis albertisi \\
\hline & & Python molurus \\
\hline & Tropidophiidae & Trachyboa boulengeri \\
\hline & & Tropidophis paucisquamis \\
\hline & Bolyeriidae & Casarea dussumieri \\
\hline & Acrochordidae & Acrochordus granulatus \\
\hline & Dipsadidae & Atractus pantostictus \\
\hline & & Helicops hagmanni \\
\hline & Colubridae & Drymarchon corais \\
\hline & & Oxybelis aeneus \\
\hline & Elapidae & Micrurus frontalis \\
\hline & & Pelamis platurus \\
\hline & & Naja haje \\
\hline & Viperidae & Bothrops moojeni \\
\hline & & Bothriopsis bilineata \\
\hline
\end{tabular}



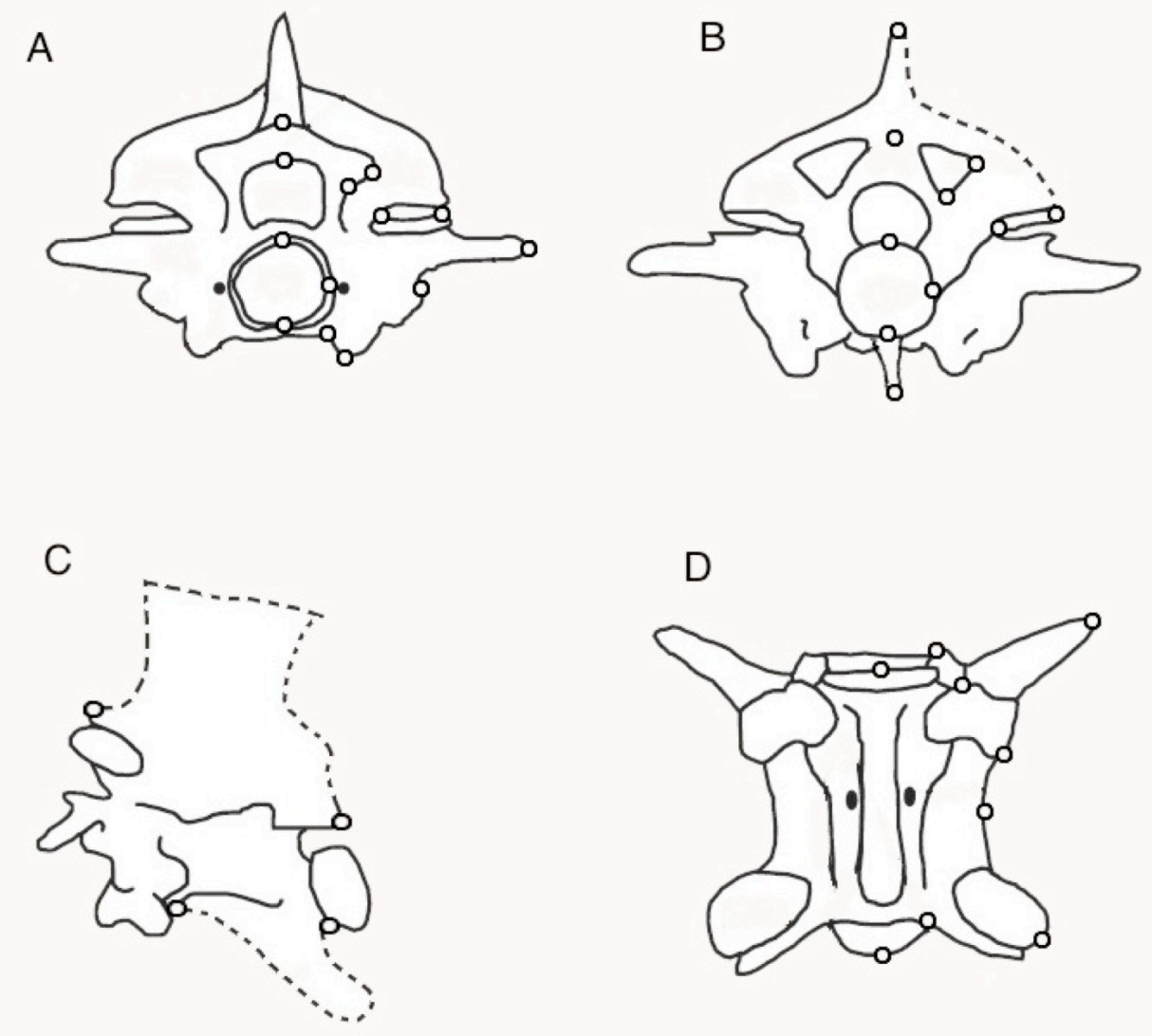

Figura 2.1. Diferentes vistas de um elemento vertebral isolado, evidenciando os marcos anatômicos (landmarks) utilizados nas análises, em cada vista. Linhas pontilhadas representam as curvas amostradas. Vistas simétricas foram amostradas apenas de um lado para evitar redundância. Modificado de HoLMAN (2000).

Vista Anterior: landmark 1- Ponto mais ventral do cótilo, landmark 2Ponto mais lateral do cótilo, landmark 3- Ponto mais dorsal do cótilo, landmark 4- Ponto mais lateral e inferior do canal neural, landmark 5ponto mais alto do canal neural na linha mesial, landmark 6- Ponto mais dorsal e mesial do zigósfeno, landmark 7- Ponto mais dorsal da articulação do zigósfeno, landmark 8- Ponto mais ventral da articulação do zigósfeno, landmark 9- Ponto mais mesial da articulação prézigapofiseal; landmark 10- Ponto mais distal da articulação prézigapofiseal; landmark 11- Ponto referente ao processo pré-articular (ou pré-zigapofiseal); landmark 12- ponto mais dorsal da sinapófise; landmark 13- Ponto mais ventral da sinapófise, landmark 14- encontro da sinapófise com o cótilo. 
Vista Posterior: landmark 1- Ponto mais ventral do Côndilo; landmark 2- Ponto mais lateral do Côndilo; landmark 3- Ponto mais dorsal do côndilo, landmark 4- Ponto mais ventral da articulação do zigantra, landmark 5- Ponto mais dorsal da articulação do zigantra, landmark 6Ponto mais dorsal e mesial do zigósfeno, Curva 1- Contorno externo do arco neural, iniciando-se no ponto mais dorsal do arco neural até o ponto mais lateral da pós-zigapófise, landmark 7- Ponto mais mesial da pószigapófise, landmark 8- Ponto extremo inferior da hipapófise.

Vista Lateral: curva 1- Contorno dorsal em vista lateral, desde a porção anterior do zigósfeno até o começo da articulação pós-zigapofiseal, curva 2- Contorno ventral em vista lateral, desde a porção ventral do côndilo até a porção imediatamente inferior à sinapófise.

Vista Ventral: landmark 1- Ponto mais mesial do côntilo, landmark 2Ponto mais lateral do côntilo, landmark 3- Ponto mais mesial do côndilo, landmark 4- Ponto mais lateral do côndilo, landmark 5- Ponto mais distal da pré-zigapófise; landmark 6- Ponto de maior inflexão do contorno lateral externo, landmark 7- Ponto mais distal da pós-zigapófise, landmark 8- ponto extremo anterior da sinapófise em vista ventral, landmark 9- ponto extremo posterior da sinapófise em vista ventral.

\subsection{Morfometria Geométrica}

Para as análises morfométricas, as configurações de landmarks referentes a cada vértebra foram agrupadas de duas formas distintas (Figura 2.2). O agrupamento do tipo A consiste em vértebras de diferentes espécies em posições equivalente, de forma a avaliar a variação interespecífica referente aos diferentes segmentos do corpo dos animais. $\mathrm{O}$ agrupamento do tipo B consiste em agrupar todas as vértebras de um mesmo espécime, de forma a avaliar a variação axial-longitudinal em cada espécie. No 


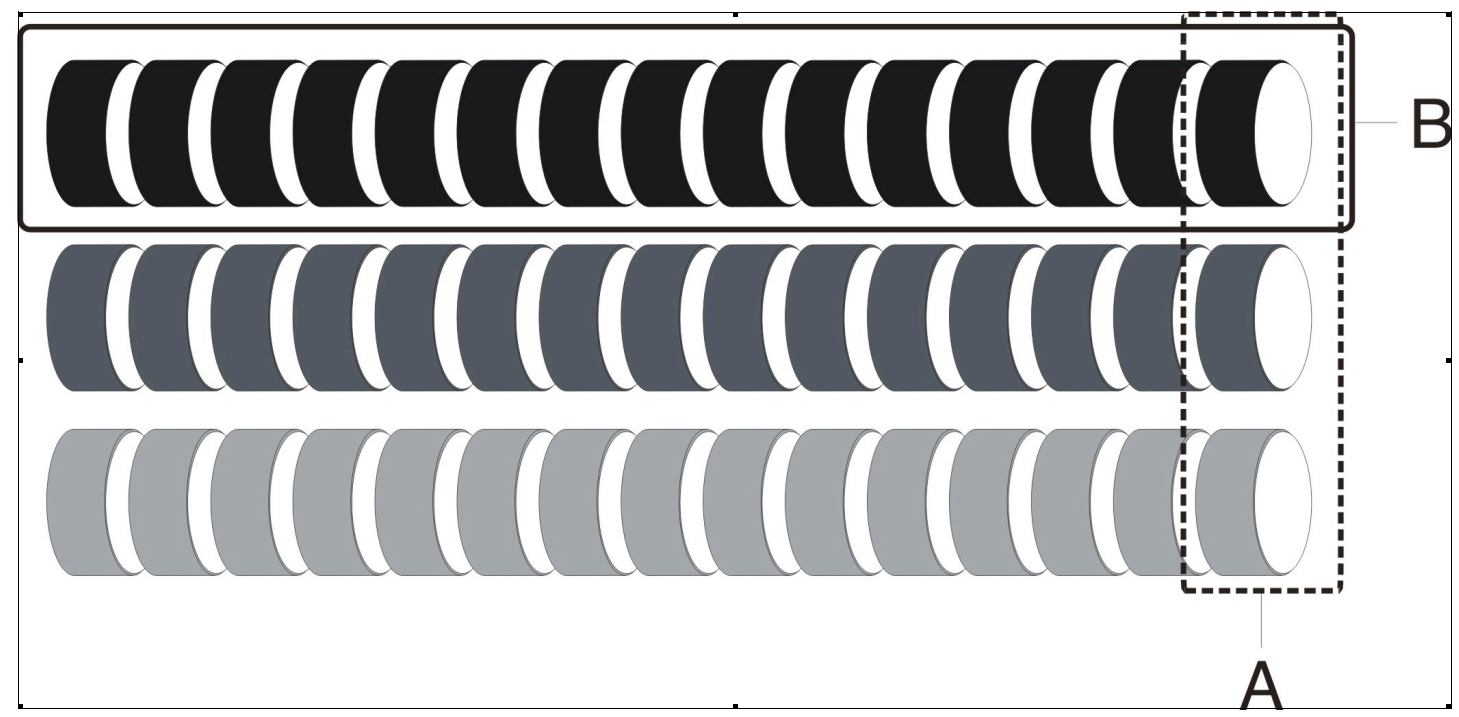

Figura 2.2. Representação esquemática dos diferentes agrupamentos empregados para avaliar a variação longitudinal e dissociação no esqueleto axial em Serpentes. Tipo A- Variação intra-específica referente a uma mesma posição vertebral; Tipo BVariação ao longo do esqueleto axial cada espécie separadamente.

total, apresentamos 15 agrupamentos do tipo A (referente a cada posição vertebral) e 35 do tipo B (referentes à variação axial de cada espécie) para cada vista.

Cada conjunto de vértebras foi superposto por Análise Generalizada de Procrustes ("Generalized Procrustes Analysis" ou GPA; ROHLF \& SLICE, 1990) e projetado ortogonalmente no espaço Tangente (SLICE, 1999). Os resíduos desta análise foram utilizados em uma análise de componentes principais ("Principal Component Analysis" ou PCA) para se obter variáveis da forma. A adequação da projeção das configurações superpostas nos espaços da tangente foi averiguada pelo coeficiente de correlação entre as distâncias de Procrustes no espaço da forma de Kendall e as distâncias euclidianas obtidas no espaço Tangente.

\subsection{Análise de dissociação}

Para avaliar a dissociação do esqueleto axial, foi seguido o protocolo delineado por Polly et al. (2001), através do qual esta é avaliada com base nas correlações entre as taxas evolutivas dos diferentes módulos. A 
análise pressupõe que se diferentes caracteres estão sendo herdados em conjunto, espera-se que estes apresentem correlações alta entre as respectivas taxas evolutivas. De forma análoga, se os caracteres estão dissociados, então se espera que a correlação entre as taxas evolutivas seja baixa ou até mesmo inexistente. Para se obter as taxas de evolução, os oito primeiros componentes principais (PCs) dos resíduos de Procrustes das GPAs, referentes aos agrupamentos do tipo B, foram otimizados por máxima-verossimilhança sobre a filogenia composta construída para essas análises (Figura 7.1 do Apêndice I), seguindo um modelo de evolução por movimento browniano (SCHLUTER, 1997). As taxas de mudança ao longo dos ramos foram então calculadas como a distância euclidiana multivariada entre as extremidades de cada ramo, normalizadas pelos tamanhos dos ramos em milhões de anos. Essa metodologia foi repetida para cada posição vertebral ao longo do corpo dos exemplares.

Devido ao caráter dos dados morfométricos analisados, um modelo de regressão por quadrados mínimos não é adequado para atingir os objetivos propostos, uma vez que não é possível estabelecer relações de dependência entre as variáveis. Por esse motivo, foi realizada uma PCA sobre as taxas evolutivas para avaliar a coevolução entre as diferentes posições vertebrais. Os PCs resultantes destas análises representam os principais eixos de covariação evolutiva e os pesos das diferentes posições nesses eixos vertebrais indicam a contribuição parcial de cada secção do corpo dos animais.

Para avaliar o impacto dos padrões de associação e dissociação encontrados na variação da forma vertebral, foram avaliados os morfoespaços representados pelos PCs referentes a cada posição vertebral (agrupamento do tipo A) através de uma Análise de Correlação de 
Procrustes ("Procrustes Correlation Analysis", PCorr). A PCorr é análoga ao GPA para a comparação de matrizes, superpondo, reescalando e rotacionando as matrizes por critério de quadrados-mínimos, sendo a correlação estimada sobre as configurações resultantes (PERES-NETO \& JACKSON 2001). No presente caso, as PCorr foram calculadas, comparando os morfoespaços referentes a cada posição vertebral a um morfoespaço médio. Esse morfoespaço foi obtido realizando um GPA sobre as formas médias obtidas por GPAs referentes à variação axiallongitudinal (agrupamento do tipo B). Esse morfoespaço é uma representação da variação interespecífica, ignorando a variação axiallongitudinal. Para se quantificar a variação evolutiva total em cada posição vertebral, calculou-se a soma das distâncias de Procrustes de cada forma em relação à forma média de cada morfoespaço. A significância das PCorr encontradas foi avaliada através de 10000 permutações das identidades das espécies ou posições vertebrais no morfoespaço médio.

Adicionalmente, a similaridade do padrão de variação longitudinal foi avaliado através da reconstrução das formas ancestrais referentes a cada posição. As formas para os diversos nós foram reconstruídas através dos valores otimizados dos PCs de agrupamentos do tipo A, utilizados para se obter as taxas evolutivas, como descrito acima. Os valores otimizados foram reconvertidos para o espaço da figura, produzindo formas vertebrais ancestrais para cada nó. As formas ancestrais referentes a cada nó foram agrupadas (agrupamento do tipo B) e re-submetidas a uma GPA. As variáveis das formas assim produzidas (PCs) foram comparadas entre os diversos nós, aplicando uma GPA sobre os três primeiros componentes principais de cada nó, resultando em um espaço que representa a variação longitudinal livre de escala, rotação e translação (ADAMS et al., 2007). Assim, esse novo espaço representa a variação 
longitudinal independente da forma média, bem como as distâncias relativas entre as vértebras no espaço da forma definido pelas formas relativas a cada nó.

\subsection{Sinal Filogenético}

Para investigar a presença de sinal filogenético nas variáveis de forma, utilizou-se uma versão multivariada do modelo linear geral (“General Linear Model" ou GLM) de BlOMBerg et al. (2001), utilizando a hipótese filogenética composta descrita no Anexo I. A significância do sinal foi avaliada através de um processo de randomização: os terminais foram trocados aleatoriamente e o sinal filogenético computado para 1000 replicações em cada análise. Resultados que apresentaram valores observados superiores a $1 \%$ dos resultados das aleatorizações foram considerados significativos no nível de $\alpha=0.01$, sugerido para processos de permutação com 1000 réplicas (MANLY, 1997).

\subsection{Ecomorfologia}

Para testar a hipótese de que os hábitos constritor e fossorial afetam a forma, foram construídos quatro modelos lineares multivariados (Tabela 2.2). O modelo nulo assume que não há diferenças entre animais com modos de vida distintos. O modelo 1 testa as possíveis diferenças na forma das vértebras entre animais fossoriais e não fossoriais. O modelo 2 testa a diferença entre animais que capturam suas presas por constrição e animais que realizam outro tipo de captura. $\mathrm{O}$ modelo 3 testa a existência de um grupo fossorial, um grupo constritor e um terceiro grupo, contendo todos os outros animais que não se encaixam nestas duas categorias. 
Tabela 2.2. Resumo dos modelos lineares utilizados para testar hipóteses ecomorfológicas sobre a forma vertebral em Serpentes.

Modelo $\quad P C 1+P C 2 \sim 1$
Nulo

Modelo $1 \quad P C 1+P C 2 \sim$ fossorialidade
Não há distinção entre a forma vertebral dos diferentes hábitos.

A fossorialidade apresenta influencia sobre a forma vertebral

A constrição apresenta influência sobre a forma vertebral

Tanto fossorialidade quanto Modelo $3 \begin{aligned} & P C 1+P C 2 \sim \text { fossorialidade }+ \\ & \text { constrição }\end{aligned}$ constrição apresentam influências sobre a forma vertebral

Cada grupo foi tratado como uma distribuição normal multivariada. A média e desvio padrão dos modelos foram estimados por verossimilhança, e o melhor modelo foi escolhido com base no Critério de Informação de Akaike de segunda ordem ("Akaike Information Criterion" ou $A I C_{c}$; AKAIKE 1973), que não apenas penaliza a verossimilhança em função do número de parâmetros, como também controla para baixas amostragens. $\mathrm{O} A I C_{c}$ pode ser calculado como:

$$
A I C_{c}=-2 \log \mathrm{L}+2 \mathrm{~K}+2 \mathrm{~K}(\mathrm{~K}+1) /(n-\mathrm{K}-1),
$$

sendo $\mathrm{L}$ a verossimilhança do modelo ajustado, $\mathrm{K}$ o numero de parâmetros na análise e $\mathrm{n}$ o tamanho amostral. $\mathrm{O} A I C_{c}$ fornece uma medida geral do ajuste entre o modelo e os dados e, para comparar dois modelos competidores, primeiro reescalonou-se a verossimilhança de cada modelo da seguinte forma:

$$
L^{\prime} \sim \mathrm{e}^{(-1 / 2)}{ }_{\triangle} A I C c
$$


com $\Delta A I C_{c}$ sendo a diferença entre o $\mathrm{AIC}_{\mathrm{c}}$ estimado e o menor $\mathrm{AIC}_{\mathrm{c}}$ na análise. Para selecionar entre os modelos competidores foi empregado um teste de razões de verossimilhança ("likelihood-ratio test"). A razão entre duas verossimilhanças é uma estimativa geral da força da evidência a favor de um modelo em detrimento do outro, favorecendo modelos mais parcimoniosos. Razões superiores a 8 representam que a força de evidência em favor do modelo no numerador é muito superior do que à referente ao modelo no denominador (RoyAL, 1997). As análises ecomorfológicas foram realizadas para cada posição vertebral (Agrupamentos do tipo A) e para a forma média de cada espécie (médias dos agrupamentos do tipo B).

\subsection{Análise de Discriminação e Classificação}

Para averiguar o poder de diagnose da forma vertebral, utilizou-se agrupamentos do tipo B, nos quais a identidade dos elementos isolados foi estimada estatisticamente. Foram investigadas três formas distintas de classificação:

\section{1) Função Linear Discriminante}

A Função Linear Discriminante (FLD) permite a classificação de observações desconhecidas em grupos conhecidos. Isso é feito resolvendo a equação:

$$
F=X W+\varepsilon,
$$

na qual $X$ é a matriz de variáveis originais e $W$ é um vetor de pesos que minimiza a variação dentro do grupo e maximiza a variação entre os grupos e $\varepsilon$ é um termo do erro (LeSTREL, 2000). Os termos dessa função seguem uma distribuição normal multivariada e podem ser estimados por máxima verossimilhança. A FLD assume, entretanto, a igualdade dos padrões de variância e covariância entre os grupos. No presente caso, isso 
implica em assumir que os padrões de variação longitudinal são constantes entre as espécies.

2) Verossimilhança

Devido à possibilidade da não-manutenção dos padrões de variação longitudinal entre as espécies, investigou-se a utilidade do emprego de um protocolo de classificação por verossimilhança adaptado de POLLY \& HEAD (2004):

$$
l(u)=\log [f(u / s)],
$$

sendo $f$ a verossimilhança do elemento vertebral $u$ em função da distribuição multivariada $s$. Operacionalmente, $s$ é definida como a distribuição multivariada dos cinco primeiros componentes principais dos resíduos de Procrustes de dado conjunto de configurações, e $u$ é o vetor de pesos da projeção do elemento vertebral a ser classificado, ajustado por Procrustes à média das configurações, no subespaço definido. A identidade é conferida com a distribuição através do melhor ajuste (maior verossimilhança ou menor log verossimilhança). Esse procedimento, diferente da FLD, não assume a igualdade da variância/covariância entre os grupos, mas necessita que as variáveis da forma sigam uma distribuição normal multivariada.

O poder dos procedimentos citados acima (FLD e verossimilhança) foi avaliado através de um protocolo de validação-cruzada, no qual os elementos vertebrais são removidos um a um da amostra e sua identidade estimada a posteriori.

3) Distância de Procrustes

Complementarmente, avaliou-se a utilização da similaridade absoluta entre as vértebras como padrão para classificar vértebras isoladas. Isso foi realizado calculando a distância de Procrustes: 


$$
d_{\text {procrustes }}\left(\eta_{n m}, \eta_{n m}^{\prime}\right)=\sqrt{\sum_{i=1}^{n} \sum_{j=1}^{m}\left(x_{i j}-\dot{x}_{i j}\right)^{2}}
$$

onde $\eta_{m n}$ e $\eta_{m n}^{\prime}$ são as configurações de $m$ marcos anatômicos e $n$ dimensões superpostas por Procrustes, e $x$ o valor das coordenadas dos marcos. Para avaliar se a similaridade pode ser usada como critério de classificação, a vértebra a ser classificada foi isolada da amostra e a distância de Procrustes entre ela e todas as demais foi computada. A identidade da vértebra isolada é considerada igual à vértebra mais similar (que apresenta menor distância de Procrustes). Esse procedimento não assume igualdade de variâncias e covariâncias nem tampouco se as formas seguem uma distribuição normal multivariada.

Todas as análises estatísticas foram realizadas no ambiente $\mathrm{R}$ ( $\mathrm{R}$ Development Core TEAM, 2009). As GPAs foram realizadas com o pacote Shapes versão 1.1-3 (DRYDEN, 2009). As PCorr foram computadas com o pacote Vegan versão 1.17-3 (OKSANEN et al., 2010). As reconstruções de caracteres ancestrais foram realizadas com o pacote APE versão 2.5-3 (PARADIS et al., 2010). 


\section{Resultados}

\subsection{Morfometria geométrica}

As distâncias do espaço da tangente apresentaram correlações altas com as distâncias equivalentes no espaço da forma para todos os agrupamentos do tipo A e B $\left(R^{2}>0.99999\right)$. De fato, mesmo quando todas as vértebras são avaliadas em conjuntos, o coeficiente de correlação se apresenta bem elevado (Figura 3.1). Isso indica que o espaço da forma das vértebras é muito restrito e que aproximações lineares (ex: projeções das formas no espaço da tangente) mantêm as distâncias reais entre as formas (distâncias de Procrustes). Sendo assim, a utilização de componentes principais dos resíduos de Procrustes projetados no espaço da tangente não afeta as interpretações sobre as variações reais da forma.

Os resumos da variação longitudinal de cada espécie se encontram no Apêndice II. O resumo da variação interespecífica da forma vertebral referente a cada posição encontra-se no Apêndice III. 

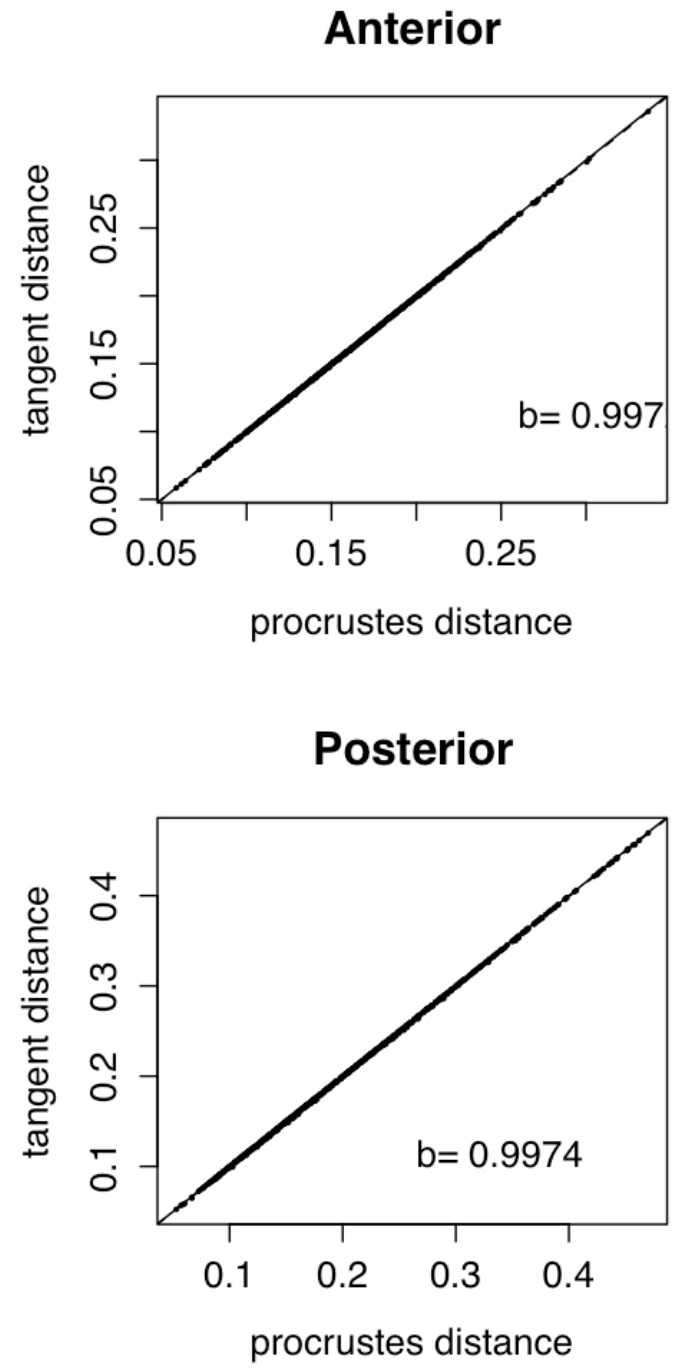

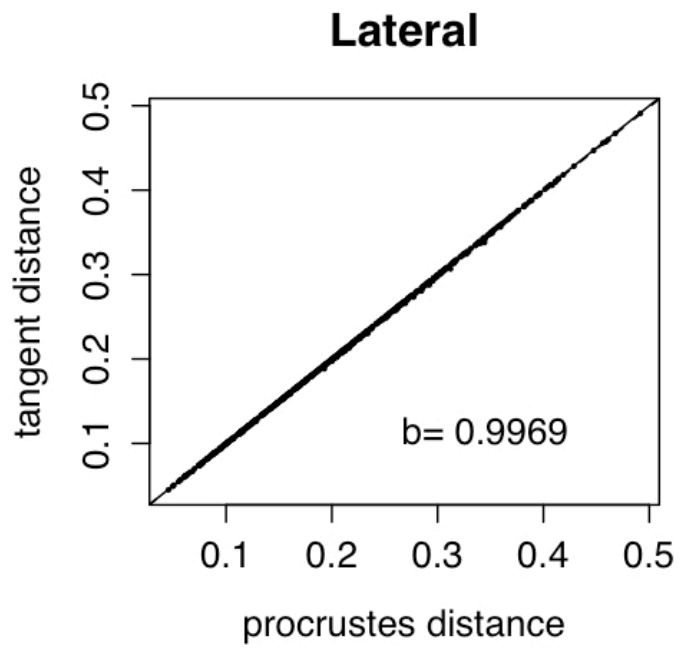

Ventral

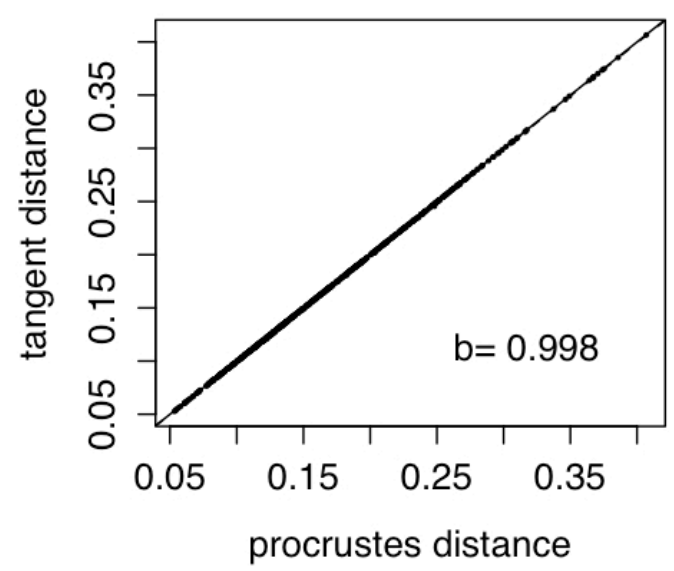

Figura 3.1. Regressão linear entre as distâncias entre as configurações no espaço da tangente e no espaço de Kendall, evidenciando o coeficiente de correlação entre as variáveis (b). 


\subsection{Análise de dissociação}

A análise das taxas evolutivas das diferentes posições vertebrais revela que o primeiro eixo de todas as vistas avaliadas concentra mais que $90 \%$ da variação (Figuras 3.2-5). Esse eixo apresenta pesos positivos e relativamente constantes ao longo de todo o corpo dos animais. O segundo eixo de variação assume um padrão diferenciado em cada uma das vistas. Em vista anterior, esse segundo eixo apresenta peso alto e positivo para a primeira posição vertebral, valores moderadamente negativos entre a $2^{\mathrm{a}}$ e $8^{\mathrm{a}}$ posições, assumindo valores levemente positivos da $9^{\mathrm{a}}$ até a $15^{\mathrm{a}}$ posições, com exceção da $10^{\mathrm{a}}$ posição que assume valores levemente negativos. As vistas laterais e posteriores apresentam um segundo eixo similar, que parece expressar um mesmo padrão, com pesos positivos em posição mais anterior, transitando gradualmente para valores negativos em posições mais posteriores. A vista ventral apresenta padrão distinto, com posições anteriores apresentando valores negativos, exceto pela $1^{\text {a }}$ posição que mantém valor positivo, e com regiões mais posteriores assumindo valores positivos. 


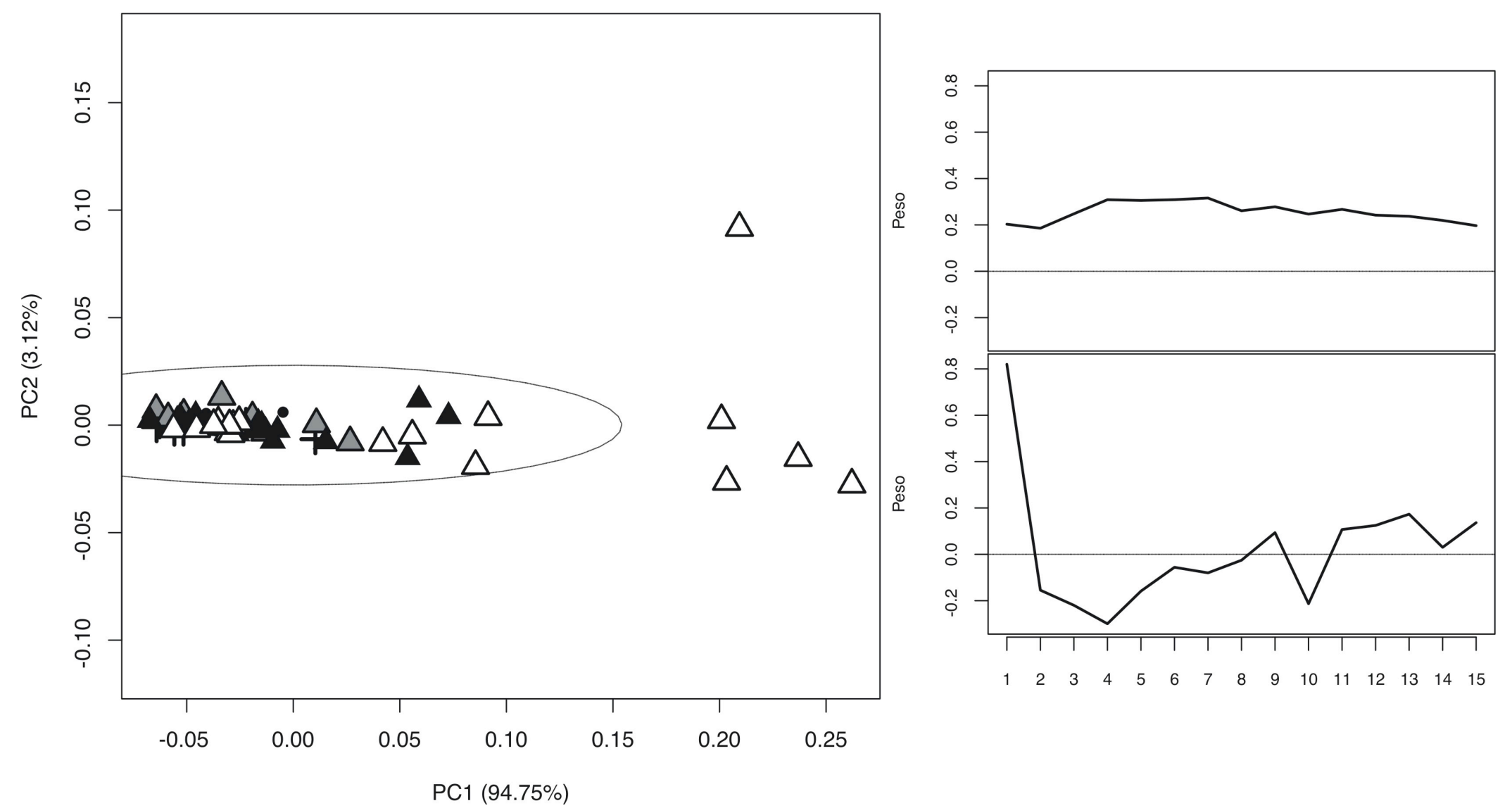

Figura 3.2. Análise de componentes principais das taxas evolutivas das formas das vértebras em vista anterior ao longo dos corpos de representantes de diversas famílias de Serpentes. Esquerda: gráfico de dispersão dos valores dos diferentes ramos no primeiro e segundo componentes principais. Cruzes = clado Scolecophidia; triângulos escuros = Boidae; triângulos cinza = Pythonidae; triângulos claros = Caenophidia; ponto = demais clados. Direita: Pesos referentes a cada posição vertebral no primeiro (cima) e no segundo componentes principais (baixo). 


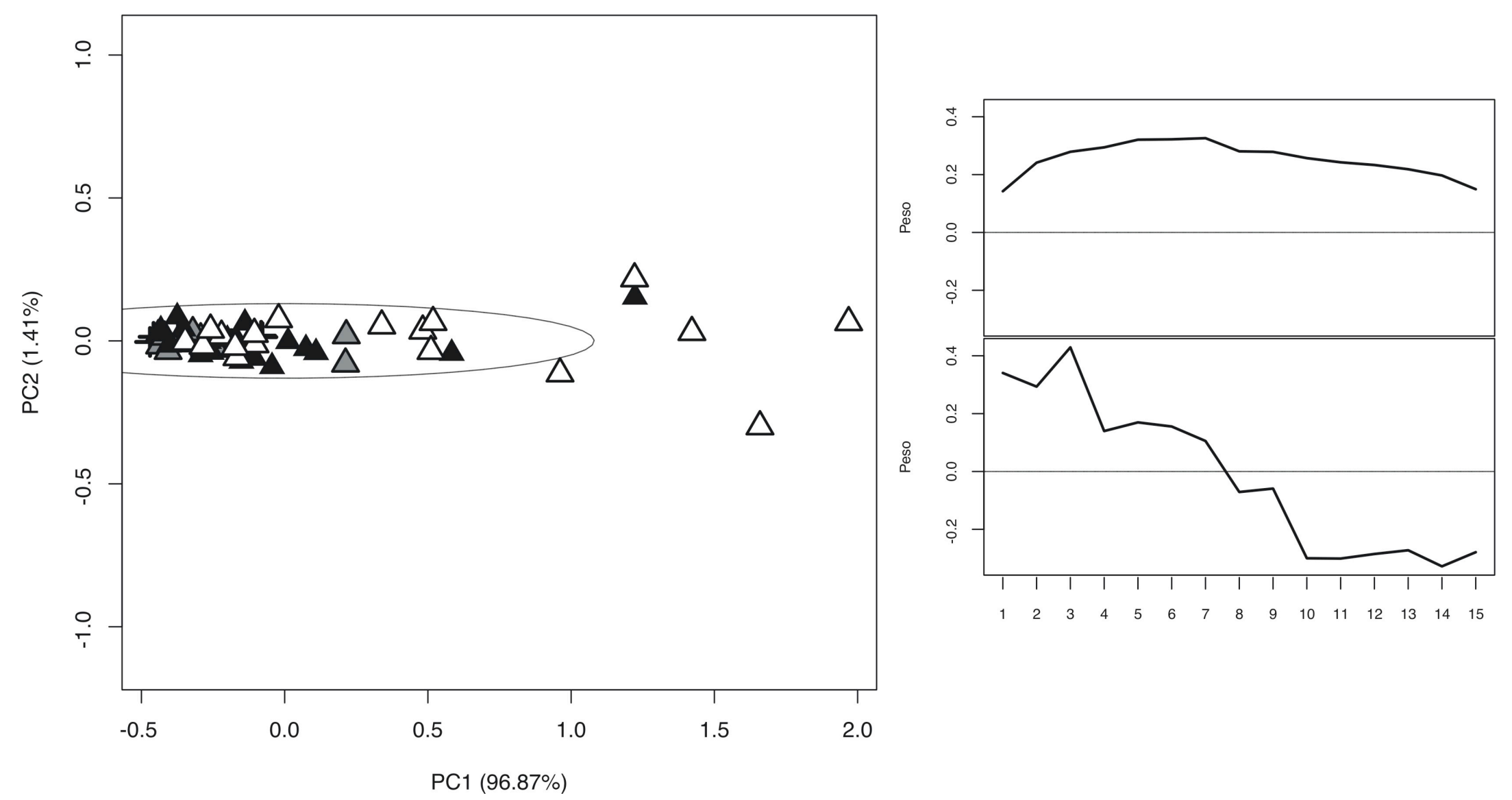

Figura 3.3. Análise de componentes principais das taxas evolutivas das formas das vértebras em vista lateral ao longo dos corpos de representantes de diversas famílias de Serpentes. Esquerda: gráfico de dispersão dos valores dos diferentes ramos no primeiro e segundo componentes principais. Cruzes = clado Scolecophidia; triângulos escuros = Boidae; triângulos cinza $=$ Pythonidae; triângulos claros $=$ Caenophidia; ponto = demais clados. Direita: Pesos referentes a cada posição vertebral no primeiro (cima) e no segundo componentes principais (baixo). 


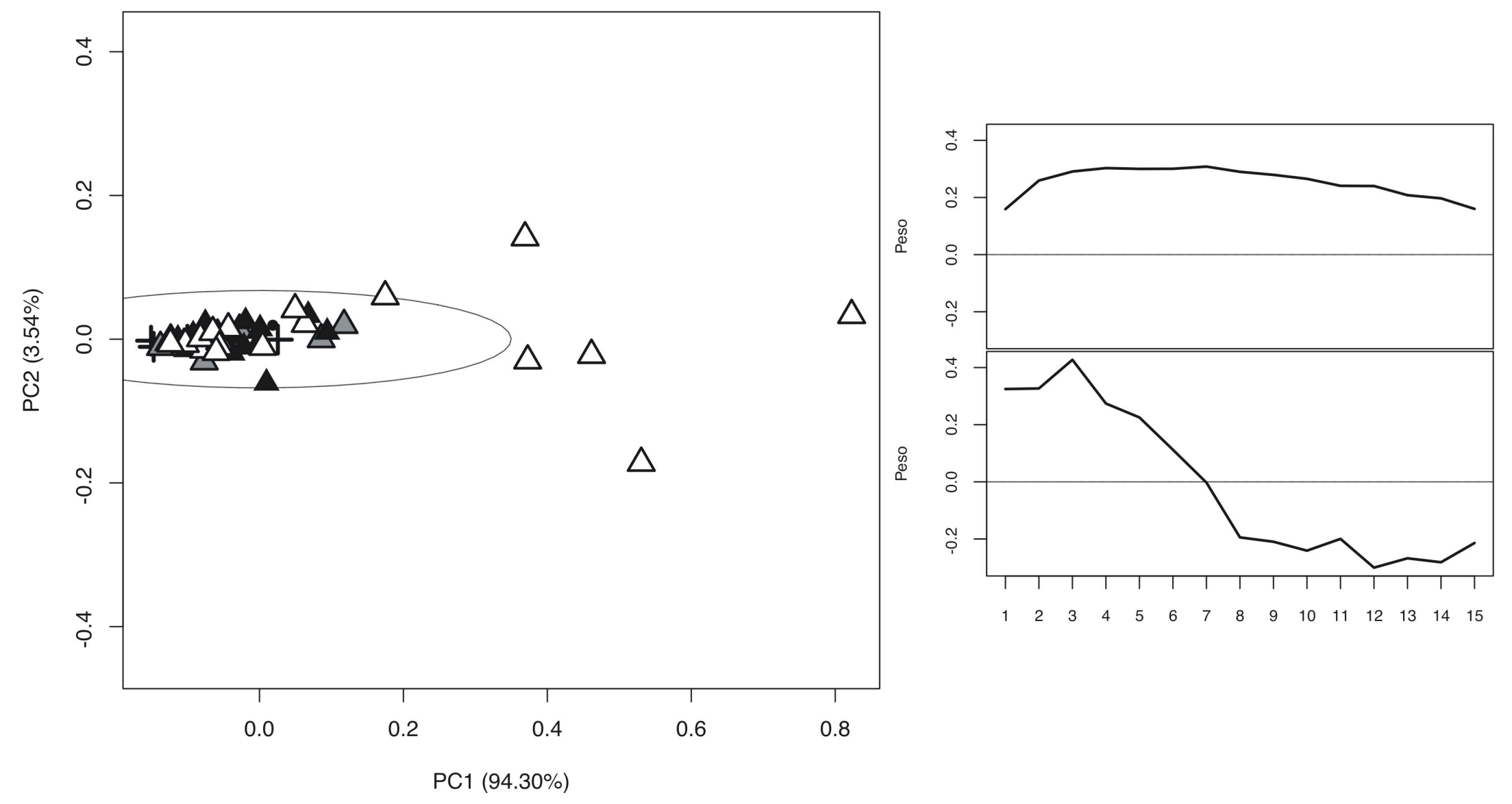

Figura 3.4. Análise de componentes principais das taxas evolutivas das formas das vértebras em vista posterior ao longo dos corpos de representantes de diversas famílias de Serpentes. Esquerda: gráfico de dispersão dos valores dos diferentes ramos no primeiro e segundo componentes principais. Cruzes = clado Scolecophidia; triângulos escuros = Boidae; triângulos cinza = Pythonidae; triângulos claros = Caenophidia; ponto = demais clados. Direita: Pesos referentes a cada posição vertebral no primeiro (cima) e no segundo componentes principais (baixo). 


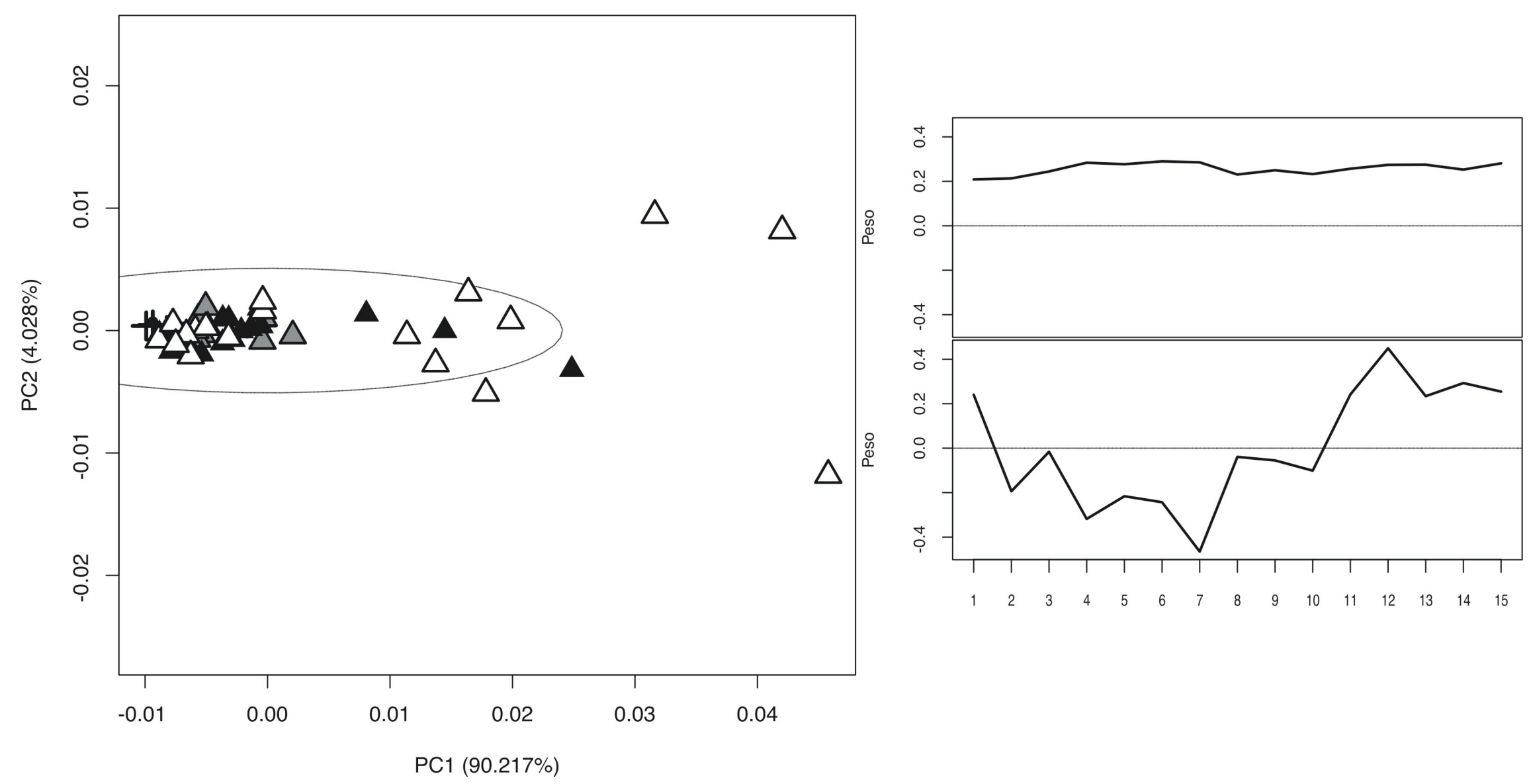

Figura 3.5. Análise de componentes principais das taxas evolutivas das formas das vértebras em vista ventral ao longo dos corpos de representantes de diversas famílias de Serpentes. Esquerda: gráfico de dispersão dos valores dos diferentes ramos no primeiro e segundo componentes principais. Cruzes = clado Scolecophidia; triângulos escuros = Boidae; triângulos cinza $=$ Pythonidae; triângulos claros $=$ Caenophidia; ponto = demais clados. Direita: Pesos referentes a cada posição vertebral no primeiro (cima) e no segundo componentes principais (baixo). 
A despeito das diferenças nos pesos dos componentes das diferentes vistas, o padrão de dispersão das taxas evolutivas é similar para todas elas. O primeiro componente resume a grande maioria da variação nas taxas evolutivas (>90\%), com a grande maioria das taxas evolutivas apresentando valores baixos. O segundo componente resume uma percentagem muito menor da variação $(<5 \%)$, com a maioria das taxas evolutivas apresentando valores próximos de zero. Os ramos que fogem deste padrão são referentes à Caenophidia, que apresentam tanto valores altos no primeiro componente e valores extremos no segundo componente. Alguns ramos pertencentes à Boidae e Pythonidae também apresentam valores altos do primeiro componente, porém, com raras exceções, não fogem ao intervalo de $95 \%$ de confiança.

Todas as correlações obtidas pelas PCorr se mostraram significativas pelos procedimentos de permutação para todas as vistas. Estas análises mostram que o subespaço médio é uma boa aproximação das relações entre as formas vertebrais ao longo de quase todo o corpo, com exceção da região mais cranial (Figura 3.6), com valores máximos nas posições 6, 7 ou 8, e voltando a cair em posições mais caudais. Em todas as vistas, a $1^{\mathrm{a}}$ posição apresenta os valores mais baixos de correlação com morfoespaço médio. O total da variação comporta-se de forma similar, assumindo valores baixos tanto em posições caudais quanto em posições craniais, aumentando sua magnitude em posições intermediárias, com a região entre a 5-8 ${ }^{\mathrm{a}}$ vértebras apresentando os valores mais elevados. A relação entre o total de variação evolutiva e correlação de Procrustes com o morfoespaço médio aparenta ser quase constante ao longo do corpo, exceto pela $1^{a}$ posição vertebral, que apresenta valores muito baixos para a correlação, indicando que esse morfoespaço não representa a variação presente nesta região. Para todas as vistas, a primeira e a última posições 
apresentaram uma quantidade de variação relativamente baixa, exceto para a vista ventral na qual a primeira posição vertebral apresenta grande variação de forma.
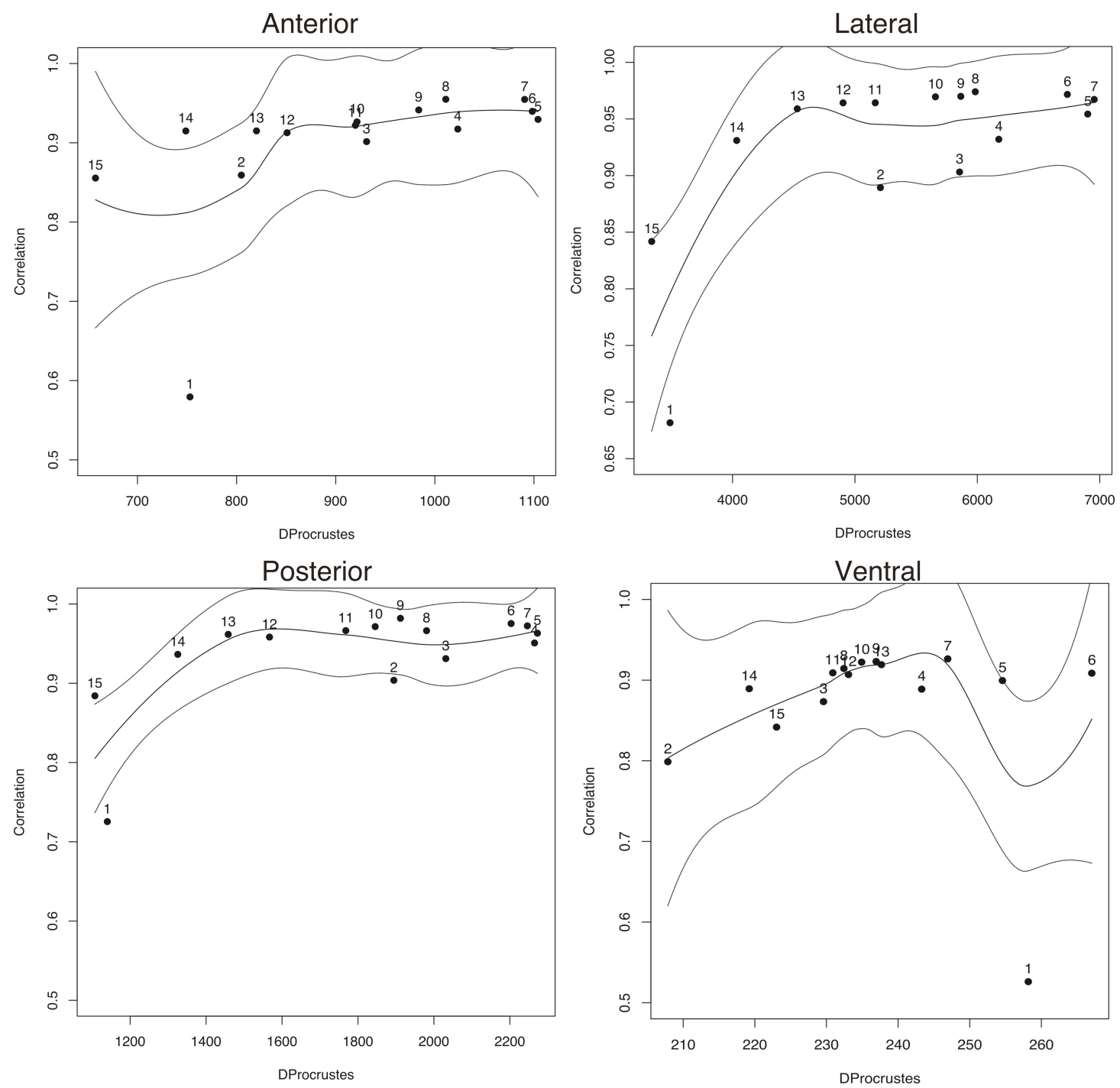

Figura 3.6. Relação entre a correlação de Procrustes com o morfoespaço médio e o total de variação referente a cada posição vertebral. 
Anterior

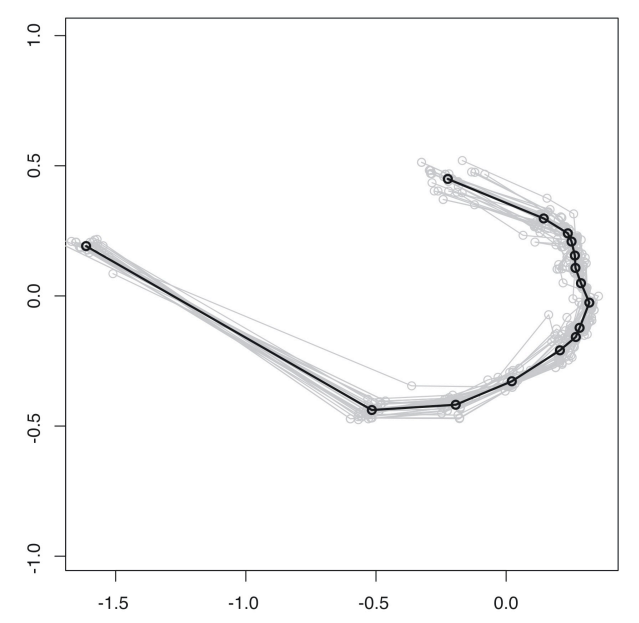

Posterior

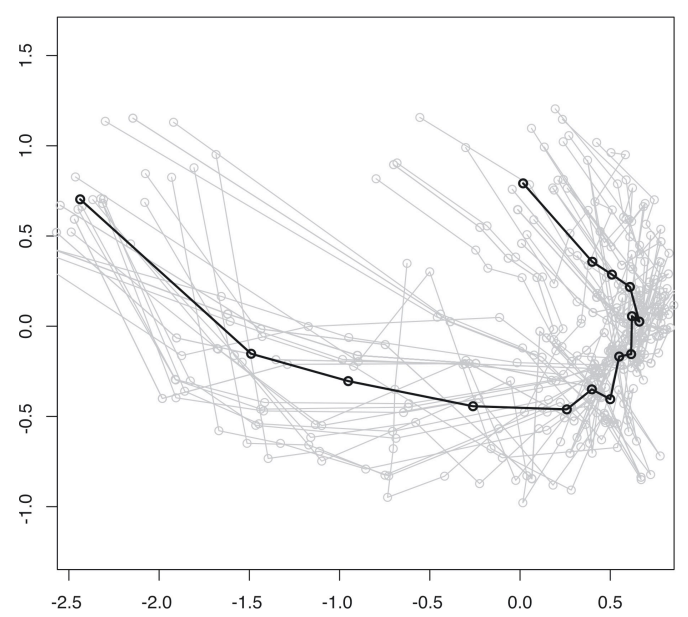

Lateral

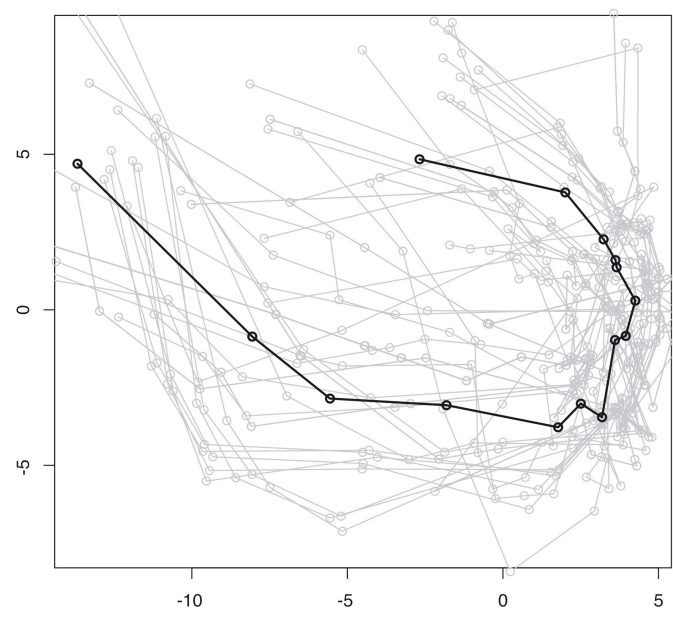

Ventral

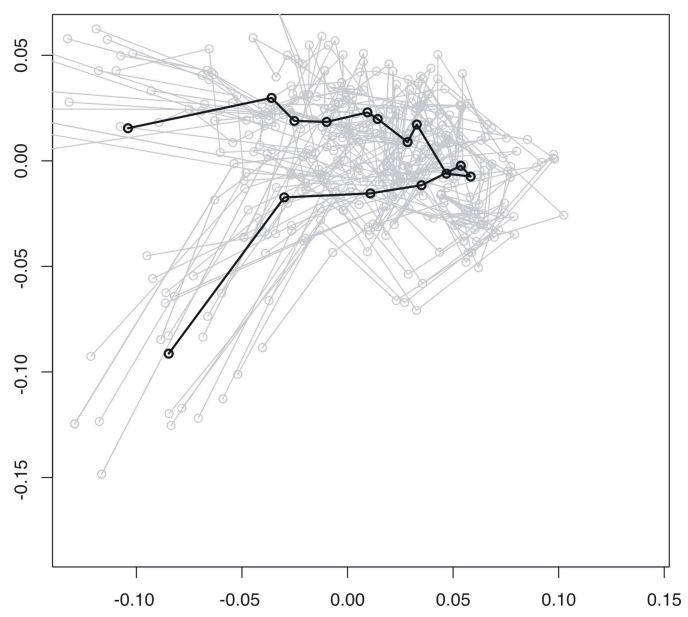

Figura 3.7. Reconstrução dos padrões de variação das formas vertebrais ao longo do esqueleto axial em Serpentes. Ponto em preto representa a vértebra mais cranial e as linhas continuas representam a ordem das vértebras ao longo do corpo dos animais. Configurações em cinza representam todas as formas reconstruídas e as configurações em preto representam as configurações médias obtidas por GPA.

As reconstruções das formas ancestrais revelaram que os padrões de variação longitudinal são conservados ao longo da filogenia (Figura 3.7). Em vista anterior, esse padrão é incrivelmente conservado, havendo pouca variação na posição relativa das vértebras nos morfoespaços referentes a cada nó. As demais vistas apresentam variação consideravelmente maior, porém com formas médias muito similares, com exceção da vista ventral. Nas vistas anterior, lateral e posterior, a primeira vértebra domina a principal fonte de variação, com a região 
média do animal (vértebras 2-13) parecem definindo um eixo de variação quase ortogonal em relação ao estabelecido pela primeira vértebra. A vista ventral apresenta um padrão distinto no qual as vértebras das regiões médias encontram-se concentradas em uma região relativamente pequena do morfoespaço, com as vértebras mais caudais e craniais distanciando-se desse padrão em um sentido similar. Em maior ou menor grau, todos esses padrões de variação descrevem um formato de “j” no morfoespaço.

\subsection{Sinal filogenético}

Nenhuma das análises resultou em um valor K significativo, indicando a ausência de sinal filogenético na forma vertebral para todas as espécies (Tabela 3.1).

Tabela 3.1. Valores da estatística K de Blomberg et al. (2001) para cada vista avaliada e valor de $P$ empírico obtido através de 1000 permutações.

\begin{tabular}{c|cc|} 
& $\mathbf{K}$ & $\boldsymbol{P}$ \\
\hline Anterior & 0.237 & 0.260 \\
Lateral & 0.361 & 0.093 \\
Posterior & 0.329 & 0.234 \\
Ventral & 0.437 & 0.059
\end{tabular}




\subsection{Ecomorfologia}

As análises de componentes principais do morfoespaço livre da variação longitudinal (médio) estão resumidas nas figuras 3.8, 3.10, 3.12 e 3.14. As figuras $3.9,3.11,3.13$ e 3.15 mostram análises de agrupamento realizadas sobre as distâncias de Procrustes do morfoespaço médio, utilizando o método de grupos pareados não-pesados sobre a média aritmética ("Unweighted Pair Group Method with Arithmetic Mean", ou UPGMA).

O primeiro componente da vista anterior (Figura 3.12) resume $31,65 \%$ da variação e exprime a diferença entre vértebras altas com processo acessório pouco desenvolvido e sinapófises e prézigapófises mais dorsalmente orientadas em valores mais baixos, e formas dorsalmente comprimidas com processos acessórios desenvolvidos, pré-zigapófise em posição mais dorsal, sinapófises mais lateralmente orientadas e cótilo elipsóide. Esse eixo parece distinguir principalmente Scolecophidia, em valores superiores extremos, de Alethinophidia, em valores mais intermediários e baixos. O segundo eixo resume 22,28\% da variação total e representa a diferença de forma entre vértebras largas com cótilos levemente elípticos e com processo acessório subdesenvolvido, e vértebras lateralmente comprimidas com zigósfeno menos desenvolvido e processo acessório em posição levemente mais ventral. O segundo componente parece separar principalmente Caenophidia dos demais Alethinophidia e de Scolecophidia. Porém, a área de superposição com o primeiro é grande. Scolecophidia parece se distribuir de forma relativamente homogênea ao longo deste eixo.

A análise de agrupamento da vista anterior (Figura 3.13) agrupa três espécies de Scolecophidia como sendo os mais dissimilares da amostra. 
Apesar de estarem no mesmo quadrante do morfoespaço, Liotyphlops aparenta ser mais similar aos Alethinophidia. Há a formação de um grupo que compartilha o hábito constritor, com o agrupamento de membros das famílias Pythonidae e Boidae. Entretanto, esse grupo não é exclusivamente constritor, incluindo outros animais de vértebras robustas, como os viperídeos amostrados e Cylindrophis. Pode-se notar também a formação de um grupo quase que exclusivamente de Alethinophidia (menos Viperidae), porém com a inclusão de Anilius e a exclusão de Naja, que parece ser mais similar a Loxocemus e Xenopeltis.

Em vista lateral (Figura 3.14), o primeiro componente resume 62,88\% da variação, com formas ântero-posteriormente comprimidas e com espinhos neurais desenvolvidos em valores mais baixos e formas mais alongadas sem espinho neural ou hipapófise evidente, em valores mais altos. $\mathrm{O}$ segundo componente principal resume $14,94 \%$ da variação da forma, separando vértebras com espinhos neurais ântero-posteriormente alongados e hipapófise desenvolvida e larga em valores baixos de vértebras sem hipapófise evidente e espinho neural "obsoleto" (sensu RAGE, 1984). Juntos, estes dois componentes parecem separar Scolecophidia e alguns grupos fossoriais com valores altos em ambos, boídeos, pitonídeos e grupos associados com valores altos no segundo vetor, mas baixos no primeiro, e Caenophidia em um quadrante distinto, principalmente com valores baixos no segundo componente.

A análise de agrupamento da vista lateral (Figura 3.15) mostra a formação de dois grandes grupos. O primeiro grupo inclui quase que exclusivamente animais constritores, com exceção de Pelamis, que aparece em posição basal no grupo. O segundo grupo inclui os Caenophidia (com exceção de Pelamis) e animais fossoriais basais (Scolecophidia) e derivados (Anilius, Cylindrophis). Os animais 
fossoriais parecem formar um grupo separado, com exceção de Micrurus que parece ser mais similar aos outros elapídeos (exceto Pelamis).

Em vista posterior (Figura 3.16), o primeiro componente principal exprime $71.83 \%$ da variação e representa a diferença entre formas mais altas, com espinho neural mais proeminente e fino e hipapófises desenvolvidas em valores baixos e formas mais comprimidas, com espinho neural ausente e hipapófise pouco desenvolvida. $\mathrm{O}$ segundo componente resume $9.58 \%$ da variação total e explica a diferença entre vértebras com arco neural levemente trapezoidal, com pós-zigapófise com uma angulatura mais demarcada e espinho neural relativamente fino em valores mais baixos e vértebras com arcos neurais mais grossos, com pós-zigapófises mais dorsalmente anguladas e espinho neural largo em valores altos.

A análise de agrupamento da vista posterior (Figura 3.17), assim como a da vista lateral, também apresenta uma divisão quase que simétrica na base, com a formação de dois grupos: um contendo animais com espinho neural desenvolvido e outro com animais com espinho neural ausente ou pouco desenvolvido. Nota-se também a formação de um agrupamento que contêm todos os animais fossoriais analisados, com a exceção de Micrurus, que se encontra agrupado com Naja.

O primeiro componente principal da vista ventral (Figura 3.18) resume $66,98 \%$ da variação de forma e exprime a variação entre vértebras curtas e largas em valores negativos, como exemplificado pelos membros das famílias constritoras como Boidae e Pythonidae, e alongadas e estreitas em valores mais positivos, como exemplificado pelos gêneros Oxybelis e Liotyphlops. O segundo componente resume 9,09\% da variação e apresenta a diferença entre formas mais robustas e com pós-zigapófises 
desenvolvidas em valores negativos e formas com processos acessórios muito desenvolvidos lateralmente em valores mais positivos, a exemplo de Scolecophidia menos Liotyphlops.

A análise de agrupamento da vista ventral (Figura 3.19) apresenta uma divisão principal entre animais com vértebras mais longas e animais com vértebras curtas e robustas, sendo que todos os animais constritores caem nesta categoria.

O padrão de variação da forma vertebral permitiu a separação de grupos para testar a presença de sinal ecológico no morfoespaço vertebral. Para as análises ecomorfológicas, os animais classificados como fossoriais foram: Typhlops, Rhinotyphlops, Leptotyphlops, Liotyphlops, Anilius, Cylindrophis, Xenopeltis, Loxocemus, Eryx, Calabaria e Atractus; e os constritores: Boa, Candoia, Epicrates, Corallus, Eunectes, Acrantophis, Eryx, Calabaria, Lichanura, Ungaliophis, Exiliboa, Python, Morelia, Liasis, Tropidophis, Trachyboa e Casarea. No modelo 3, tanto Eryx como Calabaria foram classificadas como fossoriais, uma vez que as restrições funcionais associadas à fossorialidade parecem ser mais notáveis. Não foram assumidas diferenças quanto ao grau de fossorialidade (semi-fossorial ou fossorial) e/ou performance, tanto de fossorialidade quanto de constrição. 


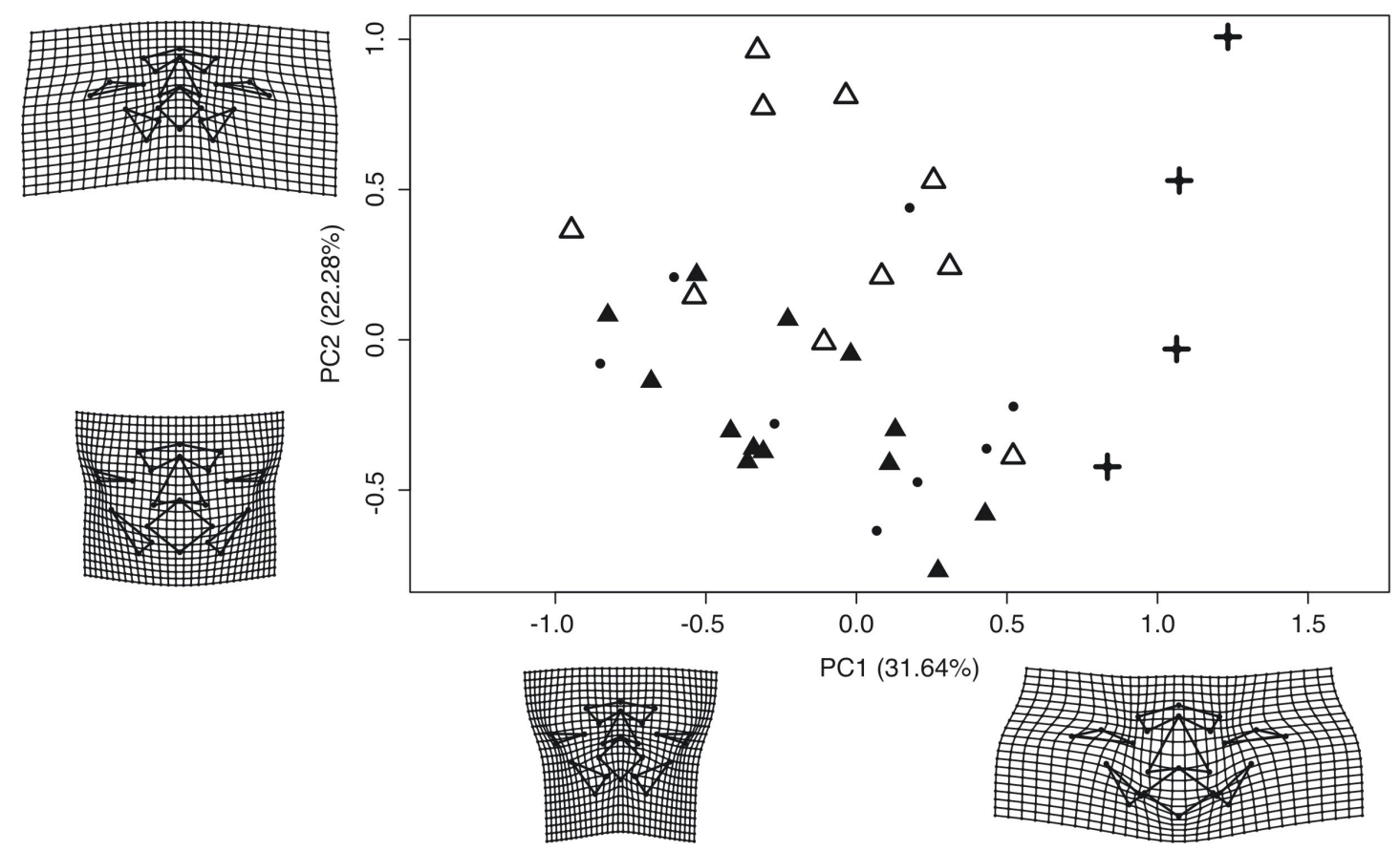

Figura 3.18. Análise de componentes principais dos resíduos de Procrustes das formas médias da vista anterior, mostrando a variação resumida pelos dois primeiros componentes. A variação referente a cada eixo está representada através de splines, mostrando a deformação da forma média aos extremos dos componentes. Ver texto para descrição. Cruzes $=$ Scolecophidia; triângulos escuros = Boidae; triângulos cinza $=$ Pythonidae; triângulos claros $=$ Caenophidia; pontos $=$ demais clados . 


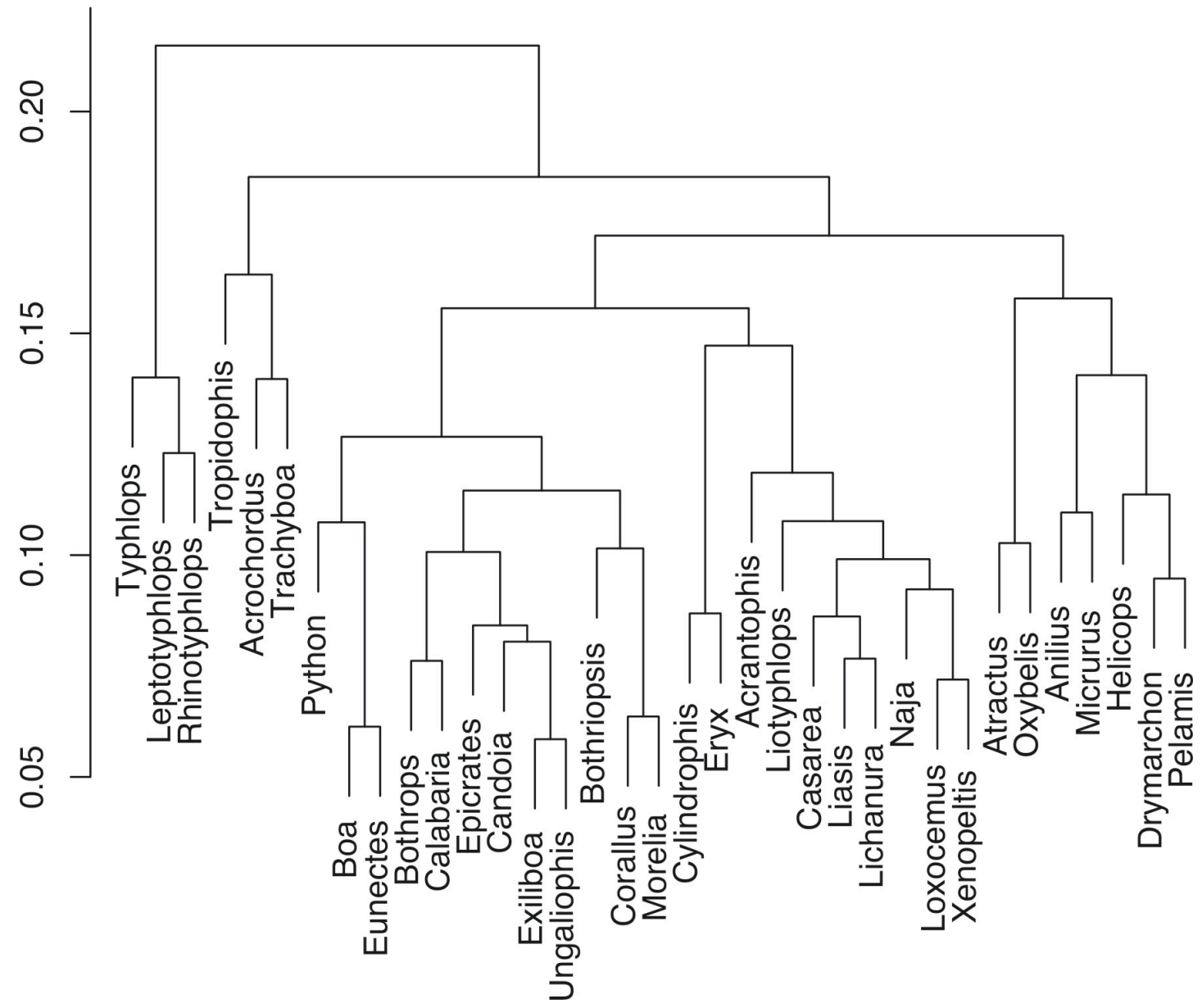

Figura 3.9. UPGMA sobre as distâncias de Procrustes das formas médias referentes à vista anterior. 


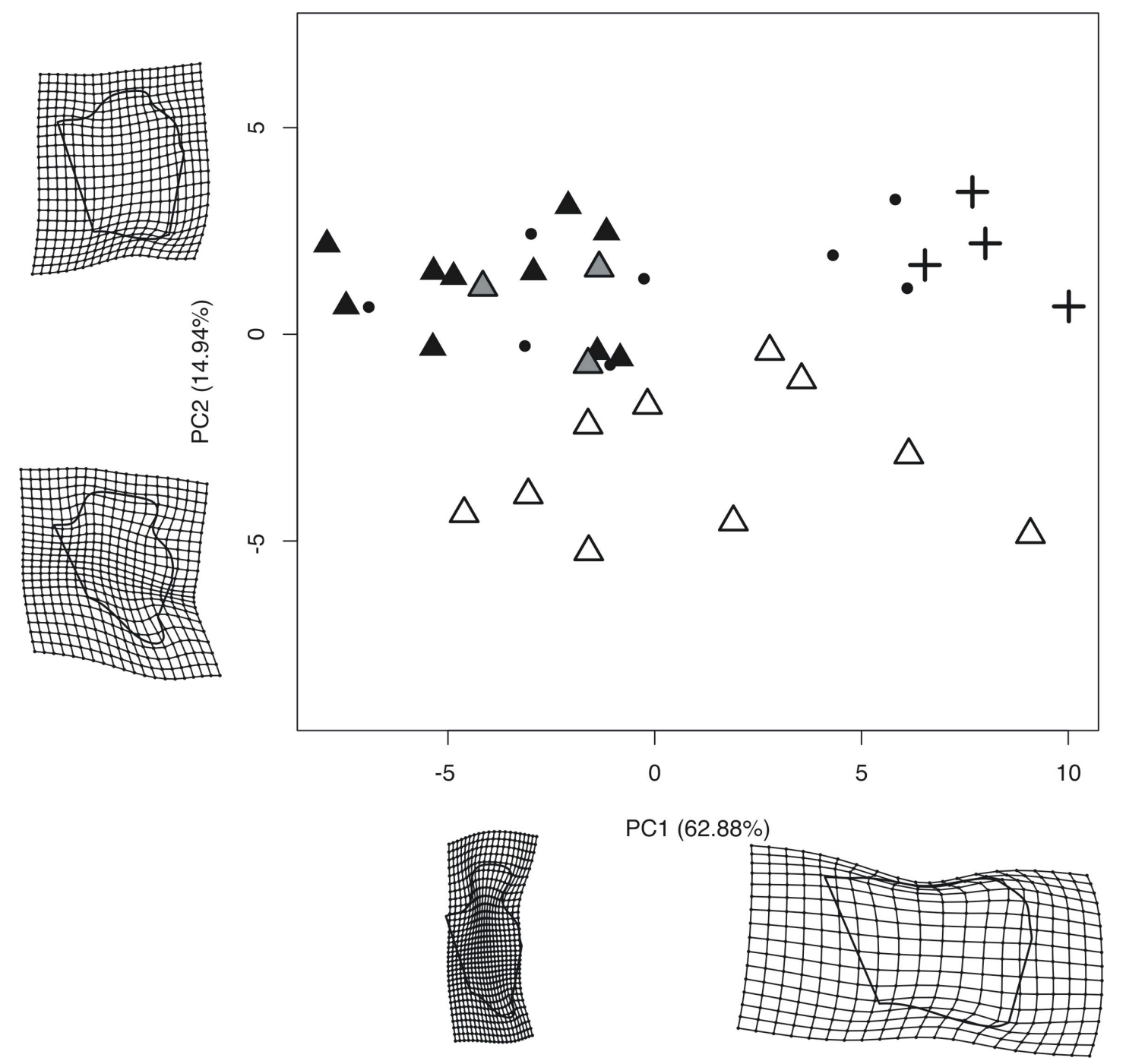

Figura 3.10. Análise de componentes principais dos resíduos de Procrustes das formas médias da vista lateral, mostrando a variação resumida pelos dois primeiros componentes. A variação referente a cada eixo está representada através de splines, mostrando a deformação da forma média aos extremos dos componentes. Ver texto para descrição. Cruzes $=$ Scolecophidia; triângulos escuros $=$ Boidae; triângulos cinza $=$ Pythonidae; triângulos claros $=$ Caenophidia; pontos $=$ demais clados . 


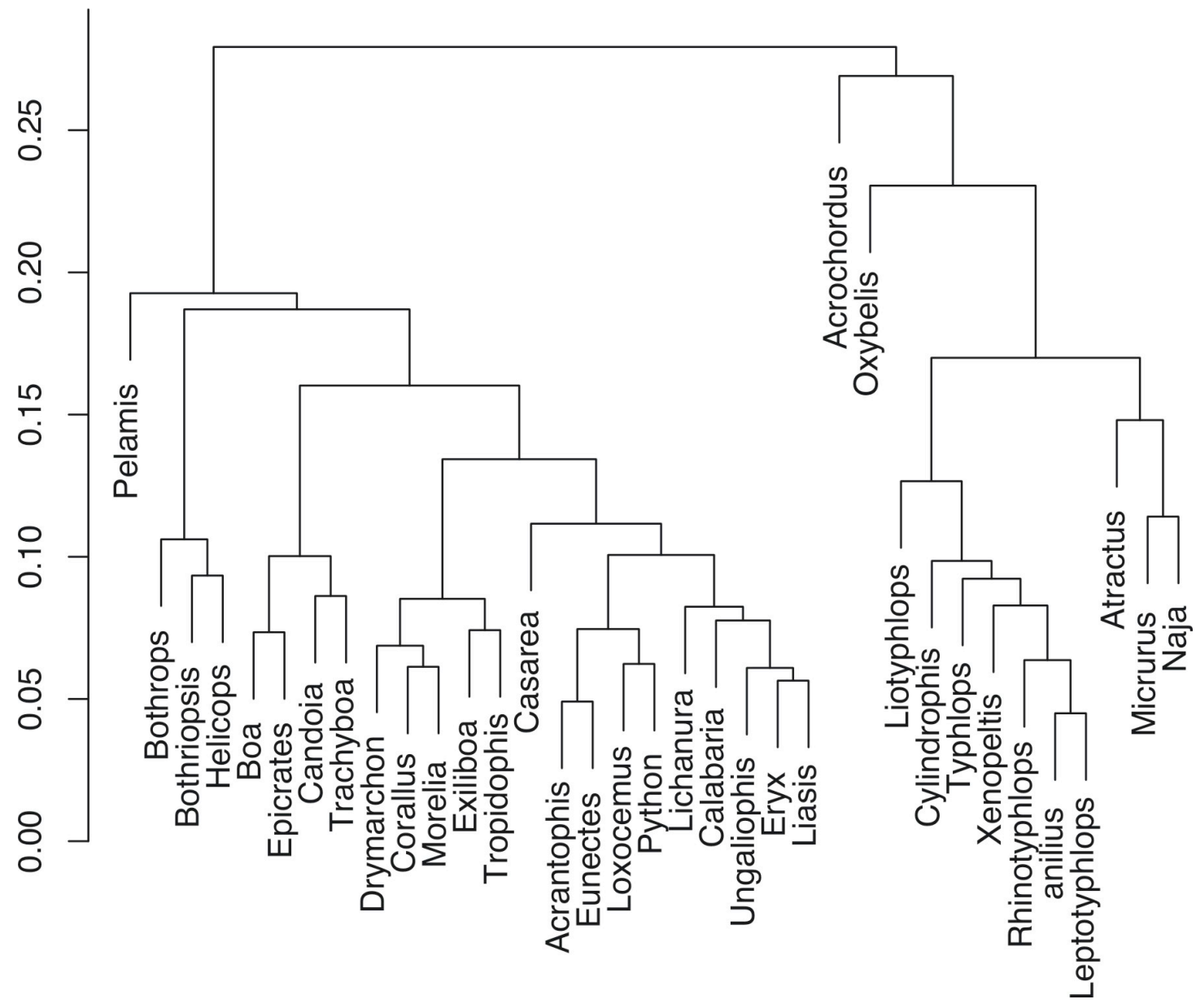

Figura 3.11. UPGMA sobre as distâncias de Procrustes das formas médias referentes à vista lateral. 

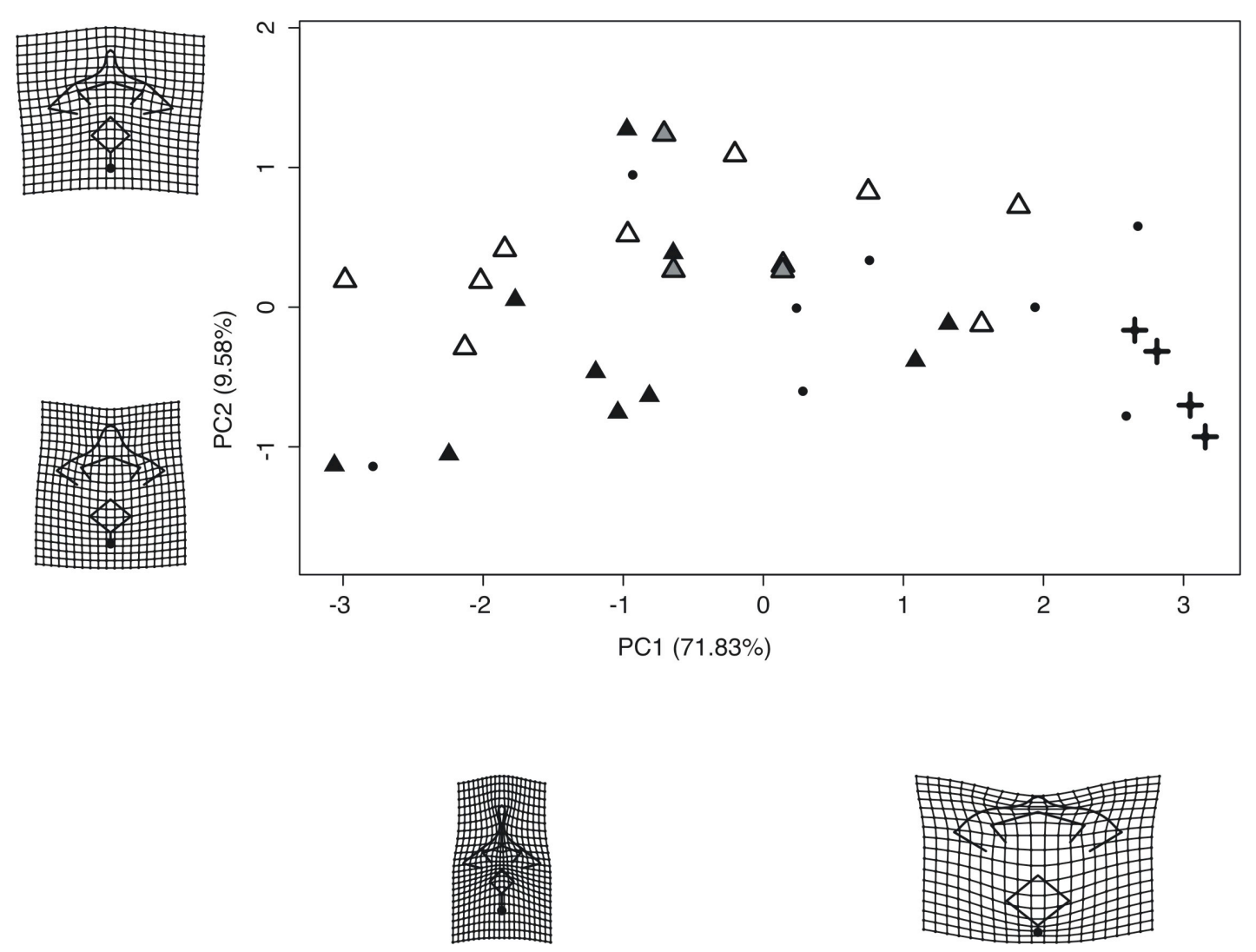

Figura 3.12. Análise de componentes principais dos resíduos de Procrustes das formas médias da vista posterior, mostrando a variação resumida pelos dois primeiros componentes. A variação referente a cada eixo está representada através de splines, mostrando a deformação da forma média aos extremos dos componentes. Ver texto para descrição. Cruzes $=$ Scolecophidia; triângulos escuros $=$ Boidae; triângulos cinza $=$ Pythonidae; triângulos claros $=$ Caenophidia; pontos $=$ demais clados . 


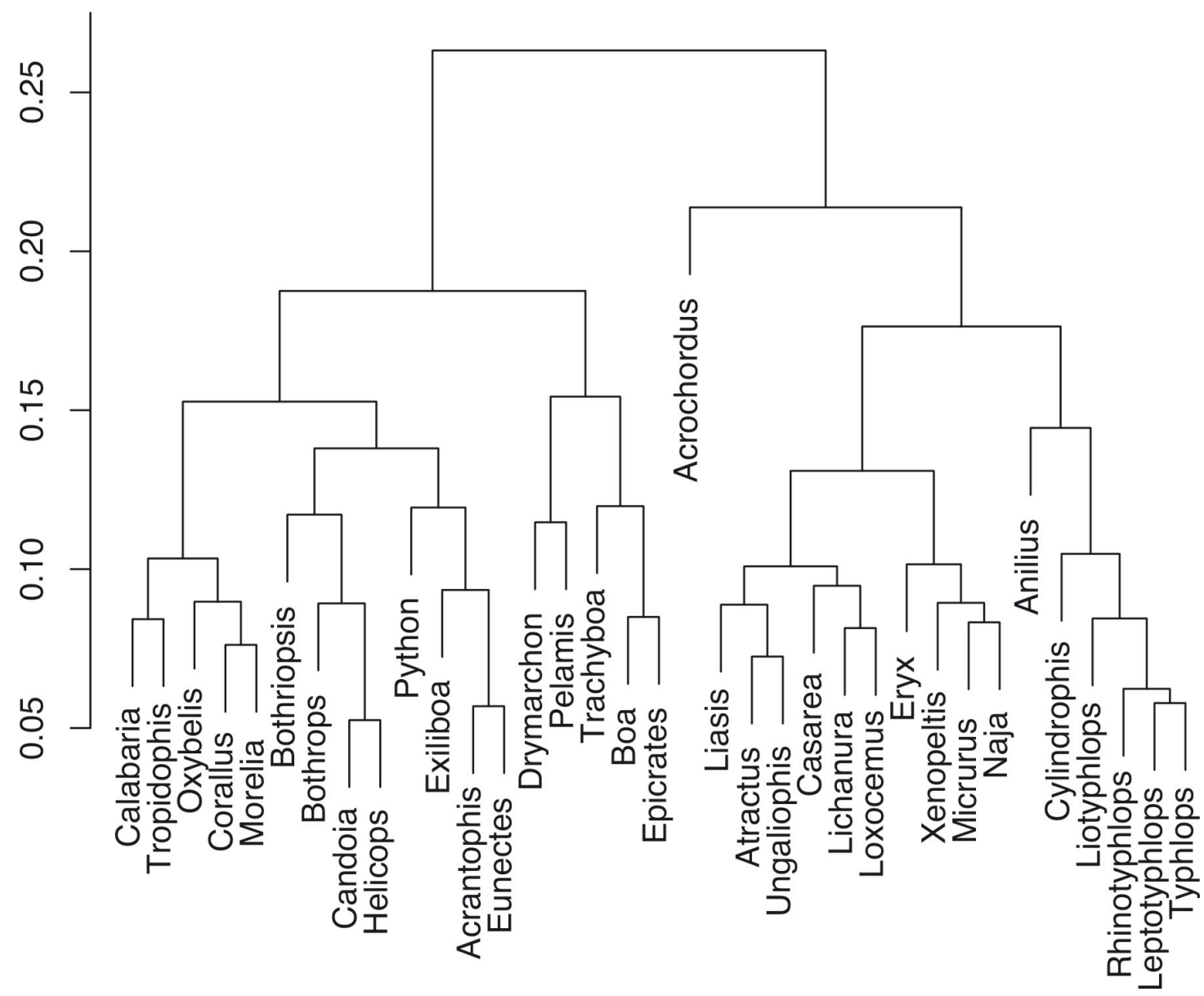

Figura 3.13. UPGMA sobre as distâncias de Procrustes das formas médias referentes à vista posterior. 


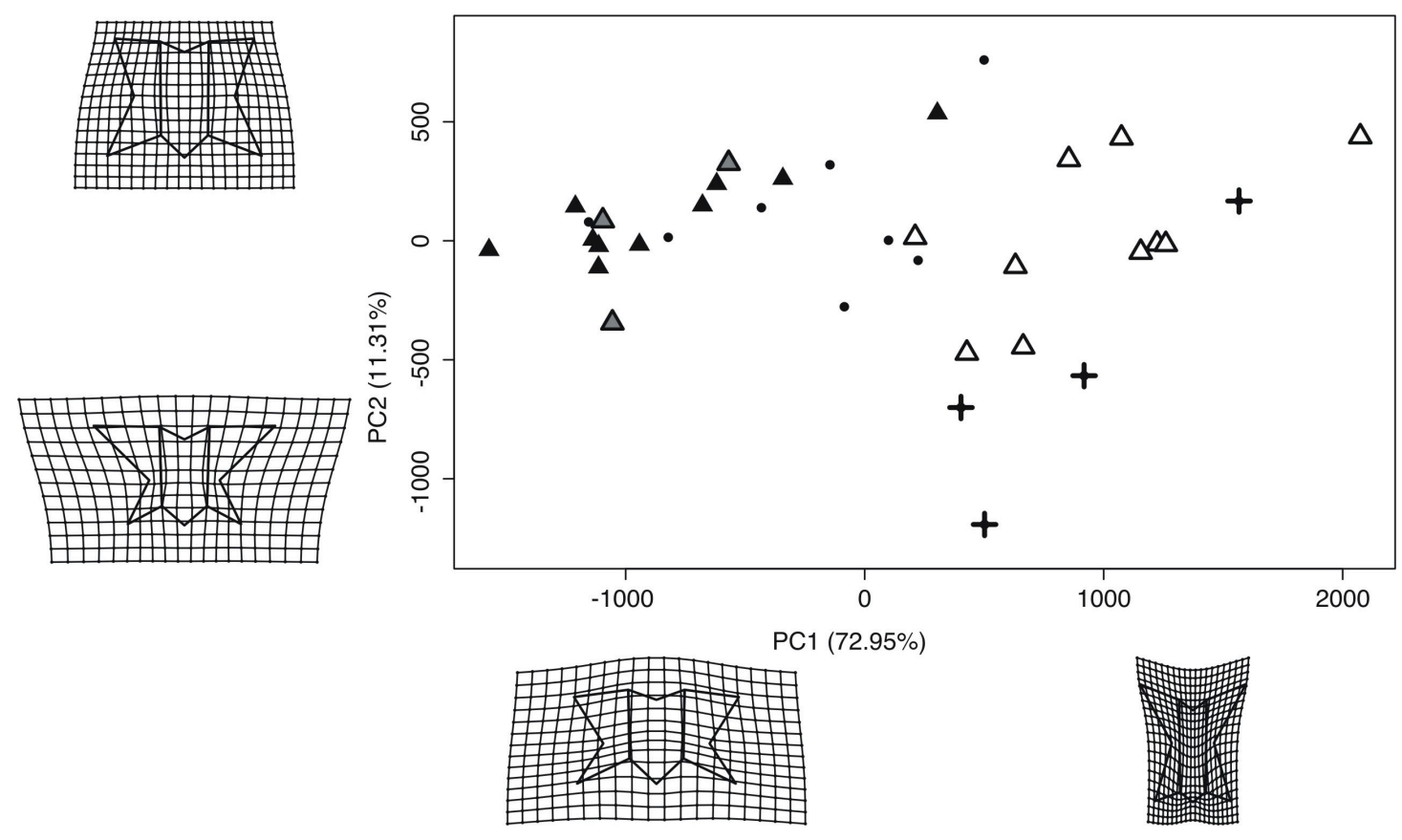

Figura 3.14. Análise de componentes principais dos resíduos de Procrustes das formas médias da vista ventral, mostrando a variação resumida pelos dois primeiros componentes. A variação referente a cada eixo está representada através de splines, mostrando a deformação da forma média aos extremos dos componentes. Ver texto para descrição. Cruzes $=$ Scolecophidia; triângulos escuros $=$ Boidae; triângulos cinza $=$ Pythonidae; triângulos claros $=$ Caenophidia; pontos $=$ demais clados . 


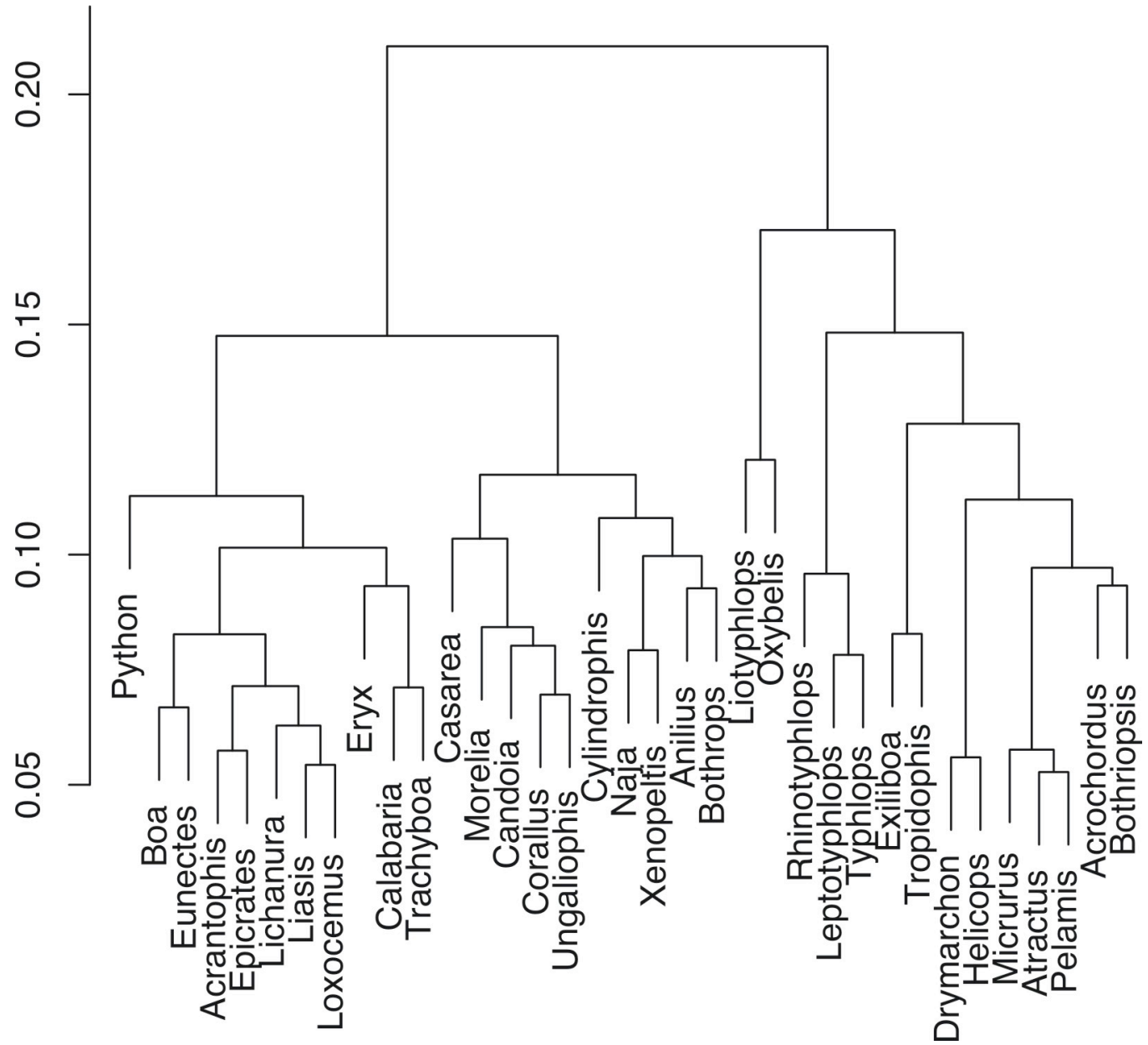

Figura 3.15. UPGMA sobre as distâncias de Procrustes das formas médias referentes à vista ventral. 
A tabela 3.2 apresenta o resumo das estatísticas para os diversos modelos ecomorfológicos. A tabela 3.3 apresenta o resumo dos "Likelihood-ratio tests", indicando os modelos escolhidos.

Tanto em vista anterior quanto lateral, o modelo preferido foi o que indicou a presença de três grupos: um grupo fossorial, um grupo constritor e um grupo que não pertence a nenhuma dessas categorias (Modelo 3). Em vista ventral, o modelo com menor $\mathrm{AIC}_{\mathrm{c}}$ também indica a presença de TRÊS grupos distintos, porém esse modelo não parece ser mais corroborado pela evidência do que o modelo que identifica apenas a presença de um grupo fossorial (Modelo 1) (Tabela 3.3). Nesse caso, o modelo preferido é o modelo mais simples, pois não introduz parâmetros desnecessários para avaliar a variação morfológica dentro da amostra. A vista ventral foi a única que discriminou os animais constritores dos demais (Modelo 2). O modelo nulo foi rejeitado em todas as análises (Tabela 3.3).

$\mathrm{Na}$ vista anterior (Figura 3.16), as formas fossoriais apresentam uma tendência para o achatamento dorso-ventral da vértebra, apresentando cótilos elipsóides, sinapófises mais lateralmente orientadas, processos acessórios desenvolvidos e pré-zigapófises mais anguladas. As formas constritoras apresentam sinapófises ventralmente orientadas, cótilo largo e redondo, zigósfeno levemente mais alto, apresentando processos acessórios menos desenvolvidos. A vértebra do grupo não-constritor e não-fossorial apresenta forma mosaica, com sinapófises levemente mais orientadas ventralmente que nos constritores, assim como pré-zigapófises com processos acessórios desenvolvidos e com uma menor angulatura.

Em vista lateral (Figura 3.17), o grupo constritor apresenta vértebras altas com espinhos neurais relativamente desenvolvidos, porém ântero- 
posteriormente curtos. As formas fossoriais, por sua vez, apresentam elementos vertebrais deprimidos, sem espinho neural evidente ou hipapófise visível. O grupo não-constritor e não-fossorial apresenta hipapófise desenvolvida e espinho neural ântero-posteriormente longo, porém relativamente baixo.

Em vista posterior (figura 3.18), os grupos fossoriais destacam-se pela tendência a uma redução da altura do espinho neural, leve achatamento dorsal do arco neural e redução da hipapófise. Já os não-fossoriais apresentam arcos neurais arqueados, espinhos altos e hipapófise desenvolvida.

Em vista ventral (figura 3.19), nota-se a distinção entre grupos nãoconstritores com vértebras com centro vertebral relativamente pequeno e zigapófises mais expandidas e anguladas; e um grupos constritor, que apresenta uma vértebra larga e robusta, com centros vertebrais maiores e com articulações zigapofiseais menos proeminentes. 
Tabela 3.2. Estatísticas dos modelos ecomorfológicos (ver tabela 2.1 para detalhe dos modelos). $\mathbf{A I C}_{\mathbf{c}}-$ critério de informação de Akaike de segunda ordem. $\mathbf{\Delta} \mathbf{A I C}_{\mathbf{c}}-$ diferença entre o $\mathbf{A} \mathbf{I C}_{\mathbf{c}}$ do modelo e o do melhor modelo. L'- verossimilhança reescalonada.

\begin{tabular}{|c|c|c|c|c|}
\hline Vista & Modelo & $\mathrm{AIC}_{\mathrm{c}}$ & DAICc & $\mathbf{L}^{\prime}$ \\
\hline \multirow{4}{*}{ Anterior } & Modelo nulo & 367.295 & 39.416 & $2.76 \mathrm{E}-09$ \\
\hline & Modelo 1 & 353.117 & 25.238 & $3.31 \mathrm{E}-06$ \\
\hline & Modelo 2 & 336.711 & 8.832 & 0.012 \\
\hline & Modelo 3 & 327.879 & 0 & 1 \\
\hline \multirow{4}{*}{ Lateral } & Modelo nulo & 845.195 & 41.045 & $1.22 \mathrm{E}-09$ \\
\hline & Modelo 1 & 820.802 & 16.653 & $2.42 \mathrm{E}-04$ \\
\hline & Modelo 2 & 818.611 & 14.462 & $7.24 \mathrm{E}-04$ \\
\hline & Modelo 3 & 804.150 & 0 & 1 \\
\hline \multirow{4}{*}{ Posterior } & Modelo nulo & 547.466 & 20.051 & $4.43 \mathrm{E}-05$ \\
\hline & Modelo 1 & 527.442 & 0.0273 & 0.986 \\
\hline & Modelo 2 & 540.486 & 13.071 & 0.002 \\
\hline & Modelo 3 & 527.415 & 0 & 1 \\
\hline \multirow{4}{*}{ Ventral } & Modelo nulo & 2304.623 & 43.920 & $2.90 \mathrm{E}-10$ \\
\hline & Modelo 1 & 2305.833 & 45.131 & $1.58 \mathrm{E}-10$ \\
\hline & Modelo 2 & 2260.703 & 0 & 1 \\
\hline & Modelo 3 & 3339.548 & 1078.845 & $5.39 \mathrm{E}-235$ \\
\hline
\end{tabular}


Tabela 3.3. Testes do tipo "likelihood-ratio test" de todos os modelos ecomorfológicos de forma par-a-par (Modelo na Linha/Modelo na Coluna). Valores em negrito indicam razões superiores a 8 , evidenciando forte corroboração do modelo no numerador. Asteriscos indicam modelos escolhidos seguindo critérios de corroboração (definidos pelo teste) e parcimônia (menor numero de parâmetros).

\begin{tabular}{|c|c|c|c|c|c|}
\hline Vista & & $\begin{array}{l}\text { Modelo } \\
\text { nulo }\end{array}$ & Modelo 1 & Modelo 2 & Modelo 3 \\
\hline \multirow{4}{*}{ Anterior } & $\begin{array}{l}\text { Modelo } \\
\text { nulo }\end{array}$ & - & 8.34E-04 & $2.28 \mathrm{E}-07$ & 2.76E-09 \\
\hline & Modelo 1 & 1198.853 & - & $2.74 \mathrm{E}-04$ & $3.31 \mathrm{E}-06$ \\
\hline & Modelo 2 & $4.377 \mathrm{E}+06$ & $3.651 \mathrm{E}+03$ & - & 0.012 \\
\hline & Modelo 3* & $3.623 E+08$ & $3.022 \mathrm{E}+05$ & 82.764 & - \\
\hline \multirow{4}{*}{ Lateral } & $\begin{array}{l}\text { Modelo } \\
\text { nulo }\end{array}$ & - & $5.05 \mathrm{E}-06$ & $1.69 \mathrm{E}-06$ & 1.22E-09 \\
\hline & Modelo 1 & $1.980 \mathrm{E}+05$ & - & 0.334 & $2.42 \mathrm{E}-04$ \\
\hline & Modelo 2 & $5.923 E+05$ & 2.91 & - & 7.24E-04 \\
\hline & Modelo 3* & 8.181E+08 & 4130.919 & 1381.271 & - \\
\hline \multirow{4}{*}{ Posterior } & $\begin{array}{l}\text { Modelo } \\
\text { nulo }\end{array}$ & - & 4.49E-05 & 0.0305 & 4.43E-05 \\
\hline & Modelo $1^{*}$ & $2.229 \mathrm{E}+04$ & - & 679.847 & 0.986 \\
\hline & Modelo 2 & 32.783 & 0.002 & - & 0.001 \\
\hline & Modelo 3 & $2.259 \mathrm{E}+04$ & 1.014 & 689.186 & - \\
\hline \multirow{4}{*}{ Ventral } & $\begin{array}{l}\text { Modelo } \\
\text { nulo }\end{array}$ & - & 1.832 & $2.90 \mathrm{E}-10$ & $5.38 \mathrm{E}+224$ \\
\hline & Modelo 1 & 0.546 & - & $1.58 \mathrm{E}-10$ & $2.94 \mathrm{E}+224$ \\
\hline & Modelo 2* & $3.445 \mathrm{E}+09$ & $6.310 \mathrm{E}+09$ & - & $1.85 \mathrm{E}+234$ \\
\hline & Modelo 3 & $1.86 \mathrm{E}-225$ & $3.40 \mathrm{E}-225$ & $5.39 \mathrm{E}-235$ & - \\
\hline
\end{tabular}



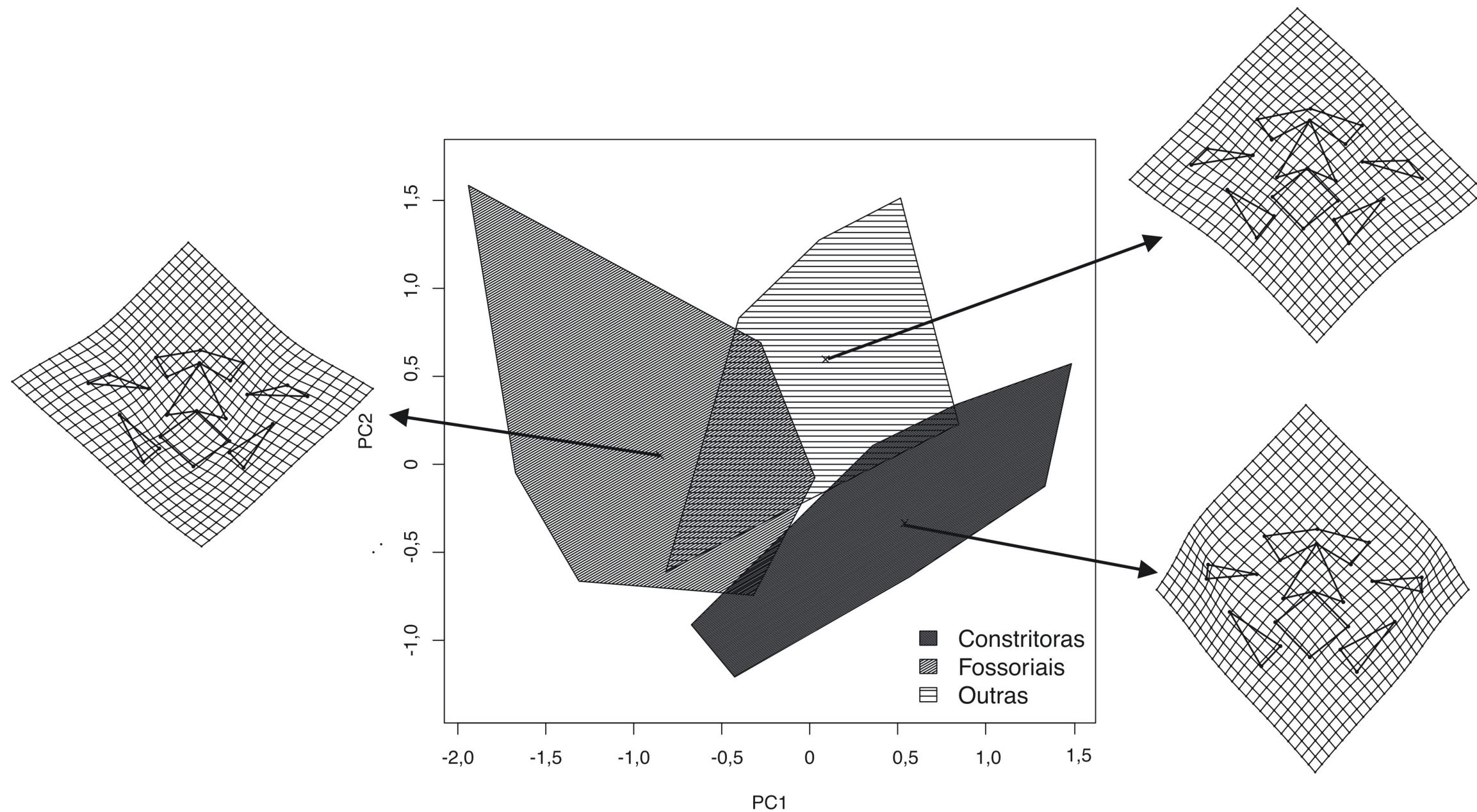

Figura 3.16. Representação gráfica dos parâmetros dos melhores modelos ecomorfológicos para a vista anterior. Os polígonos convexos amostram todas as observações de cada grupo. Splines indicam a deformação da forma média global para a forma média dos grupos estimados por verossimilhança para os 2 componentes principais avaliados. 


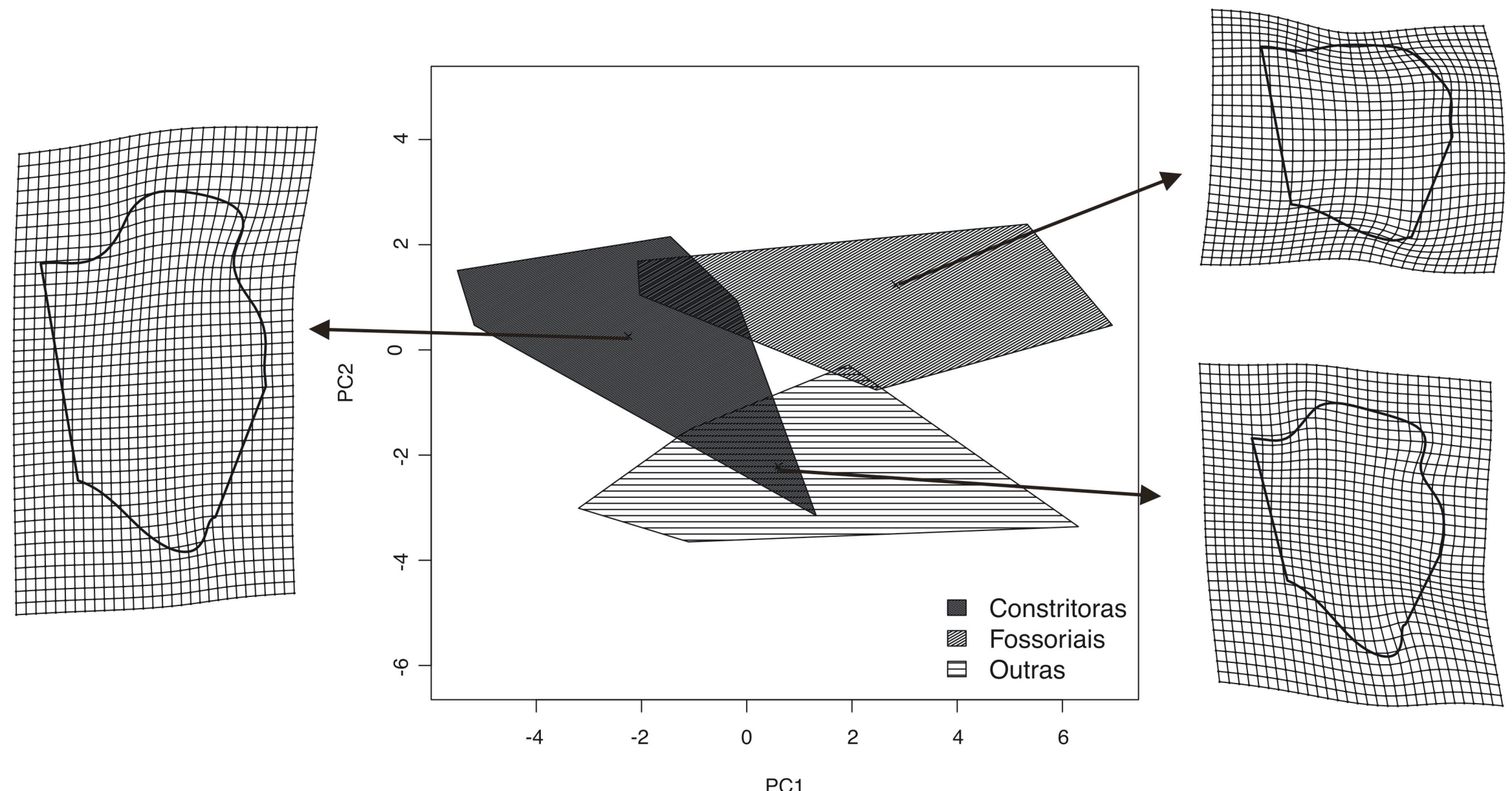

Figura 3.17. Representação gráfica dos parâmetros dos melhores modelos ecomorfológicos para a vista lateral. Os polígonos convexos amostram todas as observações de cada grupo. Splines indicam a deformação da forma média global para a forma média dos grupos estimados por verossimilhança para os 2 componentes principais avaliados. 

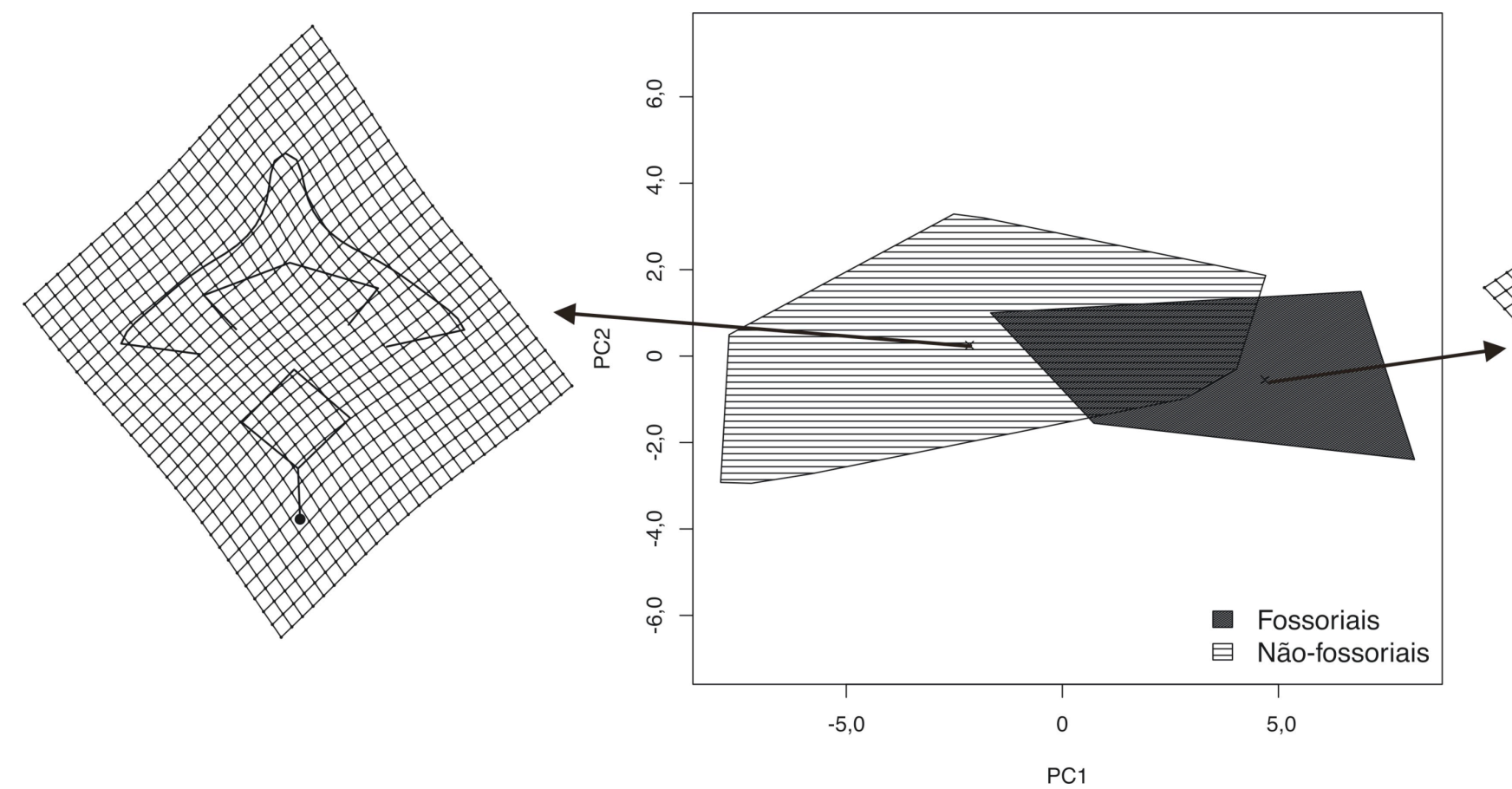

Figura 3.18. Representação gráfica dos parâmetros dos melhores modelos ecomorfológicos para a vista posterior. Os polígonos convexos amostram todas as observações de cada grupo. Splines indicam a deformação da forma média global para a forma média dos grupos estimados por verossimilhança para os 2 componentes principais avaliados. 


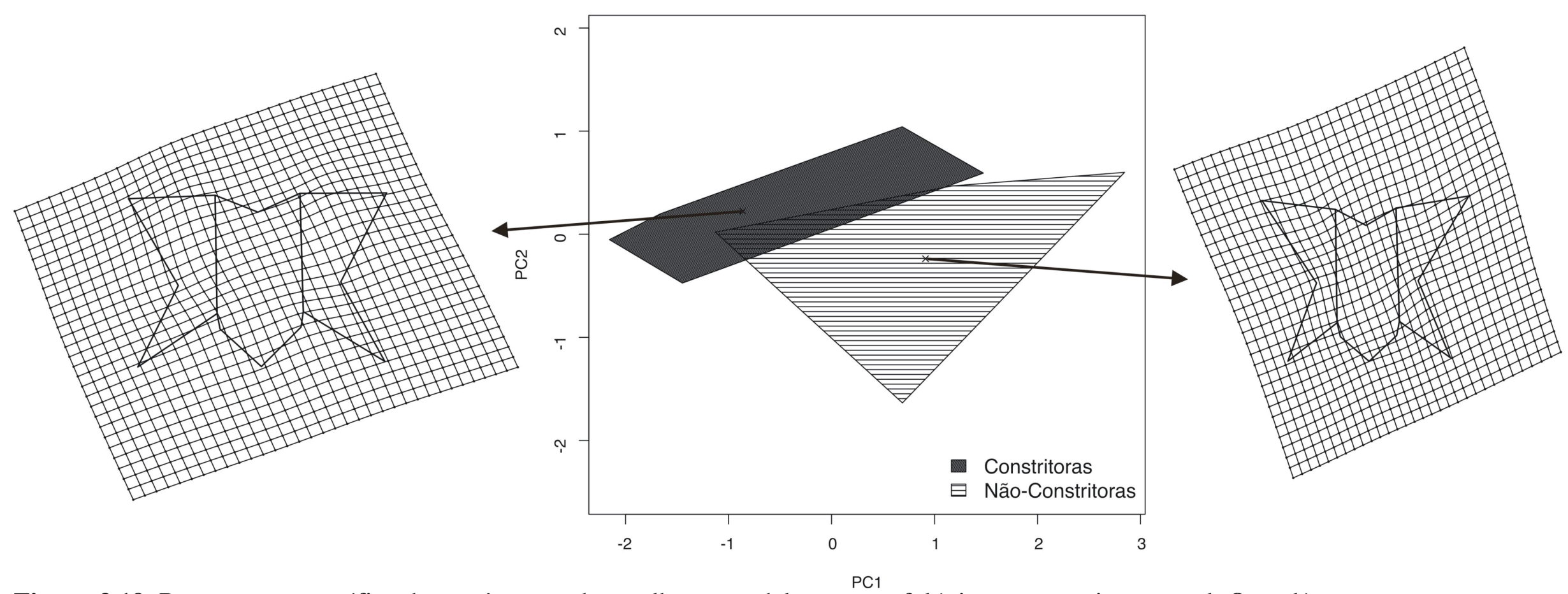

Figura 3.19. Representação gráfica dos parâmetros dos melhores modelos ecomorfológicos para a vista ventral. Os polígonos convexos amostram todas as observações de cada grupo. Splines indicam a deformação da forma média global para a forma média dos grupos estimados por verossimilhança para os 2 componentes principais avaliados. 


\subsection{Discriminação e Classificação}

Os resultados dos testes de validação cruzada no protocolo de Função Linear Discriminante (FLD) apresentaram índices relativamente baixos de classificação correta (Tabela 3.4). A vista ventral foi a que se classificou corretamente menos vezes, apresentando valores inferiores a $60 \%$, seguida pela vista lateral, apresentou um índice de classificação correta de $61 \%$. As vistas posteriores e anteriores foram as que apresentaram os índices de classificação mais elevados, com $73 \%$ e $71 \%$ das vértebras sendo corretamente classificadas, respectivamente, para identificar as vértebras que qualquer uma das outras vistas.

No protocolo por máxima-verossimilhança (Tabela 3.5), os valores de classificação se mostraram superiores, com a vista posterior sendo a melhor classificada, com $83 \%$ de classificações corretas, seguida da vista a vista anterior, com $82 \%$ de classificações corretas. As vistas laterais e ventrais ainda apresentam índices relativamente baixos de classificação correta em relação às duas primeiras vistas. Porém, esses índices são claramente superiores àqueles presentes no protocolo de FLD: 73\% e $61 \%$, respectivamente.

O protocolo de classificação por mínima distância de Procrustes (Tabela 3.6) demonstrou ser o melhor protocolo de classificação. A vista anterior foi a melhor classificada, apresentando cerca de $88 \%$ de classificações corretas. É seguida pela vista posterior, com $85 \%$ e pela vista lateral, com $82 \%$ de classificações corretas. A vista ventral foi a única que não apresentou classificação inferior a 80\%, apresentando apenas $66 \%$ de classificações corretas.

Segundo a análise de integração e padrão de variação longitudinal, as primeiras e últimas porções do corpo dos animais apresentam formas que 
não seguem o mesmo padrão de variação relativamente linear presente nas outras porções, e também apresentam vértebras com formas mais dissimilares em relação às outras. De fato esta região parece apresentar chances de classificação corretas proporcionalmente baixas no protocolo por verossimilhança e por distância de Procrustes, mas não na FLD (figuras 3.20-22). Para avaliar se esse padrão pode influenciar negativamente o índice de classificações corretas, os três protocolos de classificação foram repetidos para toda a amostra, exceto para as vértebras referentes às posições mais caudais e craniais de cada animal.

Os resultados dessas análises indicam que há uma melhora proporcional nos índices de classificação frente à remoção da primeira e das últimas vértebras (Tabelas 3.7-9). No protocolo por FLD as vistas anterior, lateral, posterior e ventral apresentaram índices de classificação corretas iguais a $85 \%, 76 \%, 83 \%$ e $67 \%$, respectivamente. No protocolo por máxima-verossimilhança os índices foram de 90\%, $87 \%, 92 \%$ e $60 \%$ para as vistas anterior, lateral, posterior e ventral, respectivamente. $\mathrm{O}$ protocolo por mínima distância de Procrustes apresentou a mais notável melhora, apresentando índices de 96\%, 91, 93\% e 74\% para as vistas anterior, lateral, posterior e ventral, respectivamente. É importante notar ainda que, com a remoção da primeira e segunda vértebras, grande parte das espécies nas análises apresentou índices individuais de quase 100\% de classificação em alguma de suas vistas, se não em mais de uma. 
Tabela 3.4. Proporções de vértebras referentes a cada espécie, que foram corretamente classificadas segundo o protocolo de classificação por função linear discriminante realizado sobre todas as vértebras.

\begin{tabular}{ccccc} 
& Anterior & Lateral & Posterior & Ventral \\
\hline Acrantophis & 0.8667 & 0.5333 & 0.6000 & 0.2667 \\
Acrochordus & 1.0000 & 0.9333 & 0.9333 & 0.6000 \\
Anilius & 0.5333 & 0.4000 & 0.8667 & 0.4667 \\
Atractus & 0.8000 & 0.8000 & 0.6667 & 0.6000 \\
Boa & 0.7333 & 0.8000 & 0.6000 & 0.0000 \\
Bothriopsis & 0.7333 & 0.8000 & 0.6667 & 0.7333 \\
Bothrops & 0.4000 & 0.6667 & 0.6000 & 0.9333 \\
Calabaria & 0.6000 & 0.5333 & 0.7333 & 0.8667 \\
Candoia & 0.6667 & 0.4000 & 0.6000 & 0.6667 \\
Casarea & 0.7333 & 0.6667 & 0.8000 & 0.6667 \\
Corallus & 0.8000 & 0.6000 & 0.9333 & 0.3333 \\
Cylindrophis & 0.6667 & 0.6000 & 0.8667 & 0.6000 \\
Drymarchon & 0.8000 & 0.6667 & 0.9333 & 0.7333 \\
Epicrates & 0.5333 & 0.8667 & 0.8667 & 0.1333 \\
Eryx & 0.7333 & 0.4000 & 0.5333 & 0.5333 \\
Eunectes & 0.4667 & 0.5333 & 0.4667 & 0.4000 \\
Exiliboa & 0.5333 & 0.6000 & 0.8000 & 0.9333 \\
Helicops & 0.8000 & 0.9333 & 0.8000 & 0.3333 \\
Leptotyphlops & 0.7333 & 0.2667 & 0.6000 & 0.6667 \\
Liasis & 0.6667 & 0.2667 & 0.9333 & 0.2000 \\
Lichanura & 0.6667 & 0.5333 & 0.8000 & 0.1333 \\
Liotyphlops & 0.7333 & 0.6667 & 0.7333 & 0.8000 \\
Loxocemus & 0.6667 & 0.5333 & 0.7333 & 0.1333 \\
Micrurus & 0.8000 & 0.8000 & 1.0000 & 0.7333 \\
Morelia & 0.8000 & 0.3333 & 0.5333 & 0.2667 \\
Naja & 0.4000 & 0.7333 & 0.5333 & 0.4667 \\
Oxybelis & 0.8667 & 1.0000 & 0.8000 & 0.9333 \\
Pelamis & 0.8000 & 0.8667 & 0.7333 & 0.4000 \\
Python & 0.8000 & 0.0667 & 0.4667 & 0.8000 \\
Rhinotyphlops & 0.8667 & 0.4000 & 0.6000 & 0.6667 \\
Trachyboa & 0.8667 & 0.9333 & 0.8667 & 0.6000 \\
Tropidophis & 0.8000 & 0.8667 & 0.9333 & 0.9333 \\
Typhlops & 0.8667 & 0.6000 & 0.4667 & 0.8667 \\
Ungaliophis & 0.5333 & 0.4000 & 0.8667 & 0.5333 \\
Xenopeltis & 0.4667 & 0.3333 & 0.6000 & 0.3333 \\
\hline TOTAL & $\mathbf{0 . 7 1}$ & $\mathbf{0 . 6 1}$ & $\mathbf{0 . 7 3}$ & $\mathbf{0 . 5 5}$
\end{tabular}


Tabela 3.5. Proporções de vértebras referentes a cada espécie, que foram corretamente classificadas segundo o protocolo de classificação por verossimilhança realizada sobre todas as vértebras.

\begin{tabular}{|c|c|c|c|c|}
\hline & Anterior & Lateral & Posterior & Ventral \\
\hline Acrantophis & 0.8667 & 0.4667 & 0.8667 & 0.5333 \\
\hline Acrochordus & 0.9333 & 0.9333 & 0.8667 & 0.8667 \\
\hline Anilius & 0.8667 & 0.5333 & 0.8667 & 0.8000 \\
\hline Atractus & 0.9333 & 0.8667 & 0.9333 & 0.6667 \\
\hline Boa & 0.8000 & 0.8667 & 0.8667 & 0.6667 \\
\hline Bothriopsis & 0.9333 & 0.9333 & 0.7333 & 0.8667 \\
\hline Bothrops & 0.8000 & 0.8667 & 0.8000 & 0.4667 \\
\hline Calabaria & 0.8000 & 0.6667 & 0.6667 & 0.4000 \\
\hline Candoia & 0.8000 & 0.6667 & 0.8667 & 0.6667 \\
\hline Casarea & 0.4667 & 0.8667 & 1.0000 & 0.4667 \\
\hline Corallus & 0.8667 & 0.8667 & 0.8667 & 0.6000 \\
\hline Cylindrophis & 0.8667 & 0.8667 & 0.8667 & 0.8667 \\
\hline Drymarchon & 0.8667 & 0.6000 & 0.8667 & 0.7333 \\
\hline Epicrates & 0.7333 & 0.8000 & 0.8000 & 0.4667 \\
\hline Eryx & 0.8667 & 0.4667 & 0.9333 & 0.7333 \\
\hline Eunectes & 0.8000 & 0.6667 & 0.8000 & 0.0667 \\
\hline Exiliboa & 0.7333 & 0.7333 & 0.9333 & 0.7333 \\
\hline Helicops & 1.0000 & 0.7333 & 0.7333 & 0.7333 \\
\hline Leptotyphlops & 0.9333 & 0.4667 & 0.6667 & 0.8000 \\
\hline Liasis & 0.8667 & 0.5333 & 0.7333 & 0.1333 \\
\hline Lichanura & 0.4667 & 0.8667 & 0.6667 & 0.3333 \\
\hline Liotyphlops & 0.9333 & 0.8667 & 0.9333 & 0.8000 \\
\hline Loxocemus & 0.6667 & 0.6000 & 0.8000 & 0.3333 \\
\hline Micrurus & 0.9333 & 0.7333 & 0.8667 & 0.6667 \\
\hline Morelia & 0.7333 & 0.7333 & 0.8667 & 0.6667 \\
\hline Naja & 0.8000 & 0.7333 & 0.8667 & 0.7333 \\
\hline Oxybelis & 1.0000 & 0.9333 & 0.9333 & 0.7333 \\
\hline Pelamis & 0.8667 & 0.8667 & 0.8667 & 0.8000 \\
\hline Python & 0.8000 & 0.7333 & 0.8000 & 0.8667 \\
\hline Rhinotyphlops & 0.8000 & 0.2000 & 0.5333 & 0.6000 \\
\hline Trachyboa & 0.9333 & 0.7333 & 0.9333 & 0.8000 \\
\hline Tropidophis & 0.8667 & 0.8667 & 0.6667 & 0.6667 \\
\hline Typhlops & 0.8667 & 0.8000 & 0.8667 & 0.7333 \\
\hline Ungaliophis & 0.8667 & 0.7333 & 0.8667 & 0.2000 \\
\hline Xenopeltis & 0.6000 & 0.6667 & 0.9333 & 0.2667 \\
\hline$T O T A L$ & 0.82 & 0.73 & 0.83 & 0.61 \\
\hline
\end{tabular}


Tabela 3.6. Proporções de vértebras referentes a cada espécie, que foram corretamente classificadas segundo o protocolo de classificação por distância de Procrustes realizado sobre todas as vértebras.

\begin{tabular}{ccccc} 
& Anterior & Lateral & Posterior & Ventral \\
\hline Acrantophis & 0.9333 & 0.7333 & 0.8000 & 0.5333 \\
Acrochordus & 0.9333 & 0.9333 & 0.9333 & 0.8000 \\
Anilius & 0.9333 & 0.6667 & 0.8000 & 0.8000 \\
Atractus & 0.9333 & 0.8000 & 0.7333 & 0.3333 \\
Boa & 0.8000 & 0.8667 & 0.8000 & 0.4667 \\
Bothriopsis & 0.8000 & 0.8000 & 0.7333 & 0.4667 \\
Bothrops & 0.9333 & 0.9333 & 0.8667 & 0.9333 \\
Calabaria & 0.8667 & 0.8667 & 0.8000 & 0.9333 \\
Candoia & 0.8667 & 0.6667 & 0.6667 & 0.6000 \\
Casarea & 0.9333 & 0.8000 & 0.8667 & 0.4667 \\
Corallus & 0.8000 & 0.8667 & 0.8000 & 0.6667 \\
Cylindrophis & 0.8667 & 0.8667 & 0.8667 & 0.6667 \\
Drymarchon & 0.9333 & 0.8000 & 0.8667 & 0.9333 \\
Epicrates & 0.8000 & 0.8667 & 0.8667 & 0.4667 \\
Eryx & 0.8667 & 0.9333 & 0.7333 & 0.4667 \\
Eunectes & 0.8667 & 0.8000 & 0.8667 & 0.4000 \\
Exiliboa & 0.9333 & 0.8000 & 0.8667 & 0.6667 \\
Helicops & 0.8667 & 1.0000 & 0.9333 & 0.7333 \\
Leptotyphlops & 0.9333 & 0.8000 & 0.8000 & 0.8000 \\
Liasis & 0.9333 & 0.8667 & 0.9333 & 0.7333 \\
Lichanura & 0.7333 & 0.8667 & 0.9333 & 0.6667 \\
Liotyphlops & 0.8000 & 0.6000 & 0.8000 & 0.6000 \\
Loxocemus & 0.9333 & 0.5333 & 0.9333 & 0.5333 \\
Micrurus & 0.9333 & 0.8000 & 0.9333 & 0.6667 \\
Morelia & 0.8667 & 0.8667 & 0.7333 & 0.8000 \\
Naja & 0.8667 & 0.8000 & 0.9333 & 0.4667 \\
Oxybelis & 1.0000 & 1.0000 & 1.0000 & 0.8667 \\
Pelamis & 0.8000 & 0.9333 & 0.8000 & 0.7333 \\
Python & 0.7333 & 0.6667 & 0.8000 & 0.6667 \\
Rhinotyphlops & 1.0000 & 0.6667 & 0.8667 & 0.6000 \\
Trachyboa & 0.9333 & 0.9333 & 0.9333 & 0.8000 \\
Tropidophis & 0.8667 & 0.9333 & 0.9333 & 0.8667 \\
Typhlops & 0.8667 & 0.8667 & 0.8000 & 0.8667 \\
Ungaliophis & 0.8000 & 0.7333 & 0.8667 & 0.6667 \\
Xenopeltis & 1.0000 & 0.8667 & 0.9333 & 0.6000 \\
\hline TOTAL & $\mathbf{0 . 8 8}$ & $\mathbf{0 . 8 2}$ & $\mathbf{0 . 8 5}$ & $\mathbf{0 . 6 6}$
\end{tabular}


Tabela 3.7. Proporções de vértebras referentes a cada espécie, que foram corretamente classificadas segundo o protocolo de classificação por função linear discriminante realizado sobre as vértebras da região média do tronco.

\begin{tabular}{ccccc} 
& Anterior & Lateral & Posterior & Ventral \\
\hline Acrantophis & 0.9231 & 0.6923 & 0.6923 & 0.3077 \\
Acrochordus & 1.0000 & 1.0000 & 1.0000 & 0.6923 \\
Anilius & 0.5385 & 0.6154 & 1.0000 & 0.7692 \\
Atractus & 0.8462 & 0.9231 & 0.7692 & 0.7692 \\
Boa & 0.8462 & 0.7692 & 0.8462 & 0.0769 \\
Bothriopsis & 0.6923 & 0.9231 & 0.7692 & 0.8462 \\
Bothrops & 0.5385 & 0.8462 & 0.7692 & 1.0000 \\
Calabaria & 0.7692 & 0.6923 & 0.8462 & 0.9231 \\
Candoia & 1.0000 & 0.9231 & 0.6923 & 0.7692 \\
Casarea & 1.0000 & 0.8462 & 0.9231 & 0.8462 \\
Corallus & 1.0000 & 0.7692 & 1.0000 & 0.3077 \\
Cylindrophis & 0.9231 & 0.6923 & 0.9231 & 1.0000 \\
Drymarchon & 1.0000 & 0.7692 & 1.0000 & 0.8462 \\
Epicrates & 0.8462 & 0.9231 & 1.0000 & 0.3846 \\
Eryx & 0.8462 & 0.4615 & 0.3846 & 0.6923 \\
Eunectes & 0.8462 & 0.8462 & 0.6154 & 0.3077 \\
Exiliboa & 0.7692 & 0.6923 & 1.0000 & 1.0000 \\
Helicops & 0.8462 & 1.0000 & 0.8462 & 0.6154 \\
Leptotyphlops & 0.8462 & 0.3846 & 0.7692 & 0.8462 \\
Liasis & 0.9231 & 0.6923 & 1.0000 & 0.3846 \\
Lichanura & 0.7692 & 0.6923 & 0.8462 & 0.5385 \\
Liotyphlops & 0.7692 & 0.7692 & 0.7692 & 0.9231 \\
Loxocemus & 0.6923 & 0.5385 & 0.7692 & 0.0000 \\
Micrurus & 1.0000 & 0.8462 & 1.0000 & 0.7692 \\
Morelia & 0.8462 & 0.3077 & 0.9231 & 0.5385 \\
Naja & 0.6923 & 0.8462 & 0.6923 & 0.5385 \\
Oxybelis & 0.8462 & 1.0000 & 0.8462 & 1.0000 \\
Pelamis & 0.9231 & 0.9231 & 0.7692 & 0.3846 \\
Python & 0.9231 & 0.3077 & 0.5385 & 0.9231 \\
Rhinotyphlops & 1.0000 & 0.5385 & 0.8462 & 0.6923 \\
Trachyboa & 1.0000 & 1.0000 & 0.9231 & 0.6154 \\
Tropidophis & 0.9231 & 0.9231 & 1.0000 & 1.0000 \\
Typhlops & 0.9231 & 1.0000 & 0.6923 & 0.9231 \\
Ungaliophis & 0.8462 & 0.7692 & 0.9231 & 0.8462 \\
Xenopeltis & 0.7692 & 0.6154 & 0.7692 & 0.5385 \\
\hline TOTAL & $\mathbf{0 . 8 5}$ & $\mathbf{0 . 7 6}$ & $\mathbf{0 . 8 3}$ & $\mathbf{0 . 6 7}$
\end{tabular}


Tabela 3.8. Proporções de vértebras referentes a cada espécie, que foram corretamente classificadas segundo o protocolo de classificação por verossimilhança realizado sobre as vértebras da região média do tronco.

\begin{tabular}{|c|c|c|c|c|}
\hline & Anterior & Lateral & Posterior & Ventral \\
\hline Acrantophis & 0.9231 & 0.7692 & 1.0000 & 0.3846 \\
\hline Acrochordus & 1.0000 & 1.0000 & 0.9231 & 0.7692 \\
\hline Anilius & 1.0000 & 0.5385 & 1.0000 & 0.9231 \\
\hline Atractus & 1.0000 & 1.0000 & 0.9231 & 0.8462 \\
\hline Boa & 1.0000 & 1.0000 & 1.0000 & 0.4615 \\
\hline Bothriopsis & 1.0000 & 0.9231 & 0.9231 & 0.8462 \\
\hline Bothrops & 1.0000 & 0.9231 & 0.8462 & 0.6923 \\
\hline Calabaria & 0.8462 & 1.0000 & 0.8462 & 0.5385 \\
\hline Candoia & 0.8462 & 1.0000 & 0.9231 & 0.4615 \\
\hline Casarea & 0.8462 & 1.0000 & 0.9231 & 1.0000 \\
\hline Corallus & 0.7692 & 0.9231 & 1.0000 & 0.6154 \\
\hline Cylindrophis & 1.0000 & 0.8462 & 0.8462 & 0.7692 \\
\hline Drymarchon & 1.0000 & 0.8462 & 1.0000 & 0.6923 \\
\hline Epicrates & 0.9231 & 0.9231 & 0.9231 & 0.0769 \\
\hline Eryx & 0.8462 & 0.9231 & 1.0000 & 0.6154 \\
\hline Eunectes & 0.9231 & 0.6923 & 0.9231 & 0.0000 \\
\hline Exiliboa & 0.9231 & 0.9231 & 1.0000 & 0.6154 \\
\hline Helicops & 0.9231 & 0.9231 & 0.7692 & 0.4615 \\
\hline Leptotyphlops & 1.0000 & 0.7692 & 0.7692 & 0.8462 \\
\hline Liasis & 1.0000 & 0.8462 & 0.9231 & 0.3846 \\
\hline Lichanura & 0.6923 & 0.9231 & 0.9231 & 0.6923 \\
\hline Liotyphlops & 1.0000 & 0.8462 & 0.9231 & 0.9231 \\
\hline Loxocemus & 0.6923 & 0.8462 & 1.0000 & 0.2308 \\
\hline Micrurus & 0.9231 & 0.9231 & 1.0000 & 0.0000 \\
\hline Morelia & 0.9231 & 0.7692 & 1.0000 & 0.4615 \\
\hline Naja & 0.6154 & 0.8462 & 1.0000 & 0.0769 \\
\hline Oxybelis & 1.0000 & 1.0000 & 1.0000 & 0.8462 \\
\hline Pelamis & 0.9231 & 1.0000 & 0.8462 & 0.9231 \\
\hline Python & 0.9231 & 0.6923 & 0.8462 & 0.6154 \\
\hline Rhinotyphlops & 0.8462 & 0.0000 & 0.6154 & 0.5385 \\
\hline Trachyboa & 0.9231 & 1.0000 & 1.0000 & 0.8462 \\
\hline Tropidophis & 0.9231 & 1.0000 & 1.0000 & 0.8462 \\
\hline Typhlops & 0.8462 & 0.9231 & 0.8462 & 0.9231 \\
\hline Ungaliophis & 1.0000 & 1.0000 & 0.9231 & 0.6154 \\
\hline Xenopeltis & 0.6154 & 0.8462 & 0.8462 & 0.5385 \\
\hline TOTAL & 0.90 & 0.87 & 0.92 & 0.60 \\
\hline
\end{tabular}


Tabela 3.9. Proporções de vértebras referentes a cada espécie, que foram corretamente classificadas segundo o protocolo de classificação por distância de Procrustes realizado sobre as vértebras da região média do tronco.

\begin{tabular}{ccccc} 
& Anterior & Lateral & Posterior & Ventral \\
\hline Acrantophis & 1.0000 & 0.9231 & 0.9231 & 0.5385 \\
Acrochordus & 1.0000 & 1.0000 & 1.0000 & 0.8462 \\
Anilius & 1.0000 & 0.6923 & 0.9231 & 0.9231 \\
Atractus & 1.0000 & 0.9231 & 0.8462 & 0.3846 \\
Boa & 0.9231 & 1.0000 & 0.9231 & 0.5385 \\
Bothriopsis & 0.8462 & 0.8462 & 0.8462 & 0.6154 \\
Bothrops & 1.0000 & 1.0000 & 0.9231 & 1.0000 \\
Calabaria & 1.0000 & 1.0000 & 0.9231 & 1.0000 \\
Candoia & 0.9231 & 0.7692 & 0.7692 & 0.6923 \\
Casarea & 1.0000 & 1.0000 & 0.9231 & 0.5385 \\
Corallus & 0.9231 & 0.9231 & 0.9231 & 0.6923 \\
Cylindrophis & 1.0000 & 1.0000 & 1.0000 & 0.7692 \\
Drymarchon & 1.0000 & 0.8462 & 0.9231 & 1.0000 \\
Epicrates & 0.9231 & 1.0000 & 1.0000 & 0.5385 \\
Eryx & 0.9231 & 1.0000 & 0.7692 & 0.6154 \\
Eunectes & 0.9231 & 0.9231 & 0.9231 & 0.6154 \\
Exiliboa & 1.0000 & 0.9231 & 1.0000 & 0.8462 \\
Helicops & 0.9231 & 1.0000 & 0.9231 & 0.8462 \\
Leptotyphlops & 0.9231 & 0.8462 & 0.8462 & 0.9231 \\
Liasis & 1.0000 & 1.0000 & 1.0000 & 0.7692 \\
Lichanura & 0.8462 & 0.9231 & 1.0000 & 0.7692 \\
Liotyphlops & 0.8462 & 0.6923 & 0.8462 & 0.6923 \\
Loxocemus & 1.0000 & 0.6154 & 1.0000 & 0.5385 \\
Micrurus & 1.0000 & 0.9231 & 1.0000 & 0.7692 \\
Morelia & 1.0000 & 0.9231 & 0.9231 & 0.7692 \\
Naja & 1.0000 & 0.9231 & 1.0000 & 0.6154 \\
Oxybelis & 1.0000 & 1.0000 & 1.0000 & 0.8462 \\
Pelamis & 0.9231 & 1.0000 & 0.9231 & 0.6923 \\
Python & 0.8462 & 0.7692 & 0.8462 & 0.7692 \\
Rhinotyphlops & 1.0000 & 0.7692 & 0.8462 & 0.6154 \\
Trachyboa & 1.0000 & 1.0000 & 1.0000 & 0.8462 \\
Tropidophis & 0.9231 & 1.0000 & 1.0000 & 0.9231 \\
Typhlops & 0.9231 & 1.0000 & 0.8462 & 0.9231 \\
Ungaliophis & 0.9231 & 0.8462 & 1.0000 & 0.6923 \\
Xenopeltis & 1.0000 & 1.0000 & 1.0000 & 0.6923 \\
\hline TOTAL & $\mathbf{0 . 9 6}$ & $\mathbf{0 . 9 1}$ & $\mathbf{0 . 9 3}$ & $\mathbf{0 . 7 4}$
\end{tabular}


A análise por FLD utilizando todas as vértebras, apesar de apresentar uma baixa performance geral, parece distribuir as classificações corretas de forma igual ao longo do corpo do animal (Figura 3.20). Apesar disso, todas as vistas parecem apresentar um discreto decréscimo de classificações corretas na região da última vértebra. A análise por FLD excluindo a primeira e última vértebra, apesar de aumentar a performance do teste, diminui a homogeneidade de classificações corretas ao longo do corpo, concentrando a maioria delas na região entre a $5^{\mathrm{a}}$ posição e a $10^{\mathrm{a}}$ posição, estabelecendo duas porções onde o índice classificação correta é muito reduzido: a região da $2-5^{\mathrm{a}}$ vértebra e a região da $10-14^{\mathrm{a}}$ vértebra.

A análise por máxima verossimilhança apresenta um poder classificatório mais elevado e também uma grande homogeneidade ao longo do corpo, exceto pelas regiões referentes à $1^{\mathrm{a}}$ e última vértebras, que apresentam classificações notadamente inferiores (figura 3.21). A análise realizada com a remoção desses dessas posições não eleva muito o índice de classificações corretas, porém reduz a variação das classificações corretas para a vista lateral. Nota-se ainda que a $2^{\mathrm{a}}$ posição vertebral apresenta um índice de classificações corretas relativamente reduzido.

A análise por mínima distância de Procrustes apresenta índices de classificação bastante elevados ao longo de todo o corpo, inclusive para a vista ventral, que é notadamente a pior das vistas nas análises anteriores (figura 3.22). Essa análise aparenta ter grande poder classificatório e grande homogeneidade ao longo do corpo do animal, exceto talvez pela vista posterior, que parece ser bastante heterogênea e apresentar índices de classificação baixos. Nota-se ainda que a primeira e última vértebras, assim como na análise de verossimilhança, não apresentam índices de classificação elevados. A remoção das vértebras das extremidades do tronco dos animais não parece alterar em muito esses padrões. 

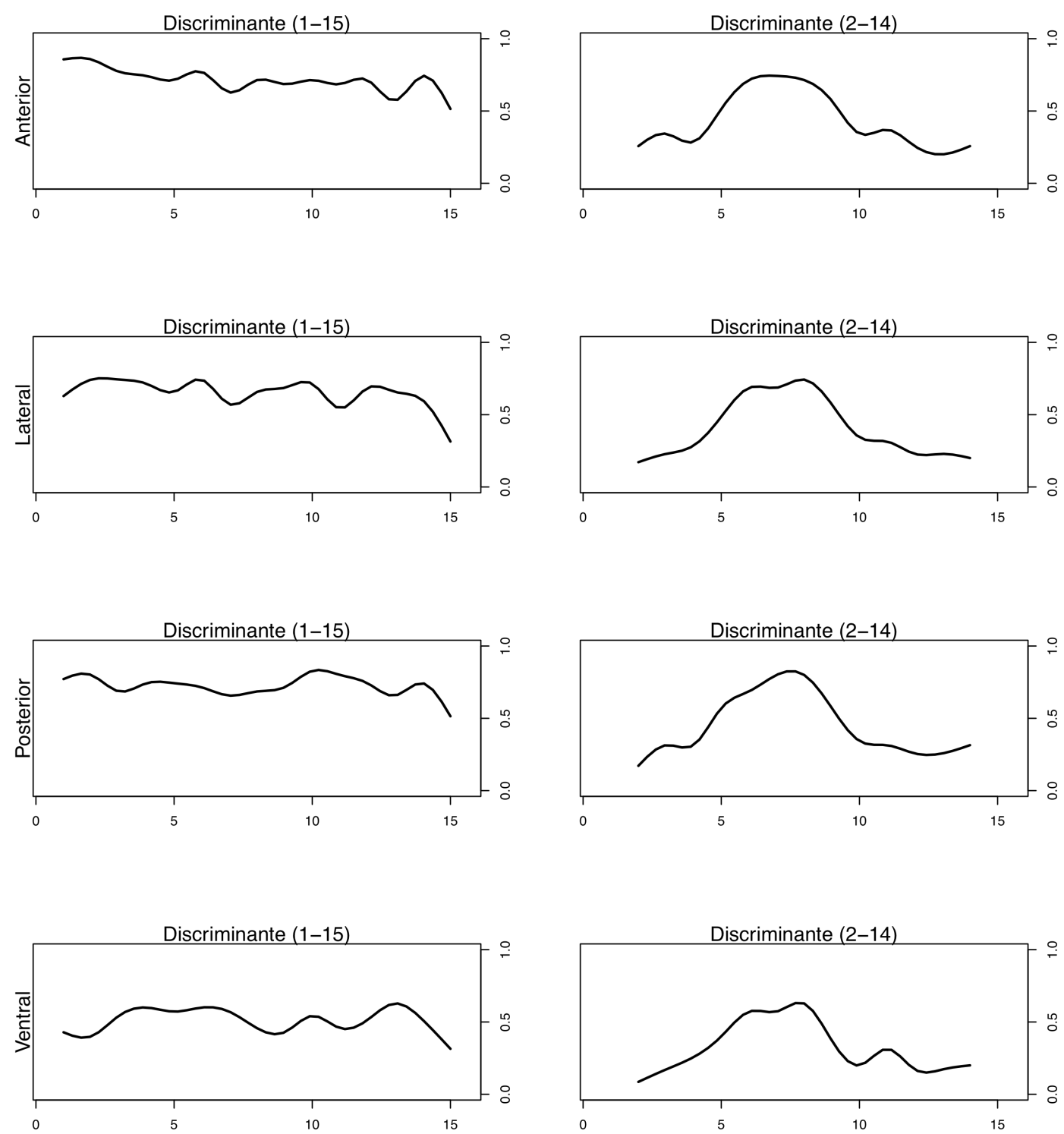

Figura 3.20. Proporção das vértebras que foram diagnosticadas corretamente, separadas por posição vertebral para as análises de Função Linear Discriminante, utilizando todas as vértebras (1-15) e apenas as vértebras da região média do tronco dos animais (2-14). 

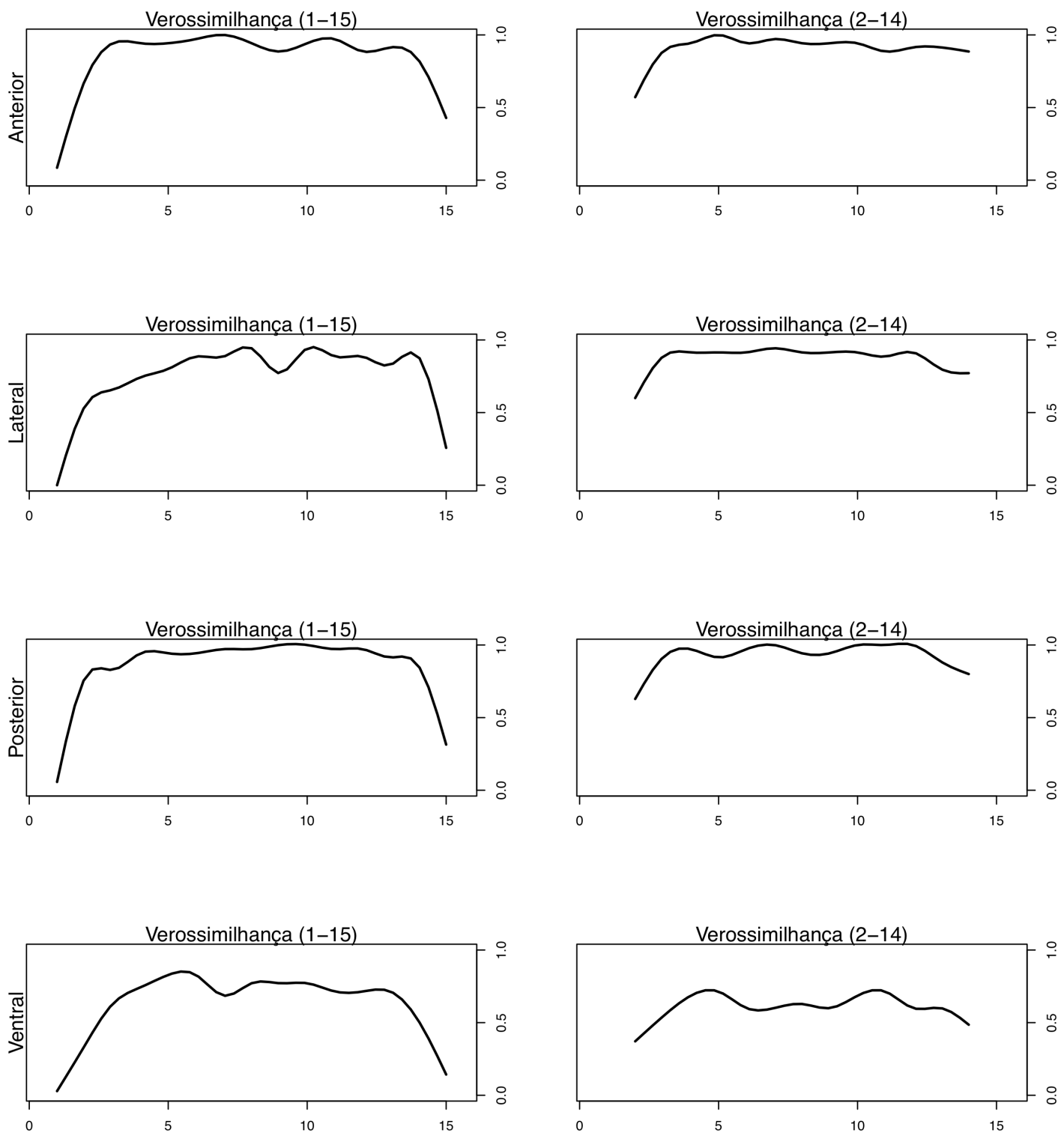

Figura 3.21. Proporção das vértebras que foram diagnosticadas corretamente, separadas por posição vertebral para as análises de máxima-verossimilhança, utilizando todas as vértebras (1-15) e apenas as vértebras da região média do tronco dos animais (2-14). 

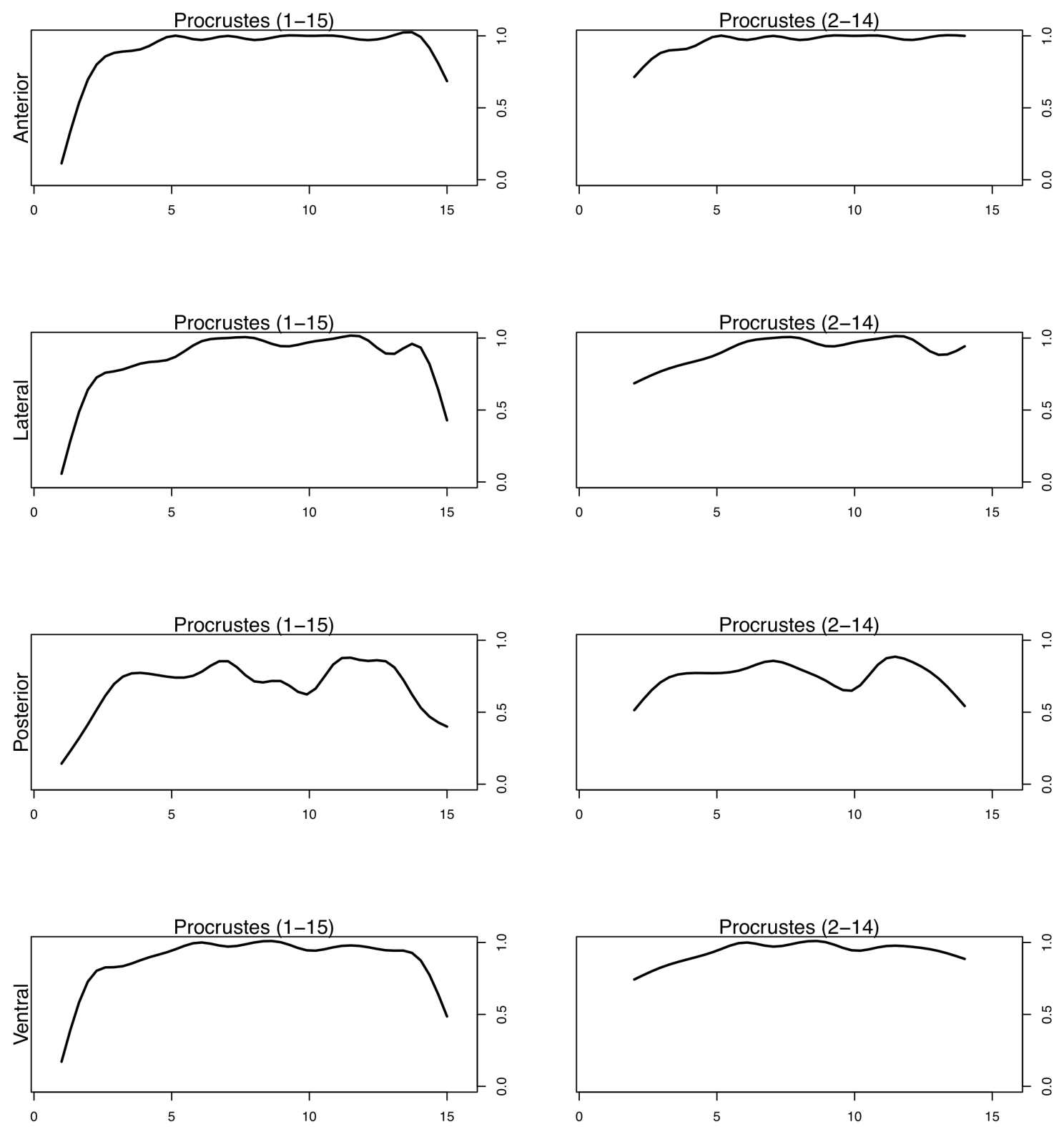

Figura 3.22. Proporção das vértebras que foram diagnosticadas corretamente, separadas por posição vertebral para as análises de mínima distância de Procrustes, utilizando todas as vértebras (1-15) e apenas as vértebras da região média do tronco dos animais (2-14). 


\section{Discussão}

\subsection{O esqueleto axial de Serpentes como complexo morfo-funcional integrado}

\subsubsection{Integração morfológica}

A análise de integração se mostrou consistente entre todas as vistas avaliadas, indicando que o esqueleto axial em Serpentes não apenas evolui como um complexo morfológico integrado, mas que o padrão de variação longitudinal presente nos diversos táxons se mantém constante. As formas referentes às posições craniais são bastante distintas das demais. As vértebras das porções intermediarias são similares entre si, porém apresentam algumas alterações graduais ao longo do corpo do animal, como por exemplo a redução progressiva das hipapófises e a diminuição da angulatura das superfícies articulares zigapofiseais. A região mais caudal do tronco apresenta formas que são relativamente mais dissimilares em relação às vértebras das regiões intermediárias, se aproximando das formas das regiões mais anteriores do corpo dos animais. Esse padrão descreve um "j” no morfoespaço, no qual a vértebra mais anterior está muito distante no morfoespaço (o pingo do "j"), com vértebras intermediárias variando de forma relativamente gradual, terminando em formas que se aproximam mais das primeiras (a curva do “j”).

O resultado da análise de componentes principais $(P C A)$ sobre as taxas evolutivas indica que a evolução da forma vertebral é dominada por um único componente principal que expressa a grande maioria da variação das taxas evolutivas. Os pesos das diferentes posições vertebrais sobre esses componentes principais são notavelmente homogêneos ao longo do corpo, mostrando que cada mudança de forma que ocorre em uma região 
do corpo é acompanhada por mudanças de igual magnitude em outras partes do corpo. As análises de correlação de Procrustes (Pcorr) indicam que a coordenação das taxas evolutivas não altera as posições relativas dos táxons nos morfoespaços de cada posição vertebral (com exceção das posições mais craniais). Isso significa que tais mudanças coordenadas (como evidenciadas pela $P C A$ ) resultam em espaços morfométricos que contêm aproximadamente a mesma informação sobre as distâncias fenotípicas entre os táxons, apesar de não gerarem exatamente as mesmas formas (Figura 4.1), sugerindo que o esqueleto axial pré-cloacal evolui de forma coordenada.

Contudo, a simples associação de taxas evolutivas pode apenas significar que diversos aspectos dos organismos estão se alterando ao mesmo tempo, e não significa, necessariamente, que esta variação ocorre de forma integrada em níveis genéticos ou ontogenéticos: sabe-se que a seleção natural tem a capacidade de estabelecer novos padrões de covariação quando os fenótipos são avaliados em uma escala taxonômica mais abrangente, principalmente quando há a presença de organismos com diferentes hábitos e nichos ecológicos (p. ex. MonTEIRO, 2009). Isso se dá, entre outros fatores, pela capacidade da seleção natural de produzir evolução fenotípica que não se correlaciona com os eixos de variação intraespecíficos (SCHLUTER, 1996). Sendo assim, poder-se-ia considerar que a conclusão de que o esqueleto das serpentes seja realmente um complexo integrado é ainda precipitada, e que estudos comparativos minuciosos, principalmente nos níveis populacionais, são necessários para testar a hipótese de integração biológica da variação do esqueleto axial no grupo. A inspeção dos padrões de variação reconstruídos para os ancestrais mostra, entretanto, que as distâncias de Procrustes entre as formas das vértebras de cada organismo se mantêm ao longo da filogenia, 

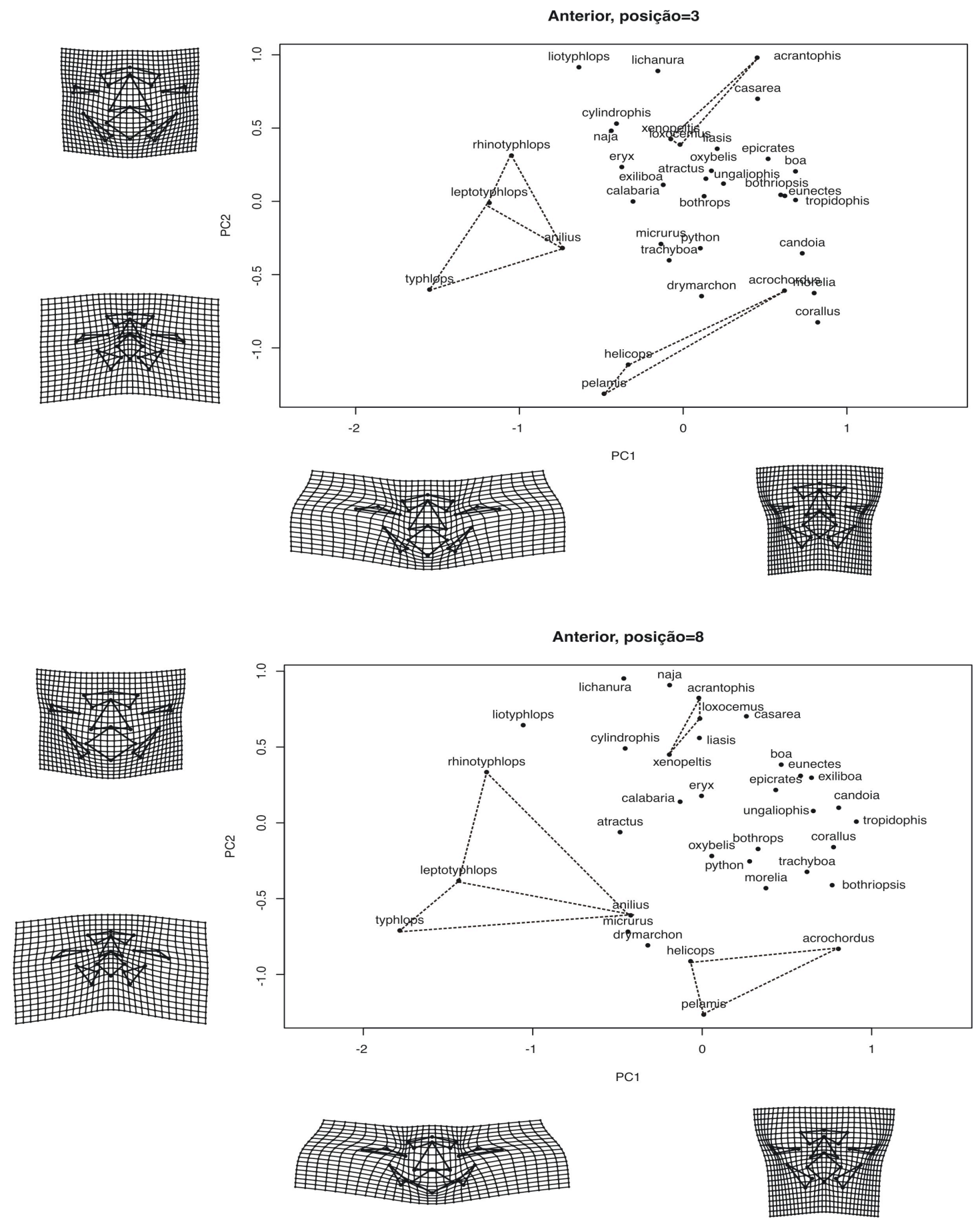

Figura 4.1. Exemplo de equivalência entre as distâncias relativas entre as espécies nos morfoespaços relativos às diferentes posições vertebrais em vista anterior. Linhas pontilhadas ligam os mesmos táxons em ambos os morfoespaços, demonstrando que as posições relativas se mantêm aproximadamente ao longo do corpo. Splines também revelam similaridade nos PCs, mostrando que as deformações relativas aos maiores componentes de variação da forma são similares entre as diversas posições. 
reforçando a idéia de que o padrão de variação longitudinal é constante em Serpentes.

O padrão de variação é surpreendentemente conservado nas análises da face anterior, demonstrando que as estruturas amostradas nessa vista (principalmente fácies articulares) apresentam a mesma relação de variação, evidenciando a existência de um padrão comum a todas as Serpentes. De fato, a vista anterior das vértebras de Serpentes foi a única a ser avaliada com morfometria de marcos ("landmarks") na literatura e, não coincidentemente, tais análises concentram-se na tentativa de identificar a posição de origem de elementos vertebrais dissociados. POLly \& HEAD (2004) avaliaram a variação da forma vertebral ao longo do esqueleto de Cylindrophis ruffus, e demonstraram que o esqueleto axial de um animal poderia ser utilizado como modelo para identificar a origem de vértebras dissociadas em outros animais da mesma espécie. HEAD et al. (2009) utilizaram diversos boídeos como modelo de esqueleto axial para identificar de que posição do corpo havia se originado um elemento vertebral de uma espécie fóssil, Titanoboa cerrejonensis, a despeito das diferenças de forma e tamanho entre as espécies. Estes trabalhos sugerem que a variação longitudinal é de certa forma equivalente entre diferentes indivíduos da mesma espécie (POLLY \& HEAD, 2004) e entre indivíduos de espécies distintas (HEAD et al. 2009). Entretanto, nenhum deles testa diretamente a hipótese de que a variação longitudinal é de fato similar, assumindo similaridade como pressuposto das análises de classificação de elementos dissociados.

O presente trabalho se baseia em uma ampla distribuição taxonômica e busca testar diretamente a manutenção da variação longitudinal dentro de Serpentes. Os resultados apresentados indicam que a variação longitudinal de Serpentes pode ser considerada equivalente entre espécies 
com formas vertebrais totalmente distintas, e que os pressupostos das análises de Polly \& HeAD (2004) e HEAD et al. (2009) são verdadeiras.

\subsubsection{Ontogenia de vértebras de Serpentes}

A explicação biológica para a conservação do padrão de variação longitudinal das vértebras do esqueleto pré-cloacal de Serpentes pode estar nas origens ontogenéticas dos elementos vertebrais. Assim como em outros vertebrados, em Serpentes podemos reconhecer três principais etapas da ontogênese do esqueleto axial: segmentação, regionalização e esqueletogênese (POLLY et al., 2001). A primeira consiste principalmente da segmentação da mesoderme para-axial ao longo do embrião. Durante a regionalização ocorre a definição das regiões do esqueleto axial através de crescimento e modificações diferenciais nos elementos. $\mathrm{O}$ processo de esqueletogênese pode ser definido como a formação do tecido ósseo propriamente dito, que ocorre invariavelmente na maior parte do esqueleto axial. Diferentemente da maioria dos outros vertebrados, entretanto, as Serpentes apresentam mudanças significativas nos processos de segmentação e regionalização (COHN \& TiCKLE, 1999; GOMEZ et al., 2008; Woltering et al., 2009; Di-PoÏ et al. 2010).

A somitogênese é uma etapa fundamental da ontogênese vertebral. Os somitos estabelecem o padrão de segmentação que se diferenciará em musculatura esquelética, derme e elementos do esqueleto axial. Sendo assim, o número de somitos gerados determina diretamente o número de vértebras que o organismo possuirá. Esse processo é mediado pela interação da regressão do nódulo de Hansen (mesoderme pré-somítica) com a expressão cíclica de genes ligados à segmentação (PALMERIM et al., 1998). Em Serpentes, a expressão de um desses genes cíclicos ("Lunatic fringe") é acelerada, determinando um número maior de ciclos de expressão que, associados à regressão do nódulo de Hansen, 
determinam um número maior de somitos com um tamanho proporcionalmente reduzido (GoMEZ et al., 2008).

Durante certo tempo, acreditou-se que a ausência de regionalização no esqueleto de Serpentes estava ligada apenas à transposição das fronteiras de expressão de genes homeóticos que, entre outras funções, atuam na formação dos membros anteriores (COHN \& TiCKLE, 1999). Análises recentes indicam que muitos dos genes que atuam na regionalização do esqueleto dos vertebrados ainda apresentam padrões de expressão regionalizados em Serpentes, mesmo na ausência de regionalização morfológica clara (WOLTERING et al., 2009; Di-POÏ et al. 2010).

Estudos sobre a esqueletogênese dos elementos vertebrais em Serpentes são escassos. Sabe-se que a forma vertebral depende, em partes, de informação direta de genes atuantes na segmentação (p. ex. determinando o tamanho da vértebra), regionalização (p. ex. suprimindo a expressão de costelas) e de interações epigenéticas com músculos associados (GANS, 1976). A ontogênese da forma vertebral em Serpentes parece se dar principalmente por crescimento diferencial das vértebras de diferentes partes do esqueleto axial, com regiões intermediárias do corpo apresentando um crescimento mais acelerado que regiões mais caudais e craniais, produzindo vértebras maiores (LADuKe, 1991; Polly et al. 2001). Os resultados apresentados neste trabalho reforçam essa interpretação, demonstrado a existência de uma região intermediária do corpo com vértebras relativamente homogêneas em forma e tamanho e regiões craniais e caudais com elementos vertebrais reduzidos e que apresentam formas que diferem das demais em um mesmo sentido (i.e. variam no mesmo sentido no espaço fenotípico).

Todavia, apenas crescimento alométrico entre diferentes posições não é o 


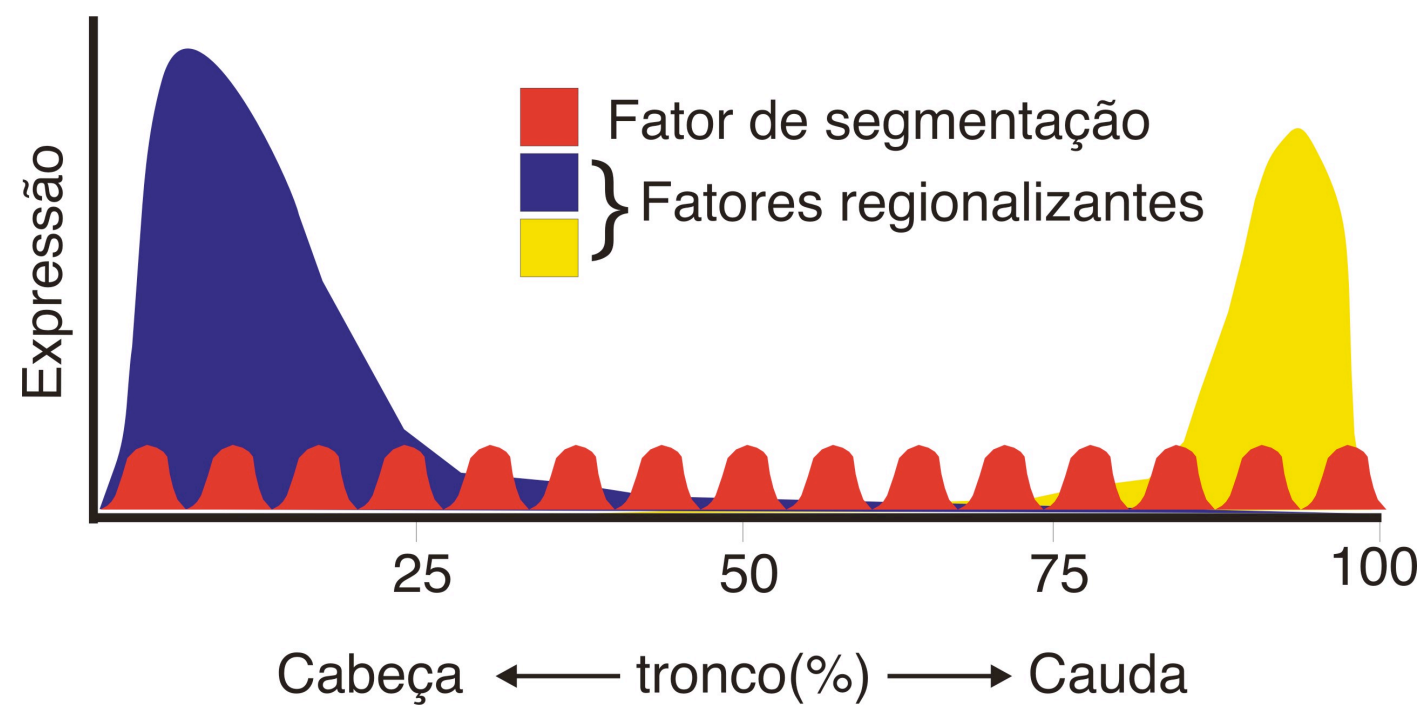

Figura 4.2. Modelo da influencia de fatores de determinação da forma das vértebras pré-cloacais em Serpentes e seu padrão de expressão hipotético ao longo do corpo. Ver texto para maiores detalhes.

suficiente para explicar a variação observada, visto que os resultados também indicam que as formas se alteram de maneira gradual e contínua o longo do corpo do animal. Assim sendo, podemos modelar a variação longitudinal do esqueleto axial pré-cloacal de Serpentes como a interação de dois principais processos: estabelecimento dos elementos (somitogênese) e regionalização das porções craniais e caudais sem limites bem definidos (figura 4.2).

A somitogênese atua no estabelecimento do número de elementos vertebrais que irão compor o corpo do animal, influenciando o tamanho relativo das vértebras e, por conseguinte, sua forma (GoMEZ et al., 2008). De fato, animais aparentados e com hábitos similares, como os Boídeos, podem apresentar formas vertebrais muito similares, a despeito de sua diferença de tamanho, provavelmente porque o mecanismo que gera essa diferença não corresponde a uma alteração do processo de segmentação, mas sim a diferenças de crescimento pós-natal (HEAD \& POLLY, 2004). 
Fatores de regionalização podem influenciar (estimulando ou suprimindo) o crescimento das vértebras, ou mesmo estimular o crescimento diferenciado de estruturas ósseas, como é o caso das costelas (BURKE et al., 1995). Em Serpentes, a quase supressão da regionalização do esqueleto axial pré-cloacal parece estar ligada à modificação no padrão de expressão de alguns genes regionalizantes, que continuam se expressando em regiões amplas do esqueleto axial, a despeito da ausência de correlatos morfológicos similares aos observados em outros grupos de tetrápodes (Woltering et al., 2009; Di-PoÏ et al. 2010). A expansão das fronteiras desses genes e manutenção de sua expressão indica que eles estariam sendo interpretados em níveis mais baixos da cascata de ação da ontogênese vertebral em Serpentes, ou mesmo atuando na formação de outros tecidos (p. ex. TsuiHIJ et al., 2006), influenciando indiretamente a forma vertebral (Woltering et al., 2009; Di-PoÏ et al. 2010). Woltering et al. (2009) e Di-PoÏ et al. (2010) sugerem que estas mudanças na interpretação pode ser resultado em um relaxamento nas restrições ontogenéticas, permitindo a extensão das fronteiras de expressão desses genes, o que poderia explicar a variação gradual de algumas estruturas do esqueleto axial de Serpentes (DI-Poï et al., 2010).

Tais fatores não são necessariamente genéticos, podendo haver influência de fatores epigenéticos na determinação da forma vertebral. Contudo, a correlação entre expressão gênica e padrões morfológicos é notável, e a manutenção deste último ao longo da filogenia, a despeito da grande variação de hábitos de vida, pode ser indicativo que, desde o início de sua evolução, Serpentes se valeram do mesmo padrão de variação corporal para explorar os mais diversos habitats. 


\subsection{Fatores determinantes da forma vertebral: Filogenia e Ecologia.}

\subsubsection{Ecomorfologia vertebral}

O ajuste de modelos ecomorfológicos revelou uma distinção clara entre três conformações vertebrais: 1- as pertencentes à animais fossoriais, 2as pertencentes à animais constritores, e 3- as pertencentes às Serpentes avançadas (Colubroides). Animais fossoriais possuem vértebras que apresentam uma compressão dorso-ventral acompanhados da supressão do espinho neural e da hipapófise. A compressão do arco neural pode ser relativamente dissociada do aumento do tamanho do zigantro, fazendo com que o contorno do arco neural seja levemente truncado (apesar desta ser uma característica também presente em animais com zigósfenos muito desenvolvidos). Apresentam também articulações zigosfeno-zigantrais e zigapofiseais relativamente menos anguladas entre si e sinapófises mais lateralmente orientadas. Animais constritores apresentam vértebras largas e altas, com espinhos neurais desenvolvidos, hipapófises proeminentes e considerável redução do processo acessório. Os animais restantes, apesar de apresentarem formas de vida distintas se agrupam no morfoespaço vertebral, formando um terceiro grupo de animais predominante derivados (Colubroides). A morfologia vertebral deste grupo apresenta aspectos intermediários quando comparados aos constritores e fossoriais. Possuem hipapófises proporcionalmente menores que em constritores (a despeito de estarem presentes ao longo do corpo dos animais). Os espinhos neurais são mais largos no sentido antero-posterior do que em constritores, apesar de mais baixos, ocupando grande parte da região dorsal da vértebra. Apresentam vértebras longas (como nos animais fossoriais) e com processos acessórios desenvolvidos. Diferente de animais fossoriais e constritores, entretanto, possuem articulações zigosfeno-zigantrais e zigapofiseais mais anguladas entre si. 
O padrão de similaridade não é inteiramente consistente entre as vistas. Em vista anterior e lateral os grupos apresentam posições distintas no morfoespaço, sendo o centróide dos grupos relativamente eqüidistantes, em uma conformação triangular. Já em vistas posterior e ventral a distinção entre grupos não é tão clara. Em vista ventral o grupo fossorial e o grupo de animais derivados parecem apresentar uma mesma forma alongada, com corpo vertebral pequeno e processos acessórios bem desenvolvidos. Em vista posterior, entretanto, apenas pode-se distinguir o grupo fossorial pela compressão dorso-ventral.

A diferença entre esses grupos é bastante similar à variação da forma entre as espécies e táxons superiores, expresso pelos componentes principais das formas médias. Visto que os diversos grupos taxonômicos apresentam certa superposição e que não foi confirmada a presença de sinal filogenético na forma vertebral, somos levados a crer que a forma vertebral é fortemente influenciada por seleção (BUTLER \& KING, 2004). Sendo assim, a ausência de sinal filogenético, mas a presença de certa padronização taxonômica no espaço fenotípico indica que a força de seleção pode ter sido responsável pela diversificação da forma vertebral em Serpentes ao restringir a forma vertebral à diferentes picos adaptativos fenotípicos (POLLY, 2008).

Tal interpretação, entretanto, falha em explicar a presença de um grupo morfometricamente distinto que se refere, quase que exclusivamente, aos animais derivados pertencentes ao grupo dos Colubroides, o grupo com o maior número de espécies de Serpentes, apresentando uma grande diversidade de hábitos de vida, incluindo animais arborícolas, fossórios, aquáticos, e até mesmo planadores. Explicações para destacada diversidade de formas e ecologias em comparação com os demais grupos de serpentes costumam se valer da presença de aparatos de inoculação de 
veneno dentro deste grupo.

\subsubsection{Relação entre evolução do veneno e forma vertebral na evolução de Colubroides}

Aparatos de inoculação de veneno estão presentes de diversas formas dentro de Serpentes (FRY et al., 2009). Este aparato pode apresentar um alto grau de complexidade, e análises cladísticas apontam para a presença de estruturas relacionadas à inoculação de veneno altamente especializada, incluindo a presença de presas tubulares, em pelo menos três grupos não relacionados: Viperidae, Elapidae e Atractaspididae (VIDAL, 2002; JACKSON, 2003). Muitos dos elementos anatômicos do sistema de inoculação encontrados nestes grupos são incrivelmente conservados, o que torna a hipótese do surgimento independente deste caráter extremamente implausível.

VIDAL (2002) argumentou que a homologia entre as glândulas de veneno e as glândulas serosas em Colubroides sem veneno indicam que o surgimento do aparato inoculador é basal no grupo. JACKSON (2003) expandiu essa análise, apontando que a similaridade de muitos elementos do aparato de inoculação dos diferentes grupos pode ser explicada por ancestralidade comum, apontando para a hipótese aparentemente menos parcimoniosa de múltiplas reversões de condições consideradas derivadas (p. ex. presas tubulares). Achados paleontológicos reforçam esse cenário, mostrando que o surgimento de presas inoculadoras é de fato muito antigo no registro fóssil, e que esses elementos são indistinguíveis dos encontrados nos diferentes grupos atuais (KUCH et al., 2006). As evidências mais surpreendentes vêem, entretanto, da biologia do desenvolvimento que aponta para a possibilidade de que a dentição presumidamente plesiomórfica vista em animais não-peçonhentos pode ser o resultado de alterações heterocrônicas em presas inoculadoras 
sendo, então, um estado derivado (JACKSON, 2007). Adicionalmente, análises de ontogenia molecular mostram que o mecanismo de desenvolvimento utilizado na produção de presas tubulares é o mesmo nos diversos grupos, independentemente da posição da presa na mandíbula do animal, argumentando em favor da homologia de todas as presas inoculadoras (VONK et al., 2008). Somadas, essas evidências apontam para o surgimento basal do aparato inoculador em Colubroides, reforçando a importância desses caracteres na diversificação desse grupo. Análises cladísticas recentes reforçam o aparecimento mais inclusivo do sistema de inoculação veneno (ex: VIDAL et al. 2007, 2009; ZAHER et al., 2009), o que levou ZAHER et al. (2009) à sugerir o estabelecimento de um novo táxon, Endoglyptodonta, em alusão ao surgimento deste caráter.

Entretanto, esse cenário apresenta problemas como hipótese explicativa da diversidade de Colubroides: se a presença de um aparato de inoculação complexo estivesse diretamente relacionada com a diversificação do grupo, os clados que não possuem tal aparato seriam consideravelmente menos diversificados que os que o possuem. Entretanto, uma porção significativa da diversidade de Colubroides se deu com a ausência ou redução de um aparato especializado de inoculação. A avaliação do registro fóssil revela problemáticas adicionais, uma vez que no Cenozóico intermediário, especificamente no Mioceno, vemos uma substituição faunística, com a diminuição da irradiação antiga de "henofídios" constritores e a expansão dos registros de Colubroides (Auffenberg, 1963; Tinen 1964; Estes \& Tihen, 1964; Estes, 1970, Holman, 1970; 1973; 1976; 1977), indicando que serpentes estavam se diversificando mesmo na ausência de um sistema de inoculação de veneno especializado e que o surgimento deste sistema está relacionado não apenas com a diversificação de Colubroides, mas também com a 
diminuição na diversificação dos grupos constritores basais ("henofídios").

Para levar em conta esses padrões, SAVITZKY (1980) sugeriu que o declínio dos grupos constritores, compostos principalmente de caçadores de emboscadas que dependem fortemente de cobertura vegetal abundante, estaria ligado à diminuição da cobertura vegetal e à redução das áreas florestais no Cenozóico intermediário (MACGinITIE, 1962; AxELROD, 1966; WolFE \& HoPKINS, 1967). Nesse contexto, animais com uma maior capacidade de locomoção e atividade estariam em vantagem, pois poderiam não apenas se deslocar entre os remanescentes de vegetação, como também perseguir ativamente presas, sem necessitar de técnicas de emboscada. Visto que a constrição parece limitar a capacidade locomotora em "henofídeos" (RUBEN, 1977; SAVITZKY, 1980), o surgimento do aparelho inoculador teria possibilitado a liberação do sistema axial das restrições funcionais impostas pela constrição, transferindo a função de captura do sistema axial para as presas (SAVITZKY, 1980). Esse processo permitiria, por sua vez, a melhora da performance locomotora, e uma melhor exploração dos nichos disponíveis. SAVITZKY (1980) baseou sua argumentação também no fato de que serpentes avançadas apresentam articulações zigapofiseais e zigantrais mais afastadas entre si do que em "henofídeos", e que tal caráter permitiria uma melhor flexibilidade do sistema axial, justificando assim a melhor performance locomotora vista em Colubroides. Os resultados aqui apresentados demonstram que há uma diferença significativa entre a forma vertebral de animais derivados (Colubroides) e de constritores basais similar à descrita por SAVITZKY (1980), indicando que o surgimento do aparelho de inoculação de veneno foi acompanhado por mudanças no sistema axial que podem ter conferido uma melhora na 
performance locomotora.

As conclusões de SAVITZKY (1980), entretanto, baseiam-se nas interpretações de RUBEN (1977) de que a presença de musculatura epaxial e tendões alongados em serpentes derivadas representariam uma restrição funcional para a constrição em Serpentes. Tal conformação muscular indica a existência de uma solução de compromisso ("trade-off") entre constrição e mobilidade. Entretanto, análises da performance constritora de animais derivados, como Pituophis melanoleucus e Lampropeltis getula, indicam que, mesmo apresentando uma conformação hipoteticamente menos propícia à constrição, segundo a interpretação de RUBEN (1977), tais animais são constritores eficientes, apresentando performances comparáveis às presentes em constritores basais ("Heanophidia"), a despeito de apresentarem grande capacidade locomotora (MoON, 2000). Adicionalmente, a constrição parece estar igualmente presente em grupos venenosos e não-venenosos de serpentes australianas derivadas (SHINE \& SchWANER, 1985), indicando que a função de tais hábitos não é mutuamente exclusiva.

Contudo, a constrição é considerada prevalente em grupos basais, com exceção de animais fossoriais (SHINE \& SCHWANER, 1985), o que sugere que a transição "Henophidia"-Caenophidia pode ter sido influenciada pela mudança das restrições sobre o esqueleto axial. Sendo assim, o surgimento e diversificação deste grupo derivado estariam ligados à perda da restrição imposta pelo habito constritor, propiciada pelo surgimento dos aparelhos de inoculação (JACKSON, 2003), permitindo que animais derivados explorassem outros picos adaptativos, mas não os impossibilitando de explorar novamente o habito constritor (figura 4.2). 


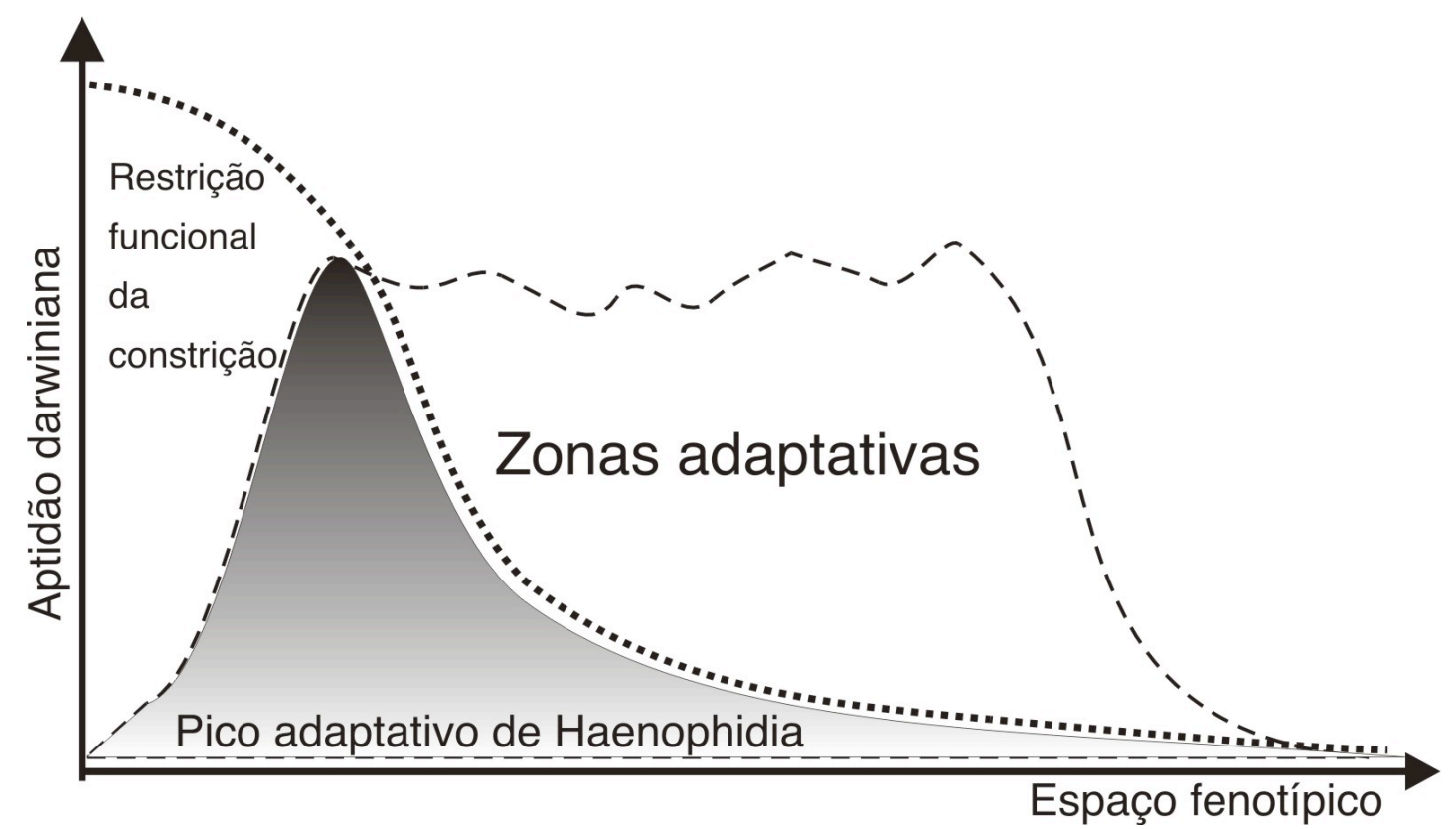

Figura 4.2. Influência da restrição funcional imposta pelo habito constritor em "Haenophidia" sobre o cenário adaptativo de Serpentes.

É importante notar, entretanto, que animais constritores são menos diversos que outras espécies não-constritoras dentro de grupos derivados (e.x. SHINE \& SCHWANER, 1985), o que pode indicar que a adoção do habito constritor em grupos de Serpentes avançadas pode estar ligada a uma menor diversidade, um padrão que seria compartilhado com os "henofídios" basais, a despeito da ausência de trade-off entre locomoção e constrição no primeiro grupo (MoON, 2000). Isso parece apontar para a existência de relações entre biodiversidade, anatomia e hábito de forrageamento ainda não totalmente exploradas em Serpentes.

\subsection{Classificação de elementos vertebrais dissociados.}

Os diferentes protocolos de classificação demonstraram diferentes graus de sucesso na classificação de vértebras dissociadas. A análise por Função Linear Discriminante (FLD) apresentou o pior desempenho em todas as vistas, seguida pela classificação por verossimilhança, com a análise por distância de Procrustes apresentando a melhor performance. De maneira geral, as vistas anteriores e posteriores apresentaram os 
melhores índices de classificação, seguidos pelas vistas lateral e ventral com as piores classificações. A distribuição das classificações corretas ao longo do corpo mostra que, apesar de apresentar baixo índice de classificação correta, a análise de FLD distribui as classificações corretas de maneira relativamente homogênea ao longo do corpo dos animais. Tanto a análise por verossimilhança quanto a de Procrustes mostram uma tendência de classificar incorretamente as vértebras mais anteriores e posteriores.

A remoção da primeira e última vértebras melhora os índices de classificação em todas as análises. Na análise por FLD, a remoção dessas vértebras parece afetar a distribuição de classificações corretas ao longo do corpo, apresentando uma melhor classificação na região da $5^{\text {a }}$ posição até a $10^{\mathrm{a}}$, com o restante do animal sendo mal classificado. Na análise por verossimilhança a remoção dessas vértebras melhora a classificação geral das posições vertebrais restantes, exceto para a segunda posição, que apresenta um índice de classificação correta baixo em relação às demais posições. Na análise por distância de Procrustes, a remoção da $1^{\mathrm{a}}$ e ultima vértebras melhora a classificação de todas as posições. Apesar da $2^{\mathrm{a}}$ posição continuar sendo proporcionalmente pior classificada, ela apresenta índices de classificação correta superior às encontradas em outras análises.

FLD já foi usada na análise de variação longitudinal por CHRISTMAN (1975) para sinonimização de Crotalus giganteus com C. adamanteus. Apesar de se tratar de um trabalho taxonômico, a utilização da FLD não estava voltada para classificação, mas sim para a identificação da posição na qual a vértebra referente ao holótipo de $C$. giganteus provinha. Para tal, Christman (1975) obteve medidas lineares de diferentes posições ao longo do corpo de diversos espécimes de C. adamanteus, e tratou cada 
região do corpo como um grupo na FLD. Apesar do sucesso da FLD nesse contexto, a presente análise demonstra que o emprego desta metodologia sobre vértebras de diversas posições falha em identificar corretamente vértebras dissociadas.

A análise de FLD funciona maximizando a variância entre-grupos e minimizando a variância intra-grupo (LESTREL, 2000), usando a matriz de variância-covariância intra-grupo ponderada ("pooled"). Sendo assim, uma das premissas da análise é da igualdade de variância-covariância entre os grupos. As análises de variação longitudinal, entretanto, indicam que este não é o caso: apesar da variação ao longo do corpo ser similar entre os diversos grupos, não há nenhum indicativo de que são as mesmas estruturas que estão variando ao longo do corpo (ver variação longitudinal das espécies avaliadas no Apêndice II). Assim sendo, a aplicação de FLD em vértebras pertencentes ao corpo de diversos animais pode resultar na distorção das relações entre as formas, o que talvez explique a baixa performance da aplicação destes testes na classificação de elementos isolados. Adicionalmente, o baixo número de observações pode comprometer a estimativa adequada das matrizes de variância/covariância, podendo explicar a baixa performance desta análise.

Assim como FLD, classificações por verossimilhança também já foram utilizadas em trabalhos com o objetivo de identificar a posição vertebral de vértebras dissociadas, seja de grupos atuais (POLLY \& HEAD, 2004) ou fósseis (HEAD et al. 2009). POLly \& HEAD (2004) estabeleceram um protocolo de classificação no qual as vértebras de um indivíduo de Cylindrophis ruffus foram agrupadas em diversas secções e digitalizadas em vista anterior e superpostas por Procrustes. A classificação foi estimada por verossimilhança, calculada como a soma das 
verossimilhanças das coordenadas $\mathrm{X}$ e $\mathrm{Y}$ de cada marco anatômico da vértebra dissociada, sem levar em conta o padrão de covariação entre os marcos. Apesar dessa premissa pouco realista, algo que é discutido por POLly \& HEAD (2004), os resultados da análise são bastante consistentes, possibilitando a identificação da posição de elementos vertebrais dissociados de outro exemplar de C.ruffus. HEAD et al. (2009) se valem da mesma metodologia para a identificação da posição intracolunar de vértebras fósseis pertencentes à Titanoboa cerrejonensi, amostrando diversas espécies para construir um modelo de coluna vertebral para Boidae. Através desse modelo, eles aplicam o mesmo processo descrito em Polly \& HeAD (2004), porém calcularam a verossimilhança como a soma das verossimilhanças de cada variável da forma (PCA sobre marcos anatômicos de todas as vértebras avaliadas superpostos por Procrustes) referente a cada posição vertebral. A classificação taxonômica de $T$. cerrejonensi, entretanto, foi realizada com base em outros caracteres morfológicos vertebrais que não foram avaliados morfometricamente.

Apesar do protocolo por verossimilhança ter resultado em índices relativamente elevados de classificação, talvez não seja o mais adequado para a identificação de vértebras dissociadas em um amplo contexto taxonômico. A razão disso é que o protocolo utilizado aqui modela a variação dentro do grupo como pertencente a uma distribuição normal multivariada, uma premissa que não parece adequada, tendo em vista a variação longitudinal presente nos grupos. É provavelmente por esse motivo que a remoção dos elementos extremos melhora a classificação média geral em todas as vistas, uma vez que são estes elementos que mais influenciam a conformação em “j” vista nos morfoespaços referentes às diversas vistas (ver variação longitudinal das espécies avaliadas no Apêndice II). 
O método proposto aqui para classificação por distância de Procrustes apresentou o melhor índice de classificação de vértebras dissociadas. Esse método não necessita que os dados estejam normalmente distribuídos, nem que os padrões de covariação sejam similares entre os grupos, o que talvez explique sua alta performance em relação aos outros protocolos. É interessante notar que mesmo as análises com os elementos mais extremos do tronco dos animais apresentam resultados relativamente altos, indicando que vértebras de diversas posições ao longo do corpo do animal são mais similares entre si do que são em relação às pertencentes as demais espécies. Nenhum protocolo similar a este foi empregado na literatura para a classificação de vértebras dissociadas. Entretanto, é válido notar que a utilização da similaridade fenotípica para a classificação é uma prática comum em taxonomia (MACLEOD, 2008).

A identificação da posição de uma vértebra dissociada é essencial para qualquer tipo de inferência a respeito de um fóssil, inclusive sua identificação taxonômica (LADuKE, 1991; MoON, 1999). O problema da variação longitudinal do esqueleto de Serpentes para a análise do registro fóssil já foi reconhecida por diversos autores (ex: ChristMAn, 1975; LaDuke, 1991; MoOn, 1999; Polly \& Head, 2004), porém as soluções mais elegantes para esse tipo de problema relegam a questão da identificação taxonômica em si para o campo anatômico e descritivo (Christman, 1975; Head et al., 2009). Nestes estudos, o processo de classificação serve apenas para a identificação das posições das vértebras ao longo do corpo como passo intermediário para novas inferências a respeito da biologia dos animais. 

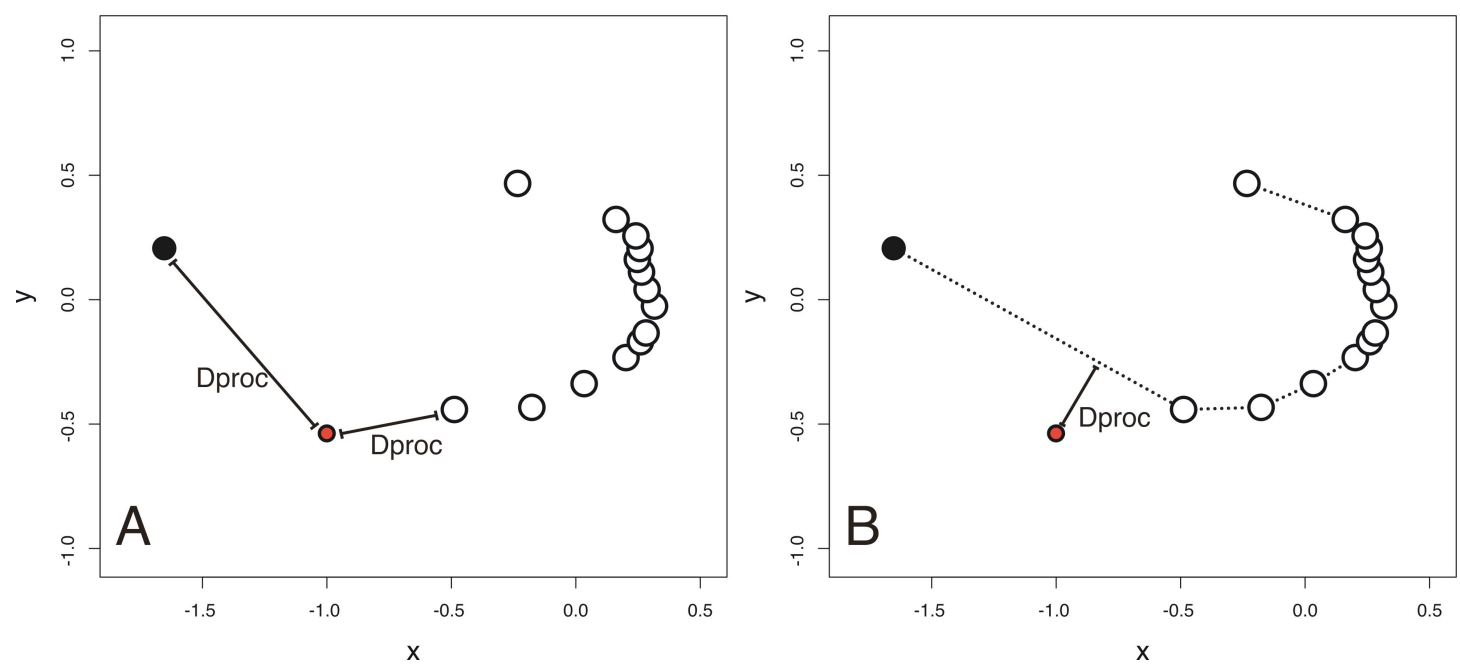

Figura 4.3. Representação gráfica do protocolo de classificação por distância de Procrustes (Dproc) utilizado. A - Utilização apenas das formas amostradas. B Utilização de formas interpoladas.

A rejeição da utilização de métodos estatísticos na diagnose de material dissociado provavelmente decorre do fato de que a identificação taxonômica baseada na forma vertebral depende de um posicionamento intracolunar correto, fato este que impossibilitaria solucionar ambas as questões com uma mesma base de dados. Entretanto, a resistência ao emprego de métodos quantitativos na avaliação de vértebras dissociadas pode ser não apenas fruto de uma real impossibilidade, mas provavelmente de uma ausência de estudos comparativos da forma vertebral em serpentes que permitam a produção de protocolos operacionais (LADUKE, 1991).

O sucesso da análise baseada na distância de Procrustes demonstra que existe uma maneira objetiva de avaliar a identidade de uma vértebra dissociada, mesmo na presença de variação longitudinal. O método pode ser facilmente expandido para possibilitar a modelagem da variação longitudinal por meio de análises de regressão e interpolação, aumentando ainda mais a eficiência de tal abordagem (Figura 4.3). 


\section{Conclusões}

\subsection{Sumário dos resultados encontrados}

Ainda existem poucos estudos acerca da variação da forma vertebral em Serpentes, e a análise de diversos fatores ainda serão necessários para a avaliação objetiva dos processos de variação da forma vertebral e para o desenvolvimento de protocolos adequados de classificação de elementos vertebrais dissociados. O presente trabalho buscou examinar a influência da posição intracolunar e da variação interespecífica na forma vertebral do esqueleto axial pré-cloacal de Serpentes, buscando ainda avaliar a efetividade de três processos de discriminação que poderiam ser aplicados em vértebras dissociadas provenientes do registro fóssil. Os seguintes pontos podem ser concluídos a partir das análises realizadas:

1- A variação longitudinal em Serpentes aparenta ser relativamente conservada ao longo de todos os grupos avaliados, onde se pode distinguir principalmente três regiões: uma região torácica anterior, uma região torácica intermediária e uma região torácica posterior. Esse padrão de variação parece ser independente da forma média da espécie e das estruturas que de fato variam ao longo do corpo, indicando que as espécies avaliadas de Serpentes se valem dos mesmos mecanismos de regionalização.

2- A forma média vertebral das diferentes espécies é altamente influenciada pelos hábitos de vida fossorial e constritor. Adicionalmente, podemos reconhecer a existência de um grupo composto por animais derivados relativos ao clado Colubroides. Isso sugere que a transição entre animais constritores primitivos ("Henophidia") e animais derivados (Colubroides) teve influência sobre o esqueleto axial pré-cloacal de Serpentes, provavelmente em 
decorrência do surgimento de sistemas de inoculação de venenos complexos. Tais aparatos permitiram o desacoplamento funcional entre $\mathrm{o}$ tronco dos animais e o hábito de forrageamento (constrição), permitindo exaptação (sensu GoULD \& VRBA, 1982) desse sistema para a locomoção, propiciando assim a invasão de novos nichos.

3- Técnicas de morfometria geométrica permitem a identificação de elementos vertebrais dissociados, a despeito da variação longitudinal presente em Serpentes, indicando que vértebras pertencentes ao mesmo animal são mais similares entre si do que vértebras pertencentes às outras espécies. Análises de variação intra-específica são necessárias para a ampliação desses achados.

\subsection{A utilidade da morfometria geométrica para o registro fóssil em Serpentes.}

A dissociação histórica da neontologia e paleontologia de Serpentes trouxe uma dicotomia em termos de prática e escopo entre estas duas áreas. Enquanto a maior parte dos estudos anatômicos em Serpentes viventes é feita com base em caracteres de anatomia mole ou caracteres cranianos (GASC, 1976), a maior parte do registro fóssil desse grupo não é constituído de elementos de nenhum desses complexos de caracteres, mas sim provém dos elementos de mais fácil fossilização e de menor importância reconhecida para grupos modernos: as vértebras (RAGE, 1987). Entre outros efeitos, essa disparidade torna qualquer fóssil de Serpente com elementos craniais um achado da mais alta importância para o estudo do grupo (ex: CALDWEll \& LeE, 1997; ZAHER, 1998; ZAHER \& RIEPPEL, 1999; SCANLON \& LEE, 2000; TCHERNOV et al., 2000; CALDWEll \& Albino, 2002; RiePPel et al., 2003; SCANLON, 2005; 2006; APESTEguia \& ZAHER, 2006; CALdwell \& CAlvo, 2008; ZAHER et al. 2009). A subvalorização de elementos vertebrais em animais atuais não é 
acompanhada na literatura paleontológica, e pode-se dizer que toda tentativa de justificar o estudo da forma de elementos vertebrais em espécies atuais é, de uma forma ou outra, justificada pela necessidade de fornecer subsídios à paleotaxonomia do grupo (ex: AUFFENBERG, 1963; SZYNDLAR, 1984; RAGE, 1984; 1987; HOLMAN, 2000).

Essa subvalorização dos elementos vertebrais tem sido ressaltada inúmeras vezes ao longo da história da herpetologia moderna (ex: JOHNSON, 1954; GASC, 1976; LADUKE, 1991), porém esses apelos costumam ser ignorados por estudiosos da área. LADukE (1991) argumentou que esse processo é mais sociológico do que acadêmico, e que a dificuldade no entendimento das fontes de variação da forma vertebral e o caráter altamente áspero das críticas voltadas à paleontologia de serpentes são fatores que desencorajam o ingresso de estudantes nesse ramo. LADUKE (1991) coloca que esses processos são incentivados pela falta de entendimento sobre o padrão de variação da forma vertebral em Serpentes. O entendimento desses padrões pode, então, incentivar o abandono dessa mentalidade e a abertura de um novo ramo para o estudo da biologia de grupos atuais e fósseis, principalmente para a paleotaxonomia baseada em elementos vertebrais isolados (LADUKE, 1991).

Estas colocações são tentadoras, porém talvez a verdade nesse caso se encontre realmente entre os dois lados da argumentação. Enquanto é verdade que o padrão de variação é sistematicamente organizado em Serpentes (LADUKE, 1991; presente trabalho), e que essa característica permite a modelagem deste padrão para a avaliação da identidade de elementos dissociados, essa prática esbarra claramente em aspectos funcionais: Serpentes apresenta um número bastante elevado de elementos vertebrais com variação ao longo do esqueleto axial dos 
animais. Sendo assim, qualquer tipo de avaliação sobre a forma vertebral necessita levar em conta uma fonte de variação a mais, fato este que multiplica o esforço de amostragem de forma considerável: LADUKE (1991) avaliou as influências do dimorfismo sexual, ontogenia e variação intra-específica no esqueleto axial de Thamnophis sirtalis com base em todas as vértebras de apenas seis indivíduos. HEAD et al. (2009) estimaram a posição de uma vértebra isolada de Titanoboa cerrejonensis a partir da variação longitudinal de 21 Boídeos, porém restringiram a análise a apenas 21 posições ao longo do corpo dos animais. O presente trabalho avaliou 35 espécies de Serpentes em uma ampla escala taxonômica, avaliando 15 posições vertebrais ao longo do corpo, resultando em 525 observações em cada uma das quatro vistas, totalizando 2100 observações. Apesar de essa ser uma amostragem considerável e satisfatória na grande maioria de estudos morfométricos, quando avaliamos a forma vertebral em Serpentes, o esforço amostral acaba sendo particionado de forma a avaliar a variação intracolunar. Tendo em vista as restrições operacionais às quais os profissionais costumam estar sujeitos, isso acaba por diminuir o número de indivíduos que podem ser avaliados de forma estatística, limitando os tipos de inferências que podem ser feitas, ou mesmo restringindo consideravelmente a precisão das conclusões tiradas. Sendo assim, por mais que seja verdade que o problema da identificação de material vertebral dissociado seja factível do ponto de vista técnico, o tipo de informação necessária para a validação de tais práticas é laborioso, podendo ser descartado como operacional quando avaliado em termos de custo-benefício.

Uma possível solução para esse dilema é tentar focar estudos de vértebras dissociadas em análises interespecíficas ou na identificação da posição da 
vértebra dissociada. De fato, HEAD et al. (2009), o único trabalho de paleotaxonomia de Serpentes que emprega morfometria geométrica em vértebras dissociadas, não se vale de técnicas estatísticas para a classificação taxonômica, e sim para a identificação da posição do corpo da qual a vértebra se originou, relegando a identificação da espécie às técnicas clássicas de comparação, anatomia e morfologia. Analogamente, talvez seja possível avaliar a variação da forma vertebral entre diferentes espécies a partir de vértebras provenientes de uma mesma posição vertebral (LADUKE, 1991) de forma a otimizar o esforço amostral em termos de indivíduos avaliados. Entretanto, a classificação taxonômica de elementos dissociados parece ser um caso especial: apesar de ser verdade que a identificação da posição vertebral de elementos dissociados por outros meios possa permitir a ampliação das amostras e da elaboração de testes mais precisos, esse tipo de análise recairia necessariamente nas críticas feitas aos trabalhos taxonômicos que não levam em conta a variação longitudinal como um possível fator de confusão (MoON, 1999). Sendo assim, estudos taxonômicos precisam levar em conta a variação longitudinal o que os tornam extremamente custosos do ponto de vista operacional.

A solução talvez esteja no desenvolvimento de métodos de amostragem mais eficientes. A morfometria geométrica é um ramo que cresce consideravelmente. Hoje diversos livros-texto básicos ensinam os fundamentos teóricos desse conjunto de técnicas, e muitos softwares estão disponíveis a qualquer pesquisador interessado em incorporar esse tipo de análise em seus estudos. Pode-se considerar que esse ramo já atingiu a maturidade em termos teóricos, e que os desenvolvimentos futuros enfocarão na ampliação e refinamento desses princípios básicos de forma a expandir as possibilidades de aplicação (ADAMS et al. 2004). 
Um aspecto relevante, porém incipiente, do desenvolvimento da morfometria moderna é o surgimento de artigos que avaliam a forma de estruturas em três dimensões, não com a utilização de equipamentos de digitalização como Microscribe ${ }^{\mathrm{TM}}$, mas com o uso de scans 3D (ex: Macleod, 2008; Polly, 2008; Polly \& Macleod, 2008; McPeeK et al., 2008; VAN DER NIET et al., 2010). Tal fato se tornou possível, principalmente, pela diminuição do custo e aumento da acessibilidade de tais equipamentos, permitindo que pesquisadores se valham dessa tecnologia para explorar questões biológicas e paleontológicas. Se tal processo continuar, pode-se esperar que novos sistemas de digitalização 3D se tornem disponíveis no mercado, podendo eventualmente aumentar o corpo de dados gerado nas áreas de morfologia e morfometria.

Entretanto, enquanto esta possibilidade não se torna realidade, é necessário encarar as limitações que emergem da paleotaxonomia baseada em vértebras, e abordá-las da forma mais realista possível. Sendo assim, pode-se indicar algumas diretrizes para esse tipo de empreitada:

1- Restringir o estudo da forma apenas à vista anterior. A vista anterior tem se mostrado muito informativa em procedimentos de identificação da posição vertebral (POLLY \& HEAD, 2004; HEAD et al. 2009) e apresenta um poder classificatório tão elevado quanto outras vistas (presente trabalho) e deveria ser privilegiado em estudos que envolvem tanto identificação de posição vertebral quanto identificações taxonômicas.

\section{2- Amostrar mais de uma vértebra ao longo do corpo do animal. A} variação longitudinal no esqueleto axial em Serpentes não parece ser facilmente modelada linearmente, e é provável que a metodologia mais prática seja a construção de modelos empíricos (p. ex. baseados 
em outros espécimes) para avaliar a posição de uma vértebra ao longo do corpo do animal (Polly \& HeAd, 2004; HeAd et al. 2009). Faz-se necessária, então, a avaliação de um número de elementos vertebrais que amostrem de maneira relativamente homogênea a variação ao longo do corpo dos animais.

3- Restringir o escopo taxonômico das análises. Dado o limite da relação entre esforço amostral e indivíduos avaliados, a restrição do escopo taxonômico possibilitaria uma melhor distribuição do esforço, permitindo assim uma melhor avaliação de táxons hipoteticamente mais aparentados.

Tais diretrizes são provisórias e dificilmente se aplicam a todos os casos. $\mathrm{Na}$ presente análise muitos táxons foram melhor identificados em vistas laterais e posteriores, e não na anterior, o que invalidaria a primeira diretriz, sugerindo que talvez estas outras vistas, ou mesmo uma abordagem 3D seja mais adequada para estes táxons. Alternativamente, talvez seja possível estimar a posição de um elemento fóssil através de outras informações, permitindo assim ignorar completamente a variação longitudinal, focalizando o estudo em apenas uma posição (LADUKE, 1991). É possível também que o estudo concentre-se em um grupo fóssil que não apresenta nenhum representante vivente ou material articulado para a realização deste tipo de análise. De qualquer maneira as diretrizes definidas aqui, mesmo não sendo universalmente aplicáveis, parecem abordar os principais pontos das análises paleotaxonômicas de vértebras de Serpentes, levando em conta os principais problemas decorrentes deste tipo de análise, incluindo às de origem operacional. 


\section{Bibliografia Utilizada}

Adams, D. C.; Cerney, M. M. 2007. Quantifying biomechanical motion using Procrustes motion analysis. Journal of Biomechanics, 40: 437444.

ADAMS. D.C.; RoHLF, F.J.; SLICE, D.E. 2004. Geometric morphometrics: ten years of progress following the 'revolution'. Italian Journal of Zoology 71:5:16.

AKAIKE, H. 1973. Information theory as an extension of the max- imum likelihood principle. Em: Petrov B.N.; Csaki, F. (eds.). Second International Symposium on Information Theory. Akademiai Kiado, Budapest. pp. 267-281 .

Apesteguia, S.; ZAHer, H. 2006. A Cretaceous terrestrial snake with robust hindlimbs and a sacrum. Nature 440(7087):1037-1040.

ARnold, S.J. 1983. Morphology, Performance and Fitness. American Zoologist 23(2):347-361.

ARNOLD, S.J., BENNETT A. F. 1988. Behavioural variation in natural populations. V. Morphological correlates of locomotion in the garter snake (Thamnophis radix). Biological Journal of the Linnean Society 34:175-190.

AufFEnberG, W. 1963. The fossil snakes of Florida. Tulane Studies in Zoology 120:131-216.

AXELROD, D.L. 1966. Origin of deciduous and evergreen habitats in temperate forests. Evolution 20:1-15.

Blomberg, S.P., Garland JR, T., IVes, A. R. (2003) Testing for phylogenetic signal in comparative data: behavioral traits are more labile. Evolution 57:717-745.

BOOKSTEIN F.L. (1997). Landmark methods for forms without landmarks: morphometrics of group differences in outline shape. Medical Image Analysis 1(3):225-243.

Bookstein F.L.; Chernoff, B.; Elder, R. 1985. Morphometrics in Evolutionary Biology. The Academy of Natural Sciences of Philadelphia. 277pp.

BooksteIN, F.L. (1991). Morphometric Tools for Landmark Data: Geometry and Biology. Cambridge University Press, Cambridge, 
$435 \mathrm{pp}$.

BubrinK, F.T. 2005. Inferring the phylogenetic position of Boa constrictor among the Boinae. Molecular Phylogenetics and Evolution 34(1):167-180.

Burke, A.C.; Nelson, C. E.; Morgan, B. A.; Tabin, C. 1995. Hox genes and the evolution of vertebrate axial morphology. Development, 121:333-346.

Butler M.; King, A.A. 2004 Phylogenetic comparative analysis: a modeling approach for adaptive evolution. The American Naturalist 164(6):683-695.

CADLE, J.E. 1988. Phylogenetic relationships among advanced snakes: a molecular perspective. University of California Publications in Zoology 119:1-70.

Caldwell M.W. LeE, M.S. 1997. A snake with legs from the marine Cretaceous of the Middle East. Nature 186(17):705-709.

Caldwell M.W.; Albino, A. 2002. Exceptionally preserved skeletons of the Cretaceous snake Dinilysia patagonica Woodward, 1901. Journal of Vertebrate Paleontology 22(4):861-866.

Caldwell, M.W.; Calvo, J. 2008. Details Of a New Skull and Articulated Cervical Column Of Dinilysia Patagonica Woodward, 1901. Journal of Vertebrate Paleontology 28(2):349-362.

Carroll, R.L. 1988. Vertebrate Paleontology and Evolution. W. H. Freeman, Nova York. 698 pp.

Christman, S.P. 1975. The status of the extinct rattlesnake, Crotalus giganteus. Copeia 1975(1):43-47.

CoAtes M., Ruta M. 2000. Nice snake, shame about the legs. Trends in Ecology and Evolution 15(12):503-507.

CoHn, M.J.; Tickle, C. 1999. Developmental basis of limblessness and axial patterning in snakes. Nature 399(6735):474-478.

ConRad, J.L. 2008. Phylogeny And Systematics Of Squamata (Reptilia) Based On Morphology. Bulletin of the American Museum of Natural History 310(182):1-61.

Di-PoÏ N.; Montoya-Burgos, J.I.; Miller, H.; Pourquié, O.; Milinkovitch, M.C.; Duboule, D. 2010. Changes in Hox genes' structure and function during the evolution of the squamate body 
plan. Nature 464(7285):99-103.

DRYDEN, I. 2009. Package shapes: Statistical shape analysis (versão 1.13). URL: http://www.maths.nott.ac.uk/ ild/shapes .

Dryden, I.; MARdia, K.1998. Statistical Shape Analysis. John Wiley and Sons, Chichester.

ESTES, R. 1970. Origin of the recent North American lower vertebrate fauna: an inquiry into the fossil record. Forma et Functio 3:139-163.

Estes, R.; Tinen, J.A. 1964. Lower vertebrates from the Valentine Formation of Nebraska. American Midland Naturalist 72:453-472.

FRY B.G.; VIDAL, N.; VAN DER WeERd, L.; KOCHVA, E. 2009. Evolution and diversification of the Toxicofera reptile venom system. Journal of Proteomics 72(2):127-136.

Garland, T. JR.; HueY, R.B. 1987. Testing Symmorphosis: Does Structure Match Functional Requirements?. Evolution 41(6):14041409.

GASC, J. P. 1976. Snake vertebrae-a mechanism or merely a taxonomist's toy? Em: Bellairs, A. D'A.; Cox, C.B. (Eds). Morphology and biology of reptiles. Linnean Society of London Symposium Series 3:177-190.

Gomez, C.; ÖzbudaK, E.M.; Wunderlich, J.; DaumanN, D.; LeWIS, J.; PourquiÉ, O. 2008. Control of segment number in vertebrate embryos. Nature 454(7202):335-339.

Gould, S.J.; VRBA, E.S. 1982. Exaptation - a missing term in the science of form. Paleobiology 8: 4-15.

Gower J.C., 1975. Generalized Procrustes analysis. Psychometrika, 40:33-51.

Grazziotin, F. G., Zaher, H.; Ferrarezzi, H.; KlaczKo, J.; Bonatto, S. L.; WILKINSON, M. 2007. Higher-Level molecular phylogeny of snakes: Conflicts and congruence. Darwiniana, 45:17-19.

Head, J.J; Bloch, J.I; Hastings, A.K., Bourque, J.R. Cadena, E.A.; Herrera, F.A.; Polly, P.D.; Jaramillo, C.A. 2009. Giant boid snake from the Palaeocene neotropics reveals hotter past equatorial temperatures. Nature 457(7230):715-717.

Head, J.J.; Polly, P.D. 2007. Dissociation of somatic growth from segmentation drives gigantism in snakes. Biology Letters, Publicado 
online: doi:10.1098/rsbl.2007.0069 .

Hedges S.B.; Couloux, A.; Vidal, N. 2009. Molecular phylogeny, classification, and biogeography of West Indian racer snakes of the Tribe Alsophiini (Squamata, Dipsadidae, Xenodontinae). Zootaxa 2067:1-28.

Holman, J.A. 1973. Reptiles of the Egelhoff Local Fauna (Upper Miocene) of Nebraska. Contributions from the Museum of Paleontology 24(12):125-134.

Holman, J.A. 1970. Herpetofauna ot the Wood Mountain Formation (Upper Miocene) of Saskatchewan. Canadian Journal of Earth Sciences 7:1317-1325.

Holman, J.A. 1976a. Snakes from the Rosebud Formation (Middle Miocene) of South Dakota. Herpetologica 32:41-48.

Holman, J.A. 1976b. Snakes of the Gering formation (Lower Miocene) of Nebraska. Herpetologica 32:88-94.

Holman, J.A. 1977a. Amphibians and reptiles from the Gulf Coast Miocene of Texas. Herpetologica 33:391-403.

Holman, J.A. 1977b. Additional snakes from Miocene of western Nebraska. Herpetologica 33:443-446.

Holman, J.A. 2000. The Fossil Snakes of North America: Origin, Evolution, Distribution, Paleoecology. Indiana University Press, Bloomington, Indiana. $376 \mathrm{pp}$.

Howey, M.O. 2005. The Encircled Serpent. A study of Serpent symbolism in all countries and ages. Noble Printers, INC. New York. NY. 424 pp.

IKeDA, T. 2007. A Comparative Morphological Study of the Vertebrae of Snakes Occurring in Japan and Adjacent Regions. Current Herpetology 26(1):13-34.

ISBELL, L.A. 2006. Snakes as agents of evolutionary change in primate brains. Journal of Human Evolution 51(1):1-35.

JACKSON, K. 2003. The evolution of venom-delivery systems in snakes. Zoological Journal of the Linnean Society 137:337-354.

JACKSON, K. 2007. The evolution of venom-conducting fangs: Insights from developmental biology. Toxicon 49(7):975-981. 
JoHnson, R.G. 1954. The adaptive and phylogenetic significance of vertebral form insnakes. Evolution 9:367-388.

JOHNSON, R.G. 1955. The origin and evolution of the venomous snakes. Evolution 10(1):56-65.

Kelly, C.; Barker, N.; Villet, M.; Broadley, D. 2009. Phylogeny, biogeography and classification of the snake superfamily Elapoidea: a rapid radiation in the late Eocene. Cladistics 25(1):38-63.

Kendall, D.G. 1977. The diffusion of shape. Advances in Applied Probability 9:428-430.

Kendall, D.G.; BARDEn, D.; CARne, T.K.; Le, E. 1999. Shape and Shape Theory (1st edition).Wiley. Chichester. West Sussex. 318 pp.

Kingsolver, J.G.; HueY, R.B. 2003. Introdution: The Evolution of Morphology, Performance, and Fitness. Integrative Comparative Biology, 43:361-366.

Kuch, U.; Müller, J.; Mödden, C.; Mebs, D. 2006. Snake fangs from the Lower Miocene of Germany: evolutionary stability of perfect weapons. Naturwissenschaften 93:84-87.

LADUKE, T.C. 1991. Morphometric variability of the precaudal vertebrae of Thamnophis sirtalis sirtalis (Serpentes: Colubridae), and implications for interpretation of the fossil record. Tese de doutorado, Graduate Faculty in Biology, City University of New York, New York. 235 pp.

LAWSON, R.; Slowinski, J.B.; BURBRINK, F.T. 2004. A molecular approach to discerning the phylogenetic placement of the enigmatic snake Xenophidion schaeferi among the Alethinophidia. Journal of Zoology (London) 263:285-294.

LAWson, R.; Slowinski, J.B.; Crother, B.I.; Burbrink, F.T. 2005. Phylogeny of the Colubroidea (Serpentes): new evidence from mitochondrial and nuclear genes, Molecular Phylogenetics and Evolution 37:581-601.

LEE, M.S.Y. 1998. Convergent evolution and character correlation in burrowing squamates: a phylogenetic analysis. Biological Journal of the Linnean Society. 65:369-453.

LEE, M.S.Y. 2005. Squamate phylogeny, taxon sampling, and data congruence. Organisms Diversity \& Evolution 5(1):25-45. 
LEE, M.S.Y. 2009. Hidden support from unpromising data sets strongly unites snakes with anguimorph 'lizards'. Journal of Evolutionary Biology 22(6):1308-1316.

LeE, M.S.Y.; CALDWell, M.W. 1998. Anatomy and relationships of Pachyrhachis problematicus, a primitive snake with hindlimbs. Philosophical Transactions of the Royal Society of London, Series B (Biological Sciences) 353:1521-1552.

LeE, M.S.Y.; Hugall, A.; Lawson, R.; Scanlon, J. 2007. Phylogeny of snakes (Serpentes): combining morphological and molecular data in likelihood, Bayesian and parsimony analyses. Systematics and Biodiversity 5(04):1-19.

LEE, M.S.Y.; SCANLON, J.D. 2002. Snake phylogeny based on osteology, soft anatomy and behaviour. Biological Reviews 77:333-401.

LELE, S. 1999. Invariance and Morphometrics: A Critical Appraisal of Statistical Techniques for Landmark Data. Em: ChaPlain, M.A.J.; Singh. G.D.; McLaChlan, J.C. (Eds.). On Growth and Form: Spatio-temporal Formation in Biology. John Wiley \& Sons Ltd., Chicester, pp. 325-336.

LeSTREL, P.E. 2000. Morphometrics for the Life Sciences. World Scientific Publishing Co. Pte. Ltd. Singapore, 261pp.

LYNCH, V. 2009. Live-Birth in vipers (Viperidae) is a Key innovation and adaptation to global cooling during the cenozoic. Evolution 63(9): 2457-2465.

MacGinitie, H.D. 1962. The Kilgore flora: a late Miocene flora from northern Nebraska. University of California Publications in Geological Sciences 35:67-157.

MACLEOD, N. 2008. Understanding morphology in systematic contexts: 3D specimen ordination and 3D specimen recognition. Em: WheEler, Q. (ed.), The New Taxonomy. CRC Press, Taylor \& Francis Group, London. Pp. 143-210.

Manly, B.F.J. 1997. Randomization, Bootstrap and Monte Carlo Methods in Biology. London, Chapman and Hall. 461pp

MARCUS, L.F.; Hingst-Zaher E.; ZAHER H. 2000. Application of landmark morphometrics to skulls representing the orders of living mammals. Hystrix. 11:27-47.

MCDowell, S.B. 1975. A catalogue of the snakes of New Guinea and 
the Solomons, with special reference to those in the Bernice P. Bishop Museum. Part II. Anilioidea and Pythoninae. Journal of Herpetology 9:1-80.

McDowell, S.B. 1987. Systematics. Em: Seigel, R.A.; Collins J.T.; NovaK, S.S. (Eds.), Snakes: Ecology and Evolutionary Biology. Macmillan Publishing Co., New York, pp.3-50.

McPeeK, M.A.; Shen, L.; Torrey, J.Z.; FARID, H. 2008. The tempo and mode of three-dimensional morphological evolution in male reproductive structure. American Naturalist 171:E158-E178.

Moon, B.R. 1999. Testing an Inference of function from structure: Snake vertebrae do the Twist. Journal of Morphology 241:217-225.

Moon, B.R. 2000. The mechanics and muscular control of constriction in gopher snakes (Pituophis melanoleucus) and a king snake (Lampropeltis getula). Journal of Zoology 252(01):83-98.

Noonan, B.P.; Chippindale, P.T. 2006. Dispersal and vicariance: The complex evolutionary history of boid snakes. Molecular Phylogenetics and Evolution 40(2):347-358.

OKsanen J.; Blanchet, F.G.; Kindt, R.; Legendre, P.; O'Hara, R. B., Simpson, G.L. Solymos, P.; Henry, M.; Stevens, H.; WAGner, H. 2010. Package Vegan: Community Ecology Package (versão 1.173). URL: http://vegan.r-forge.r-project.org/ .

Palmeirim, I., Henrique, D., Ish-Horowicz, D.; Pourquié, O. 1997 Avian hairy gene expression identifies a molecular clock linked to vertebrate segmentation and somitogenesis. Cell 91:639-648.

Paradis, E.; Bolker. B.; Claude, J.; CuOng, H.S.; DesPer, R.; Durand, B.;, Dutheil, J.; Gascuel, O.; Heibl, C.; Lawson, D.; Lefort, V.; Legendre, P.; LeMON, J.; NoEl, Y.; NYLANDER, J.; OPGEN-Rhein, R.; STRIMmer, K., DE VIENNE. D. 2010. APE: Analyses of Phylogenetics and Evolution (versão 2.5-3). URL: http://ape.mpl.ird.fr/ .

Peres-Neto, P.R.; JaCKson, D.A. 2001. How well do multivariate data sets match? The advantages of a Procrustean superimposition approach over the Mantel test. Oecologia 129: 169-178.

Perez, S.P.; Bernal, V.; GonZalez, P.N. (2006) Differences between sliding semi-landmark methods in geometric morphometrics, with na application to human craniofacial and dental variation. Journal of 
Anatomy. 208:769-784.

Polly, P. D. 2008. Adaptive Zones and the Pinniped Ankle: A 3D Quantitative Analysis of Carnivoran Tarsal Evolution. Em: SARGIS, E.; Dagosto, M. (Eds.). Mammalian Evolutionary Morphology: A Tribute to Frederick S. Szalay. Springer: Dordrecht, The Netherlands. 167-196pp.

Polly, P. D.; HeAD, J. J. 2004. Maximum-likelihood identification of fossils: taxonomic identification of Quaternary marmots (Rodentia, Mammalia) and identification of vertebral position in the pipesnake Cylindrophis (Serpentes, Reptilia). Em: ElewA, A. (Ed.). Morphometrics: Applications in Biology and Paleontology. Springer, pp. 197- 221.

Polly, P. D.; Head, J. J.; Cohn, M. J. 2001. Testing modularity and dissociation: The Evolution of regional proportions in snakes. Em: ZELDITCH, M. (Ed.). Beyond heterocrony. The Evolution of development. Wiley-Liss Publication. New York, NY. 305-335.

Polly, P.D.; MACLeOD, N., 2008. Locomotion in fossil carnivora: an application of eigenshurface analysis for morphometric comparicon. Palaeontologia Electronica 11(2);1-13.

Pough, F. H.; Handrews, R. M.; Cadle, J. E.; Crump, M. L.;SAvitzKy, A. H.; Wells, K. D. 1998. Herpetology. Prentice Hall, New Jersey, USA, 577pp.

Prange, H. D., Christman, S. P. 1975. The allometrics of rattlesnake skeletons. Copeia, 3:542-545.

R Development Core Team 2010. A language and environment for statistical computing. R Foundation for Statistical Computing, Vienna, Austria. URL http://www.R-project.org .

Rage, J. C. 1984. Serpentes. Part 11. Handbuch der Paläoherpetologie, Encyclopedia of Paleo-herpetology. Gustav Fischer Verlag., Stuttgart.

Rage, J. C. 1987. Fossil History. Em: Seigel, R.A.; Collins, J.T.; NovaK, S.S. (Eds.). Snakes. Ecology and evolutionary biology. Macmillian Publishing Company. New York. pp. 51-76.

RIEPPEL, O. 1988. A review of the origin of snakes. Evolutionary Biology 22:37-130.

ROHLF, F.J. 2000. On the use of shape spaces to compare morphometric 
methods. Hystrix (n.s.) 11(1): 8-24.

RoHLF, F.J.; SLICE, D.E. 1990. Extensions of the Procrustes method for the optimal superimposition of landmarks. Systematic Zoology, 39, $40-59$.

Royall, M.R. 1997. Statistical evidence: a likelihood paradigm. Chapman and Hall, New York. 191 pp.

RUBEN, JA. 1977. Morphological correlates of predatory modes in the coachwhip (Masticophis flagellum) and rosy boa (Lichanura roseofusca). Herpetologica 33:1-6.

Saint, K.M.; Austin, C.C.; Donnellan, S.C.; HutChinson, M.N. 1998. C-mos, a nuclear marker useful for squamate phylogenetic analysis. Molecular Phylogenetics and Evolution 10(2): 259-263.

SAVITZKY A.H. 1980. The role of venom delivery strategies in snake evolution. Evolution, 34(6):1194-1204.

SAVITZKY, A.H. 1983. Coadapted character complexes among snakes: fossoriality, piscivory, and durophagy. American Zoologist 23:397409.

SCANLON, J.D. \& LEE, M.S.Y. 2000. The Pleistocene serpent Wonambi and the early evolution of snakes. Nature 403:416-420.

SCANLON, J.D. 2005. Cranial morphology of the Plio-Pleistocene giant madtsoiid snake Wonambi naracoortensis. Acta Palaeontologica Polonica 50(1):139-180.

SCANLON, J.D. 2006. Skull of the large non-macrostomatan snake Yurlunggur from the Australian Oligo-Miocene. Nature 439(7078):839-842.

SCHLUTER, D. 1996. Adaptive radiation along genetic lines of least resistance. Evolution 50(5):1766-1774.

SChluter, D.; Price, T.; MoOers. A.O.; Ludwig, D. 1997. Likelihood of ancestor states in adaptive radiation. Evolution 51(6):1699-1711.

Shine R.; Schwaner, T. 1985. Prey Constriction by Venomous Snakes: A Review, and New Data on Australian Species. Copeia 1985(4):1067-1071.

SHINE, R. 2000. Vertebral numbers in male and female snakes: the roles of natural, sexual and fecundity selection. Journal of Evolutionary Biology, 13:455-465. 
Slice, D. E. 2001. Landmark coordinates aligned by Procrustes analysis do not lie in Kendall's shape space. Systematic Biology 50(1):141149.

Strauss, R.E.; Bookstein, F.L. 1982. The truss - body form reconstructions in morphometrics. Systematic Zoology 31:113-135.

TChernov, E.; RiepPel, O.; Zaher, H.; Polcyn, M. J.; JACOBS, L. L. 2000. A fossil snake with limbs. Science 287:2010-2012.

TIHEN, J. A. 1964. Tertiary changes in the herpetoaunas of tempretate North America. Senchenbergiana Biologica 45:265-279.

Townsend, T.M., LARson, A., Louis, E., MaCEY, J.R. 2004. Molecular phylogenetics of Squamata: the position of snakes, amphisbaenians, dibamids, and the root of the squamate tree. Systematic Biology. 53(3):735-757.

TsuiniJi, T.; KeARney, M.; RiePPel, O. 2006. First Report of a Pectoral Girdle Muscle in Snakes, with Comments on the Snake Cervicodorsal Boundary. Copeia 2006(2):206-215.

Uetz, P. 2009. The Reptile Database, http://www.reptile-database.org (Research Center Karlsruhe, Karlsruhe, Germany, 2009).

VAN DER NieT T.; ZOLLIKOFER, C.P.; PONCE DE LEÓN, M.S.P.; JOHNSON, S.D.; LINDER, H.P. 2010. Three-dimensional geometric morphometrics for studying floral shape variation. Trends in Plant Science 794:1-4.

VIDAL, N.; 2002. Colubroid Sustematics: Evodence for an early appearence of the venom apparatus followed by extensive evolutionary tinkering. Journal of Toxicology 21(1-2):21-41.

VIDAL, N.; DAVID, P. 2004. New insights into the early history of snakes inferred from two nuclear genes. Molecular Phylogenetics and Evolution 31(2):783-787.

Vidal, N.; Delmas, A.; David, P.; Cruaud, C.; Couloux, A.; Hedges, S.B.; 2006. The phylogeny and classification of caenophidian snakes inferred from seven nuclear protein-coding genes. Comptes Rendus Biologies 330(2):182-187.

Vidal, N.; Delmas, A.; Hedges, S.B. 2007. The higher-level relationships of alethinophidian snakes inferred from seven nuclear and mitochondrial genes. Em: Henderson, R.W.; Powell, R. (Eds.). Biology of the boas and pythons. Eagle Mountain Publishing, 
Eagle Mountain, Utah. pp. 27-33.

VIDAL, N.; Hedges, S.B. 2002. Higher-level relationships of snakes inferred from four nuclear and mitochondrial genes. Comptes Rendus Biologies 325(9): 977-985.

VIDAL, N.; HEDGES, S.B. 2004. Molecular evidence for a terrestrial origin of snakes. Proceedings of the Royal Society B: Biological Sciences 271(4):S226-S229.

Vidal, N.; Hedges, S.B. 2005. The phylogeny of squamate reptiles (lizards, snakes, and amphisbaenians) inferred from nine nuclear protein-coding genes. Comptes Rendus Biologies 325(2005):10001008.

VIDAL, N.; Hedges, S.B. 2009. The molecular evolutionary tree of lizards, snakes, and amphisbaenians. Comptes Rendus Biologies 332 (2-3):129-139.

Vidal, N.; Rage J.C.; Couloux A.; Hedges, S.B. 2009. Snakes (Serpentes). Em: Hedges, S.B.; Kumar, S. (Eds.). The Timetree of Life. pp. 390-397.

Vonk, F.J.; AdmiraAl, J.F.; Jackson, K/; ResheF, R.; DE BAKKeR, M.A.G.; VANDERSCHOOT, K.; VAN DEN BERGE I.; VAN ATTEN, M.; Burgerhout, E.; Beck, A.; Mirtschin, P.J.; KochVa, E.; Witte, F.; FRY, B.G.; WOODS, A.E.; RICHARDSON, M.K. 2008. Evolutionary origin and development of snake fangs. Nature 454(7204): 630-633.

WERNESS, H.B. 2006. The Continuum encyclopedia of animal symbolism in art. The Coninuum International Publishing Group Inc. New Yourk. NY. 481 pp.

Wiens, J.J.; Kuczynski, C.A.; Smith, S.A.; Mulcahy D, Sites J, TOWNSEND T, REEDER TW 2008. Branch Lengths, Support, and Congruence: Testing the Phylogenomic Approach with 20 Nuclear Loci in Snakes. Systematic Biology 57(3):420-431.

Wiens, J.J.; Sligluff, J.L. 2001. How lizards turn into snakes: a phylogenetic analysis of body-form evolution in anguid lizards. Evolution 55(11):2303-2318.

Wilcox, T.P.; Zwickl, D.J.; HeAth, T.A.; Hillis, D.M. 2002. Phylogenetic relationships of the dwarf boas and a comparison of Bayesian and bootstrap measures of phylogenetic support. Molecular Phylogenetics and Evolution 25:361-371. 
Woltering J.M.; VonK, F.K.; MÜller, H.; Bardine, N.; Tuduce, I.L.; DE BAKKeR, M.A.; KNÖChel, W.; Sirbu, I.O.; DurSTON, A.J.; RICHARDSON, M.K. 2009. Axial patterining in snakes and caecilians: evidence for an alternative interpretation of the Hox code. Developmental Biology, 332(1):82-89.

ZAHER, H,; RIEPPEL, O. 2002. On the phylogenetic relationships of the Cretaceous snakes with legs, with special reference to Pachyrhachis problematicus (Squamata, Serpentes). Journal of Vertebrate Paleontology 22(1):104-109.

ZAHER, H. 1998. The phylogenetic position of Pachyrhachis within snakes (Squamata, Lepidosauria). Journal of Vertebrate Paleontology 18(1):1-3.

Zaher, H.; Grazziotin, F.G.; Cadle, J.E.; Murphy, R.W.; MouraLEITE, J.C.DE.; BonATTO, S.L. 2009. Molecular phylogeny of advanced snakes (Serpentes, Caenophidia) with an emphasis on South American Xenodontines: a revised classification and descriptions of new taxa. Papéis Avulsos de Zoologia (São Paulo) 49(11):115-153.

ZAHER, H.; RIEPPEL, O. 1999. The phylogenetic relationships of Pachyrhachis problematicus and the evolution of limblessness in snakes (Lepidosauri, Squamata). Comptes Rendus de l'Academie des Sciences de Paris, Sciences de la Terre, France 329:831-837.

ZAHER, H.1994. Les Tropidopheoidea (Serpentes, Alethinophidia) Sontils reellement monophyletiques? Arguments en faveur de leur polyphyletisme. Comptes Rendus de L'Academie des Sciences de Paris 317:471-478.

Zelditch, M. L.; Swiderski, D. L.; SheEts, H. D.; FinK, W. L. 2004. Geometric morphometrics for biologists: a primer. Elsevier Academic Press, San Diego, CA. 


\section{Apêndice I - Filogenia e indivíduos analisados}

\subsection{Filogenia utilizada}

Para as análises comparativas, utilizou-se a filogenia proposta por GraZZiotin et al. (2007) como base inicial, pelo grande compartilhamento de táxons terminais nas análises (Figura 7.1). Entretanto, tendo em vista o grande número de análises filogenéticas recentes, e da constante prevalência de sinais conflitantes (BUBRINK, 2005; VidAl et al., 2006; APESTEGUÍA \& ZAHER, 2006; VidAL et al., 2007; LeE et al., 2007; GRAZZIOTIN et al. 2007; WIENs et al., 2008, VIDAL et al., 2009; ZAHER et al., 2009; HEDGES et al., 2009), a árvore original foi modificada de forma a refletir essa incerteza. O monofiletismo de Scolecophidia foi mantido apesar dos resultados de algumas análises moleculares recentes (WIENS et al., 2008; VIDAL et al., 2009) uma vez que muitas das análises morfológicas e moleculares apontam para existência deste clado (APESTEGUÍA \& ZAHER, 2006; VIDAL et al., 2007; LEE et al., 2007). Aniliidae e Tropidophiidae foram reunidos na base de Alethinophidia, porém não foram colocados em um grupo monofilético como sugerido por alguns autores (VIDAL et al., 2007, 2009), uma vez que a posição exata de Tropidophiidae ainda é disputada (ZAHER, 1994; WiLCOX et al. 2002; APESTEGUÍA \& ZAHER, 2006; VIDAL et al., 2007; LEe et al., 2007). A posição de Bolyeriidae também é disputada dentro de Caenophidia (APESTEGUía \& ZAHER, 2006; VIDAL $e t$ al., 2007; LEE et al., 2007), e por esse motivo também foi colocado na mesma politomia basal.

Caenophidia foi mantida com Acrochordus como grupo irmão de Colubroides, e Viperidae como grupo irmão do clado formado por 
Colubridae e Elapidae (ZAHER et al. 2009). A associação entre Pythonidae, Loxocemidae e Xonopeltidae são reconhecidas por diversas análises filogenéticas (VIDAL et al., 2007, 2009; LEE et al., 2007) e por esse motivo foram mantidos unidos. As relações entre os grupos de boídeos, entretanto, não parecem totalmente esclarecidas: apesar de muitos dos clados de Boinae achados por GRAZIOTTIN et al. (2007) estarem presentes também em outros trabalhos (e.g. NoONAN \& ChipPindale 2006), o mesmo não parece ser verdade para os grupos Erycinae e Calabariinae. Por motivos práticos foram utilizados para Boidae as relações propostas por NoONAN \& ChIPPINDALE (2006) uma vez que este trabalhado apresenta estimativas dos tempos de divergência entre as espécies analisadas.

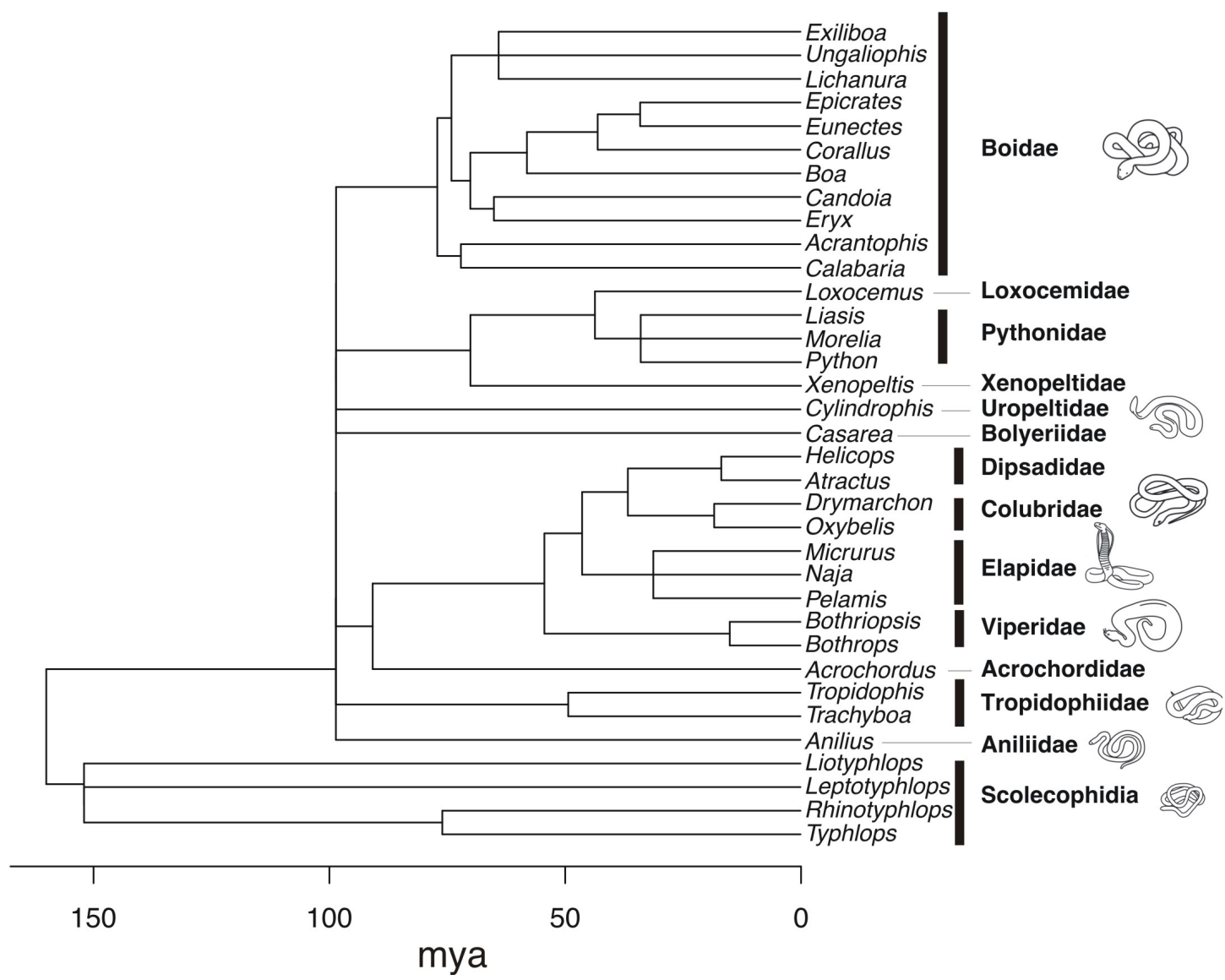

Figura 7.1. Hipótese filogenética entre as espécies analisadas utilizada nas analises comparativas. Escala em milhões de anos. Ver texto para maiores detalhes. 
Os tempos de divergência entre os grandes grupos foram obtidos de VIDAL et al. (2009). Em decorrência das incongruências tanto de clados formados quanto dos terminais usados na análise, alguns comprimentos de ramos foram obtidos de outros trabalhos. Como não há estimativas exatas para todas as espécies de elapídeos estudados, estes foram agrupados em uma politomia não-resolvida e o tamanho dos ramos igualado à data estimada para a diversificação de Elapidae (Kelly et al. 2009). As datas para colubrídeos foram obtidas utilizando Hedges et al. (2009), tendo como base os grupos monofiléticos propostos em ZAHER et al. (2009). Os tamanhos de ramos de Boidae foram obtidos diretamente de Noonan \& Chippindale (2006). Os clados (Lichanura, (Ungaliophis, Exiliboa)) e ((Liasis, Morelia),Python) foram politomizados por ausência de informação da data de divergência destes grupos. A divergência entre Bothrops e Bothriopsis foi obtida de LYNCH (2009). O tamanho dos ramos de Tropidophis e Trachyboa não foi achada na literatura. Por esse motivo, a data de divergência entre esses grupos foi estimada como a metade do comprimento do ramo exclusivo de Anilius. Esta medida, apesar de pouco precisa, é compatível com o tamanho do ramo achado por WIENS et al. (2008). O tamanho dos ramos internos que apresentam incongruência entre os trabalhos publicados foi fixado como 0.01 mya. Esse tamanho de ramo é pequeno o suficiente para não direcionar a análise para um resultado presumidamente incerto (a resolução da politomia).

Apesar dessa árvore não refletir precisamente hipóteses atuais sobre a filogenia do grupo (ver introdução), não se espera que mudanças na estrutura da árvore influenciem muito o resultado das análises aqui apresentadas. A razão disso é que em análises comparativas é a quantidade de história compartilhada que influencia as covariâncias 
evolutivas, e não o padrão exato dos eventos de cladogênese (RoHLF, 2001). Ou seja, mesmo que as decisões a respeito da estrutura da árvore e tamanho de ramos aqui tomadas sejam contestáveis, elas dificilmente terão impacto nos resultados das análises estatísticas.

Árvore em formato Newick com tamanho de ramos em milhões de anos (mya) é:

((((Typhlops:75.95,Rhinotyphlops:75.95):75.95,Leptotyphlops:151.89):0. 01,Liotyphlops:151.9):8,(Anilius:98.5,((Trachyboa:49.245,Tropidophis:4 9.245):49.245,((Acrochordus:90.7,((Bothrops:15,Bothriopsis:15):39.3,((P elamis:31.2,(Naja:31.19,Micrurus:31.19):0.01):15.1,((Oxybelis:18.3,Dry marchon:18.3):18.3,(Atractus:16.8,Helicops:16.8):19.8):9.7):8):36.4):7.7 8,(Casarea:98.47,(Cylindrophis:98.45,(Xenopeltis:70.1,((Python:34,(Mo relia:33.99,Liasis:33.99):0.01):9.7,Loxocemus:43.7):26.4):28.47):0.01,(( Calabaria:72,Acrantophis:72):5,(((Eryx:65,Candoia:65):5,(Boa:58,(Corall us:43,(Eunectes:34,Epicrates:34):9):15):12):4,(Lichanura:64,(Ungaliophi s:63.99,Exiliboa:63.99):0.01):10):3):21.46):0.01):0.01):0.01):0.01):61.4); 


\subsection{Indivíduos analisados}

Typhlopidae: Typhlops brongersmianus (MZUSP 14684); Rhinotyphlops schlegelii (MNHN 1897-25)

Leptotyphlopidae: Leptotyphlops koppesi (MZUSP 12305)

Anomalepididae: Liotyphlops beui (IBUSP 46596)

Aniliidae: Anilius scytales (IBUSP IB-46845)

Uropeltidae: Cylindrophis ruffus (USNM 523565)

Xenopeltidae: Xenopeltis unicolor (USNM 258746)

Loxocemidae: Loxocemus bicolor (MZUSP 14114)

Boidae

Boinae: Boa constrictor (MZUSP14134) , Candoia carinata (MZUSP 14112), Epicrates cenchria (IBUSP IB-52174), Corallus hortulanus (MZUSP 14128), Eunectes murinus (MZUSP 2501), Acrantophis dumerili (MZUSP 14430)

Erycinae: Eryx jaculus (MZUSP 14101)

Calabarinae: Calabaria rheinhardtii (MZUSP 14429) , Lichanura roseofusca ( MZUSP 7283), Exiliboa placata (MZUSP 8426), Ungaliophis continentalis (UTACV 31881).

Pythonidae: Morelia viridis (MZUSP 14428), Liasis albertisi (MZUSP 14098), Python molurus (MZUSP sn.)

Tropidophiidae: Trachyboa boulengeri (MZUSP 5247), Tropidophis paucisquamis (MZUSP 11286).

Bolyeriidae: Casarea dussumieri (BMNH 1992.27)

Acrochordidae: Acrochordus granulatus (USNM 497610)

Elapidae: Micrurus frontalis (MZUSP 14016), Pelamis platurus (MZUSP 9545) , Naja haje (MZUSP 10511)

Colubridae: Drymarchon corais (MZUSP 14588), Oxybelis aenaus (MZUSP 13028).

Dipsadidae: Atractus pantostictus (MZUSP 121270), Helicops haqmanni (MZUSP 5092)

Viperidae: Bothrops moojeni (MZUSP 14004), Bothriopsis bilineata (MZUSP 4399) 


\section{Apêndice II - Sumários da variação do esqueleto axial de cada espécie.}

Sumários dos morfoespaços das formas vertebrais referentes à variação do esqueleto axial em cada espécie nas vistas anterior, lateral, posterior e ventral (agrupamento do tipo B). As espécies encontram-se listadas em ordem alfabética.

Legenda dos sumários:

Sumários das vista Anterior: A-8

Sumários das vista Lateral: A-43

Sumários das vista Posterior: A-78

Sumários das vista Ventral A-113 


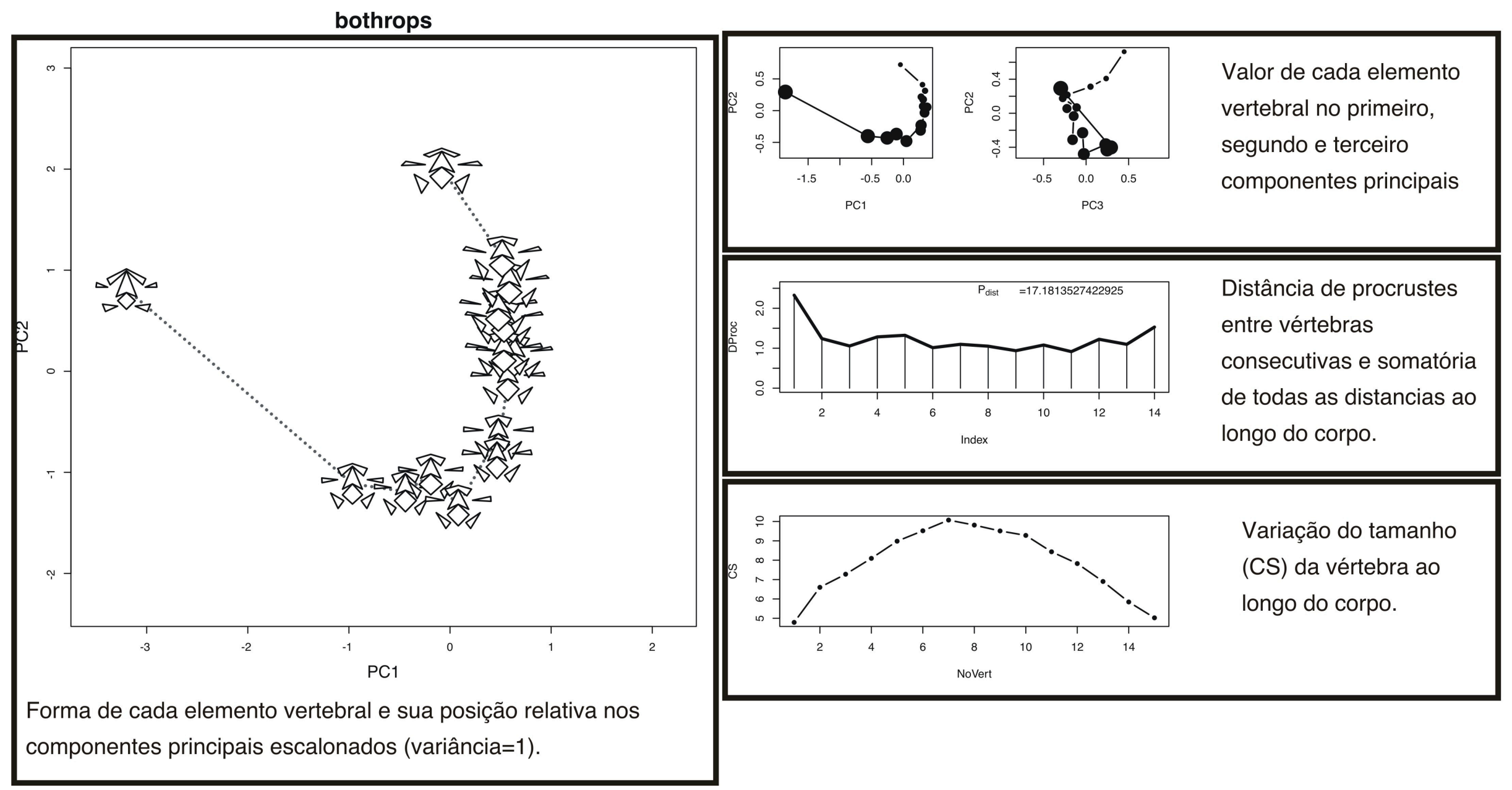

Legenda dos sumários para cada espécie. 

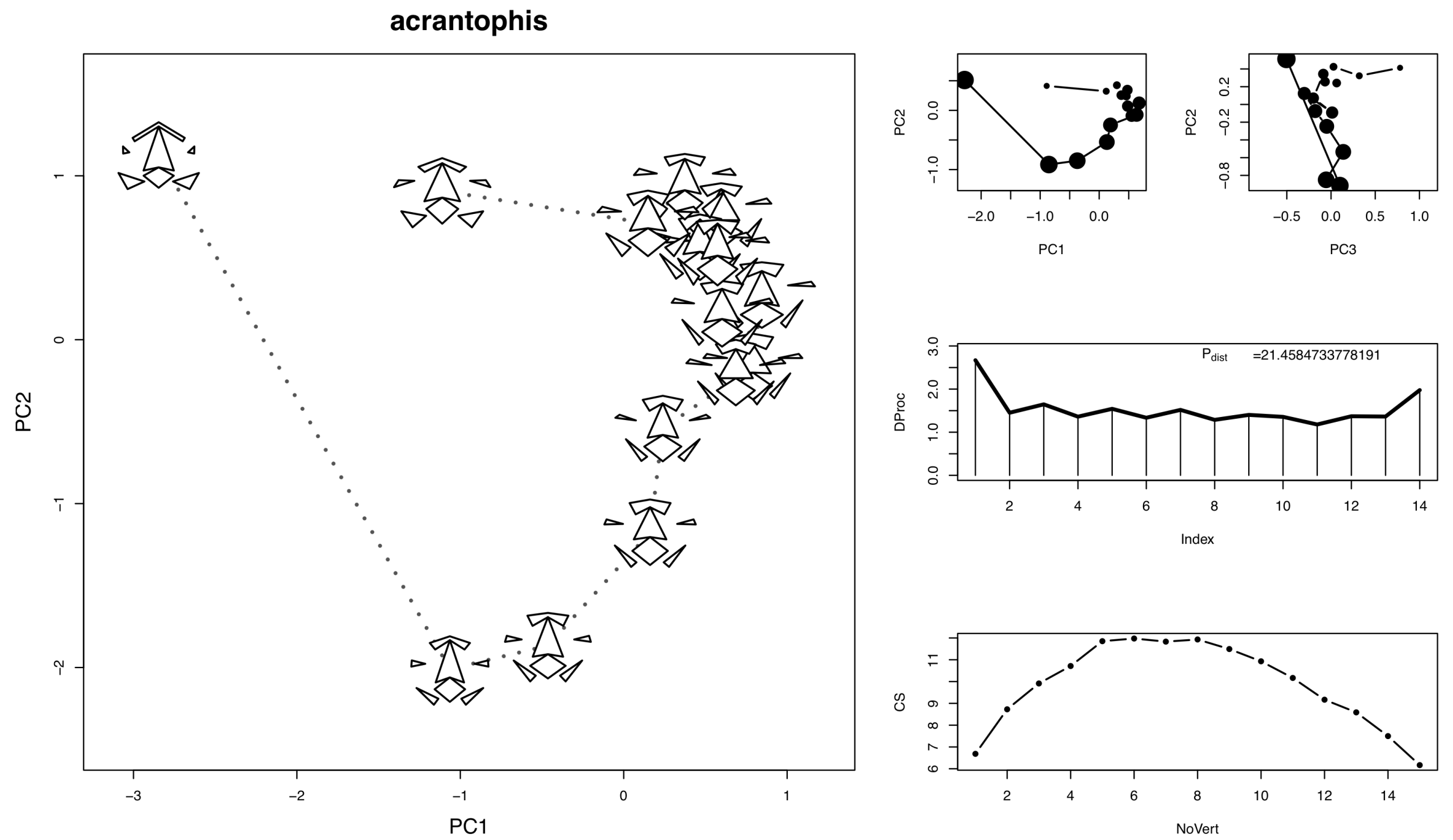

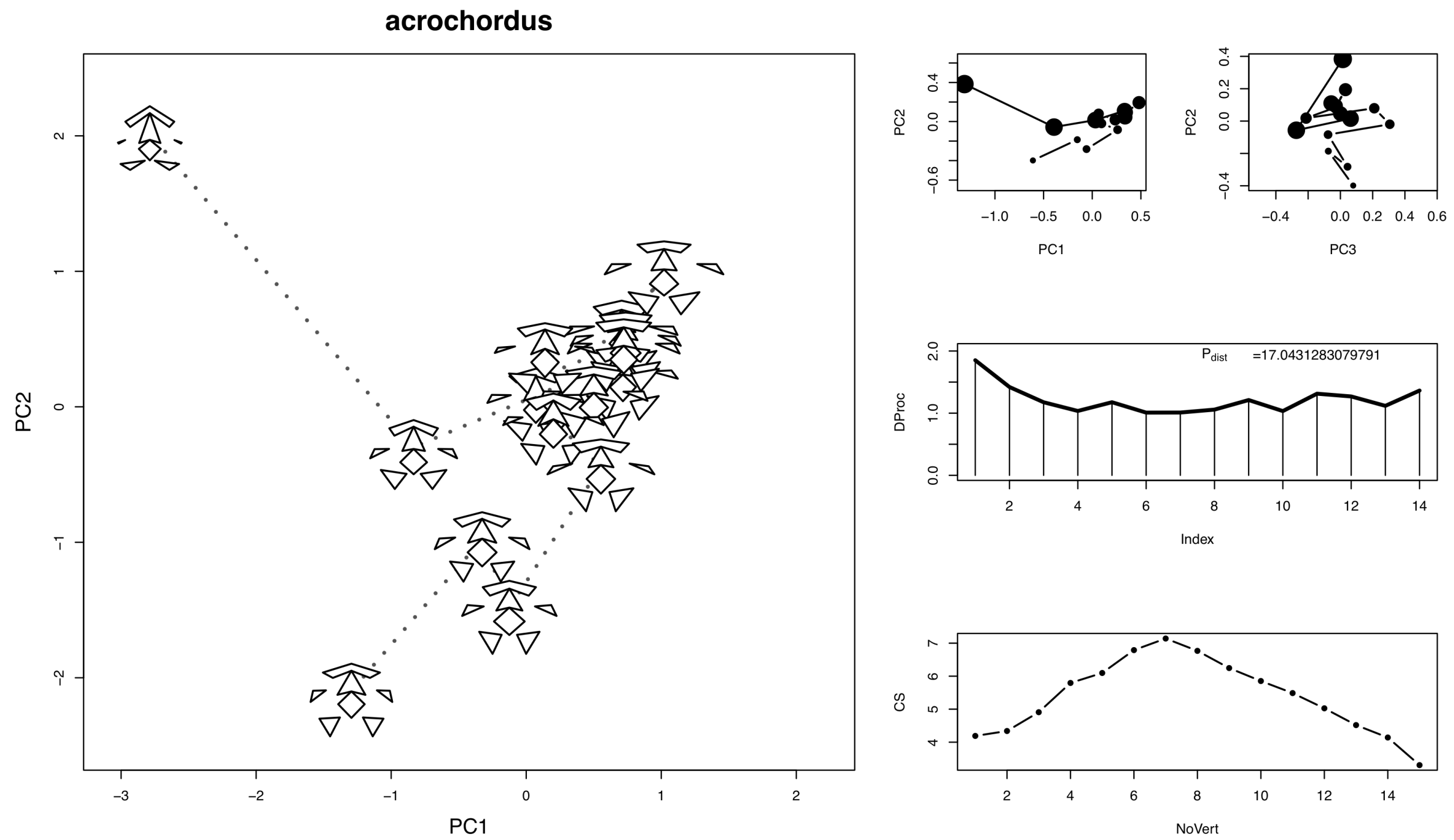

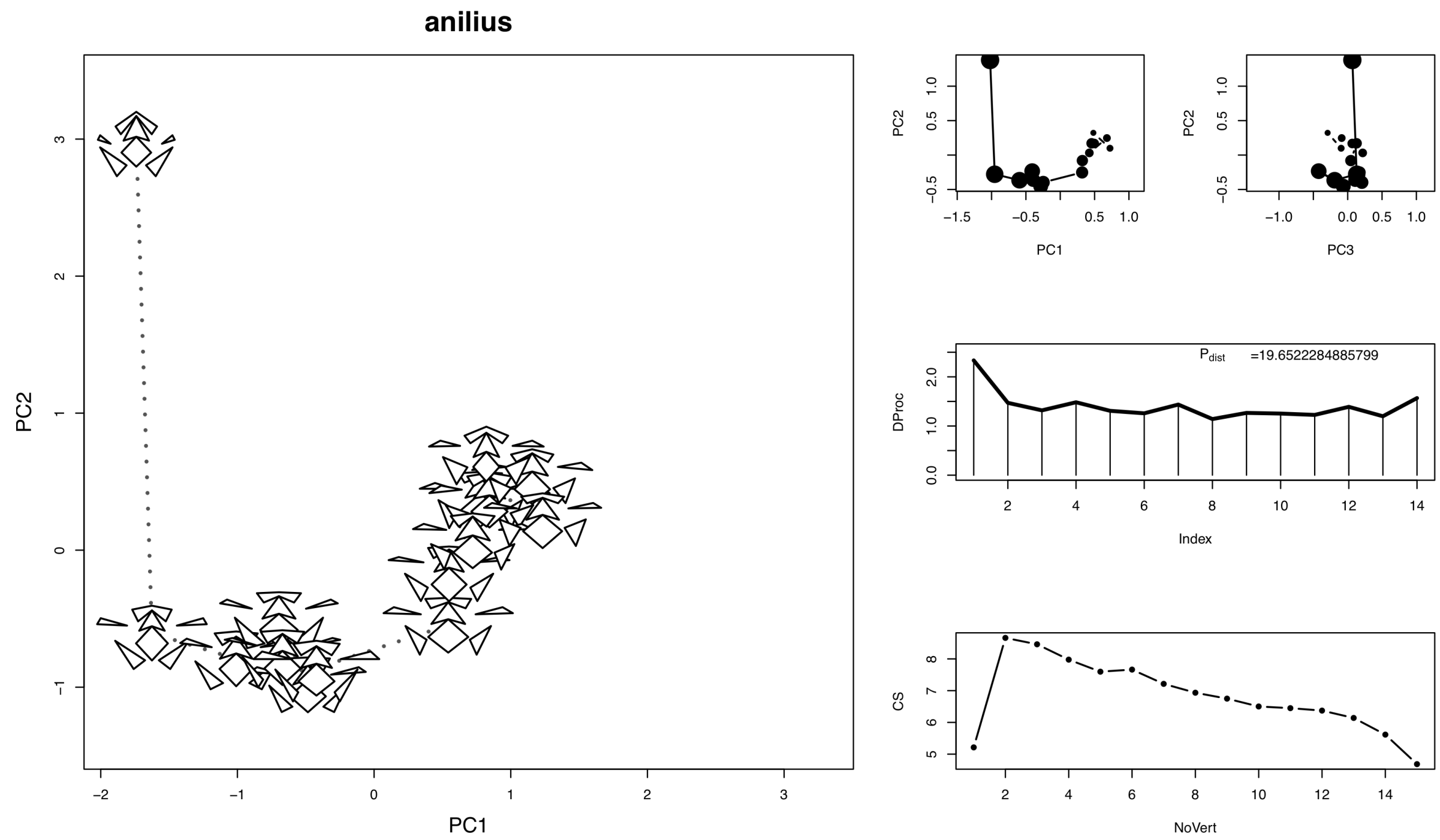
atractus
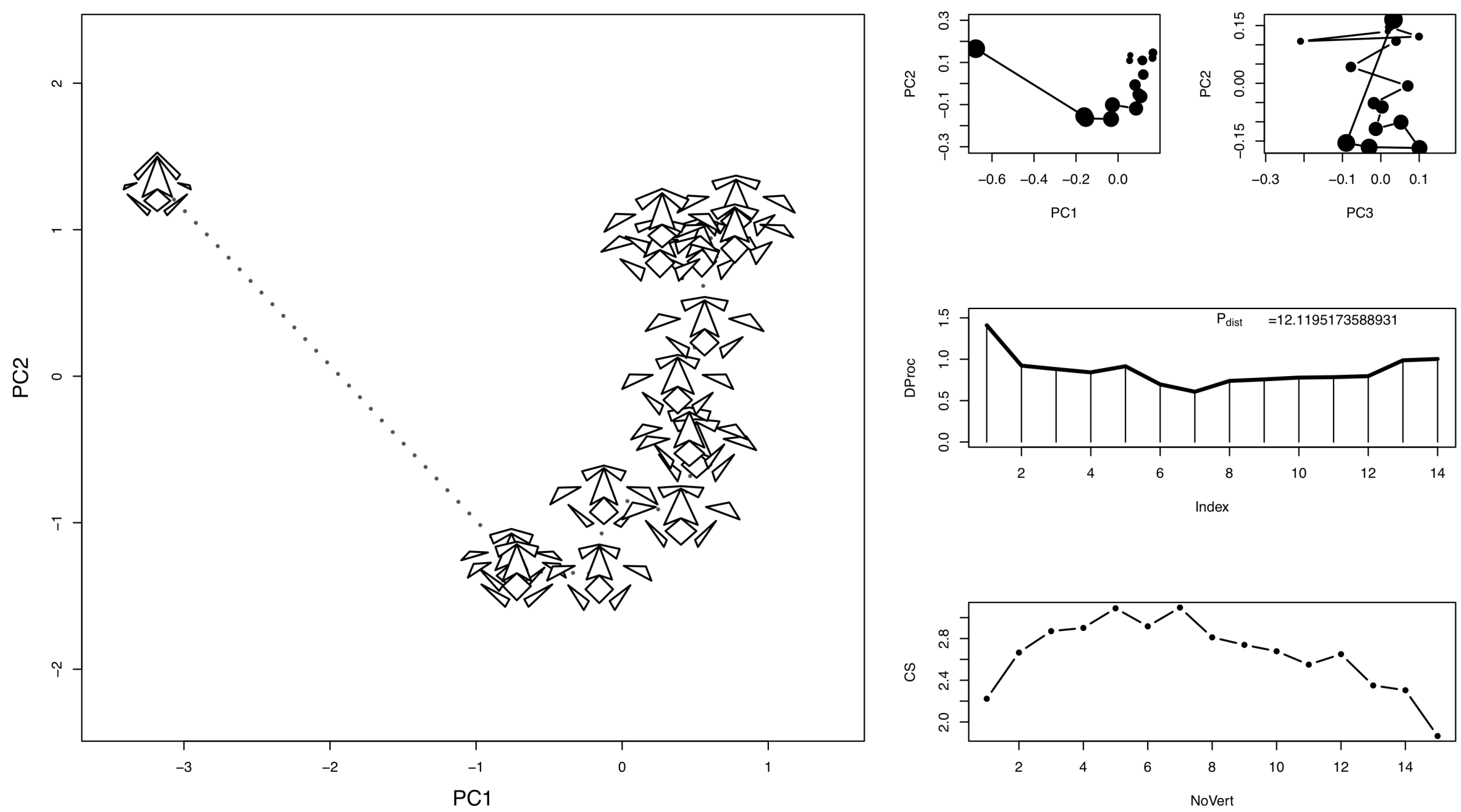

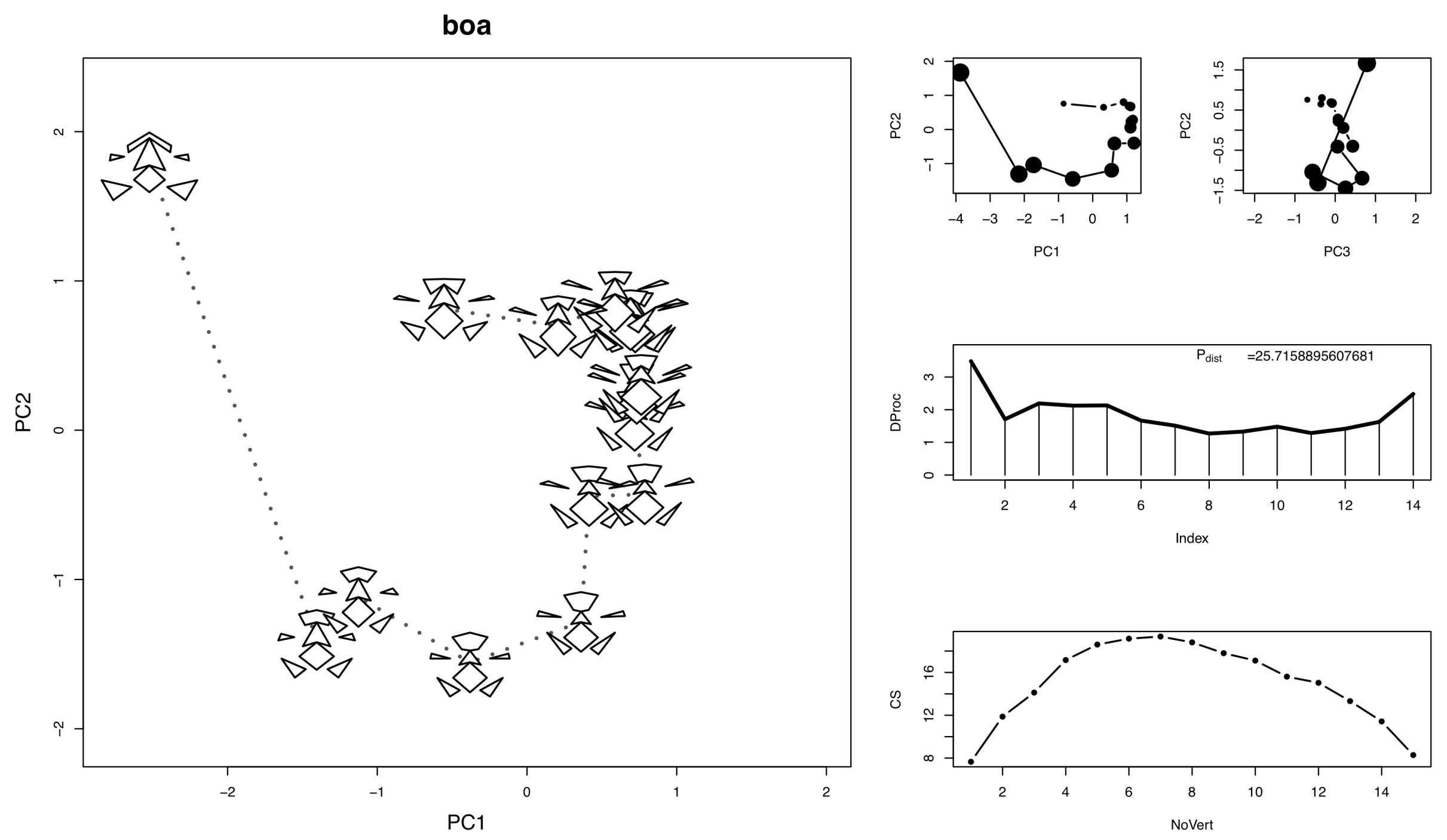

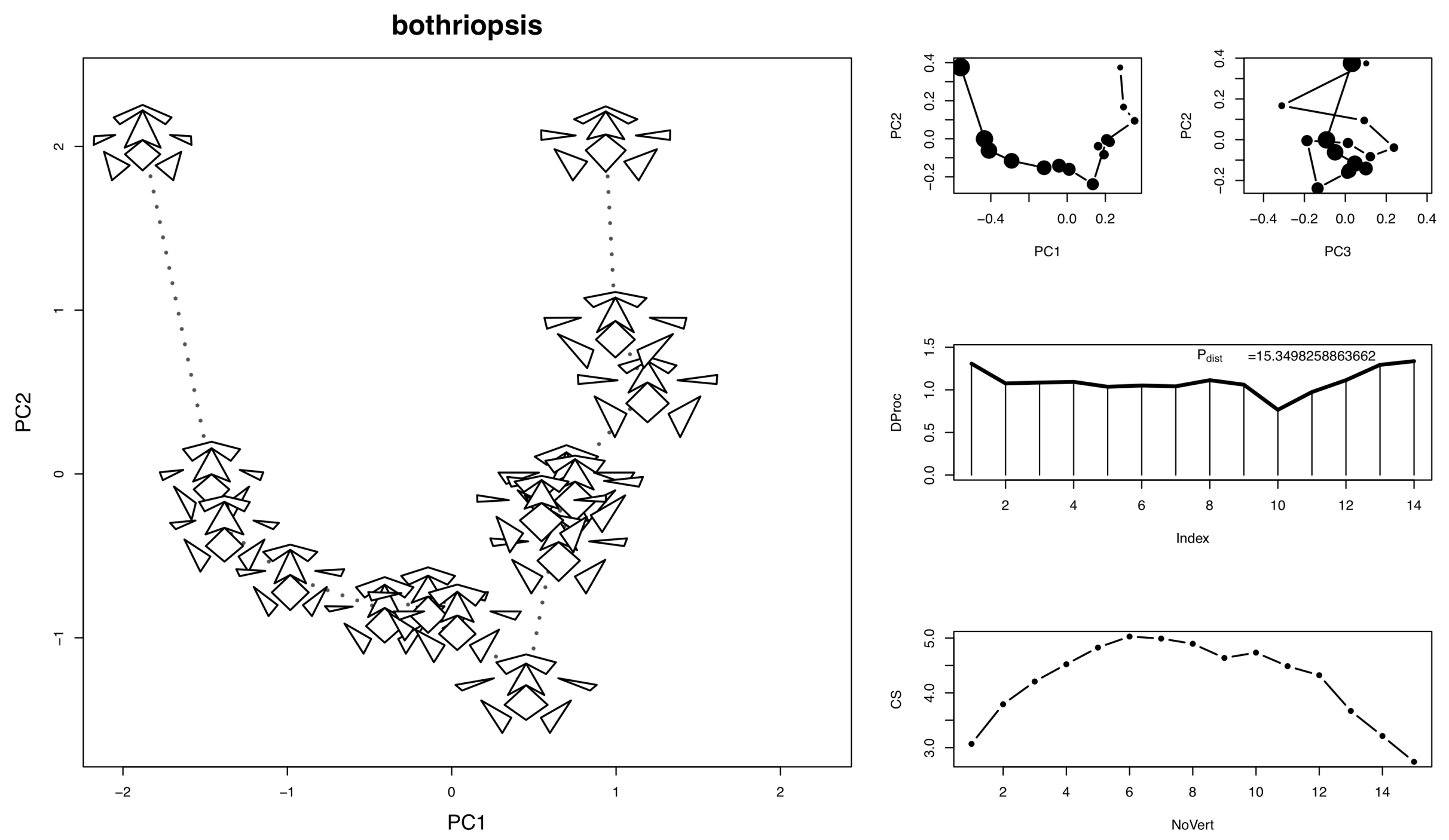

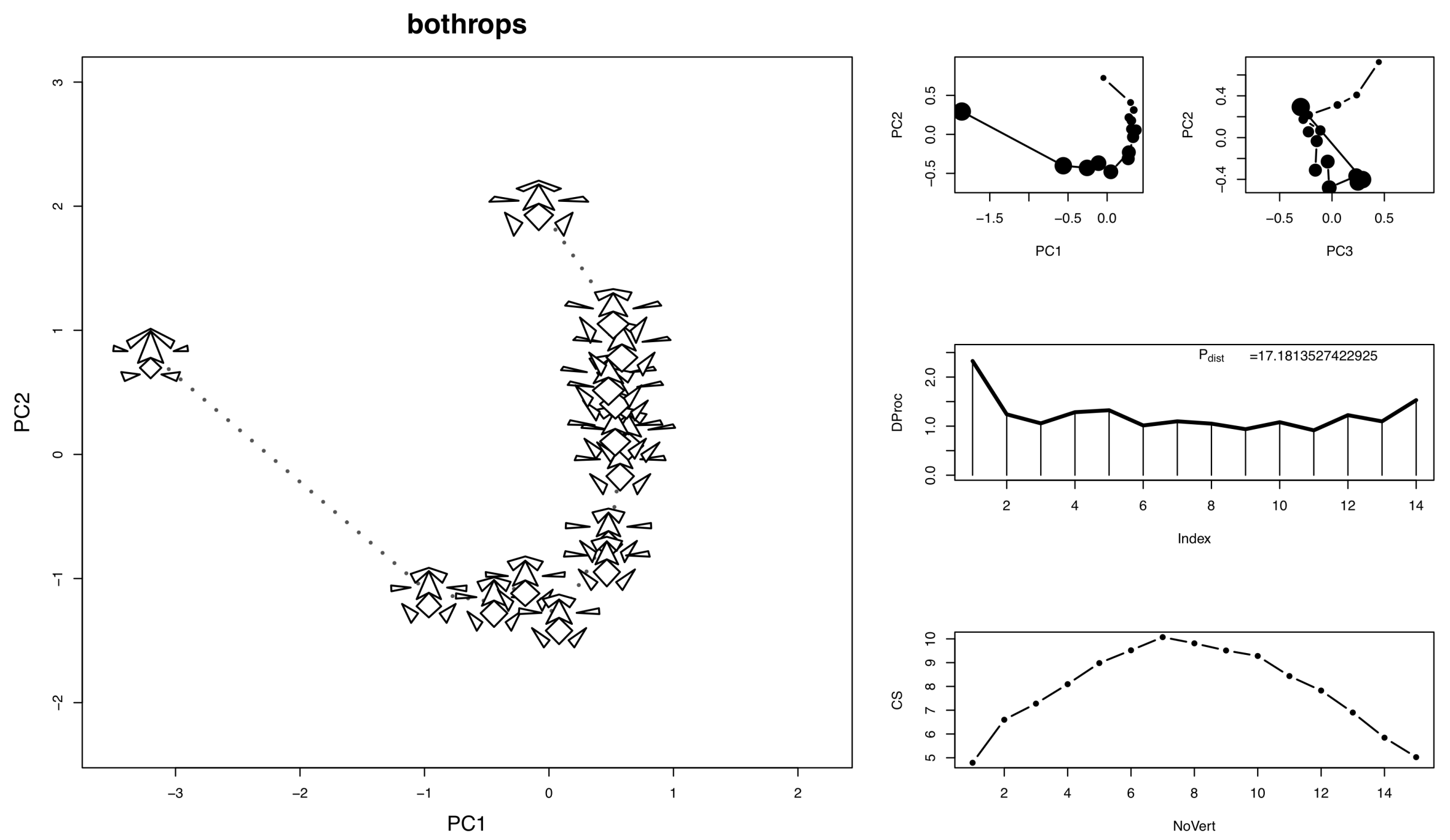

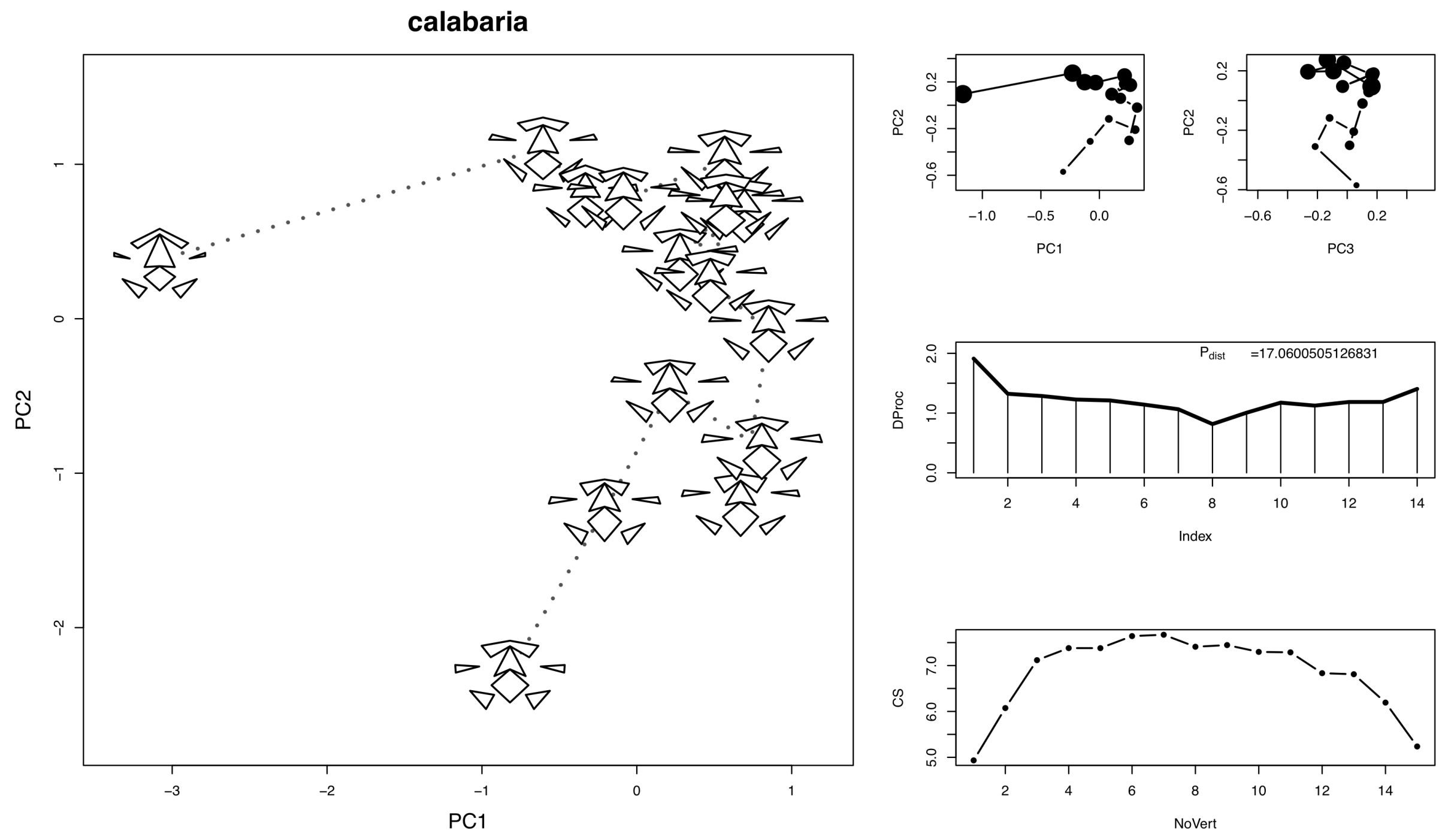

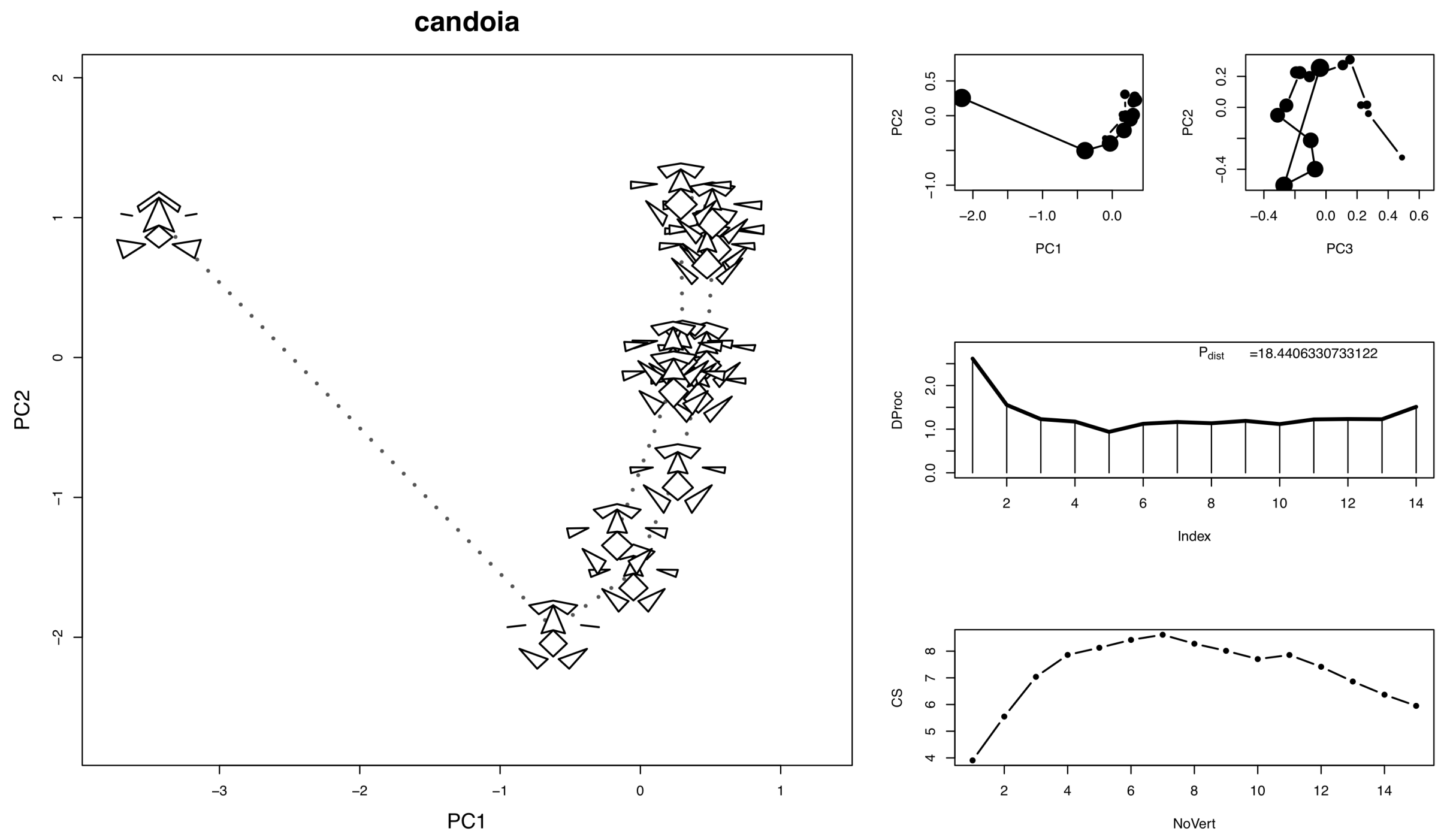

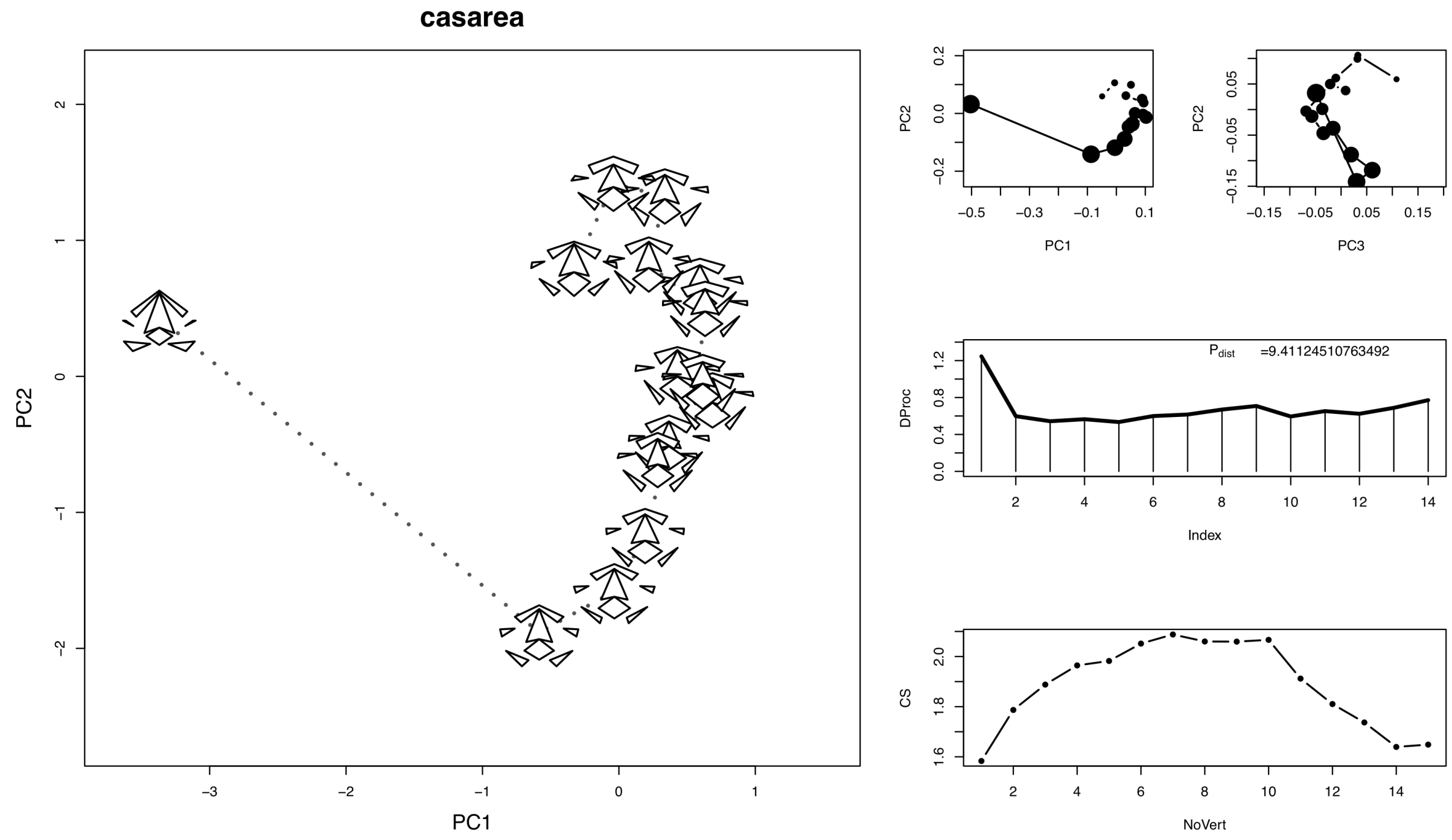

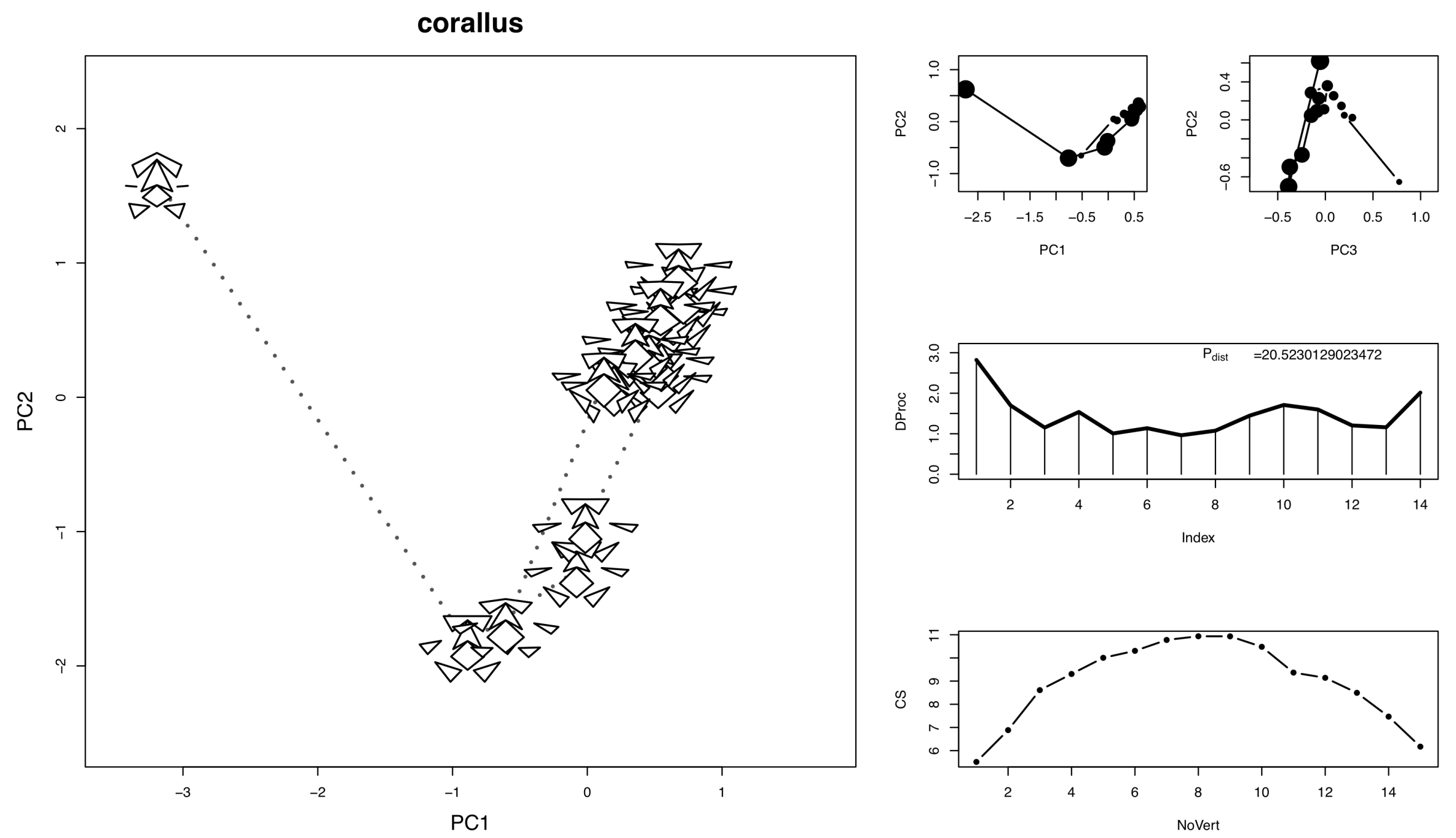

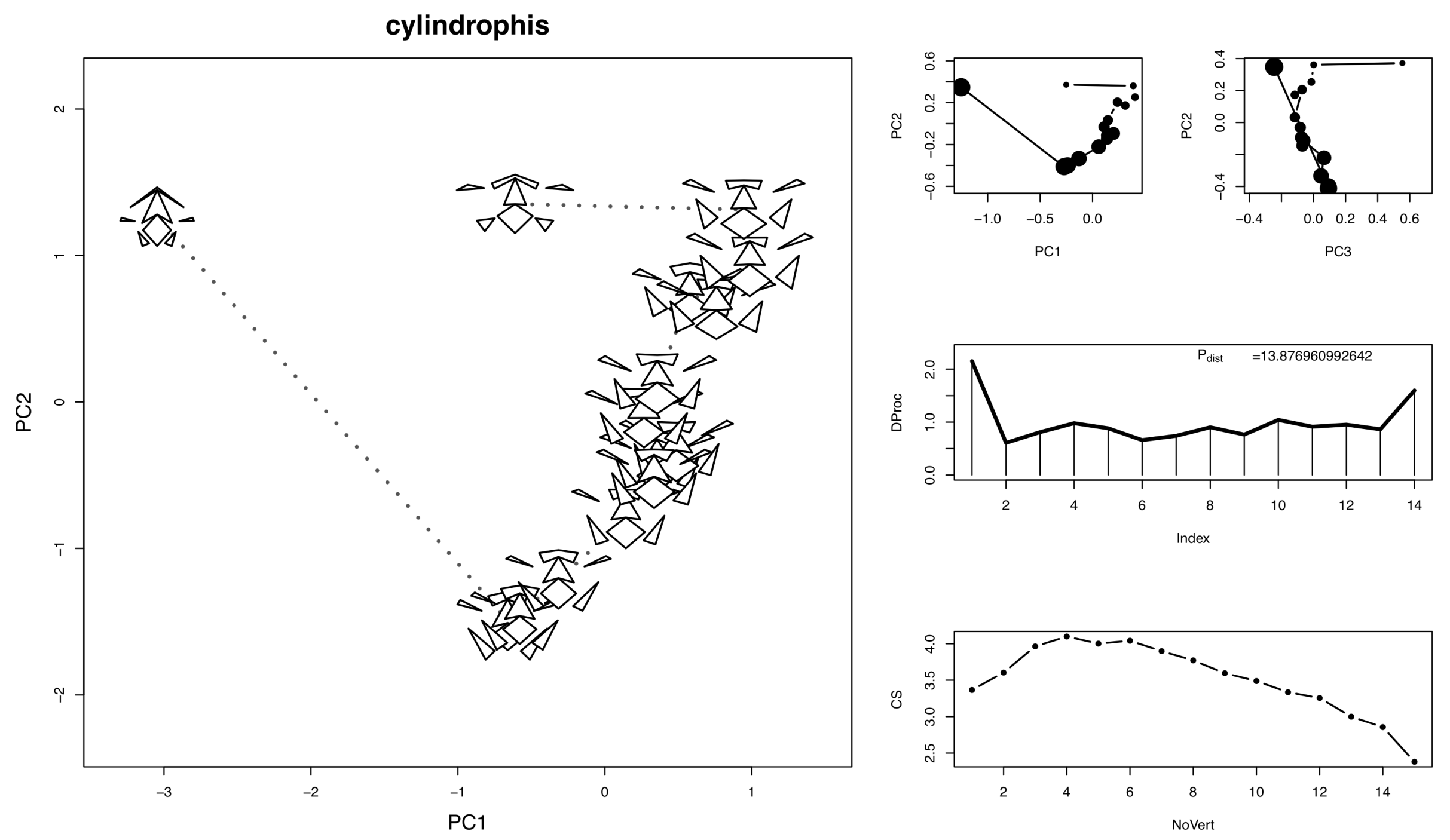

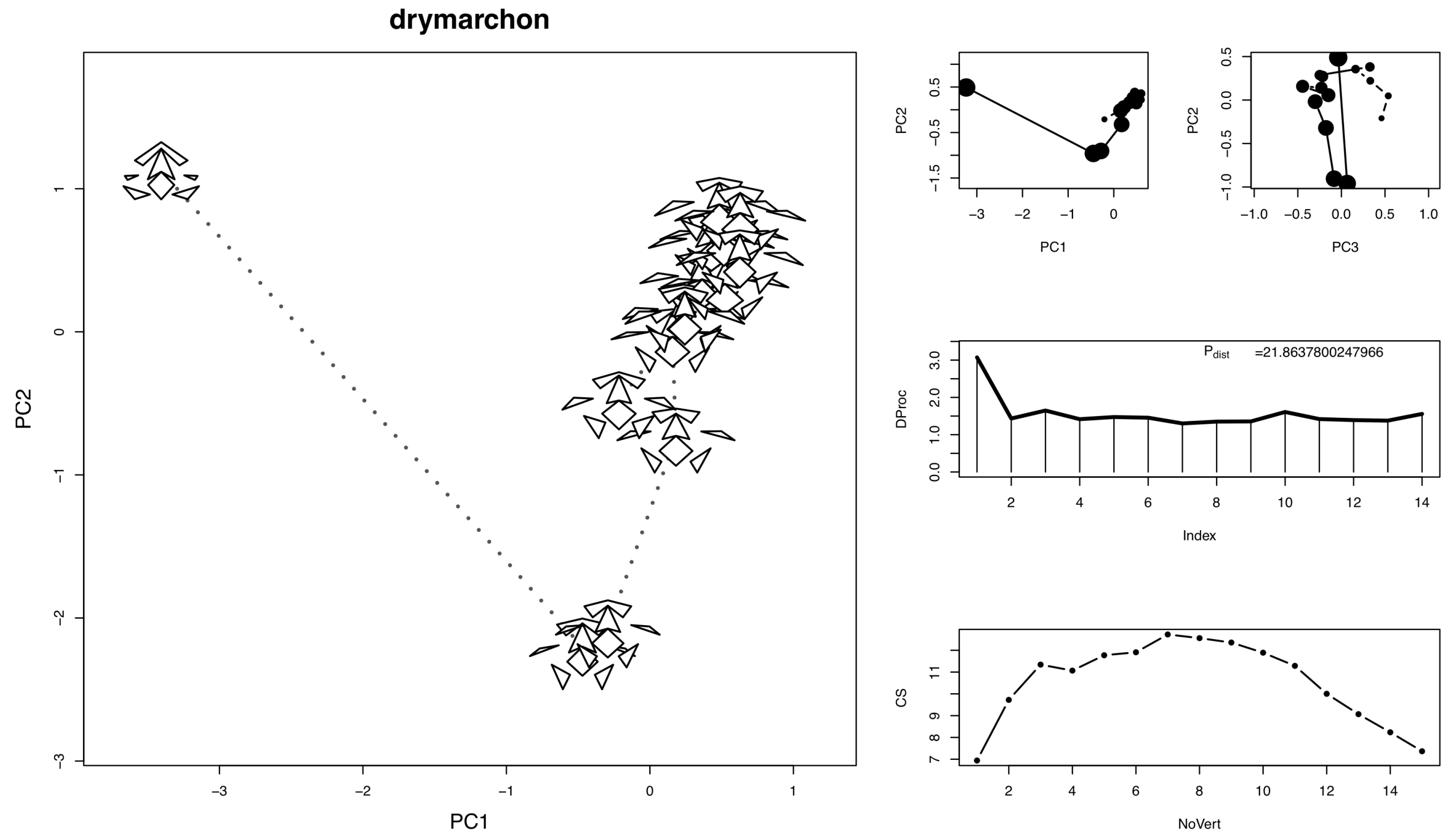

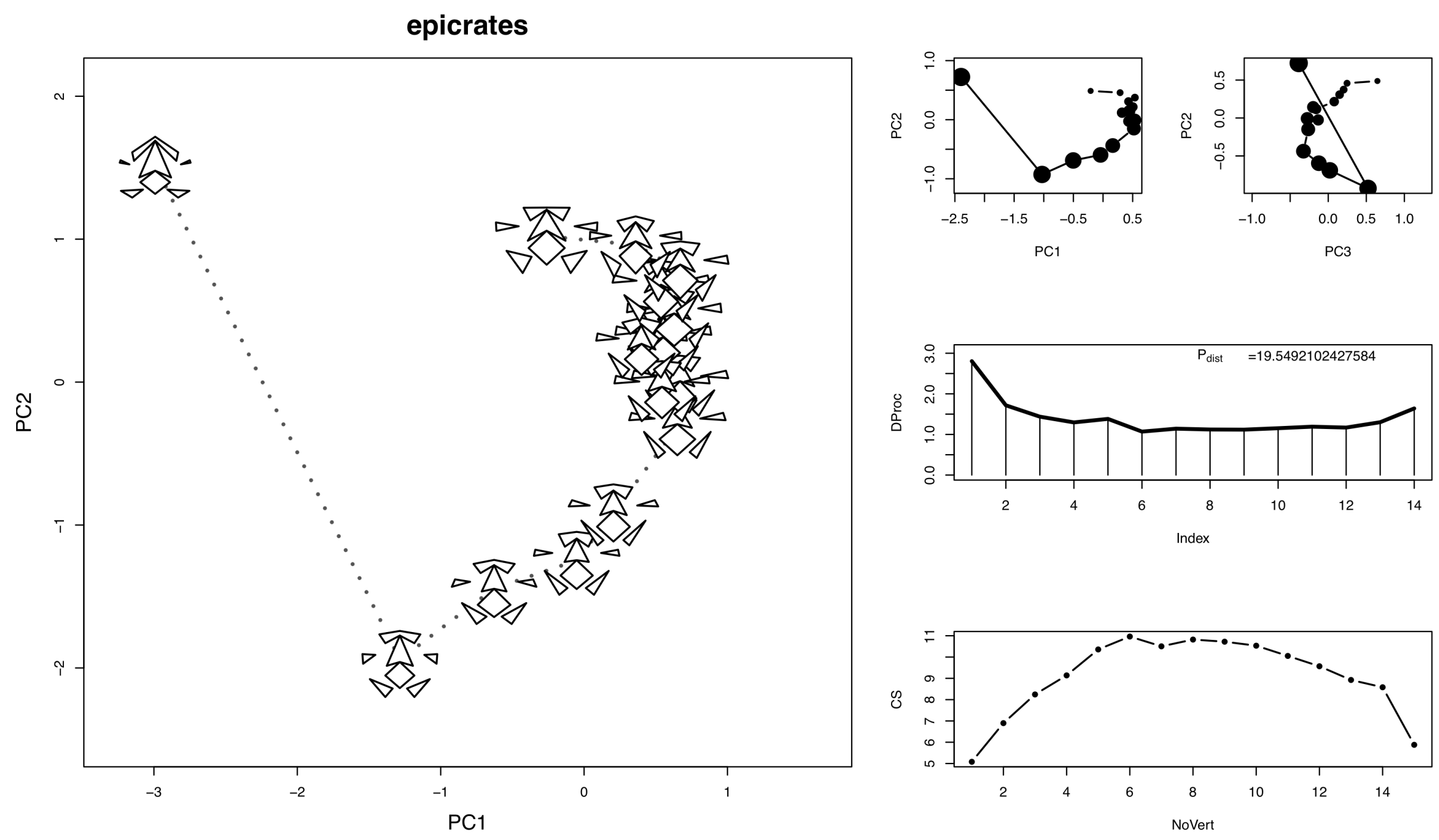

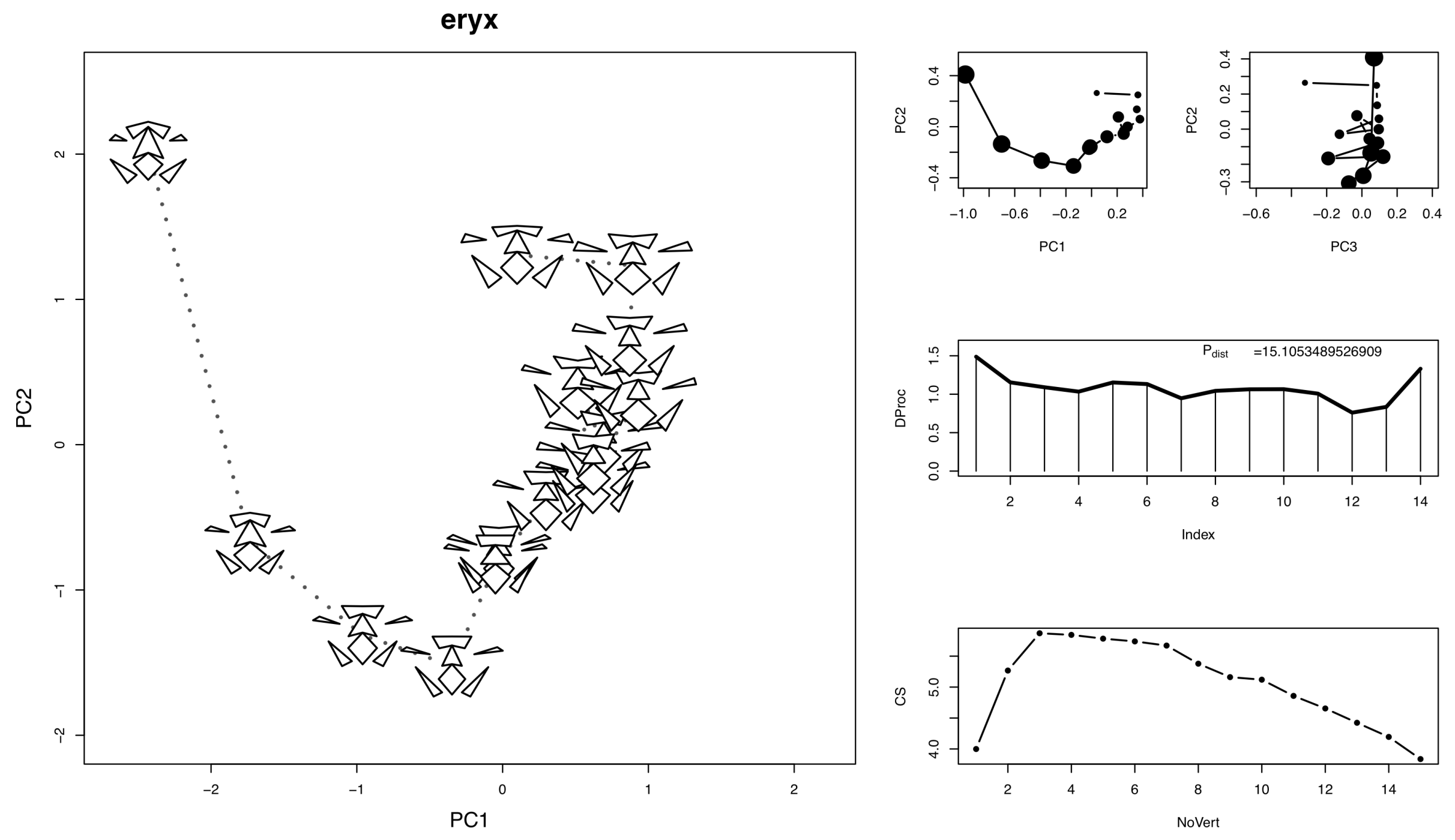


\section{eunectes}
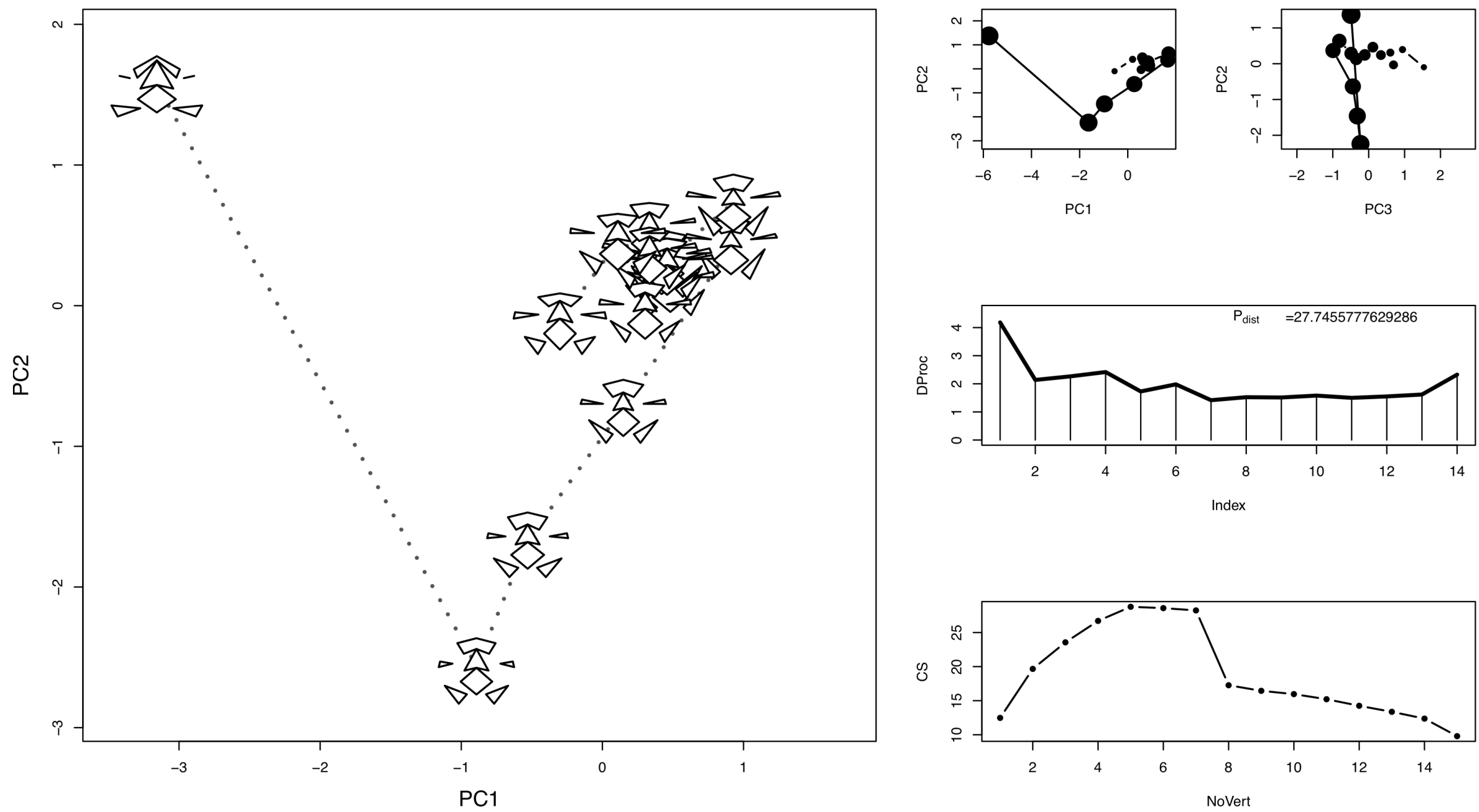

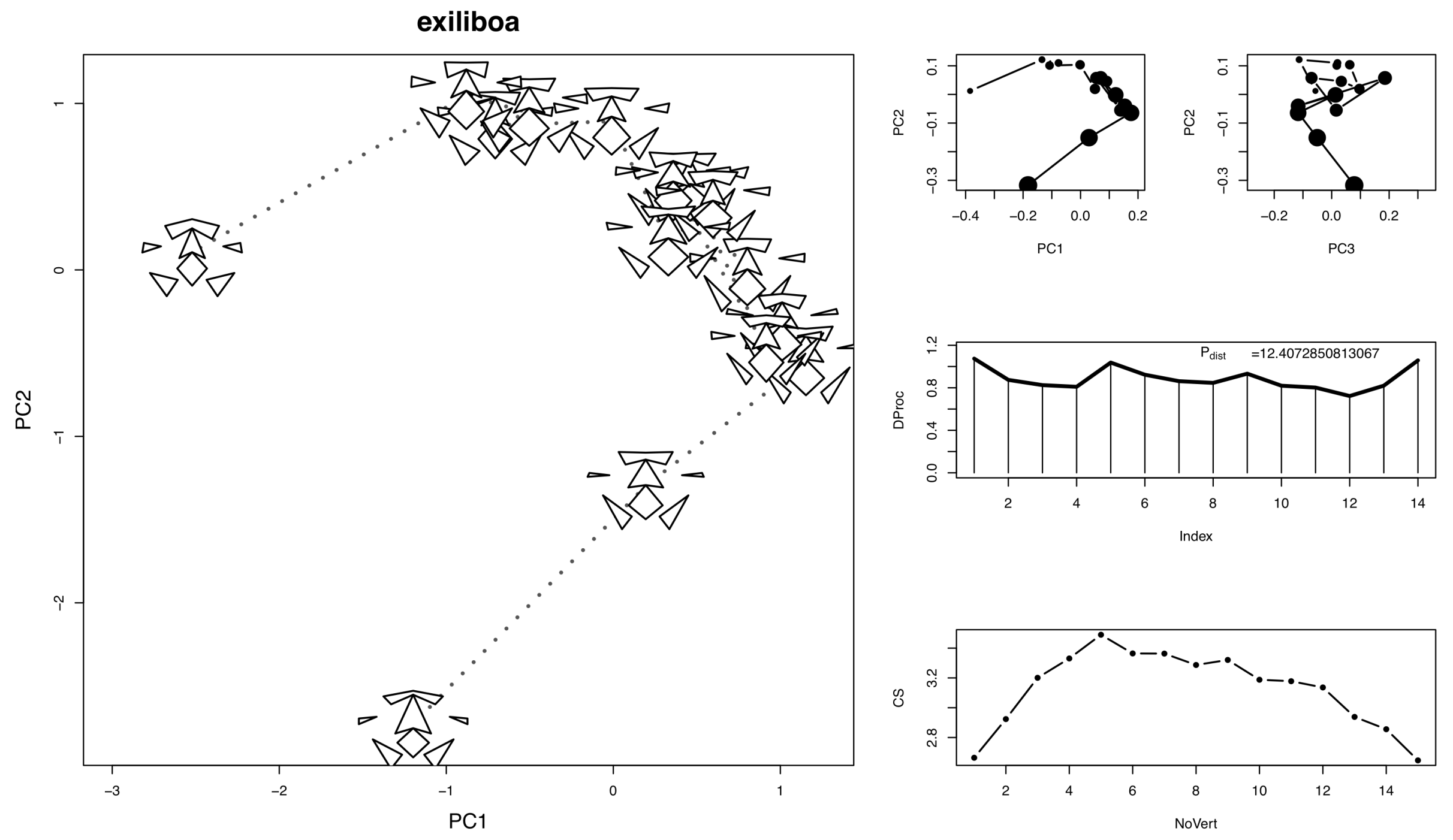

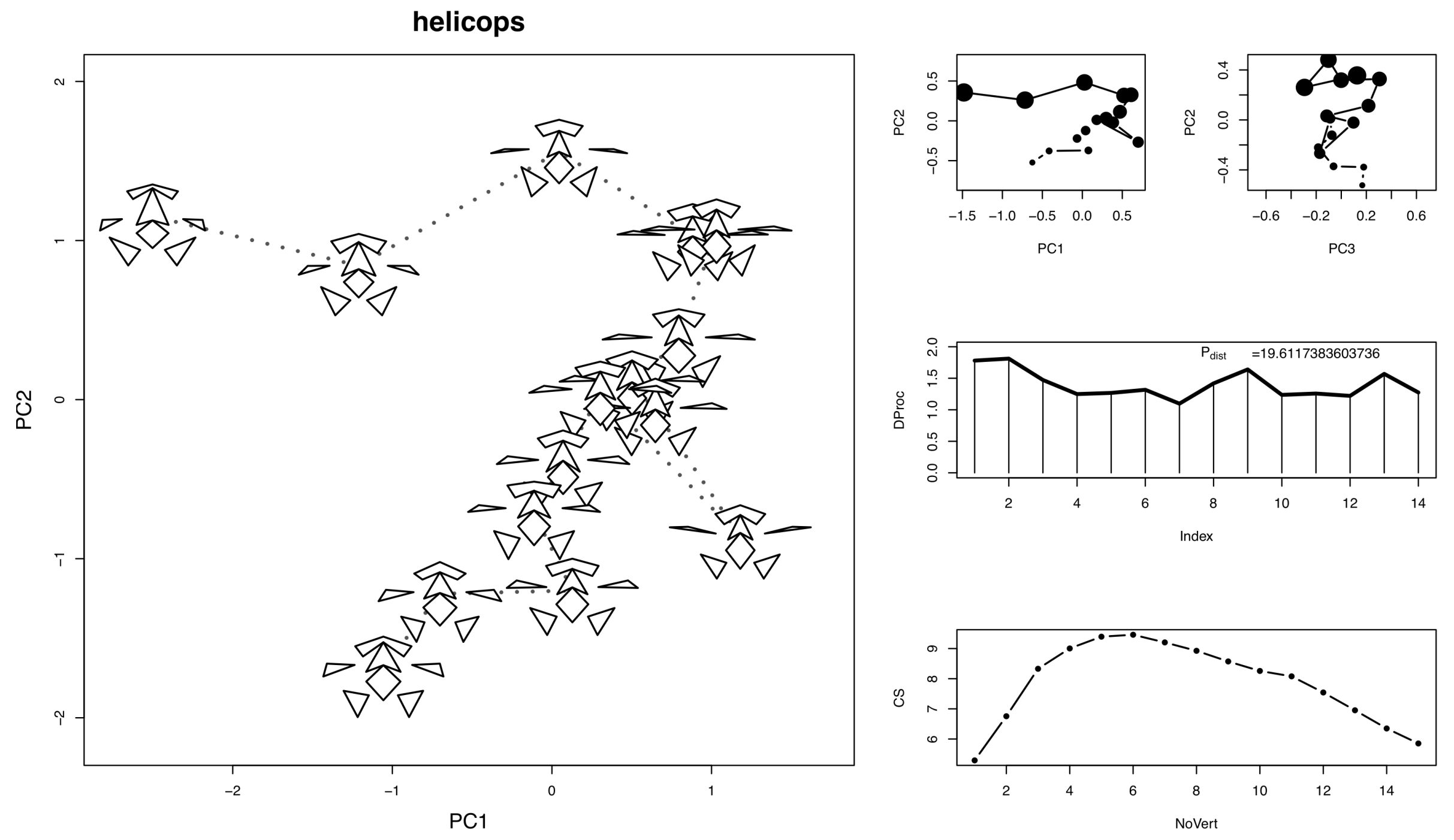

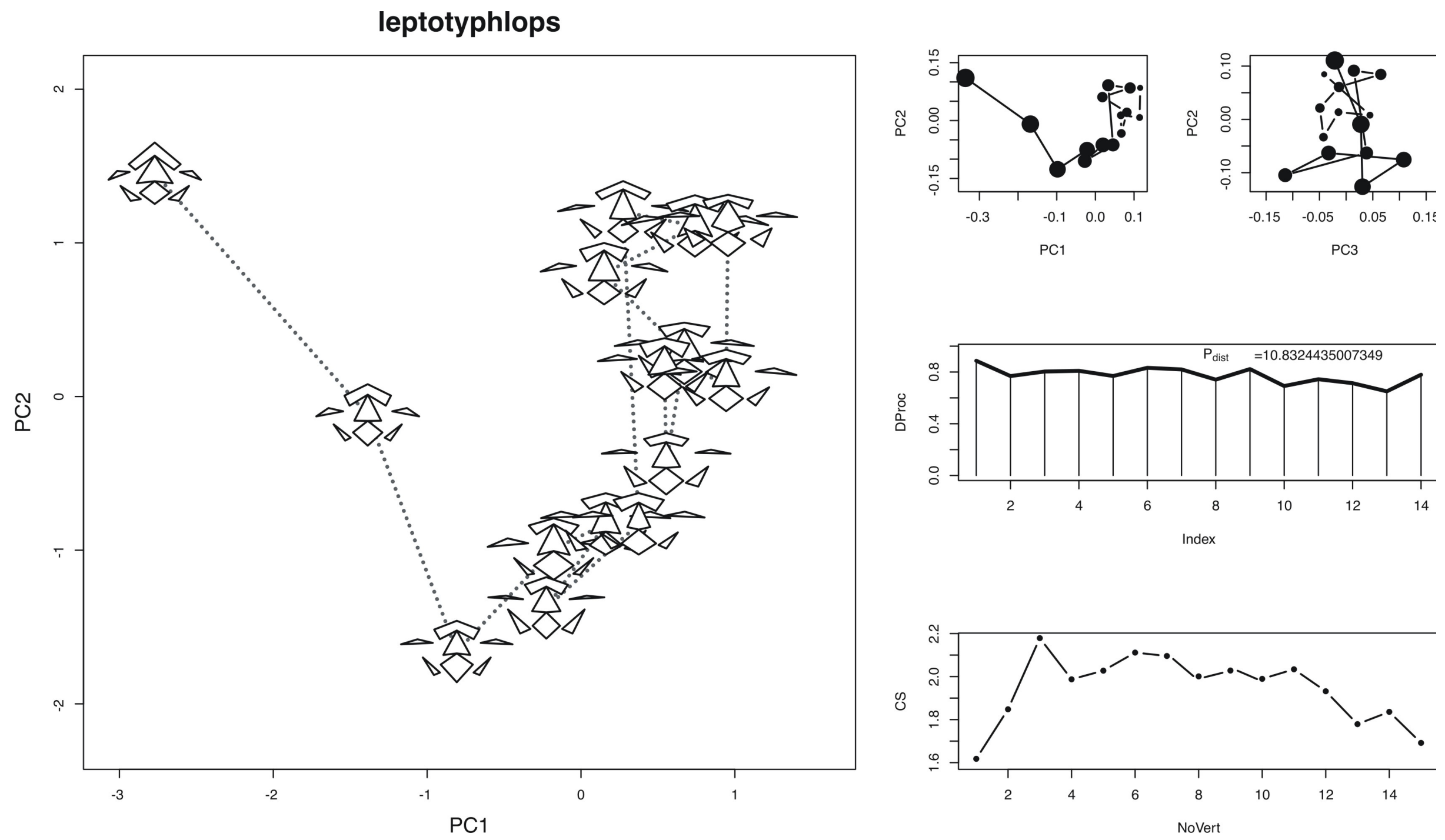
liasis
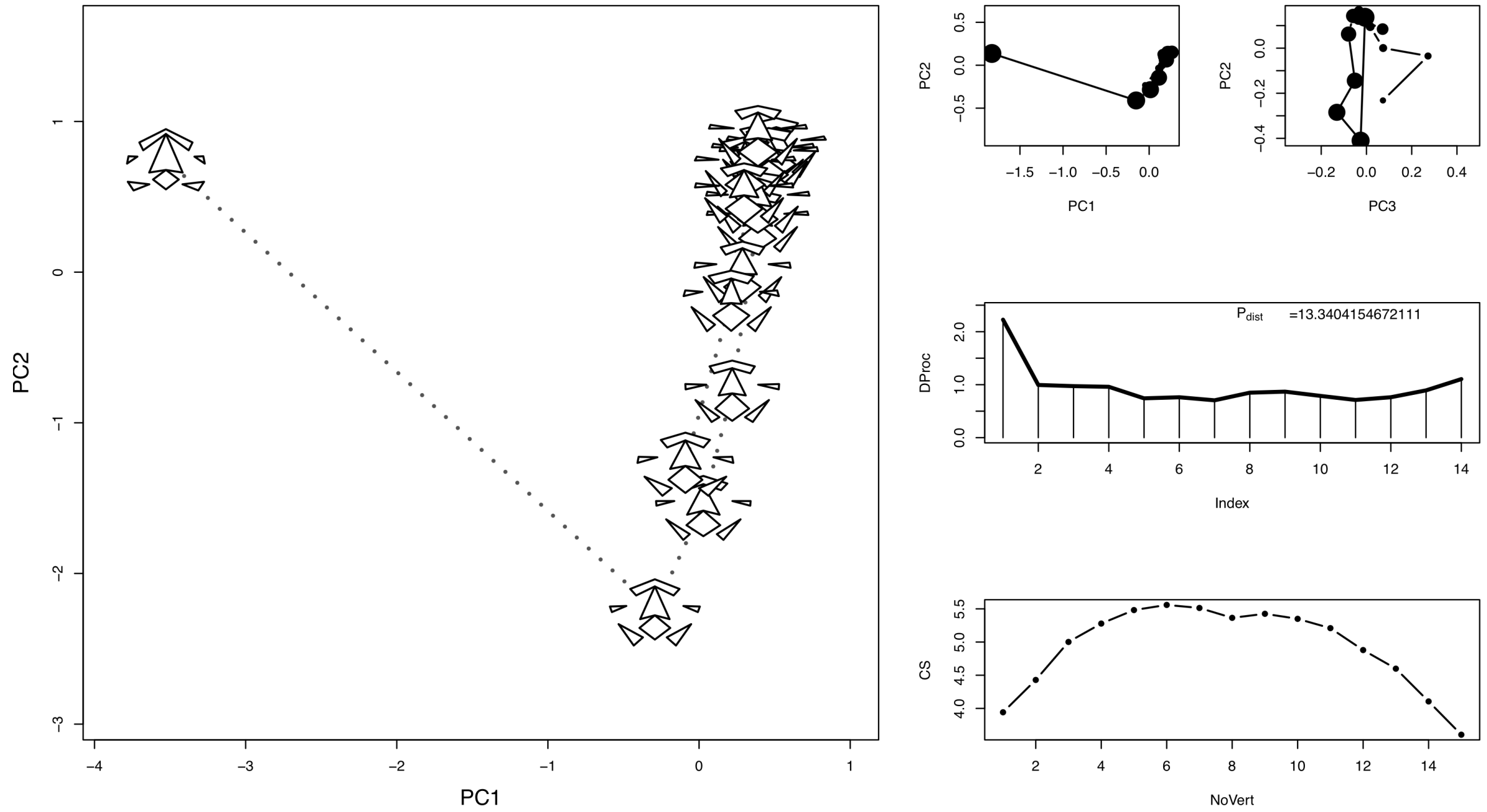


\section{lichanura}
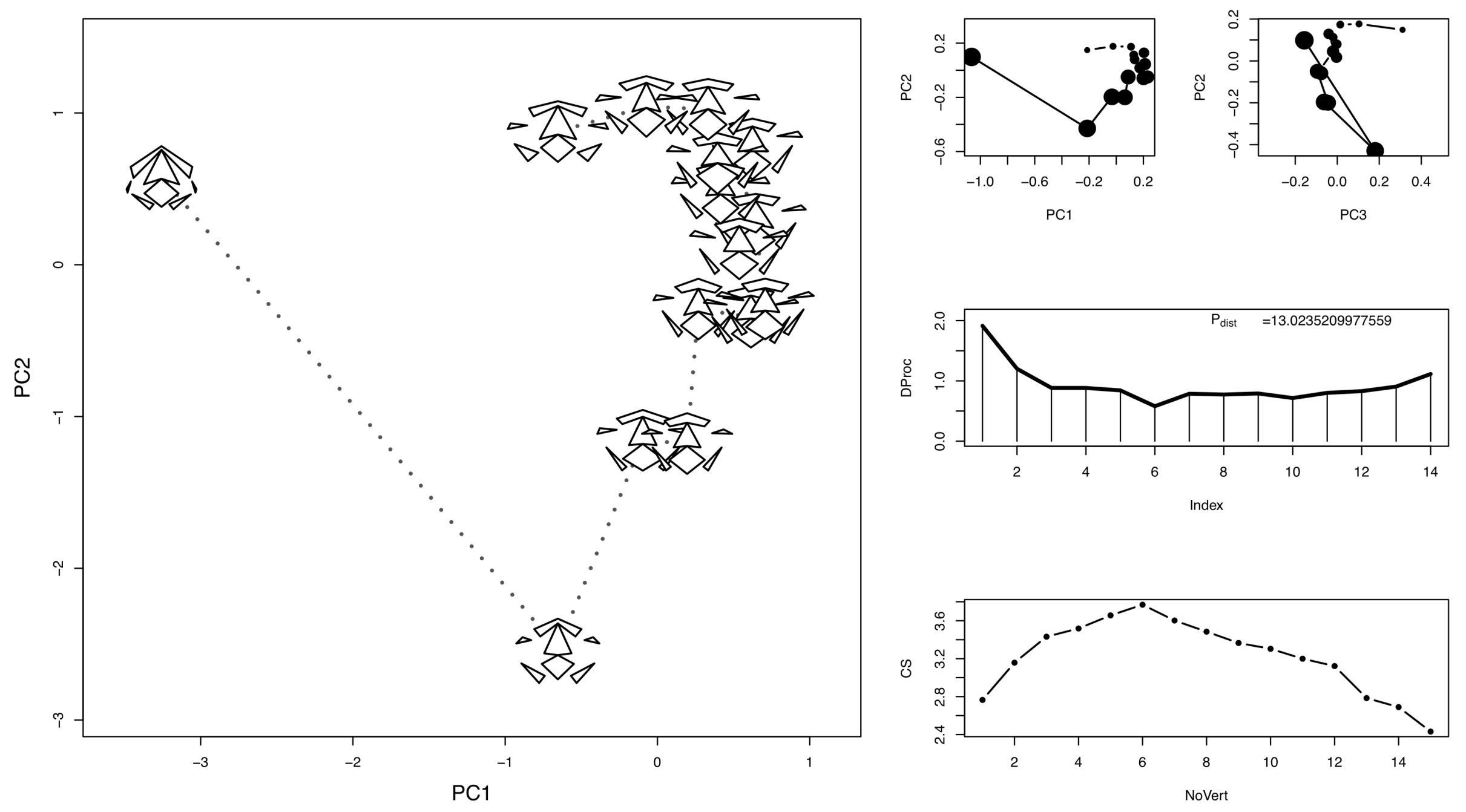


\section{liotyphlops}
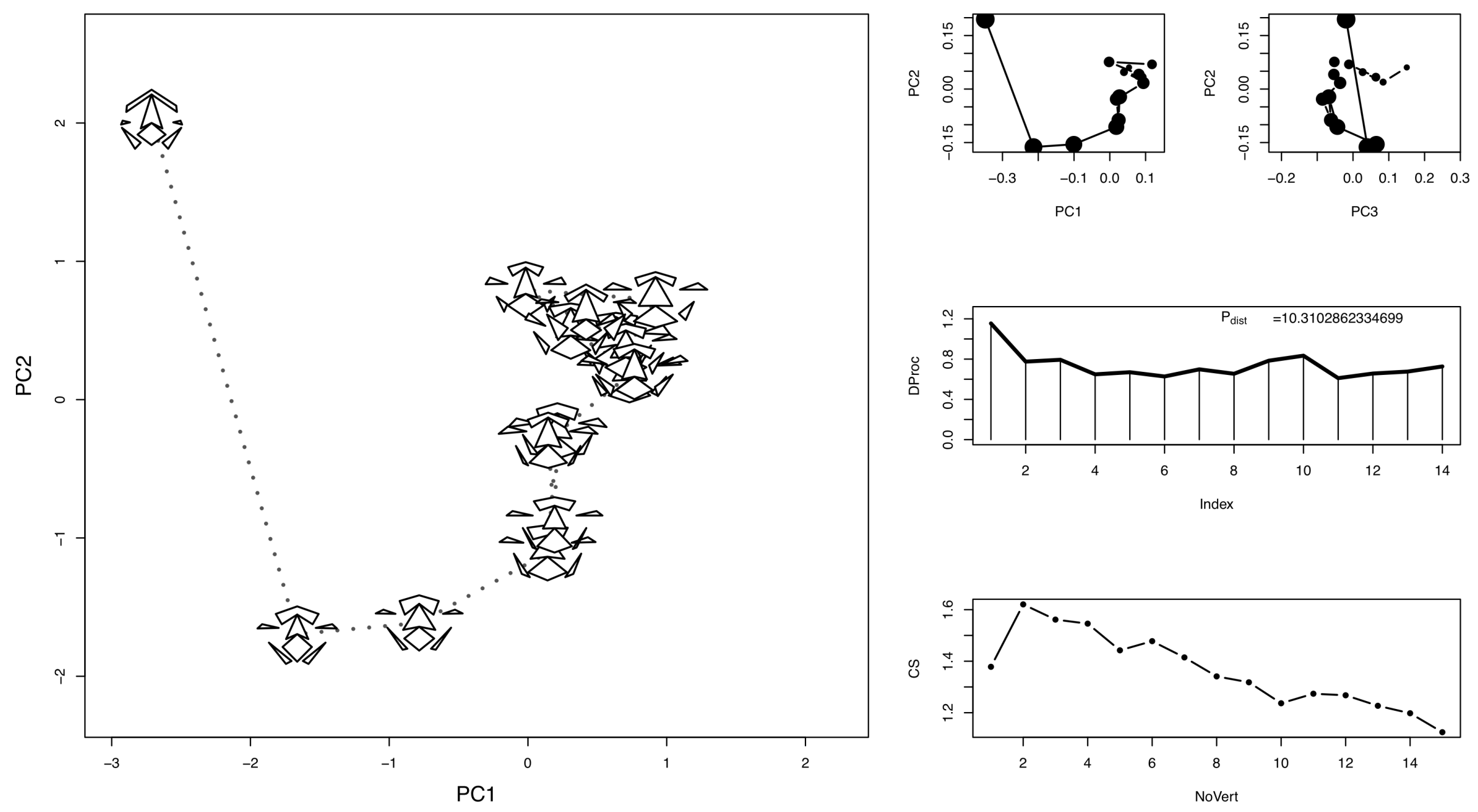


\section{loxocemus}
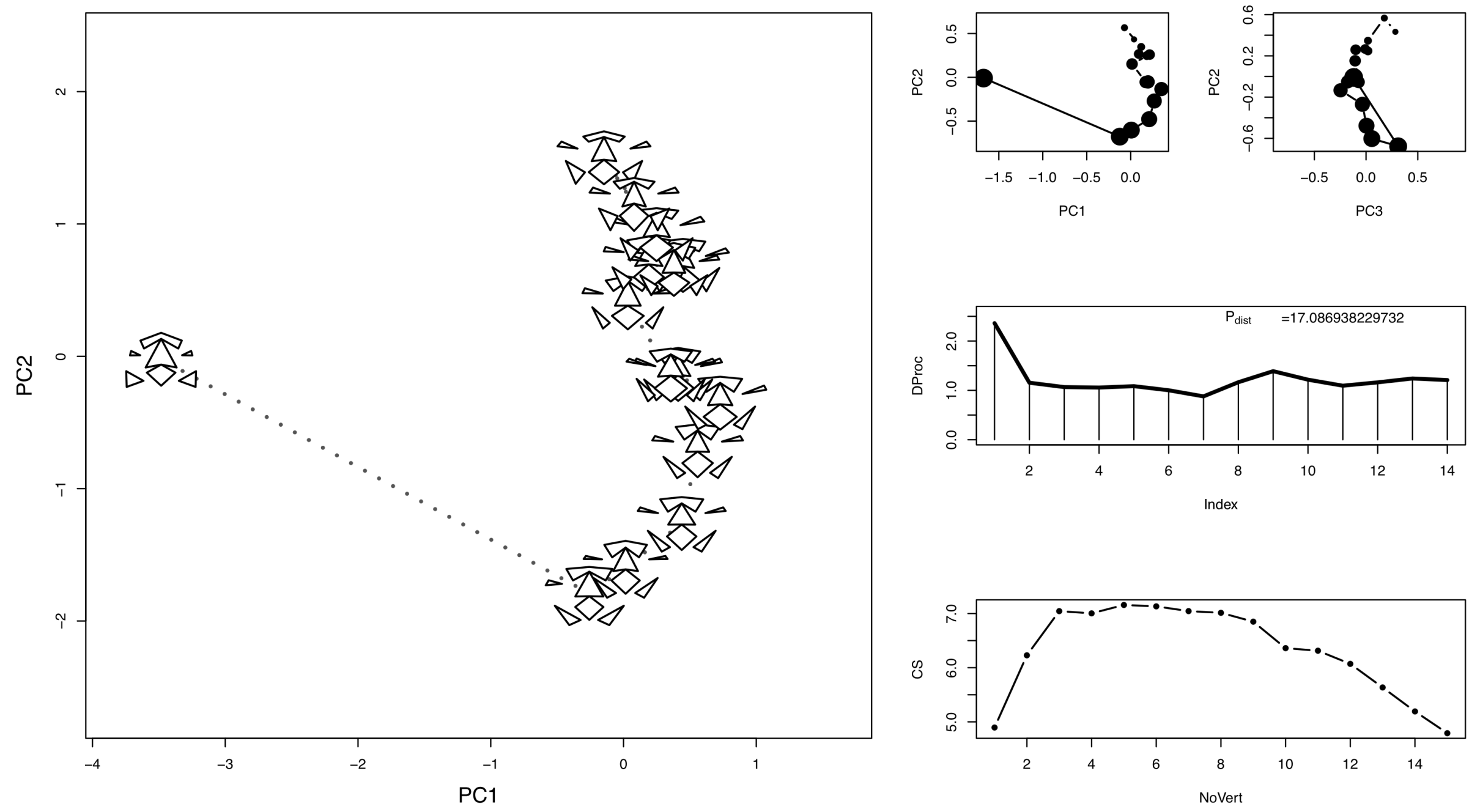
micrurus

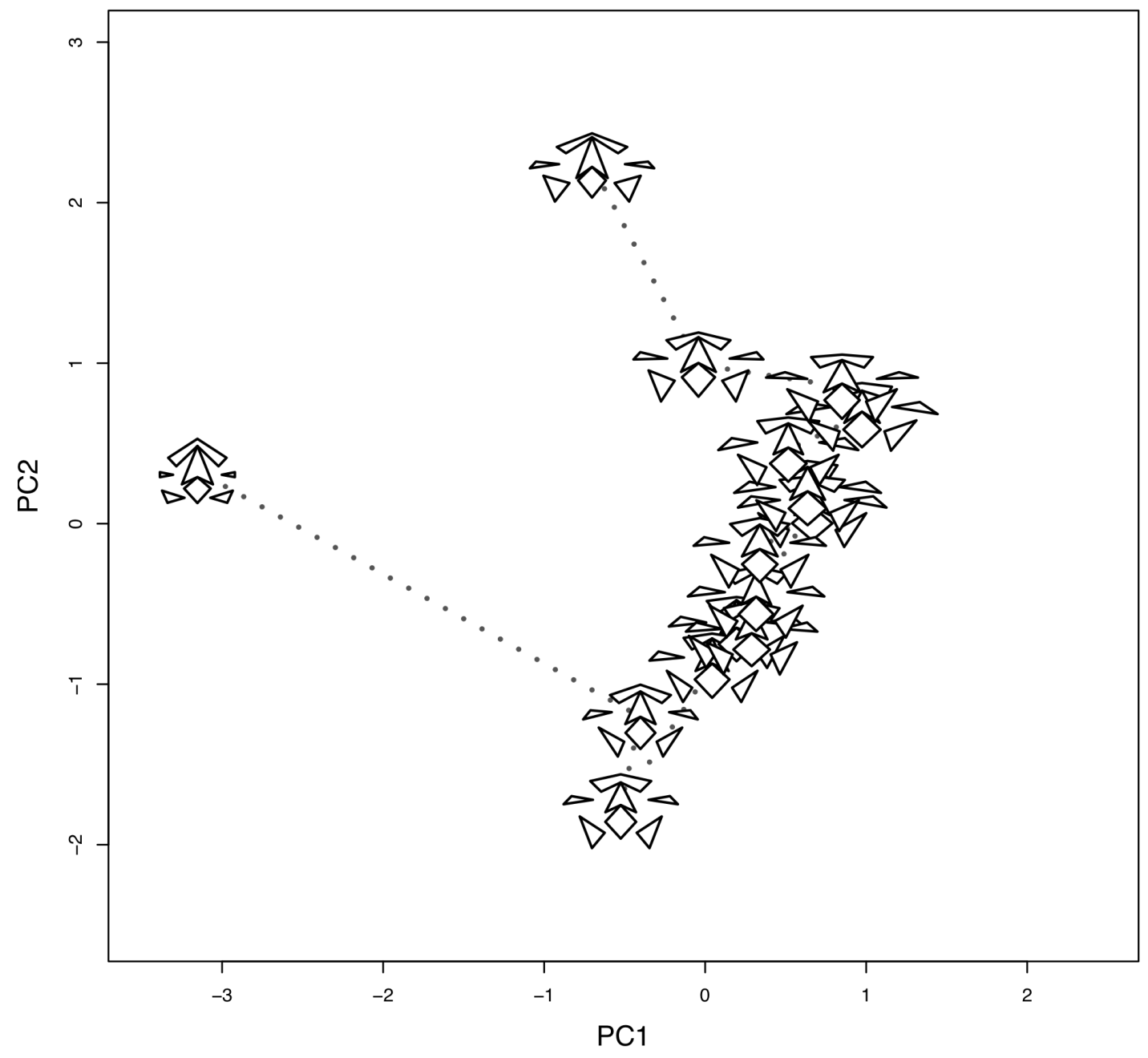

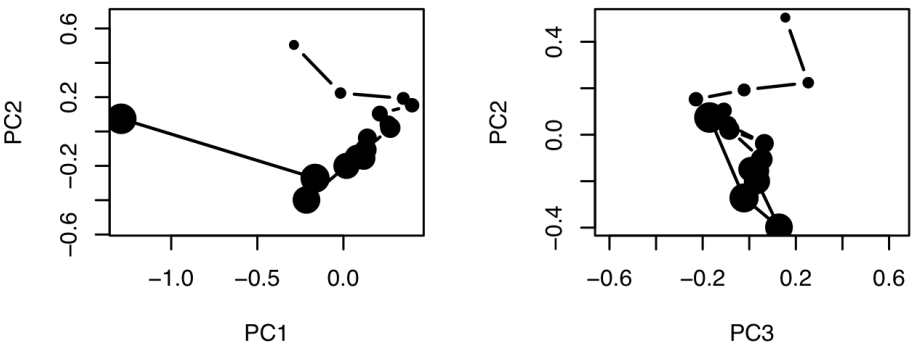
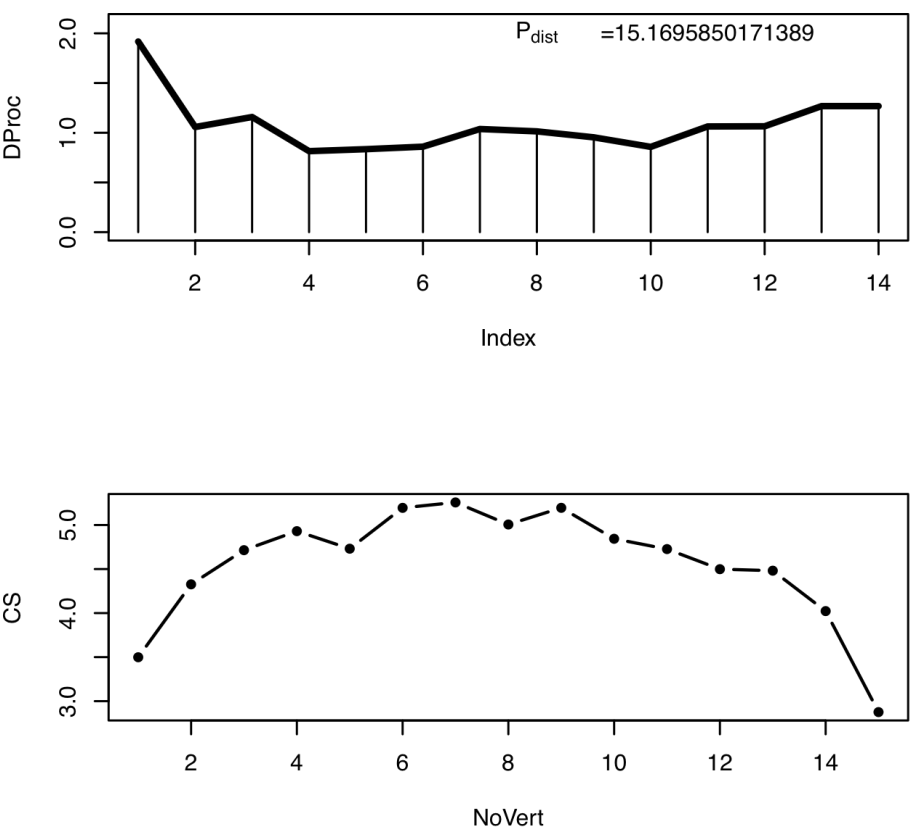

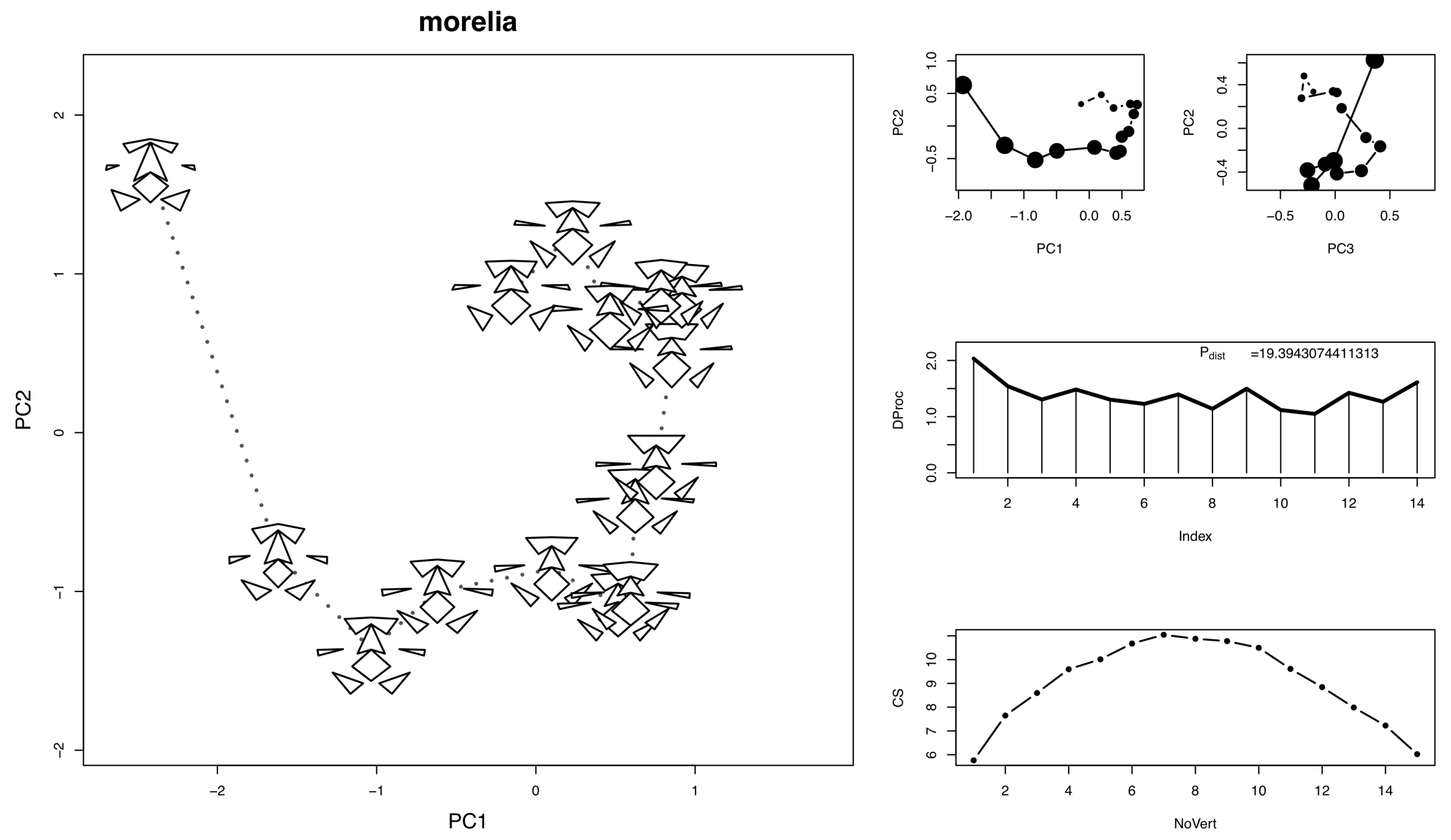

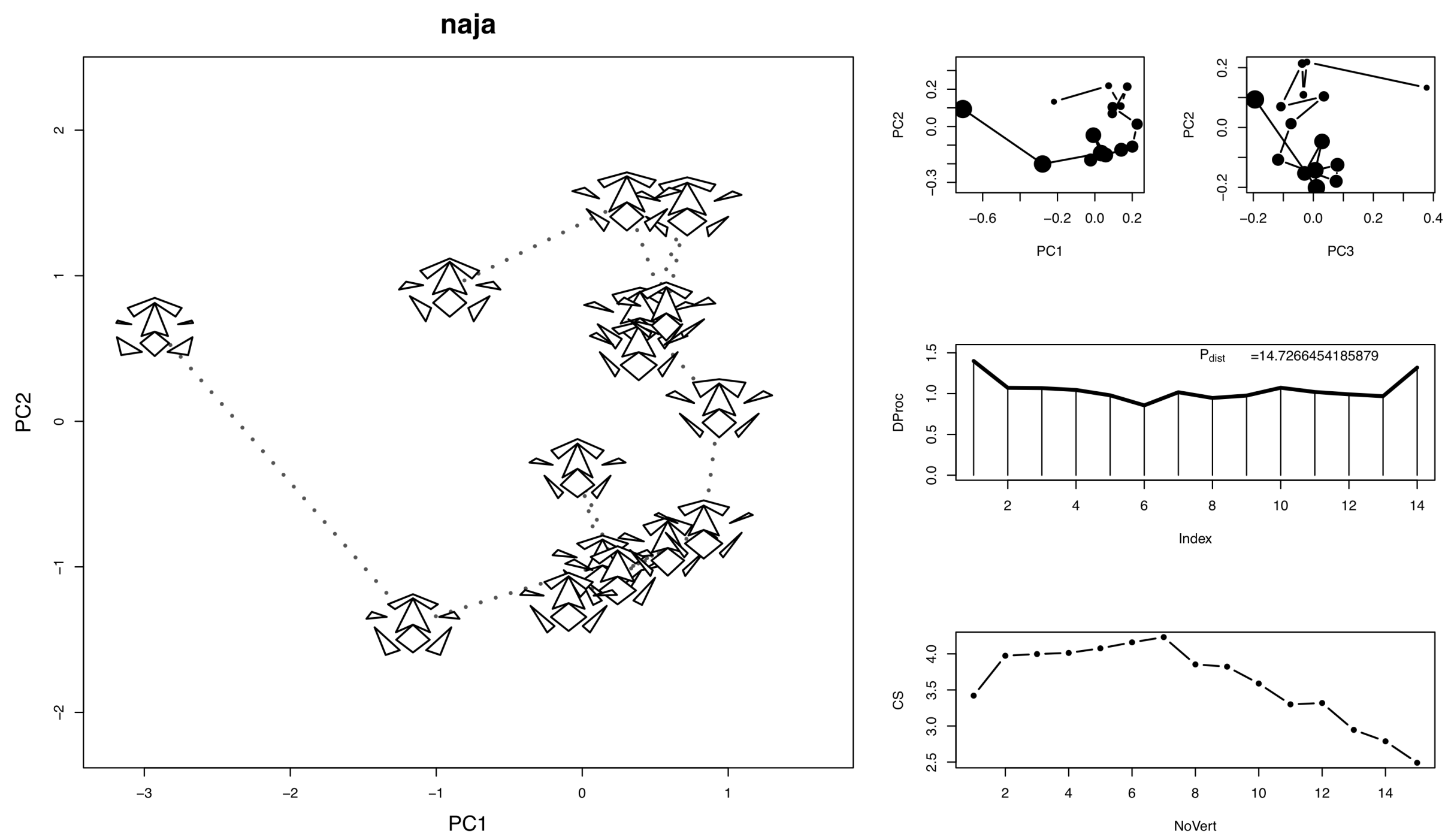

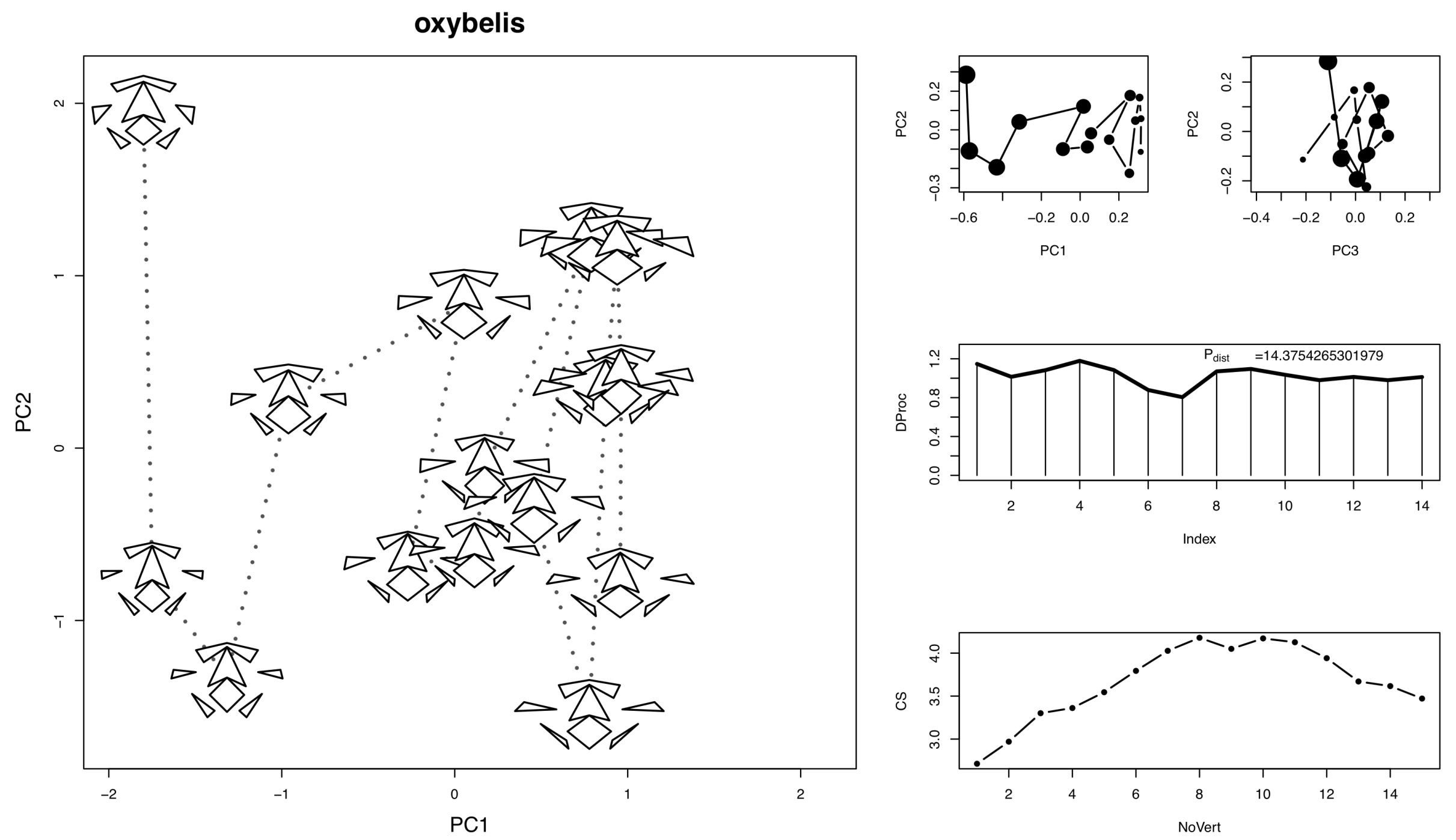

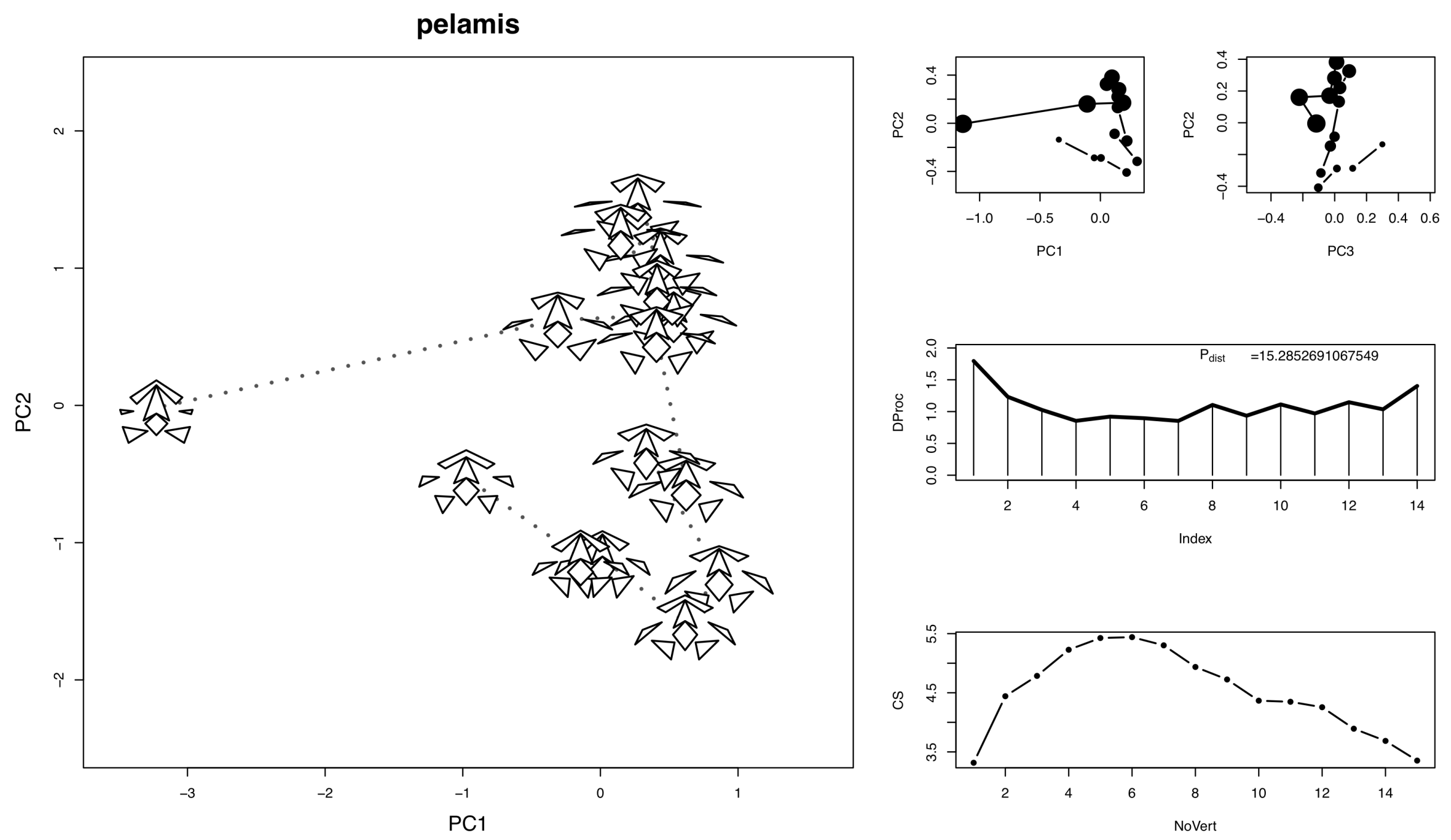

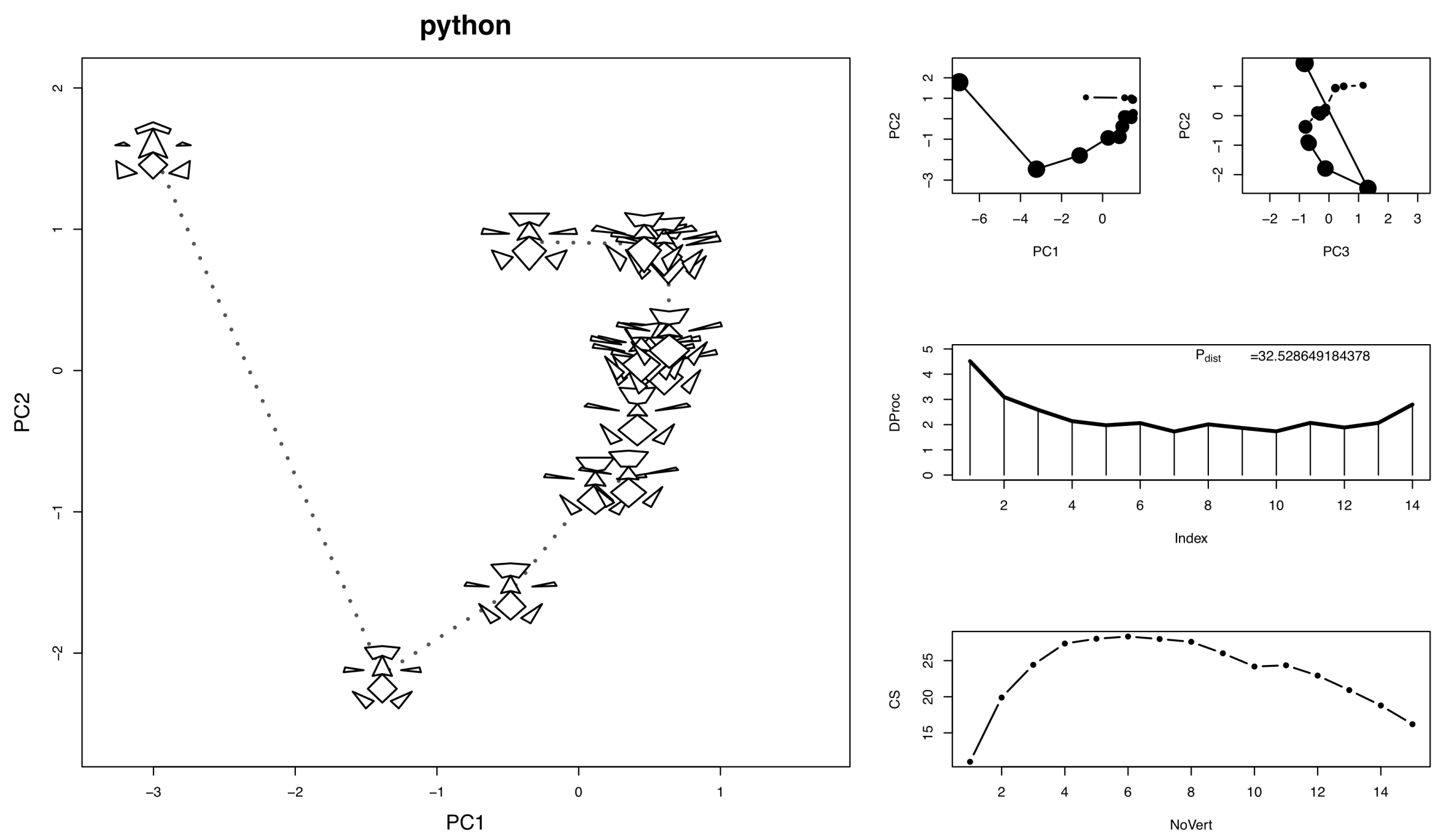


\section{rhinotyphlops}

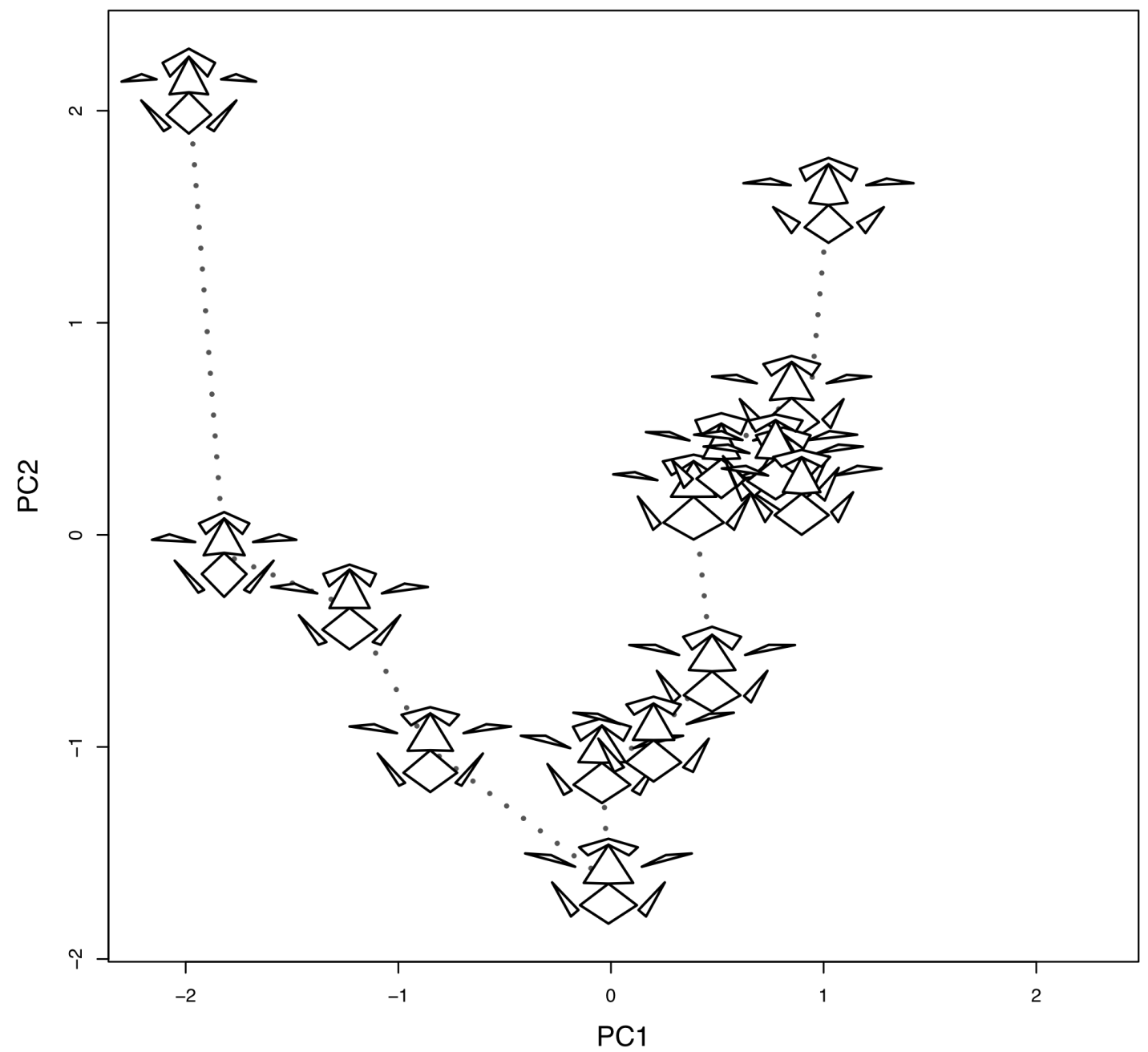

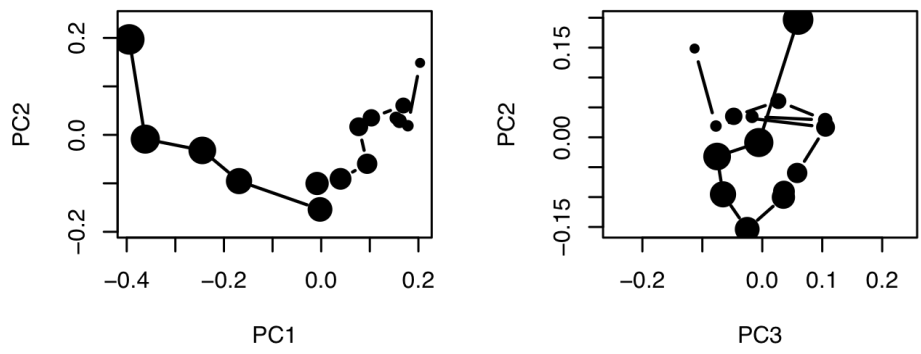

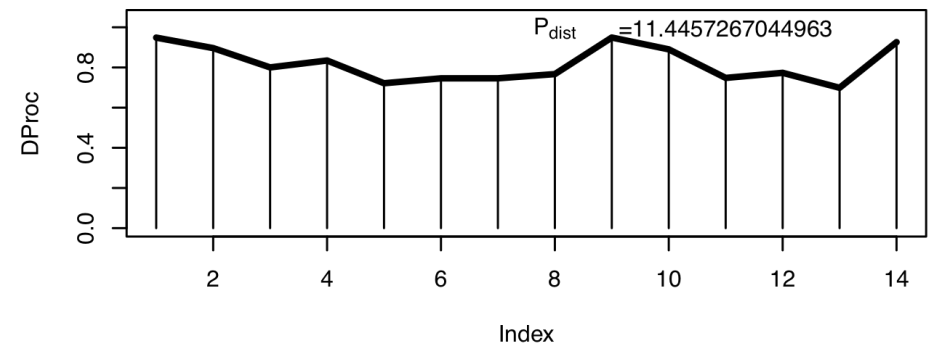

8

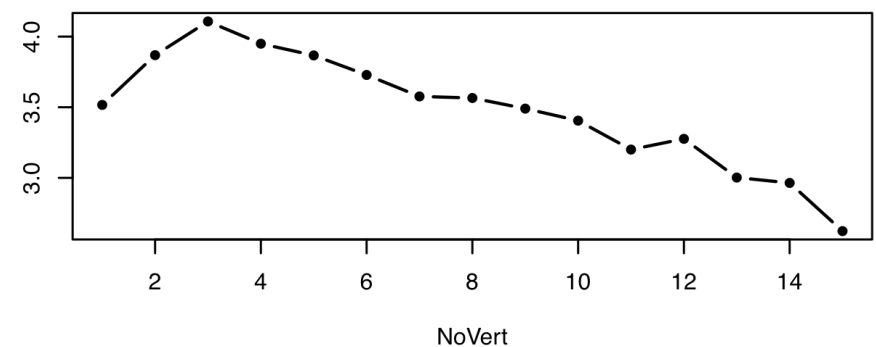



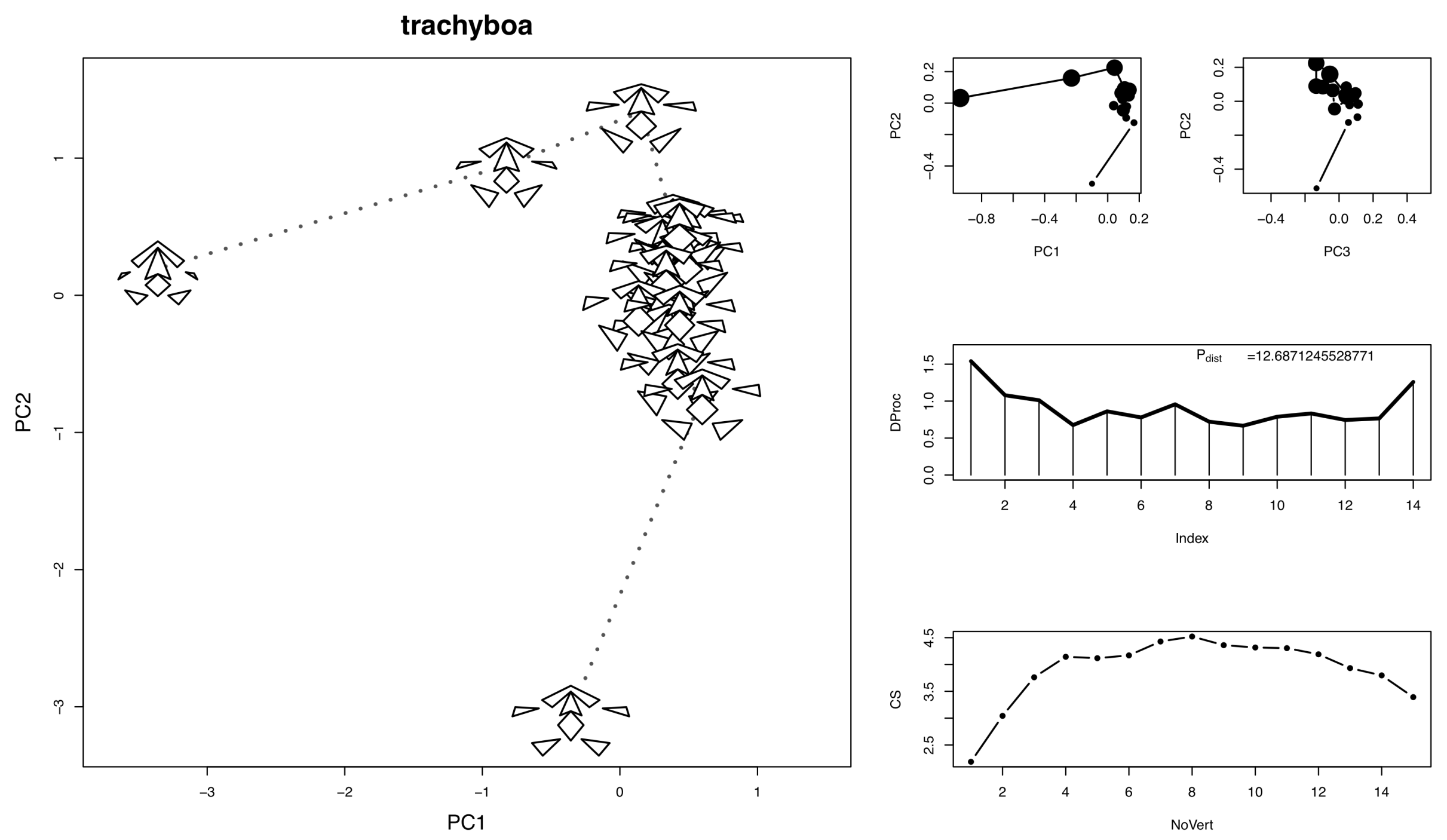

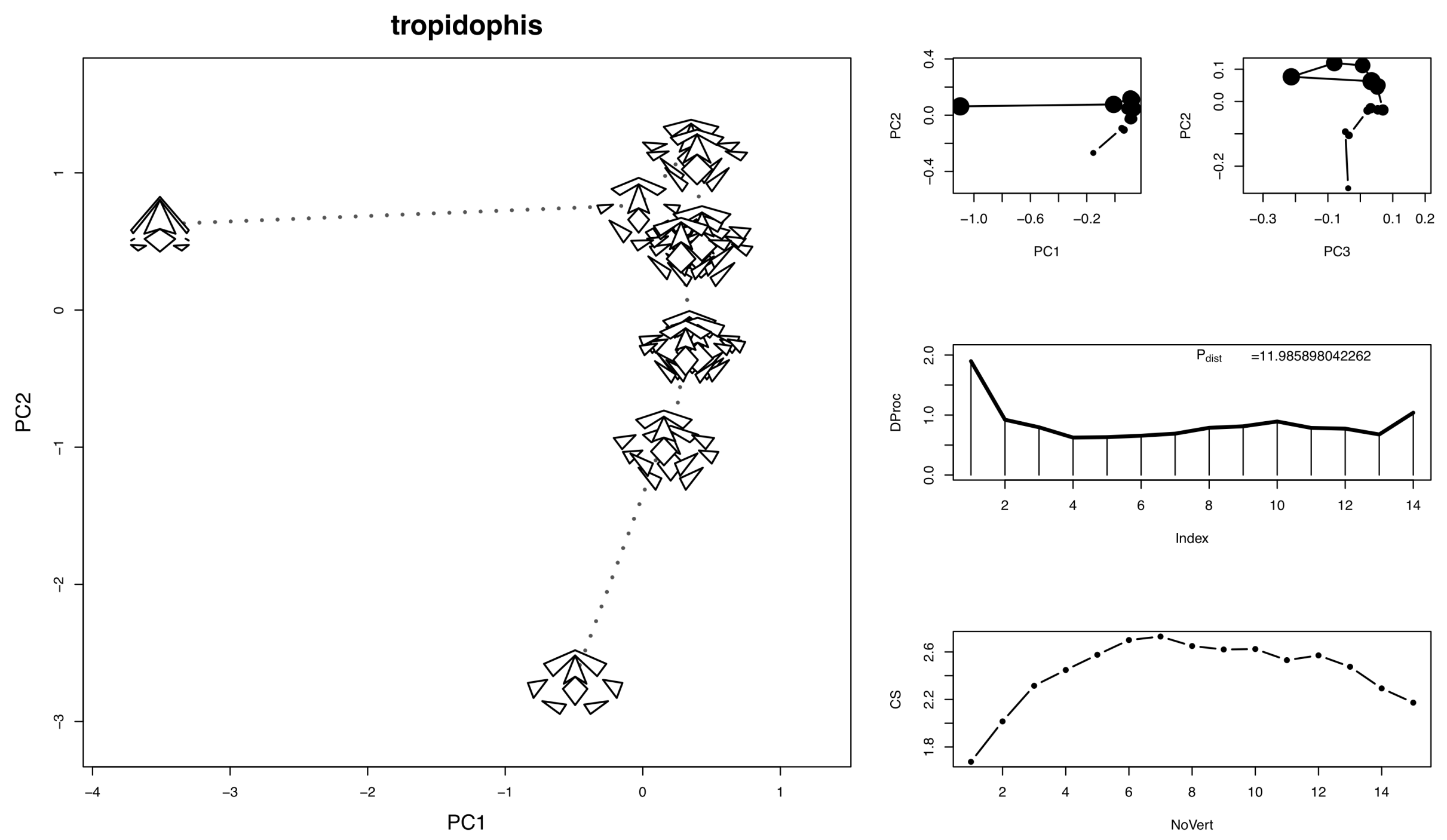

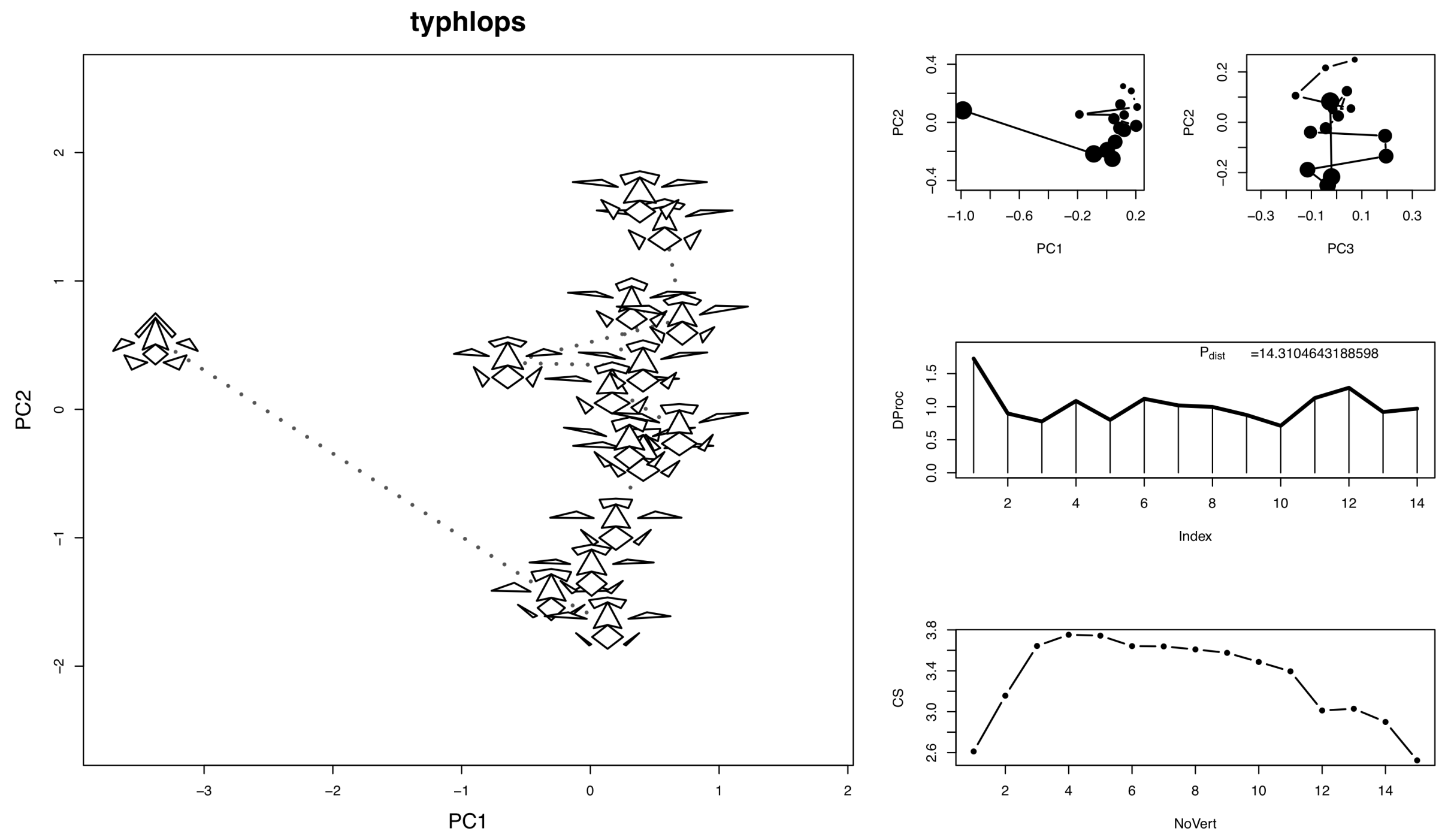

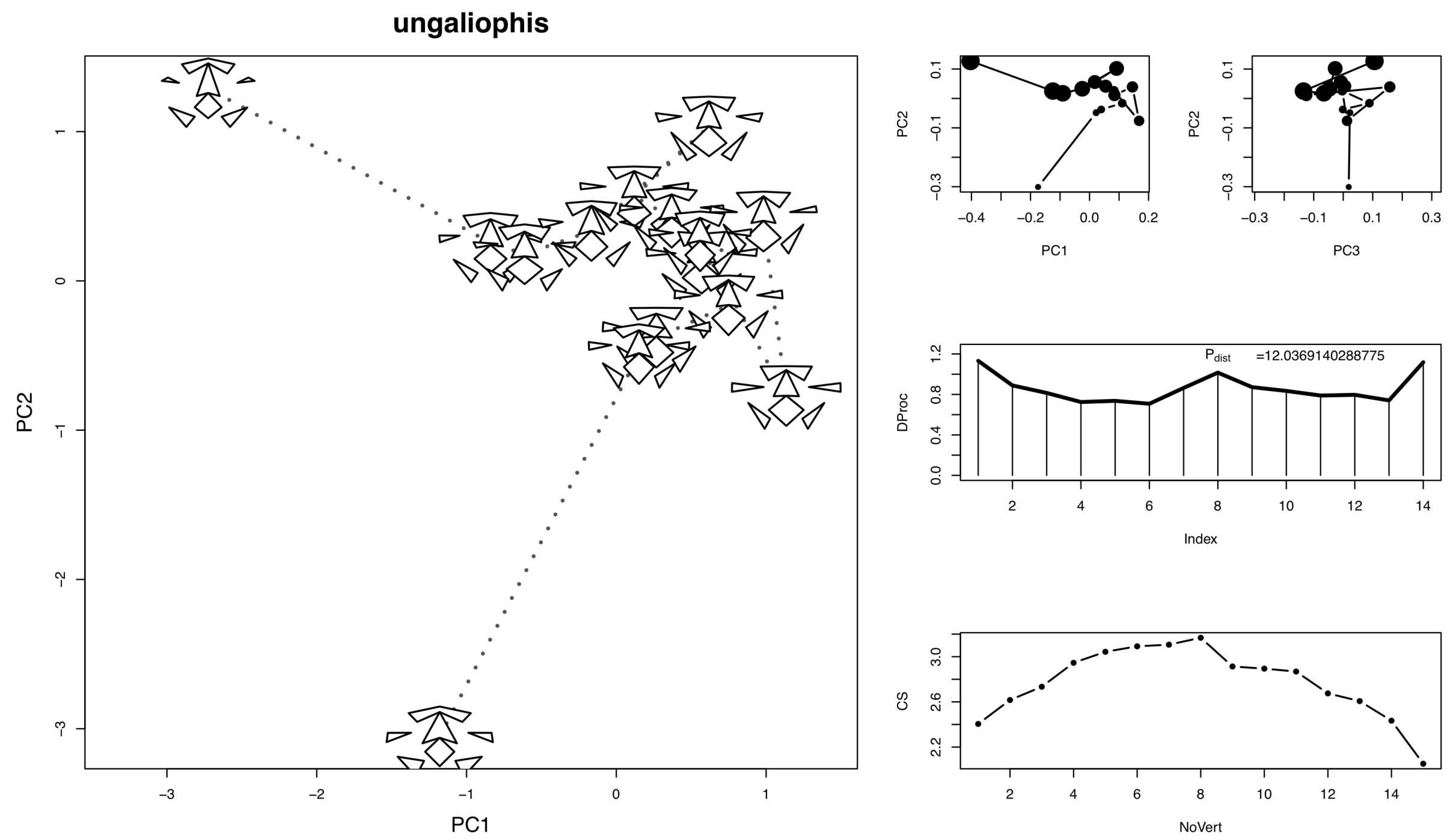

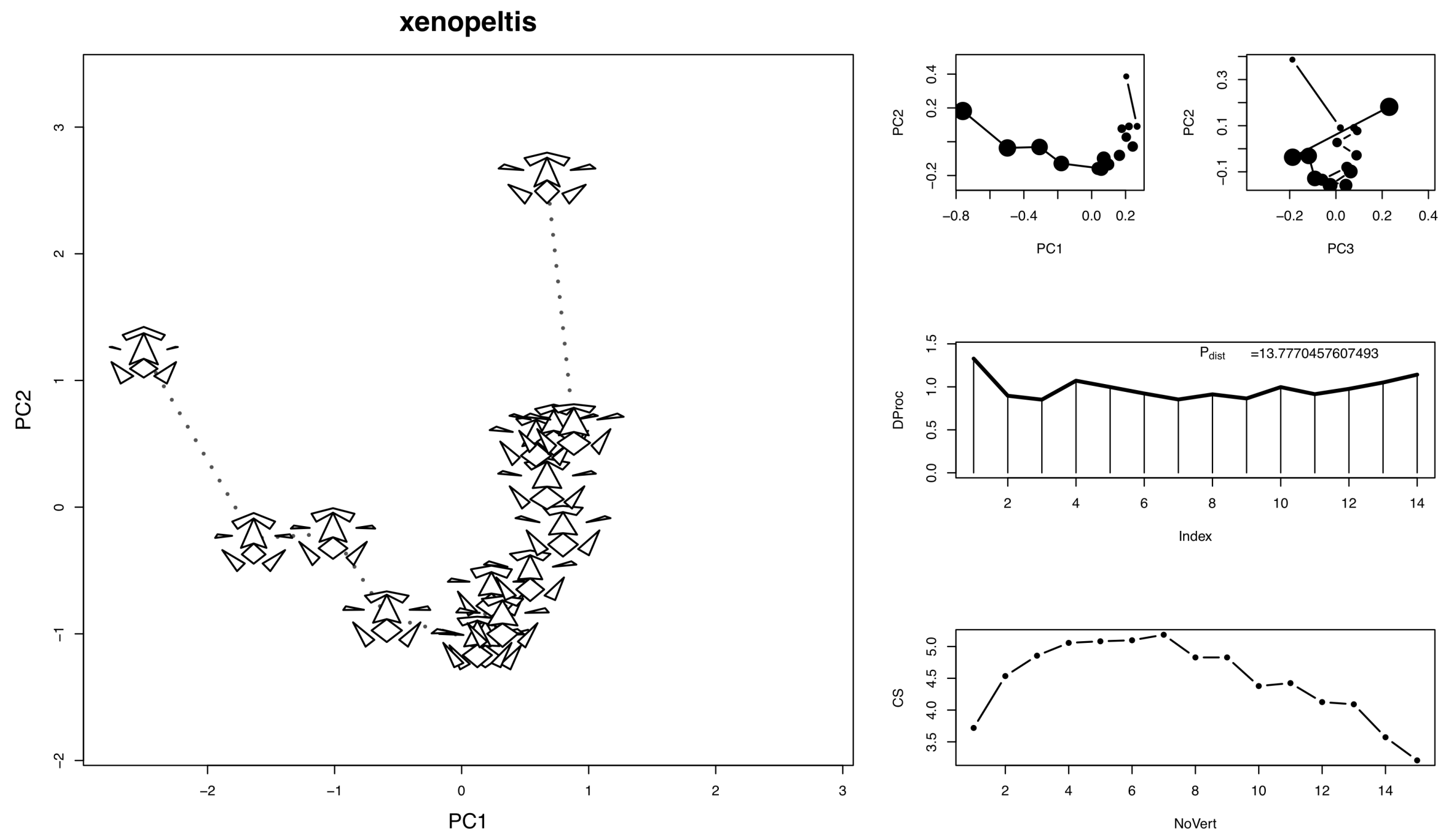
acrantophis
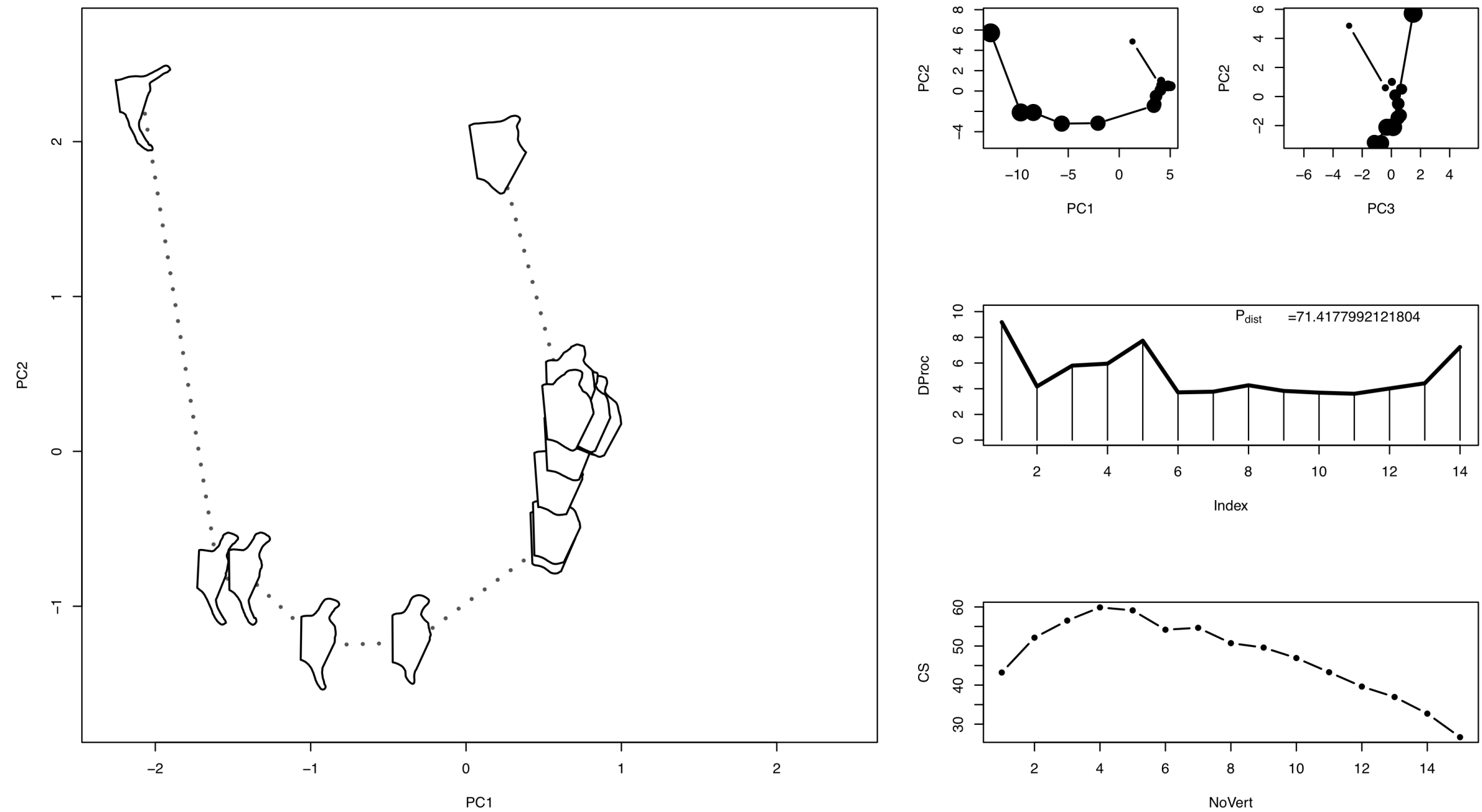
acrochordus
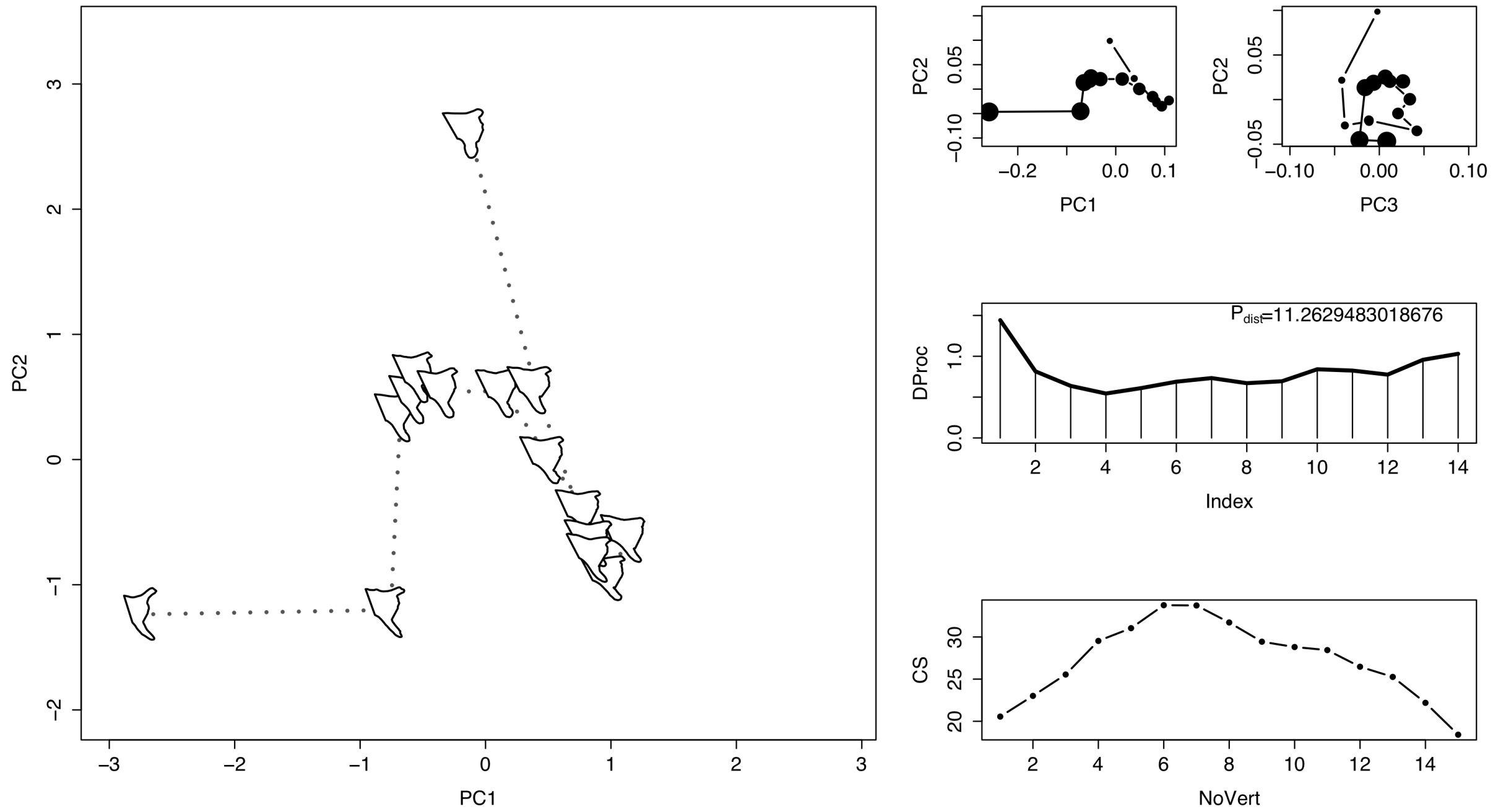
anilius

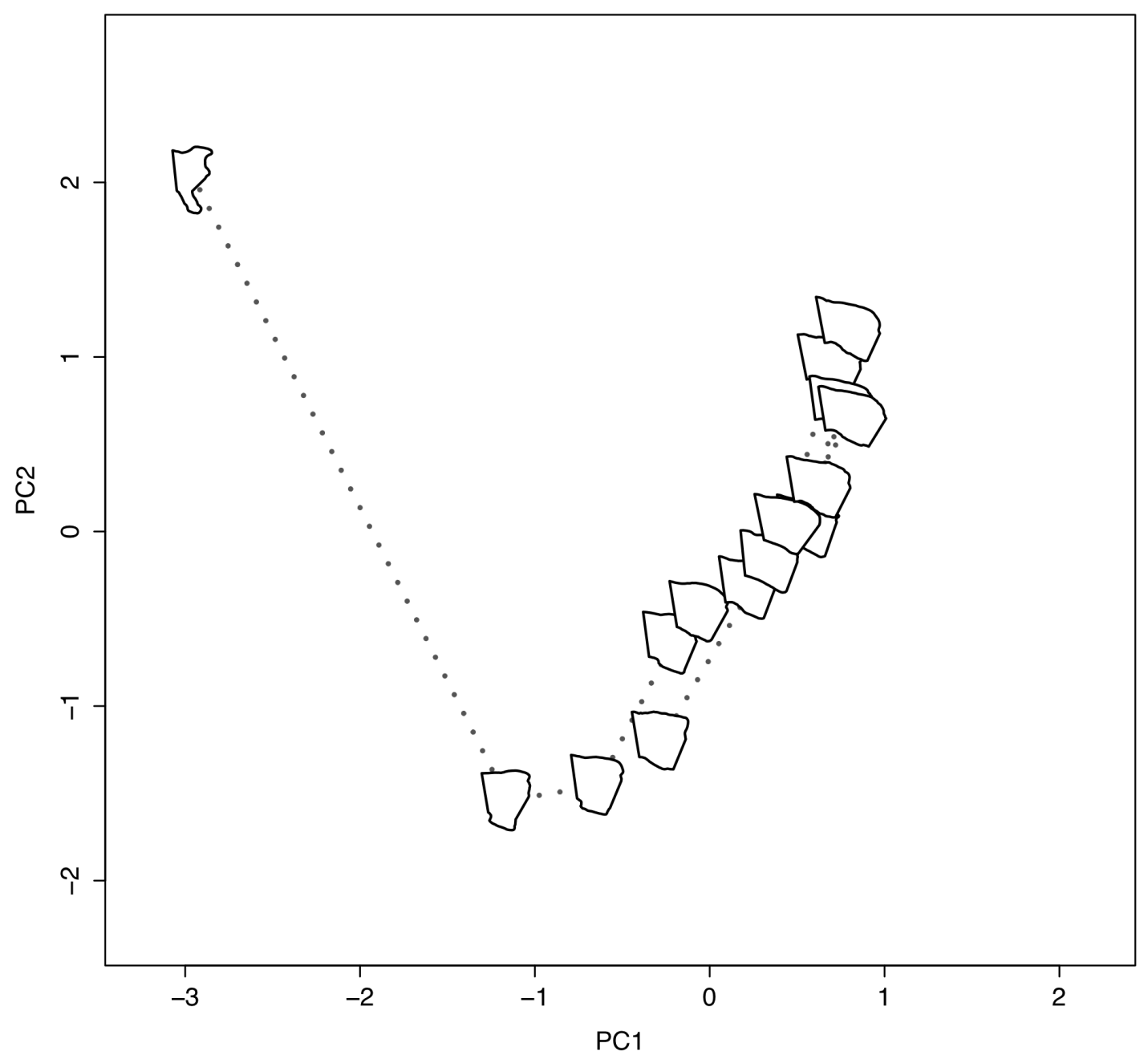

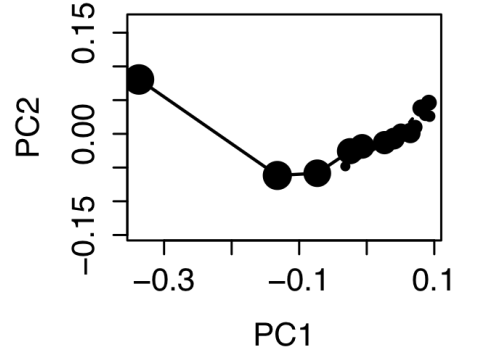
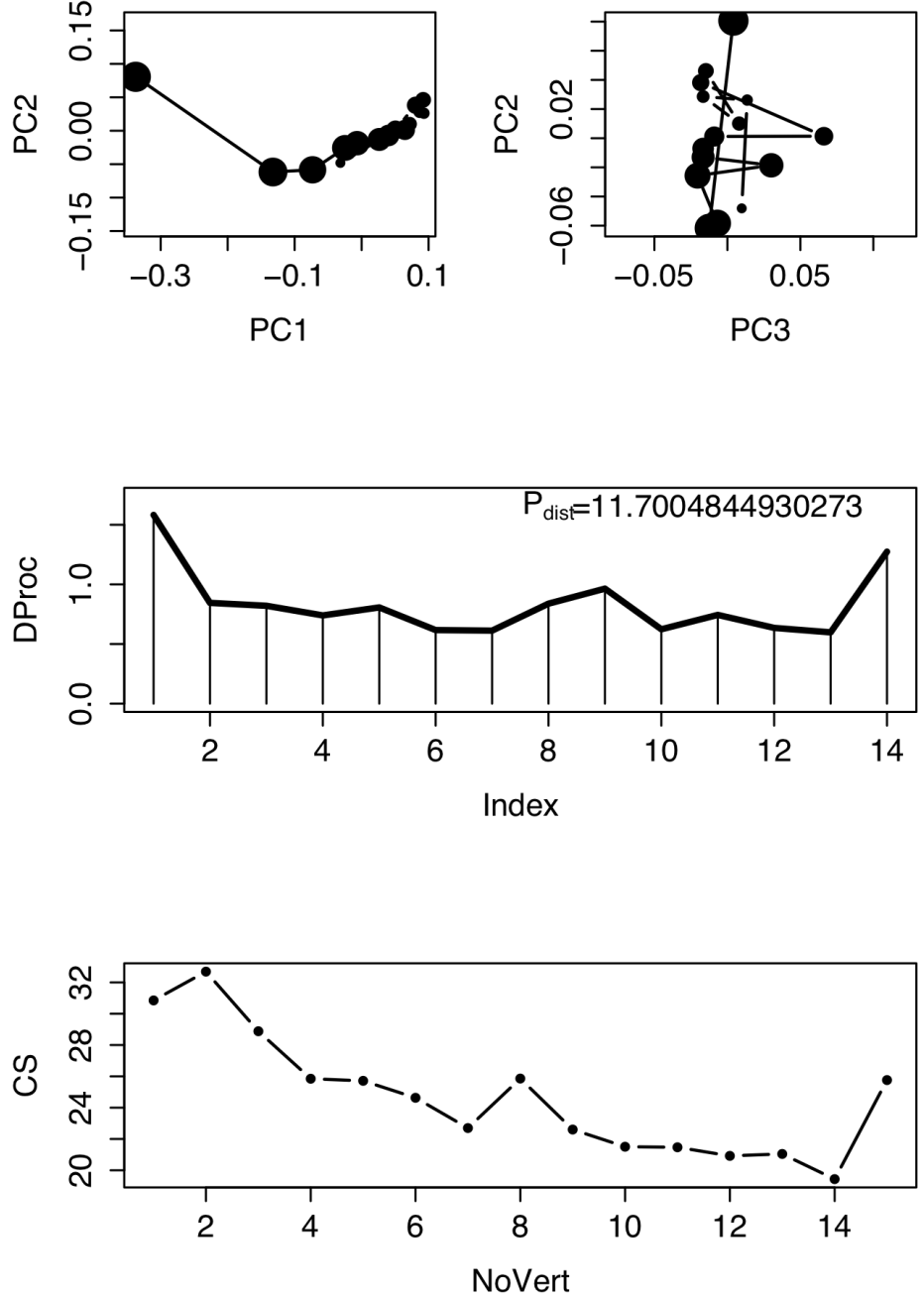
atractus

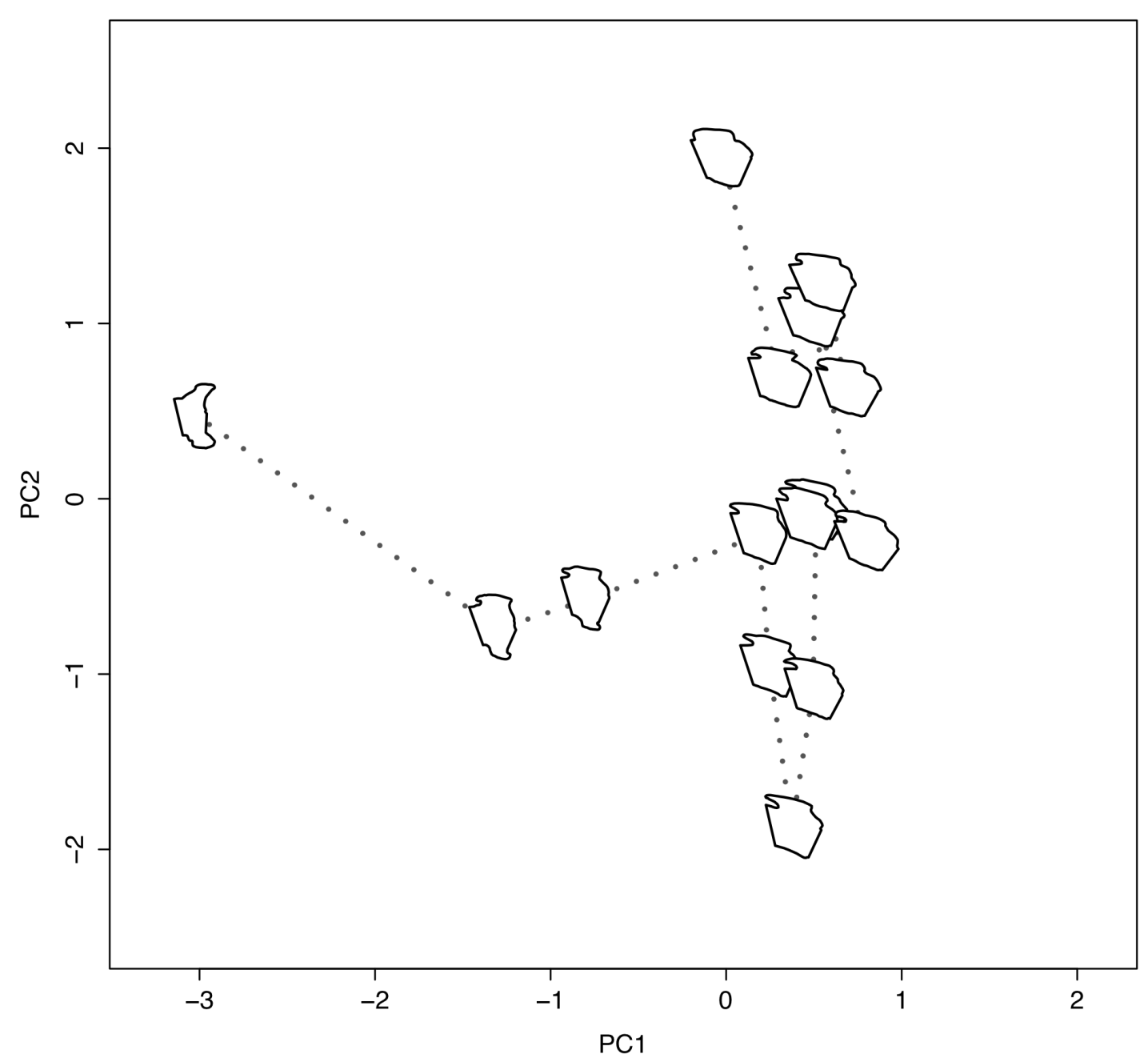

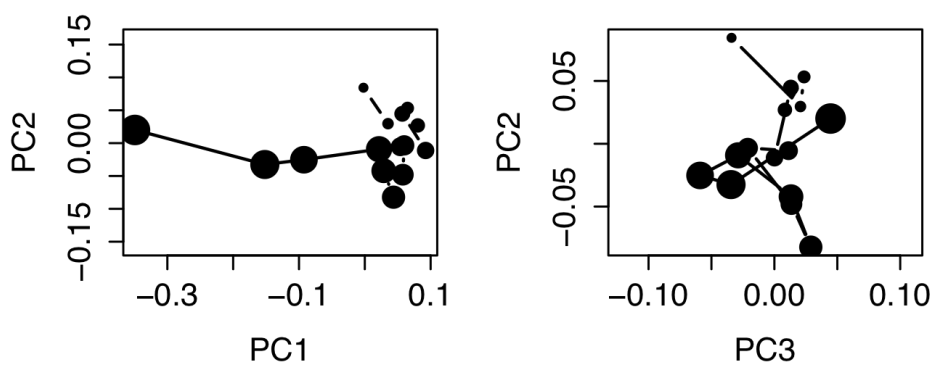
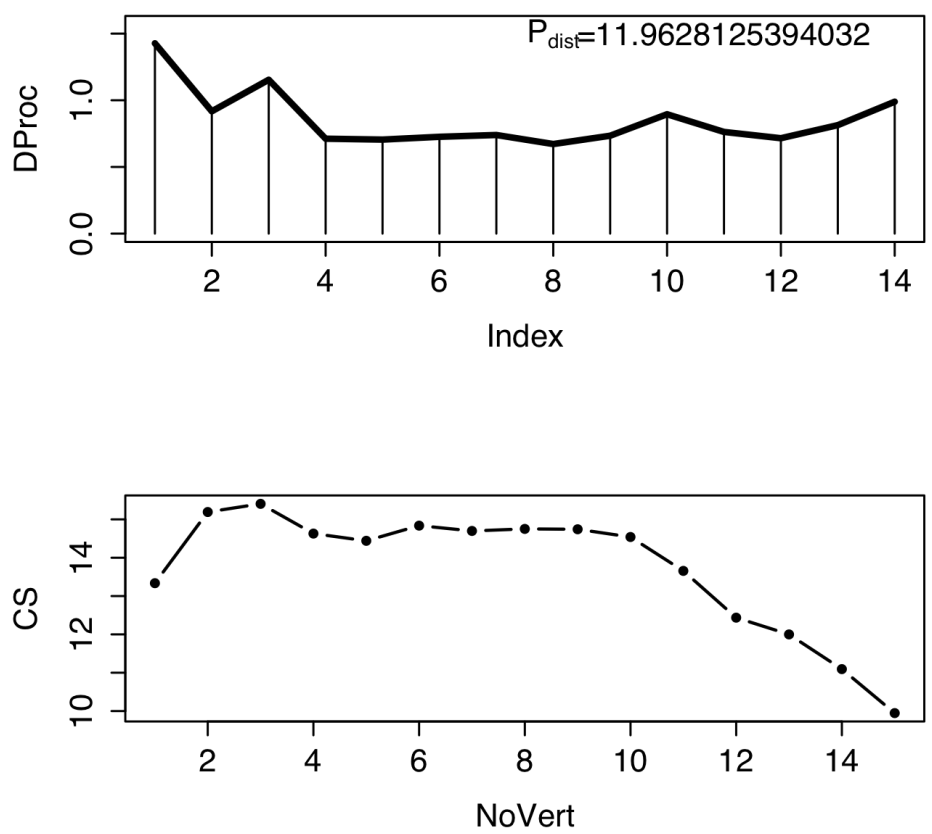
boa
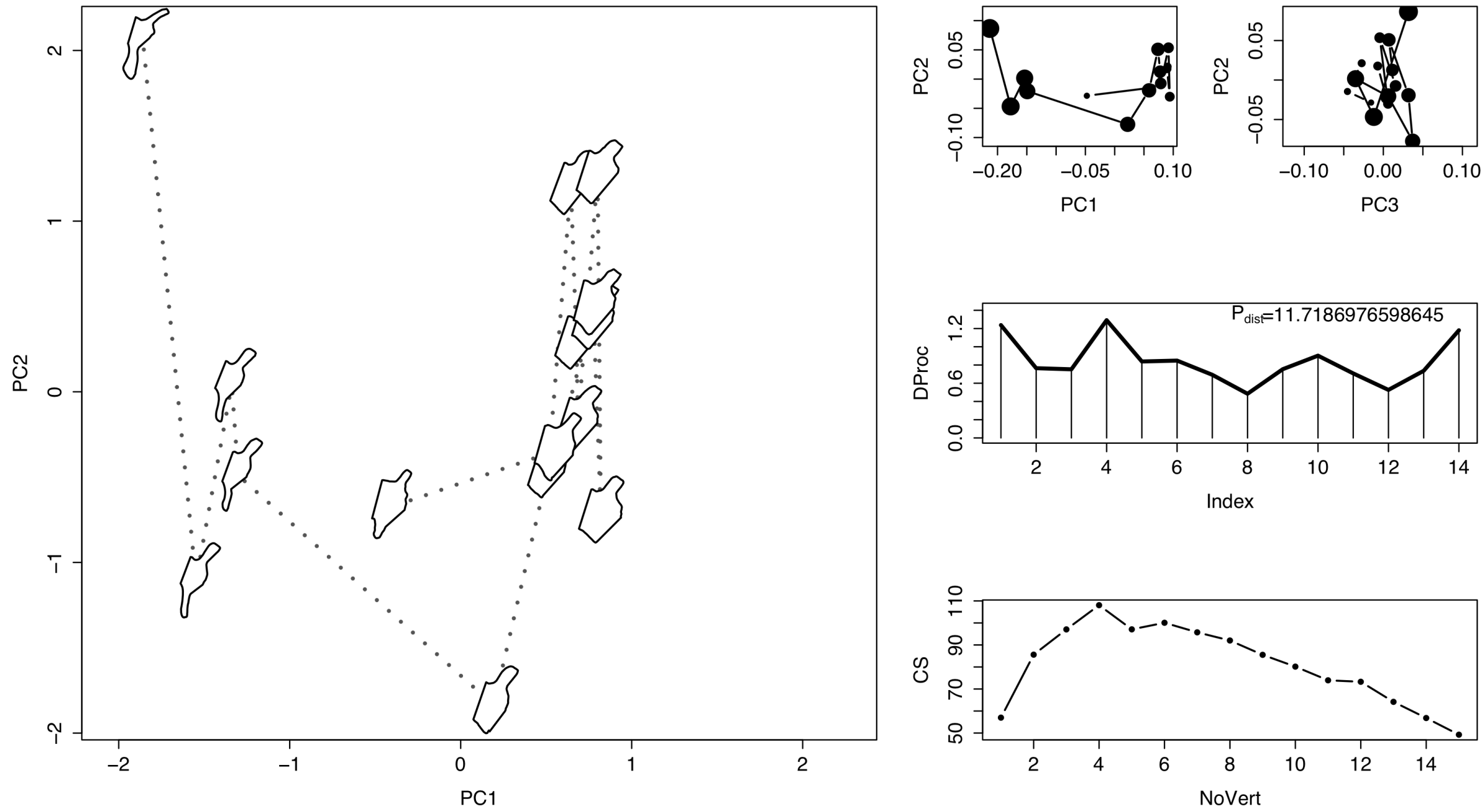
bothriopsis
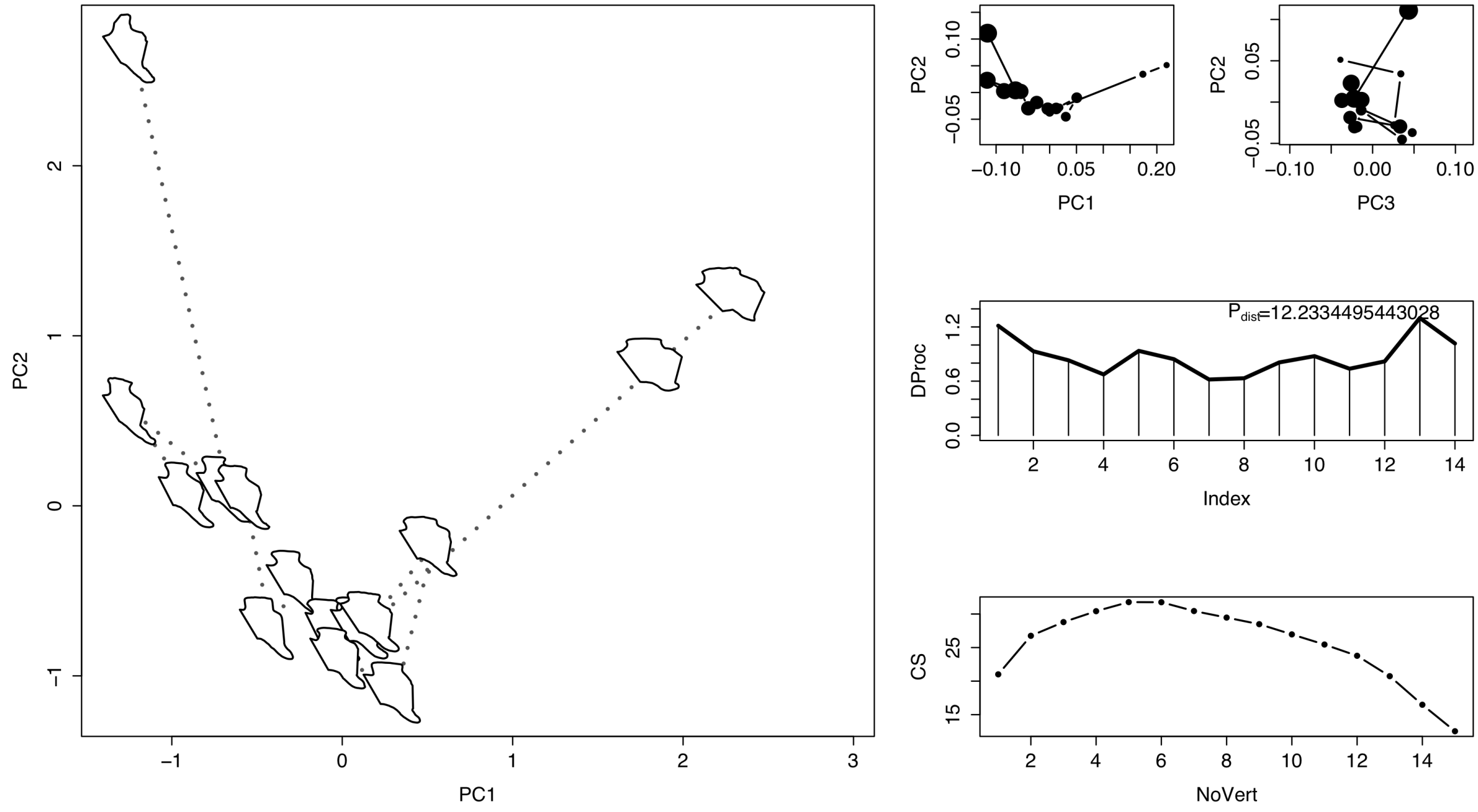

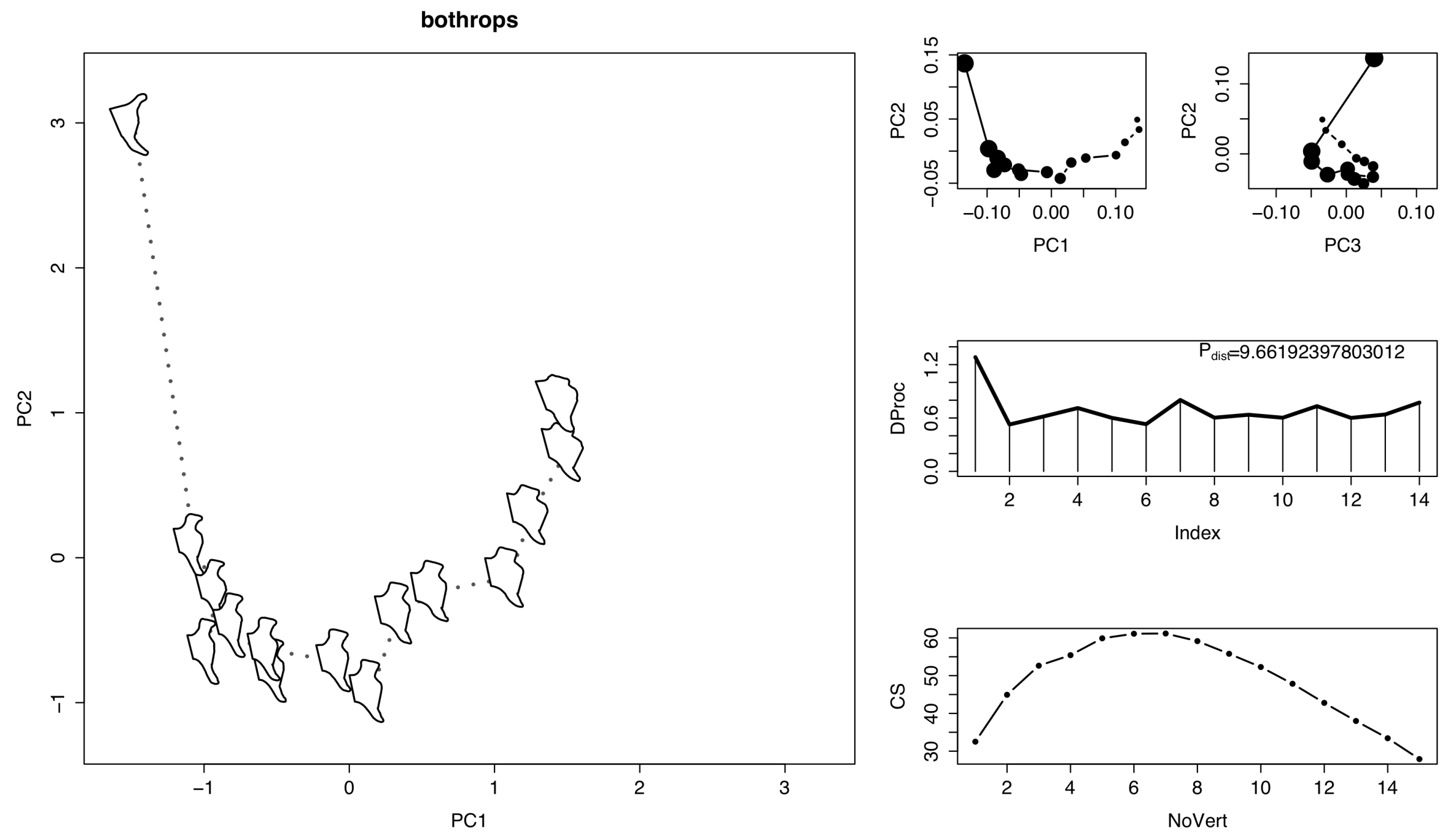
calabaria

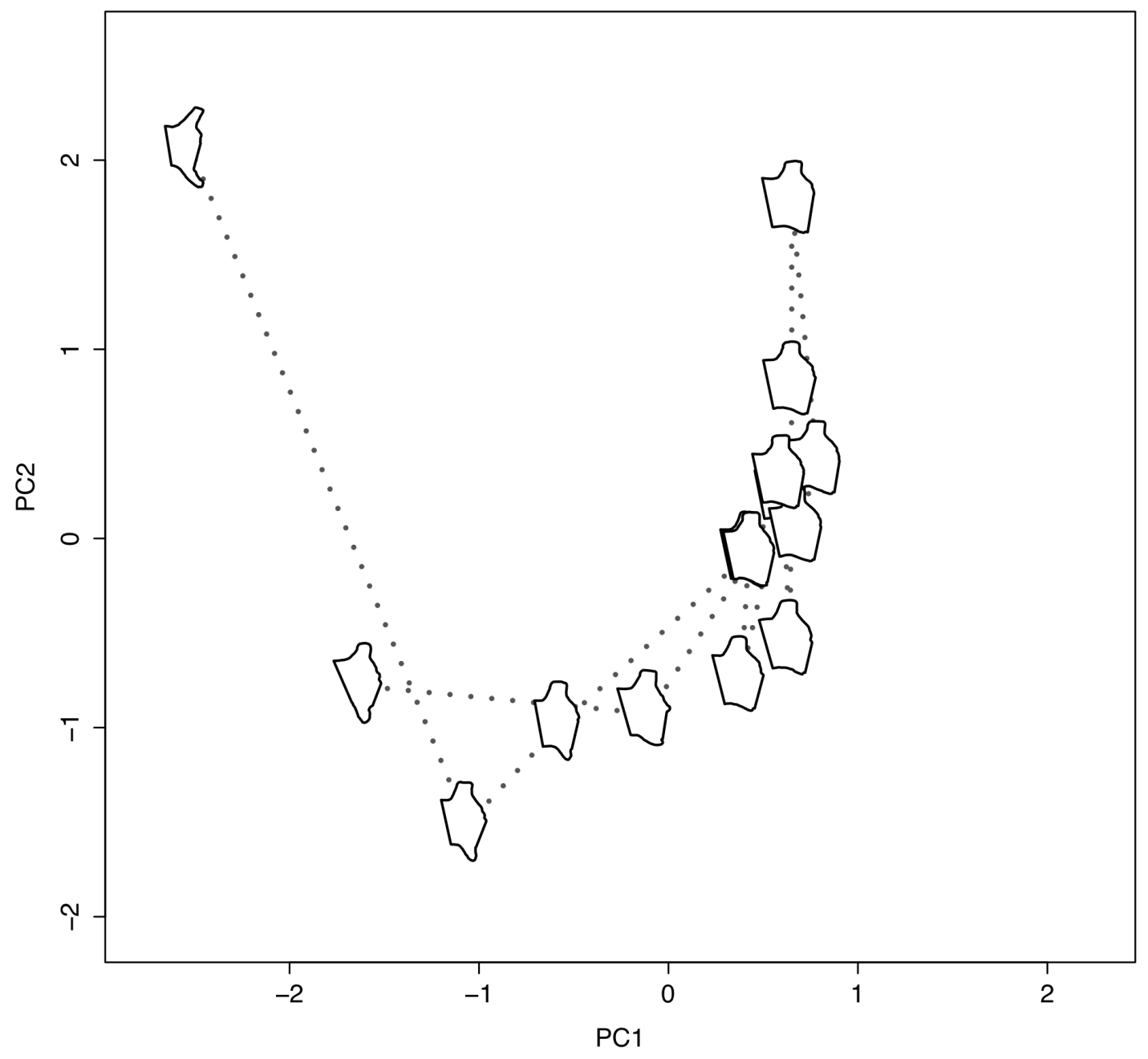

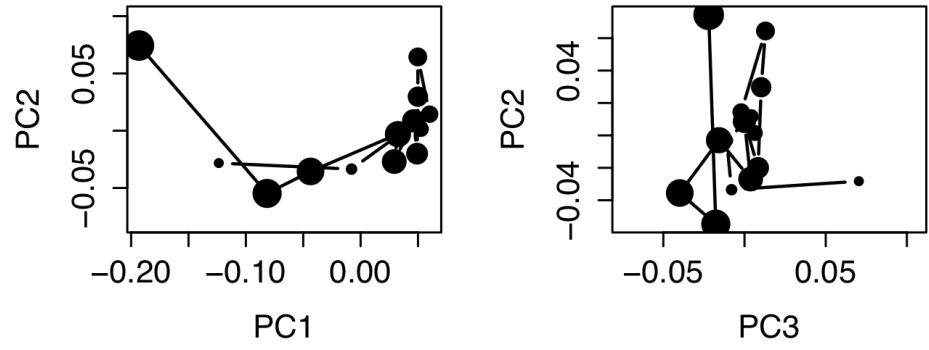
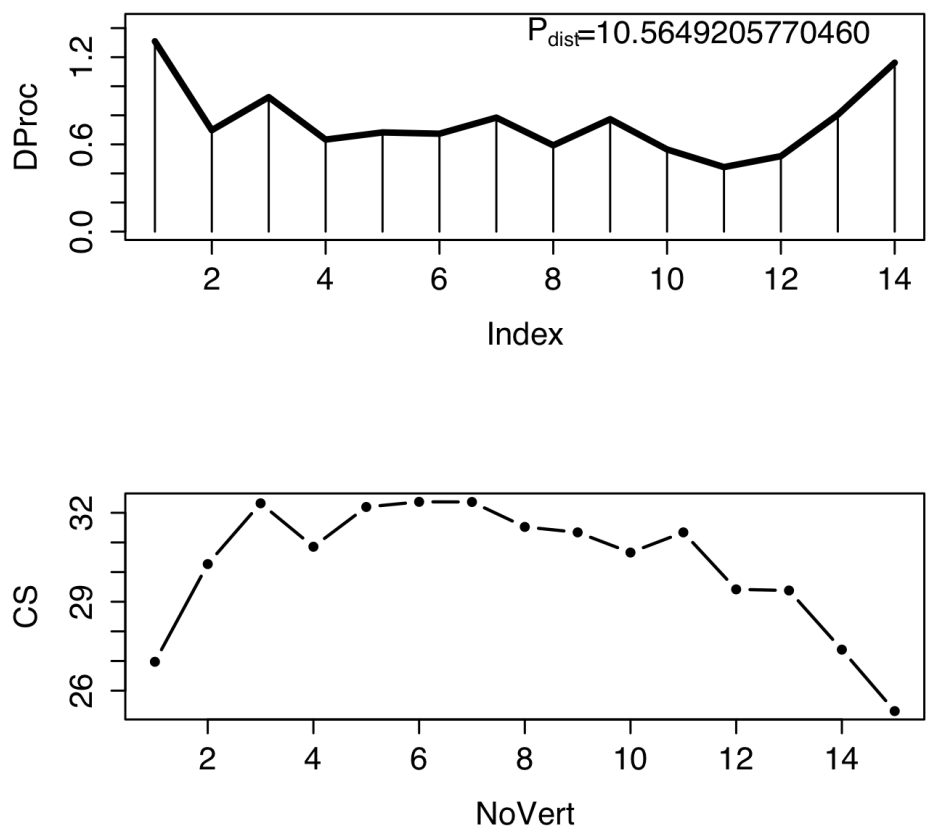

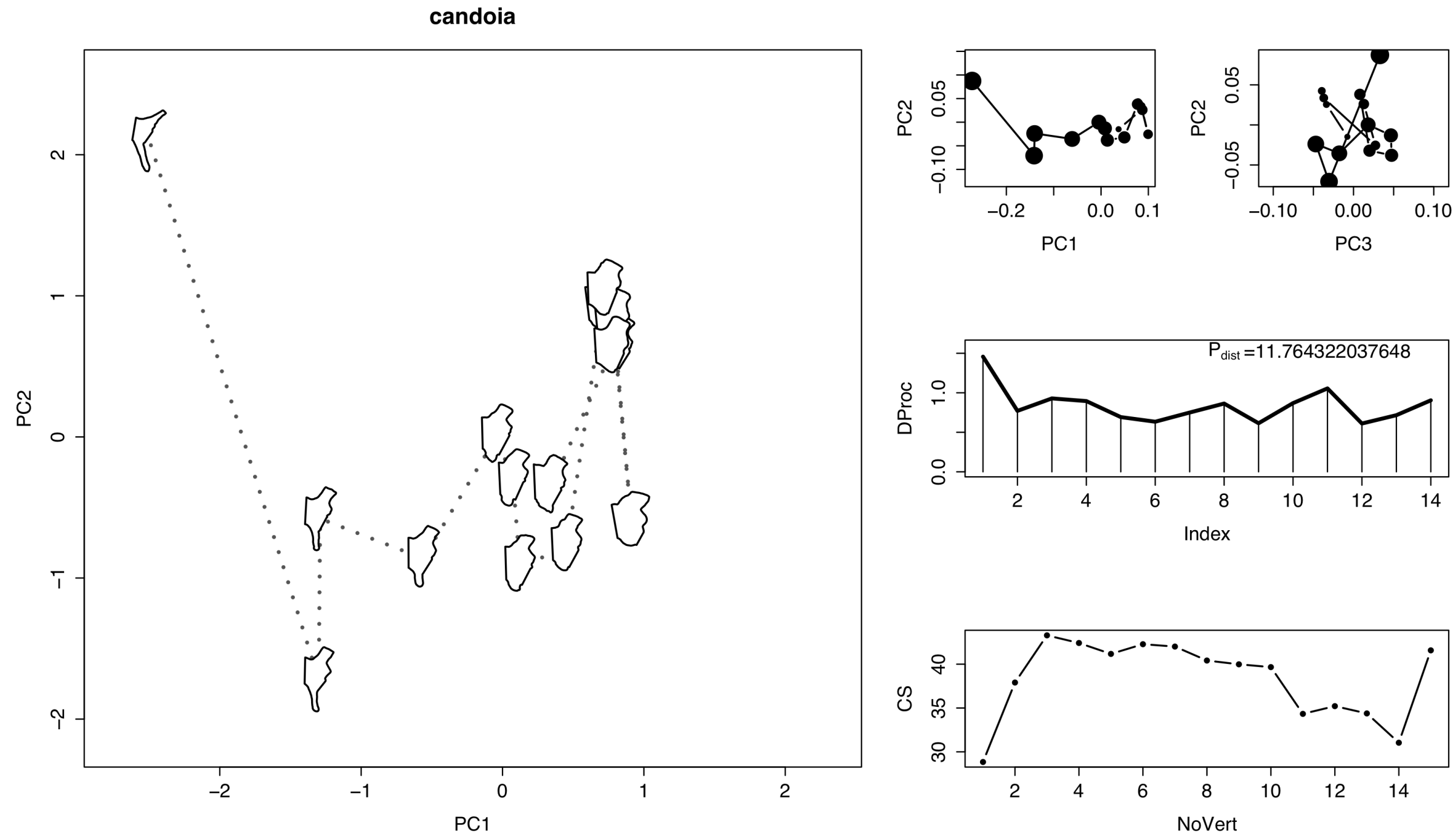
casarea
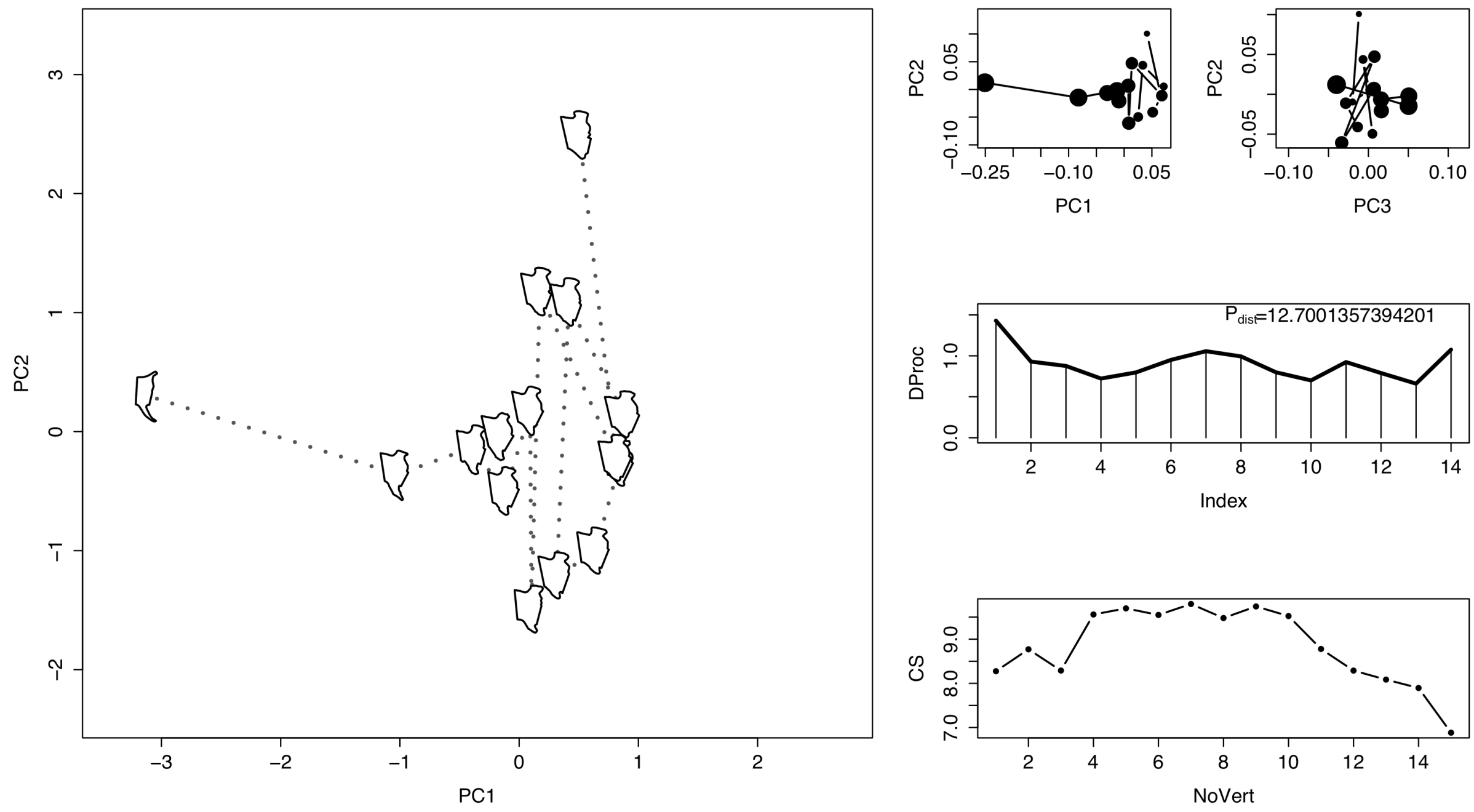

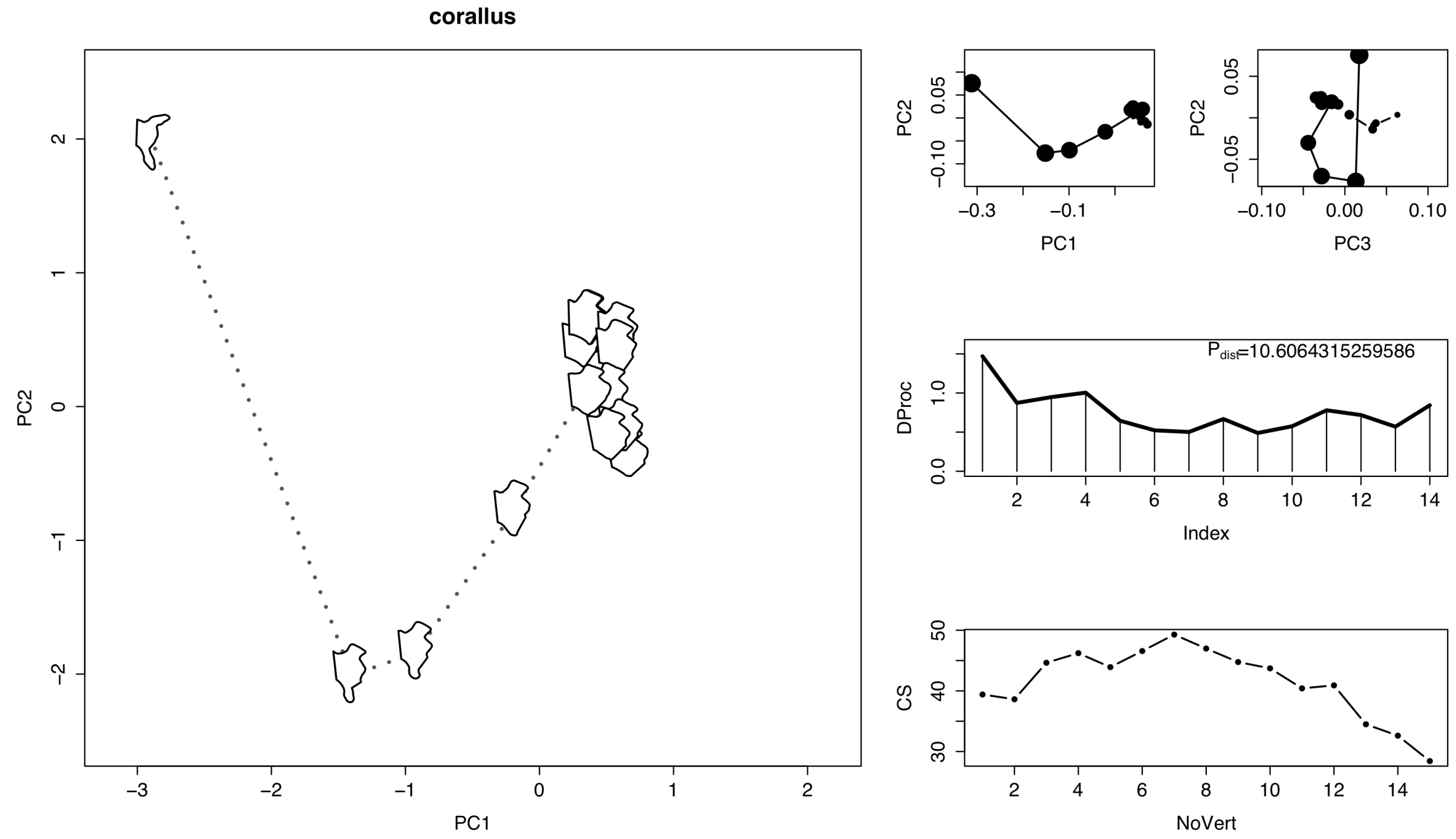


\section{cylindrophis}
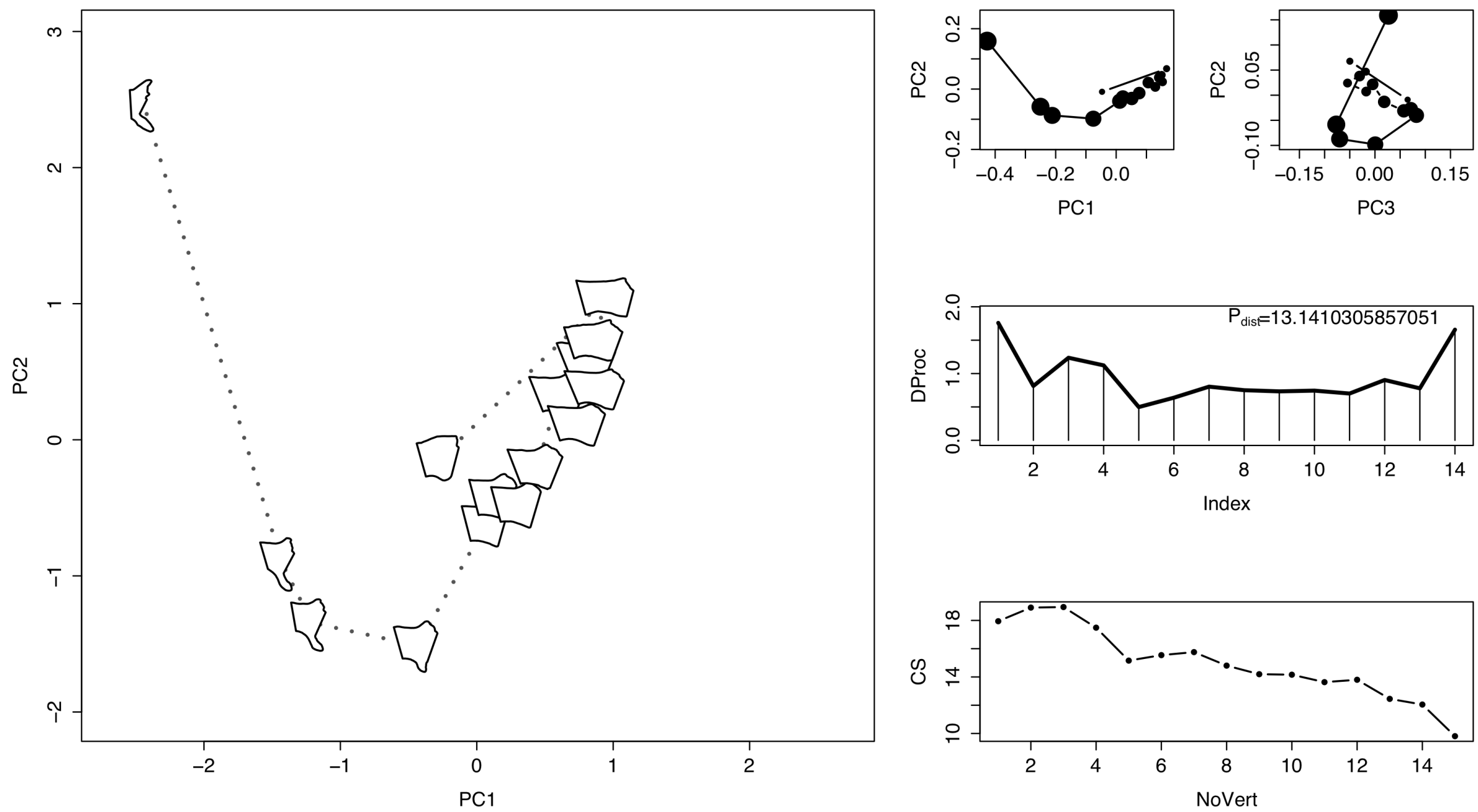

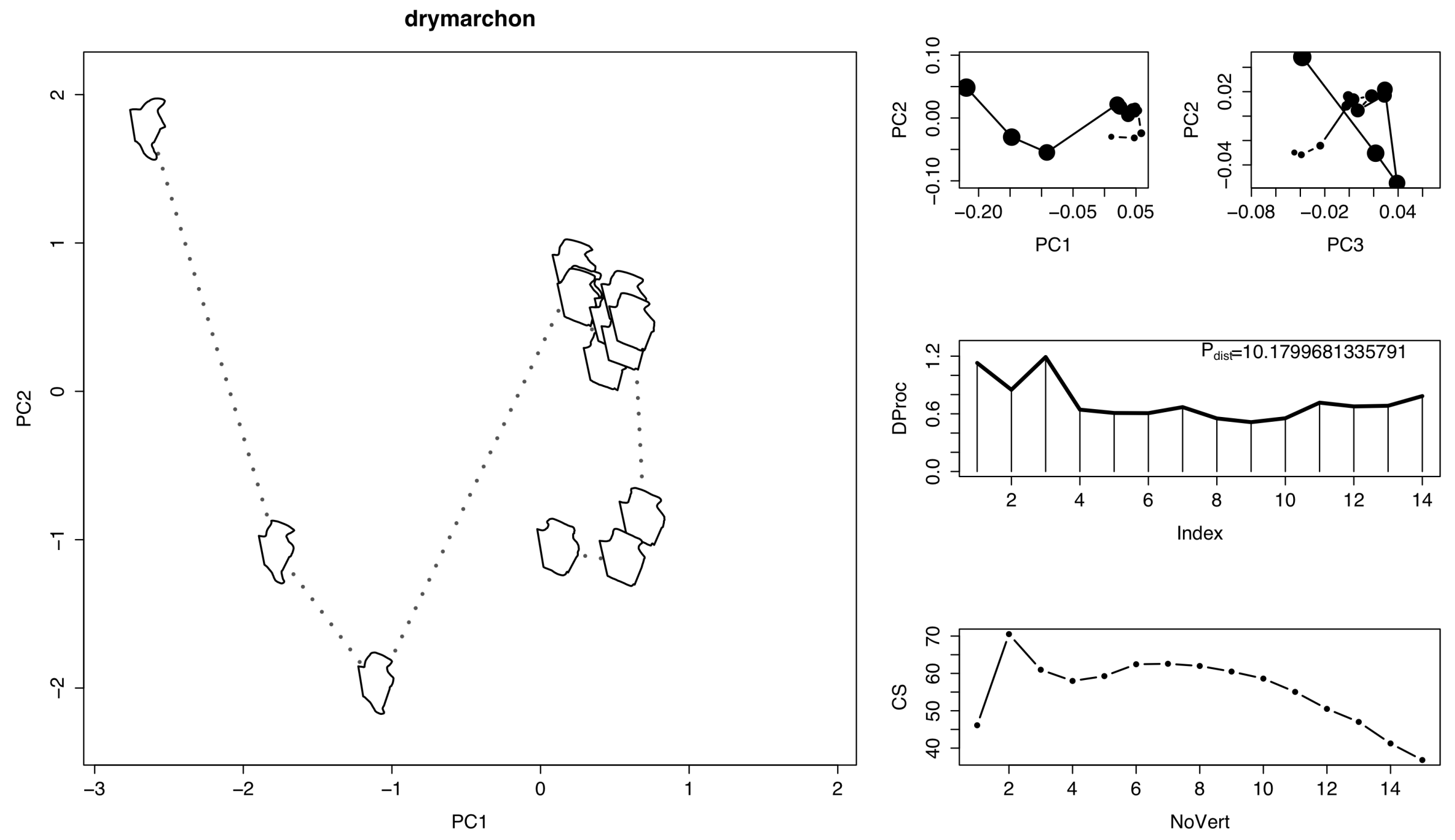
epicrates
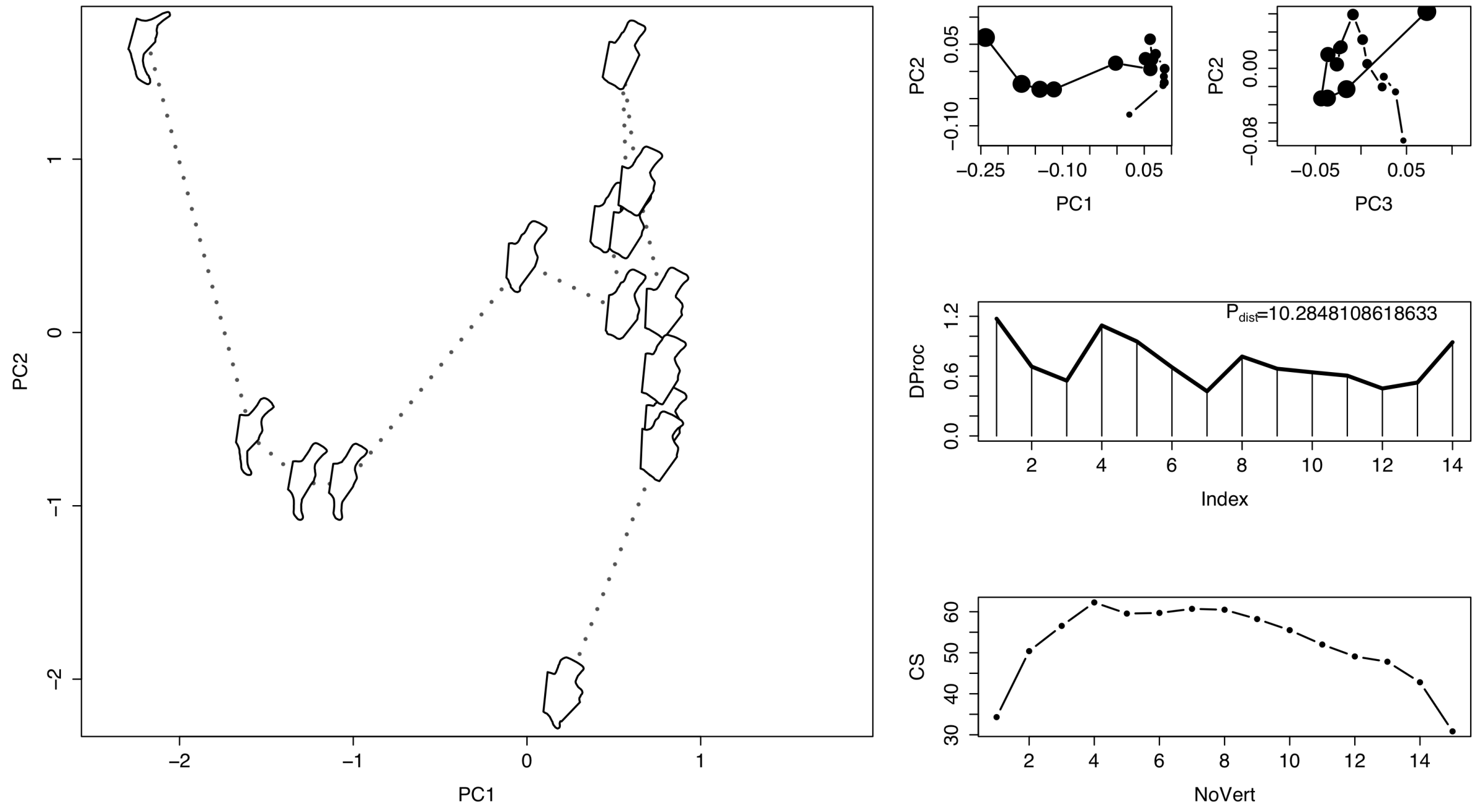
eryx

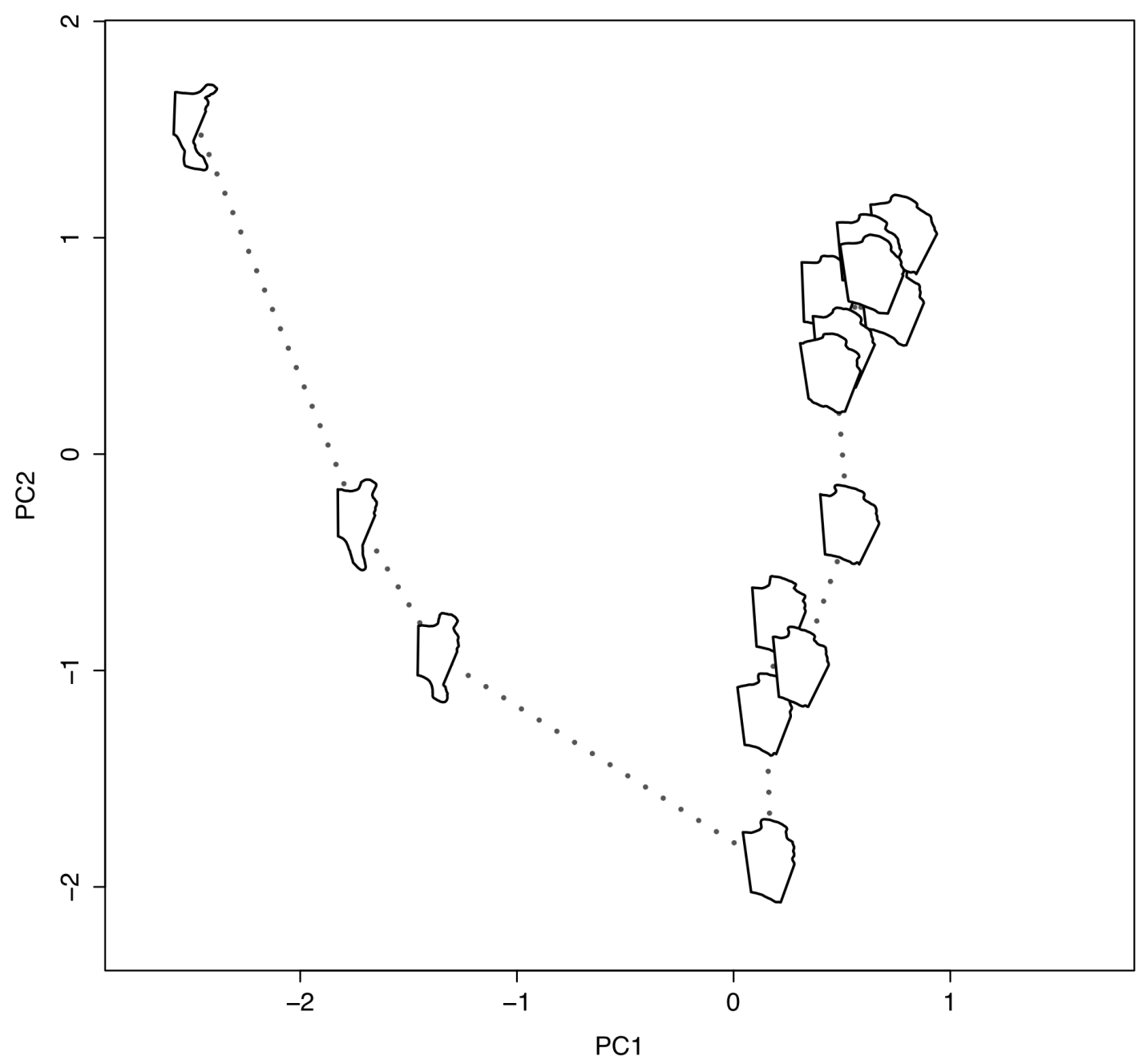

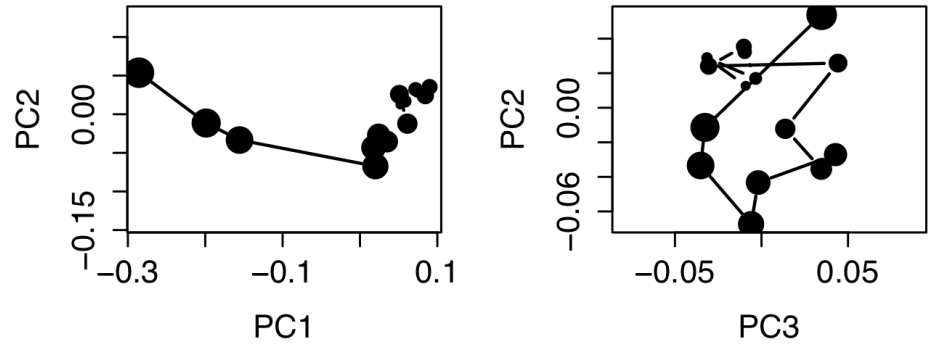
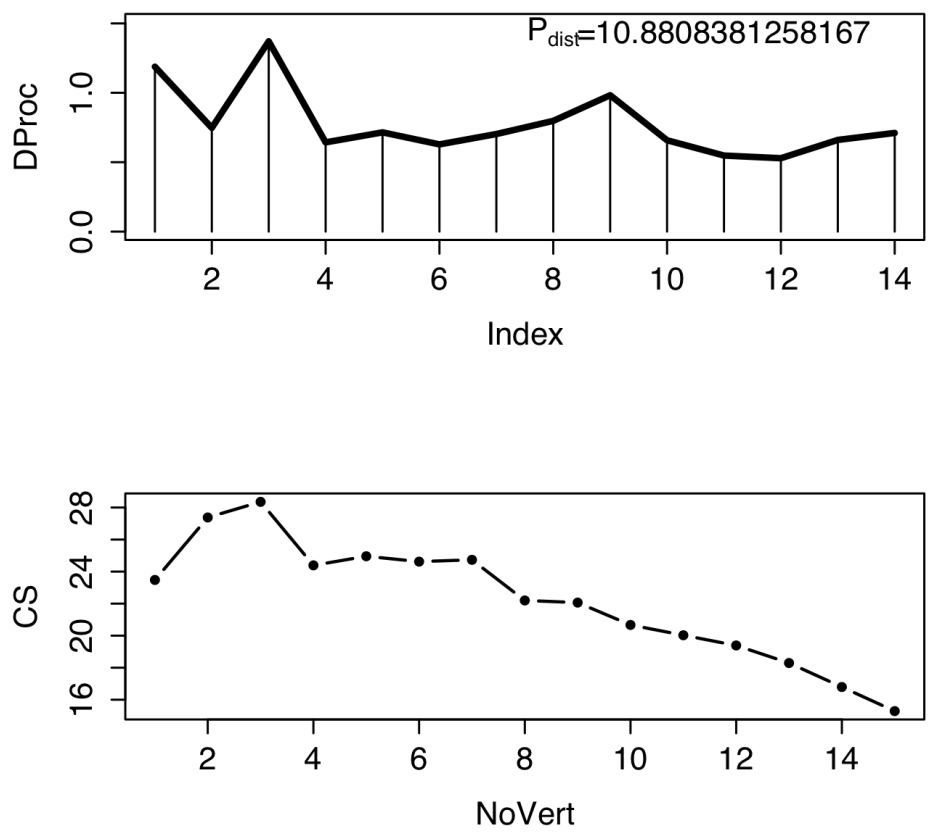
eunectes
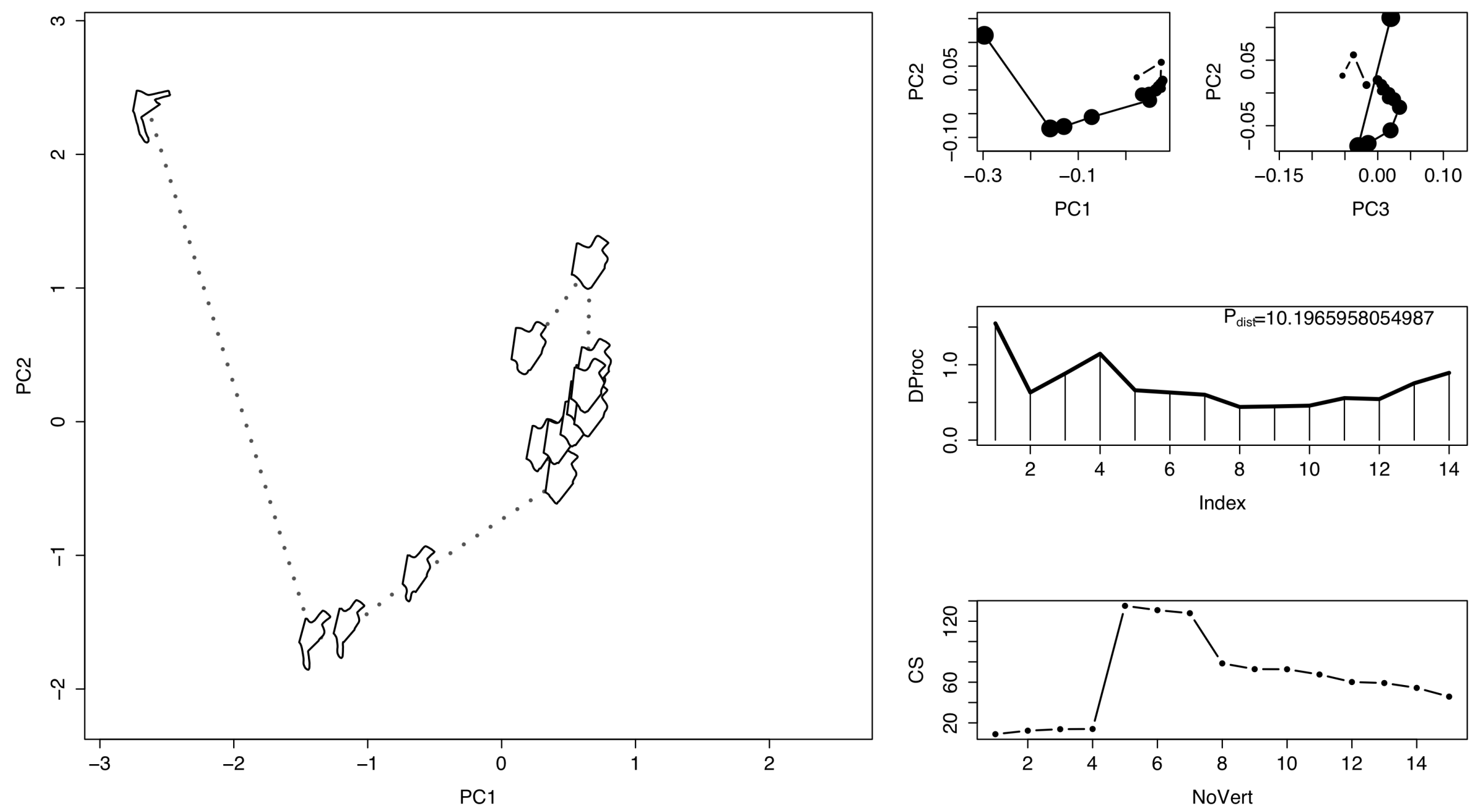

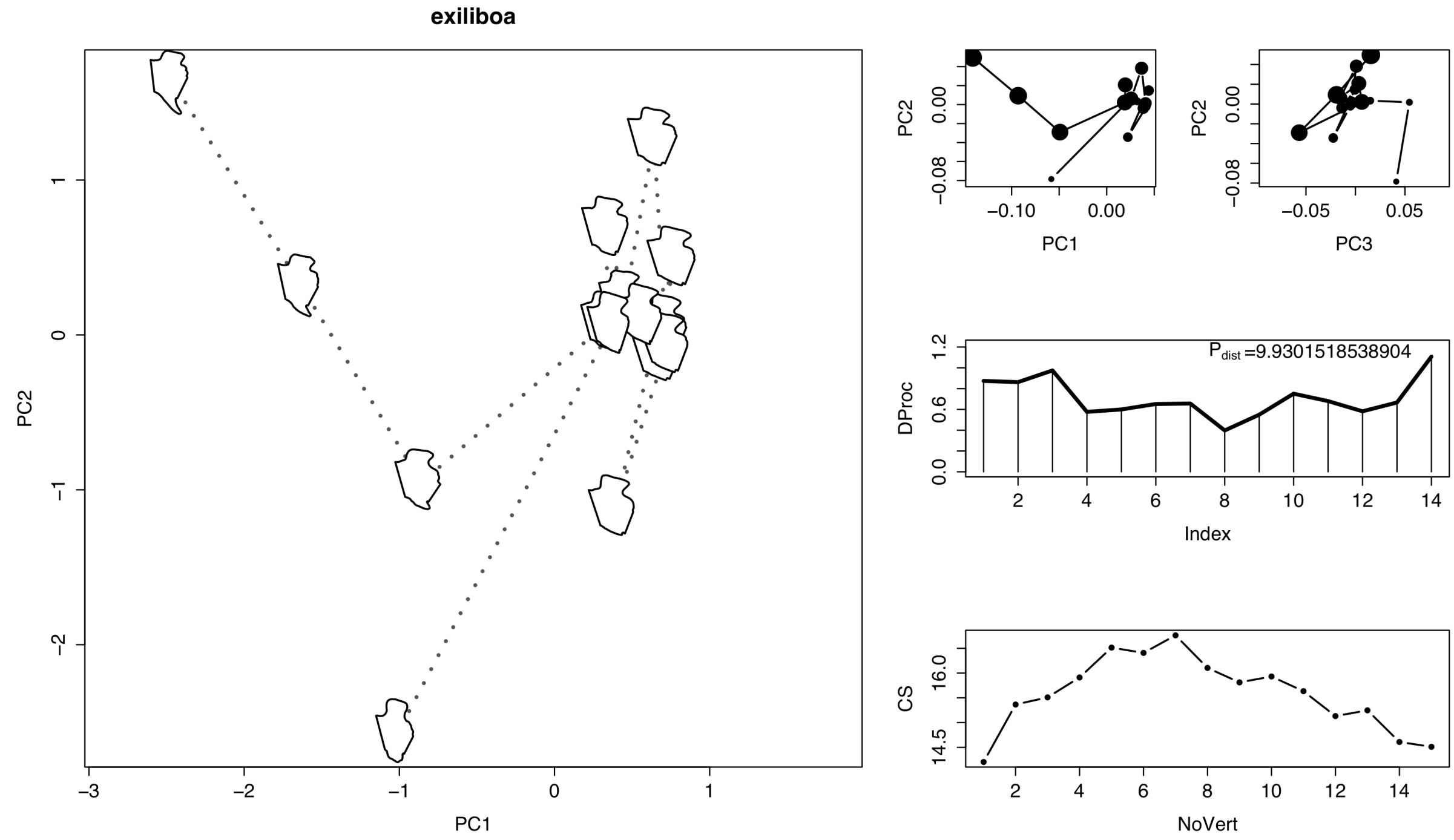
helicops

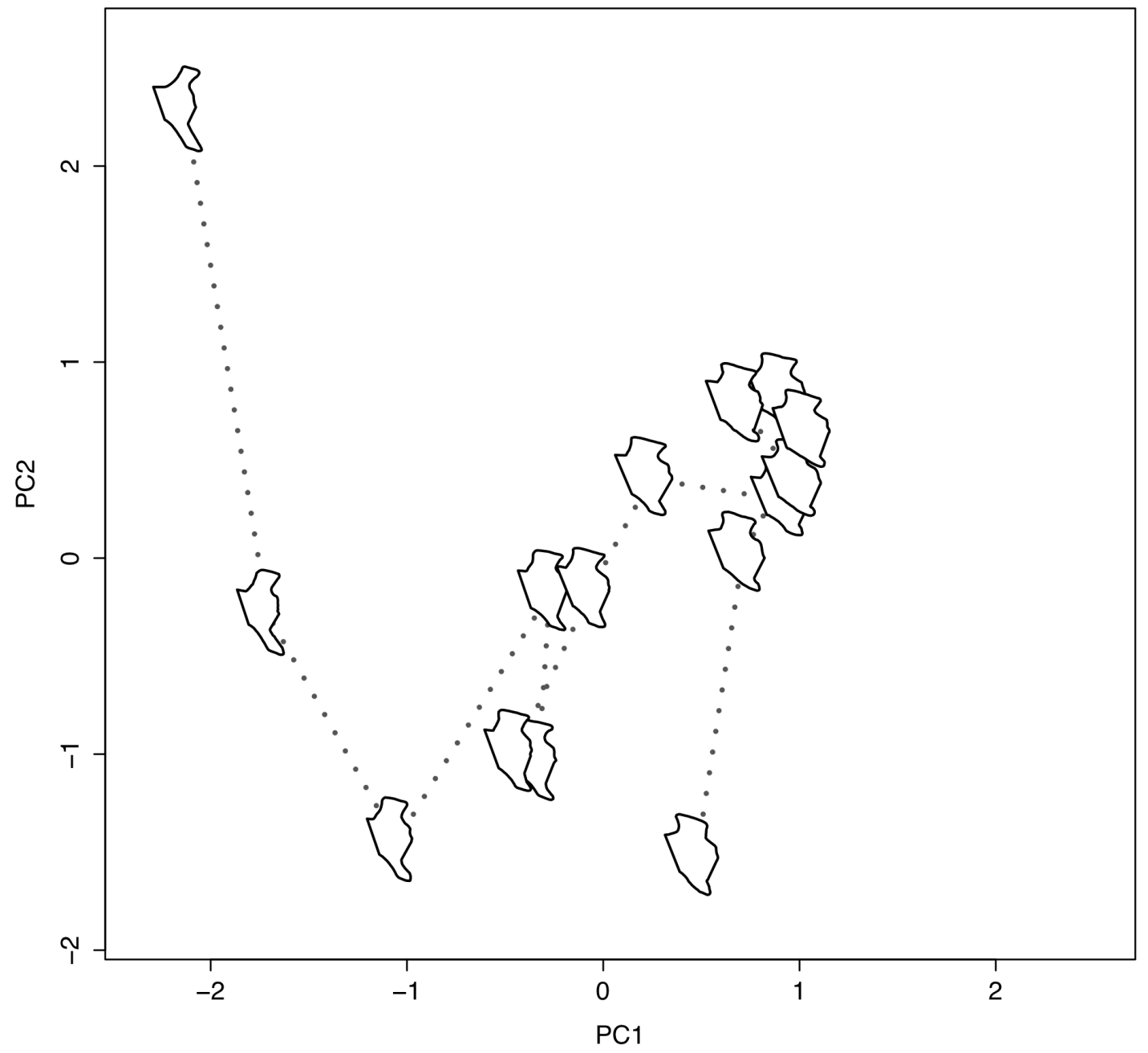

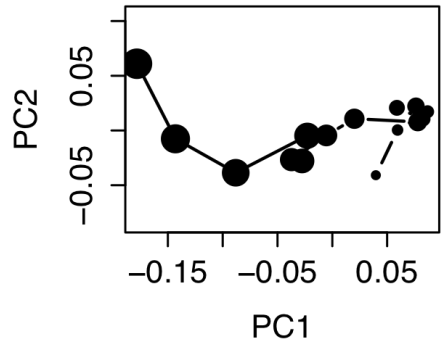
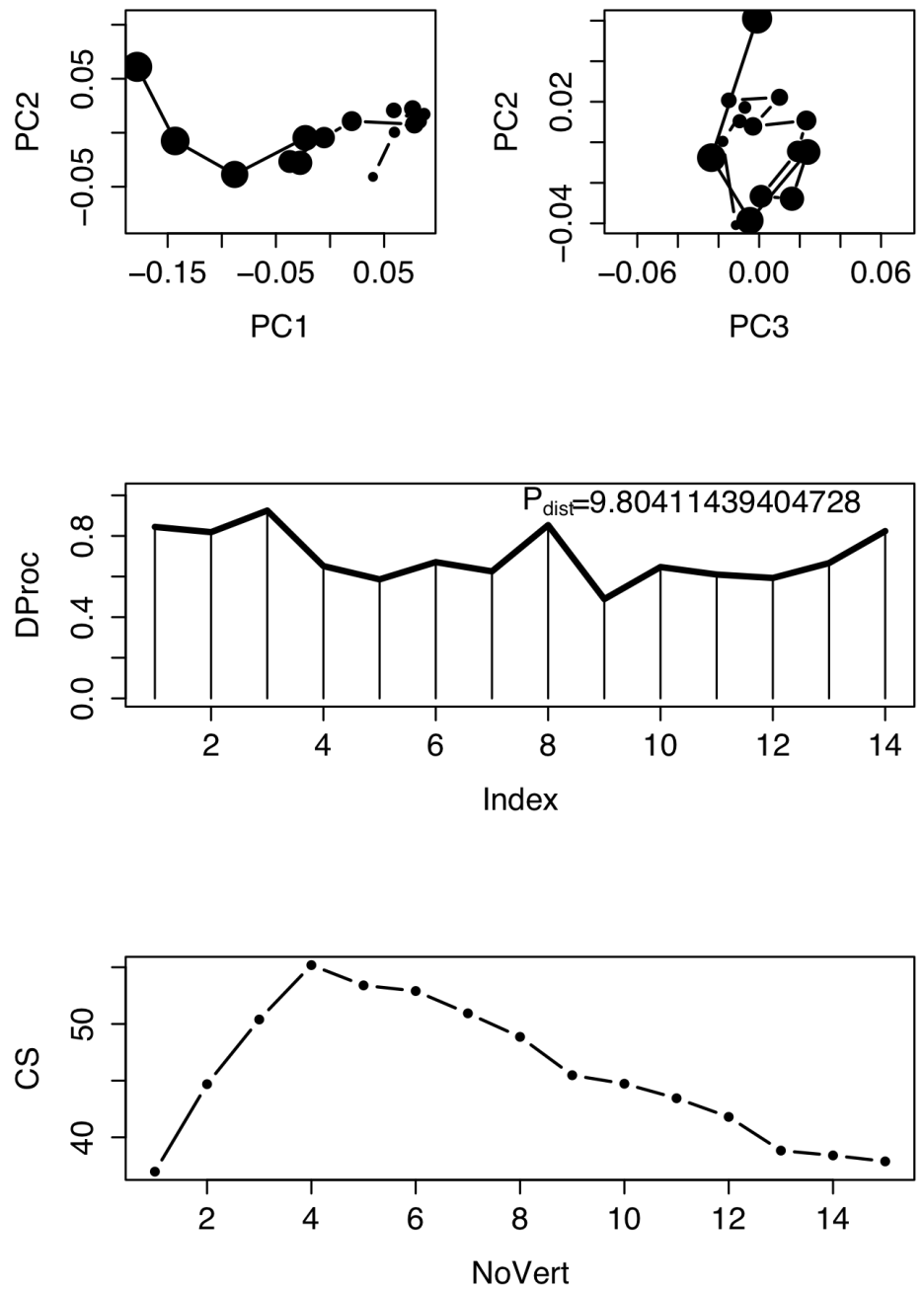


\section{leptotyphlops}

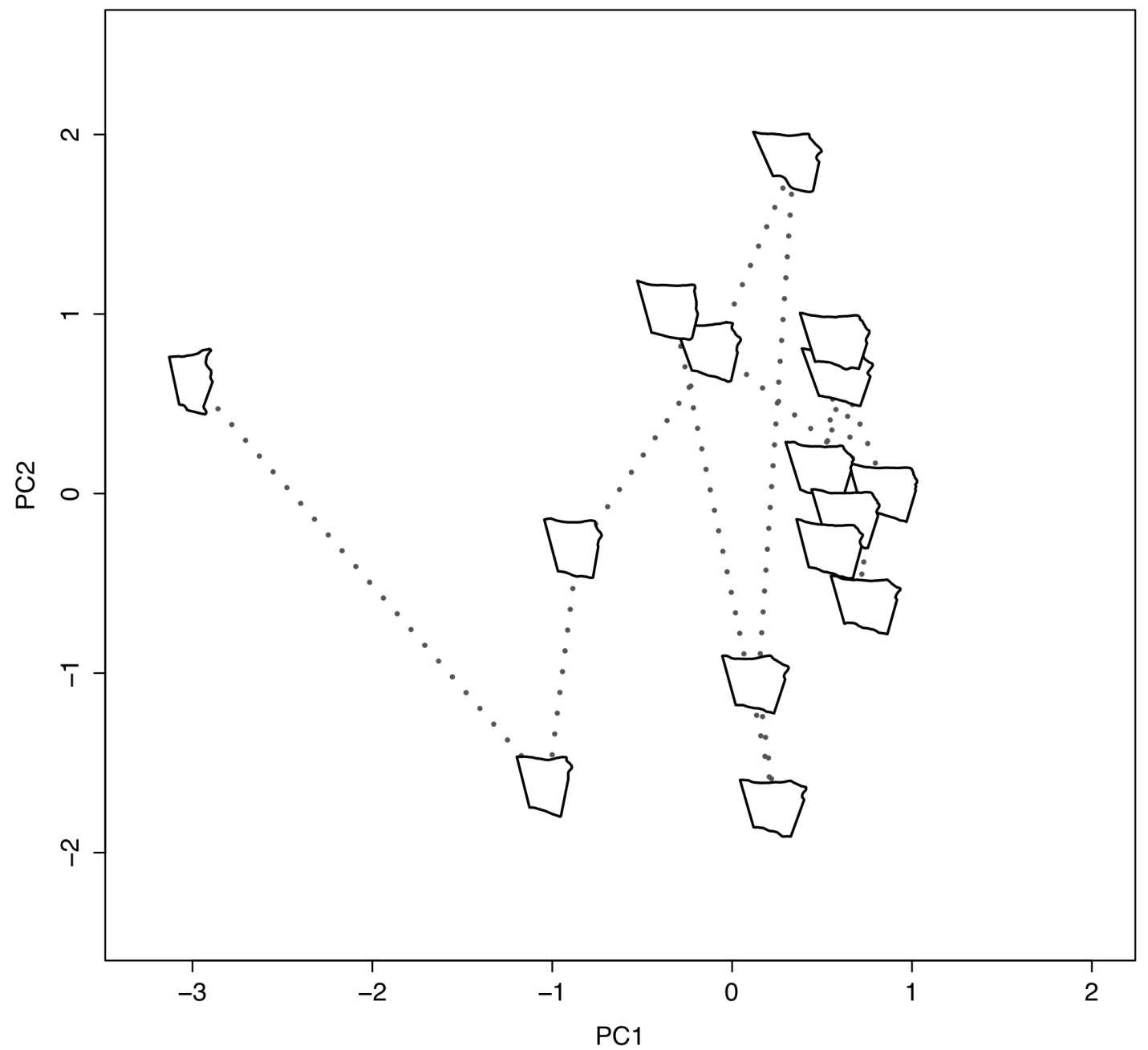

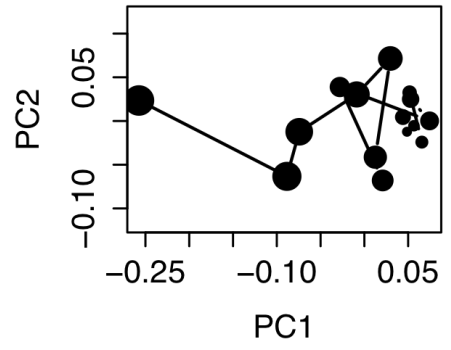
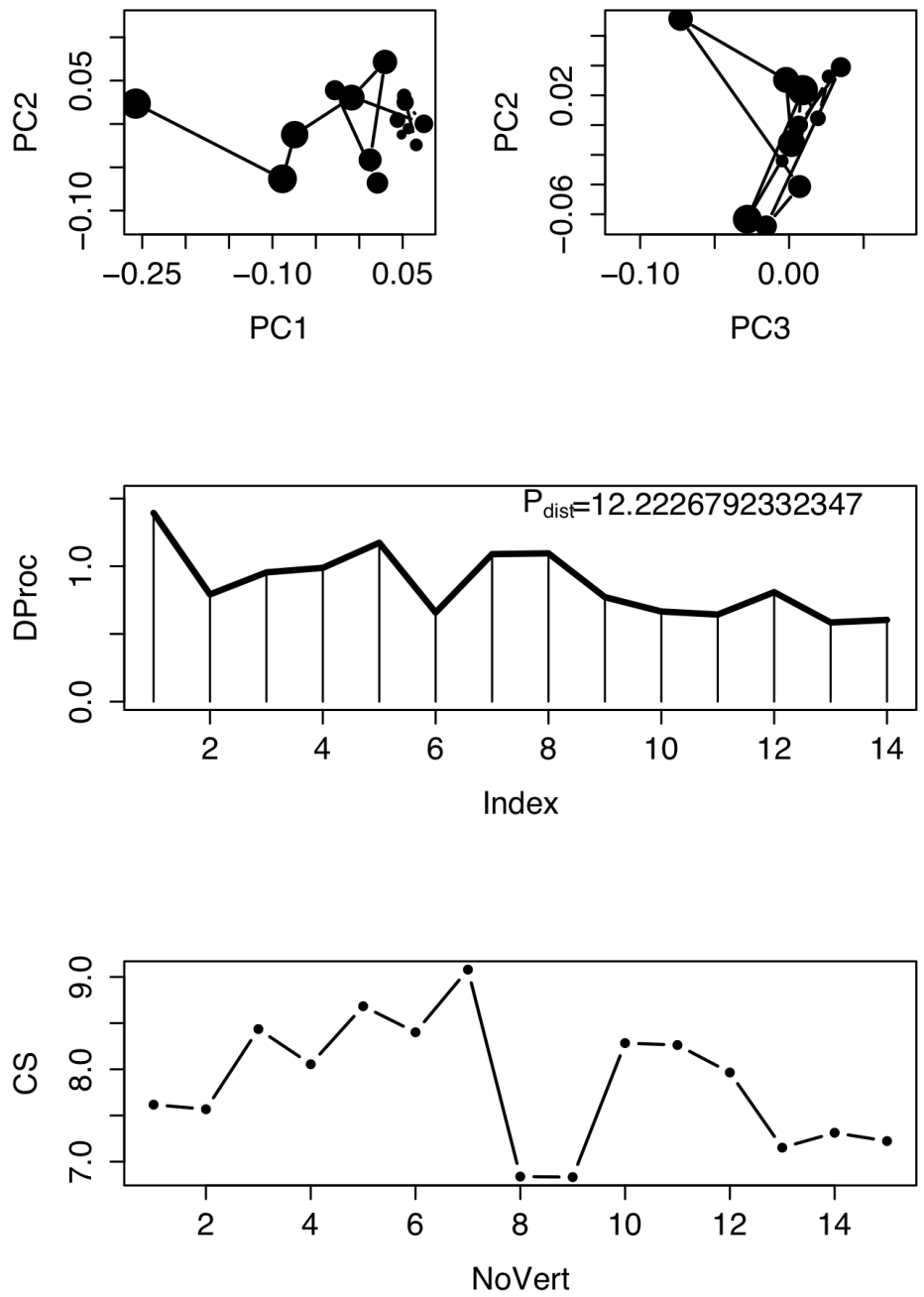
liasis

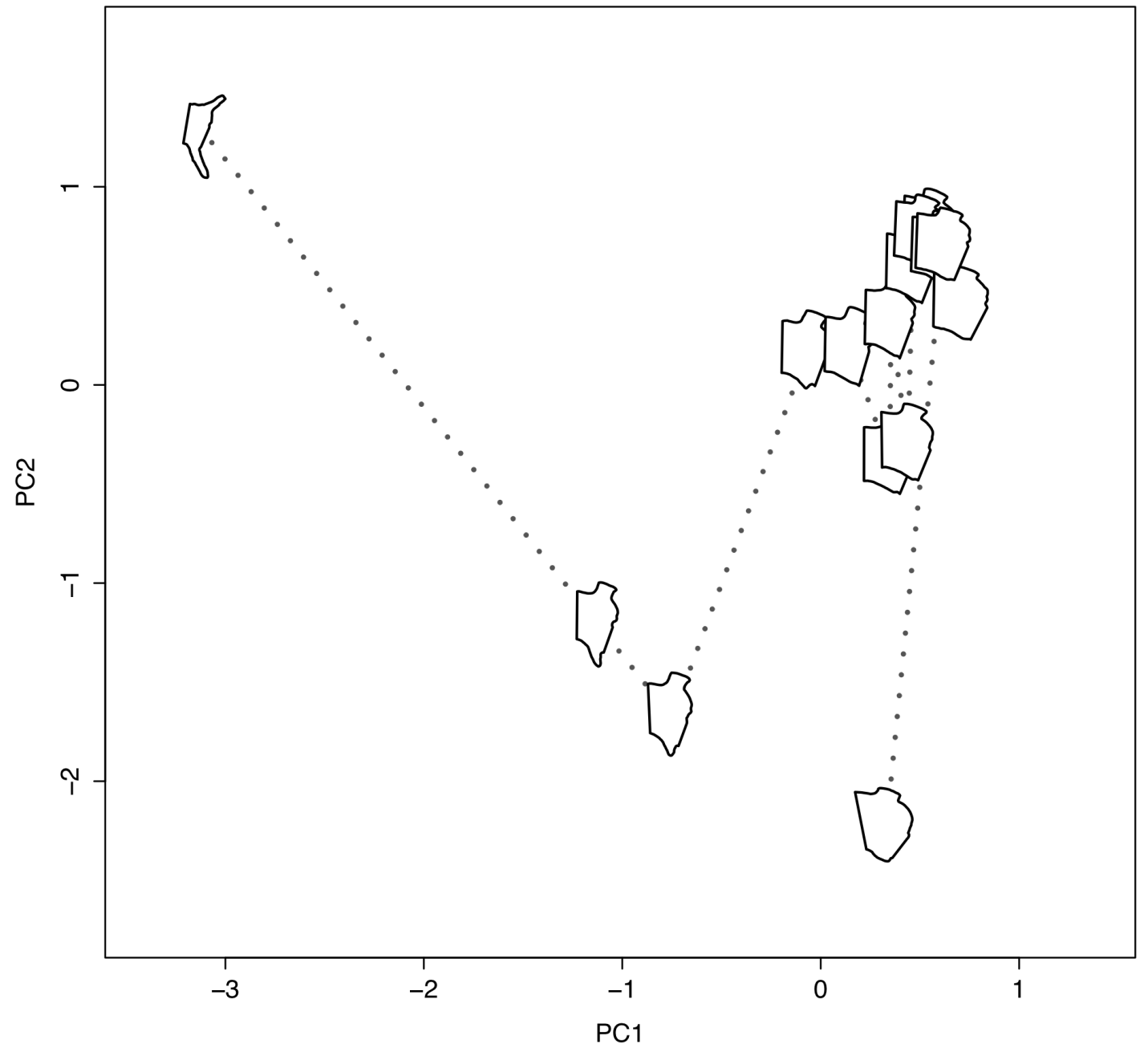

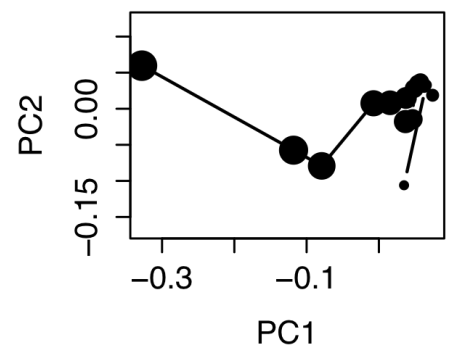
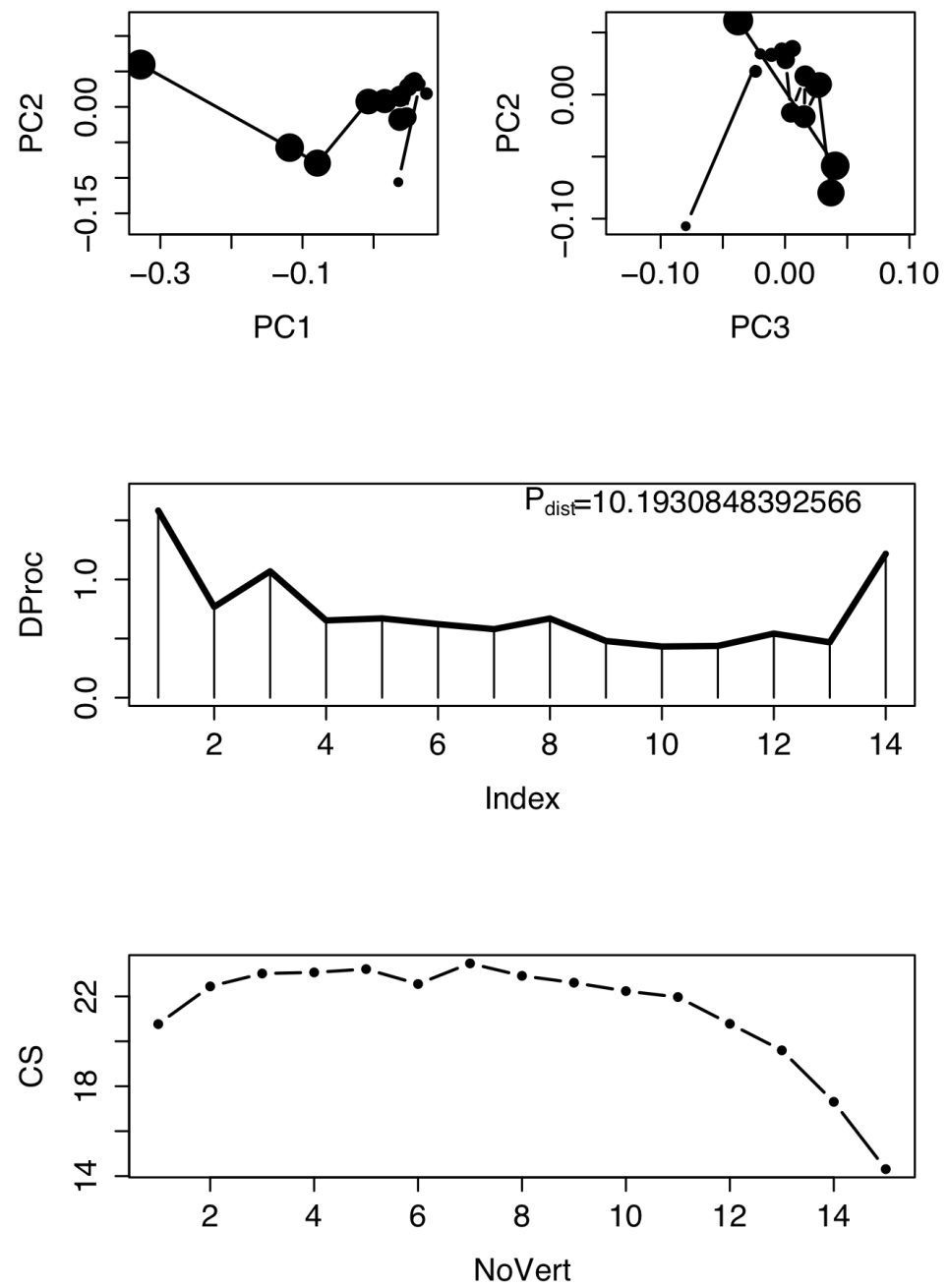
lichanura
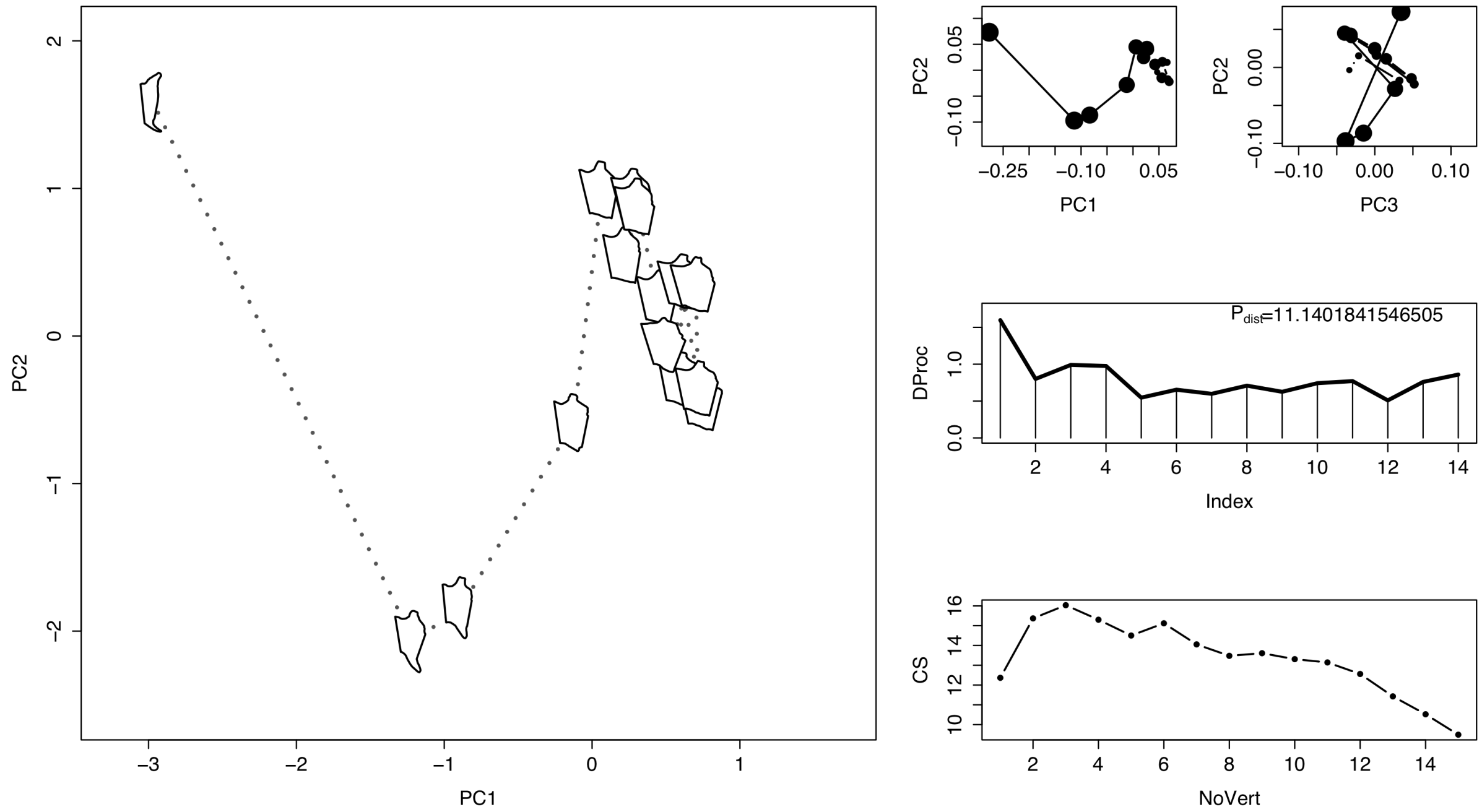
liotyphlops

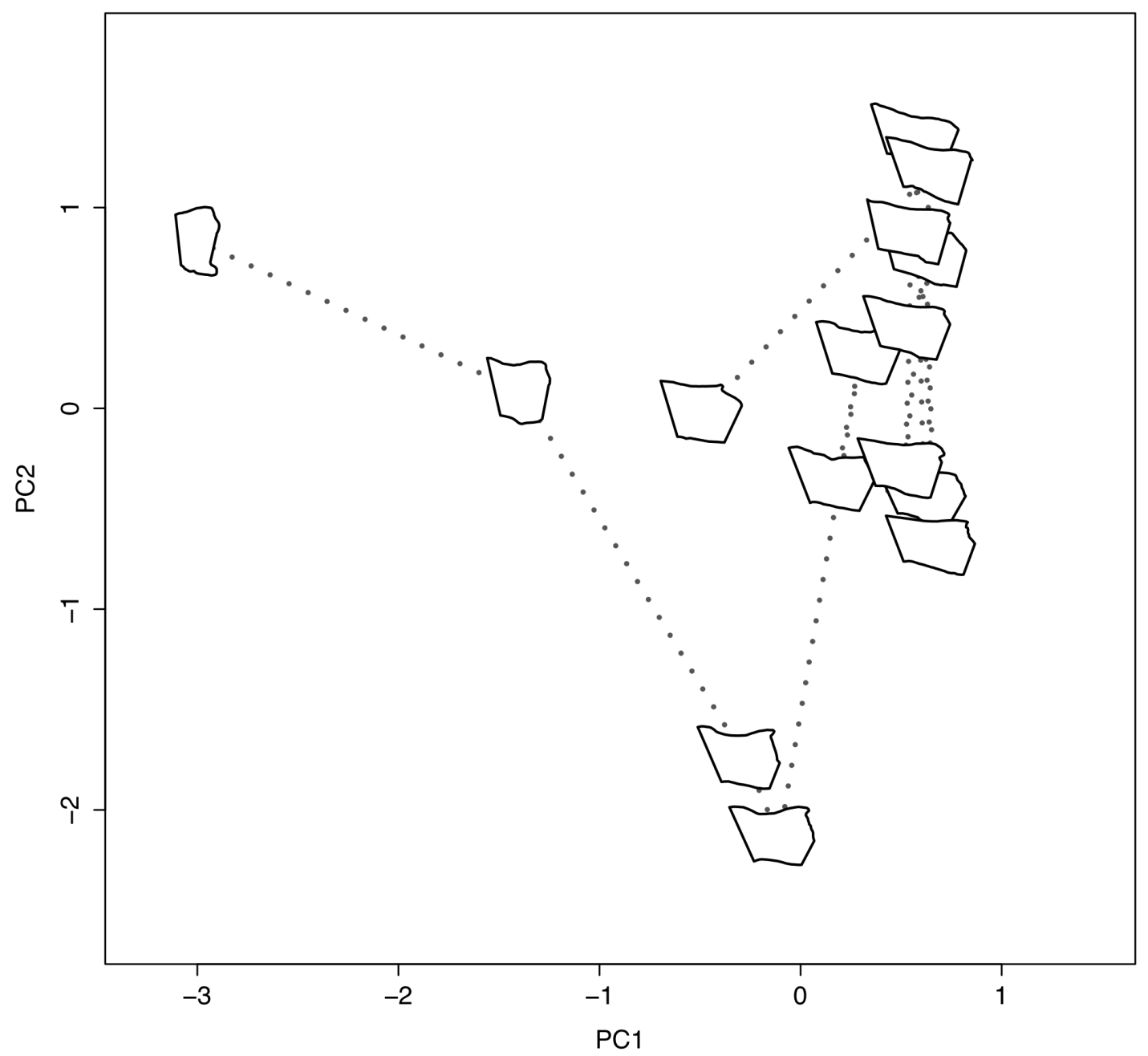

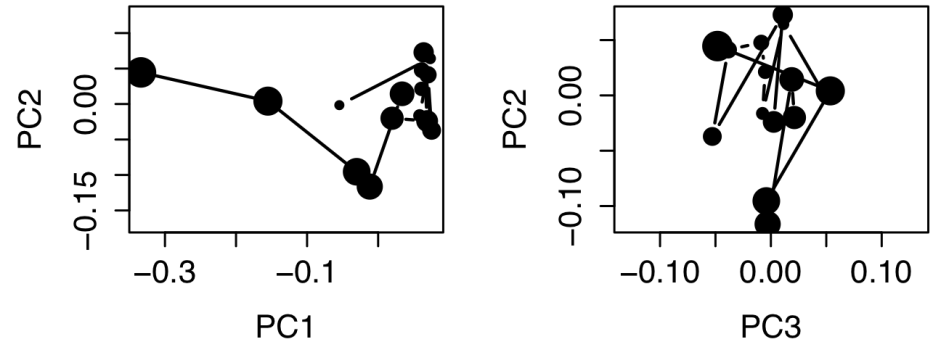
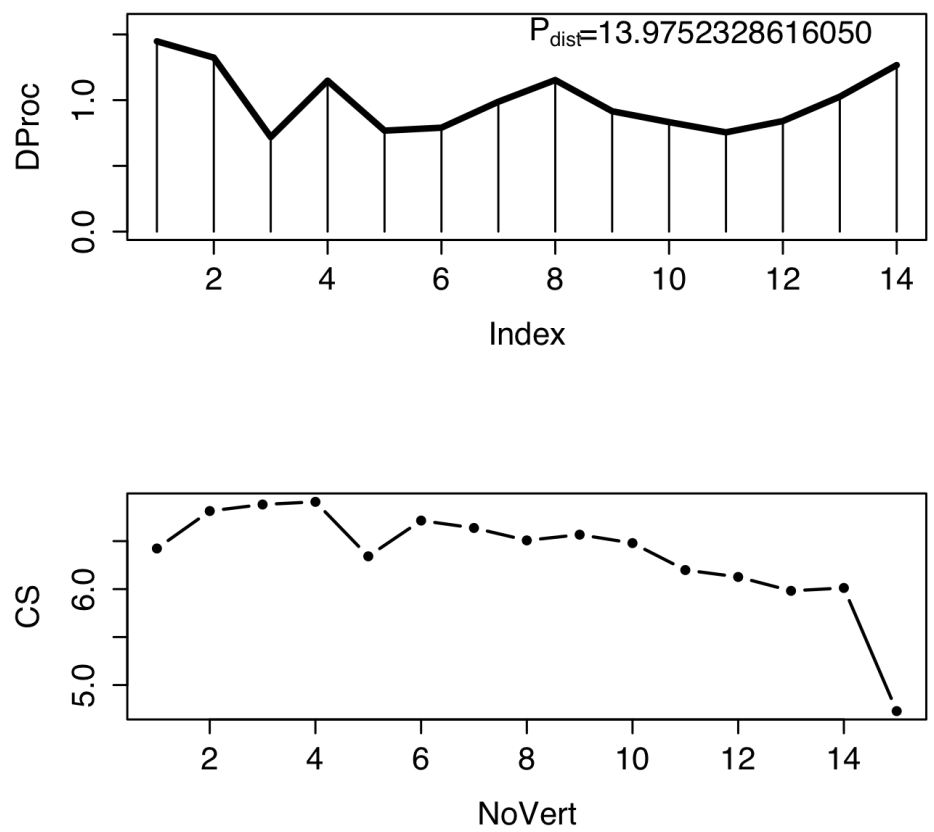

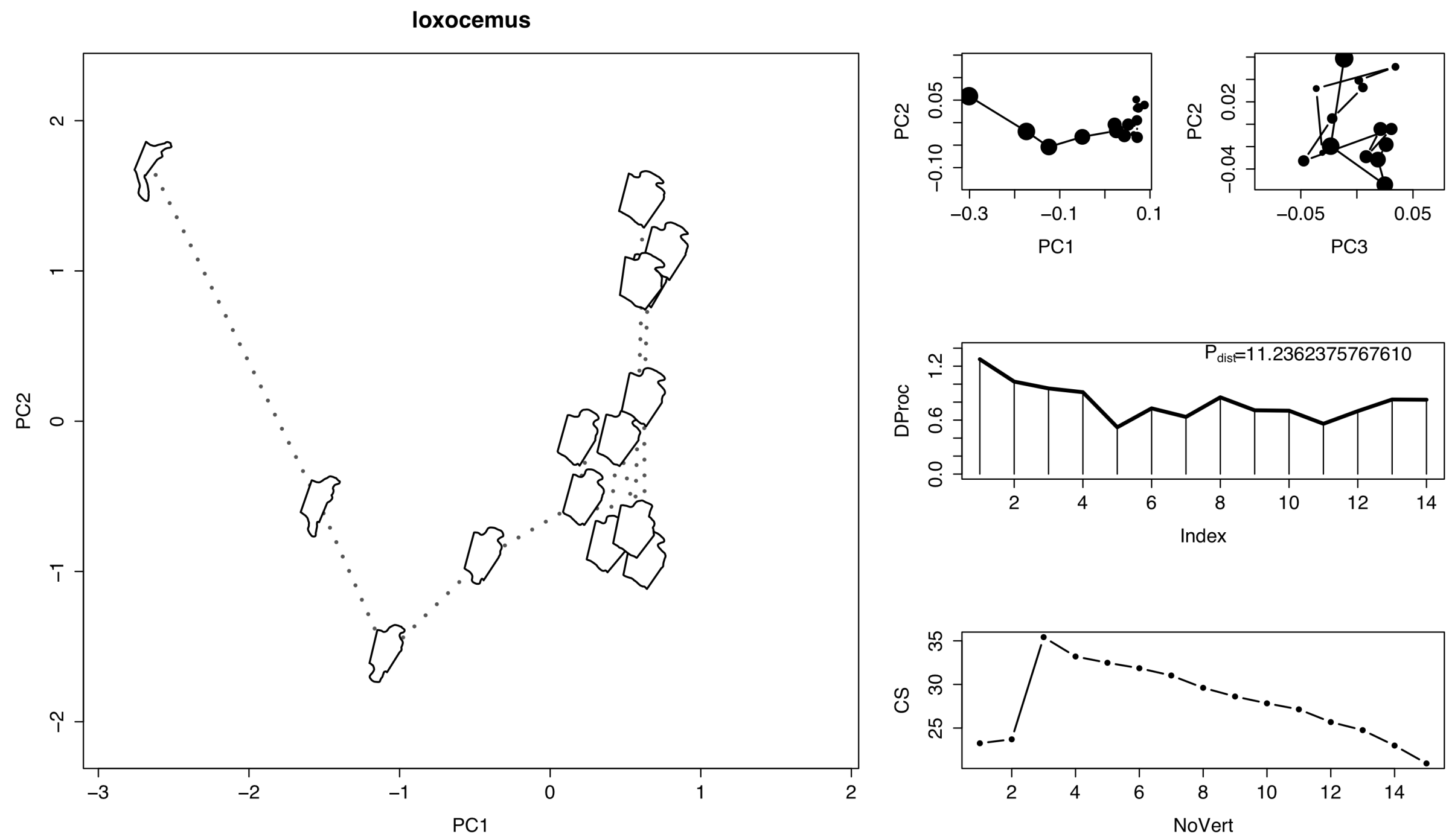
micrurus
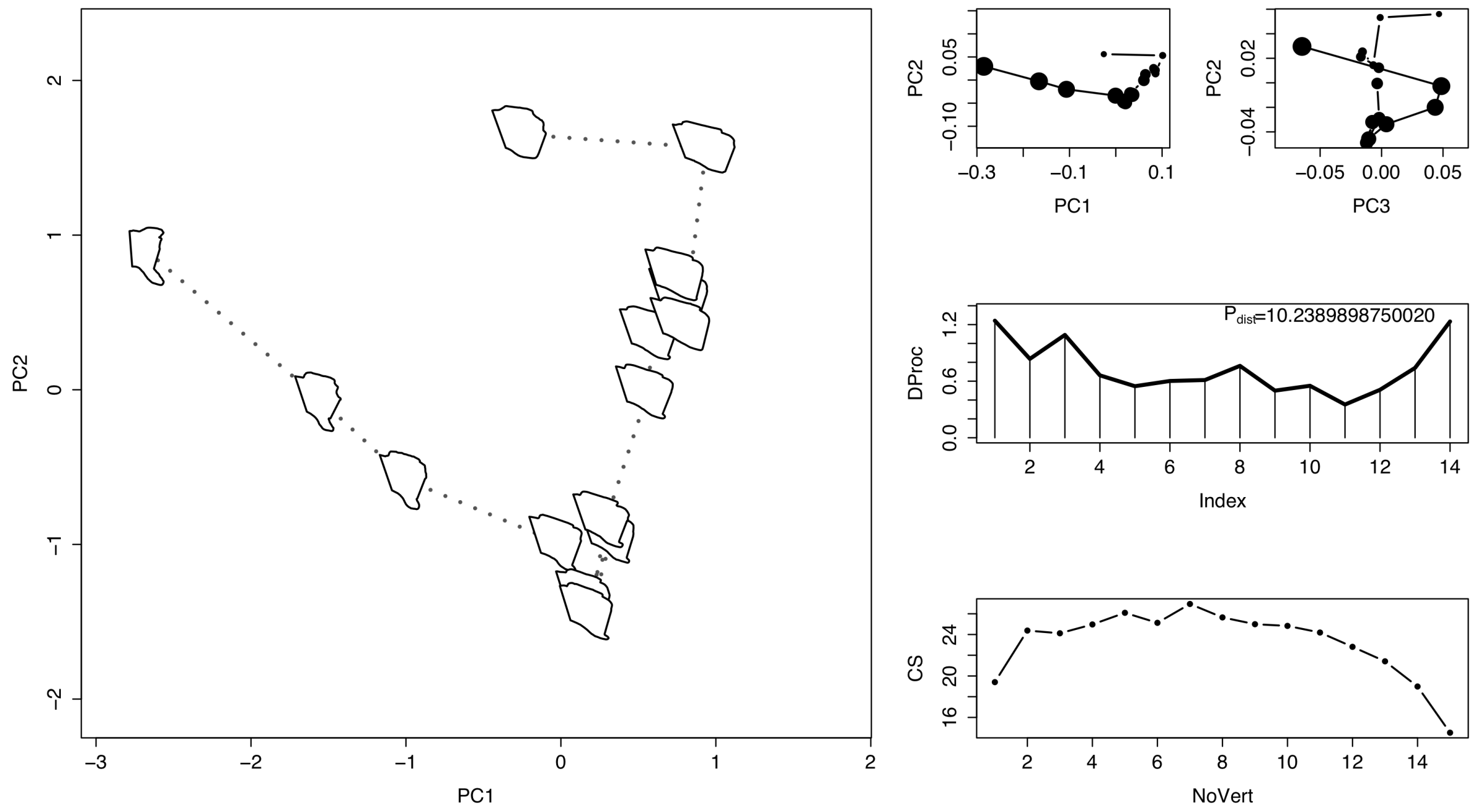

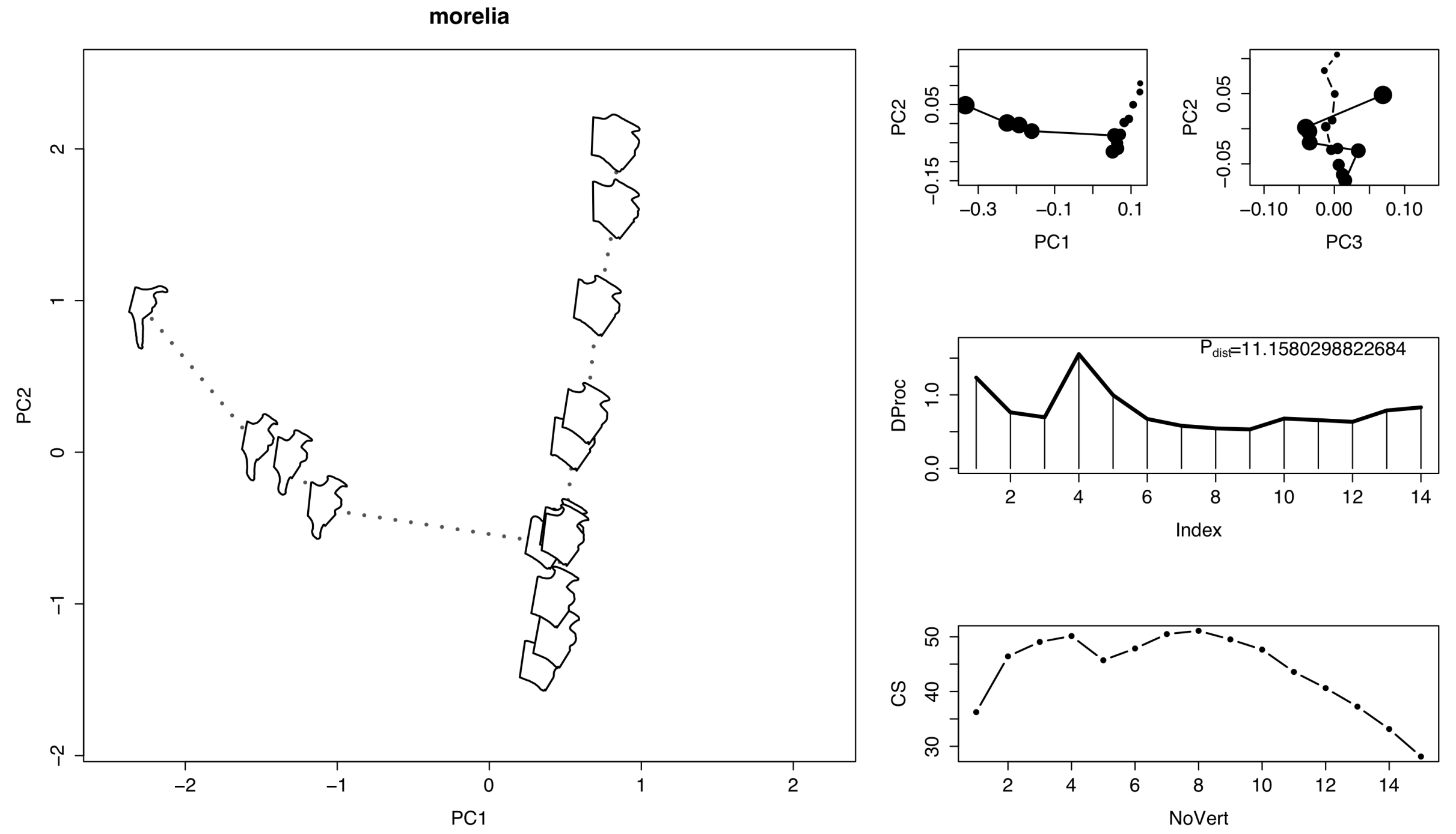
naja

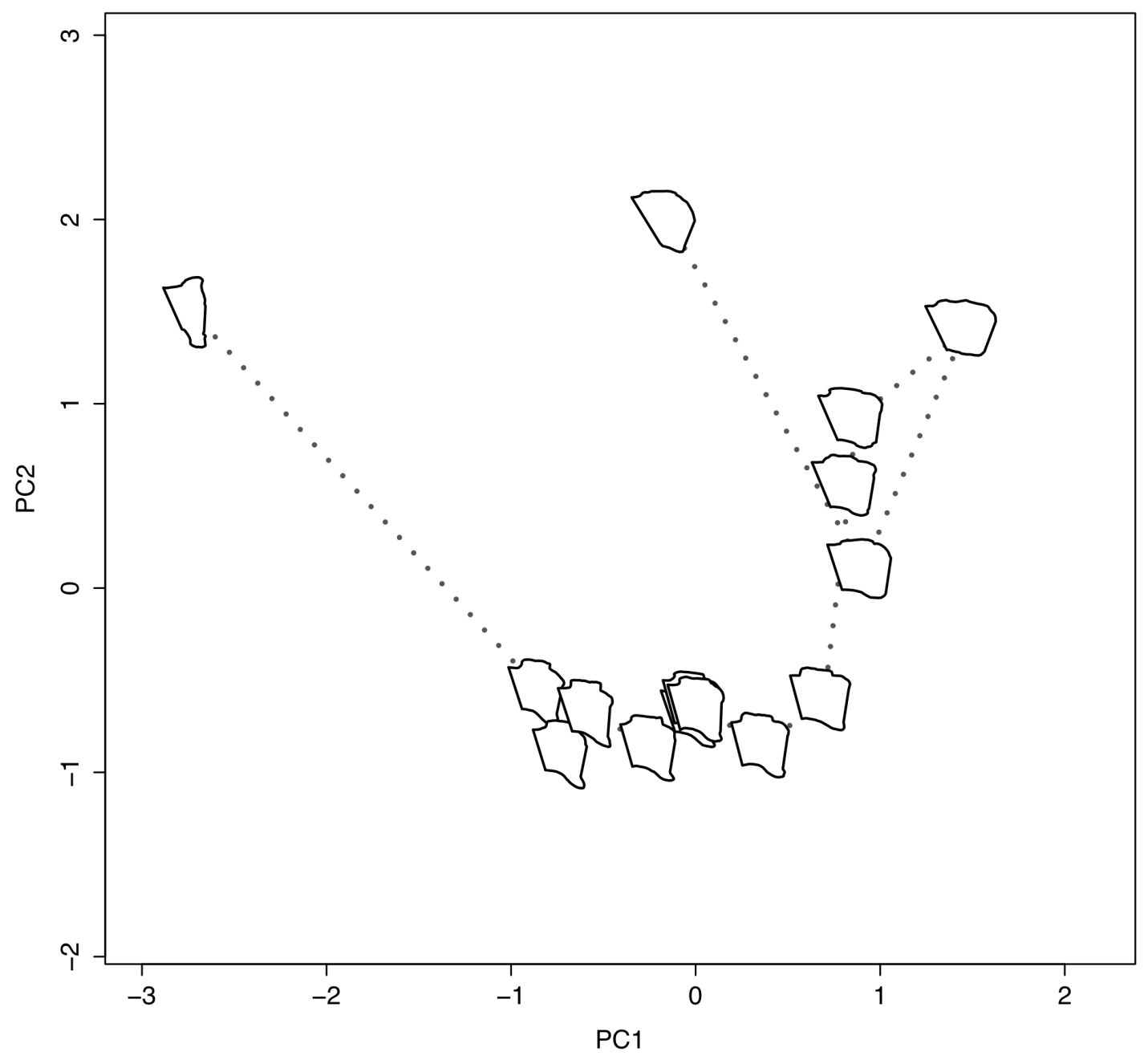

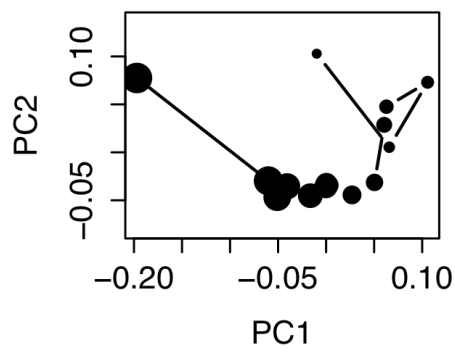
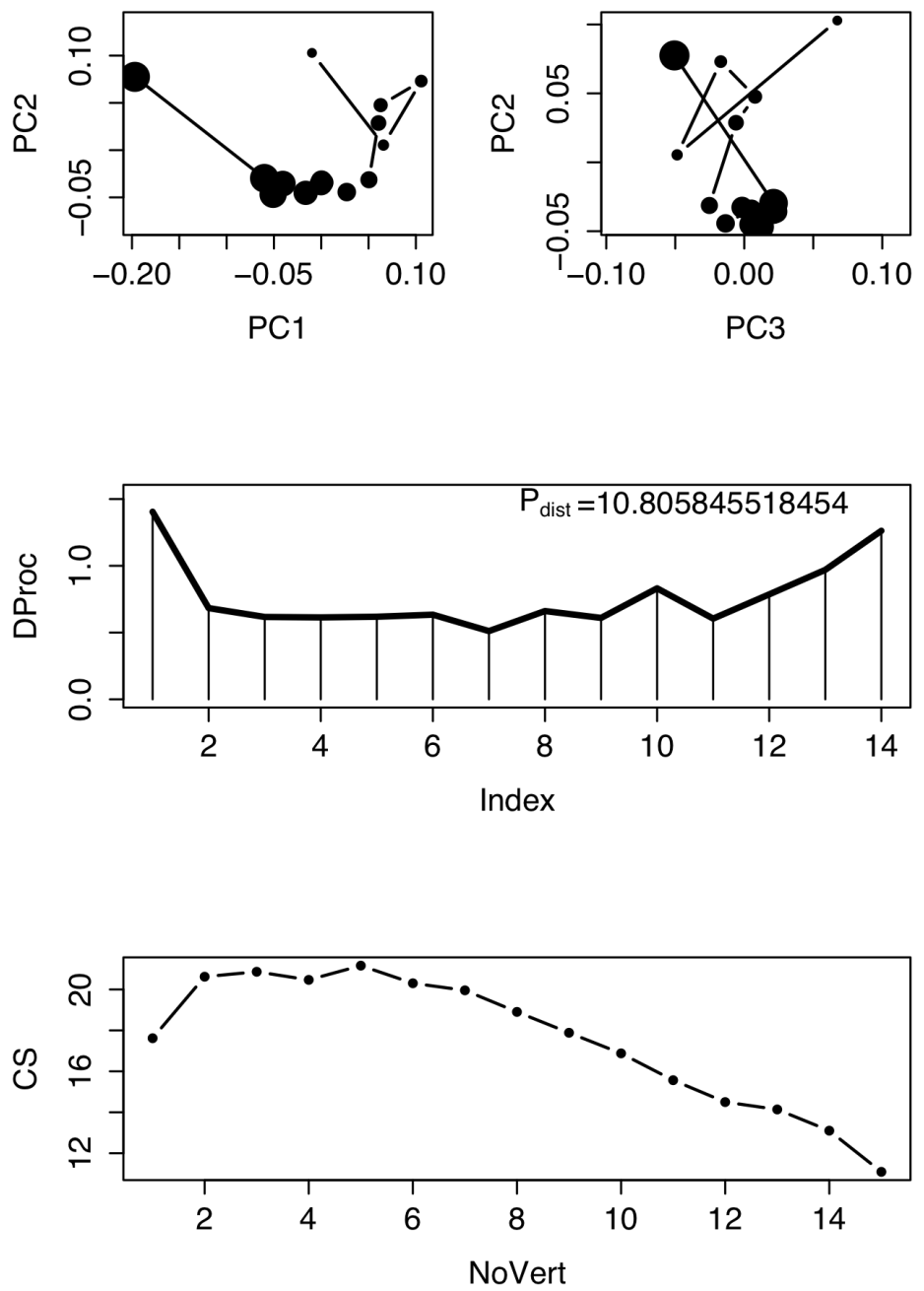
oxybelis

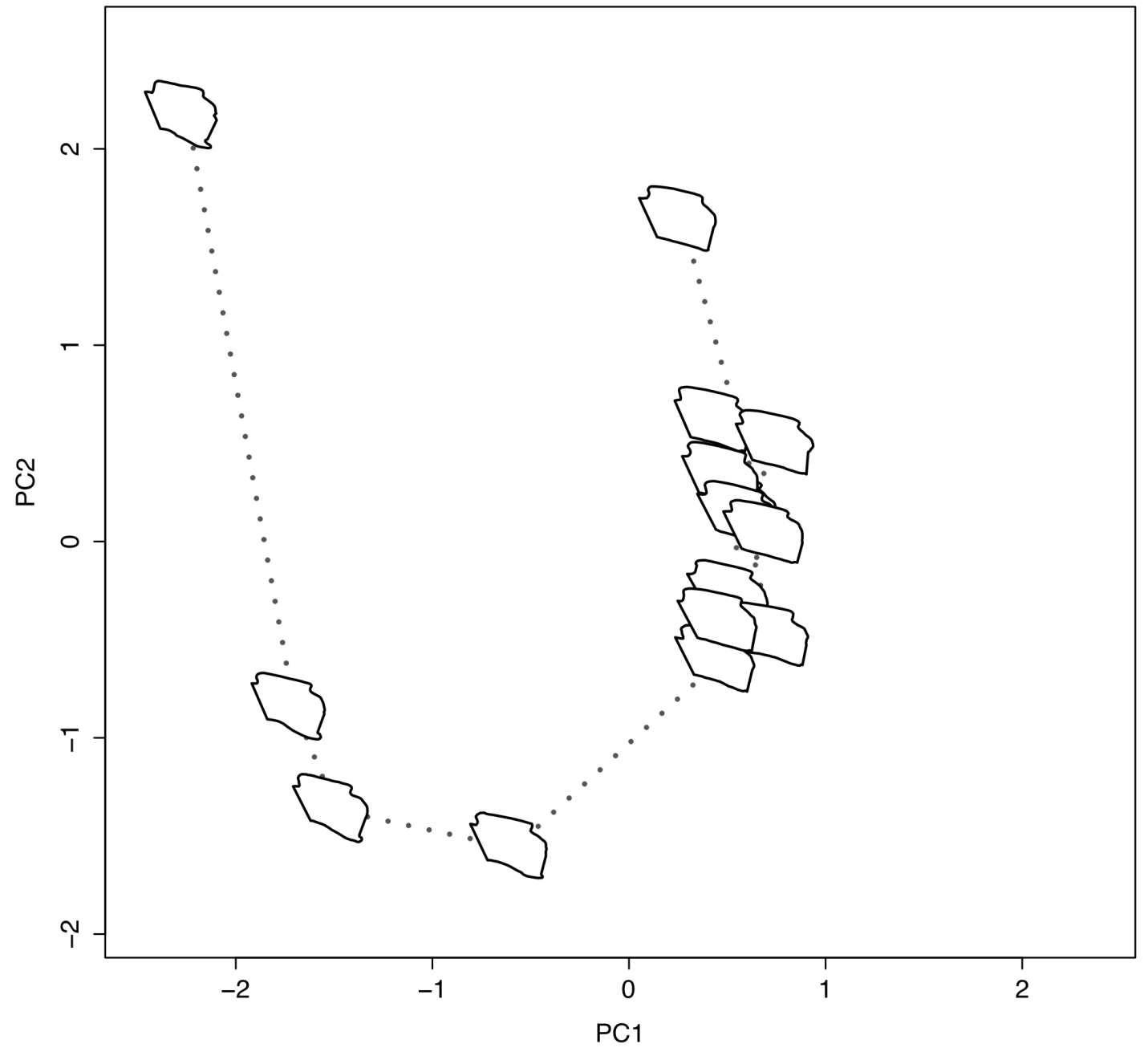

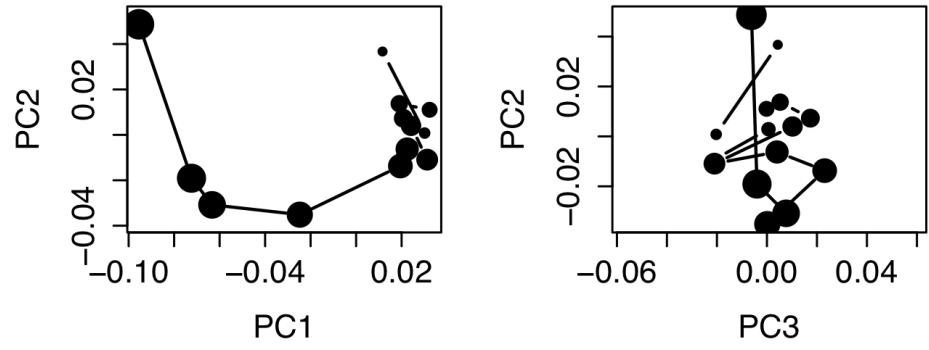
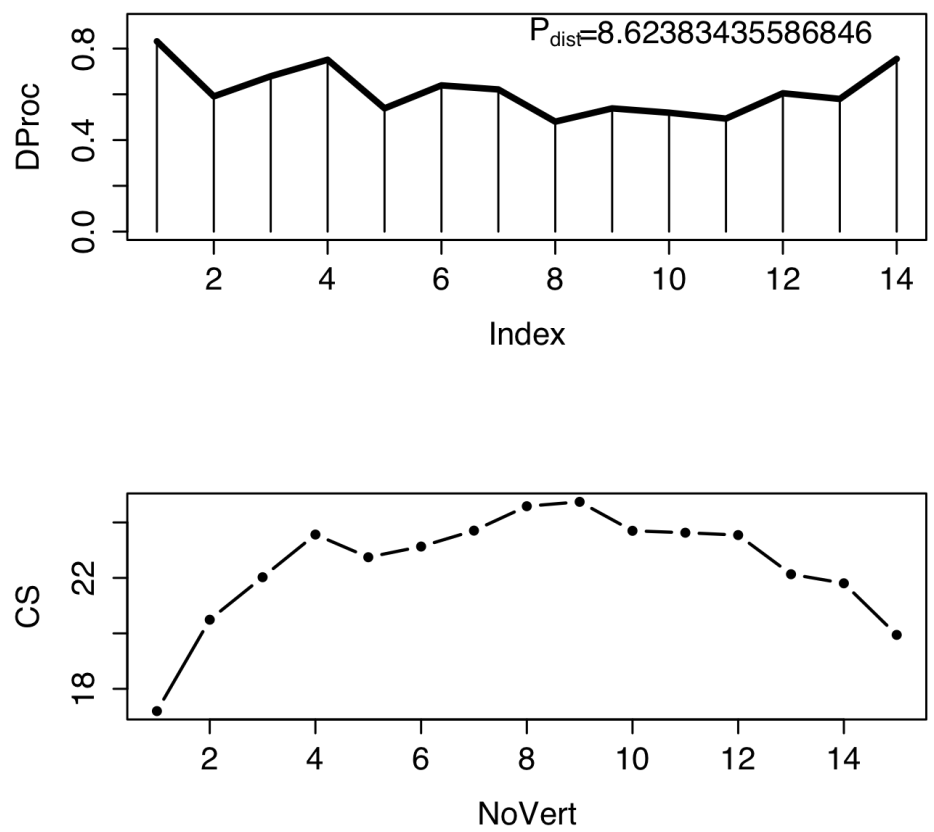

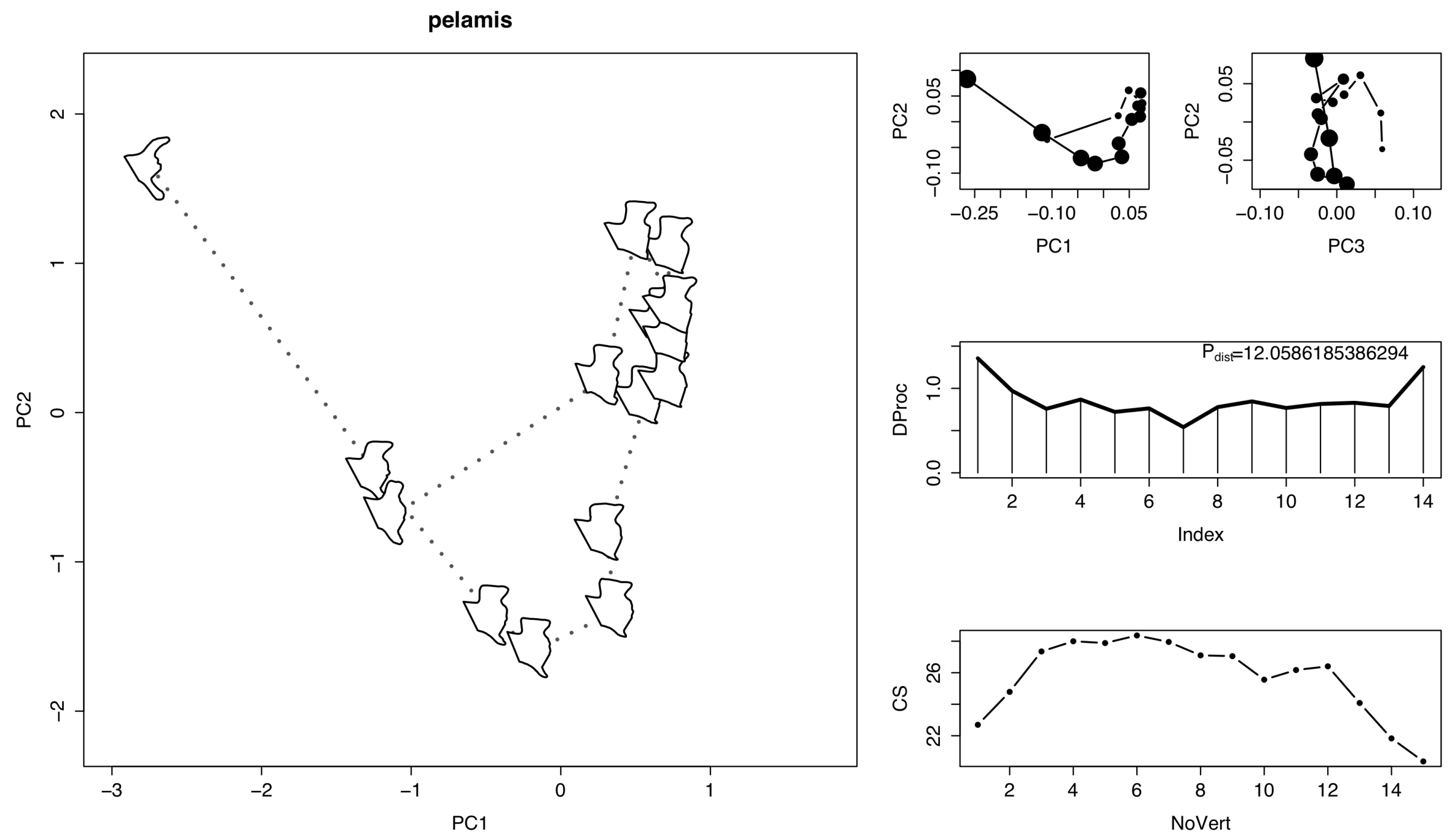

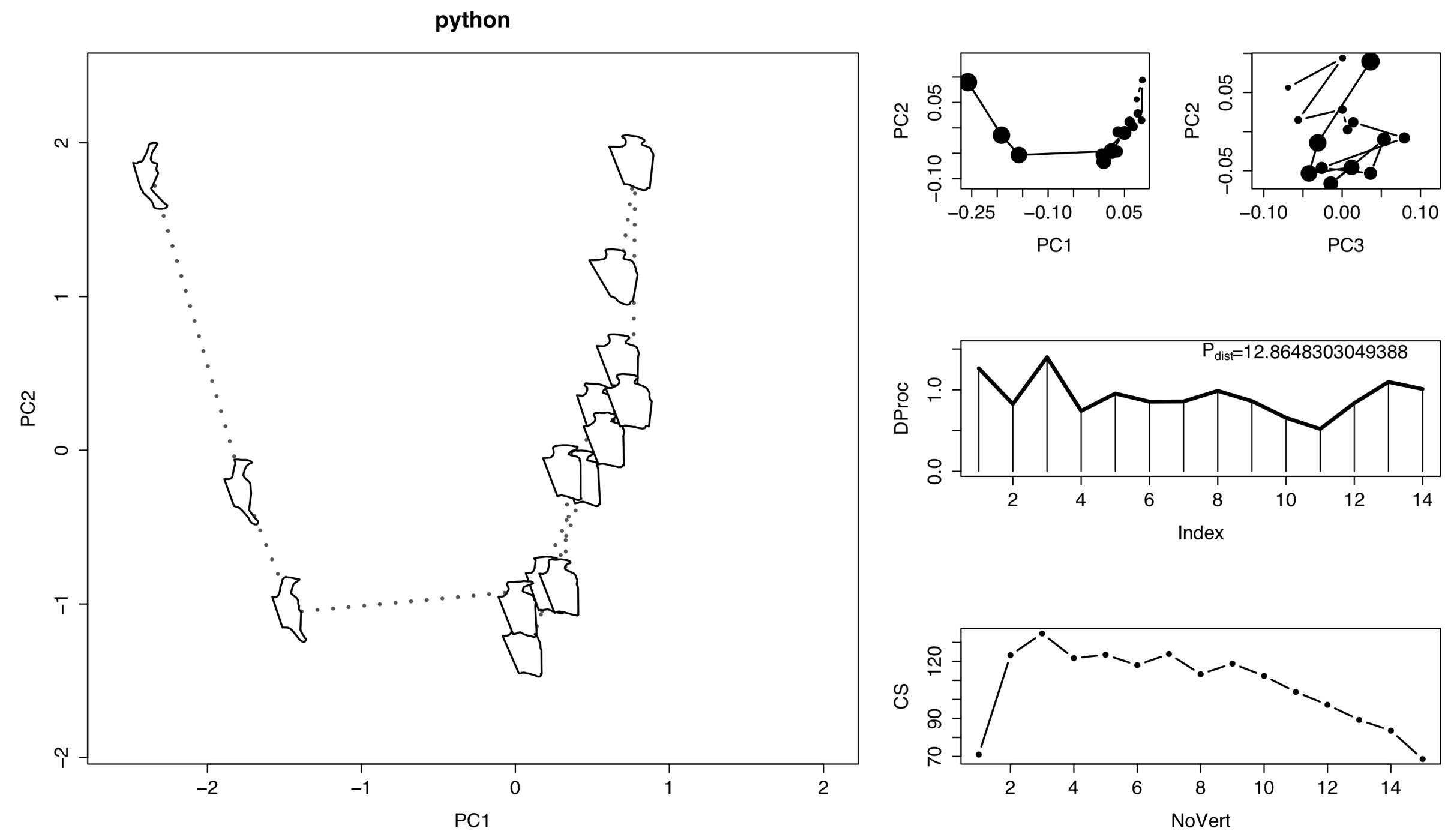
rhinotyphlops

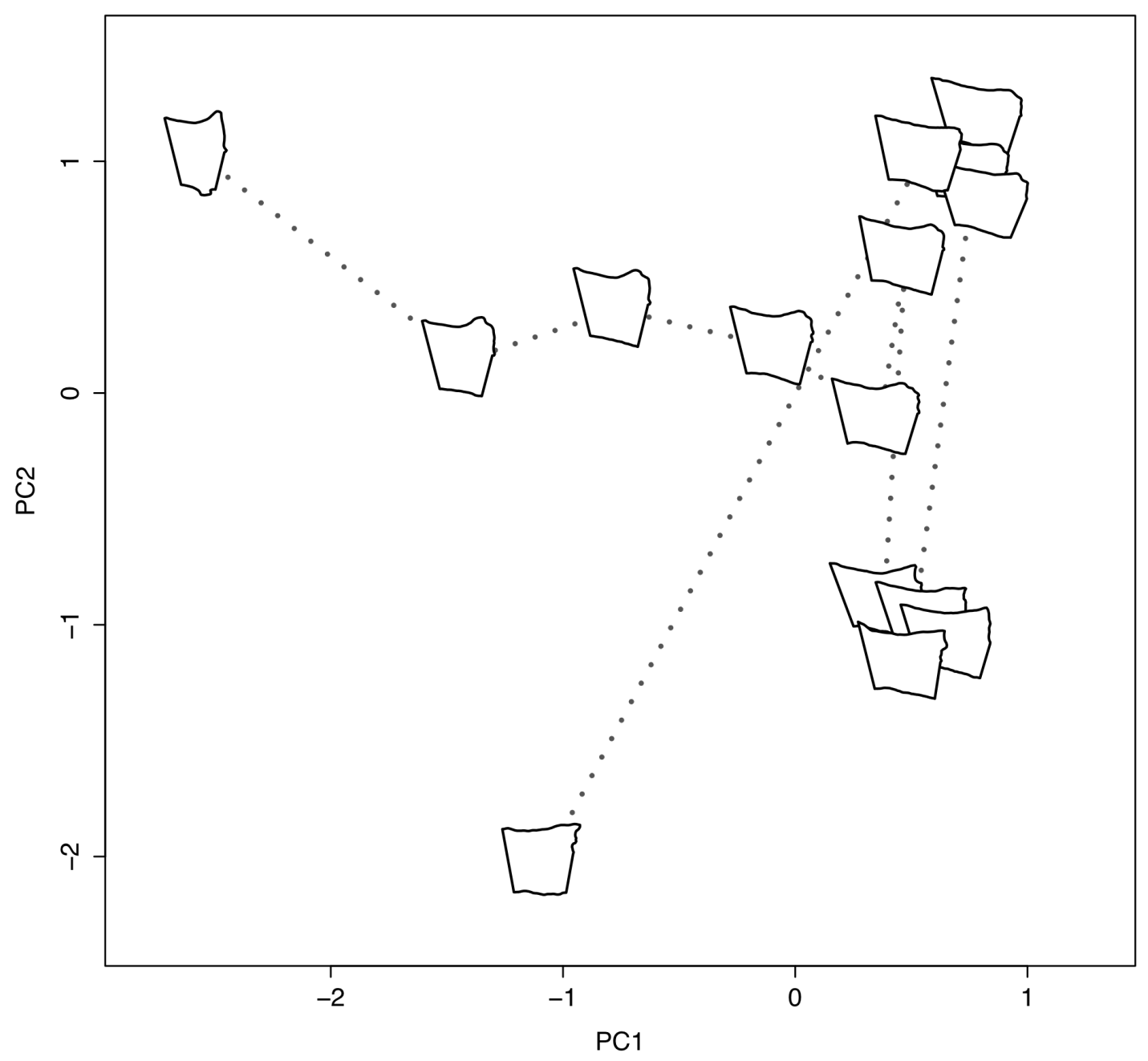

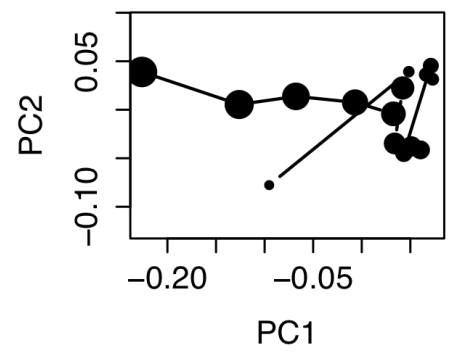
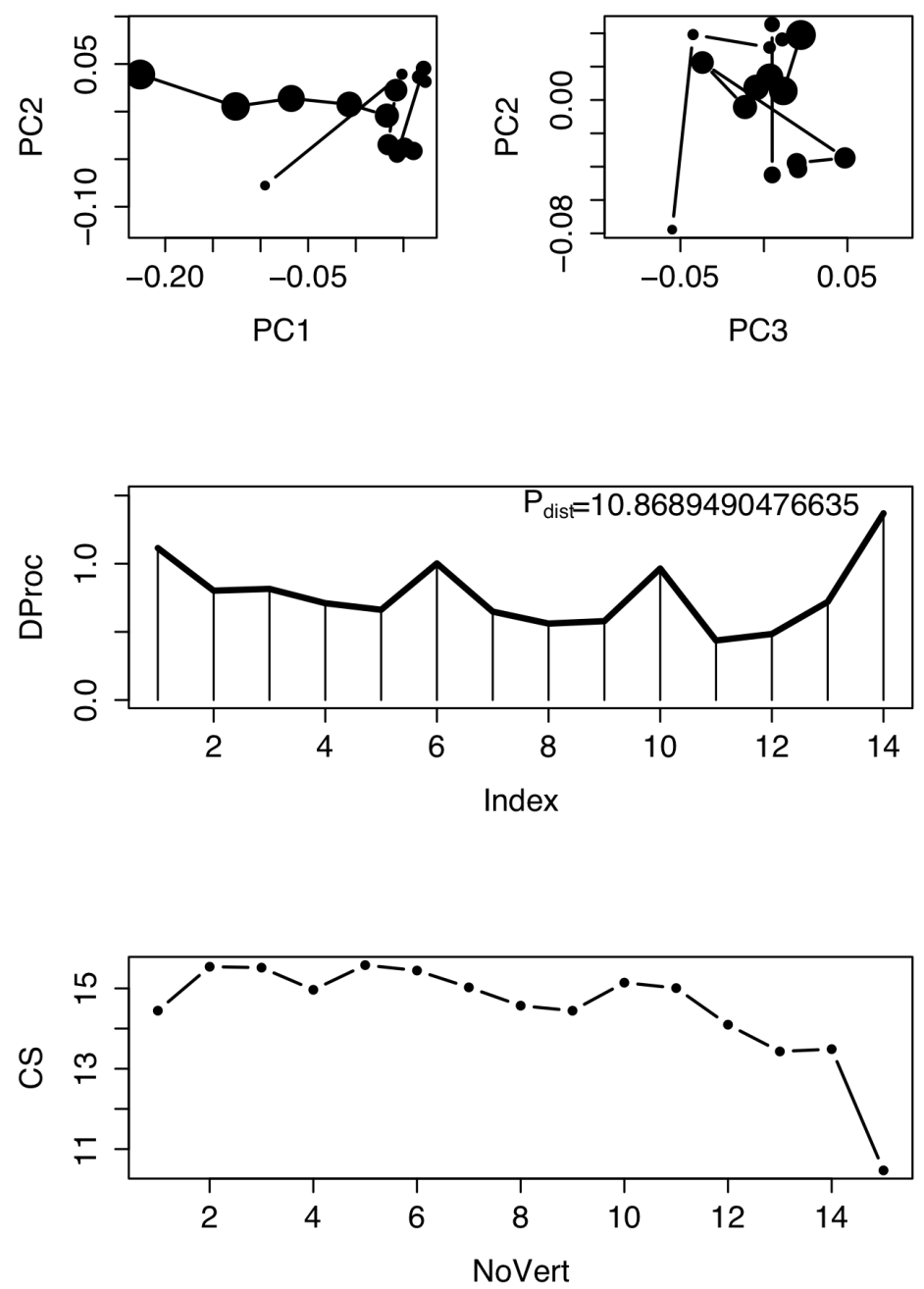
trachyboa
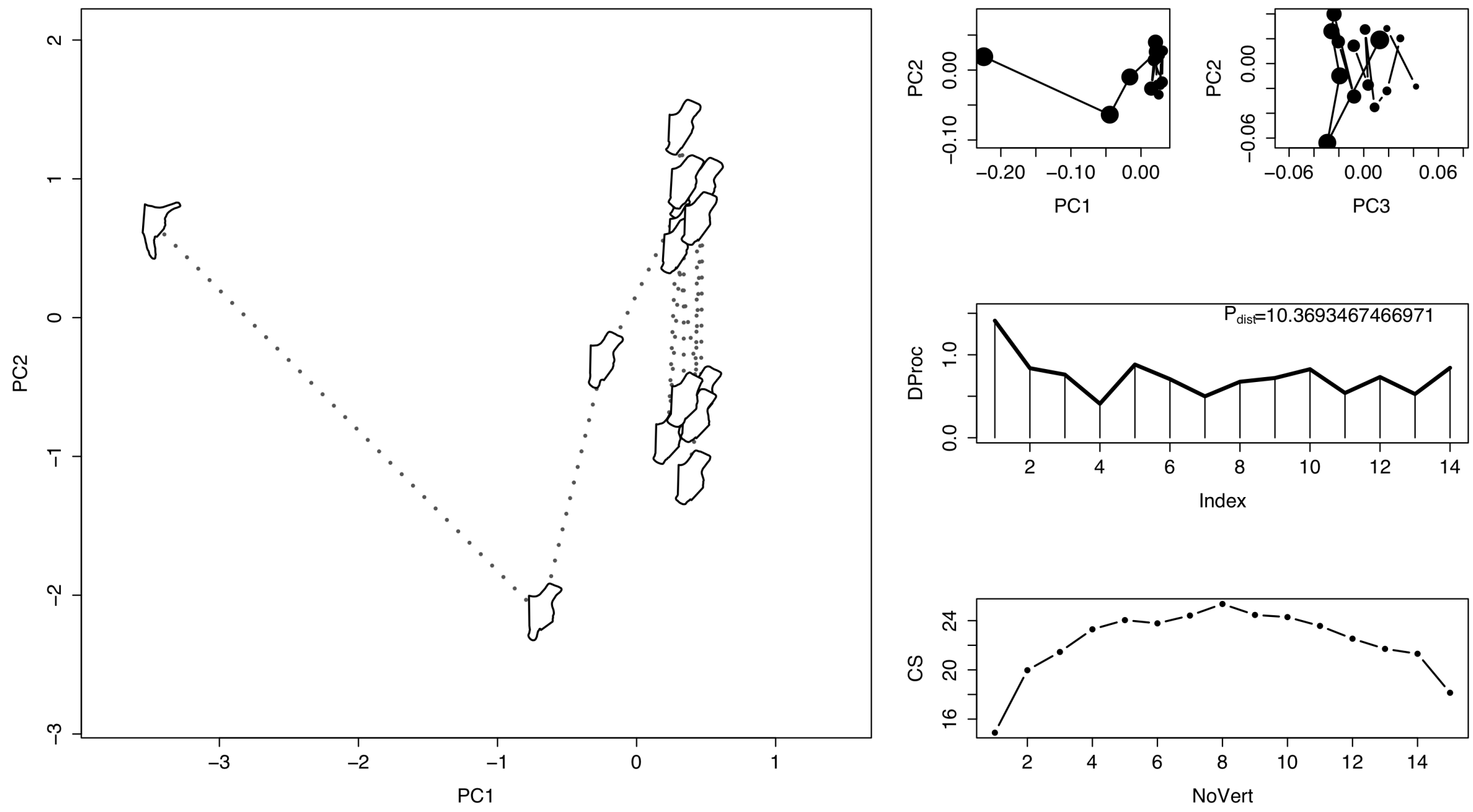


\section{tropidophis}
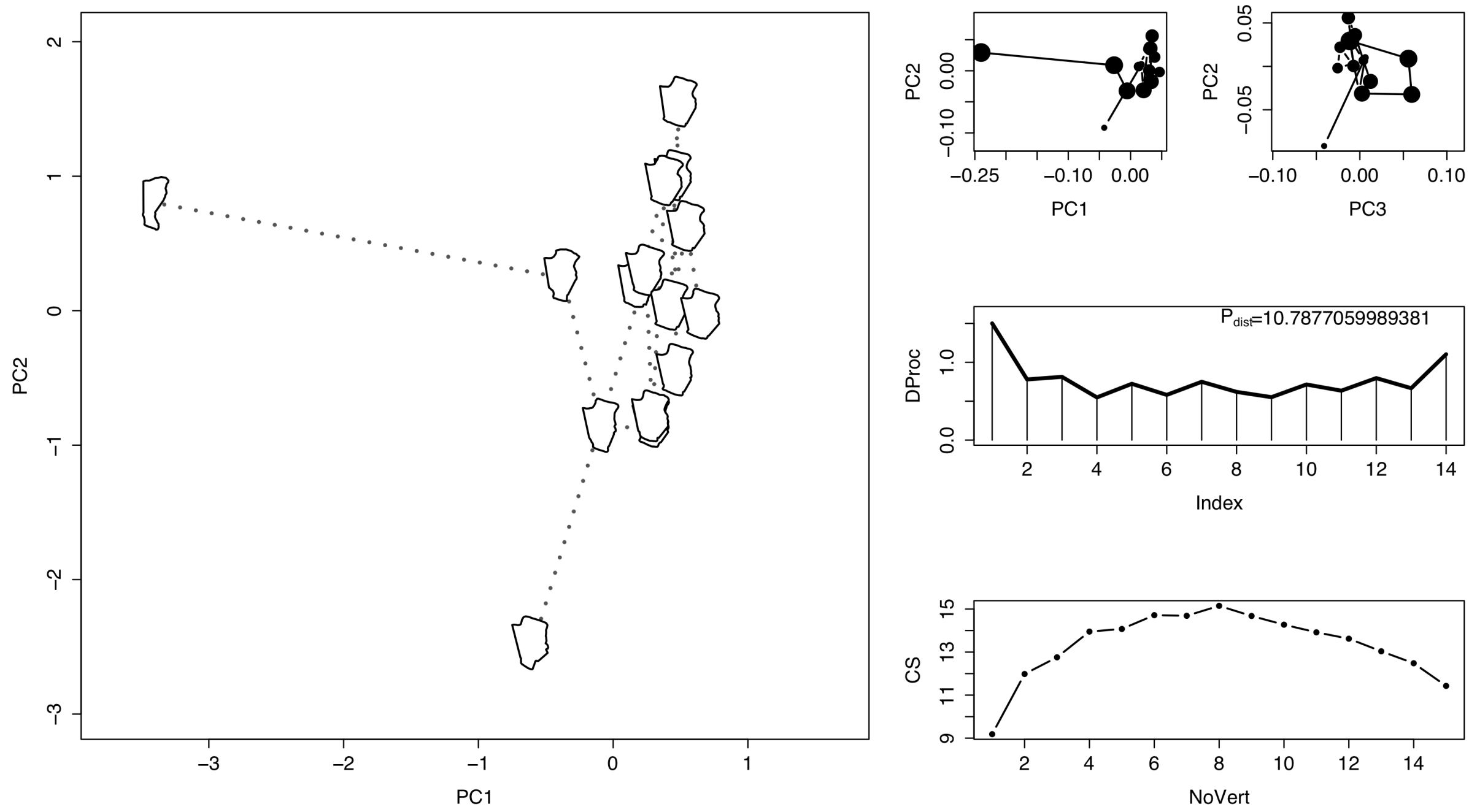

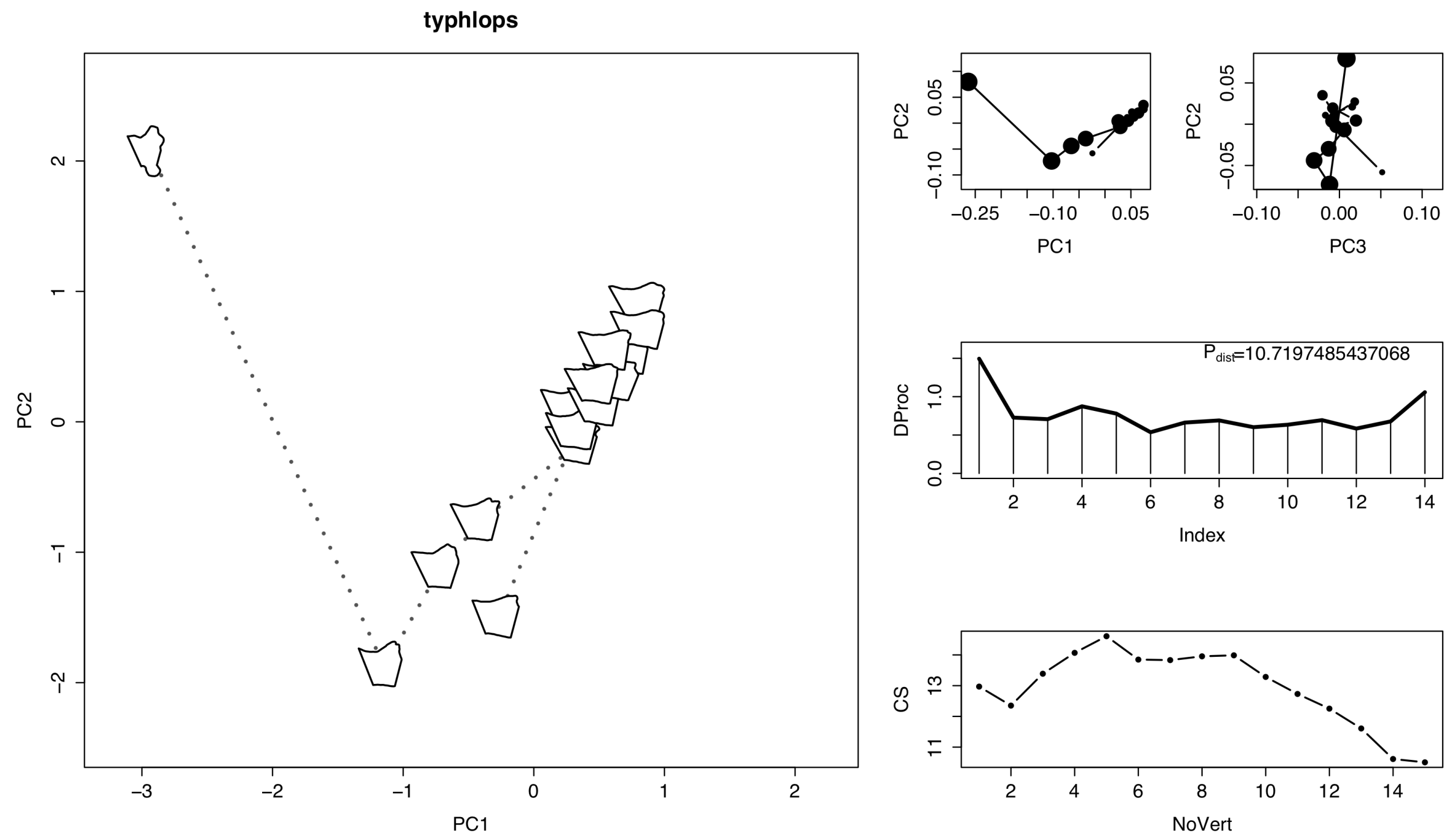

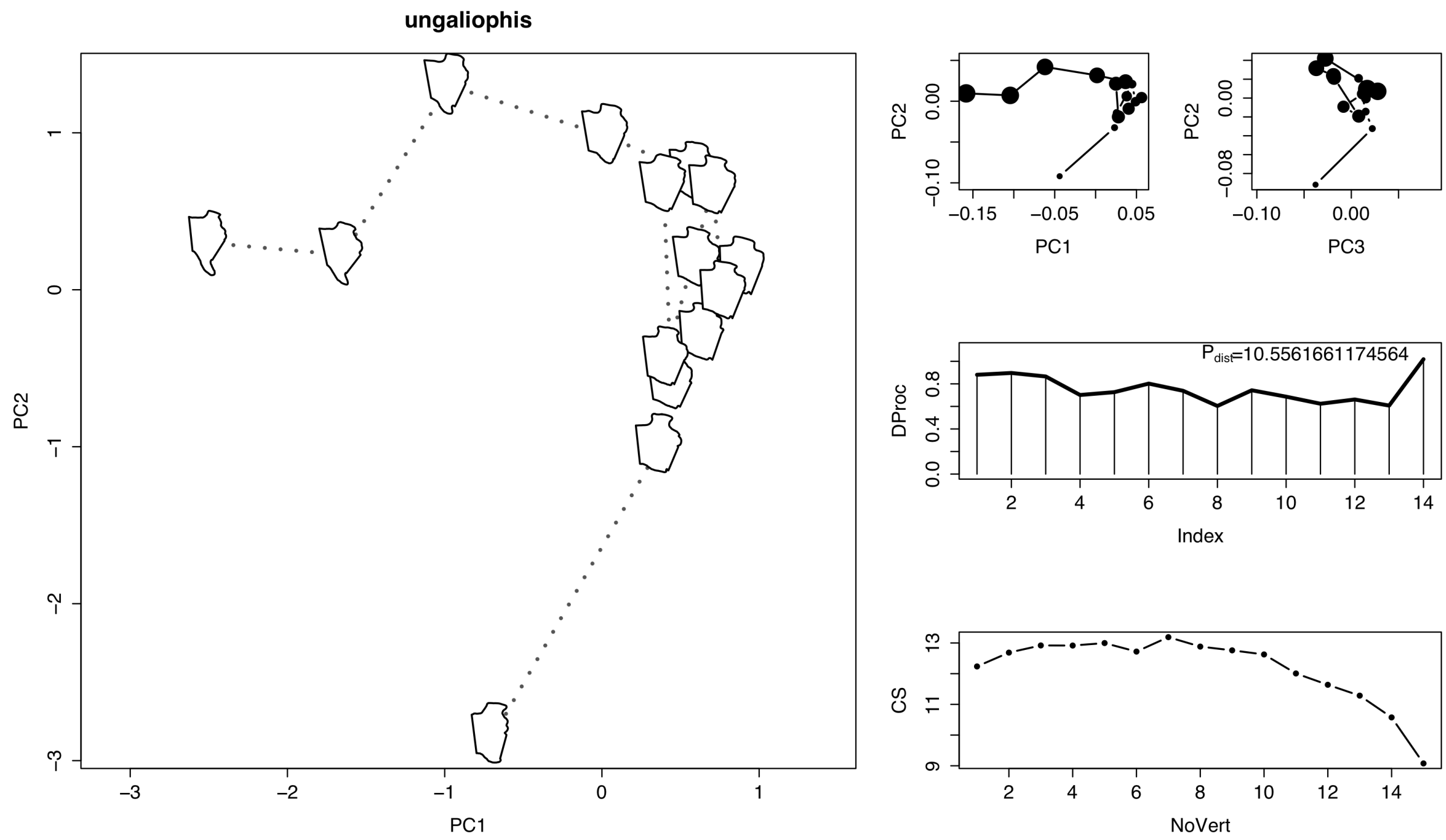
xenopeltis
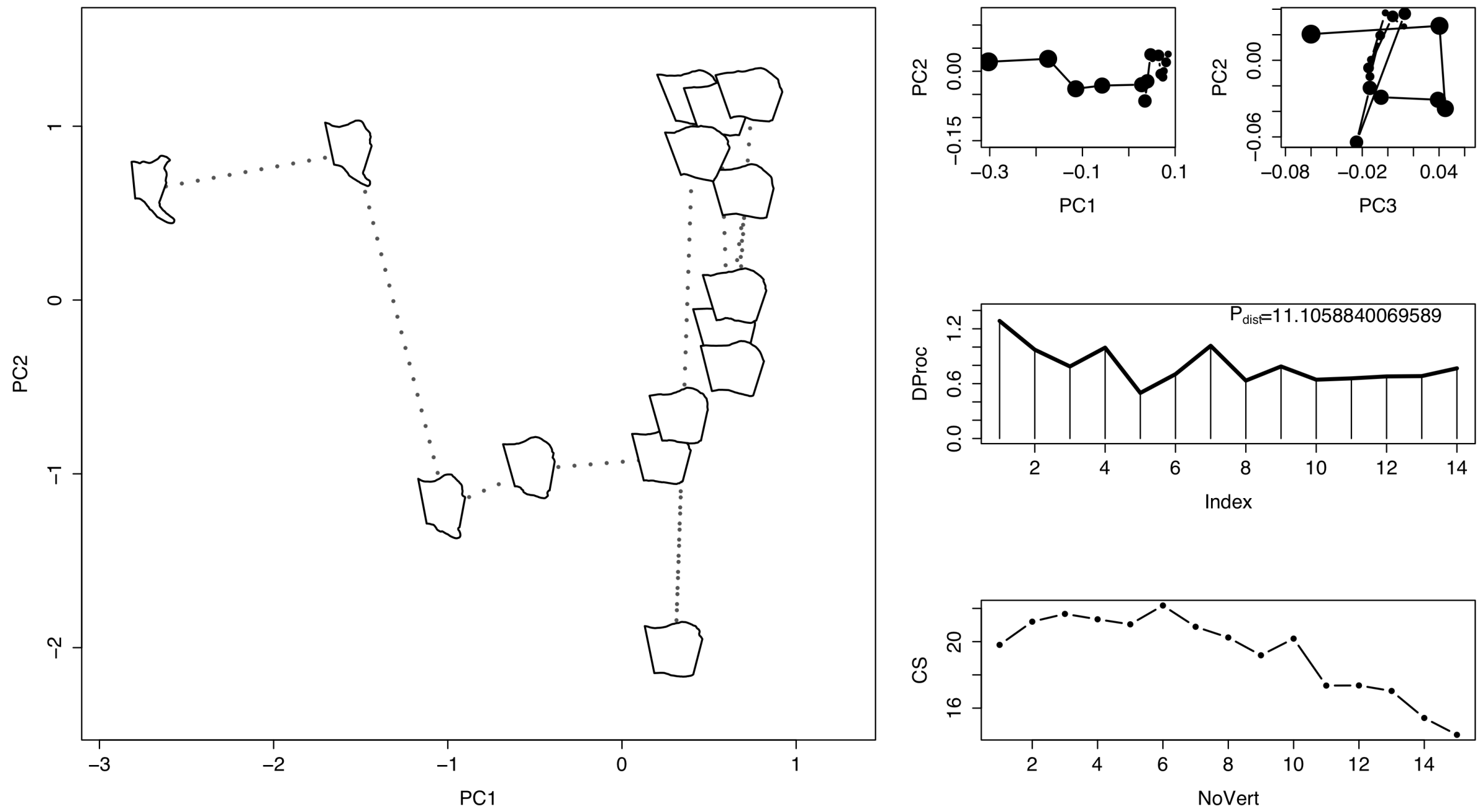

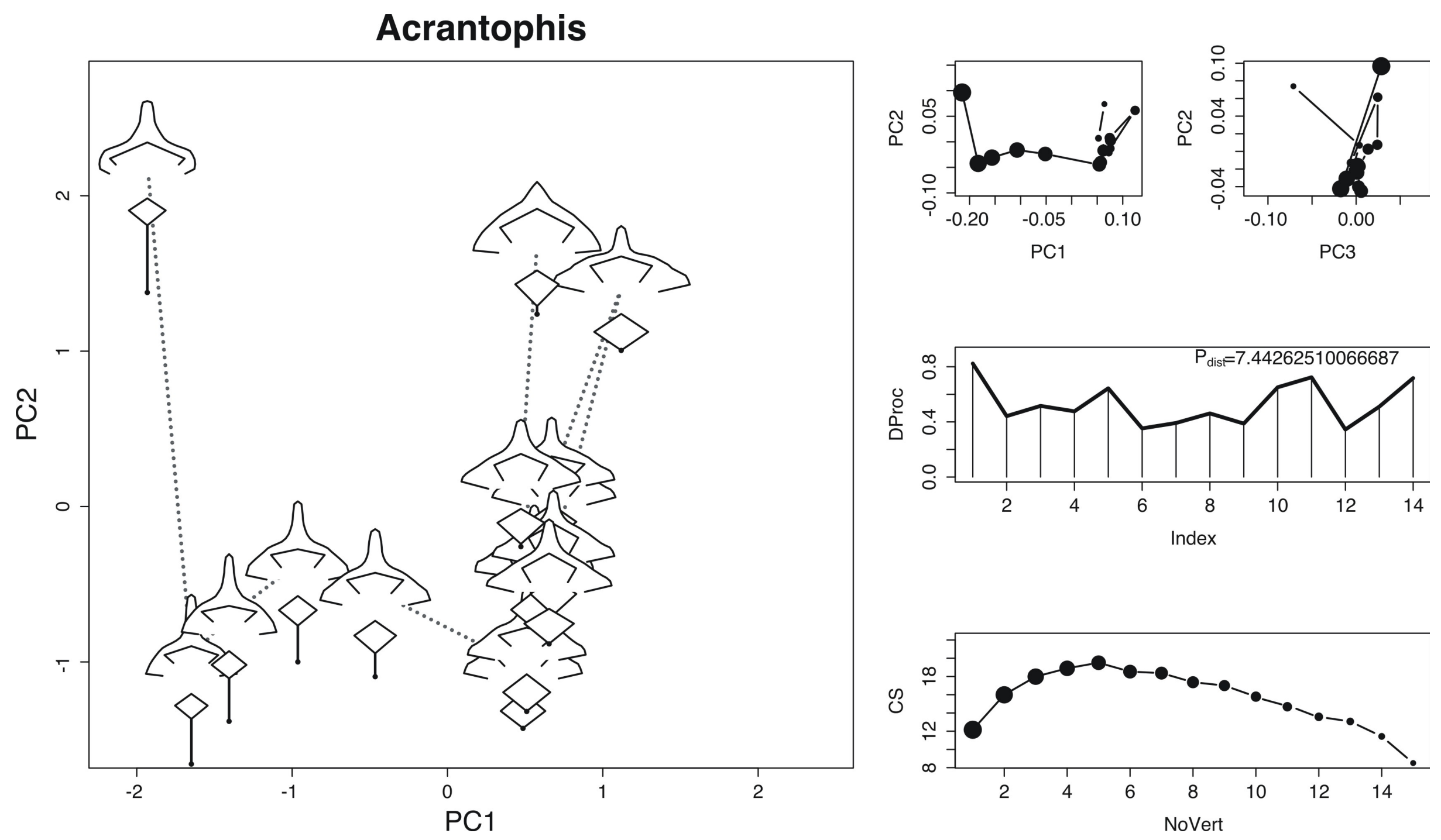

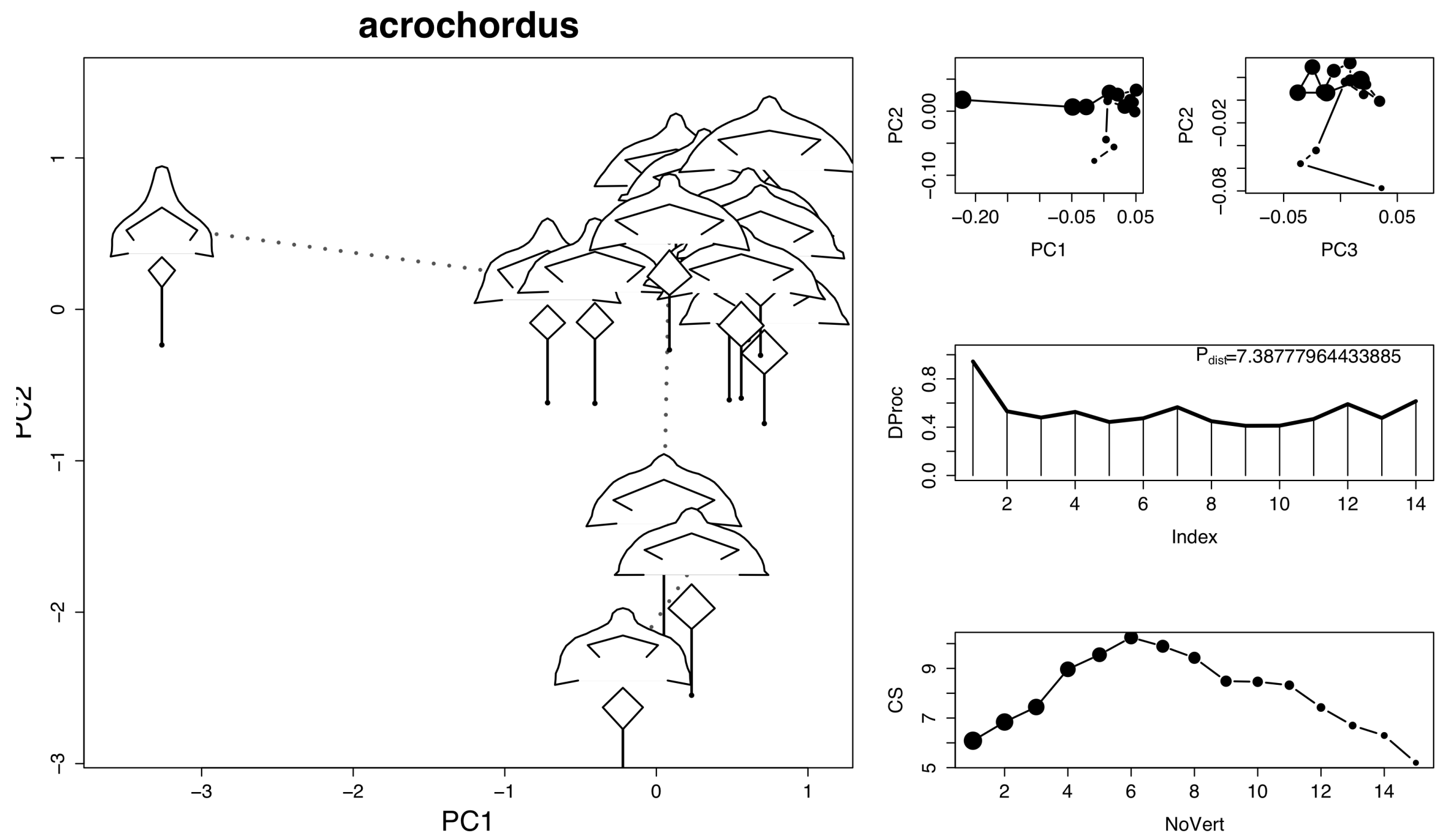

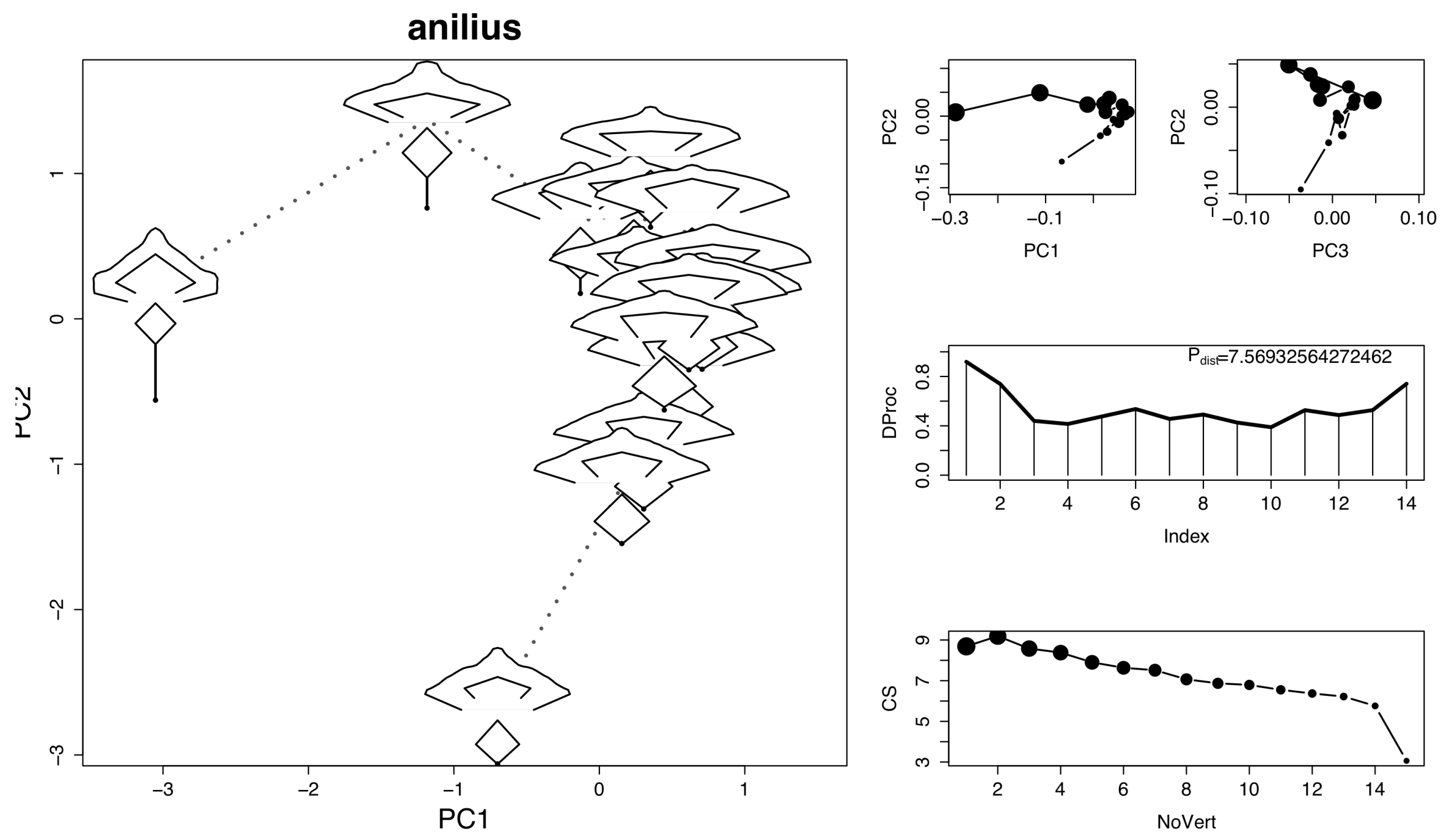

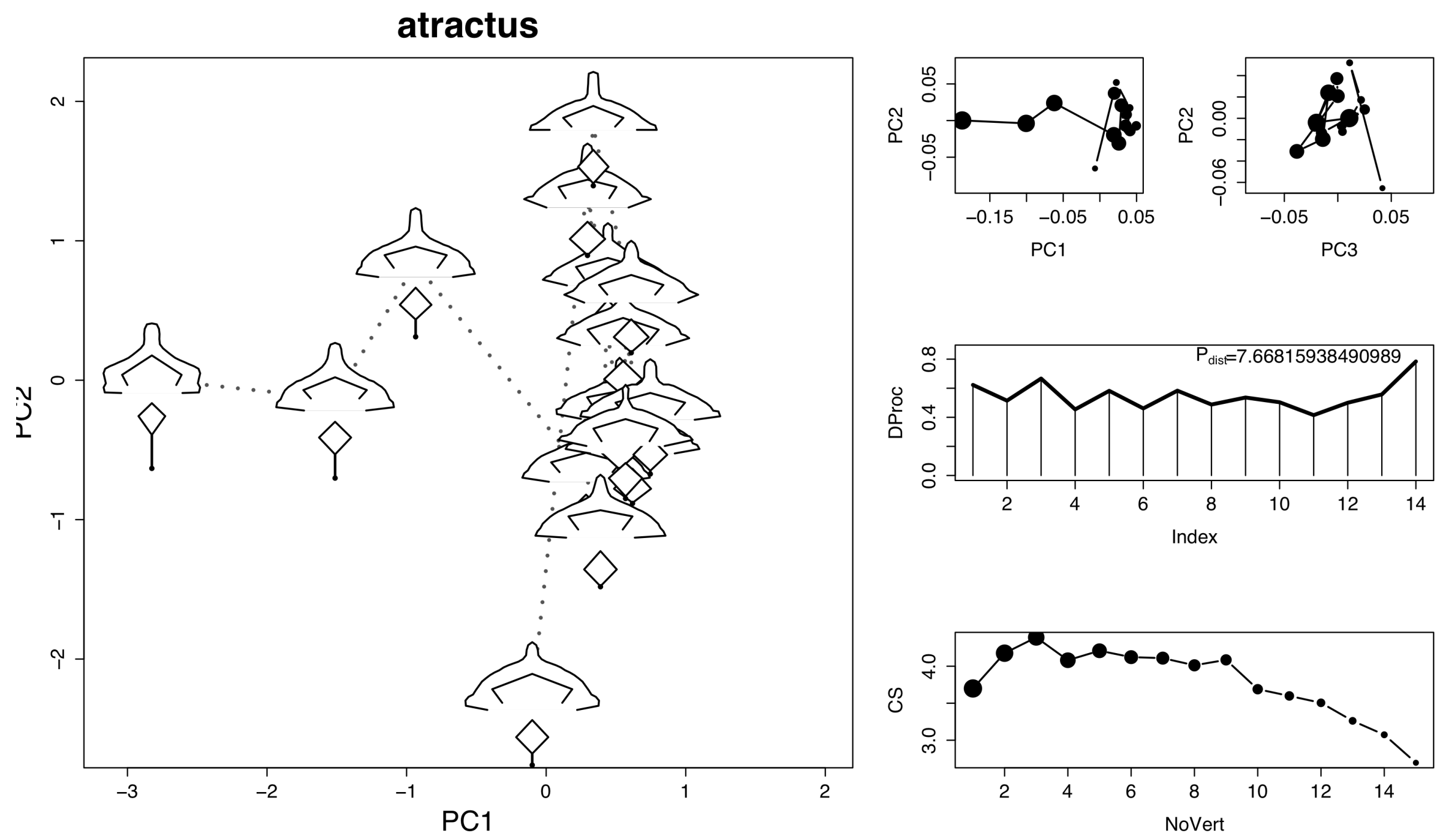

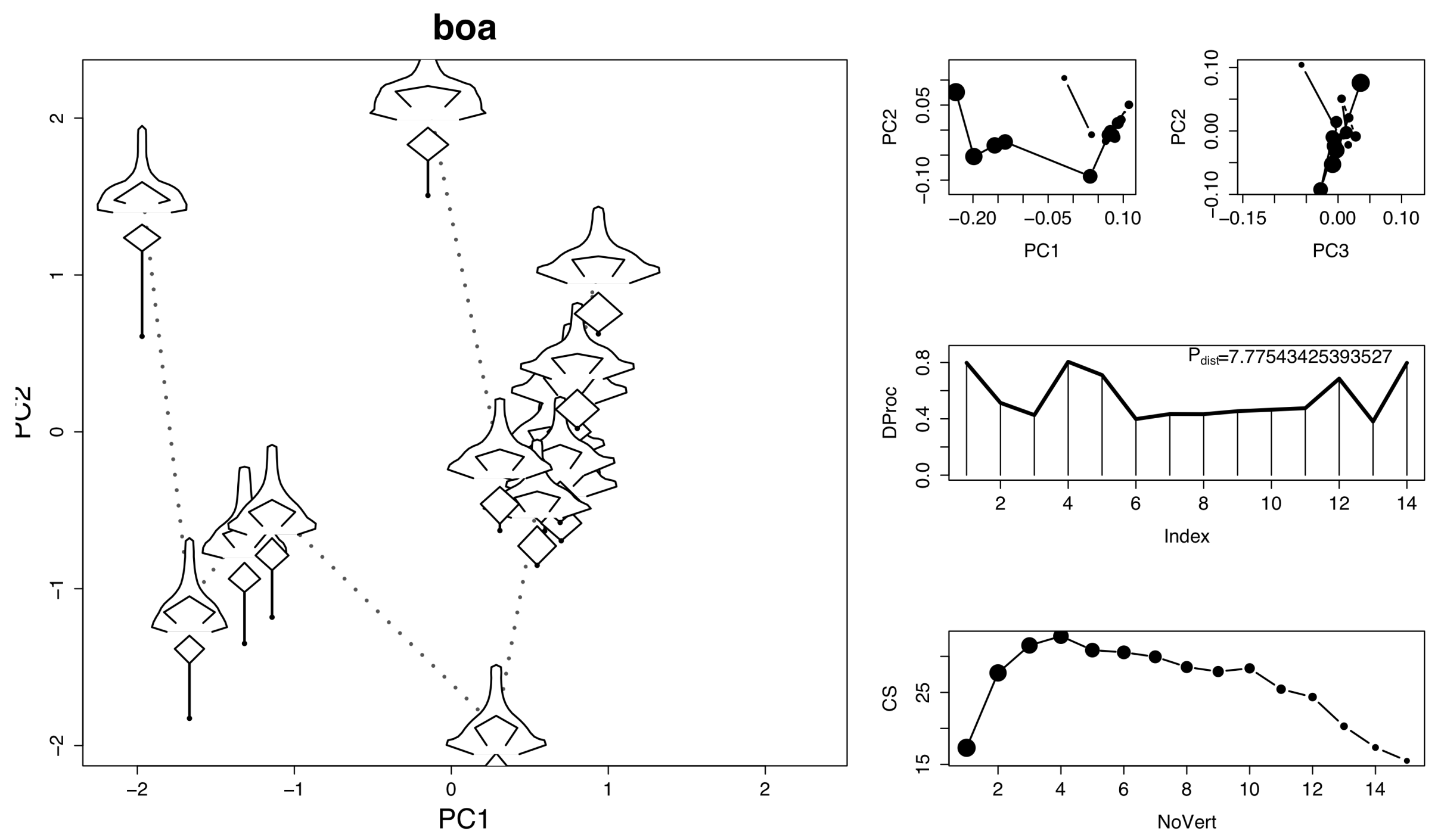


\section{bothriopsis}
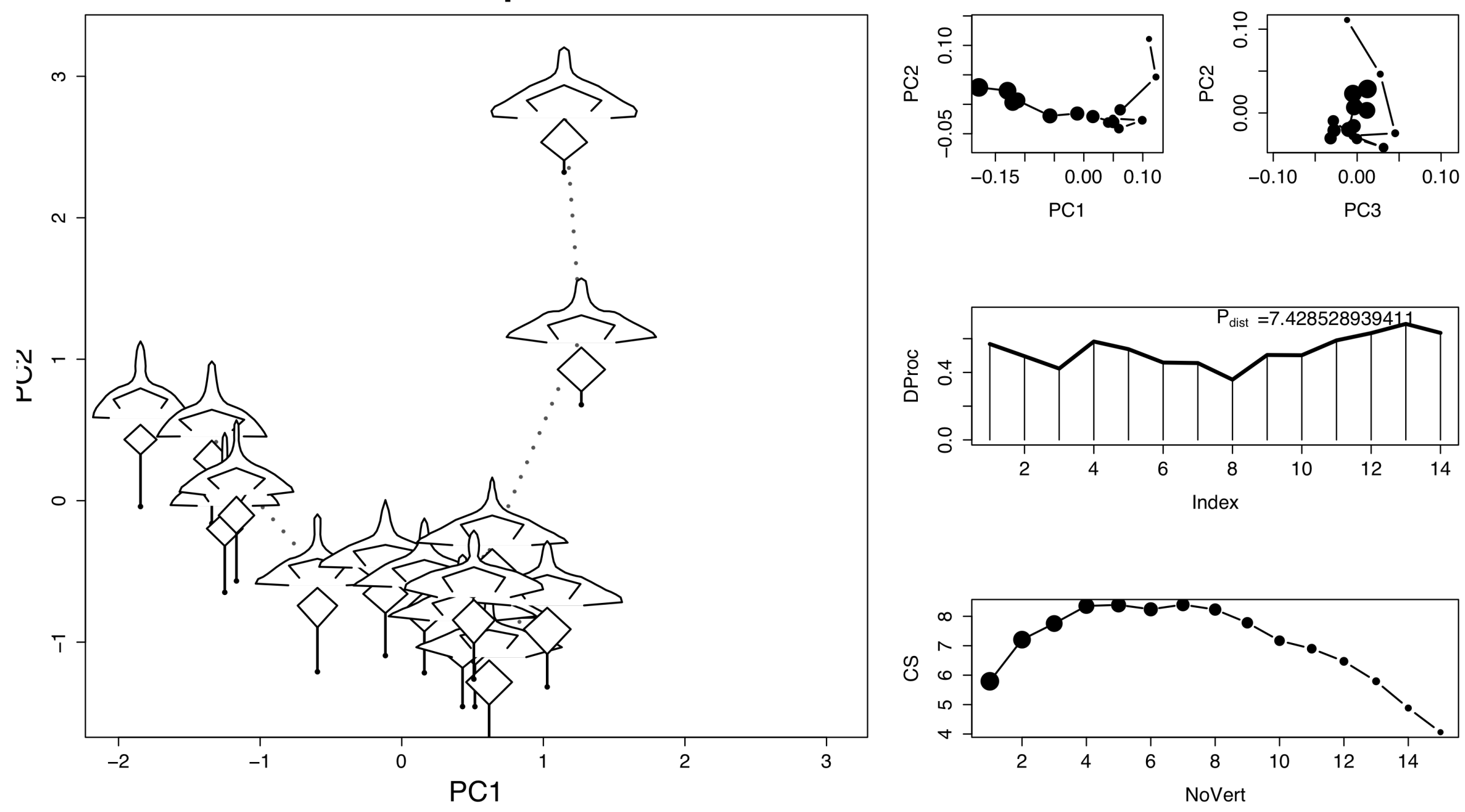

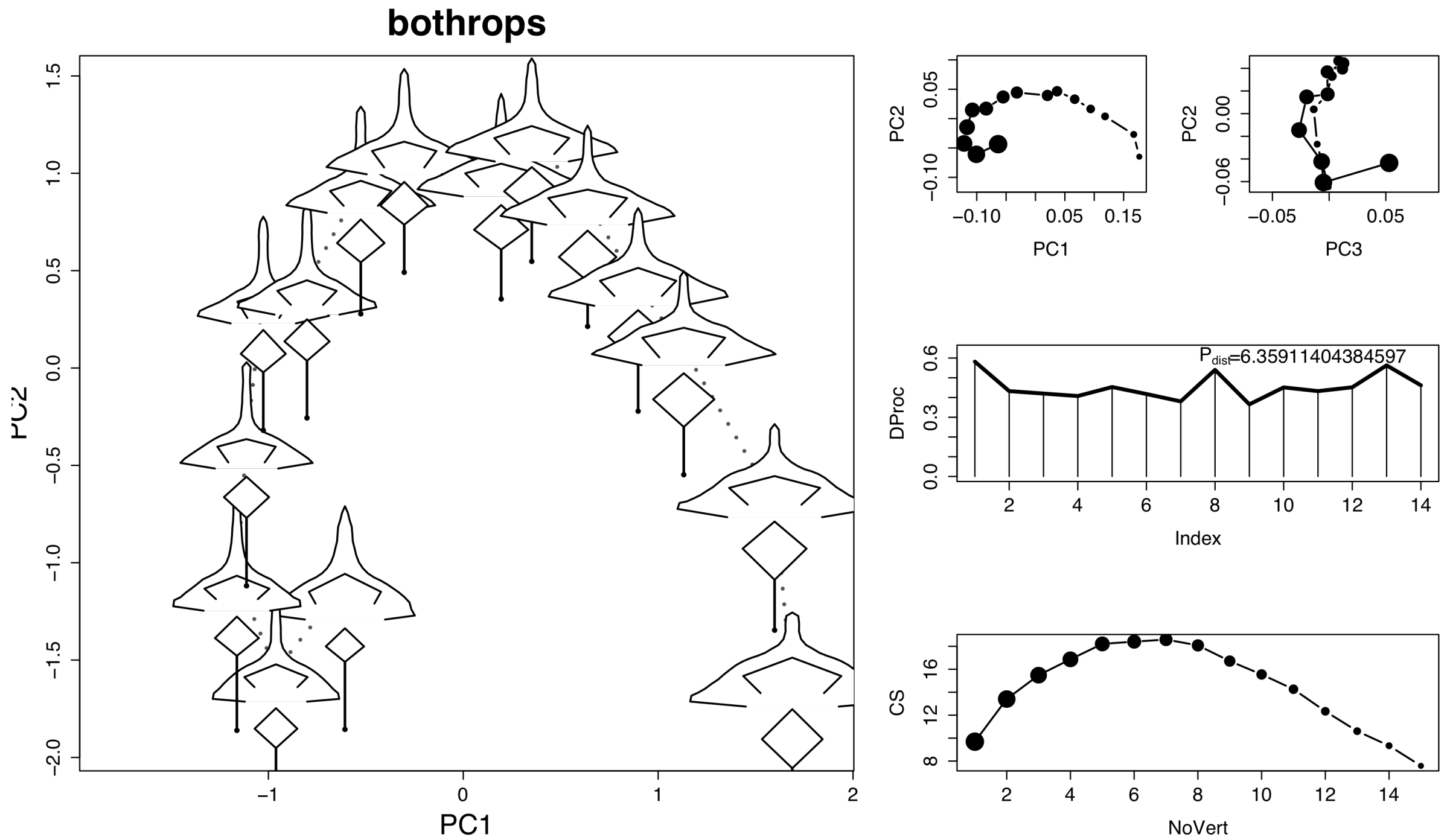

A-84 

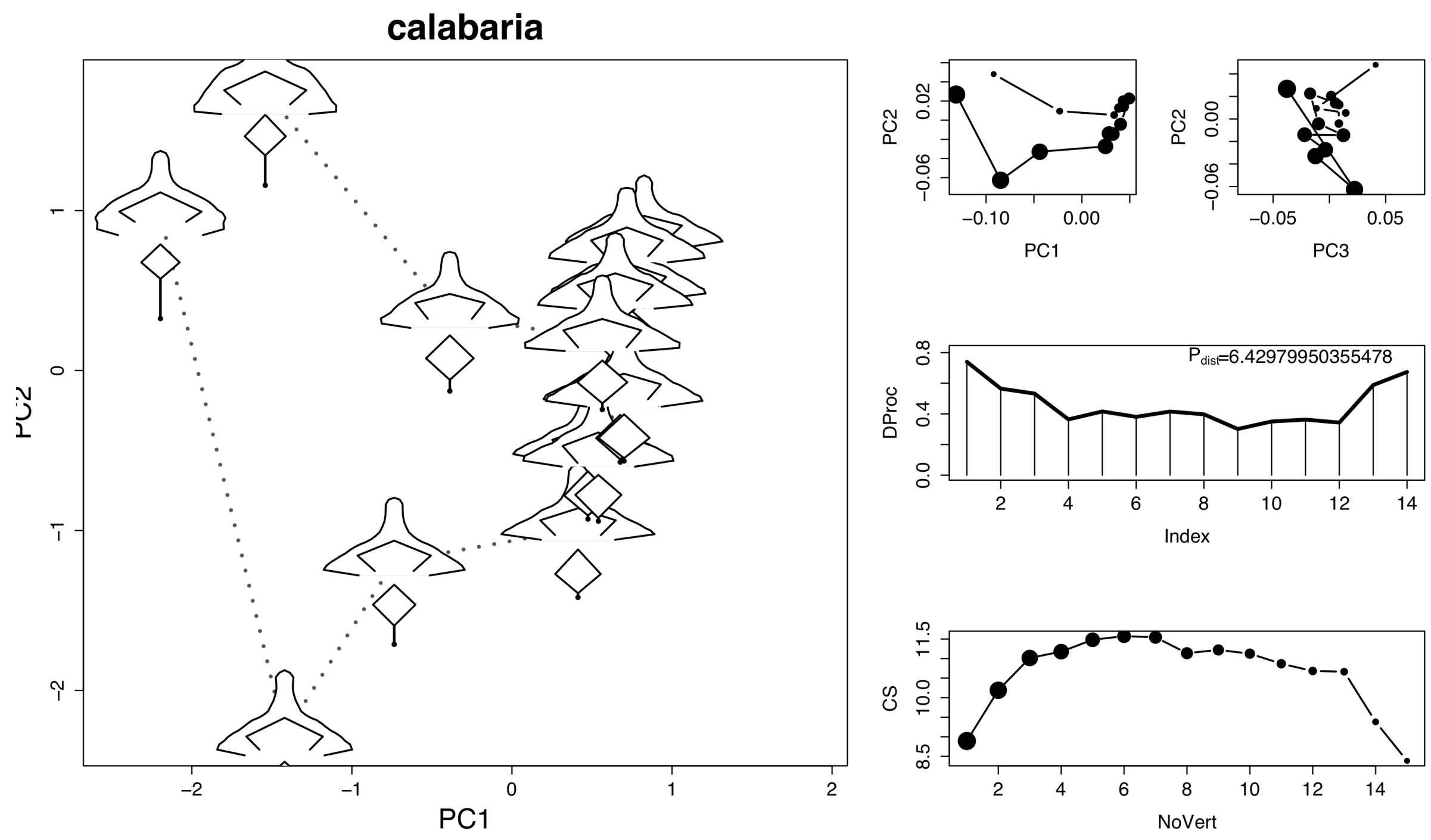

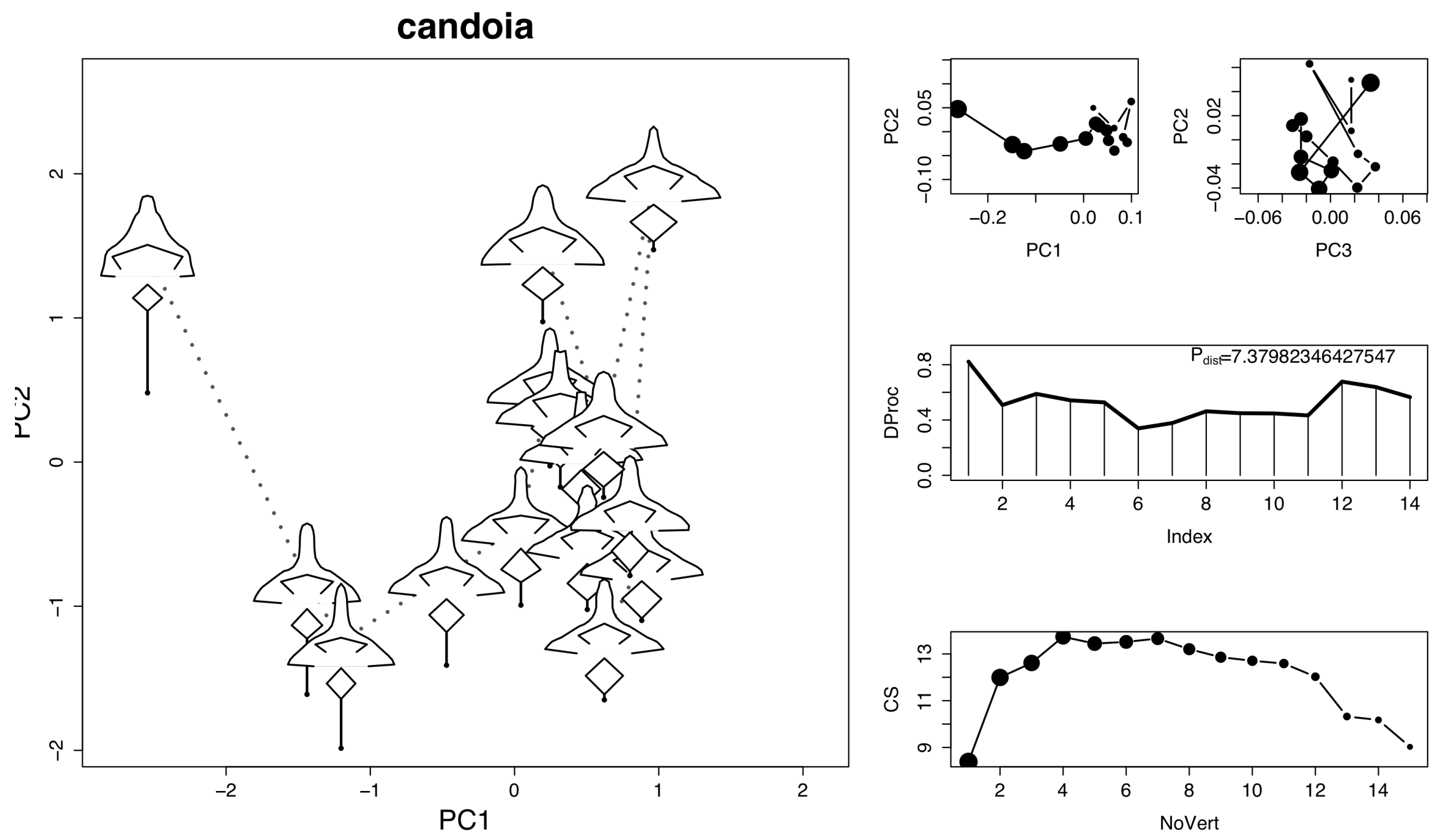

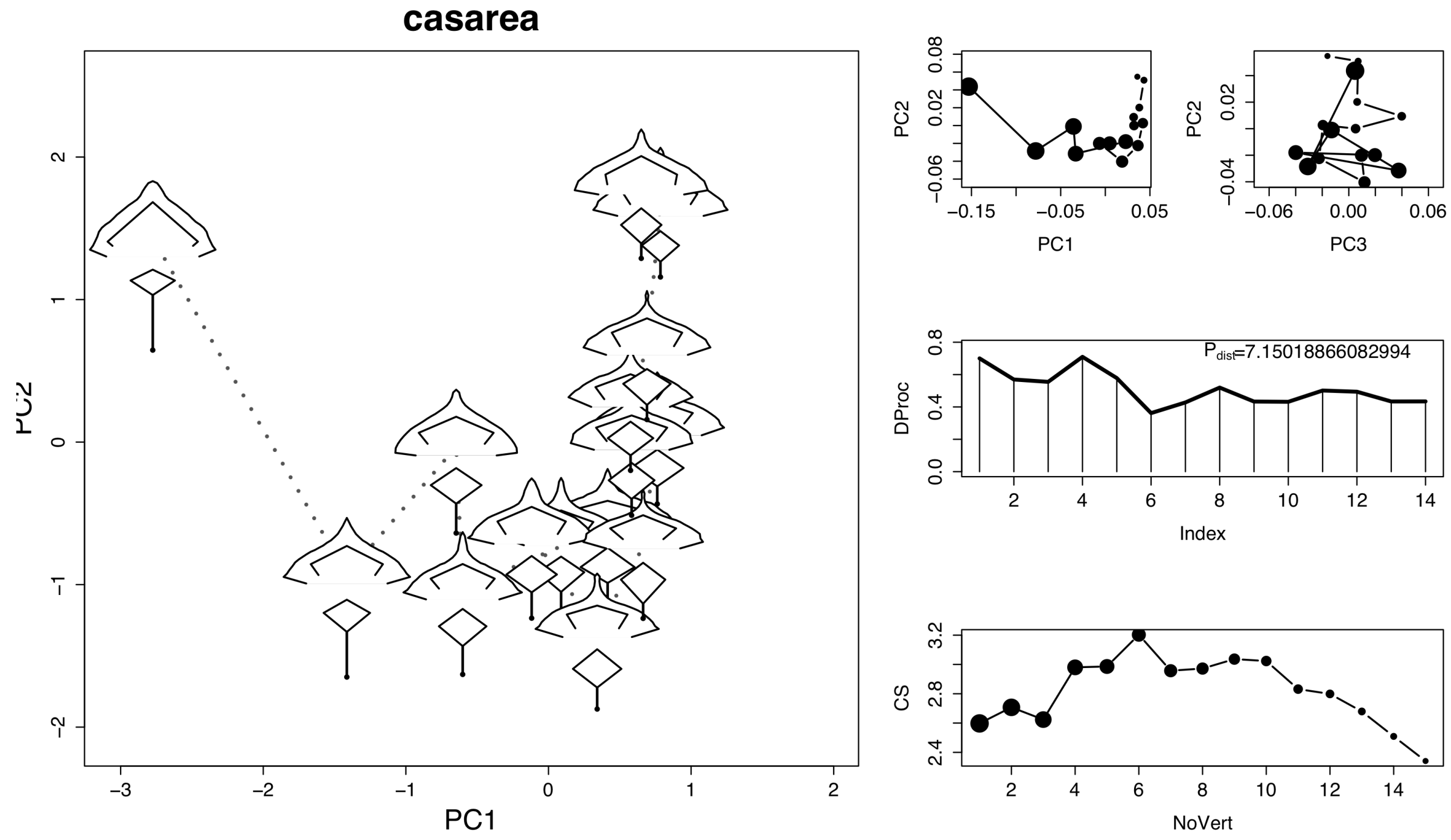

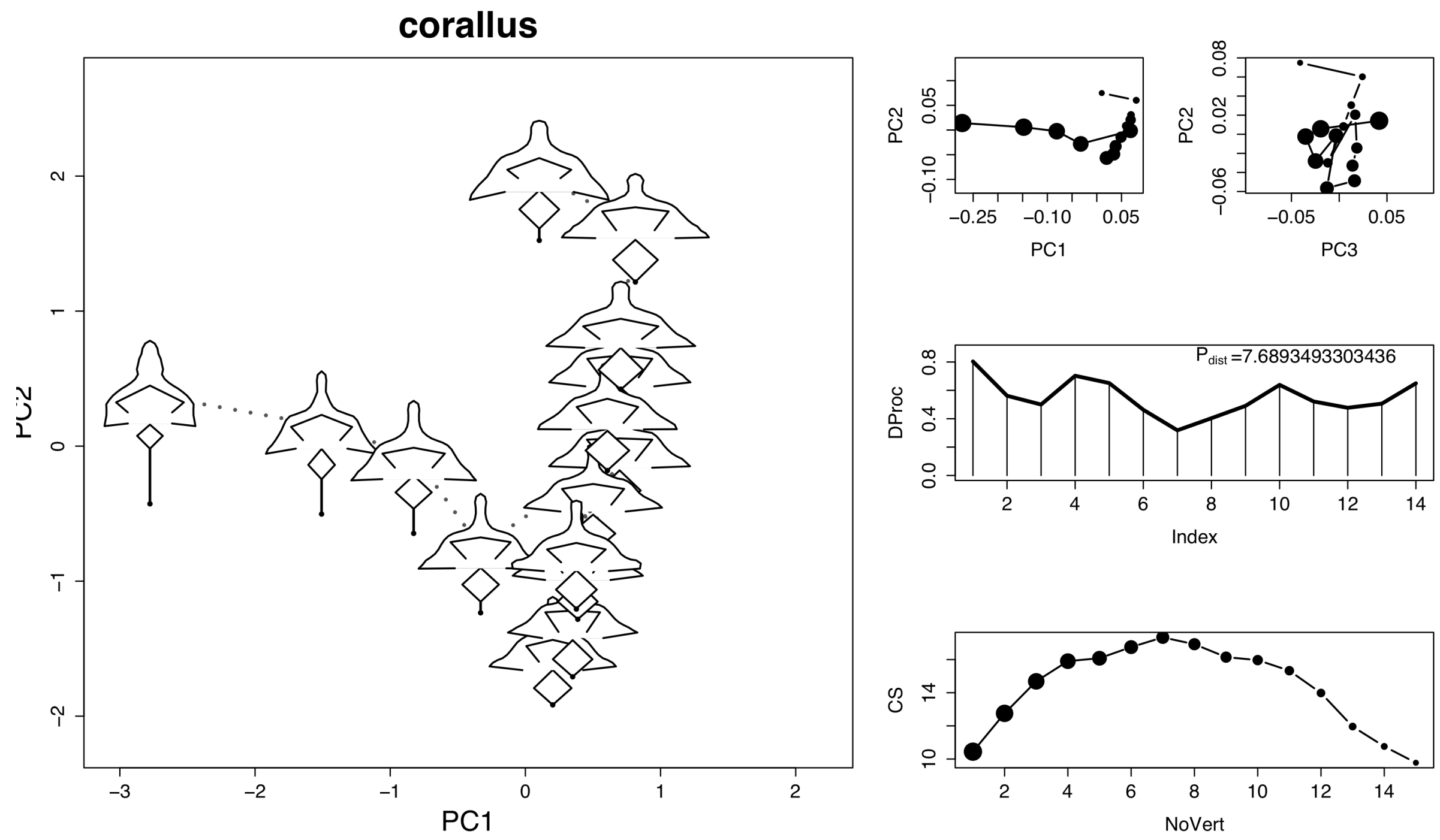

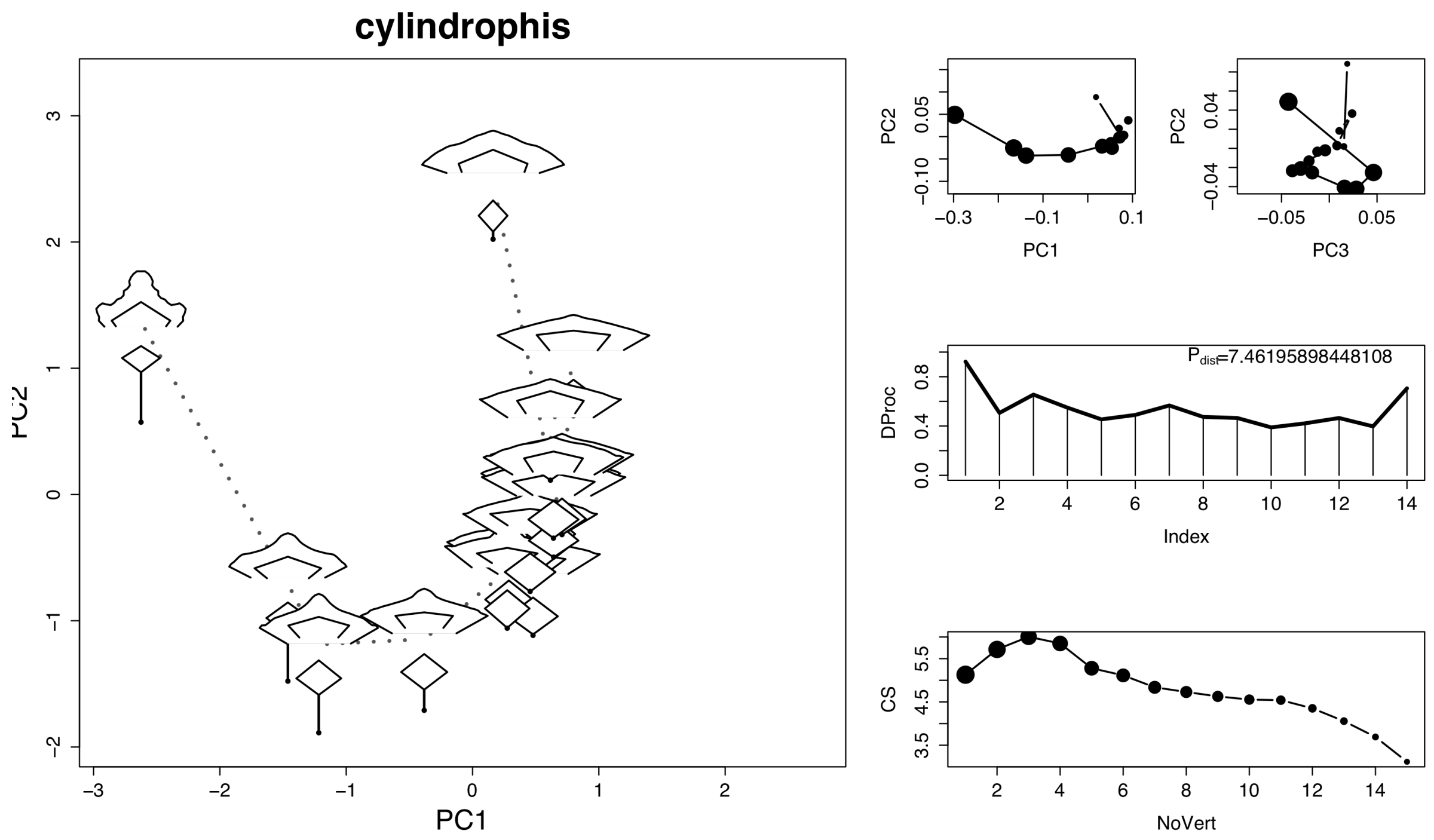

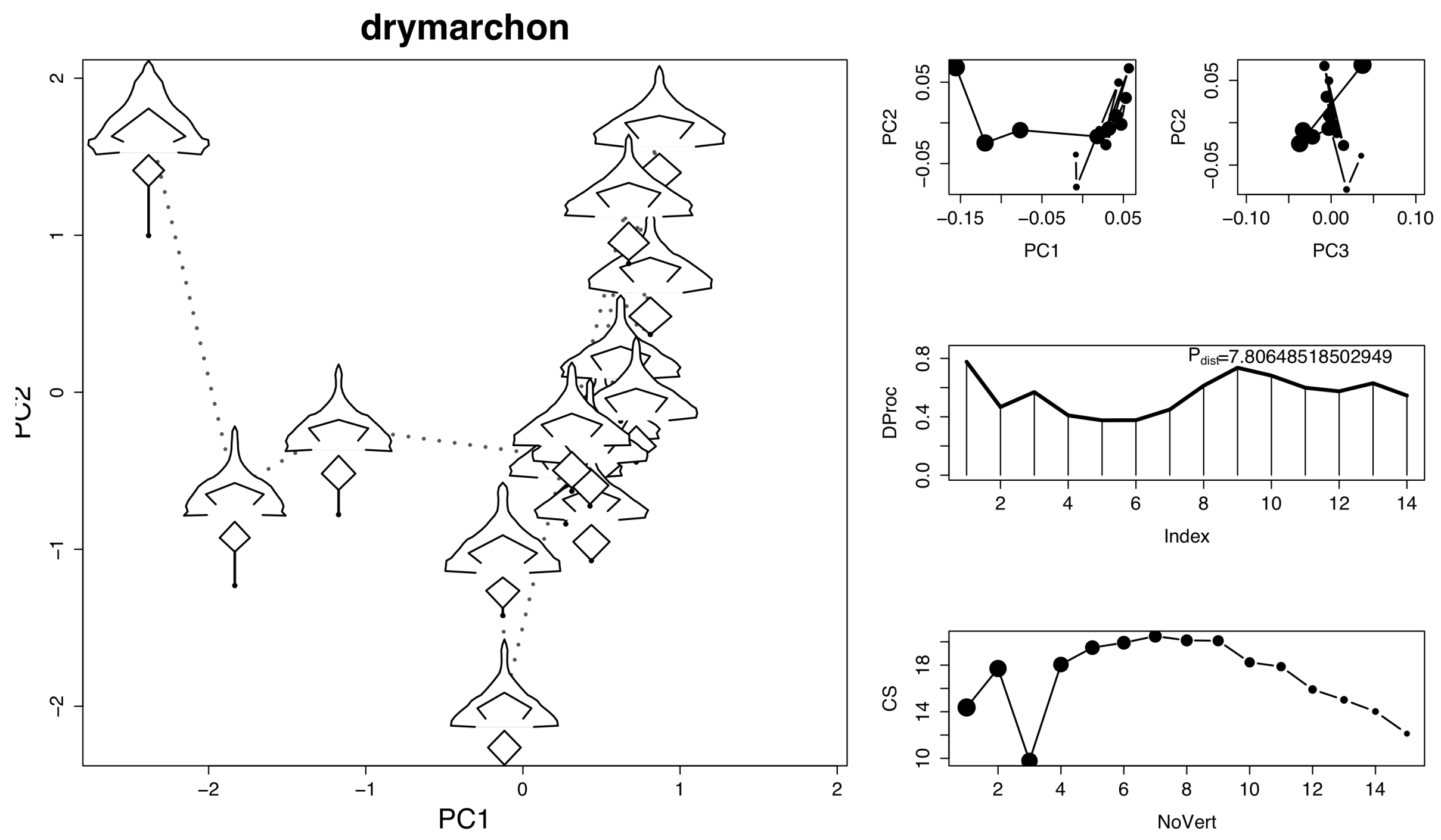

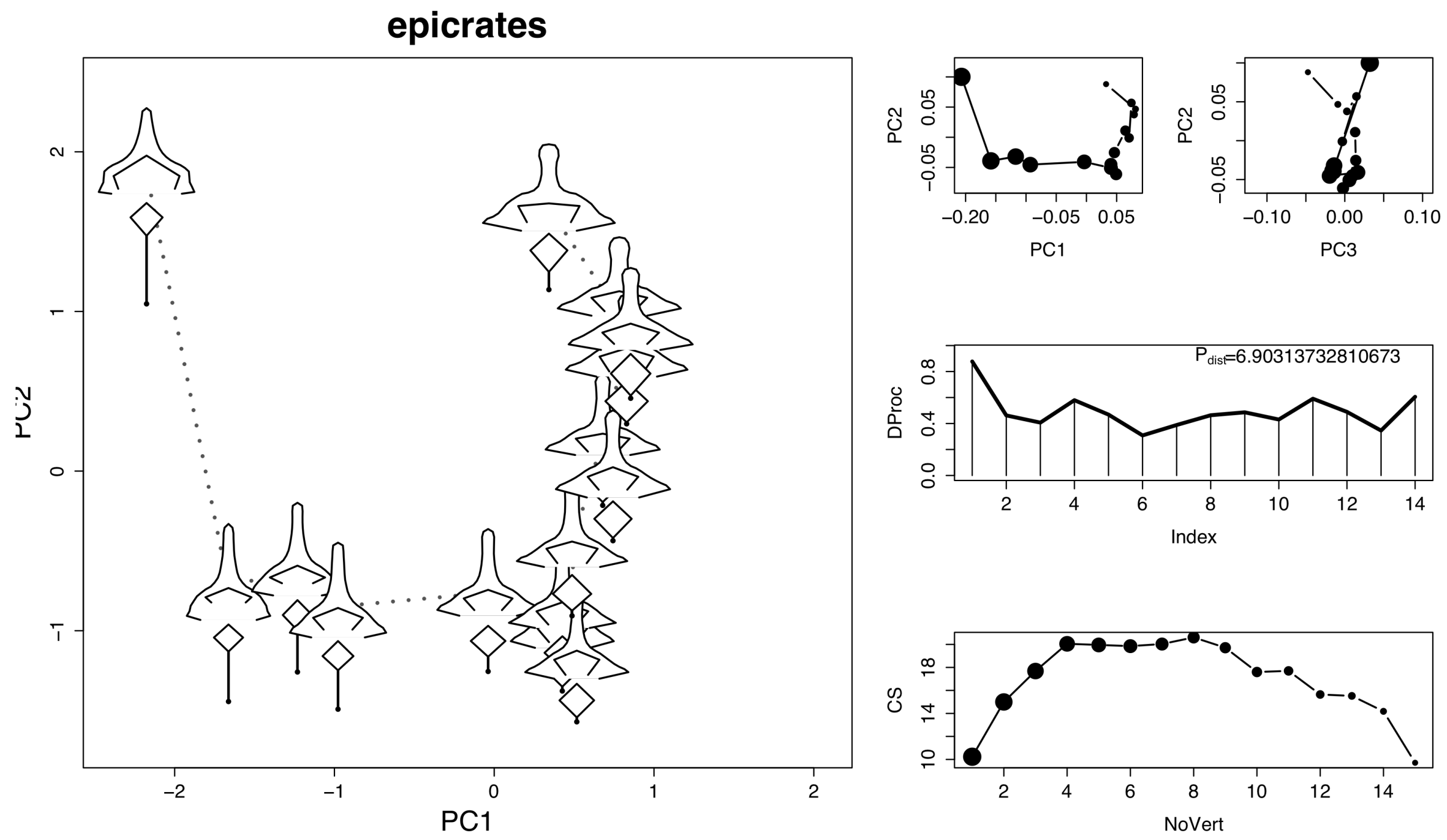

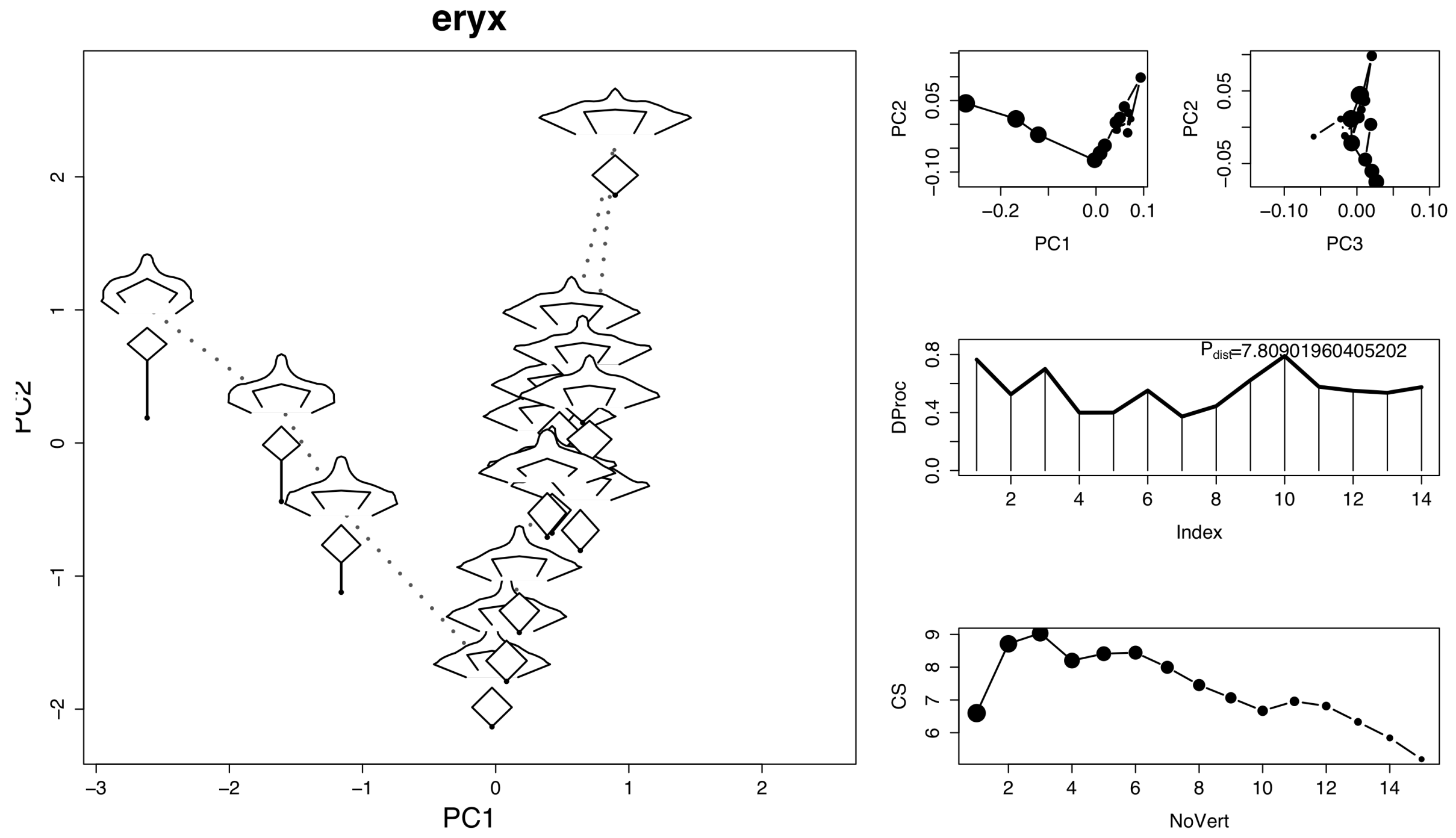

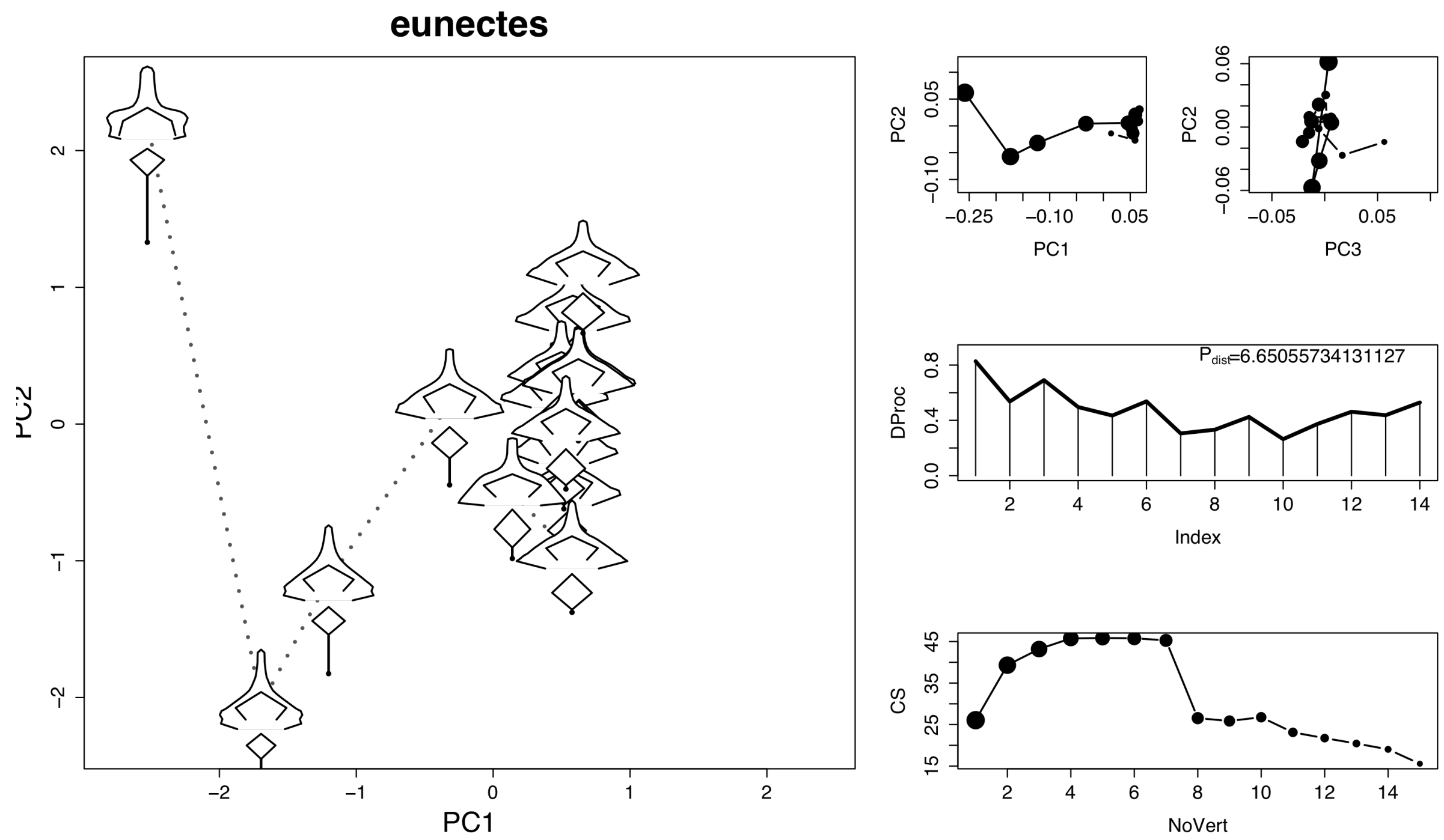

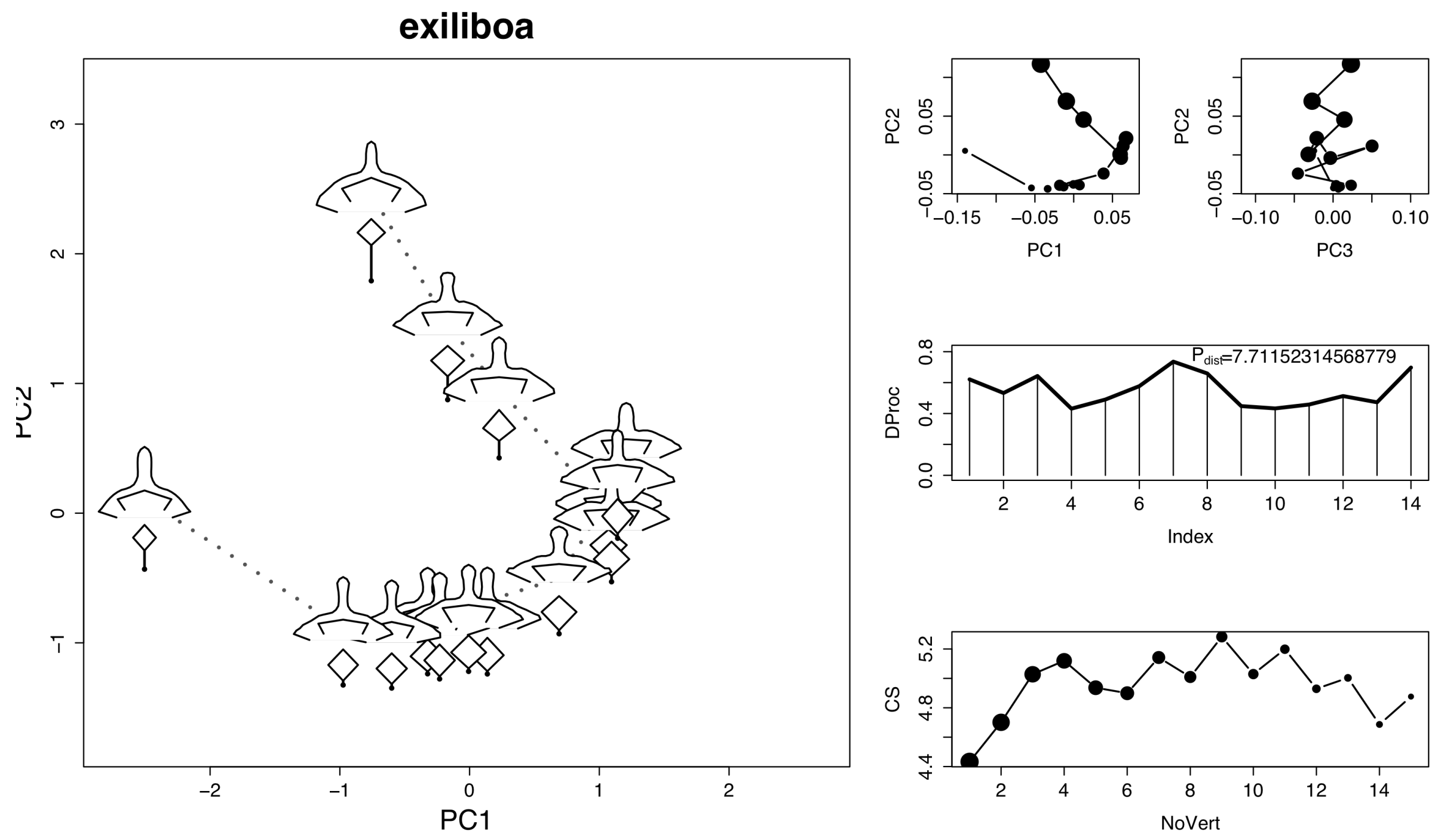

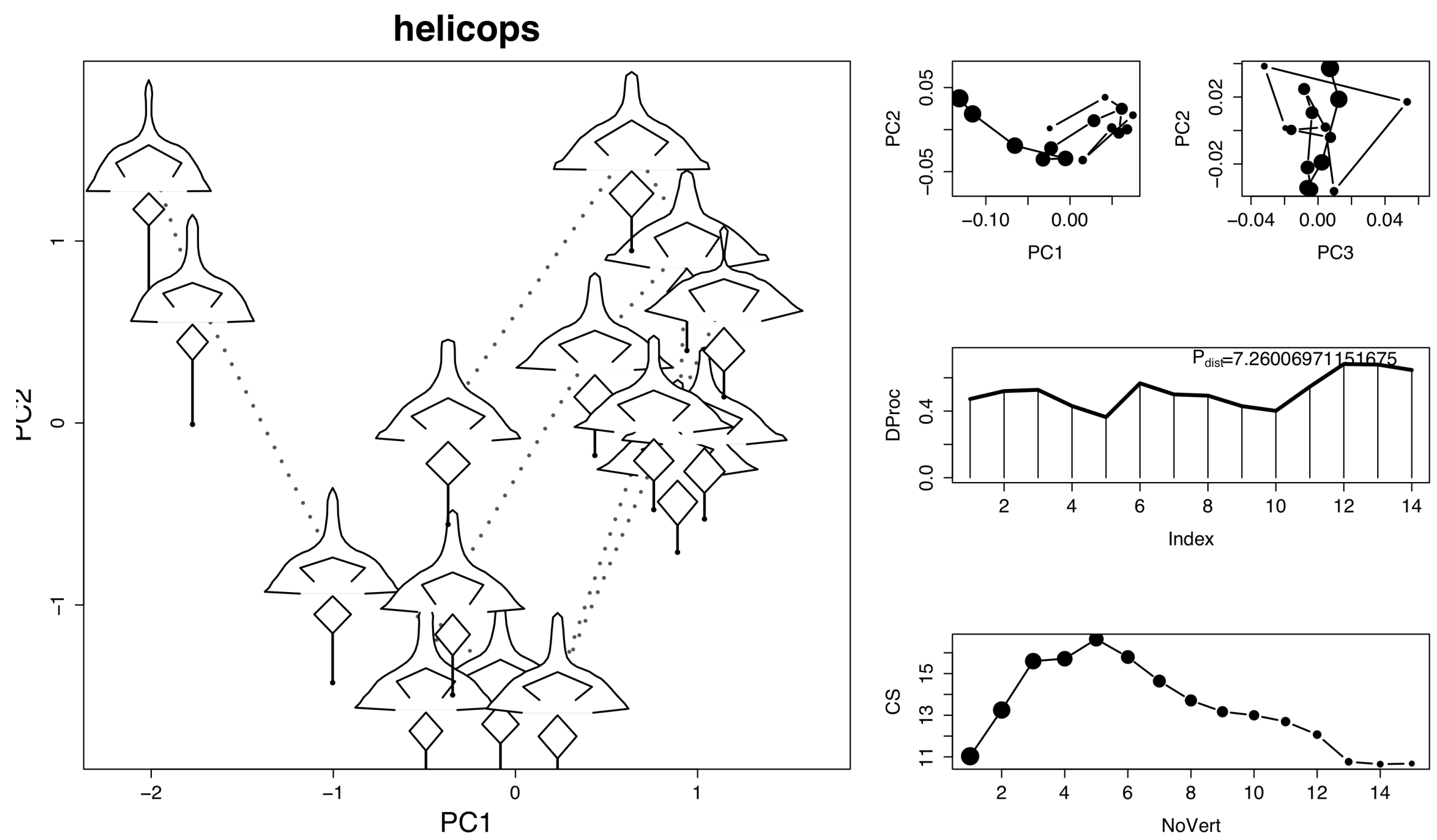




\section{liasis}
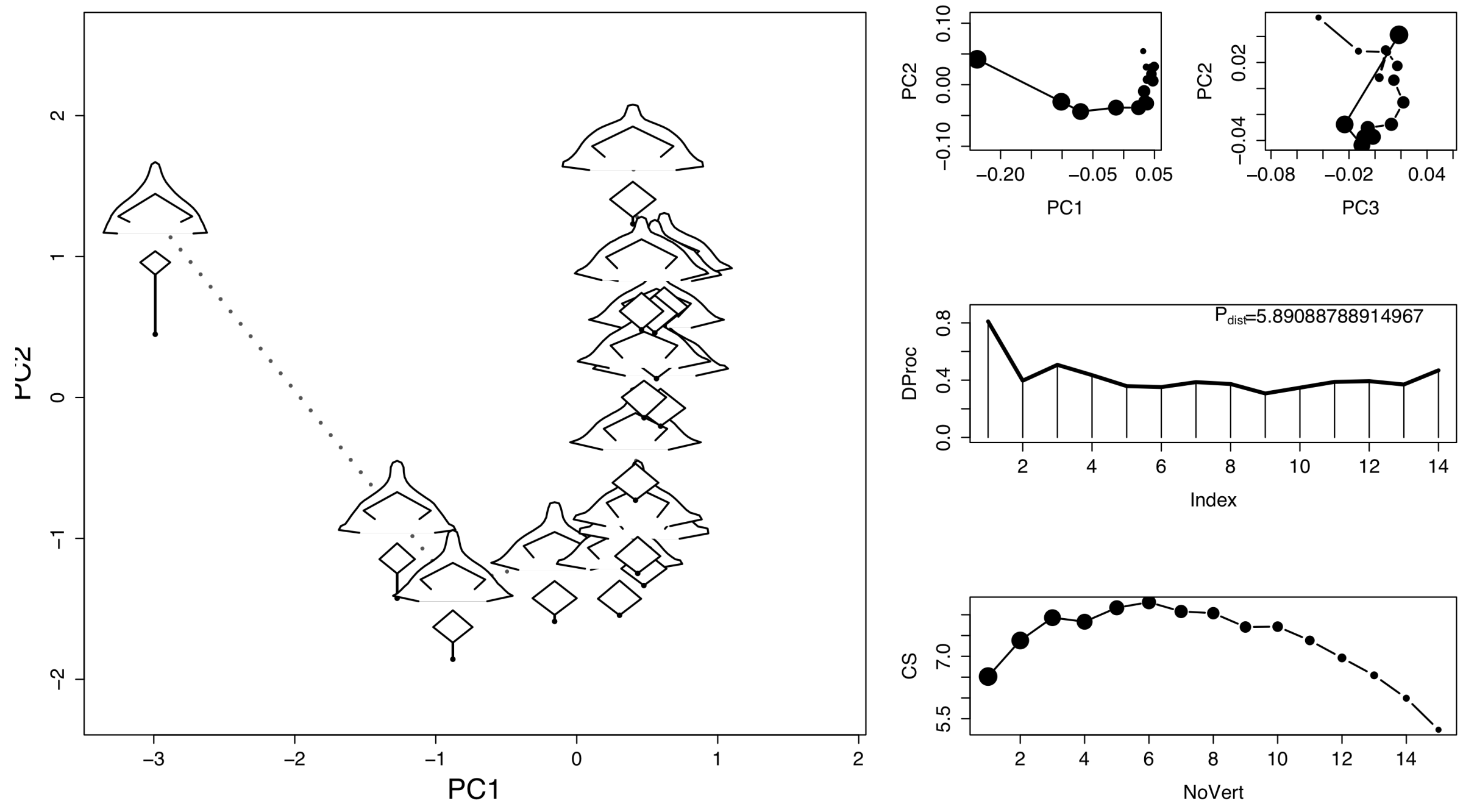


\section{lichanura}
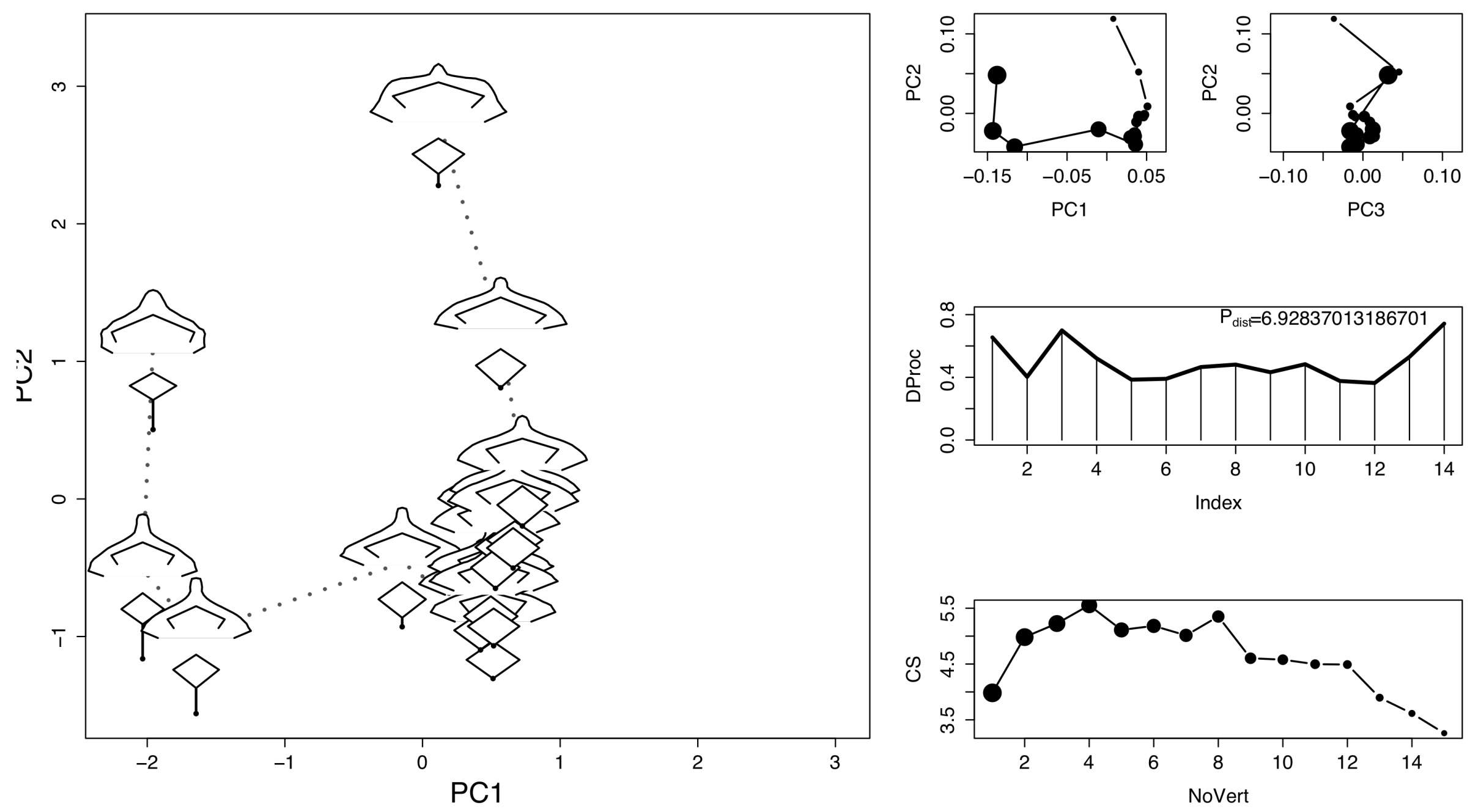


\section{liotyphlops}
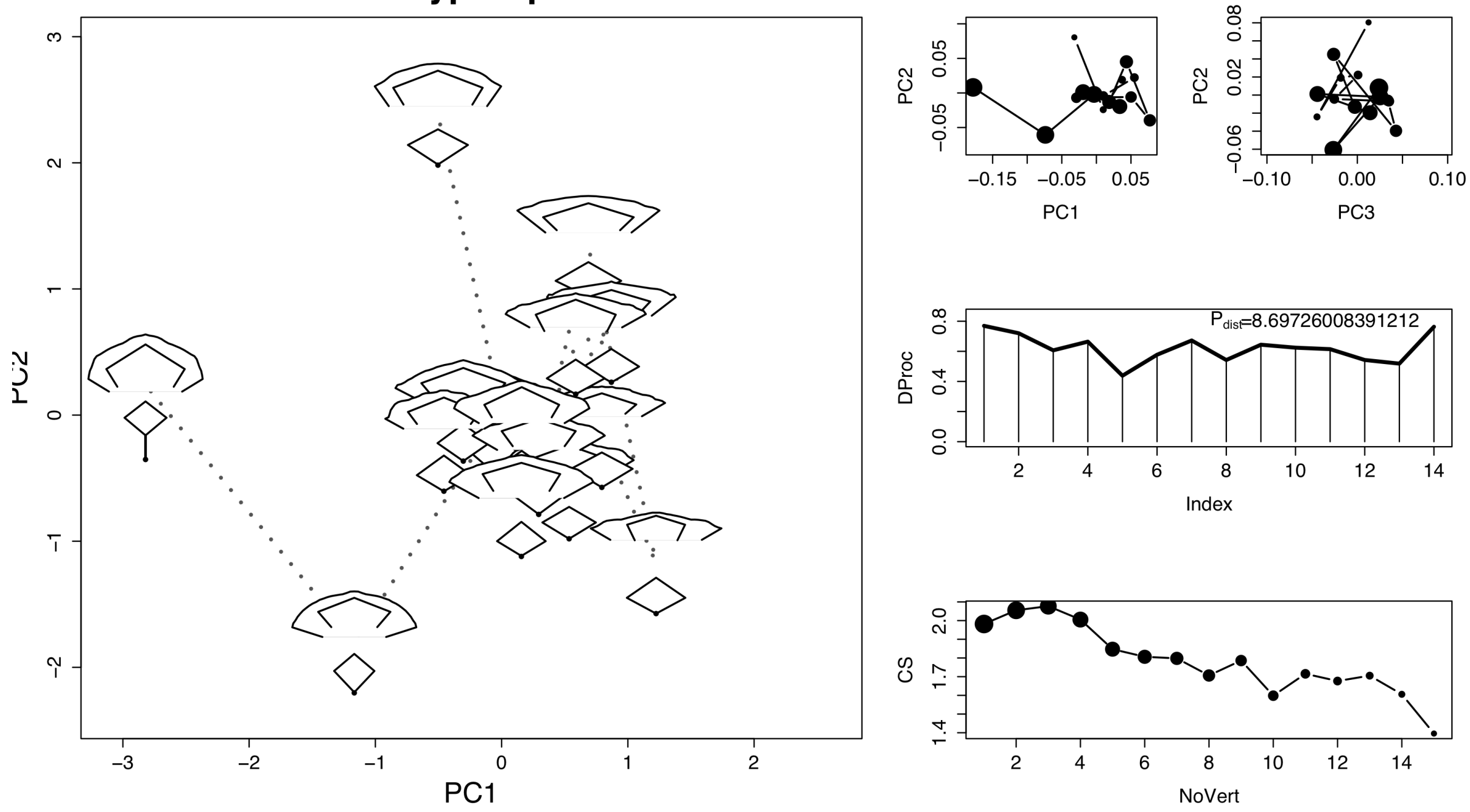

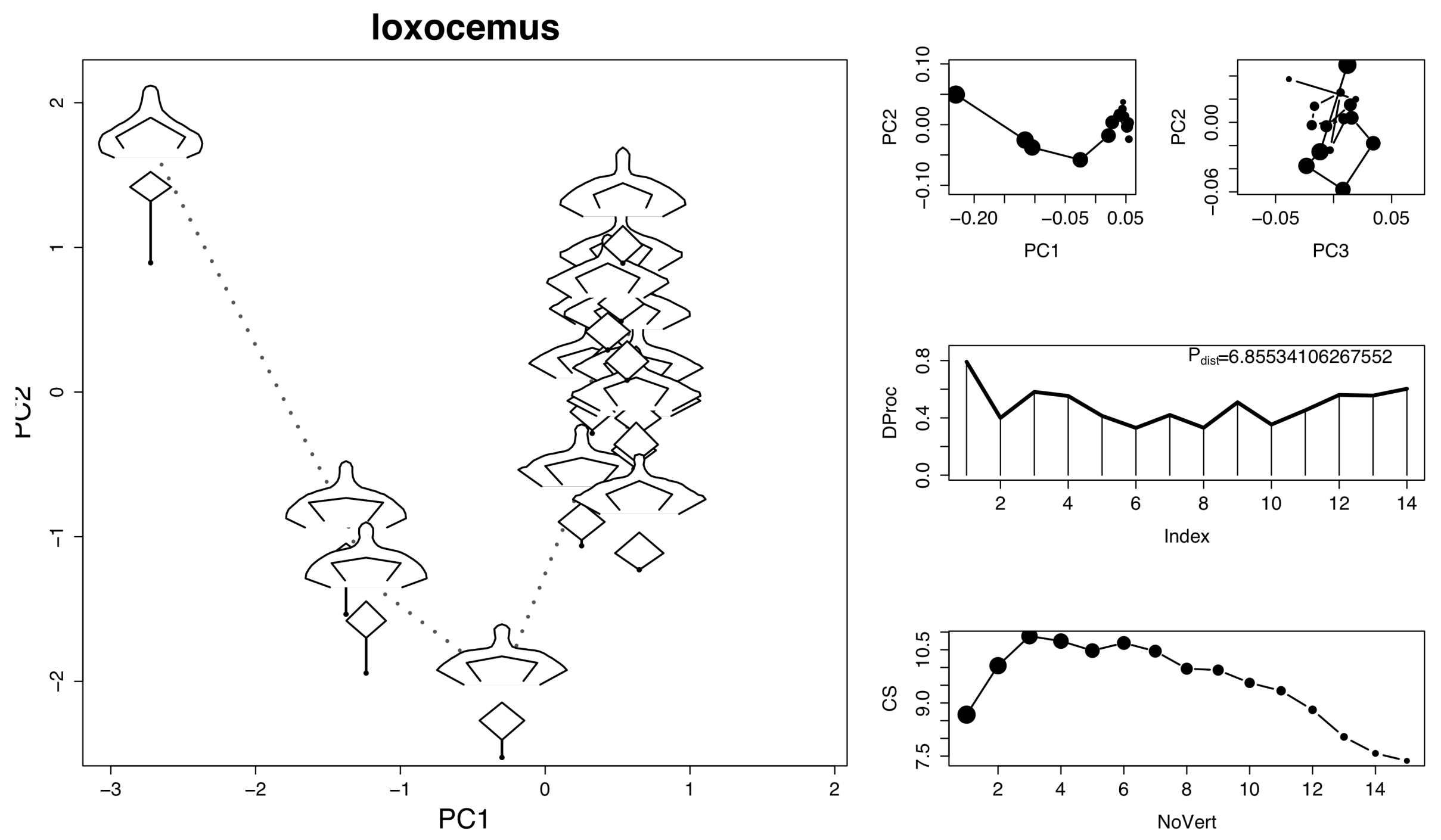

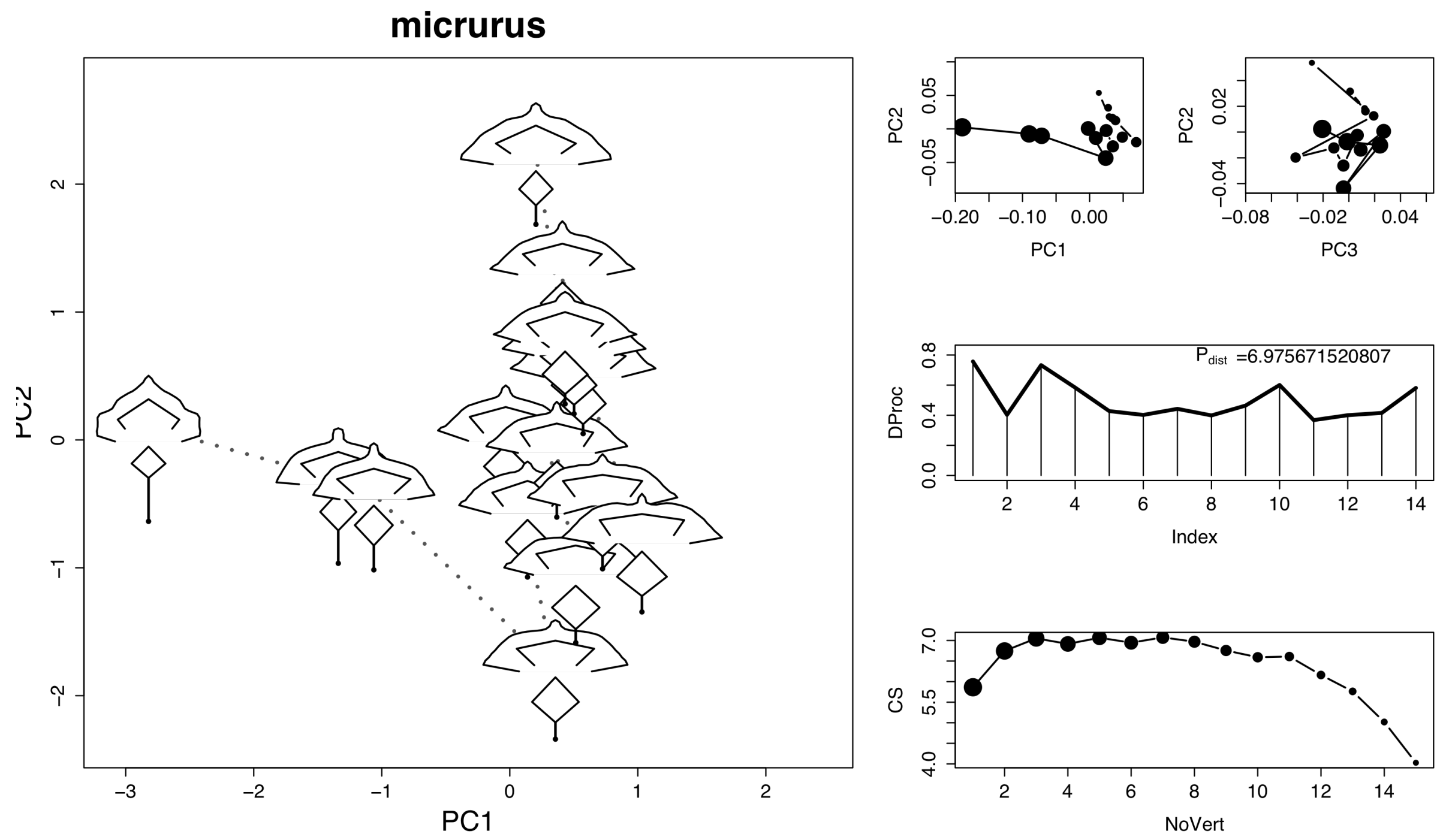

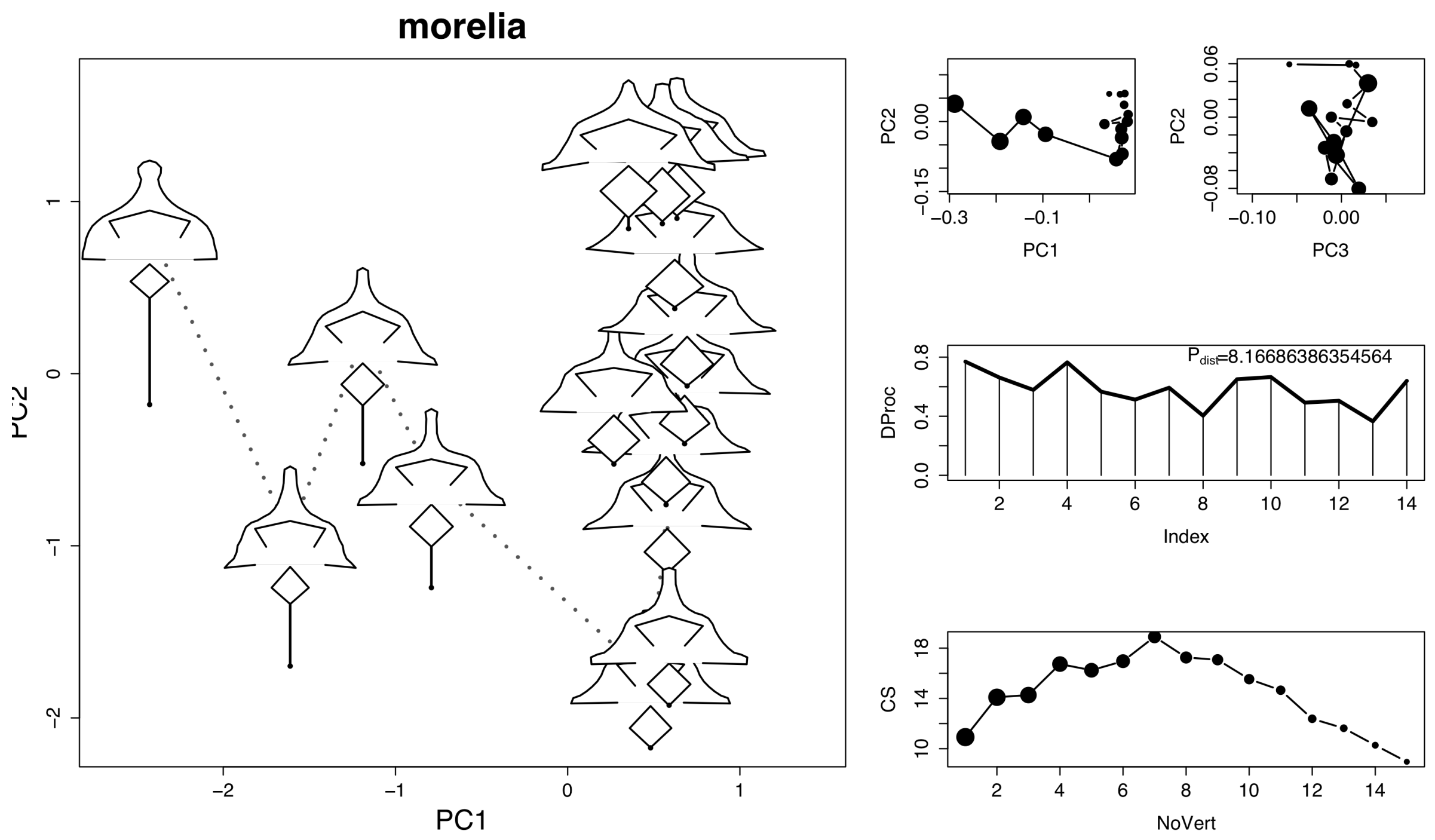

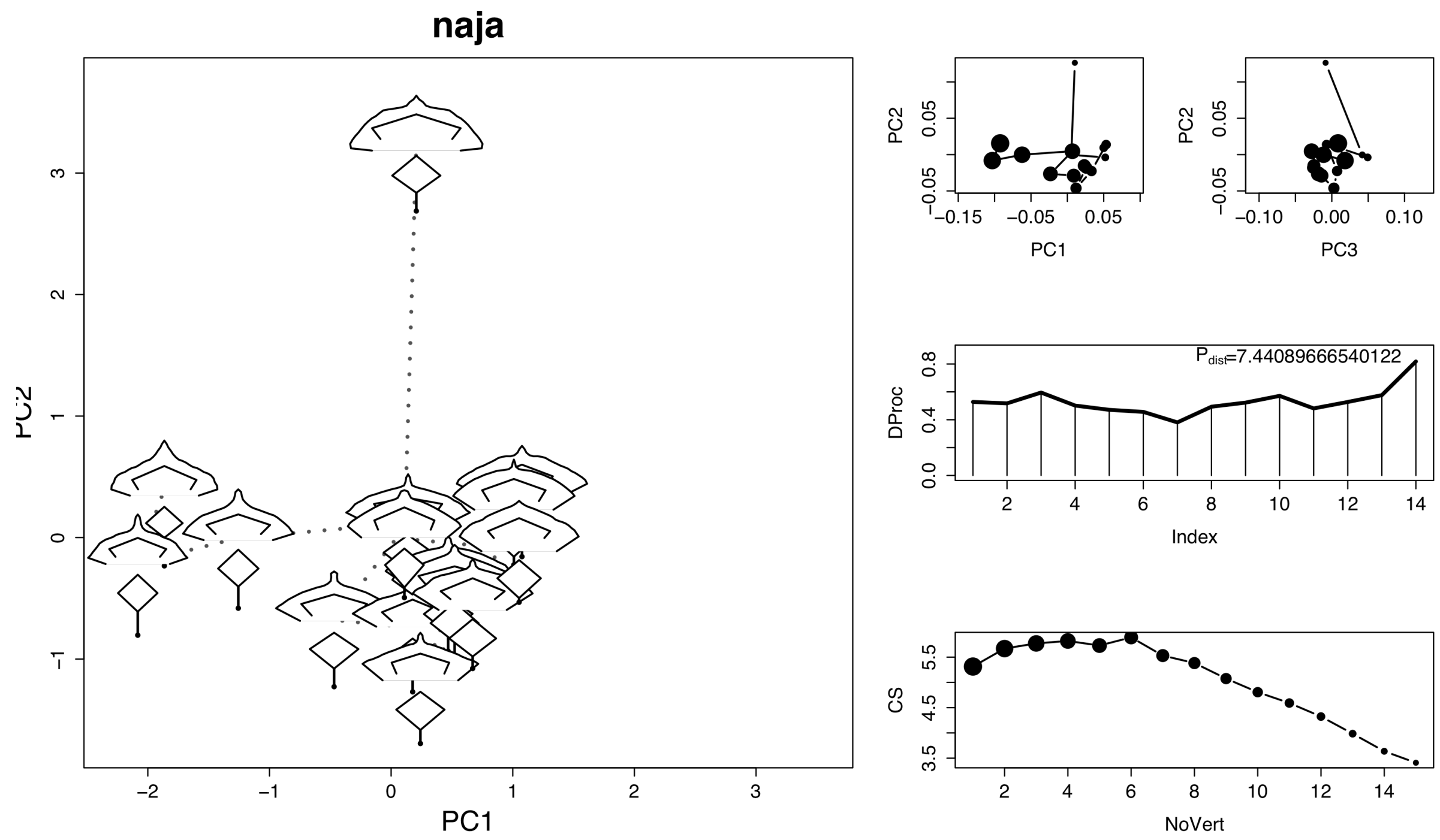

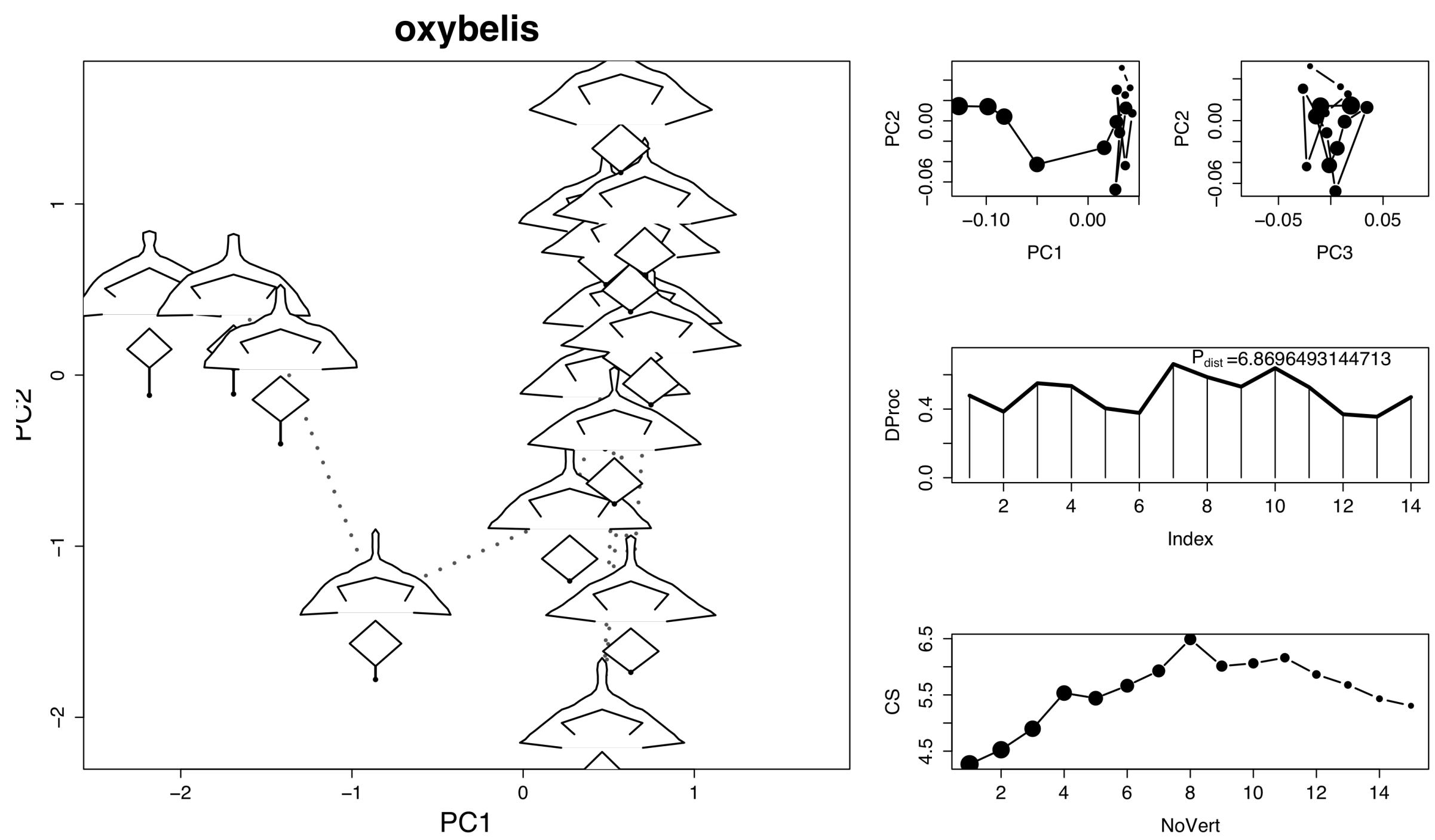

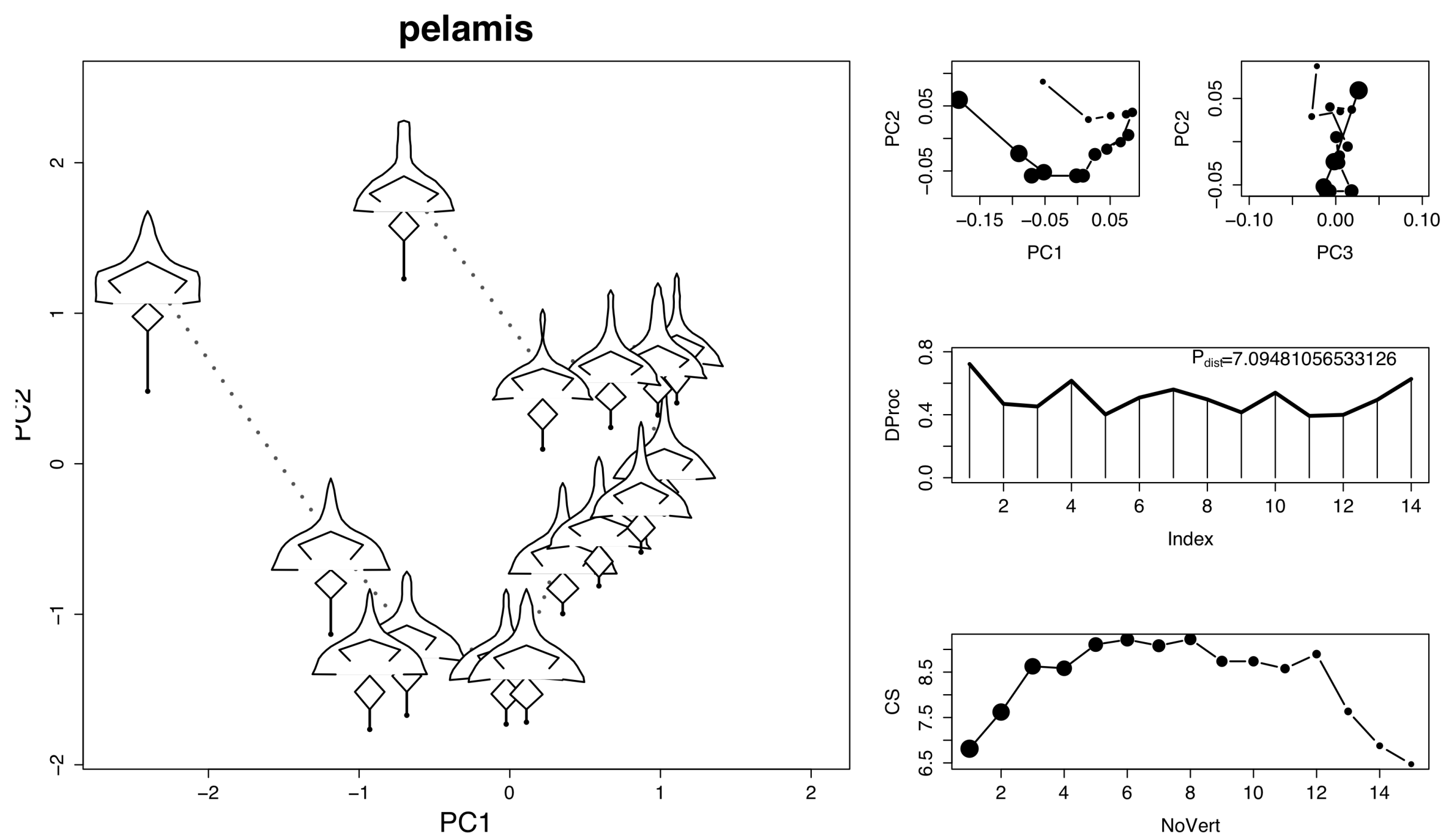

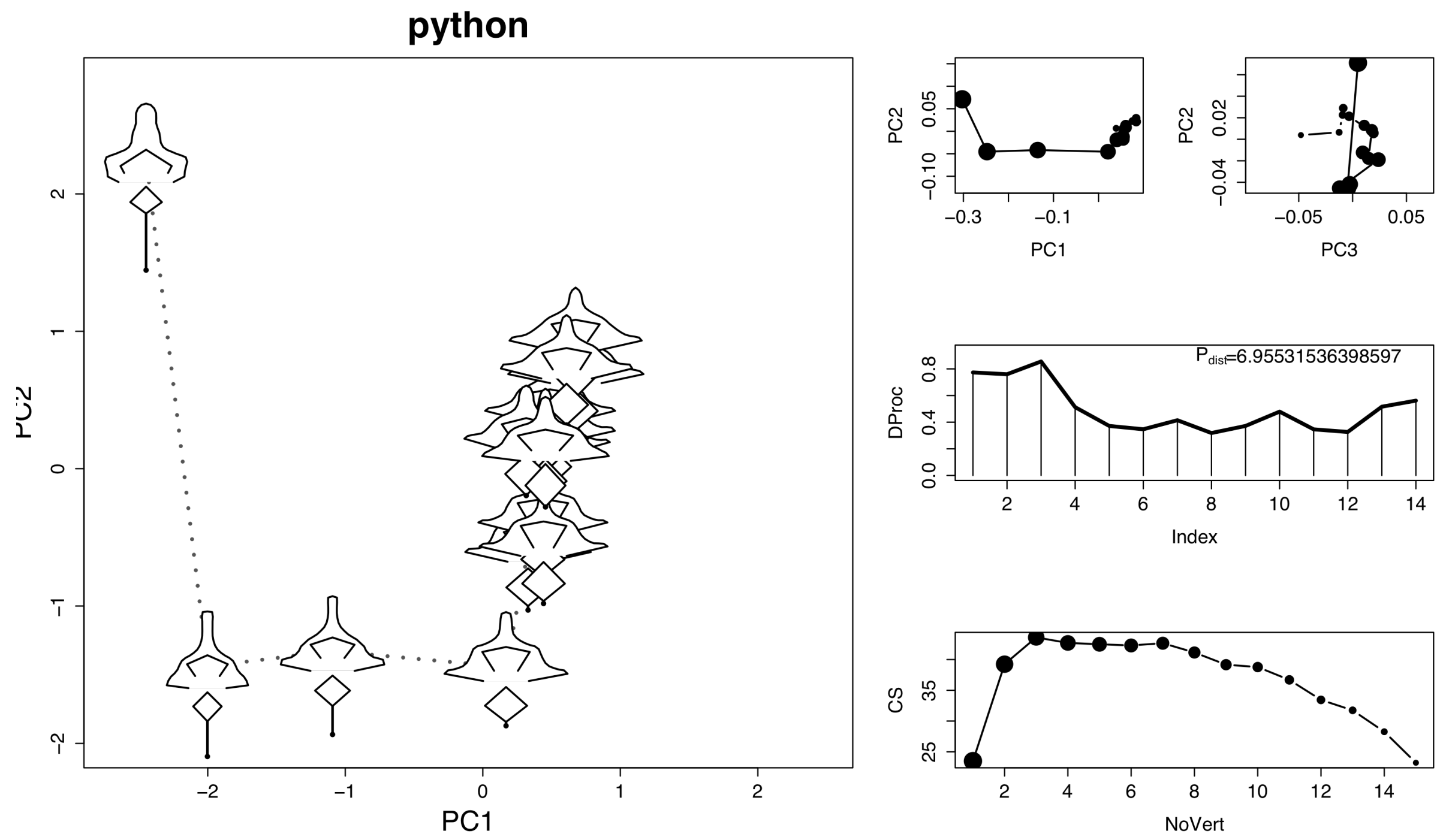

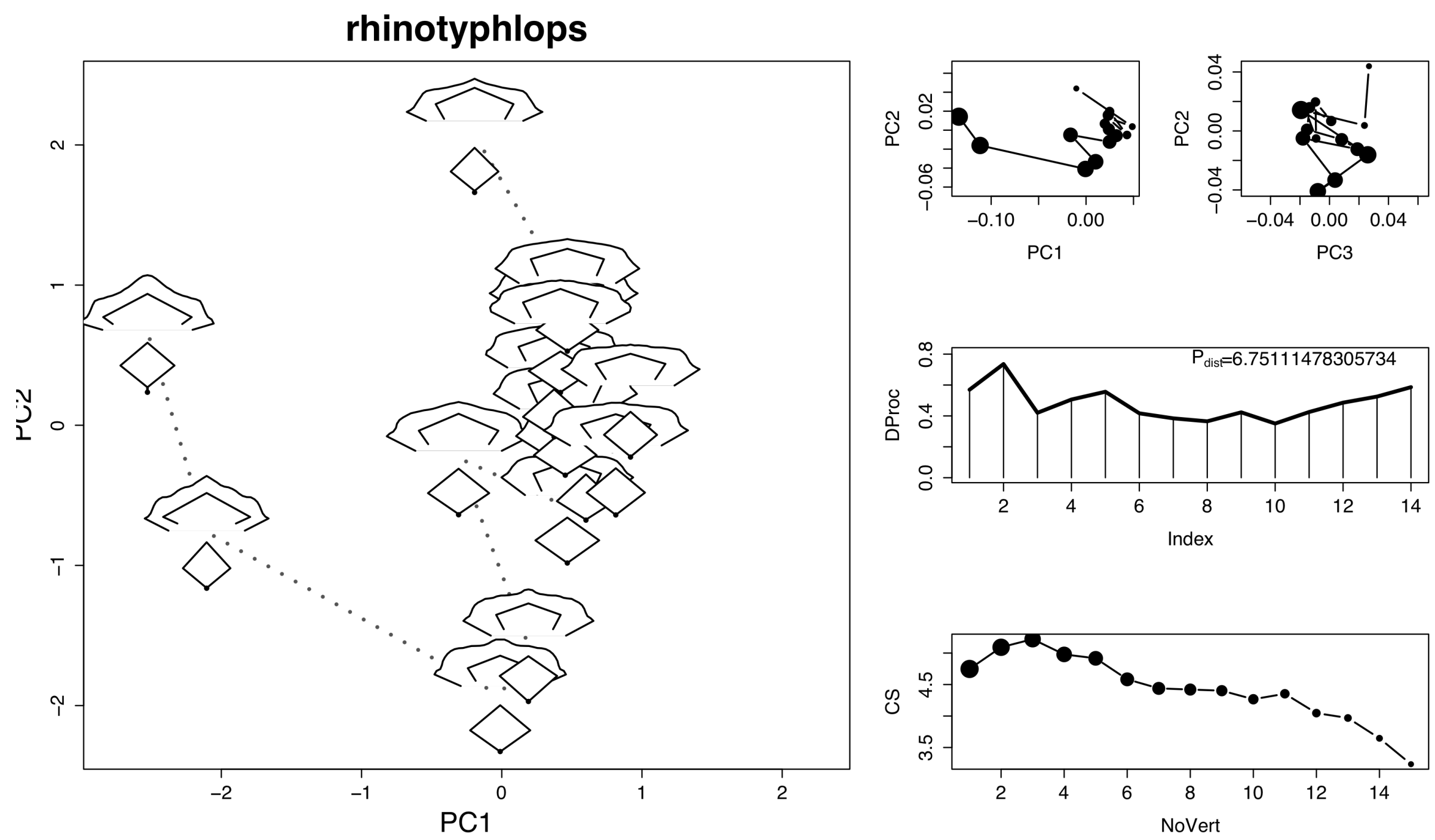

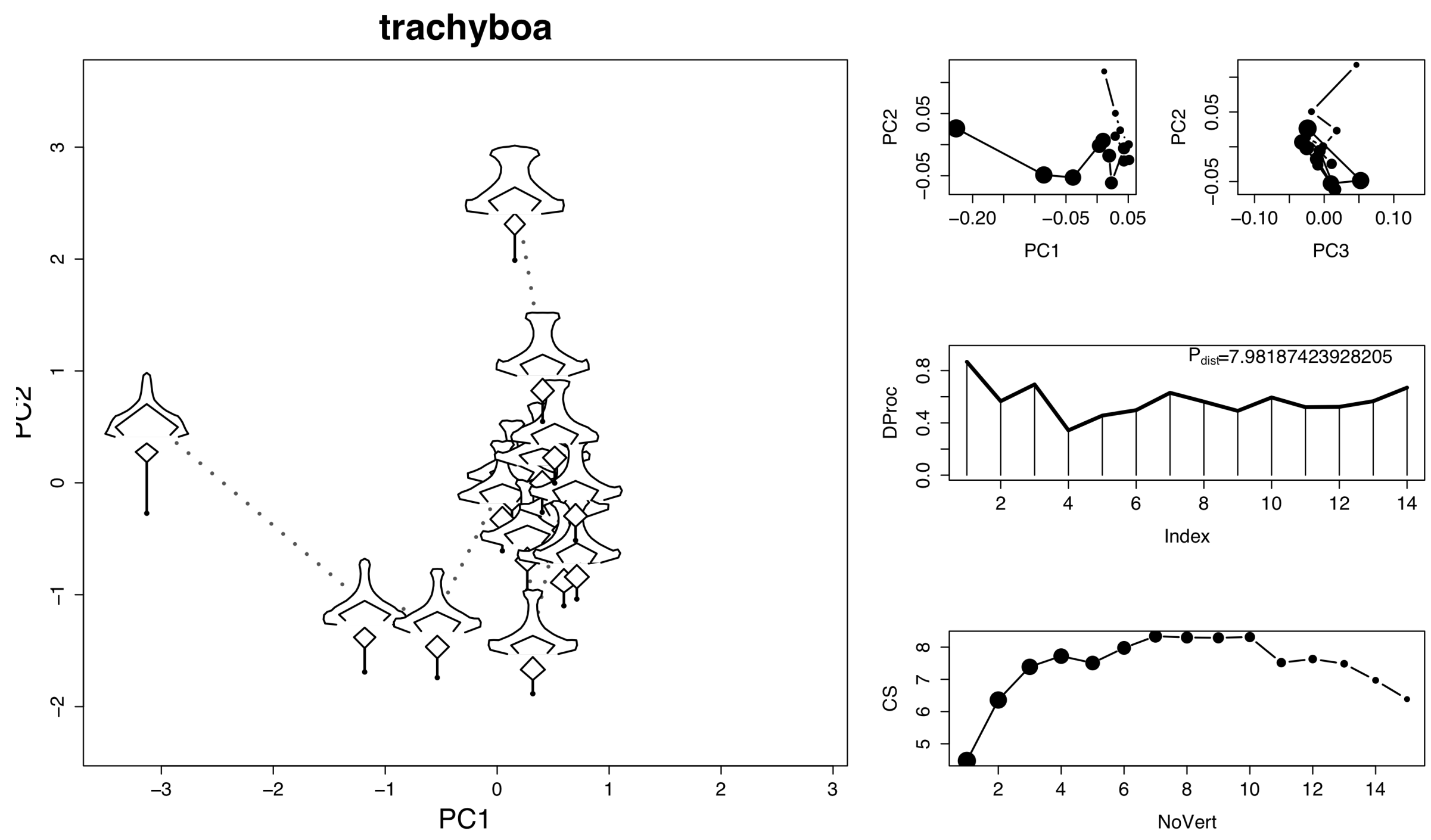

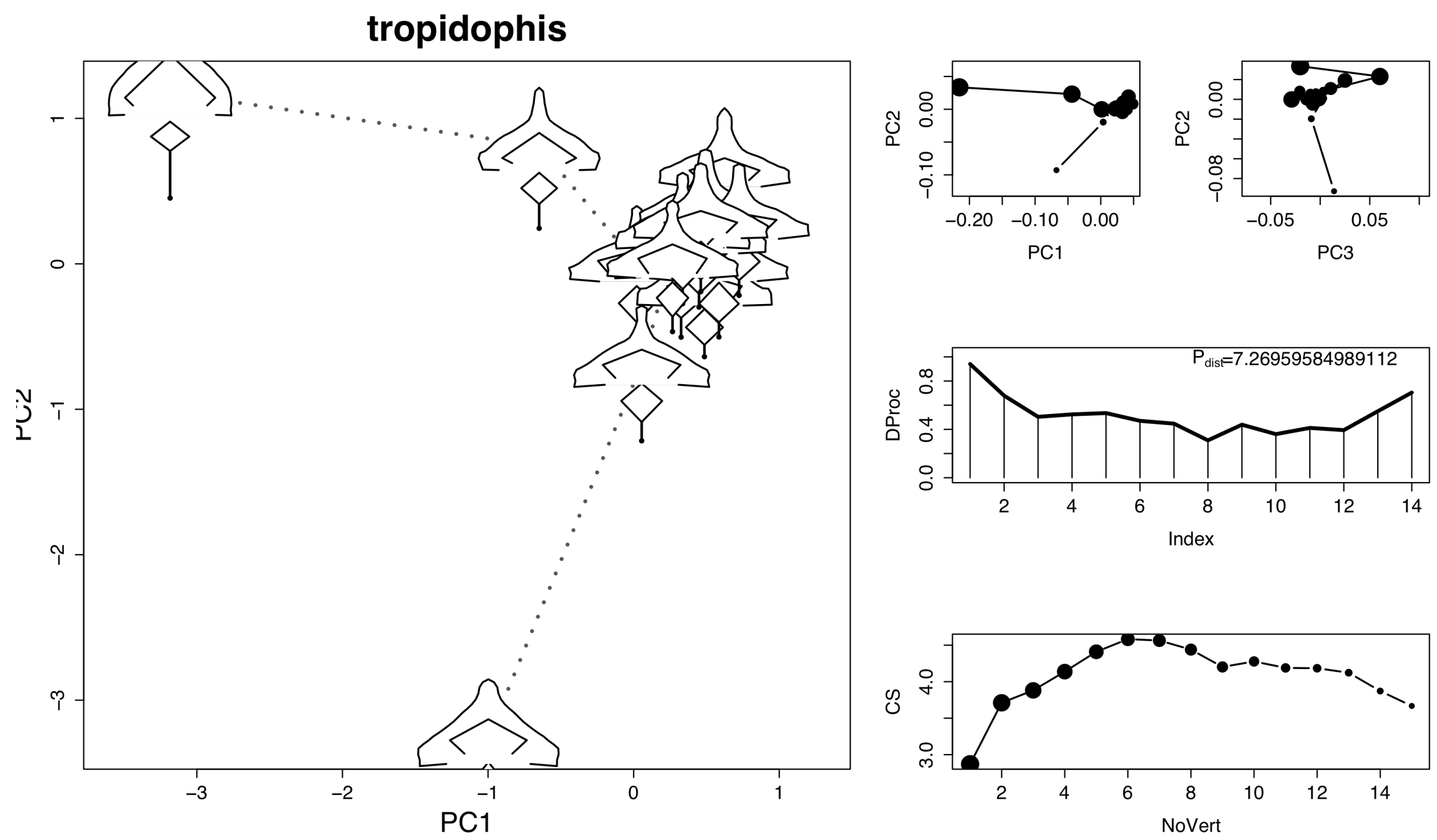

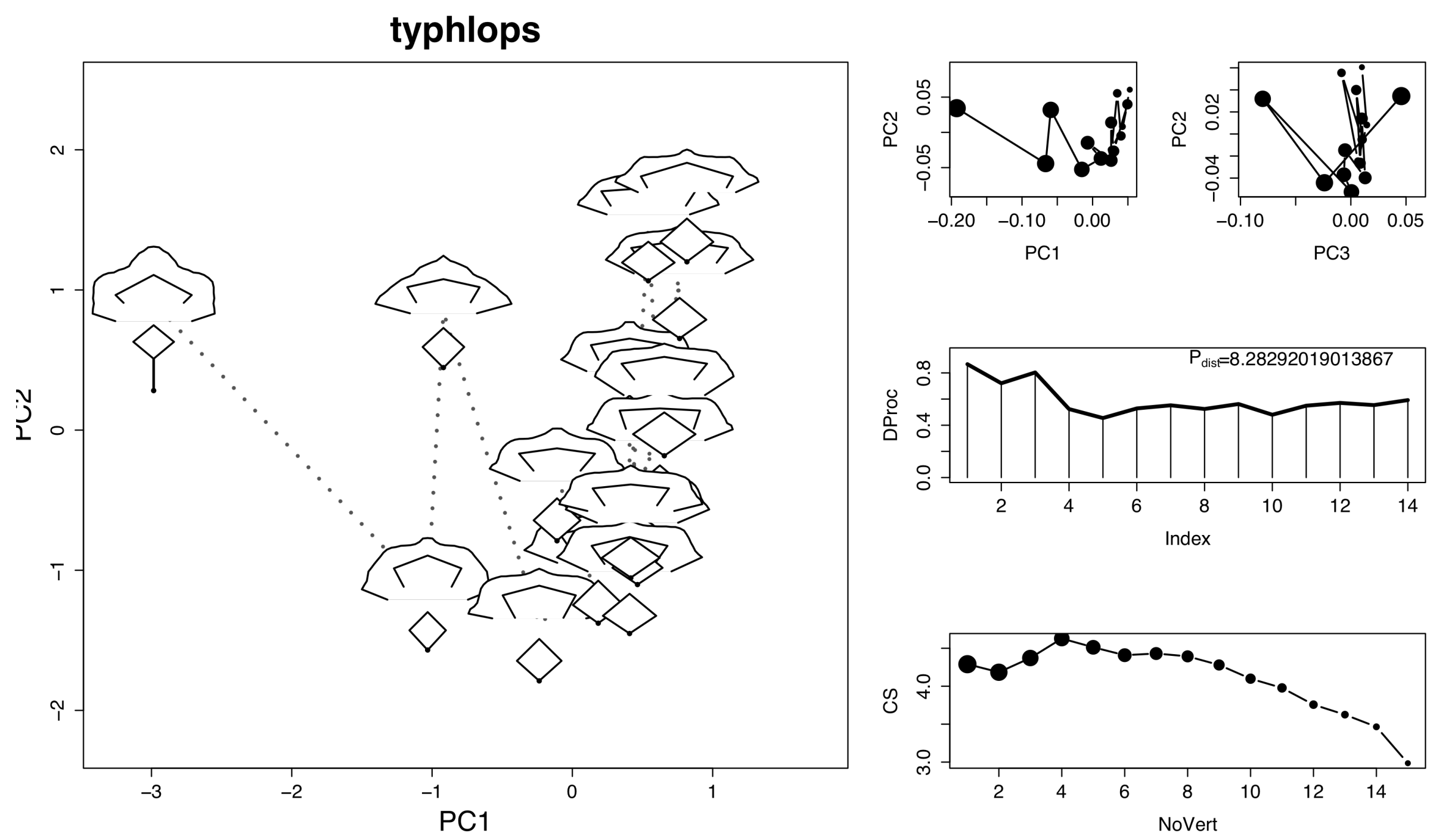

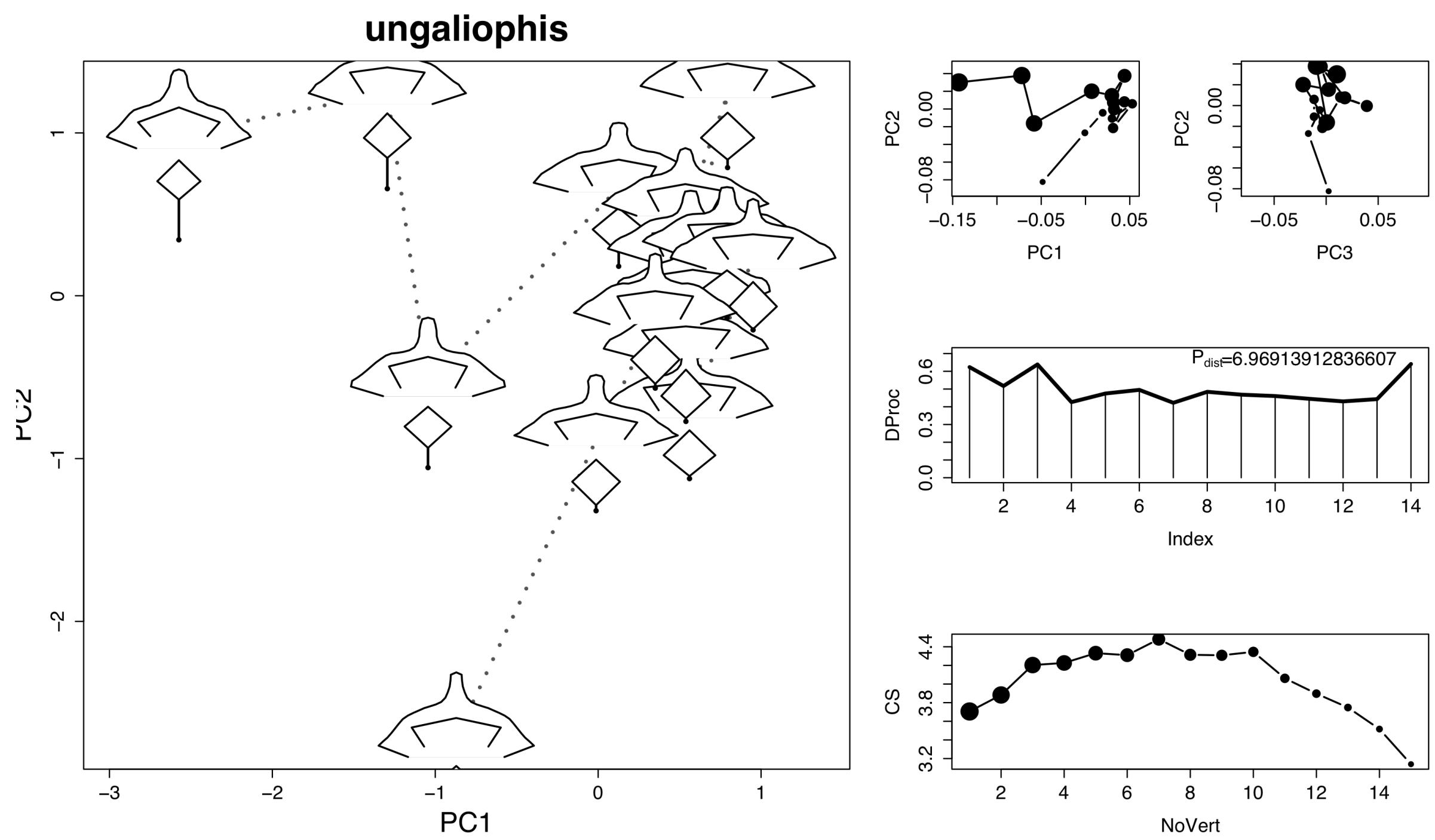

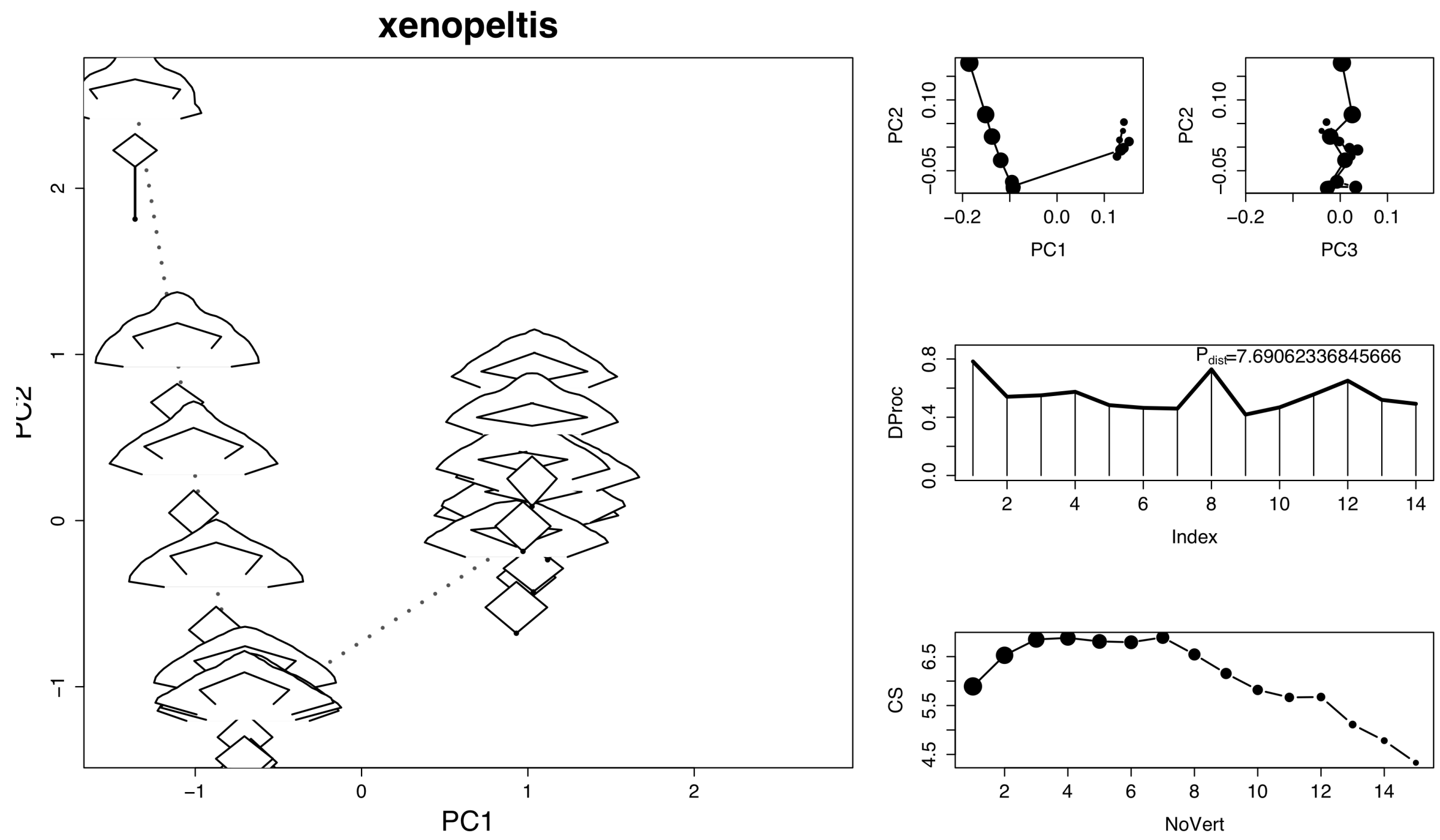

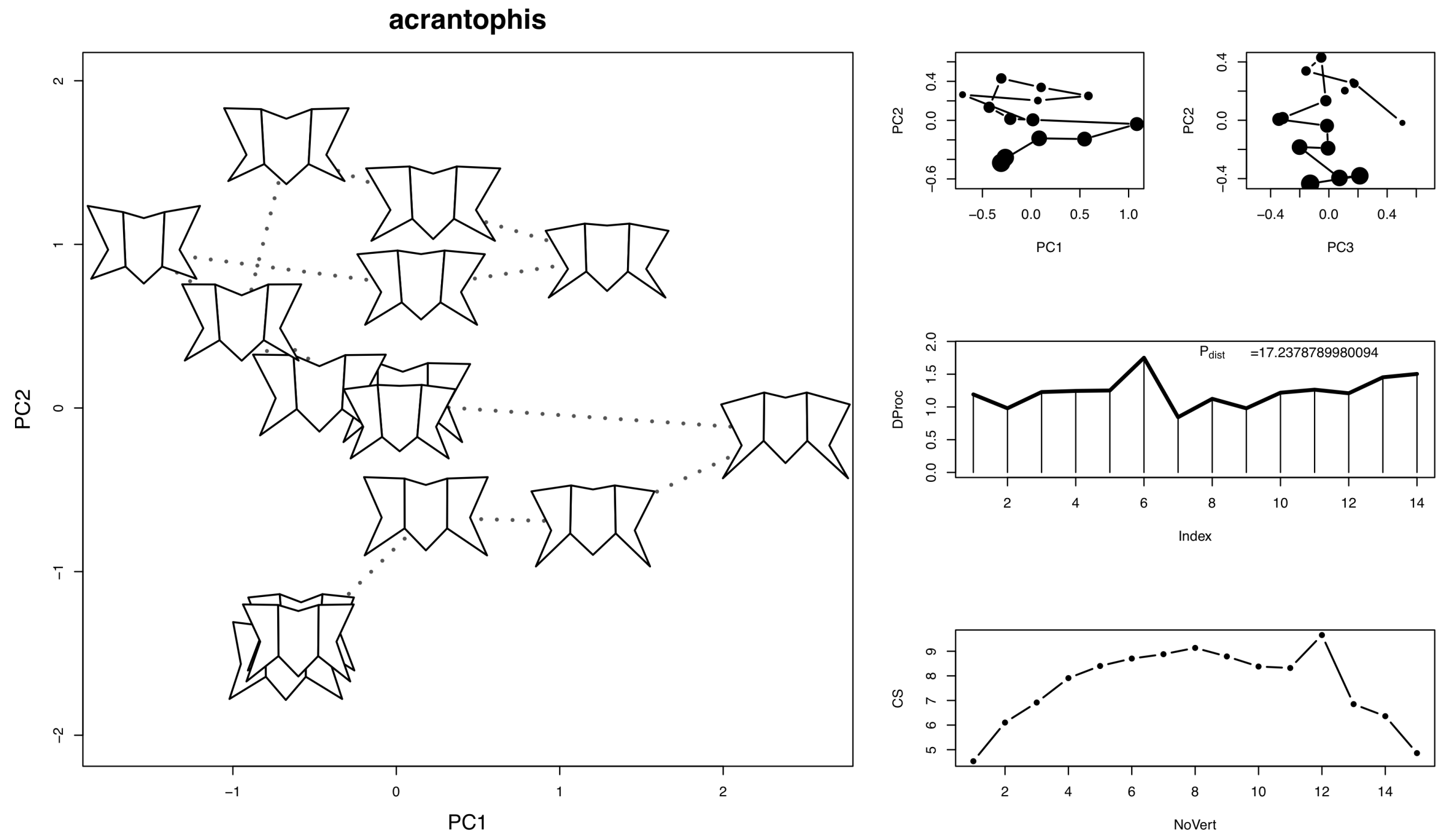

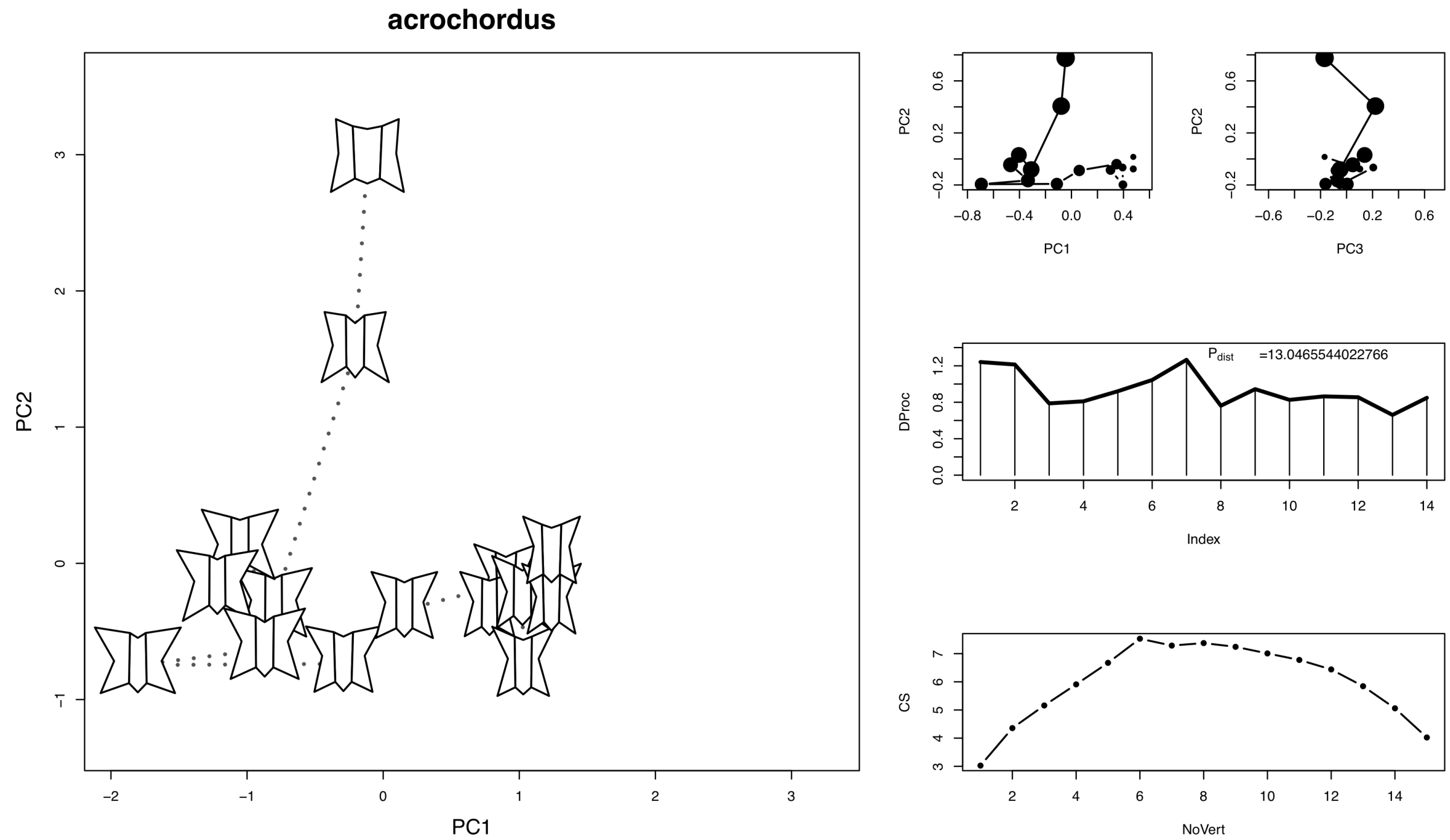
anilius

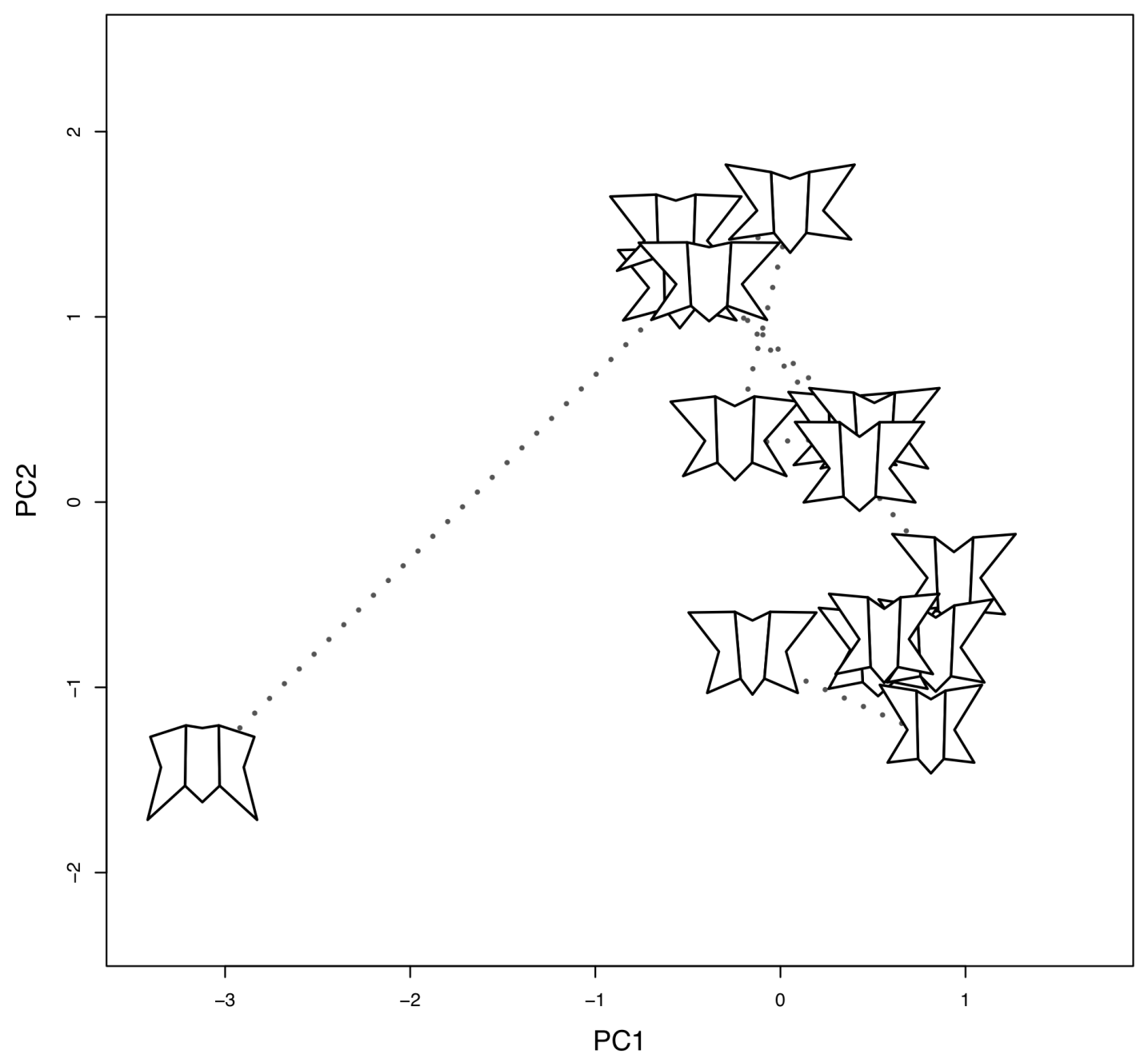

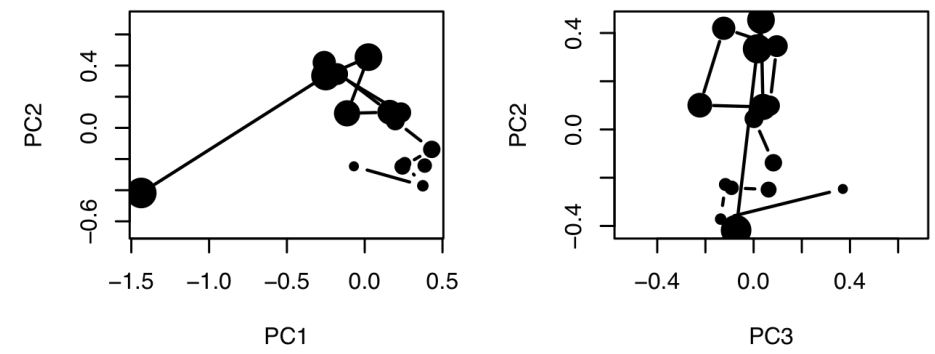
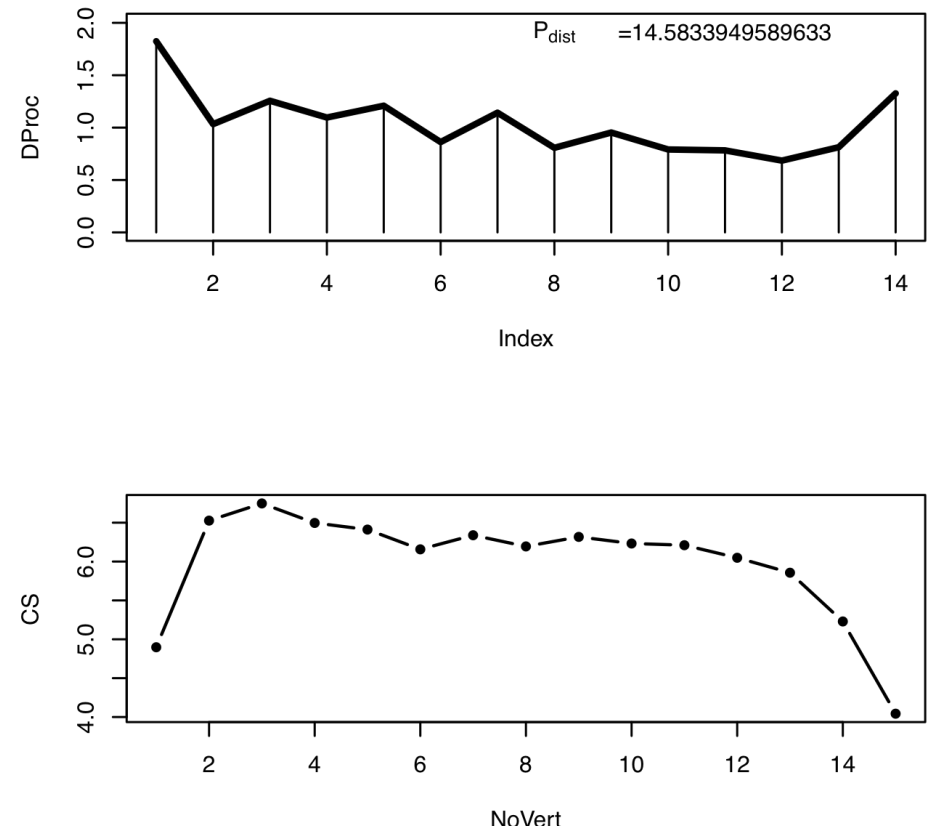

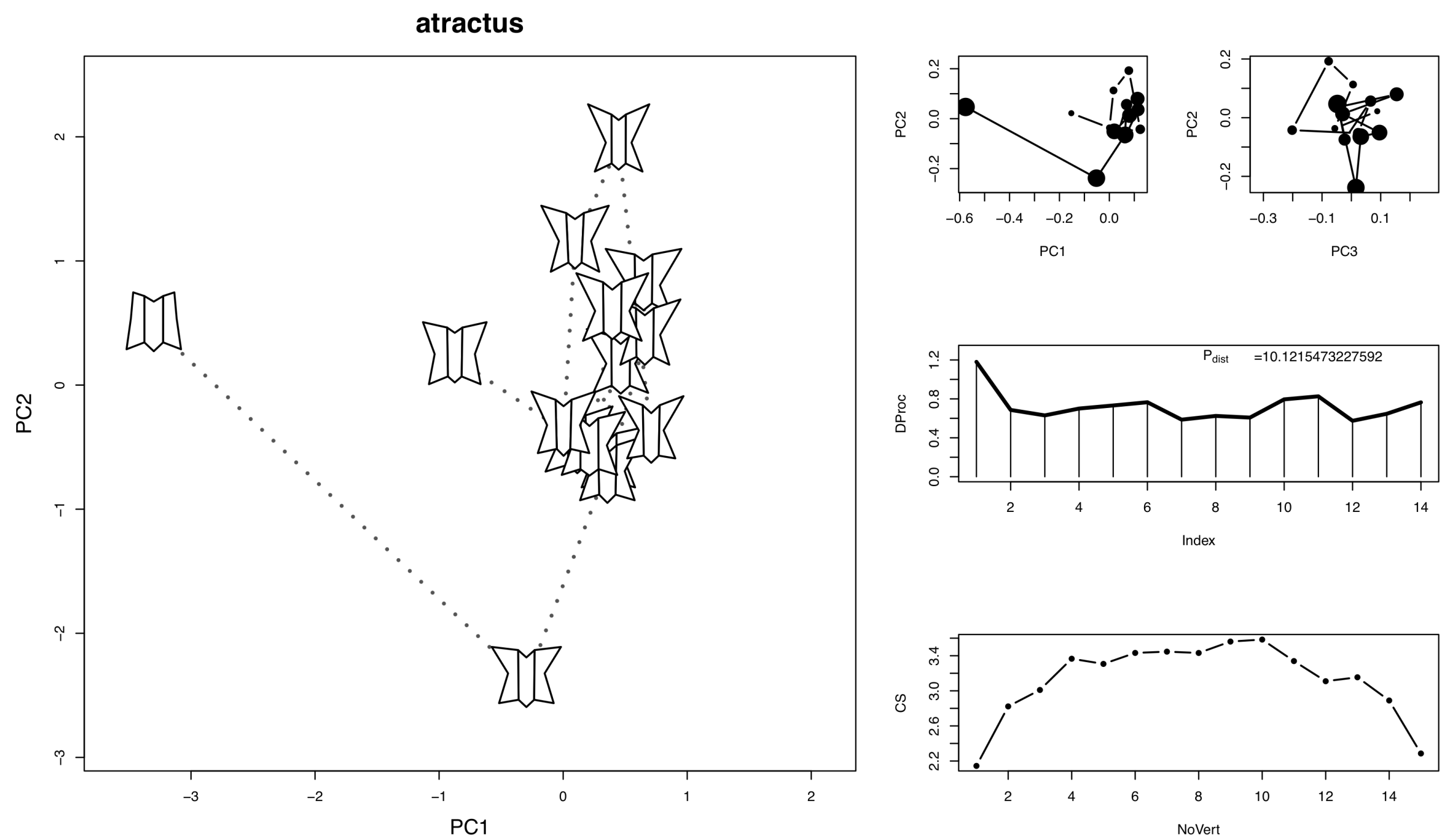

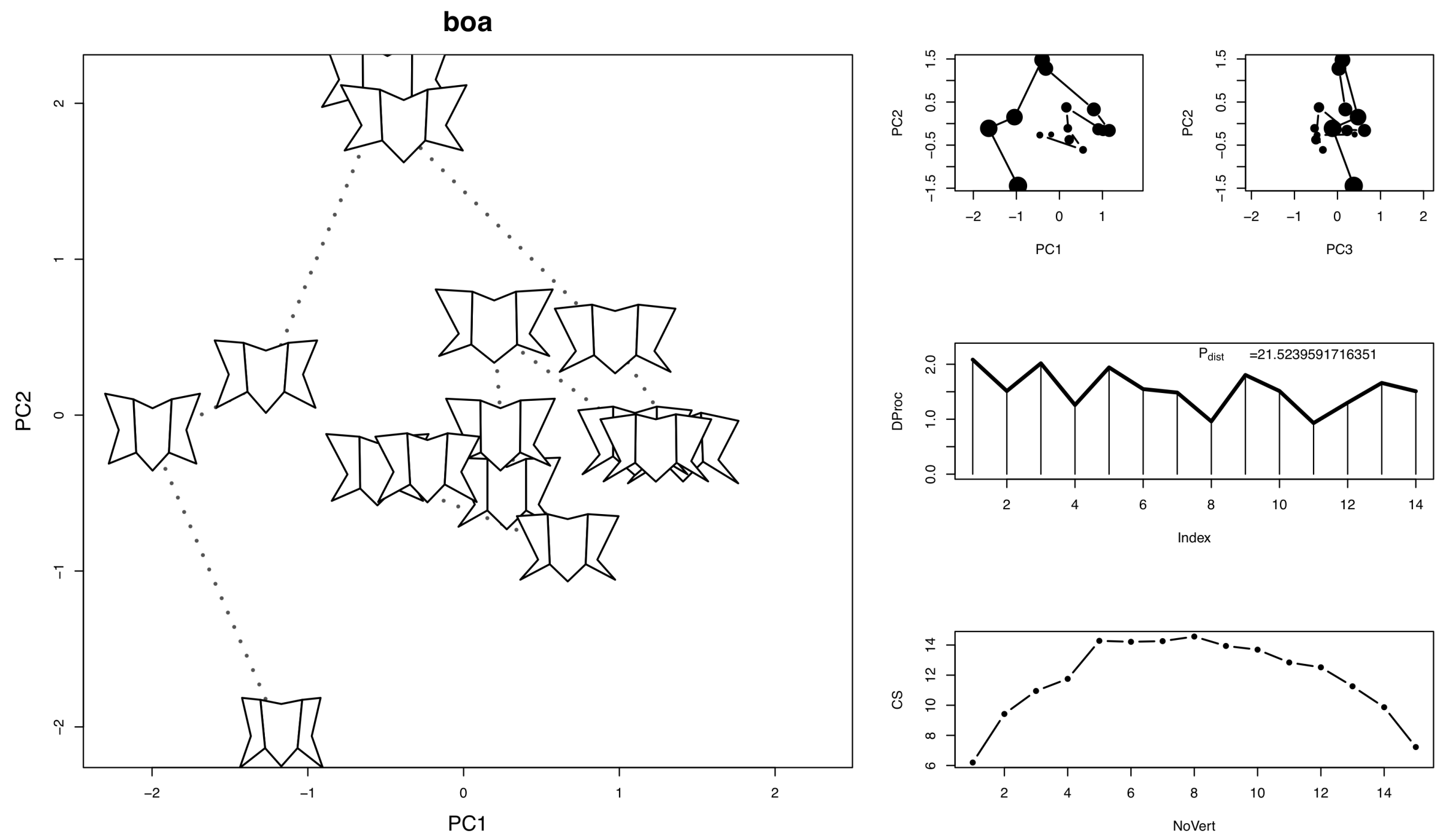


\section{bothriopsis}
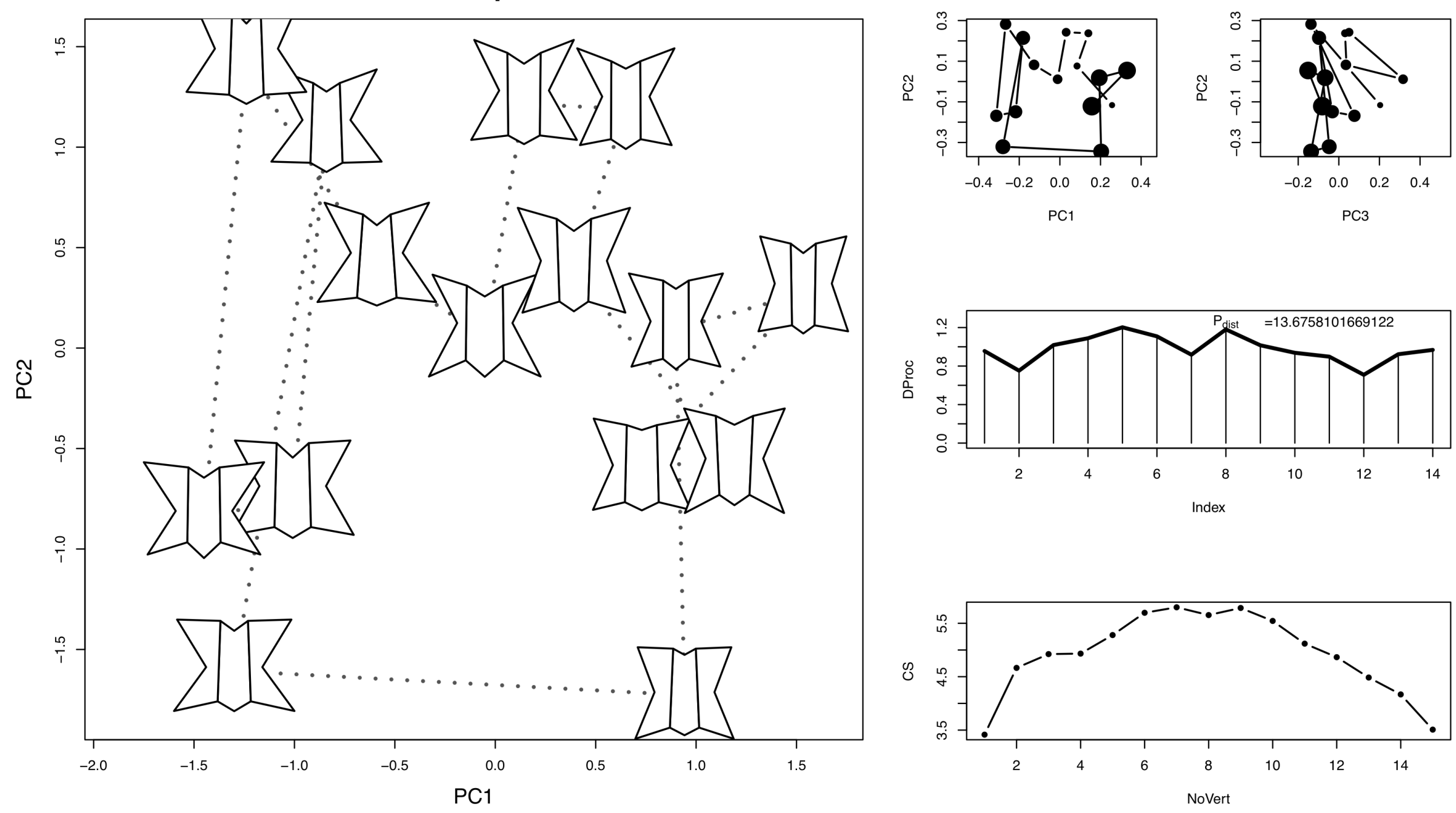


\section{bothrops}
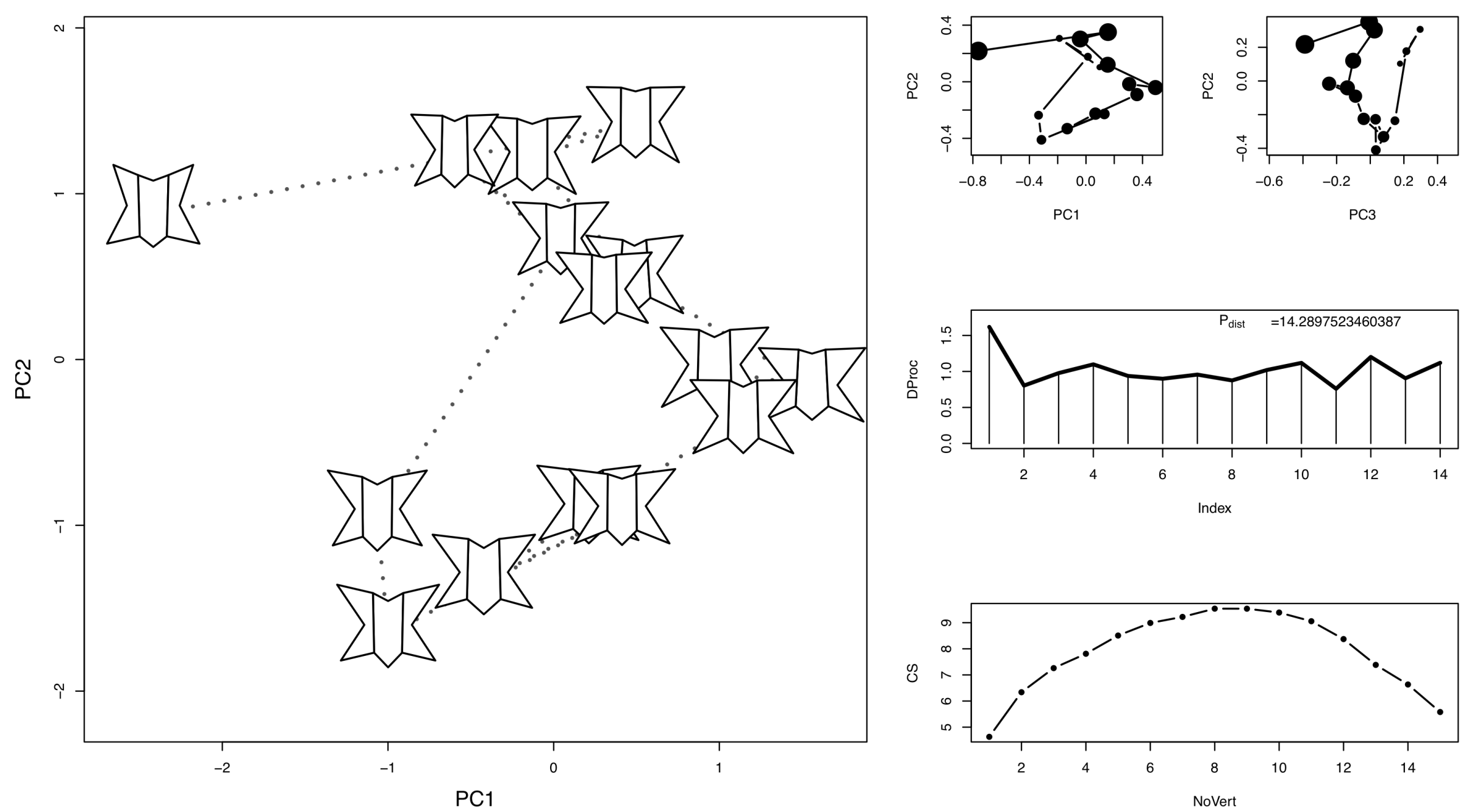

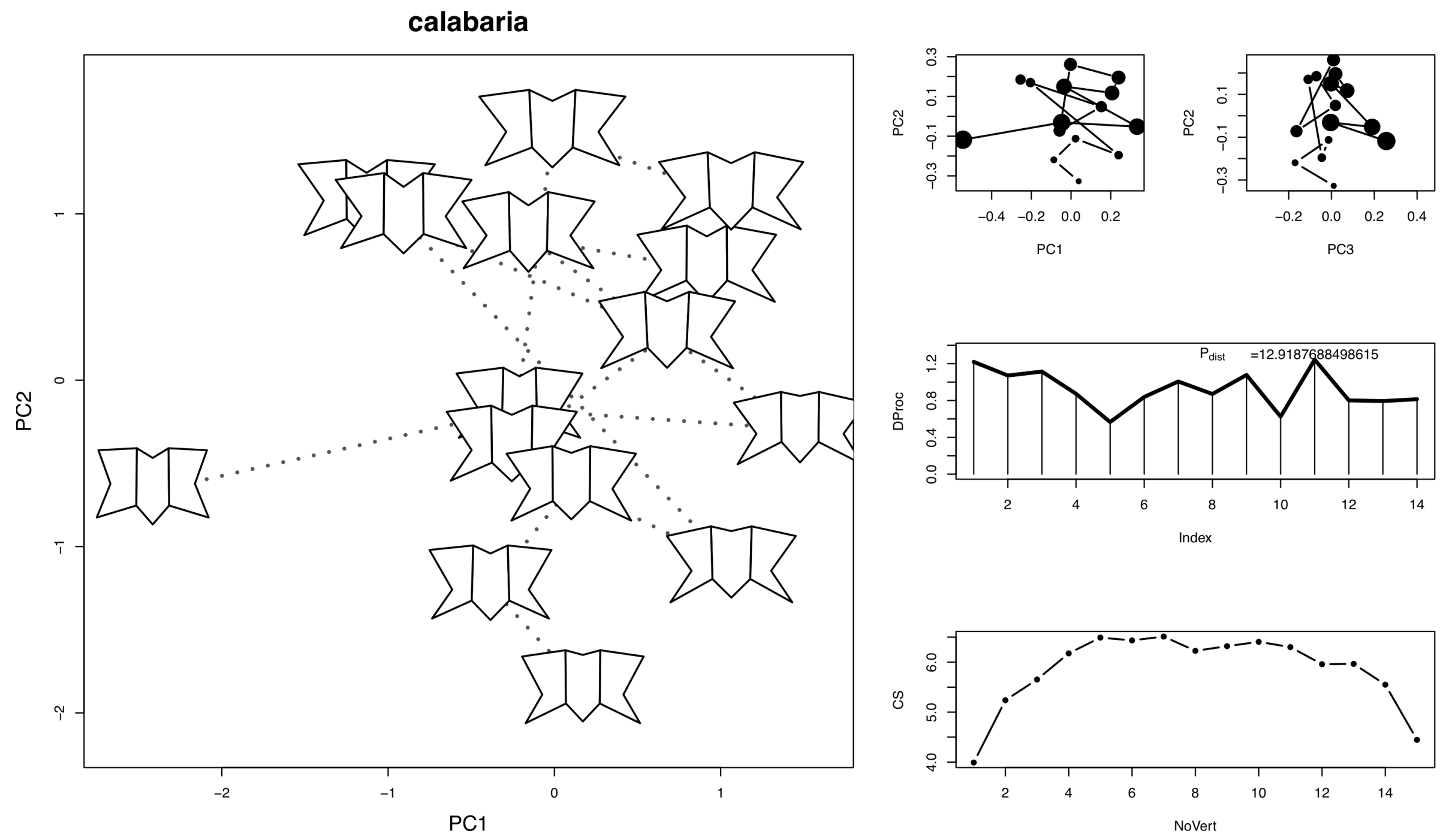

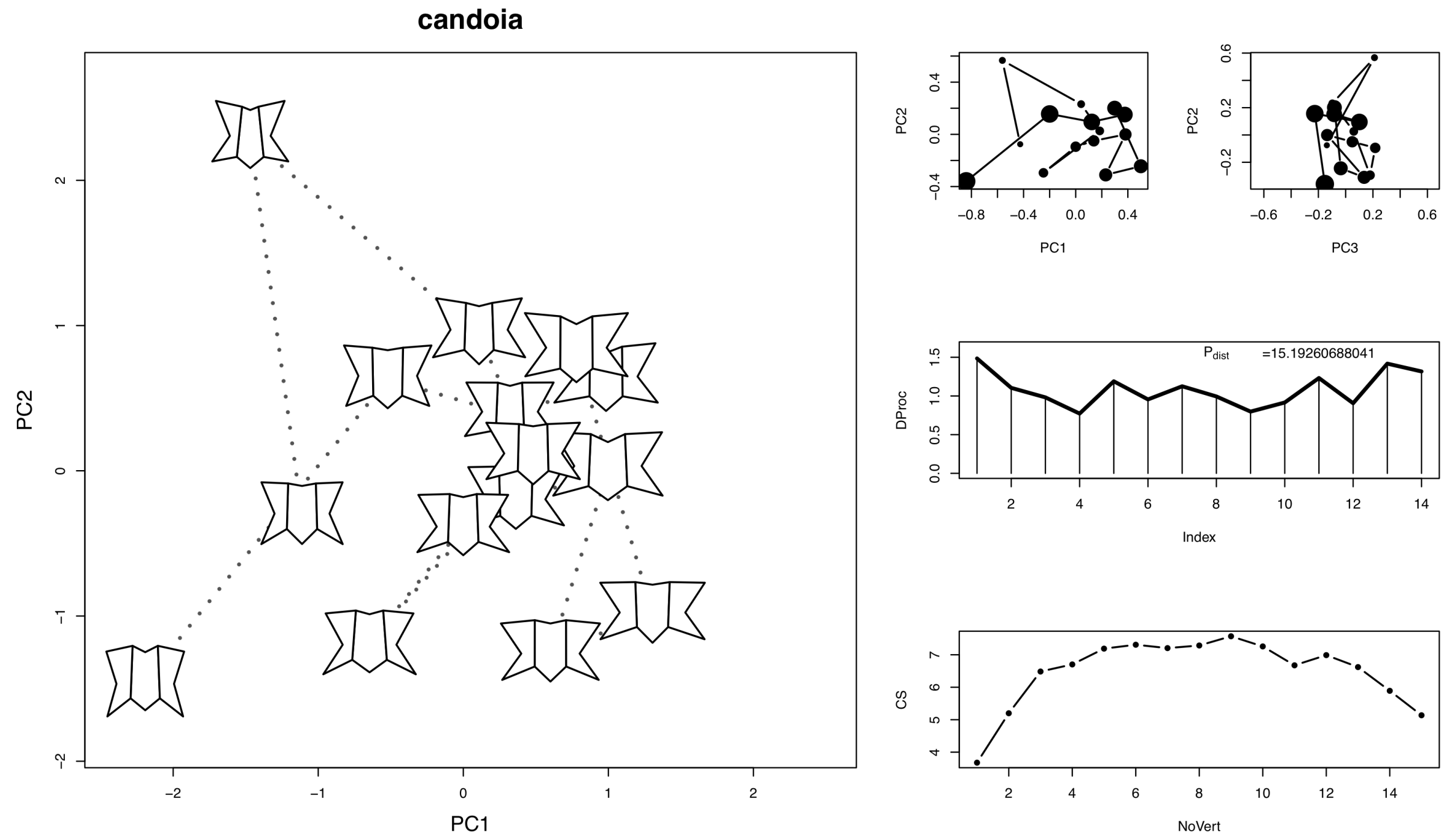

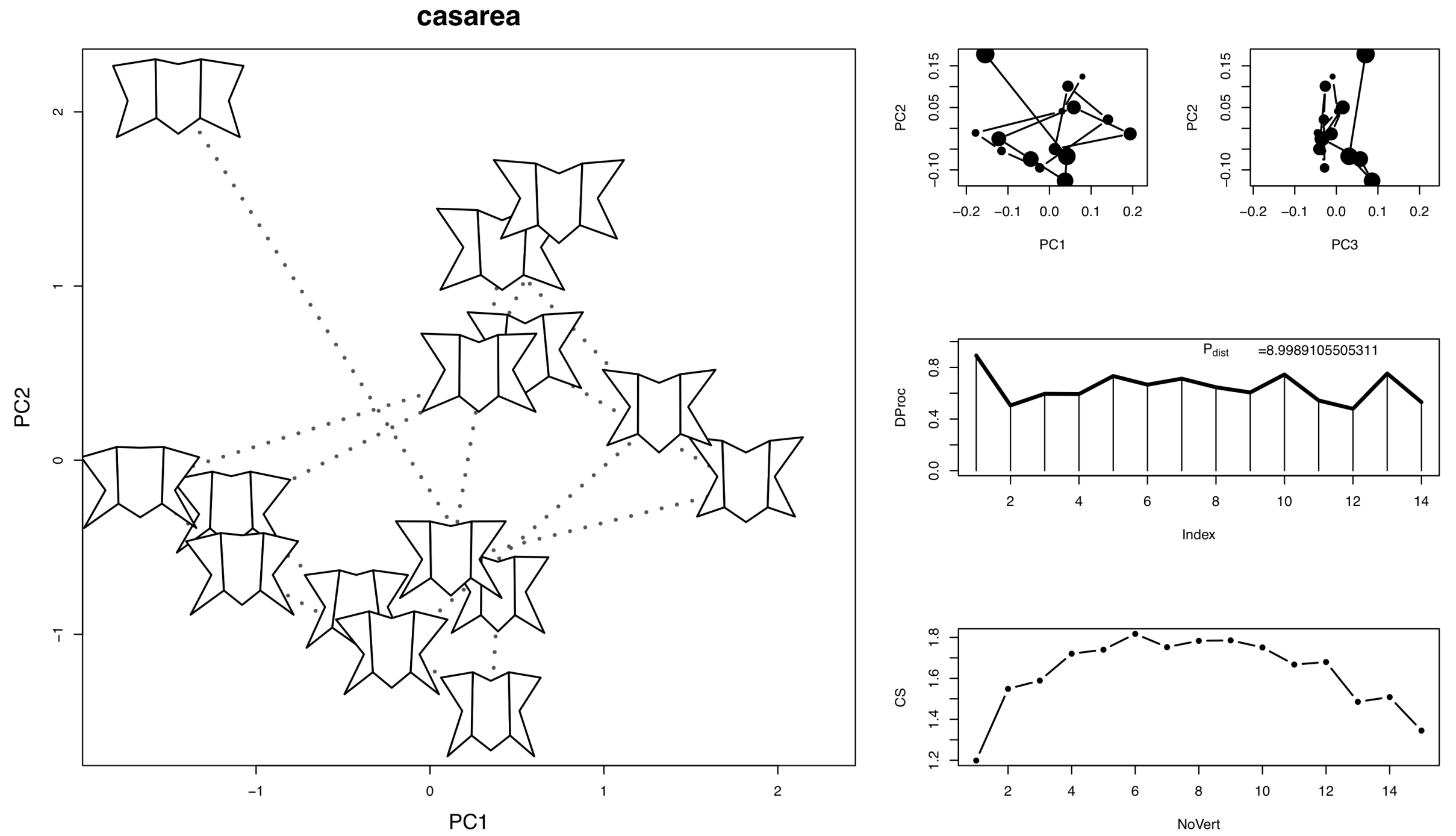

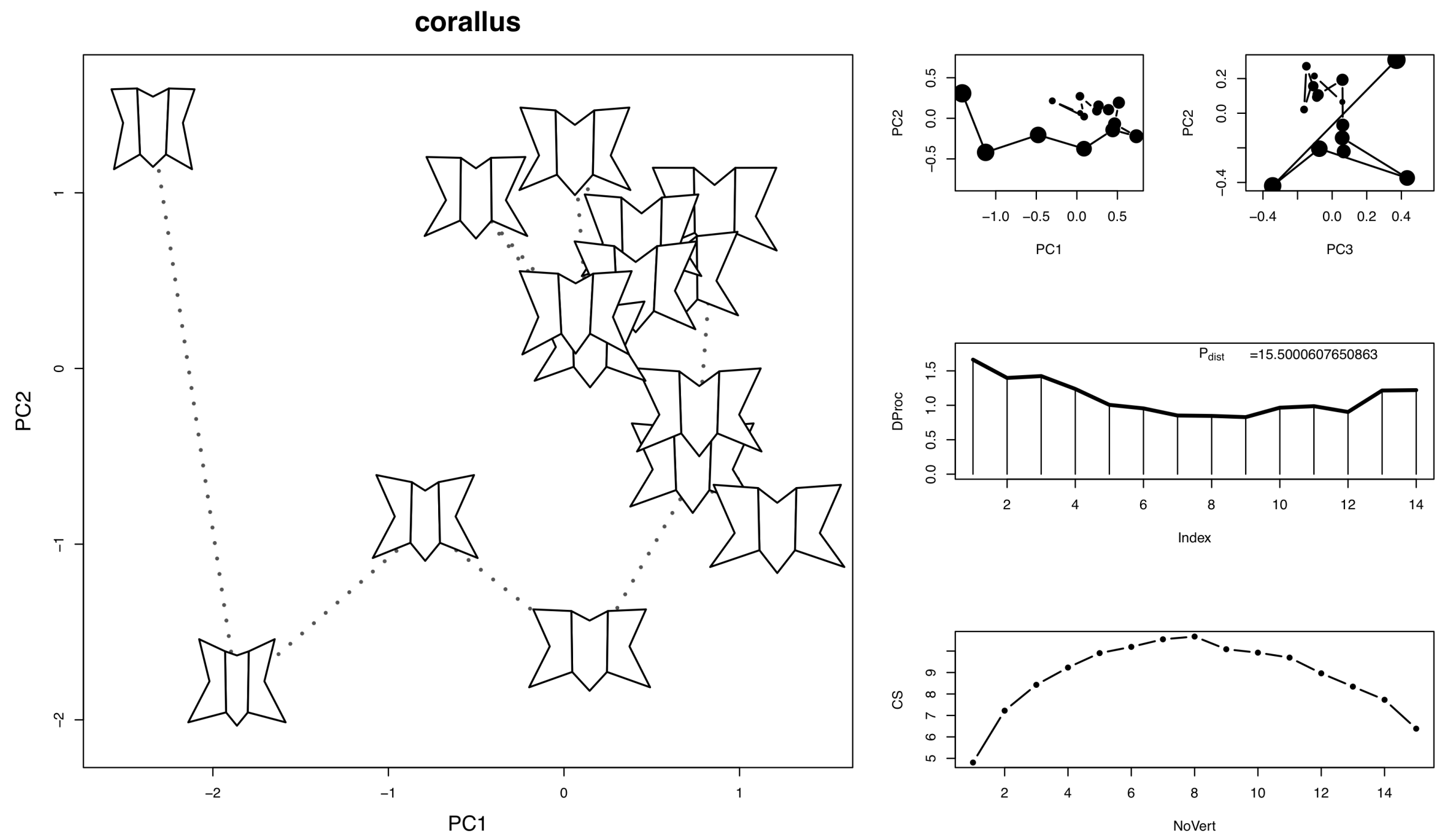


\section{cylindrophis}
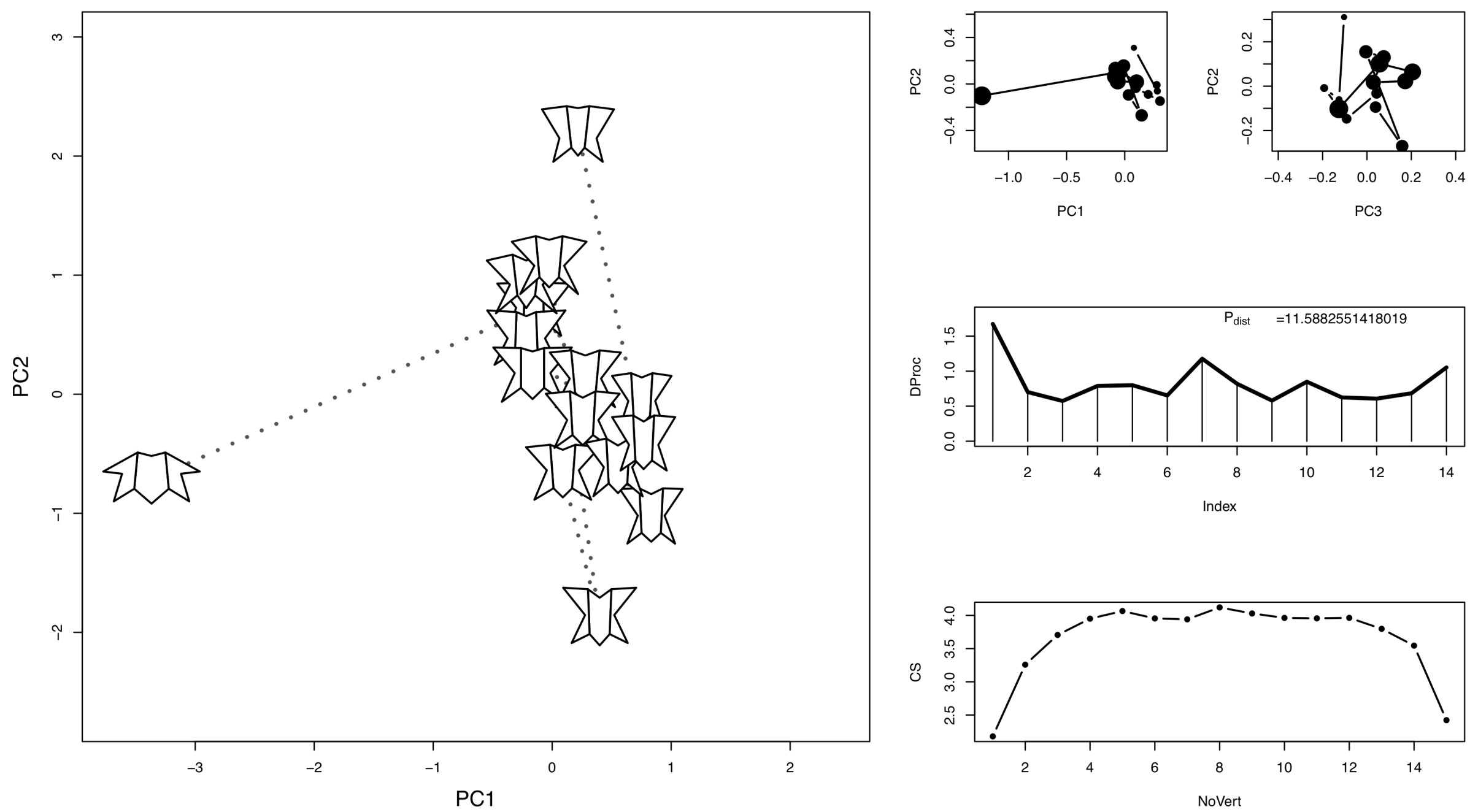

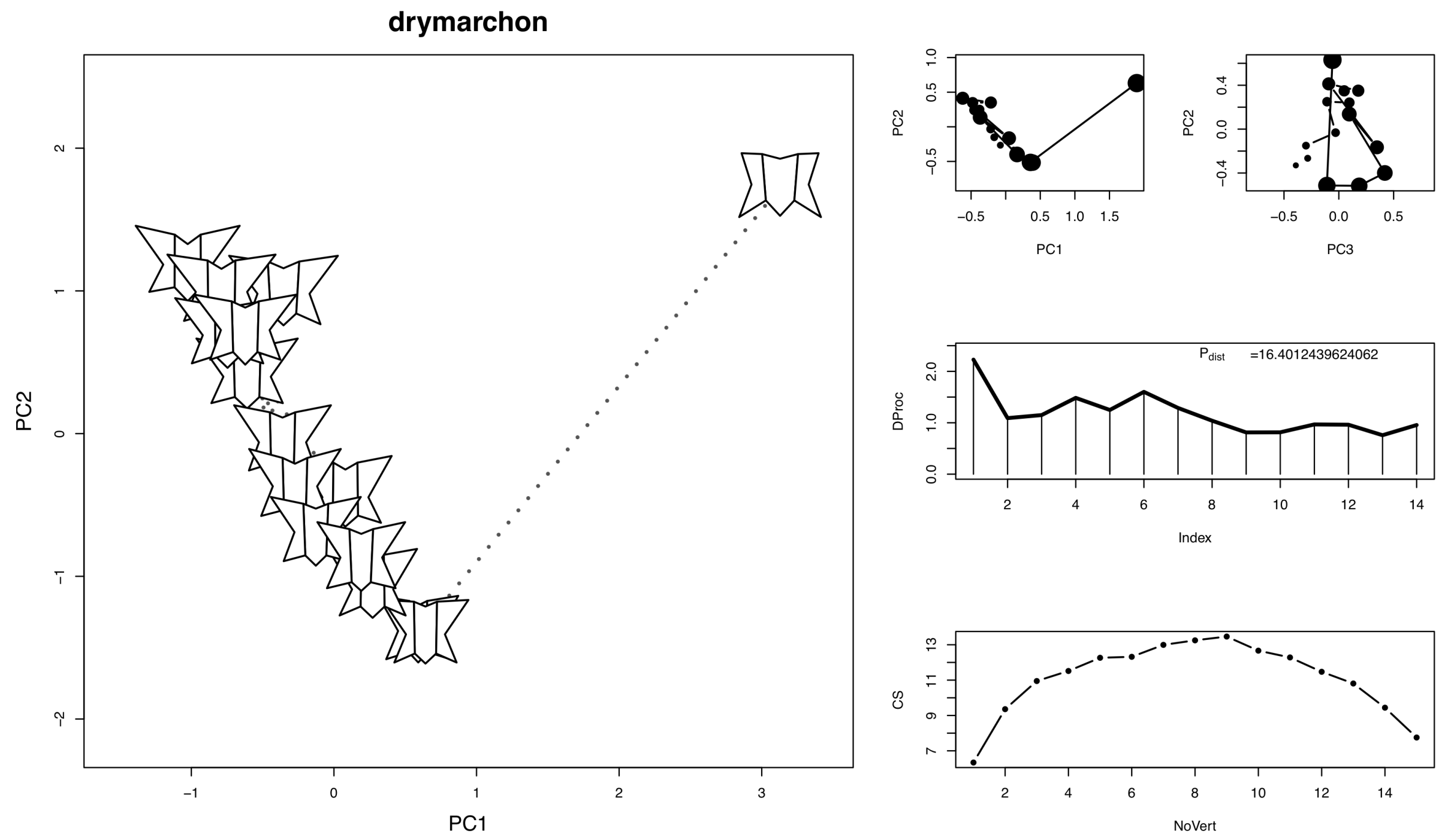

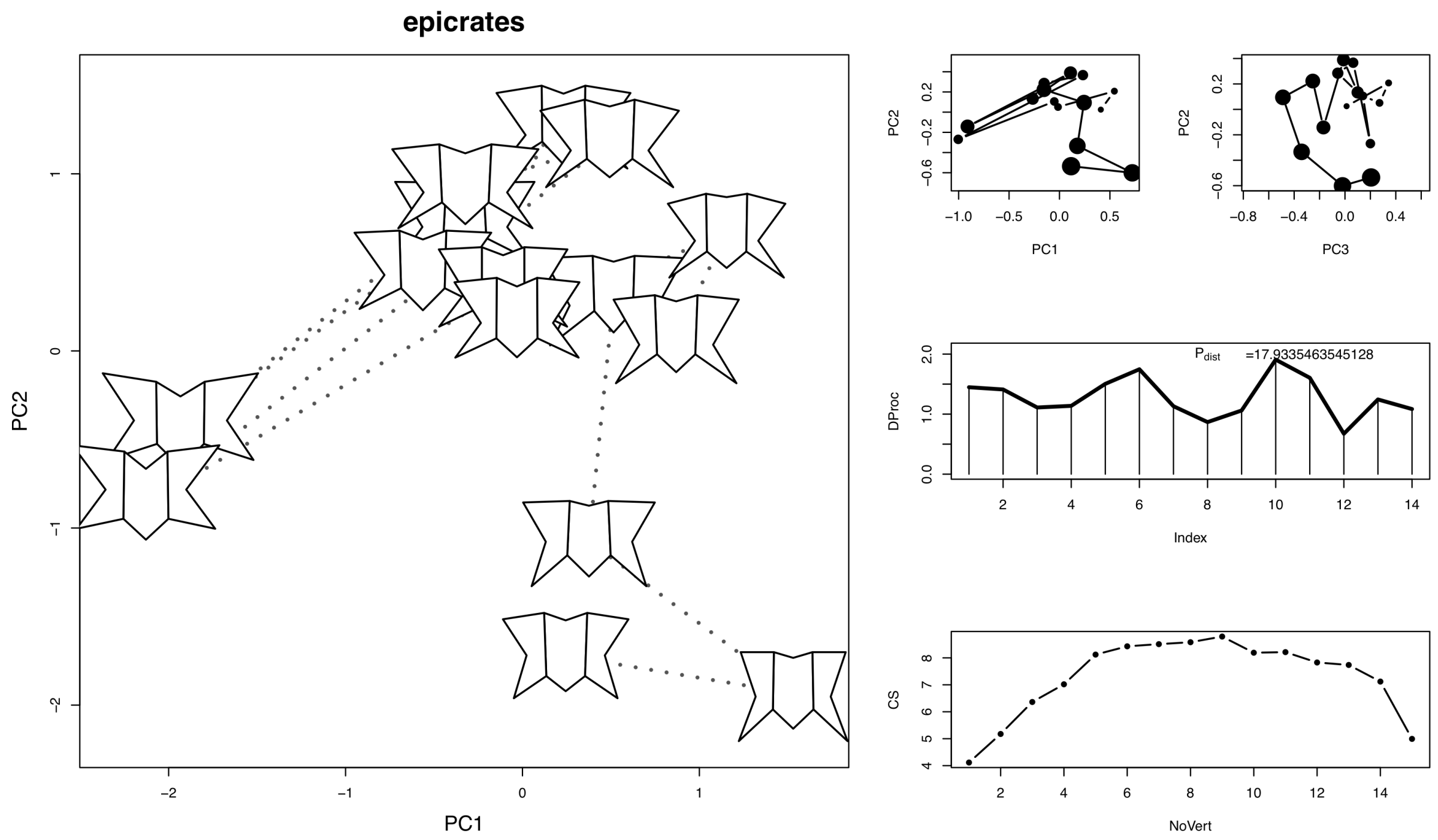
eryx
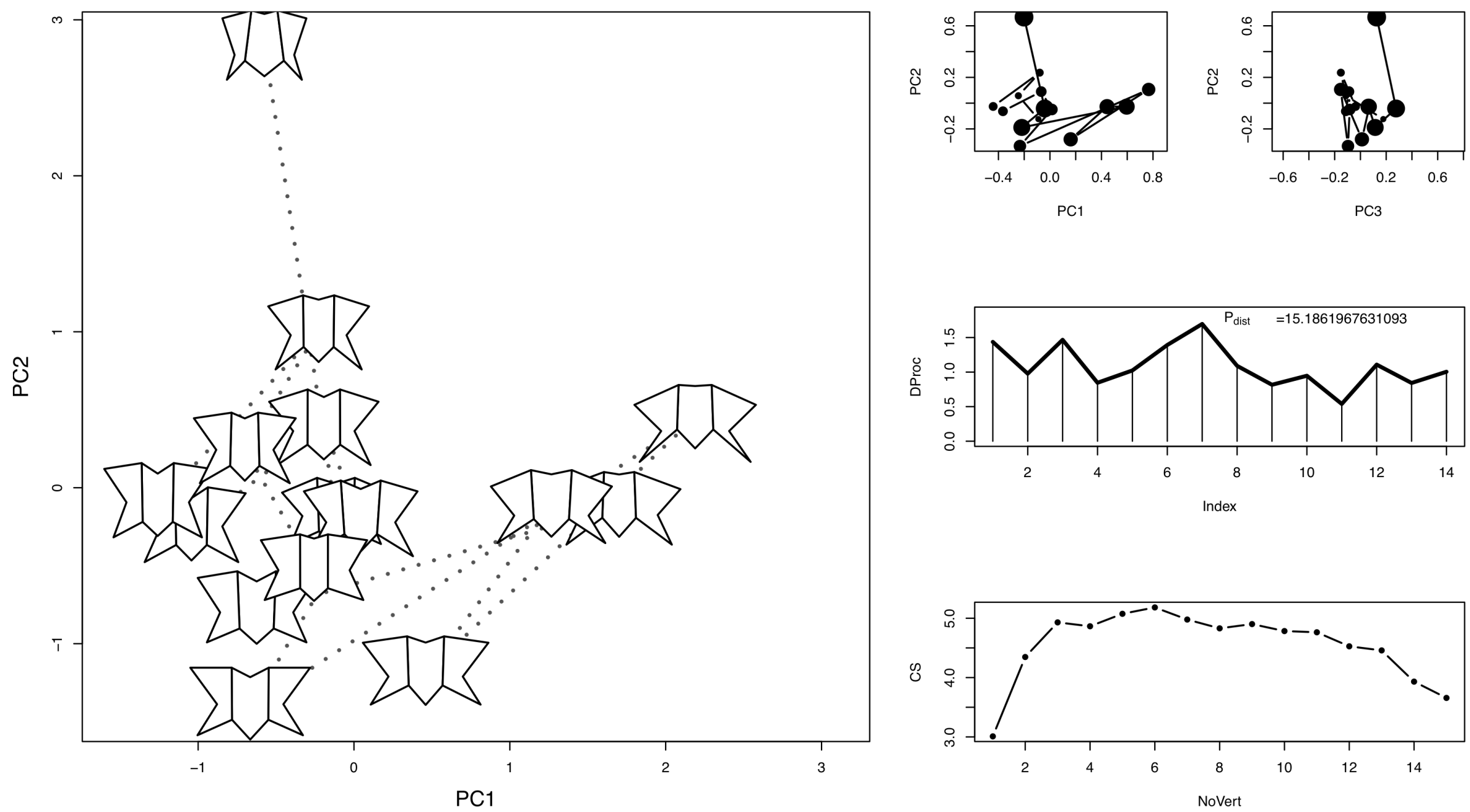

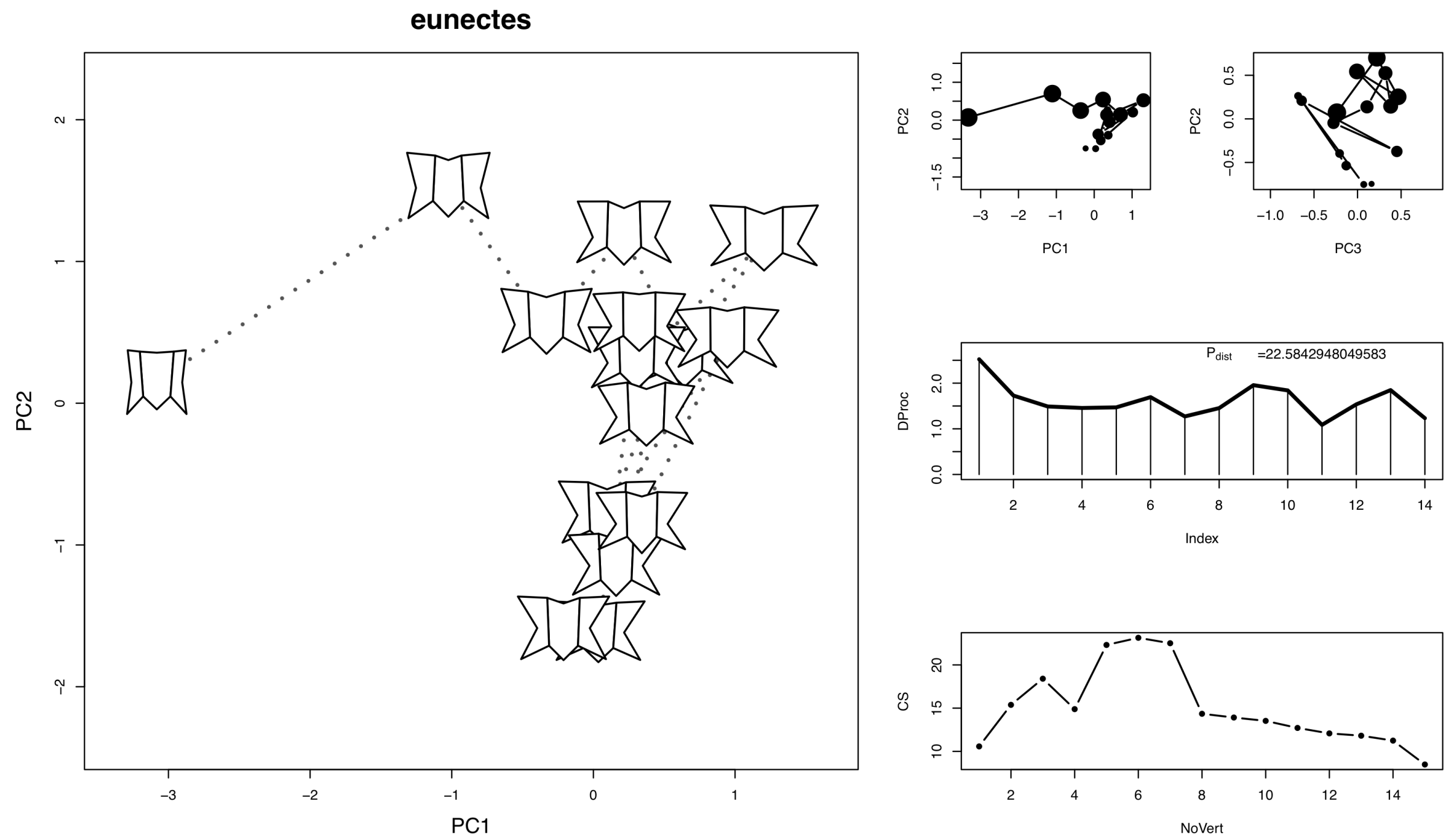

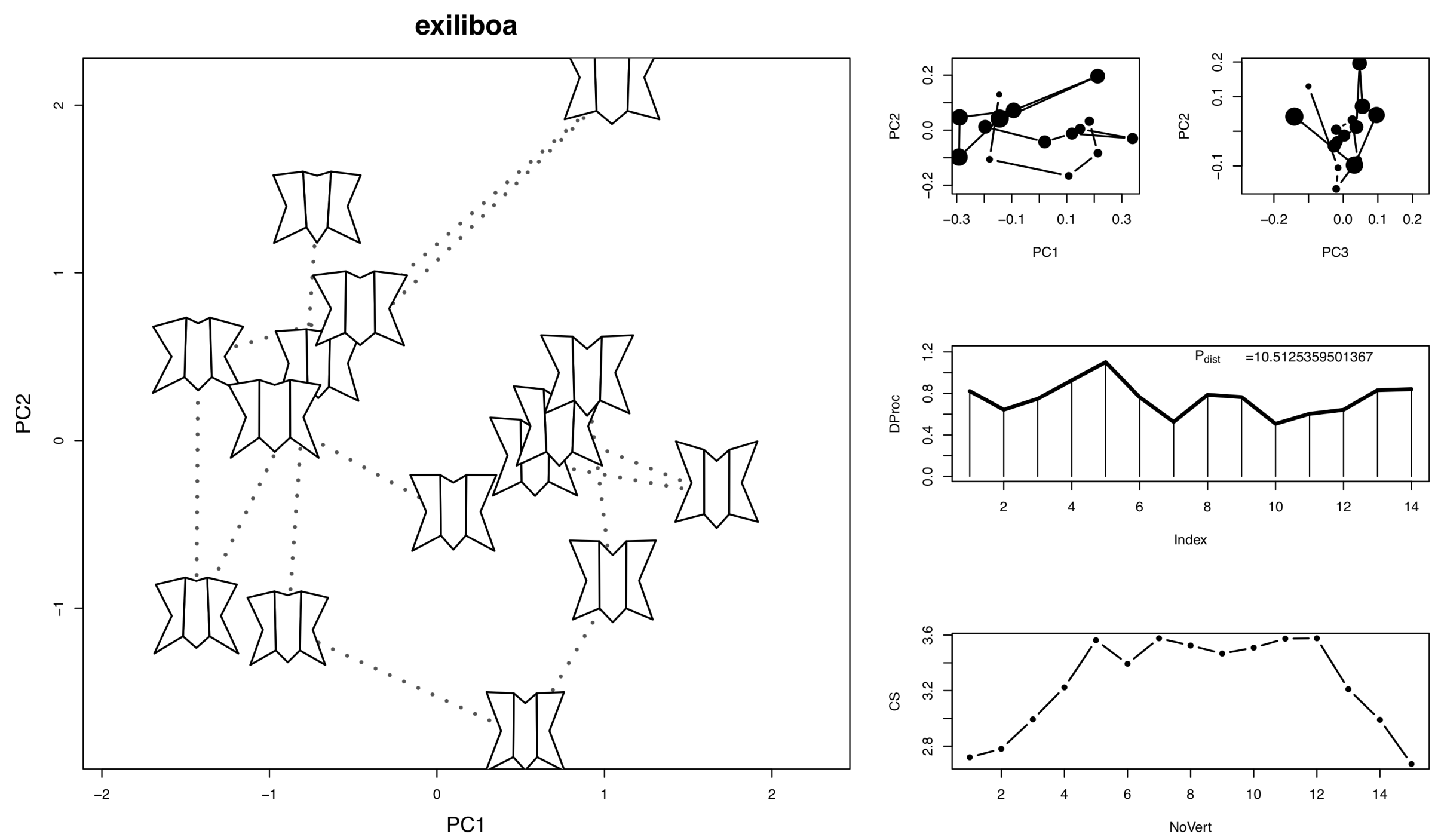


\section{helicops}
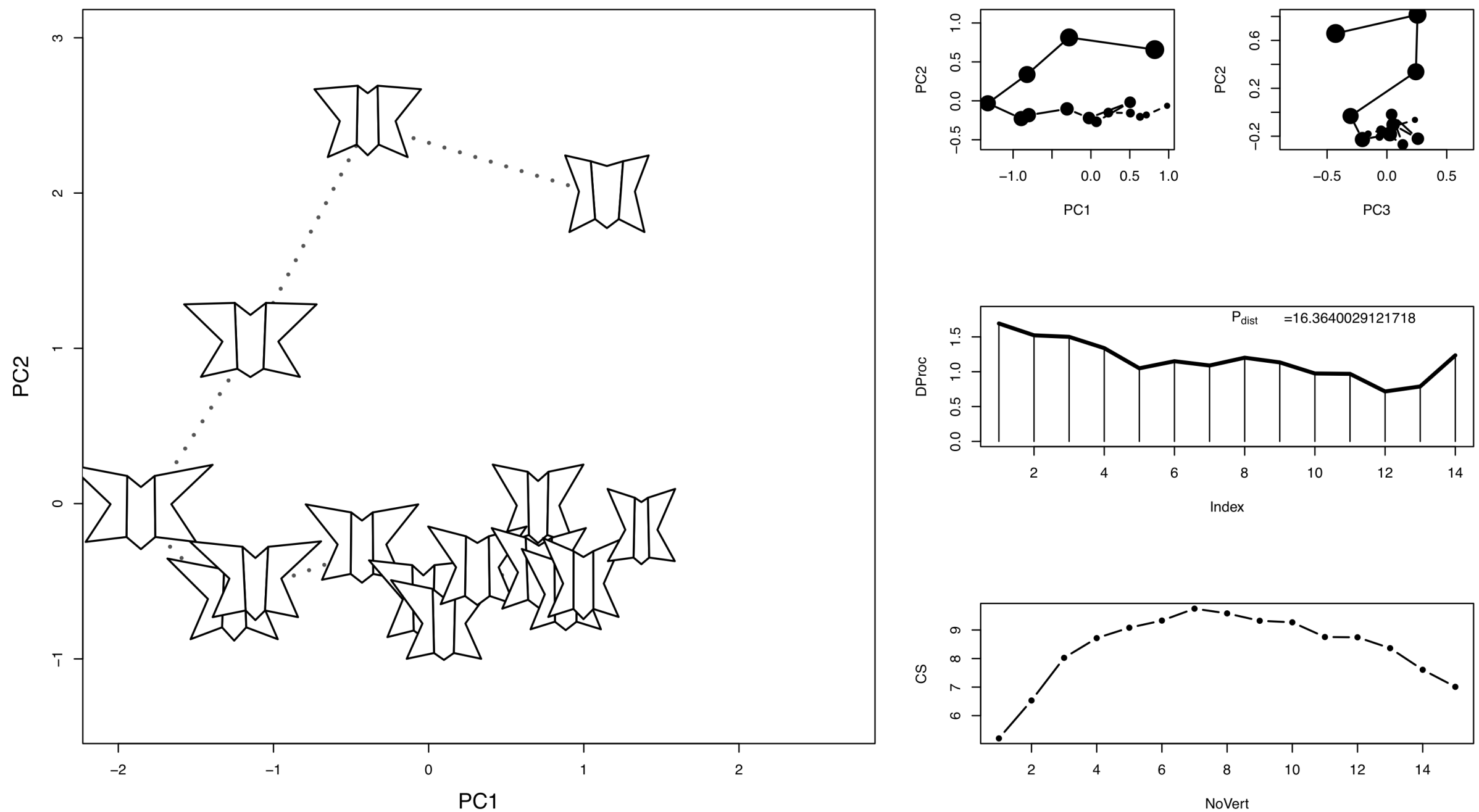

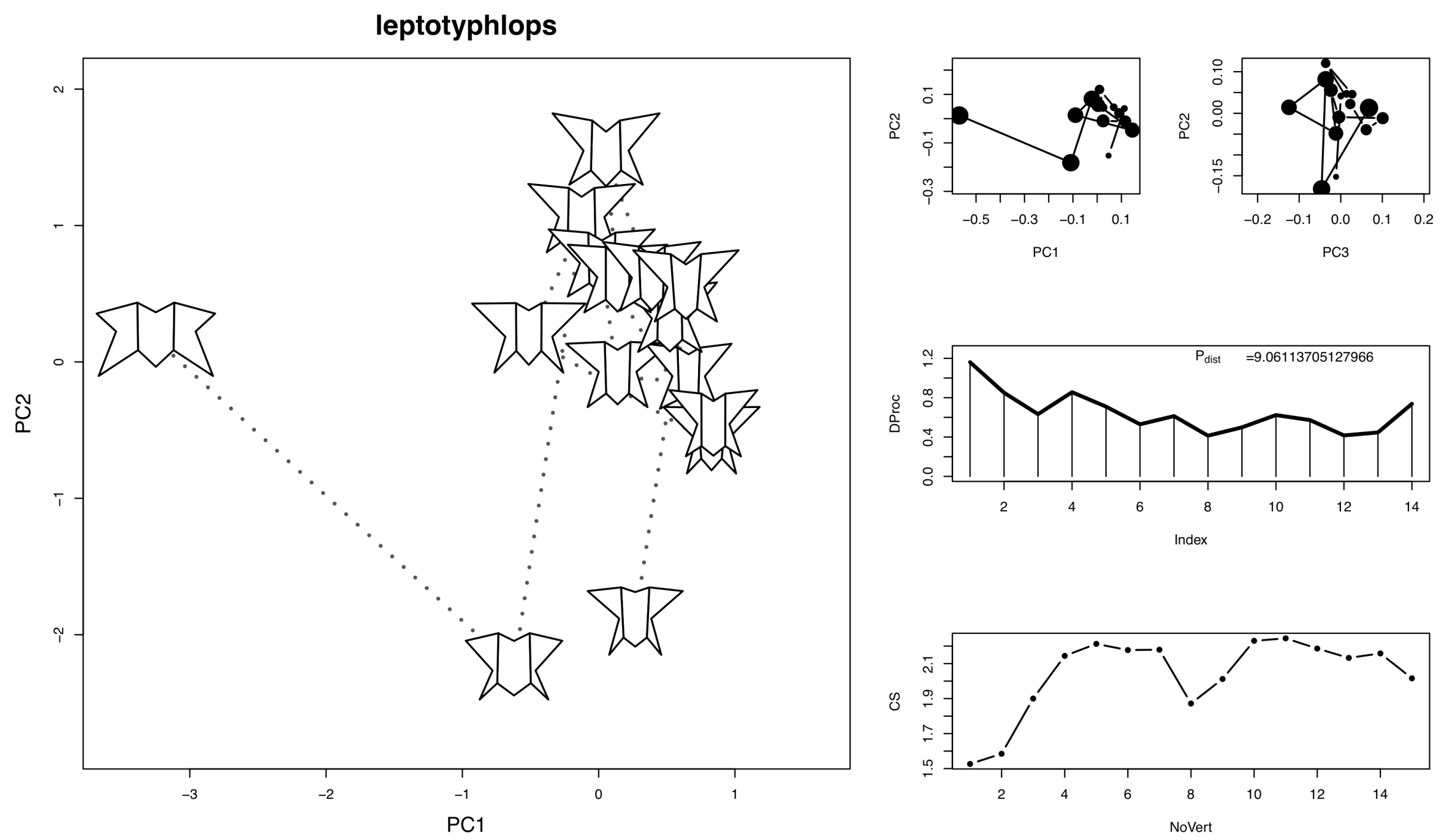

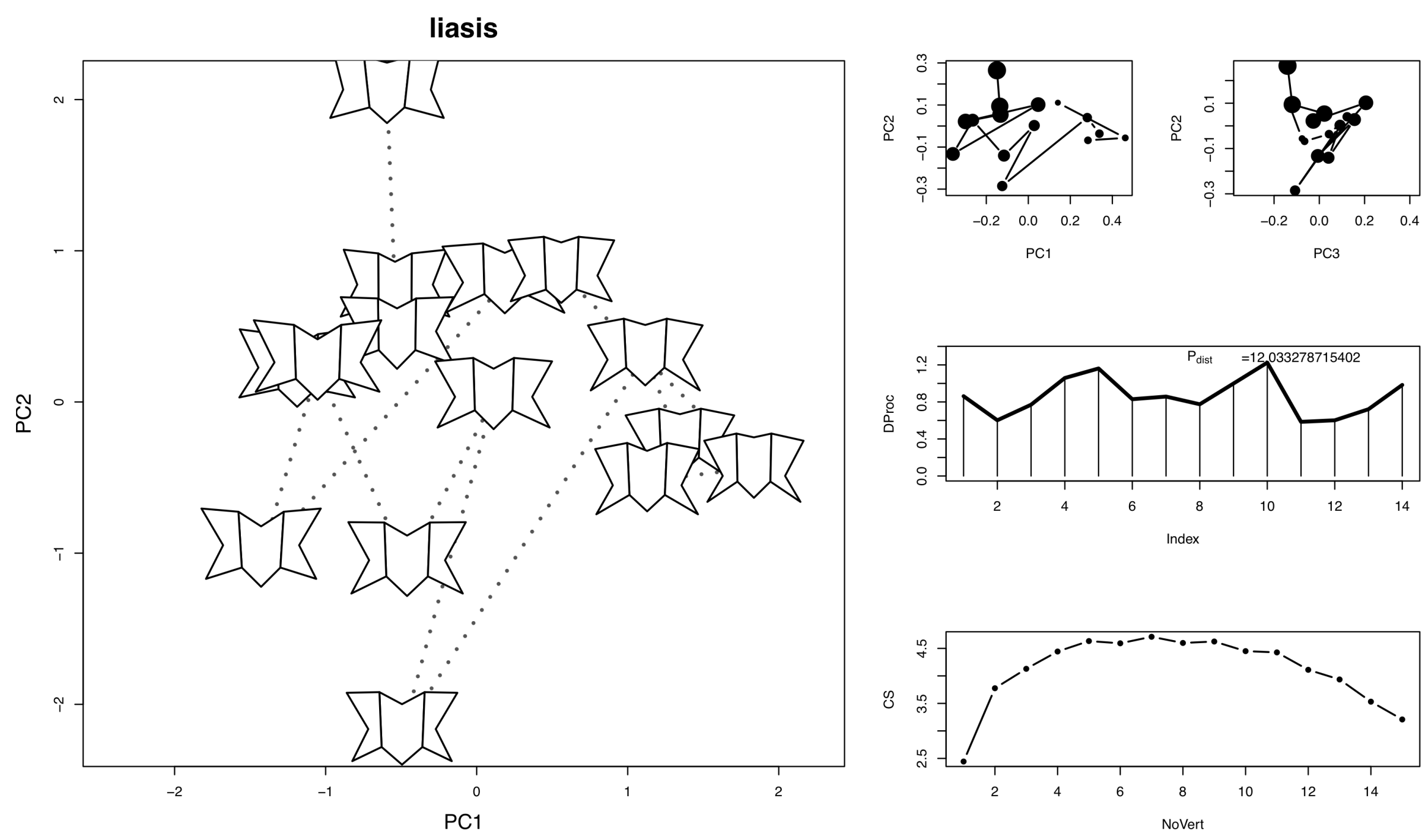

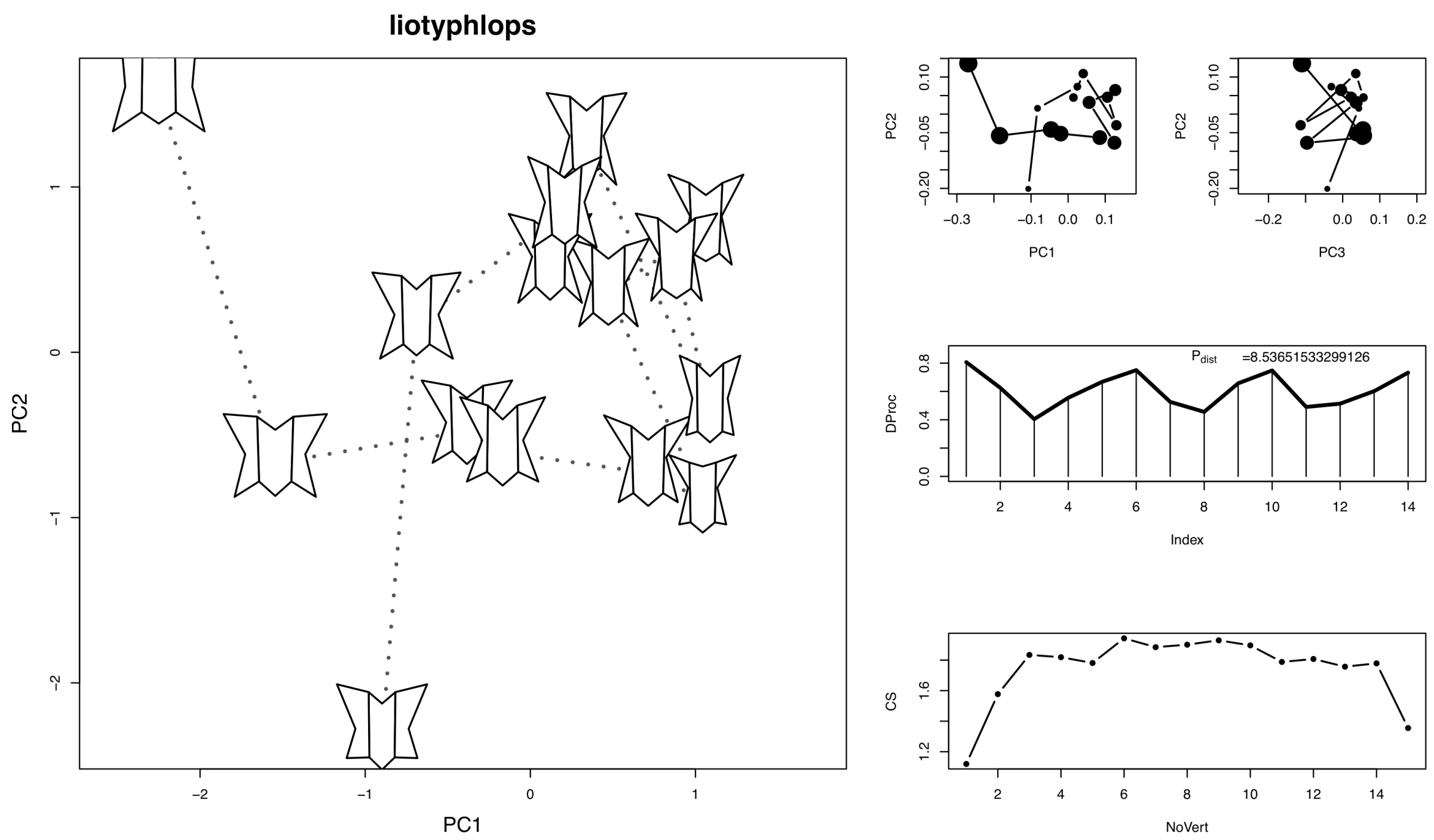
lichanura
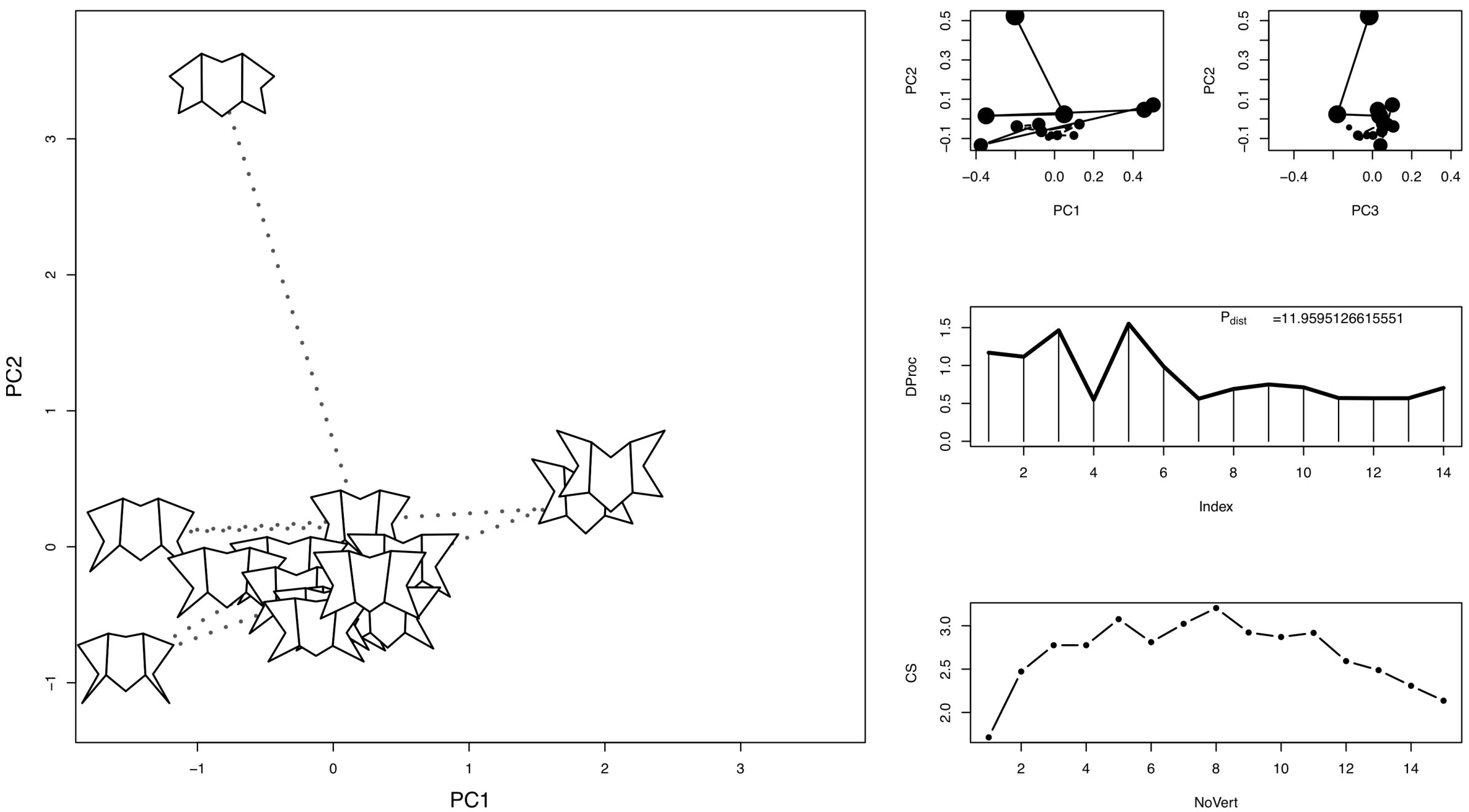

A-134 

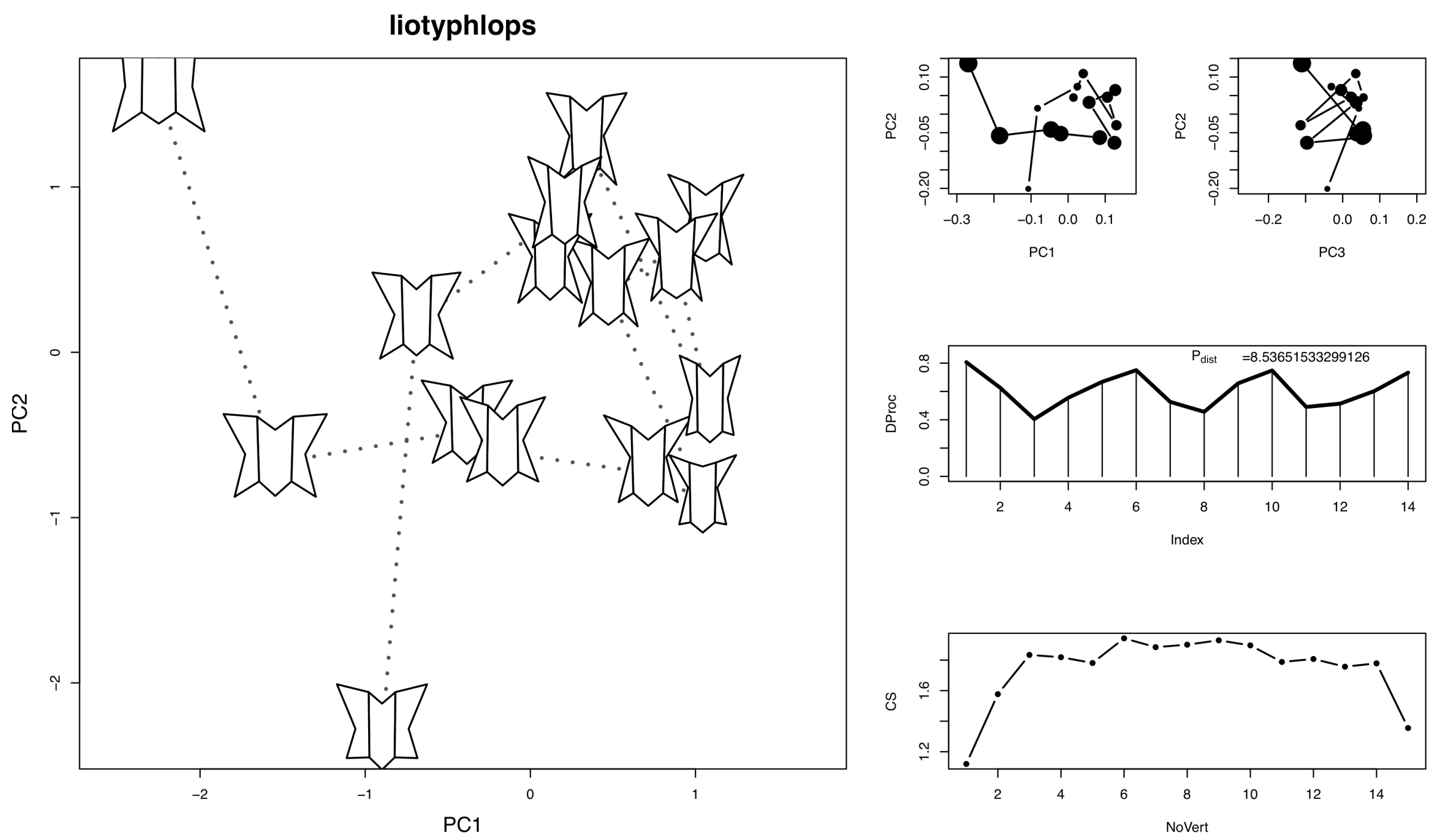

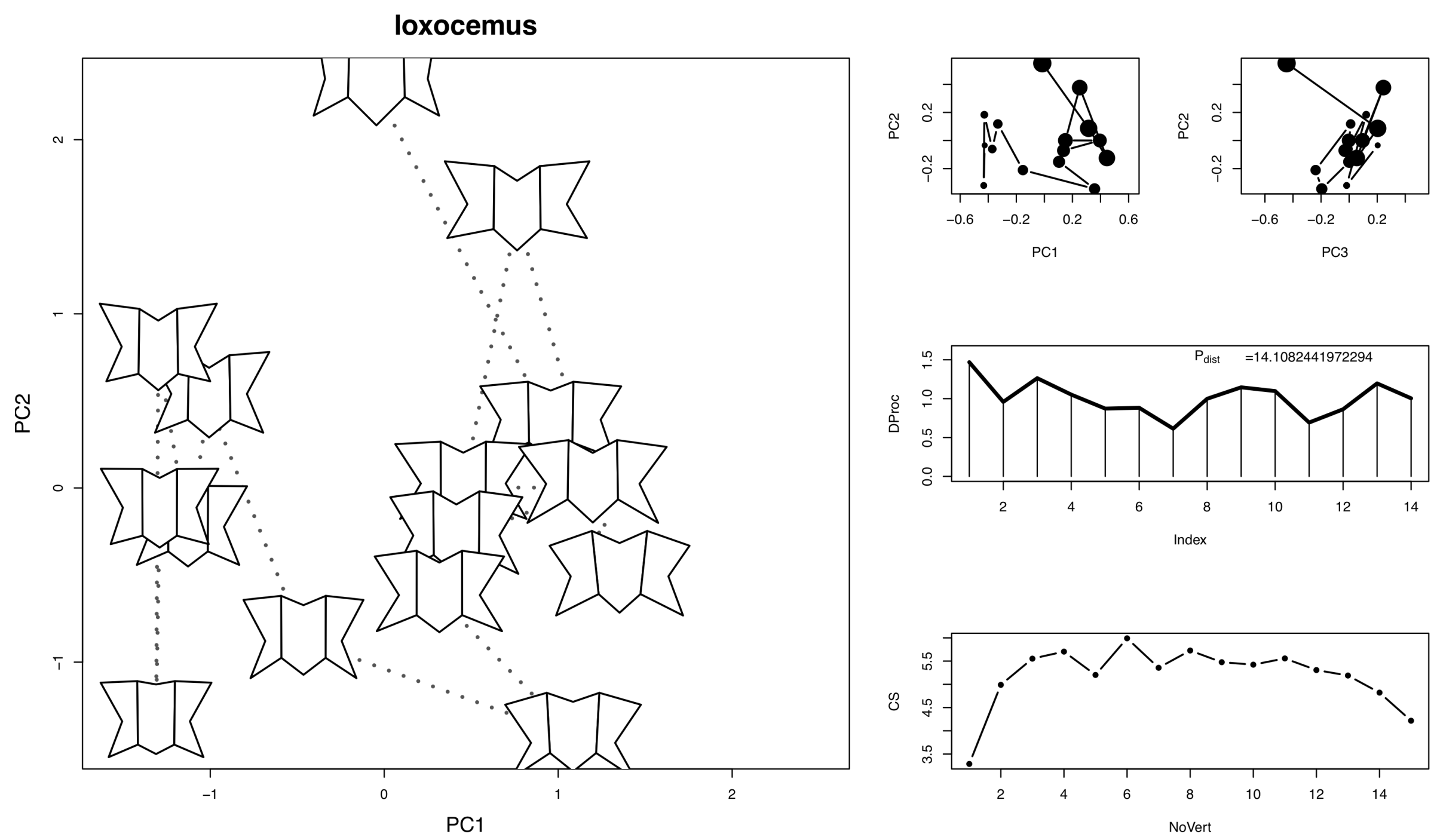

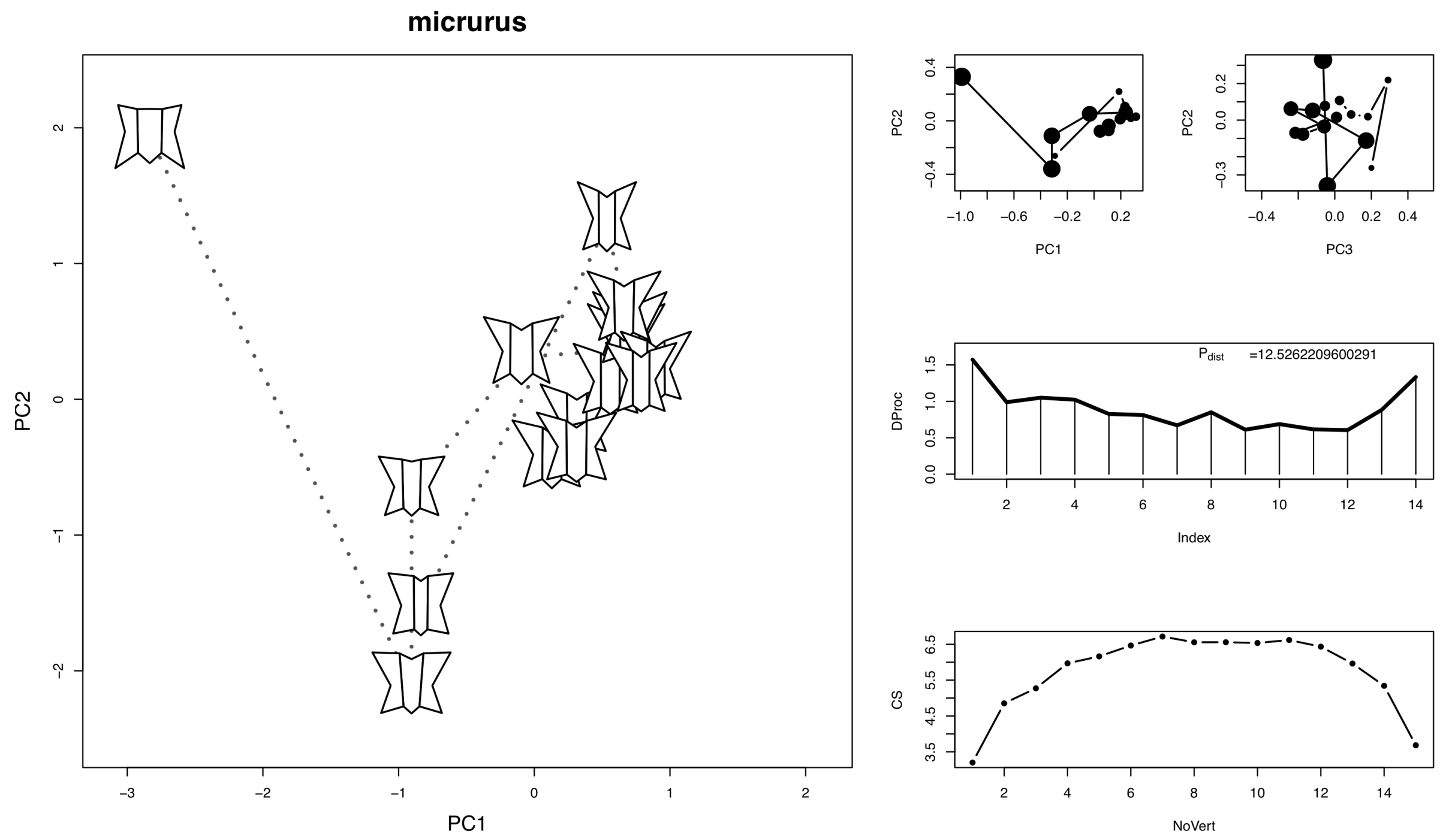

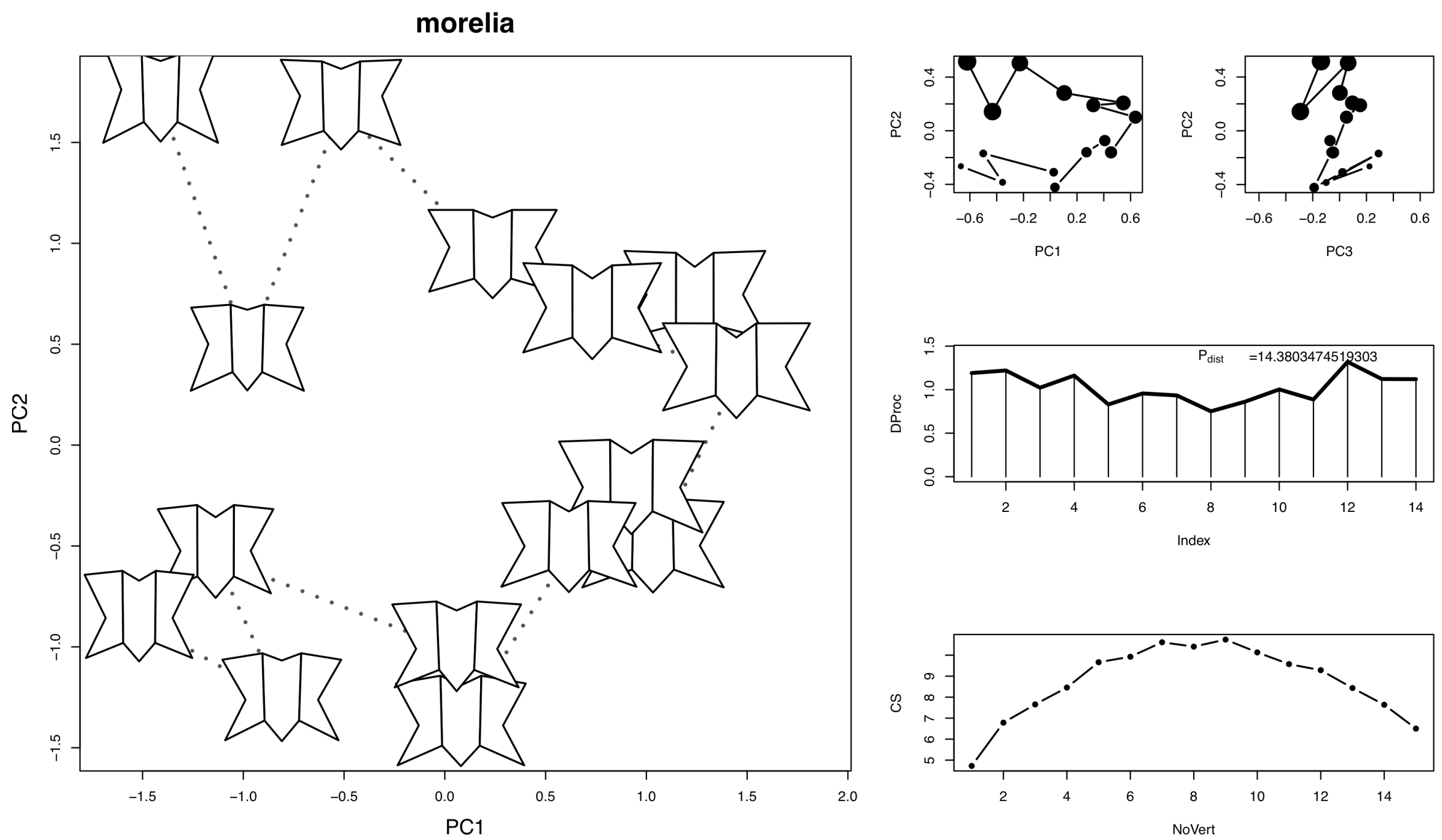

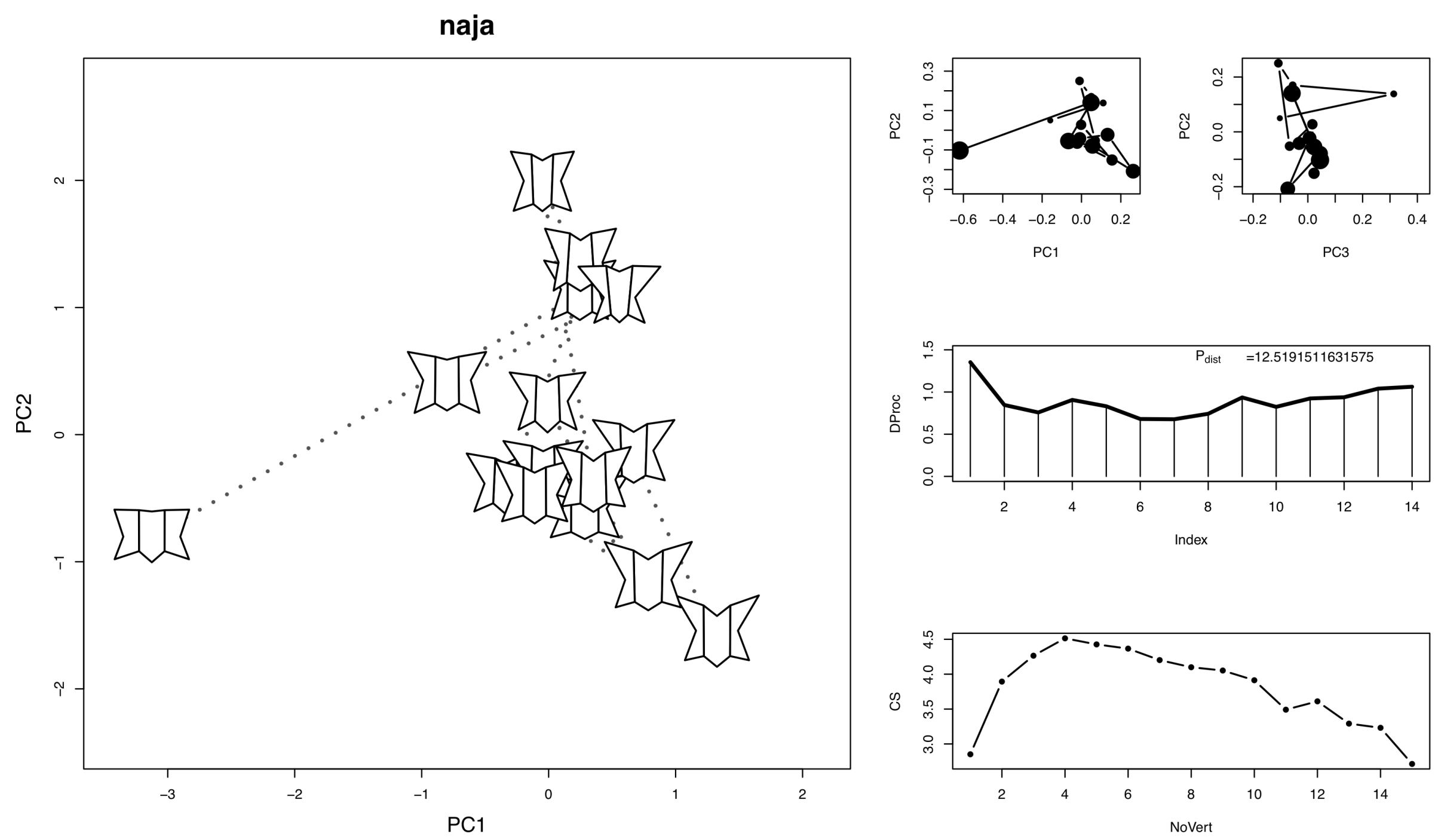

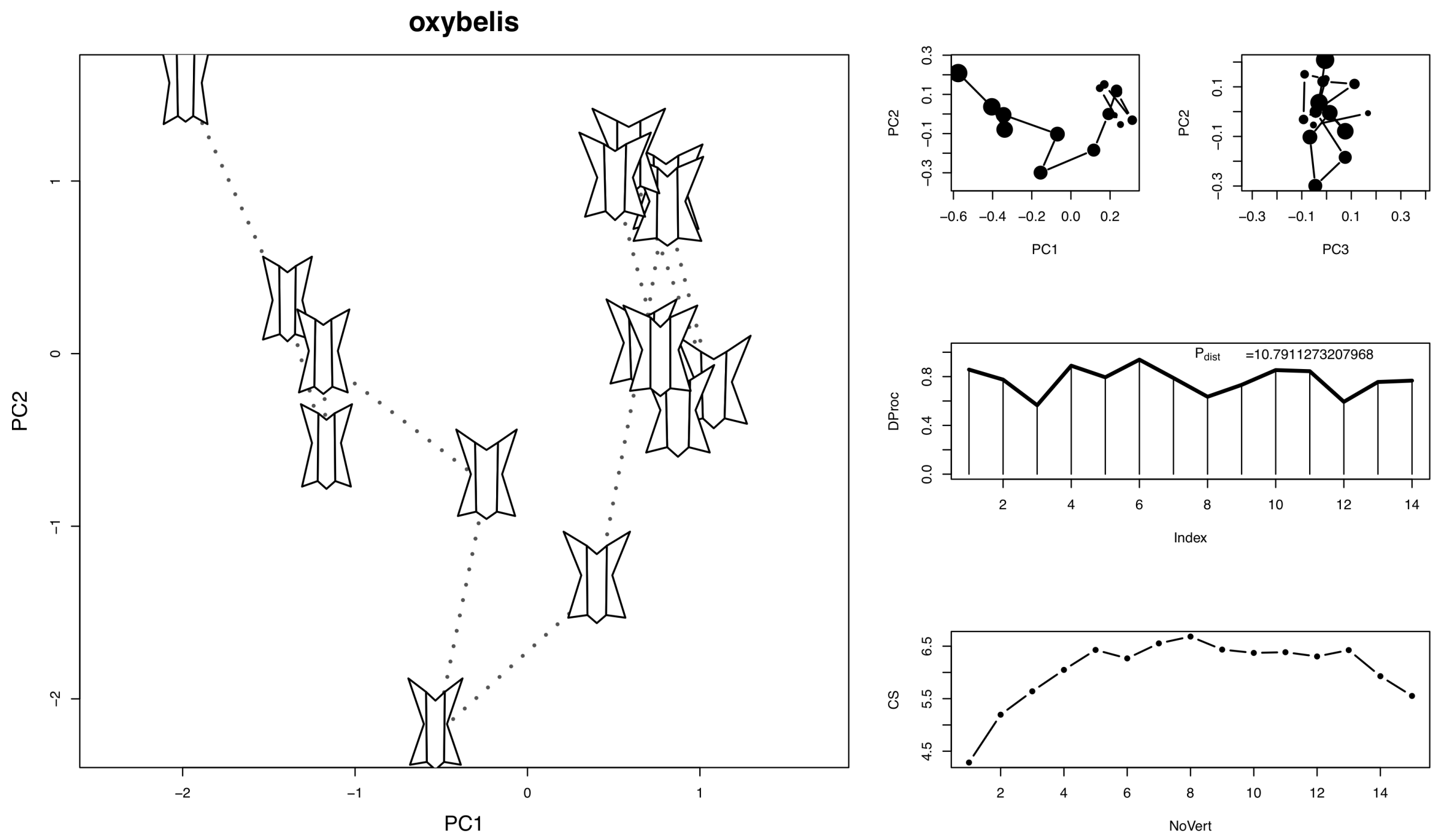

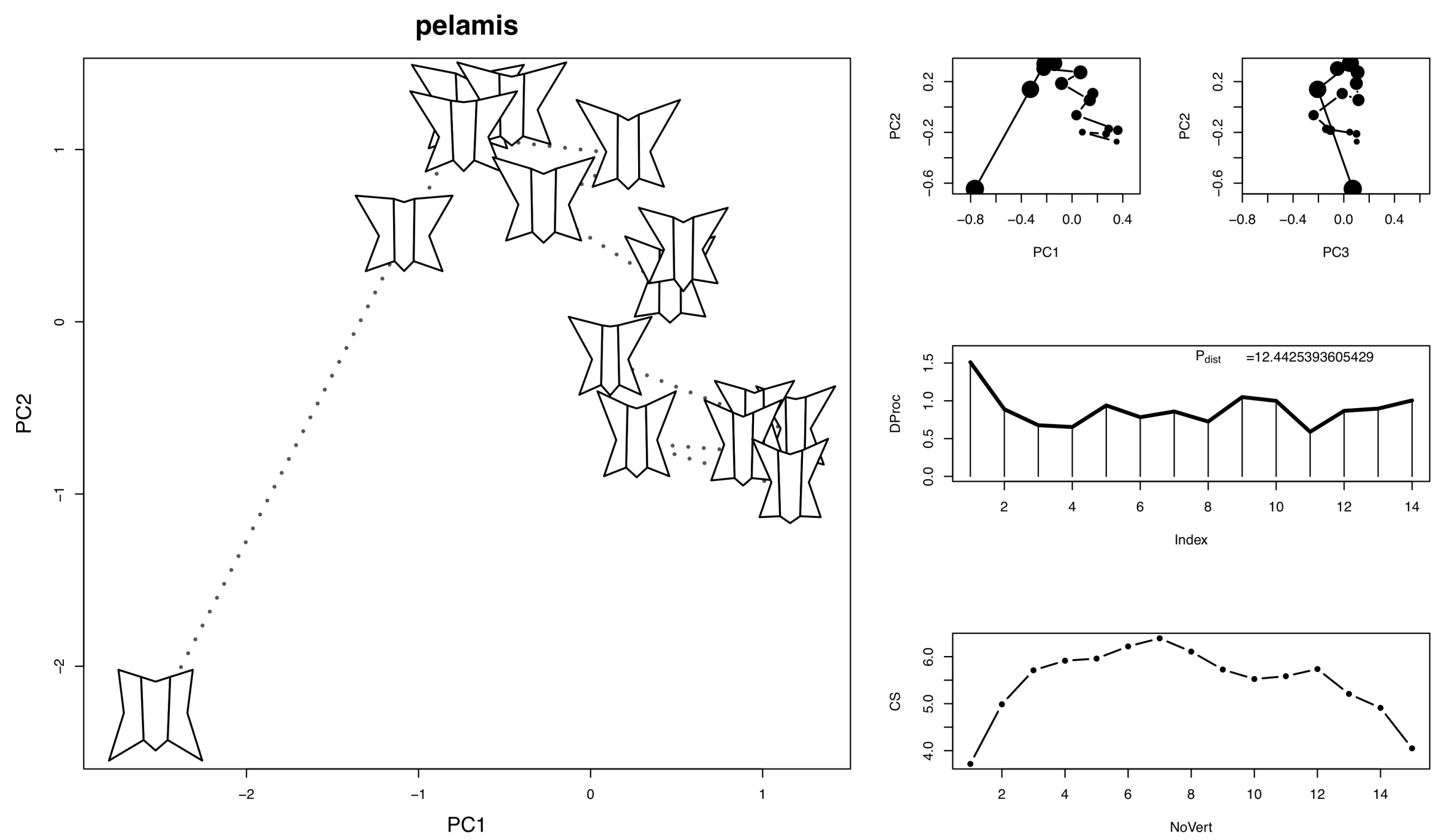

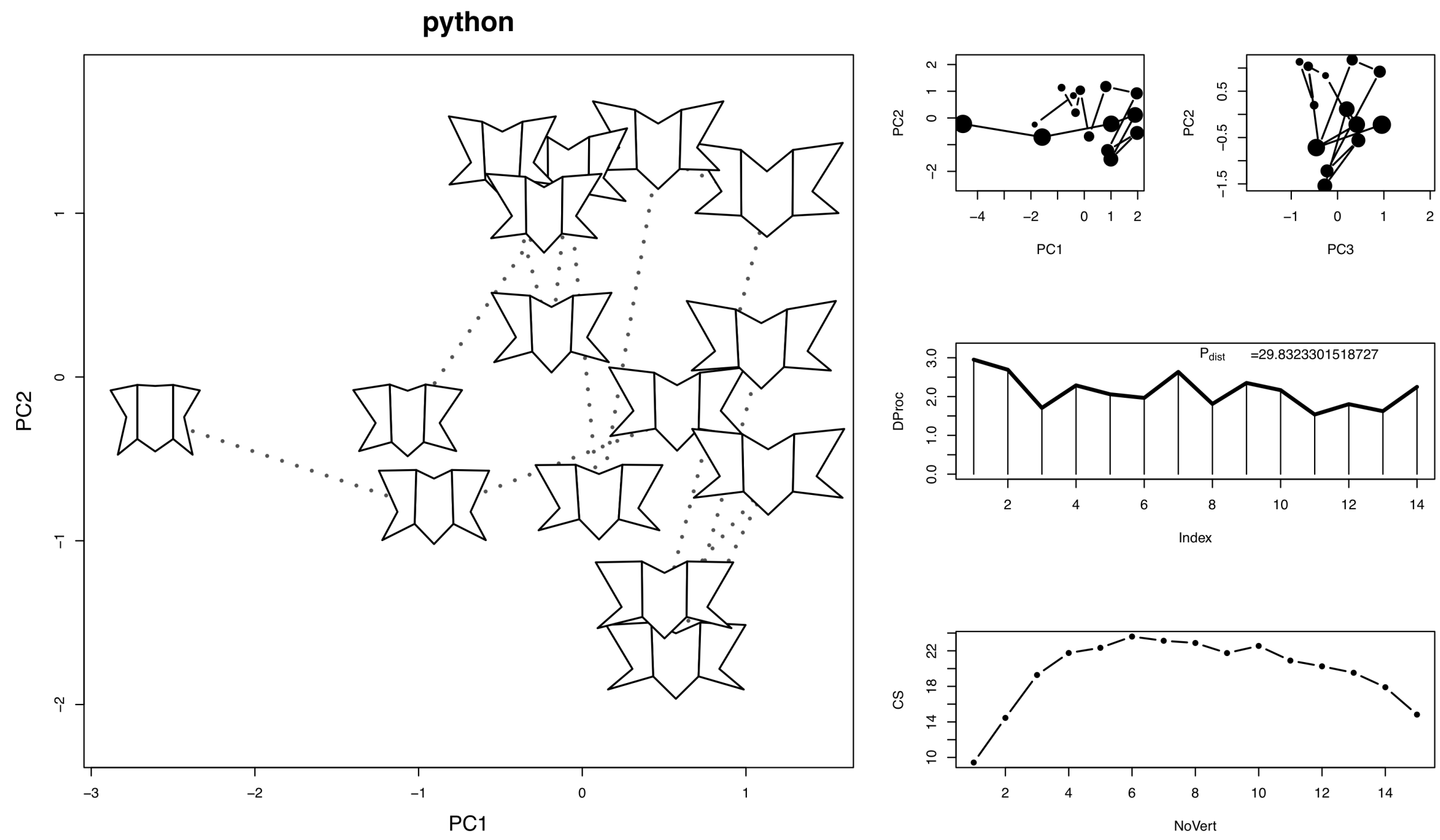

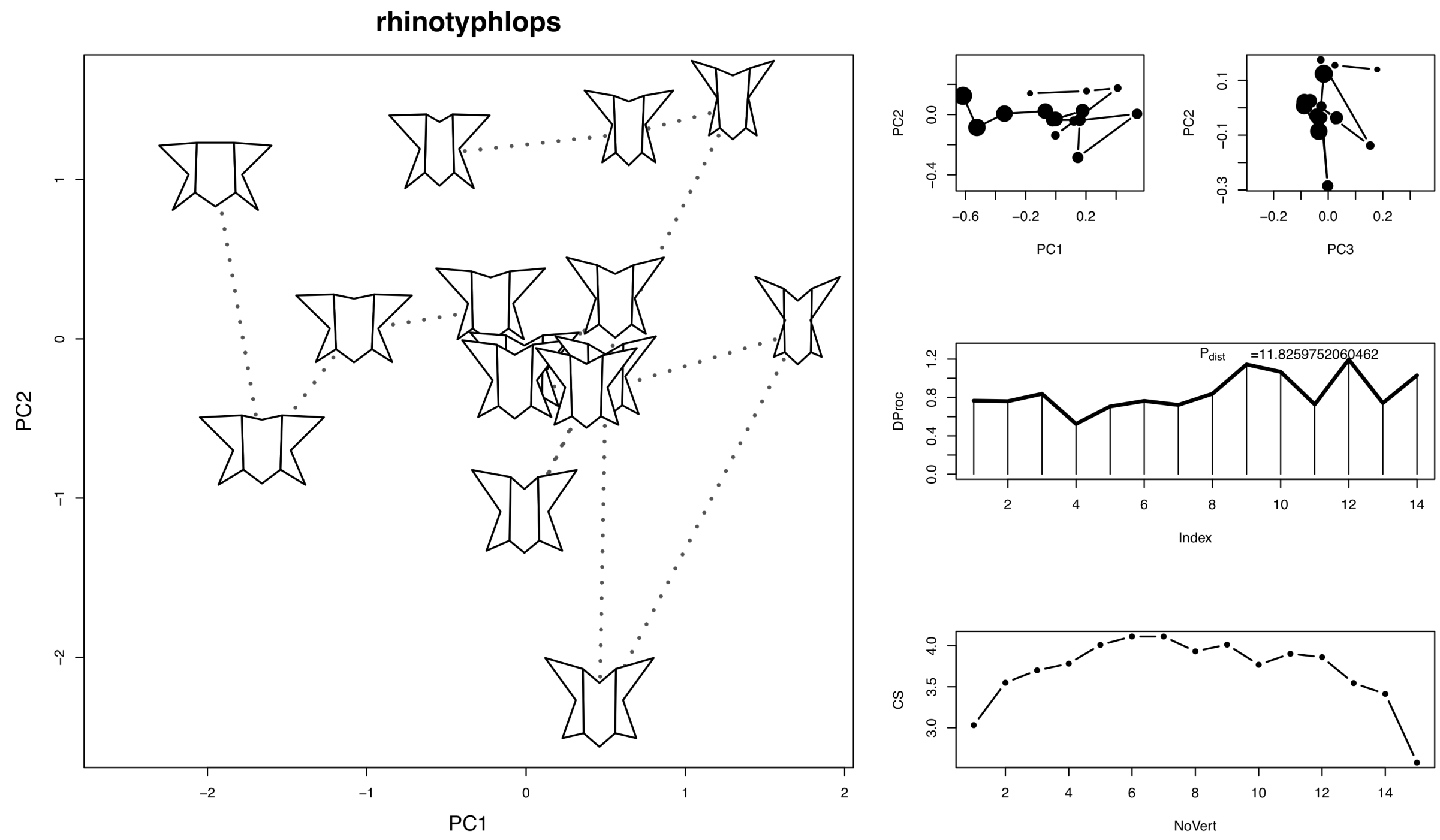

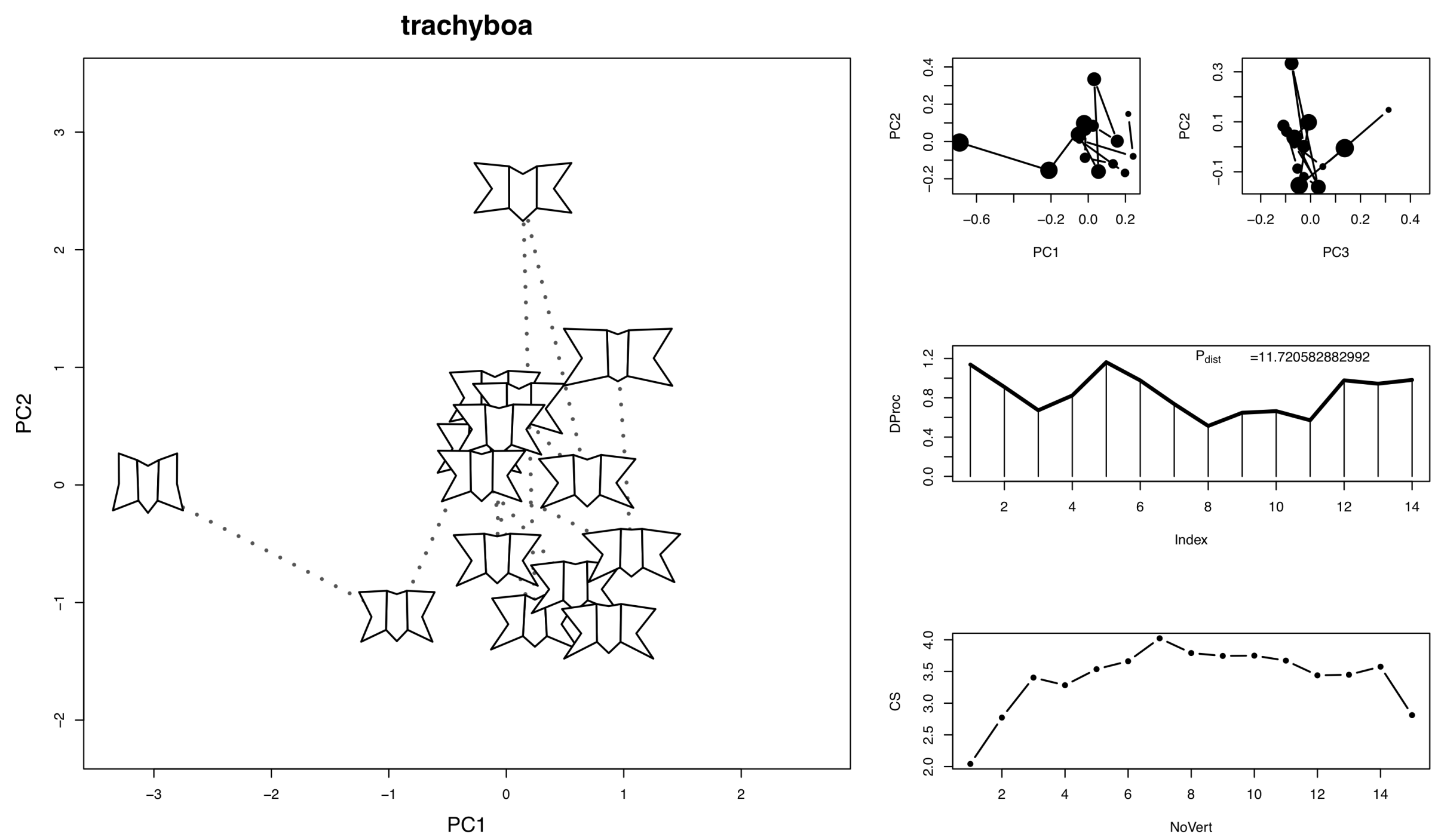



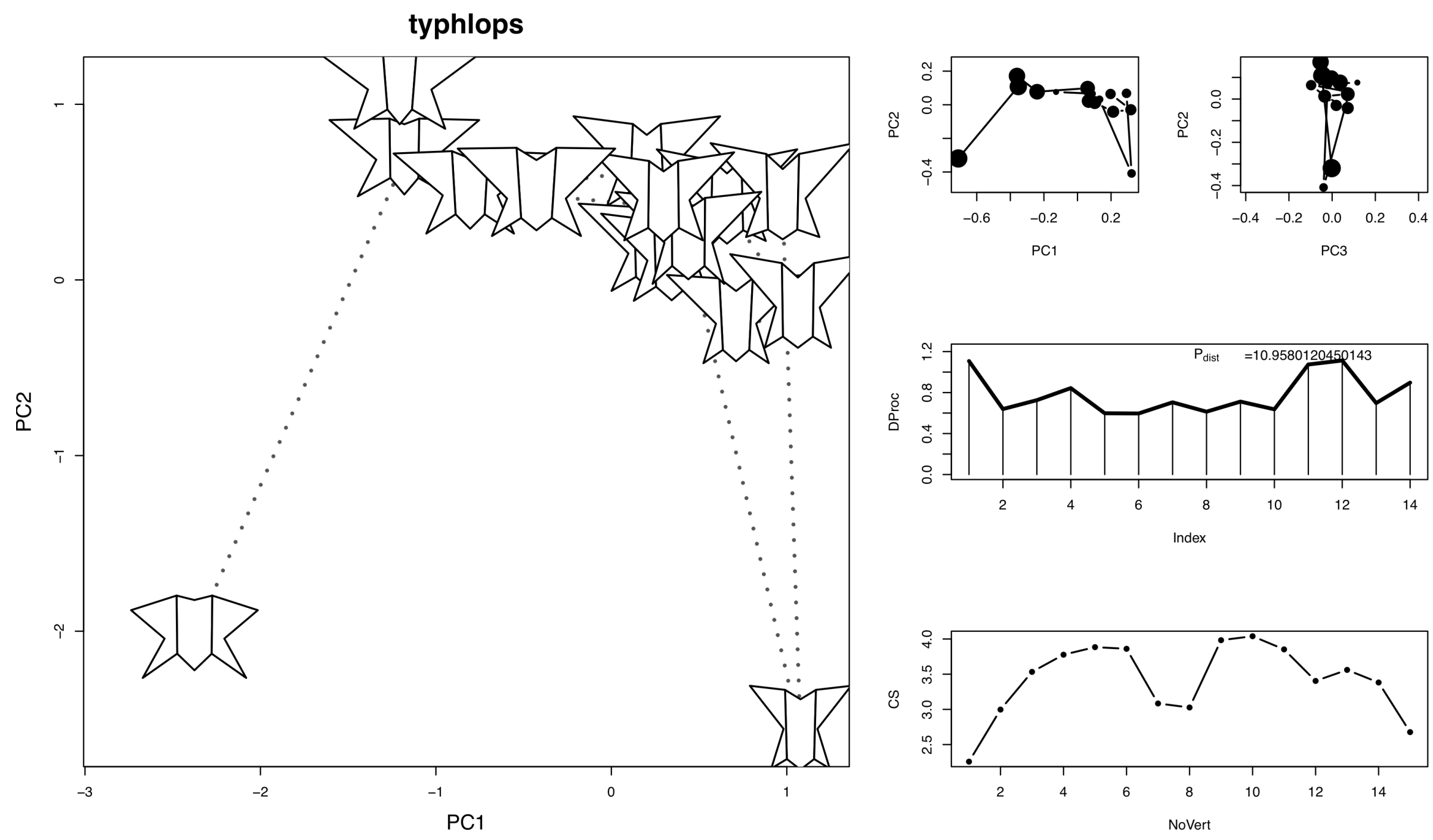

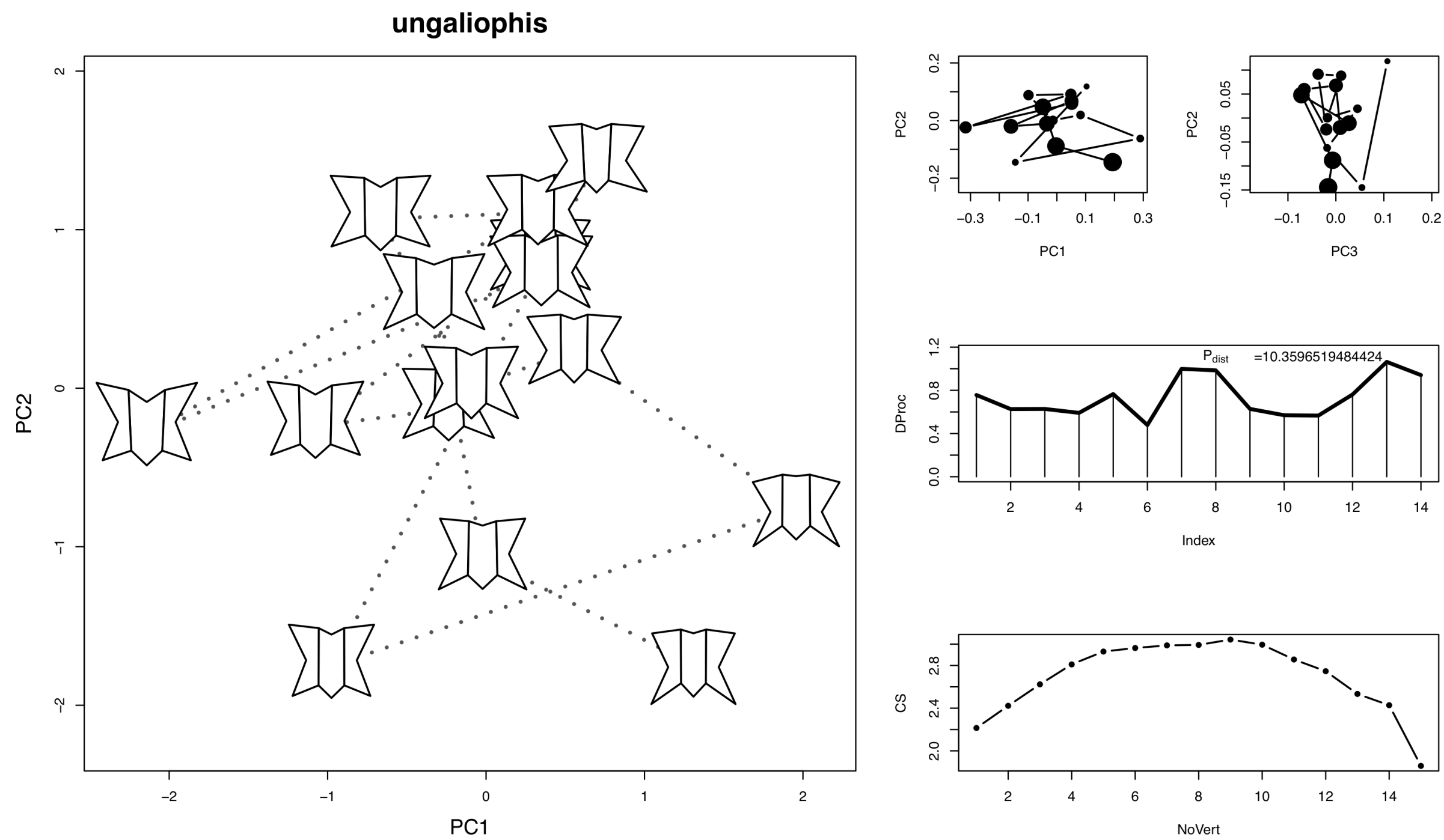

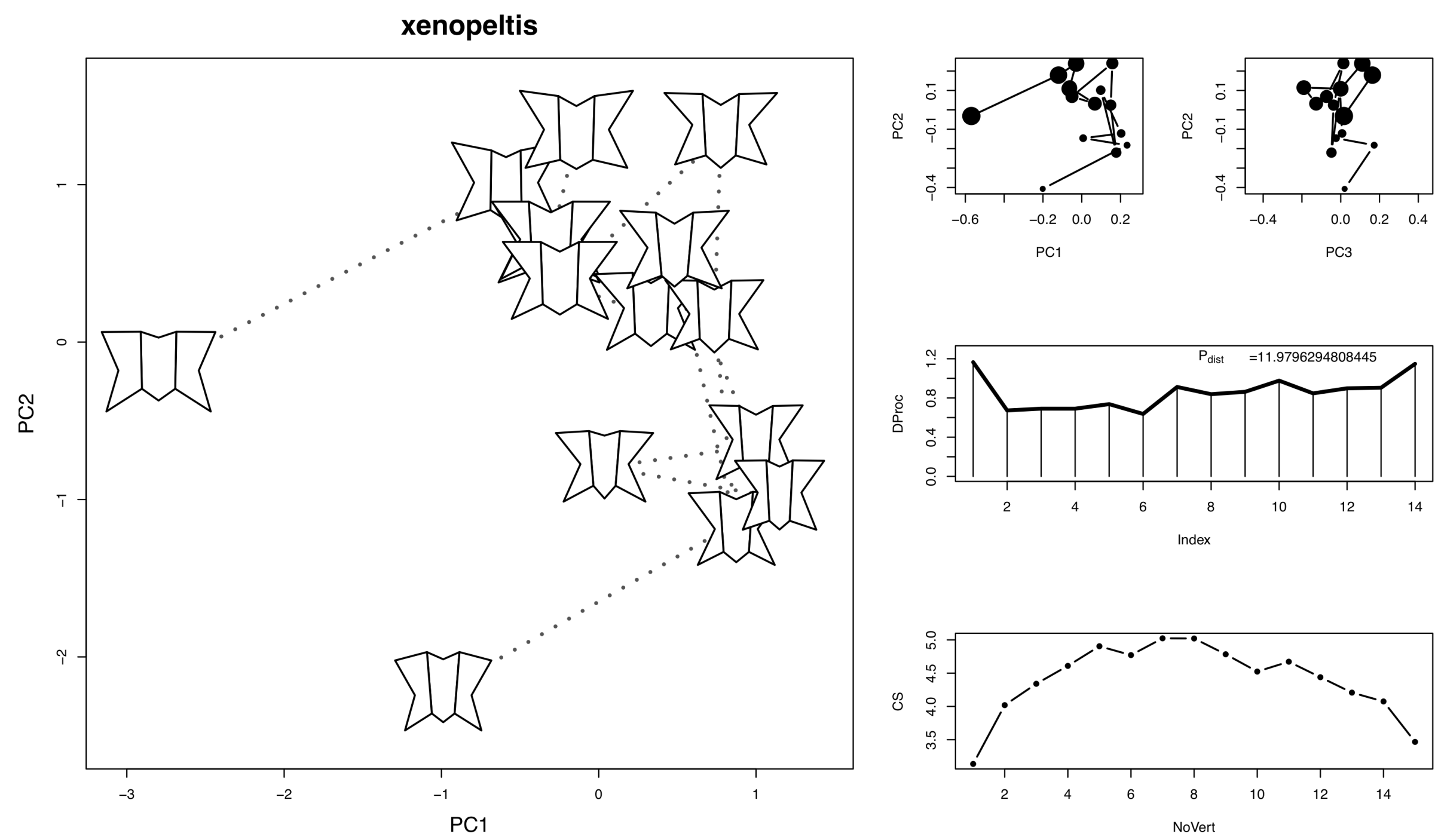


\section{Apêndice III - Sumários da variação taxonômica das diferentes posições vertebrais.}

Sumários dos morfoespaços (primeiro e segundo componentes principais) definidos pelas formas vertebrais de cada posição (agrupamento do tipo A) nas vistas anterior, lateral, posterior e ventral.

Sumários da vista Anterior: A-150

Sumários da vista Lateral: A-166

Sumários da vista Posterior: A-181

Sumários da vista Ventral A-196 

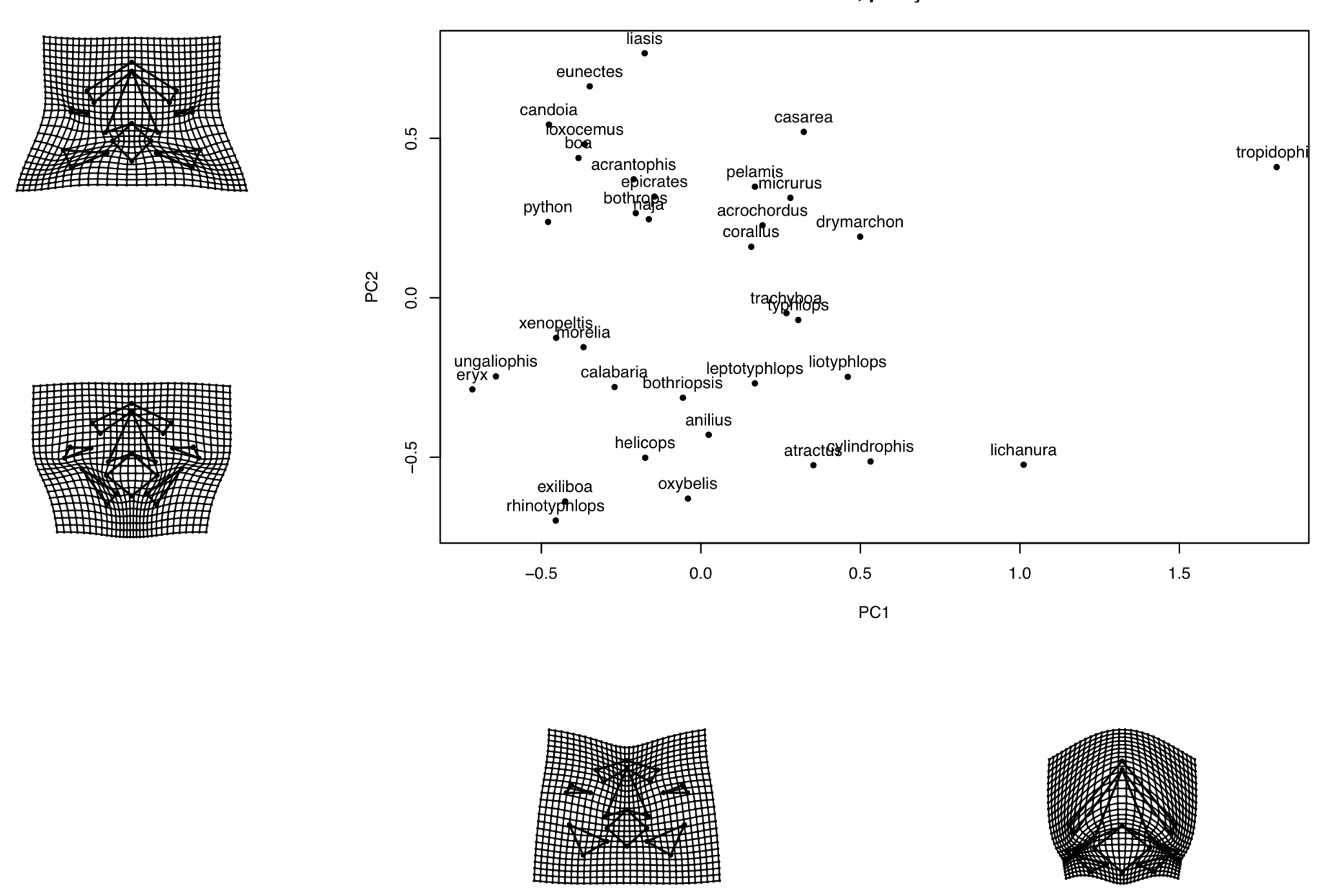

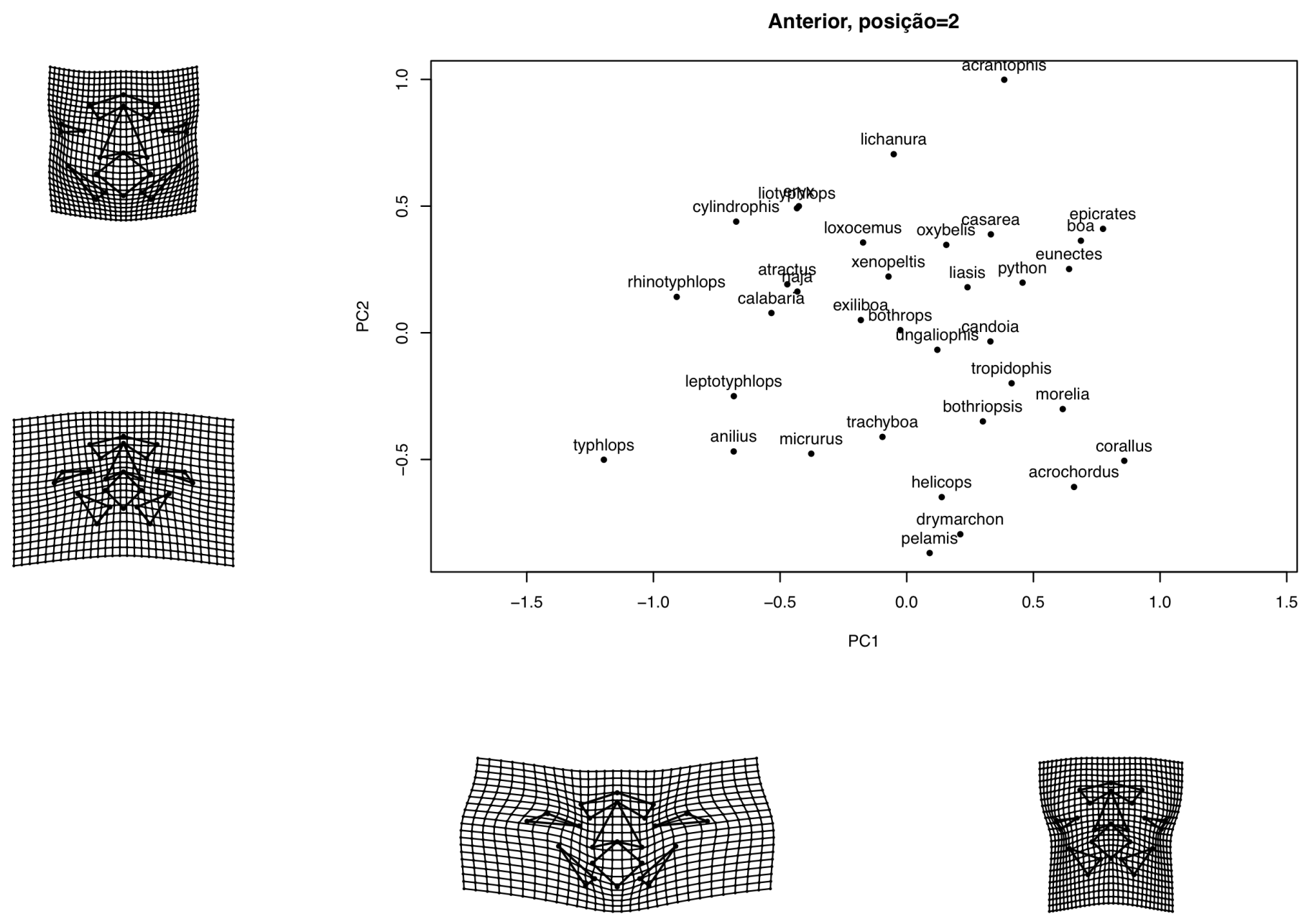

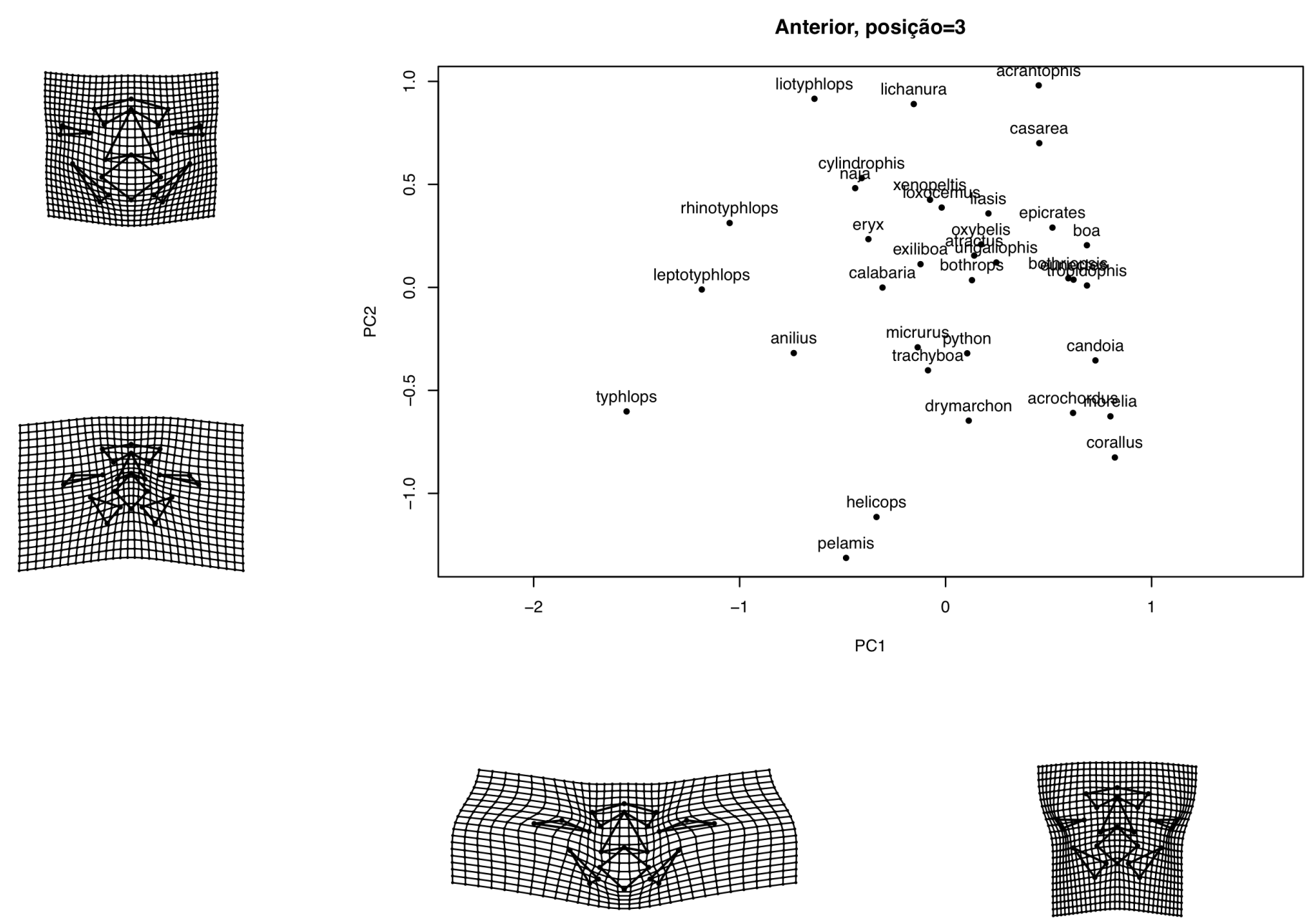

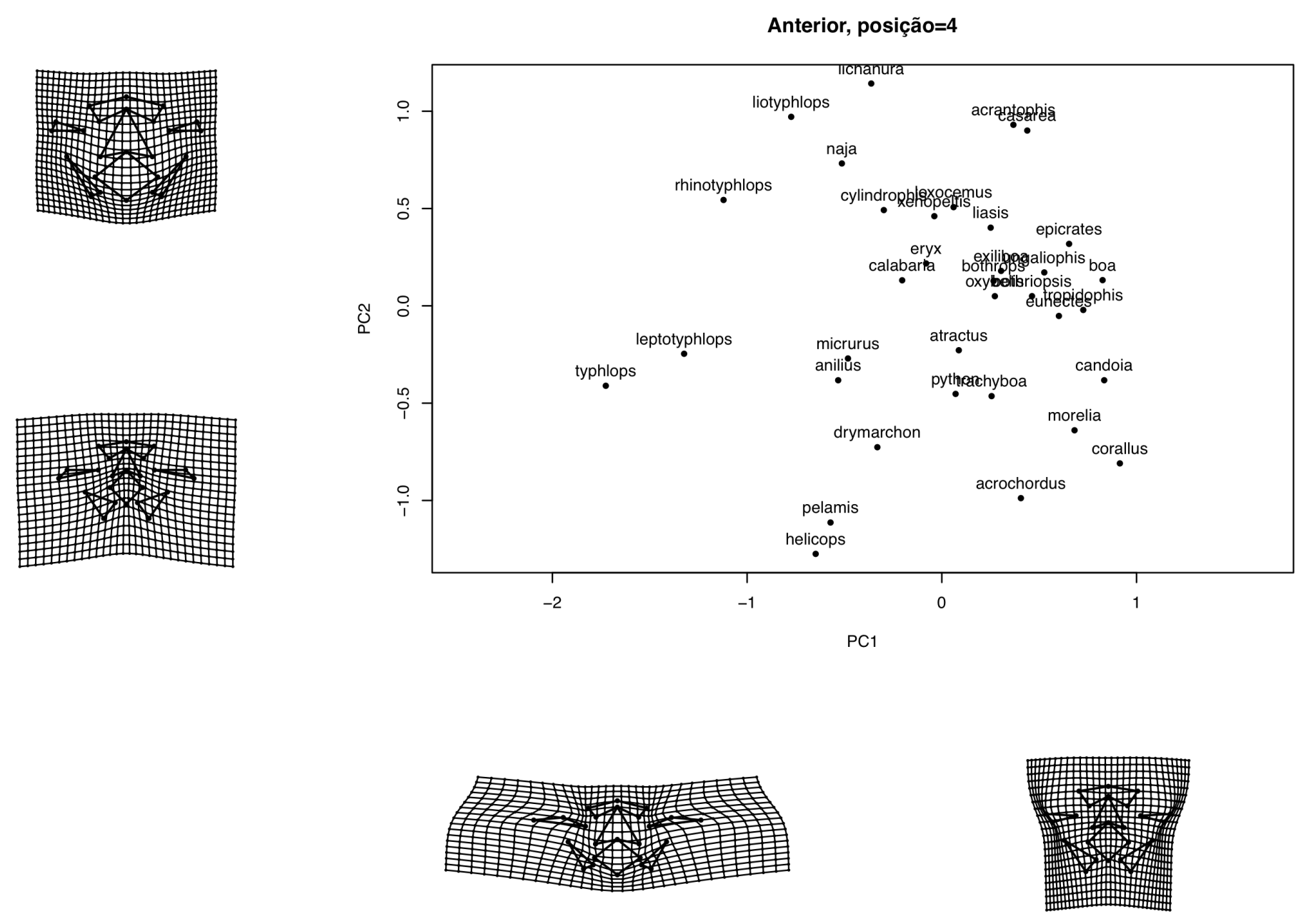

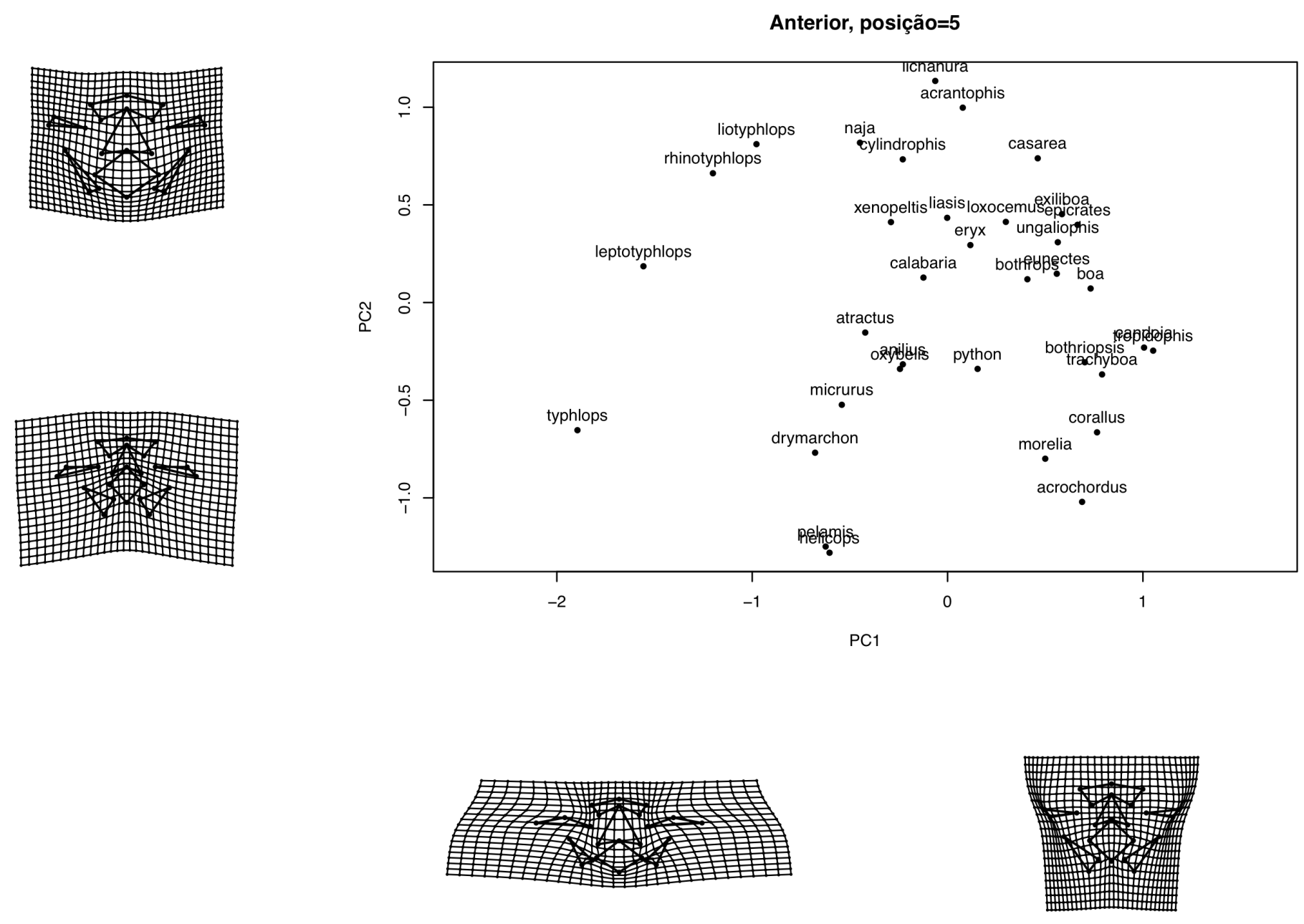

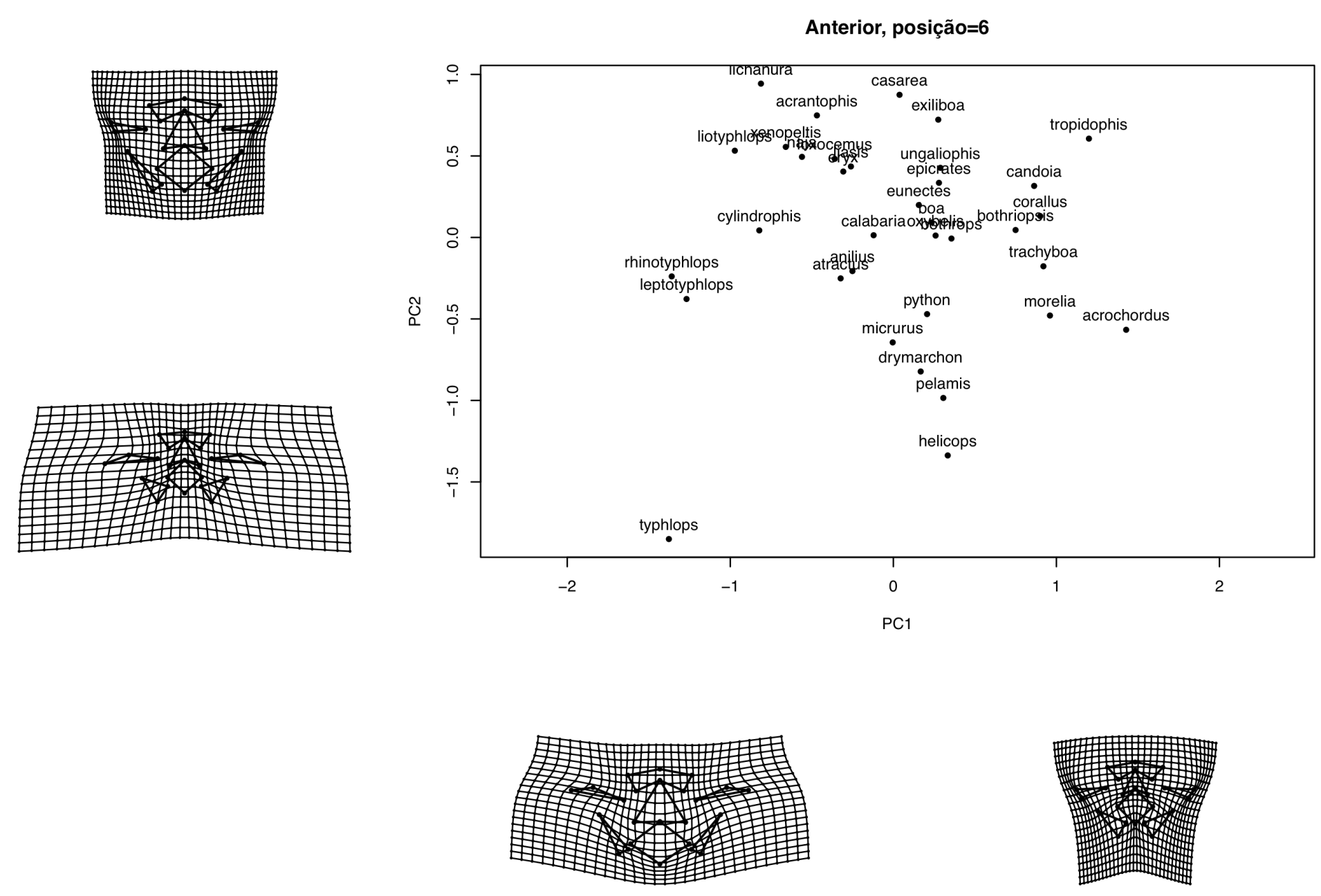

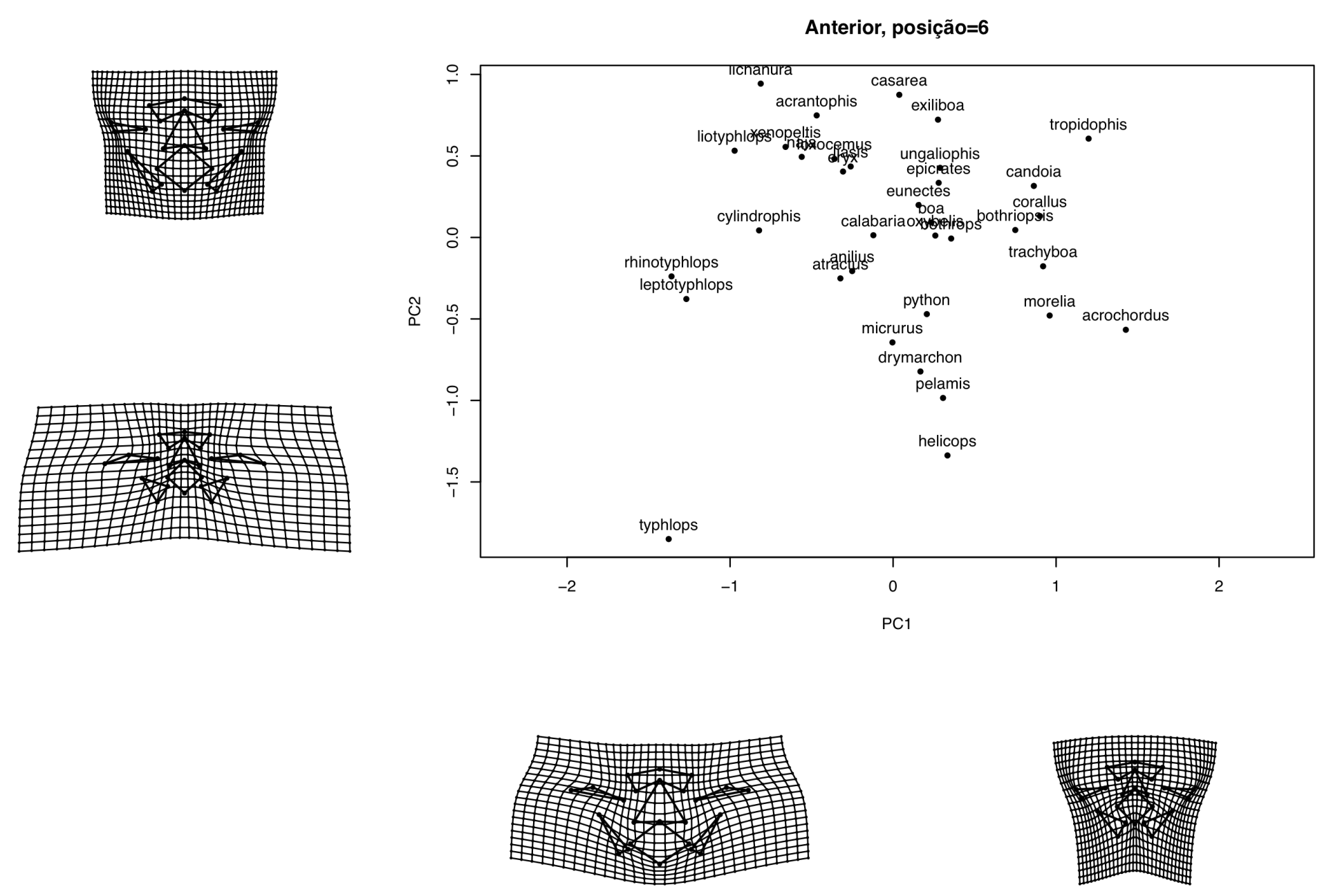
Anterior, posição=7
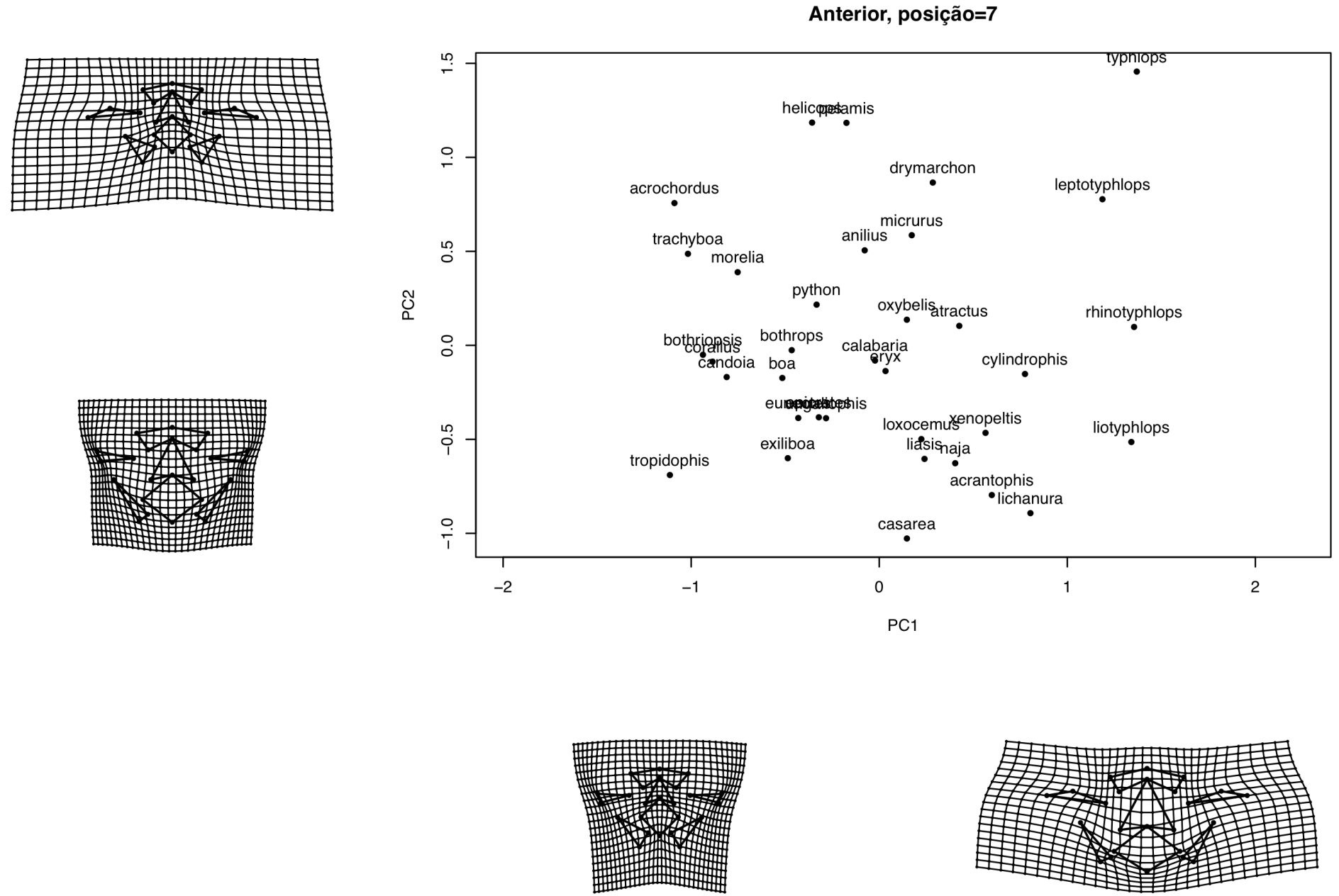

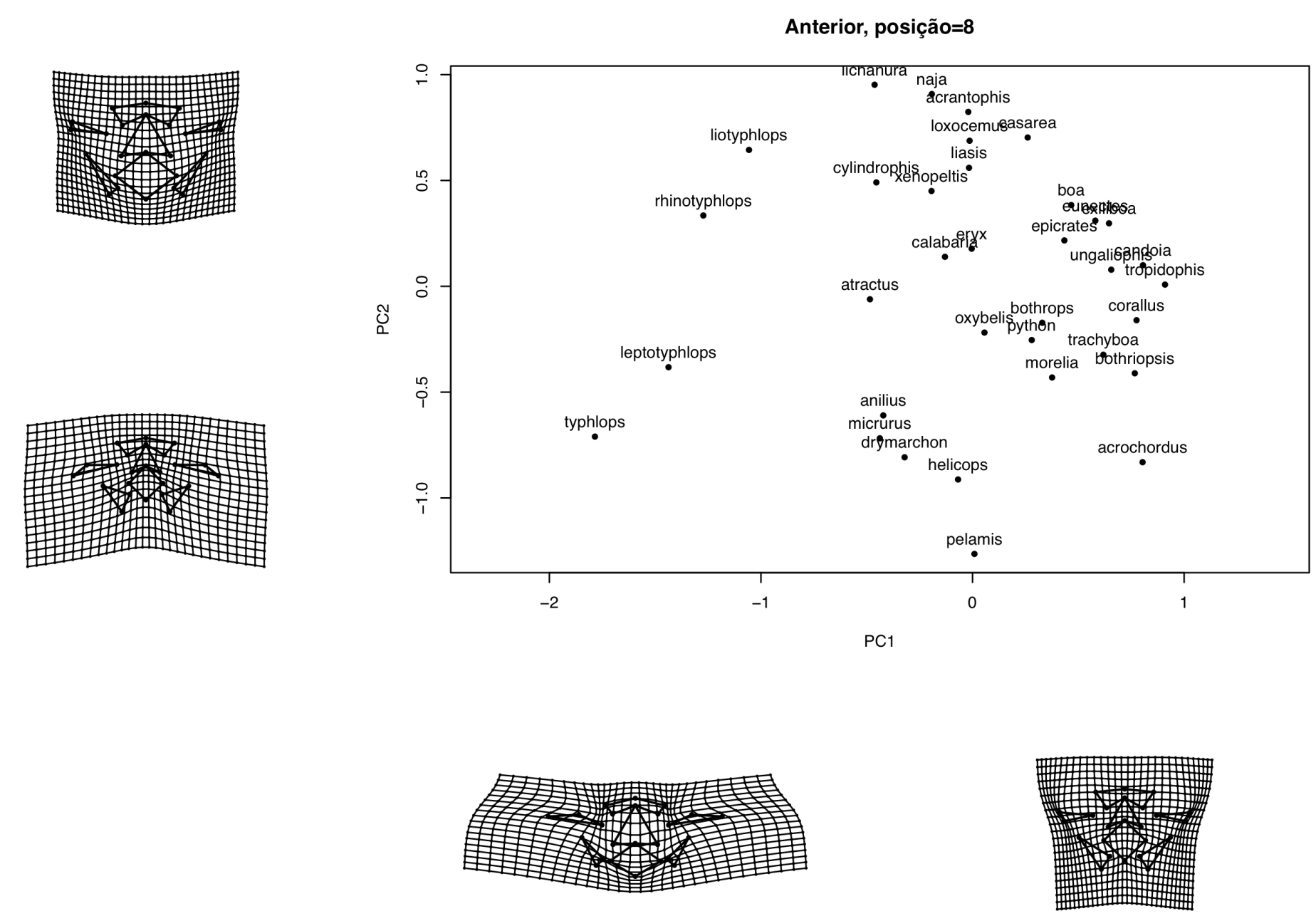
Anterior, posição=9
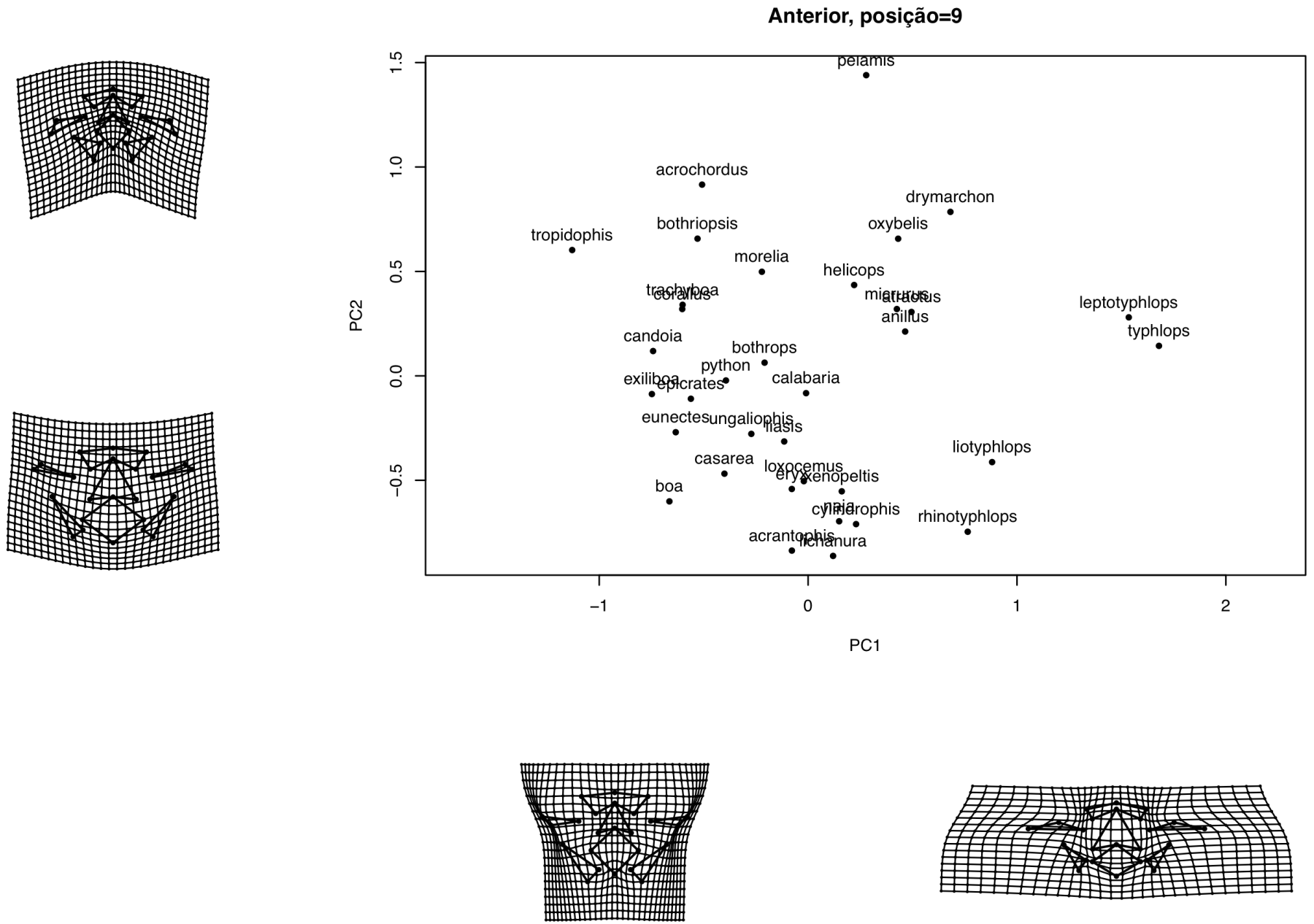

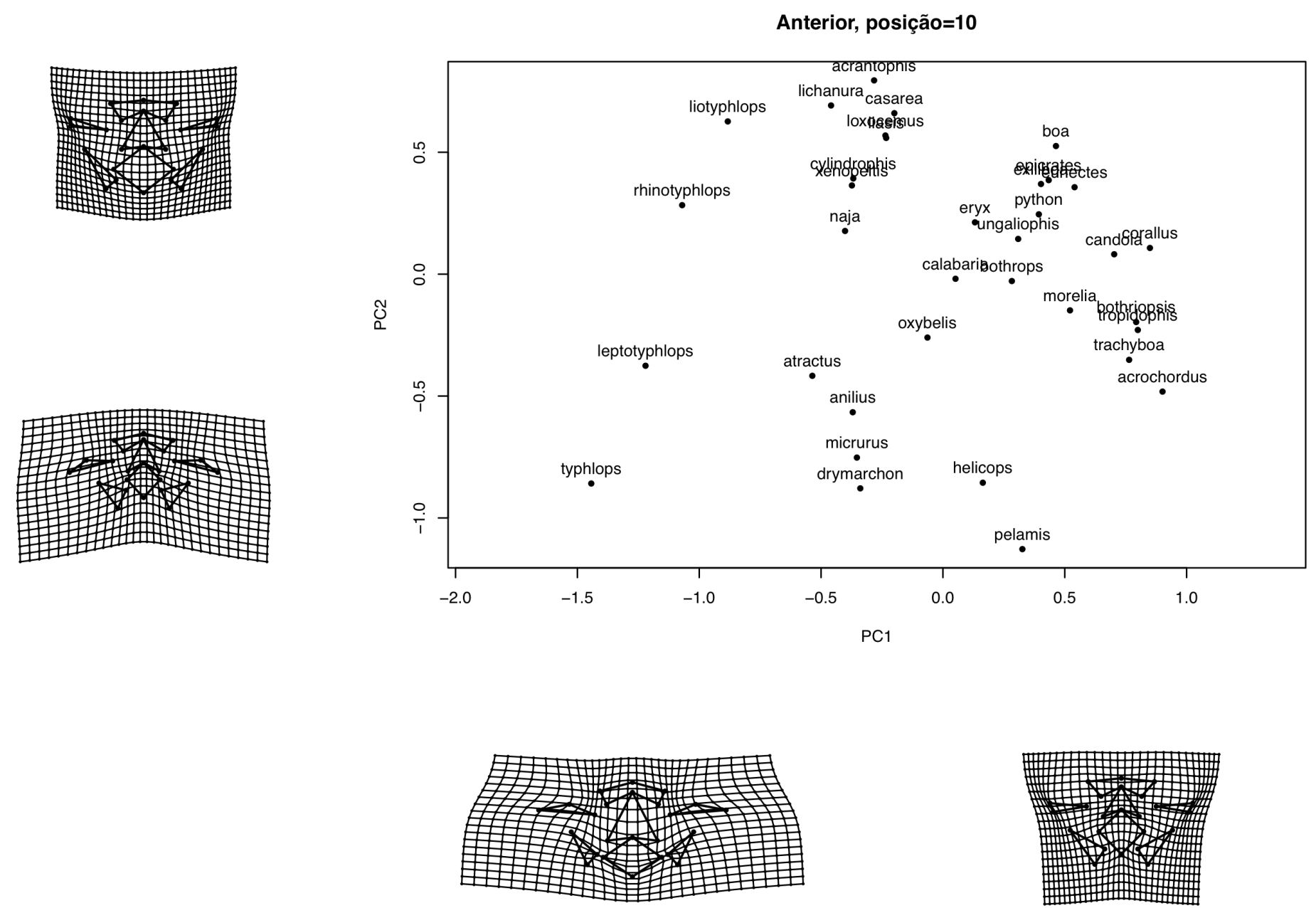

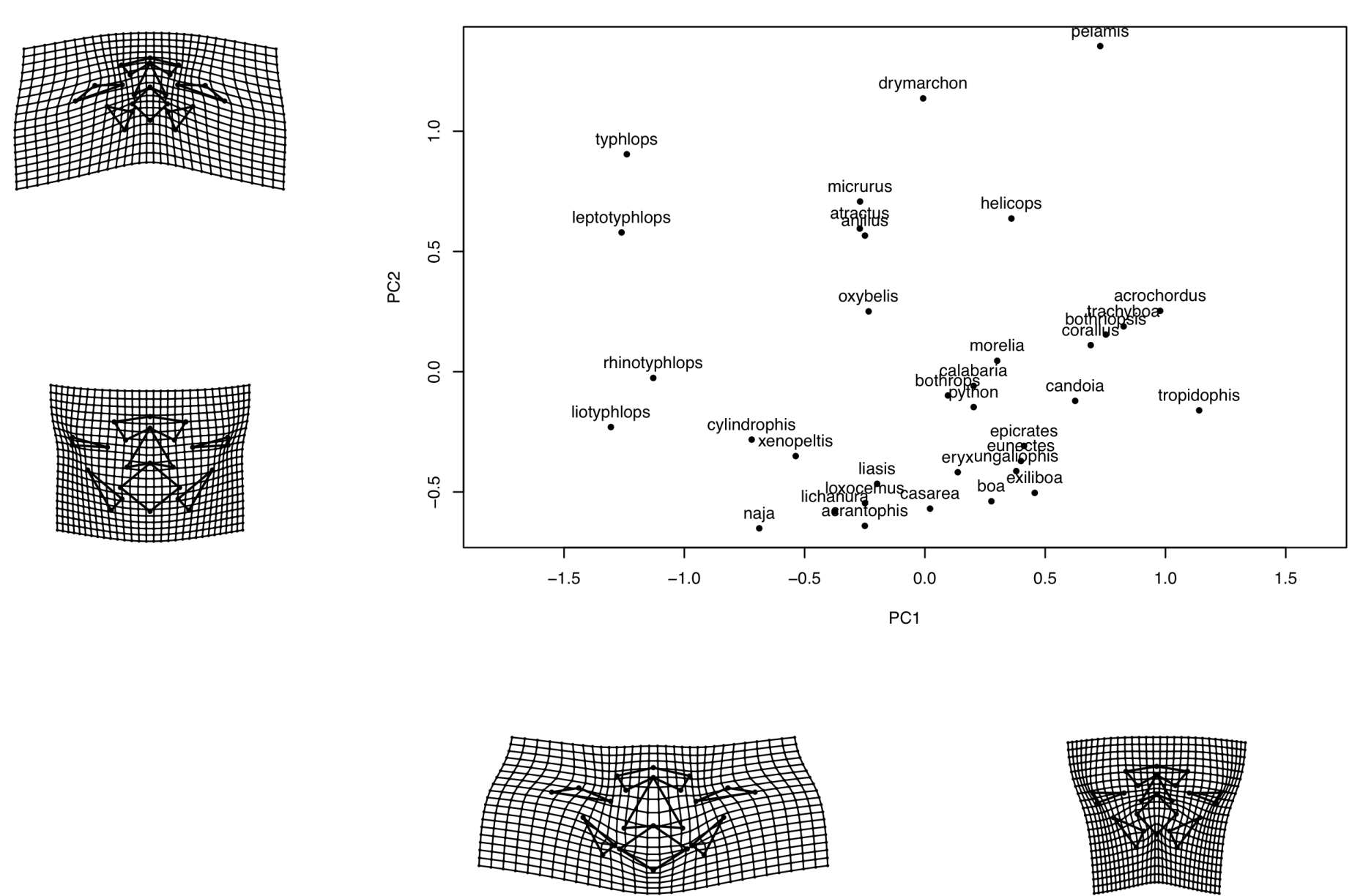
Anterior, posição=12
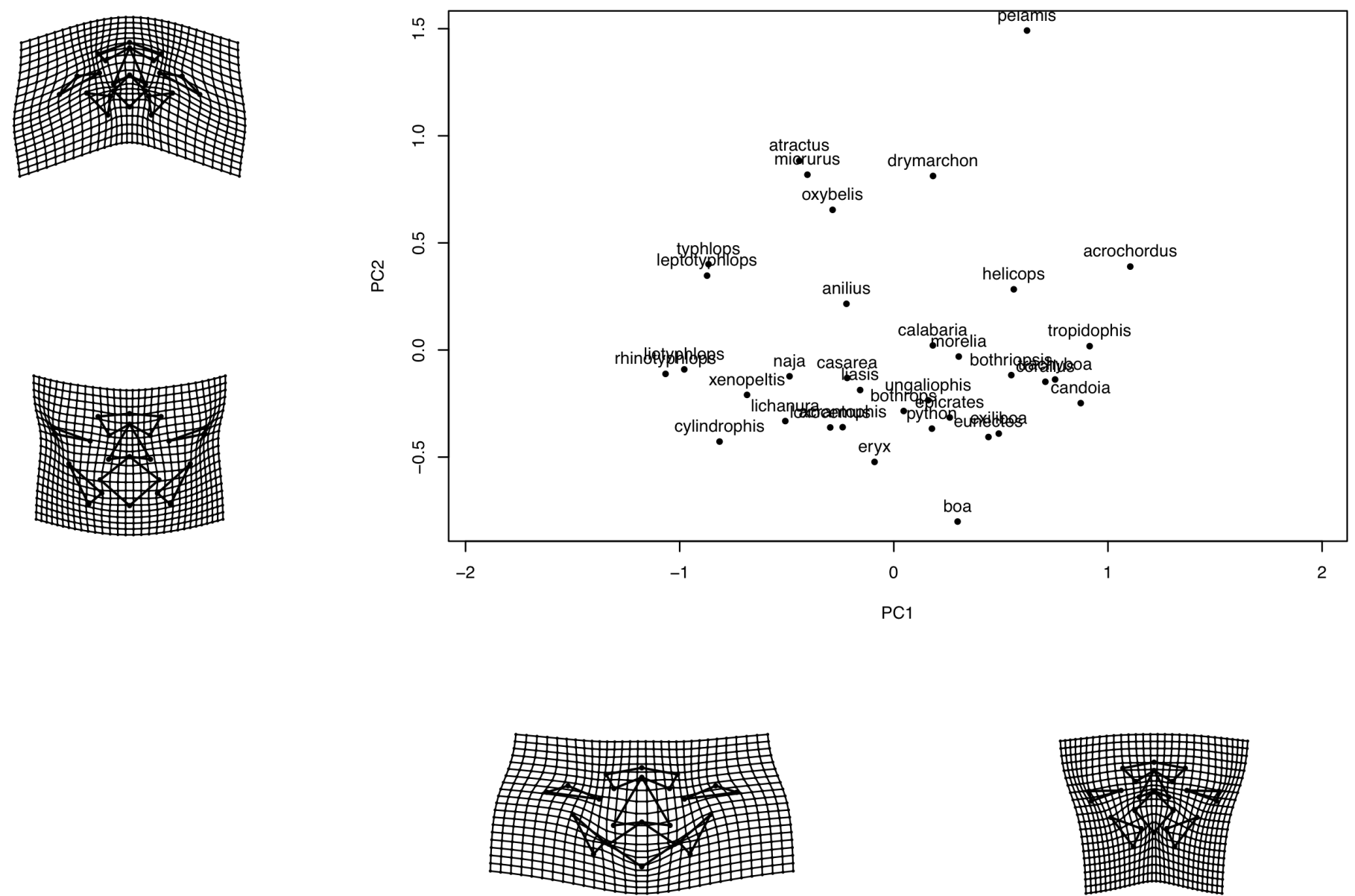

A-162 

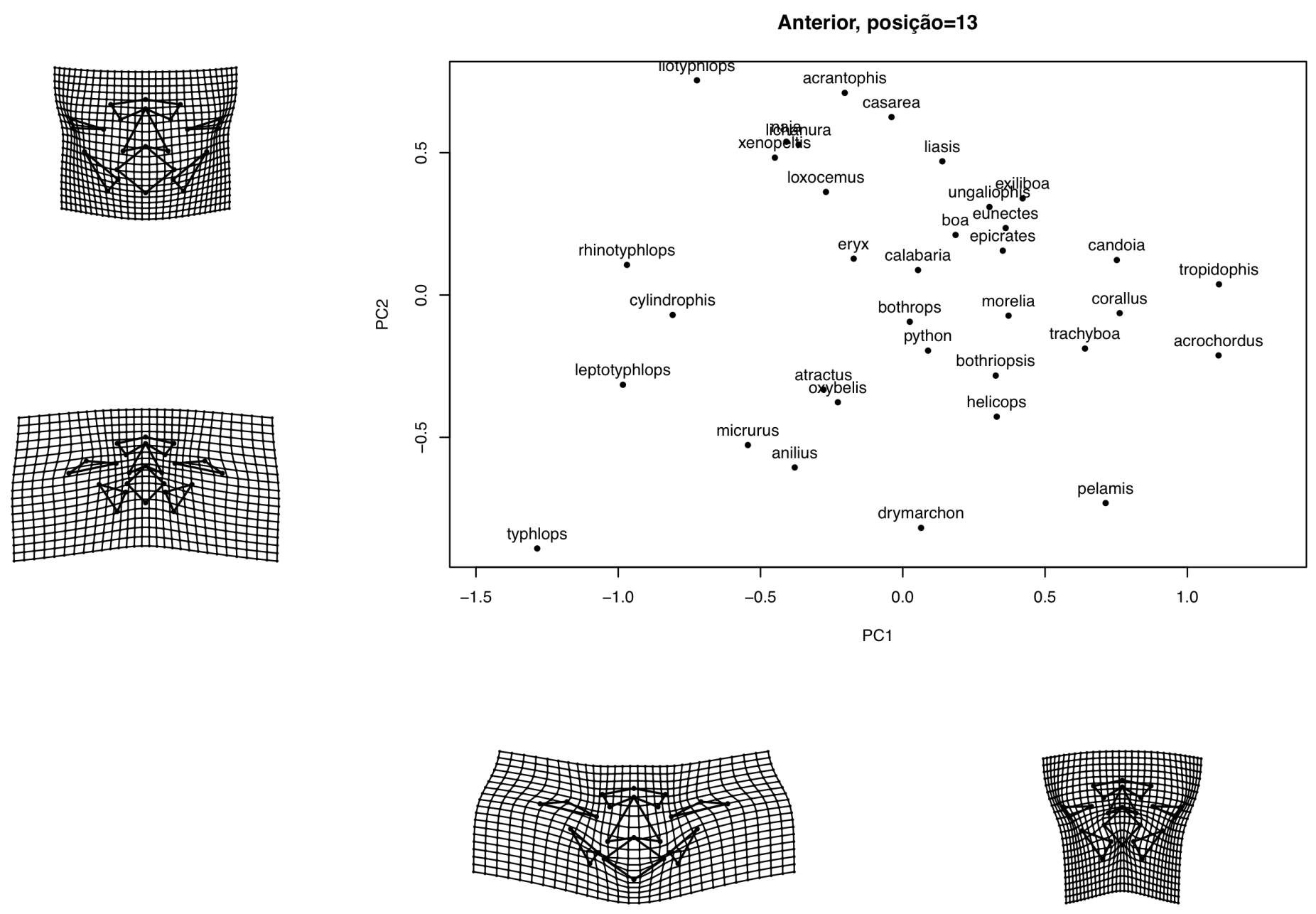
Anterior, posição=14
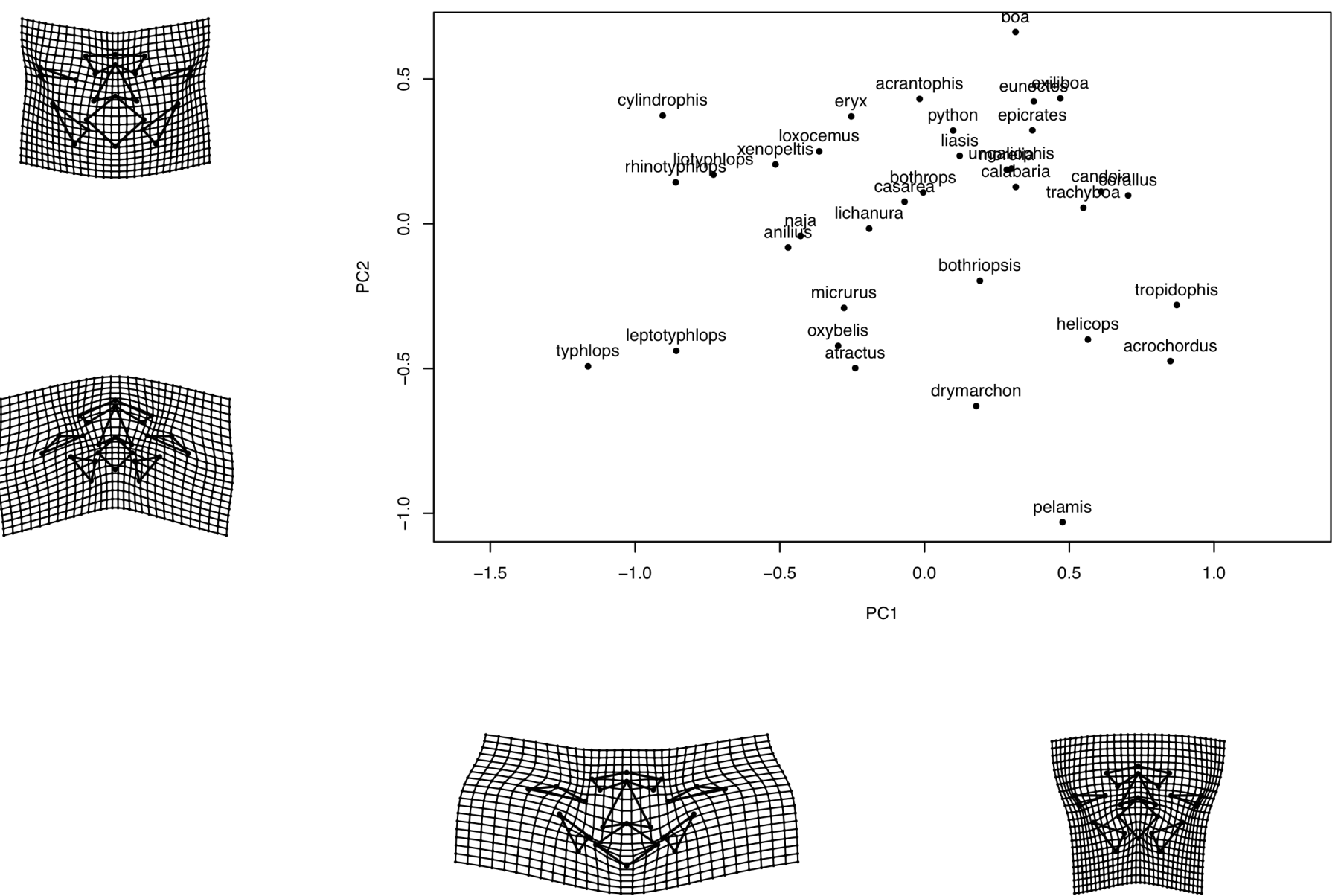

A-164 
Anterior, posição=15
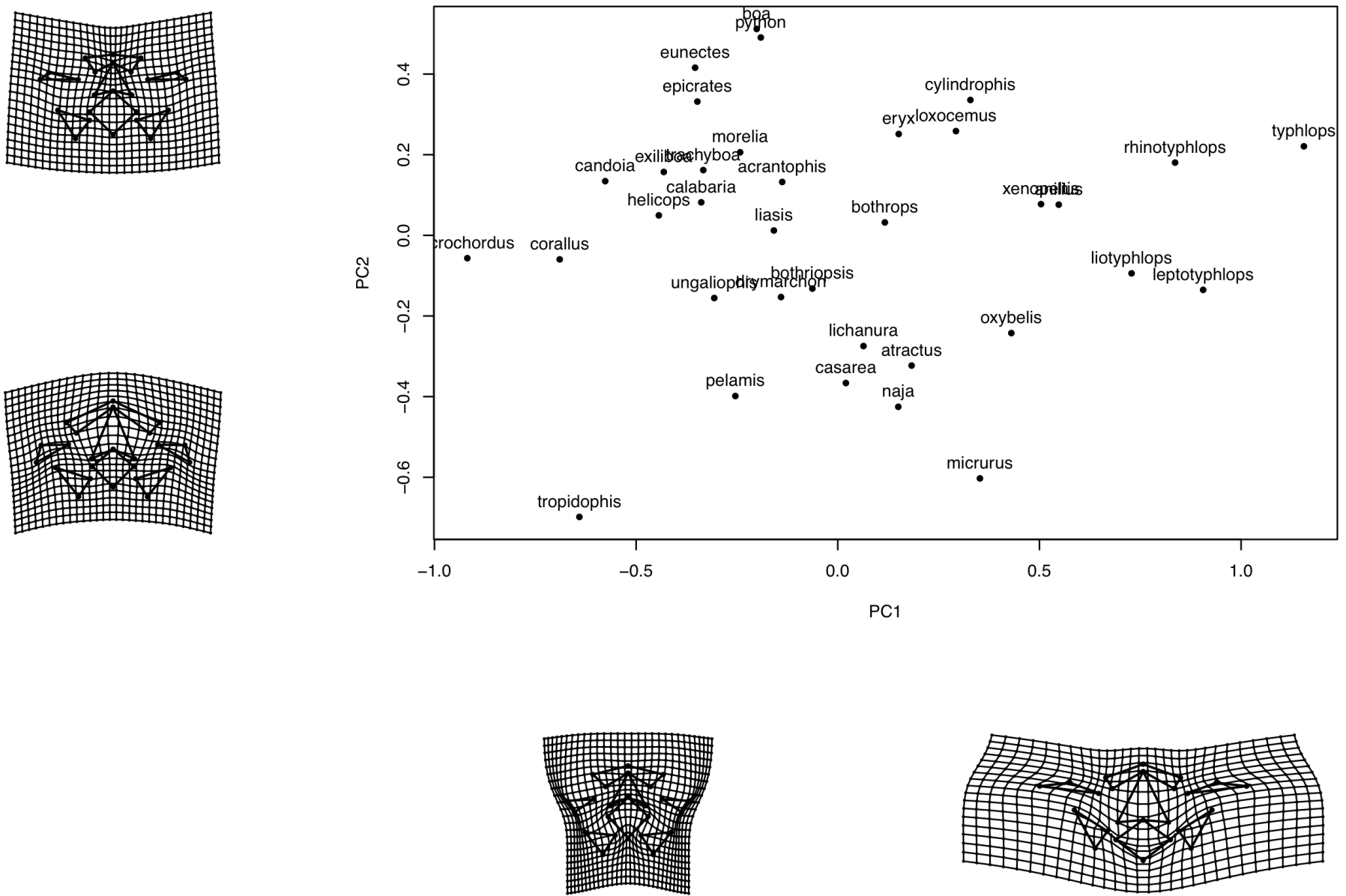
Lateral, posição=1
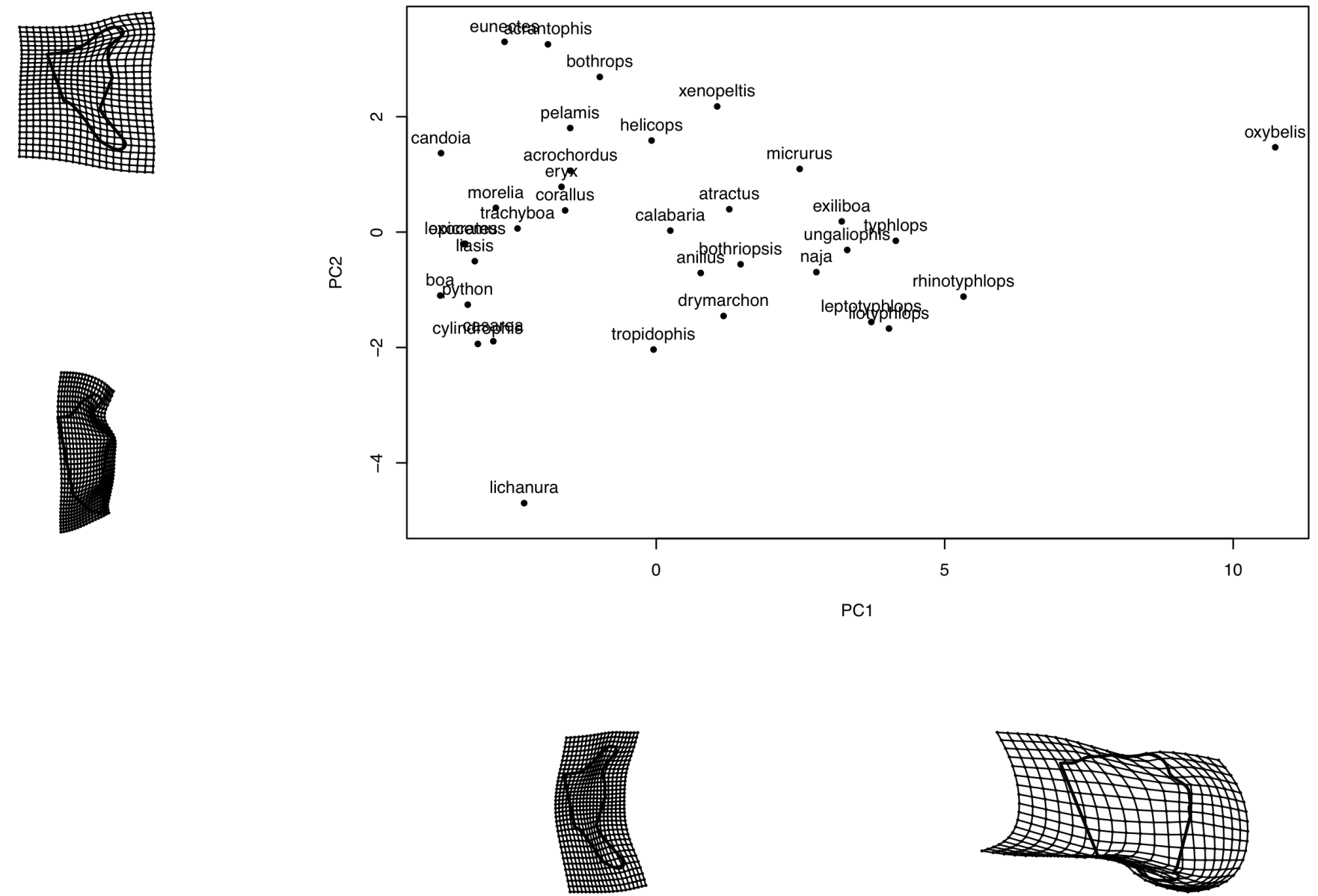
Lateral, posição=2
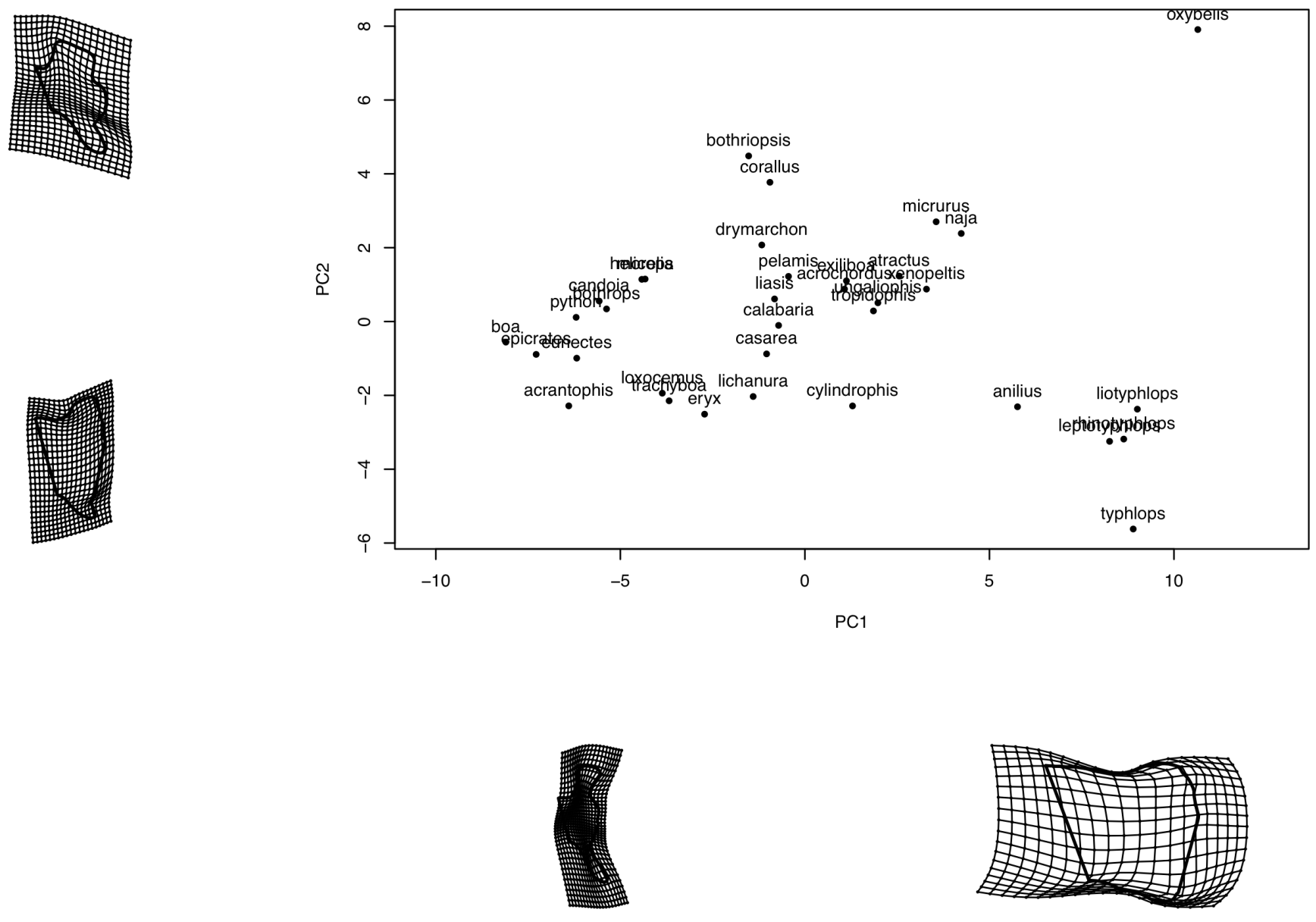
Lateral, posição=3
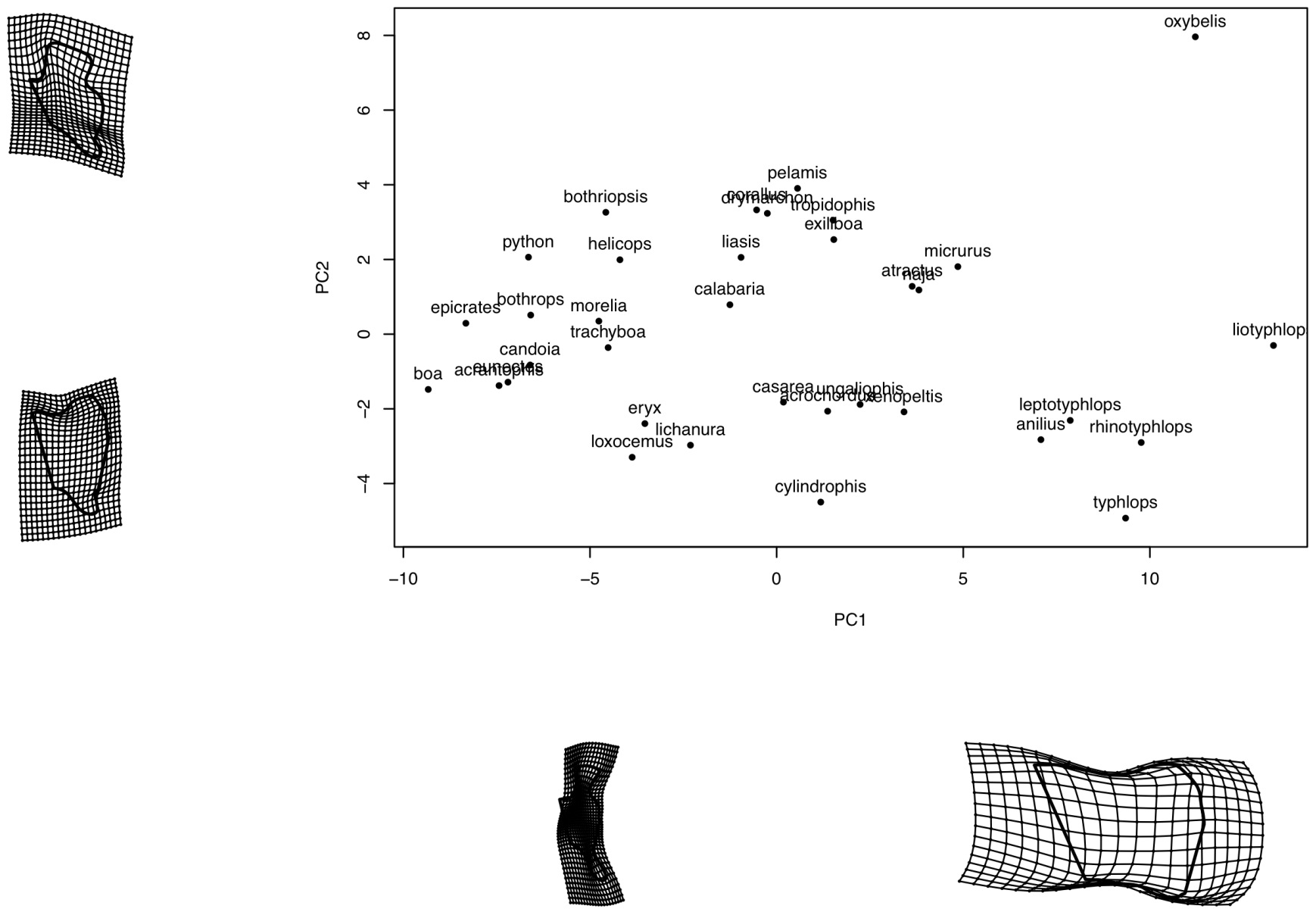
Lateral, posição=4
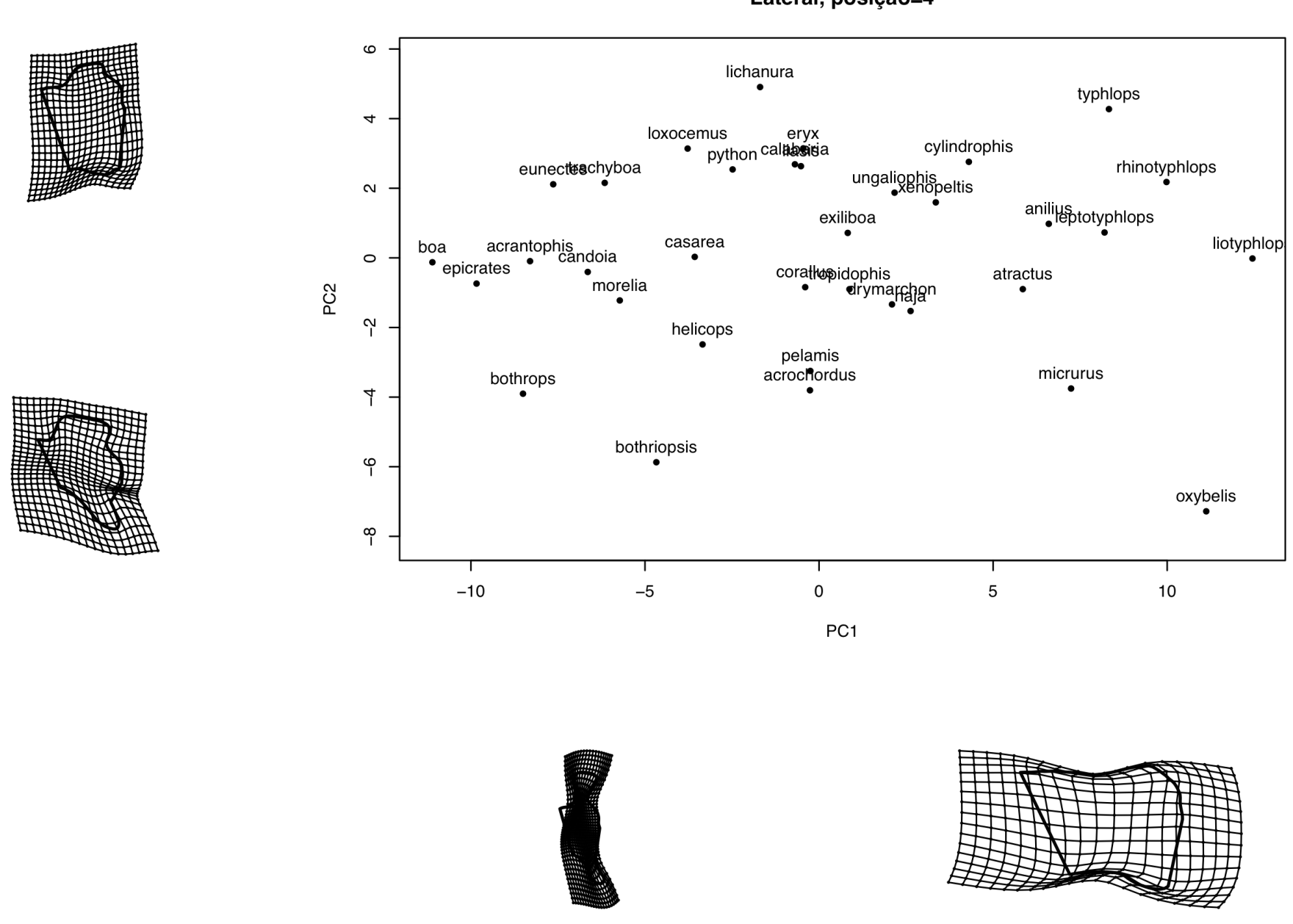

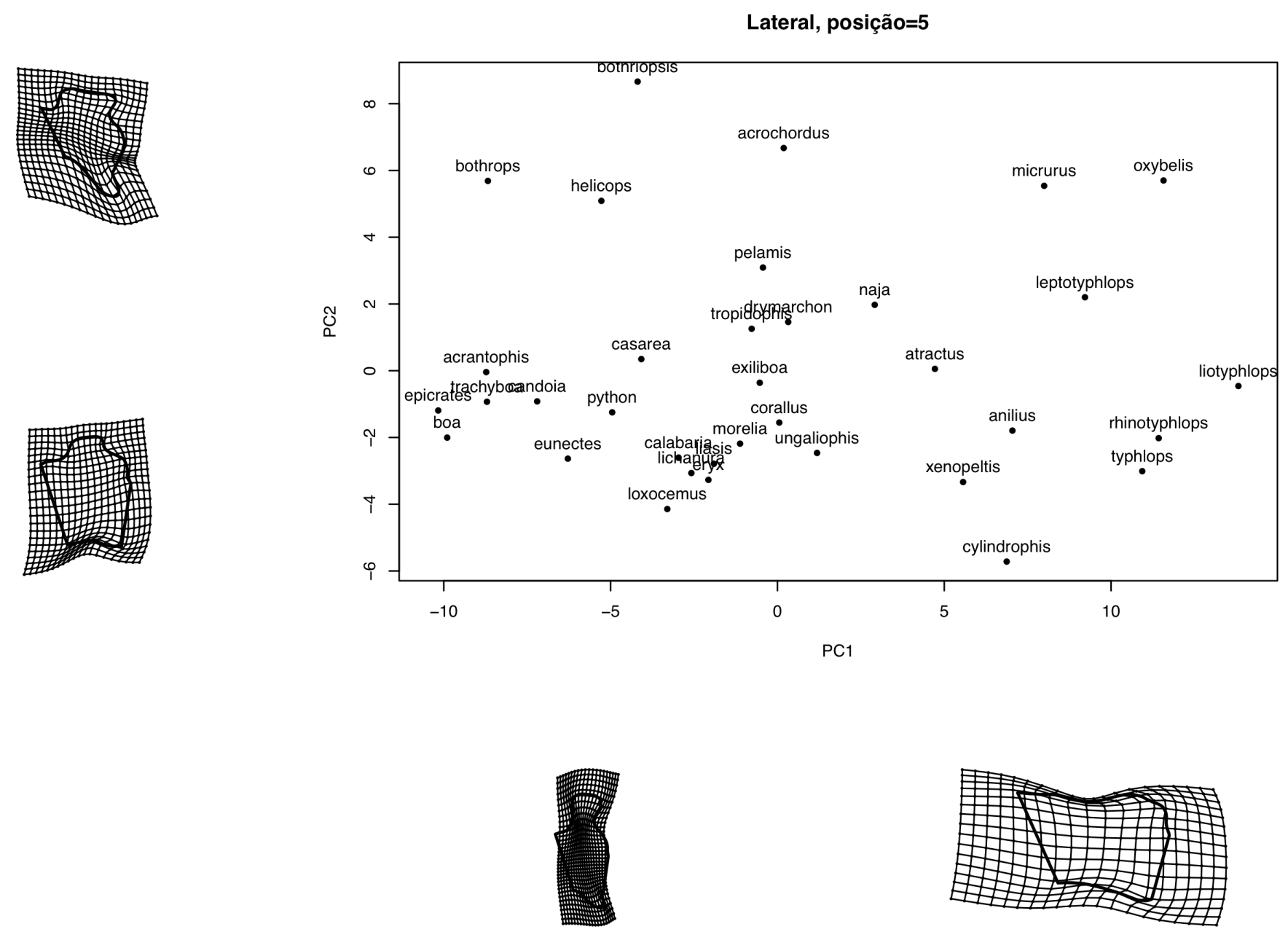

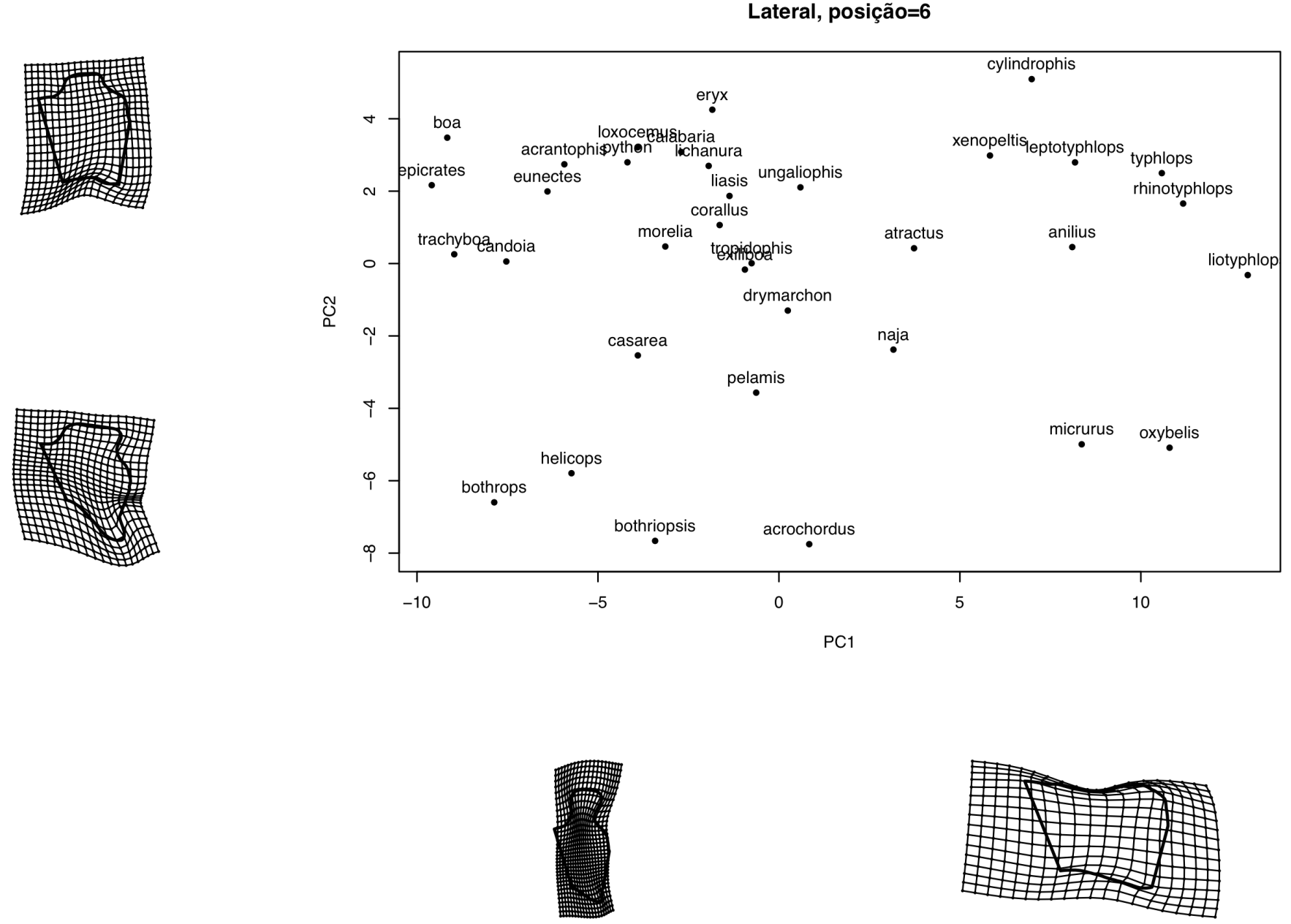

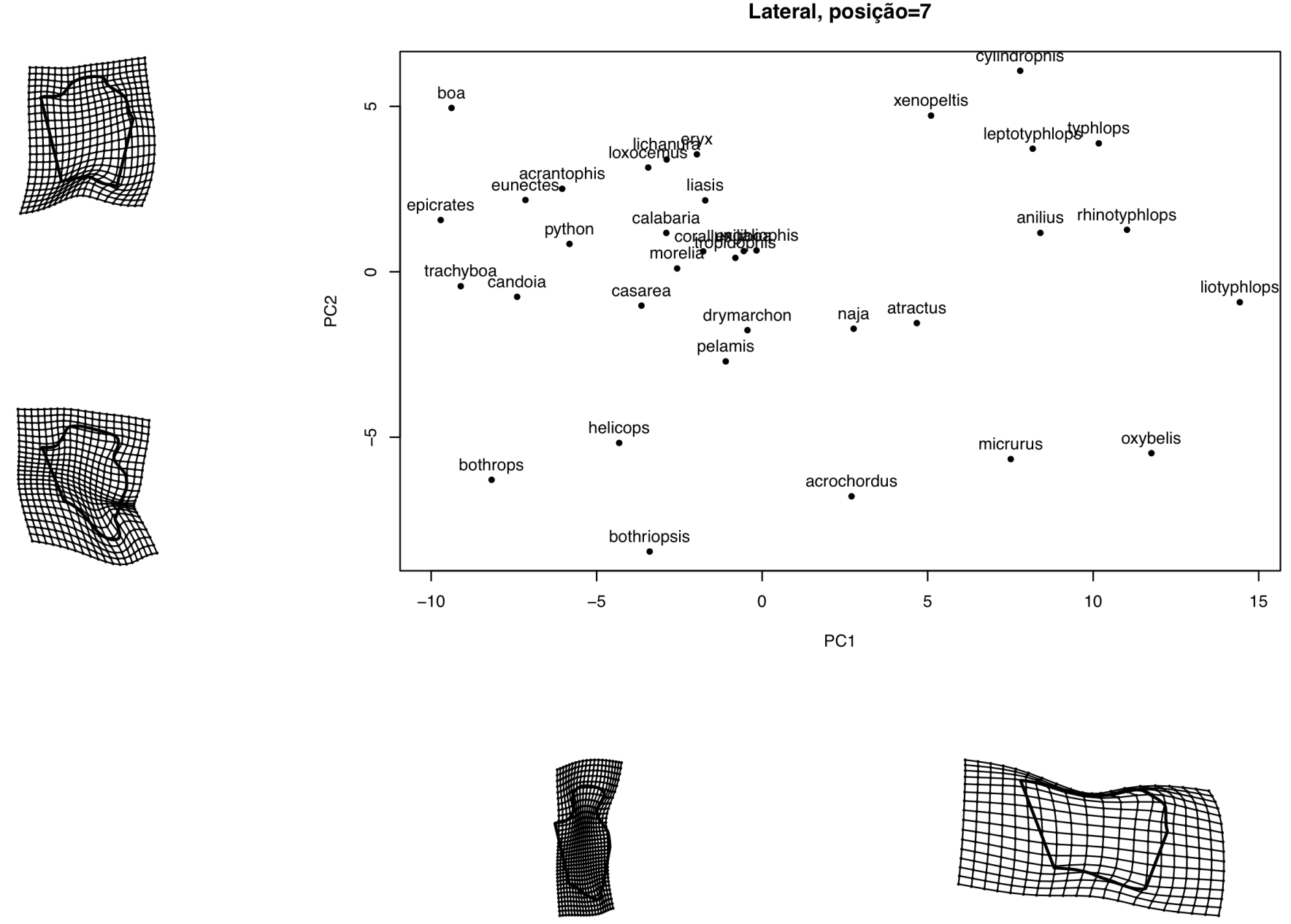
Lateral, posição=8
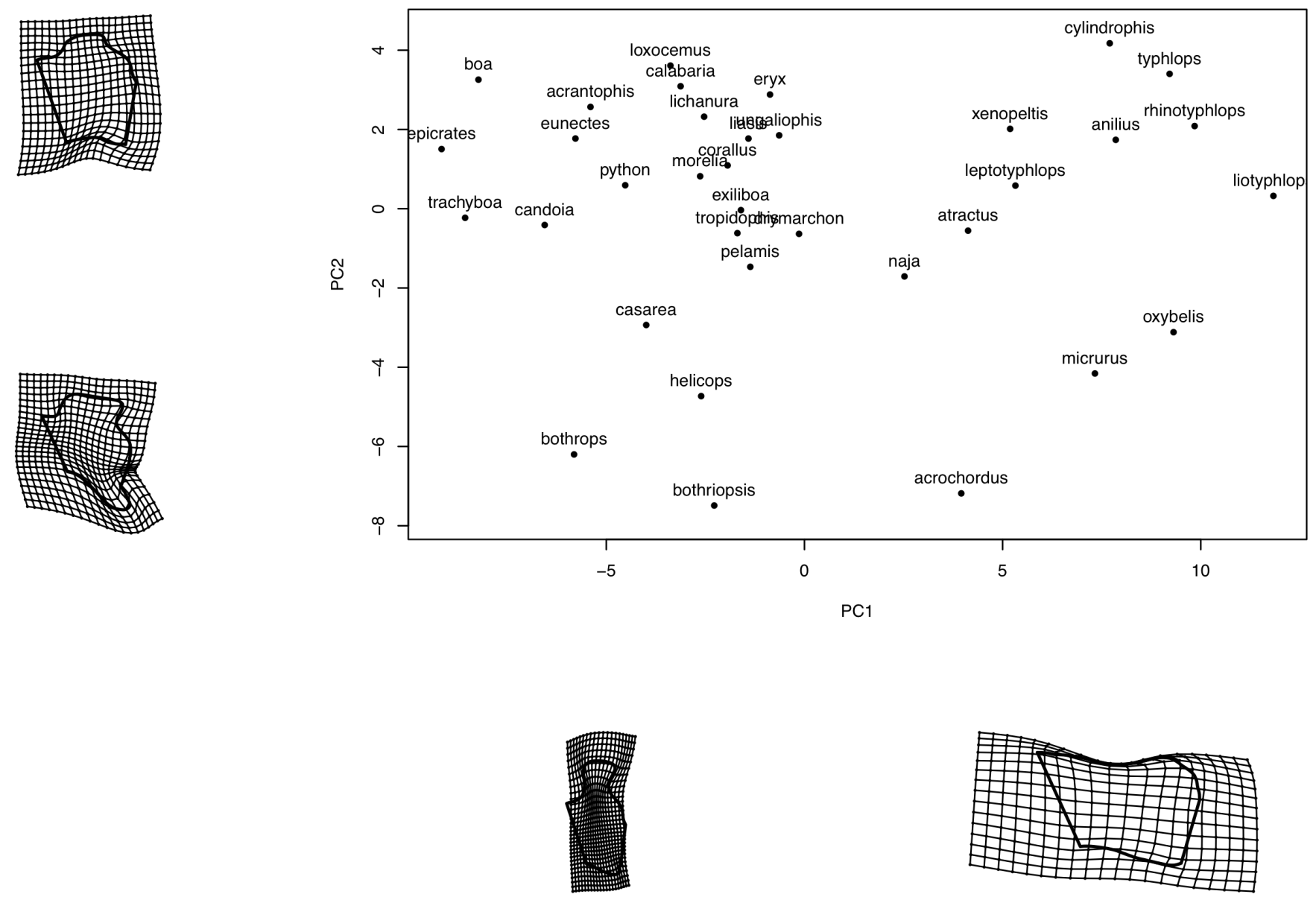

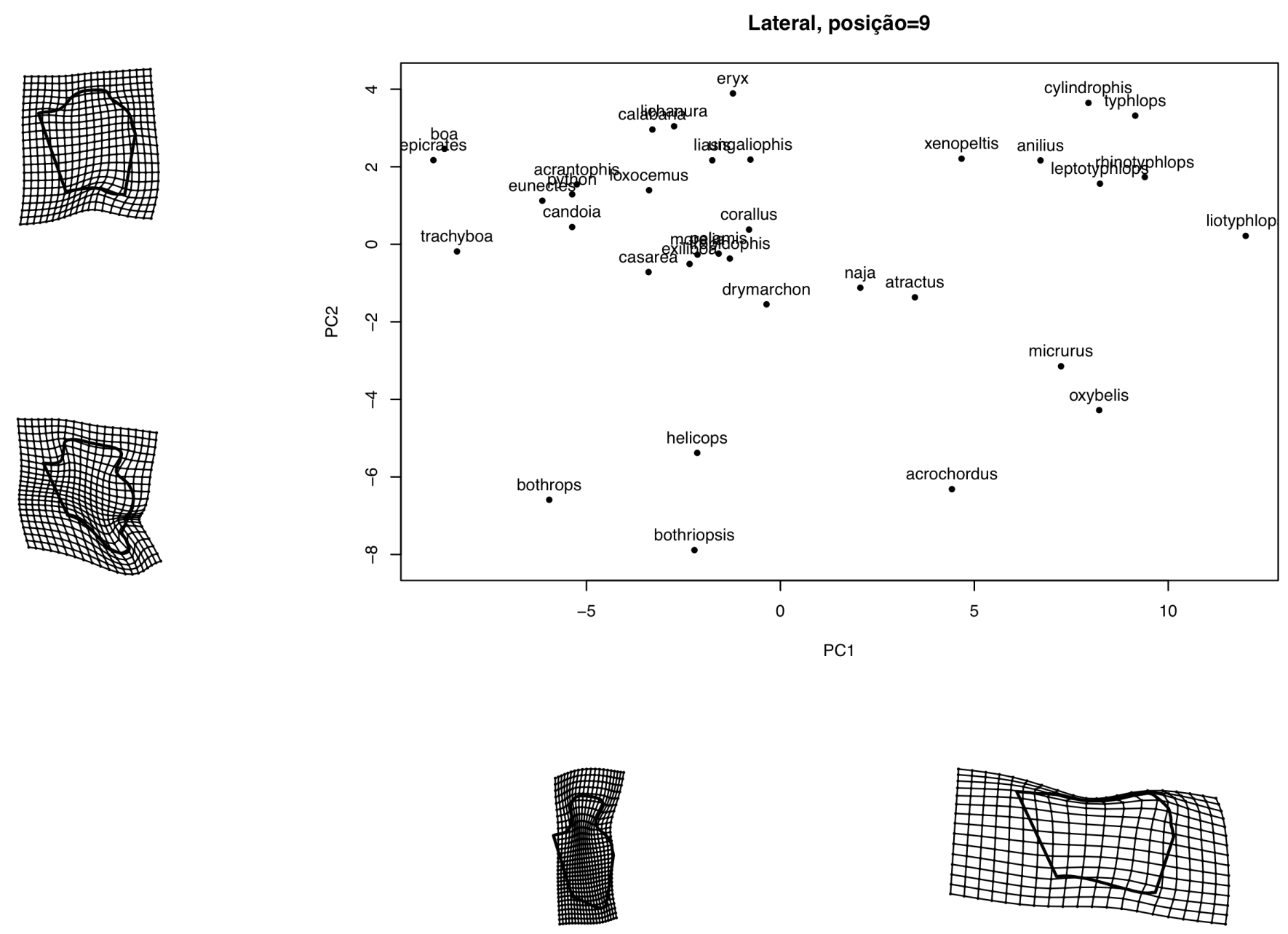

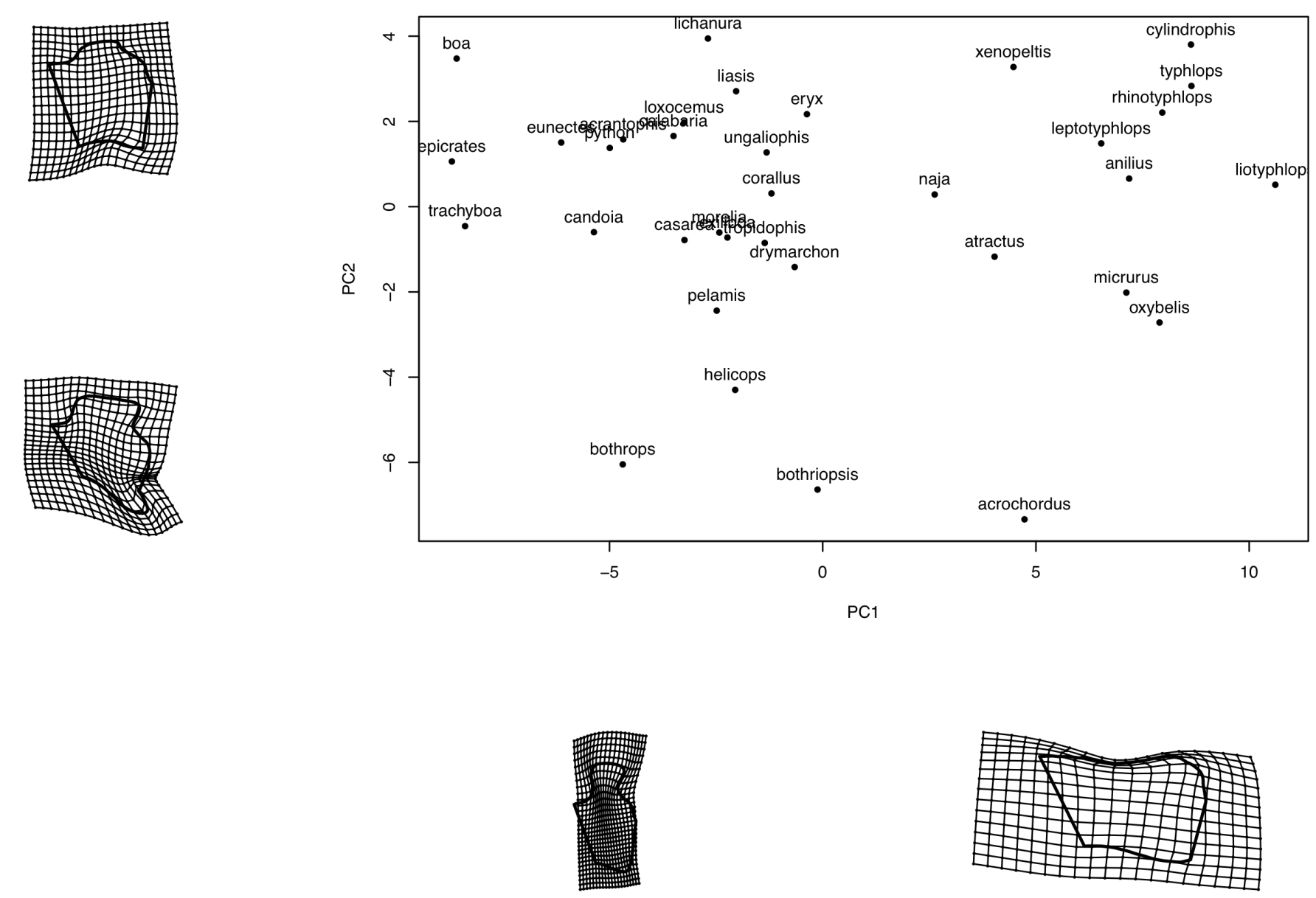

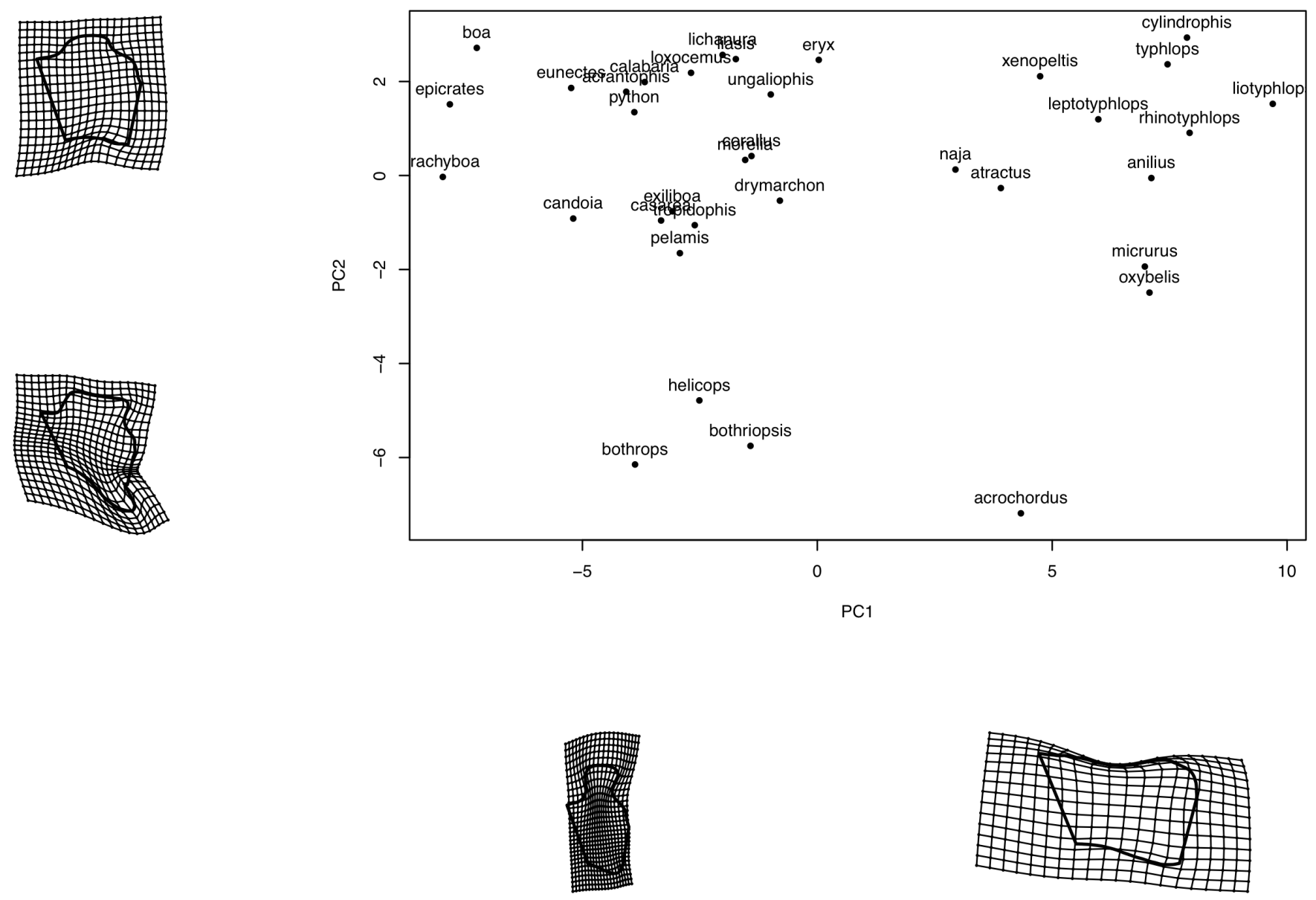

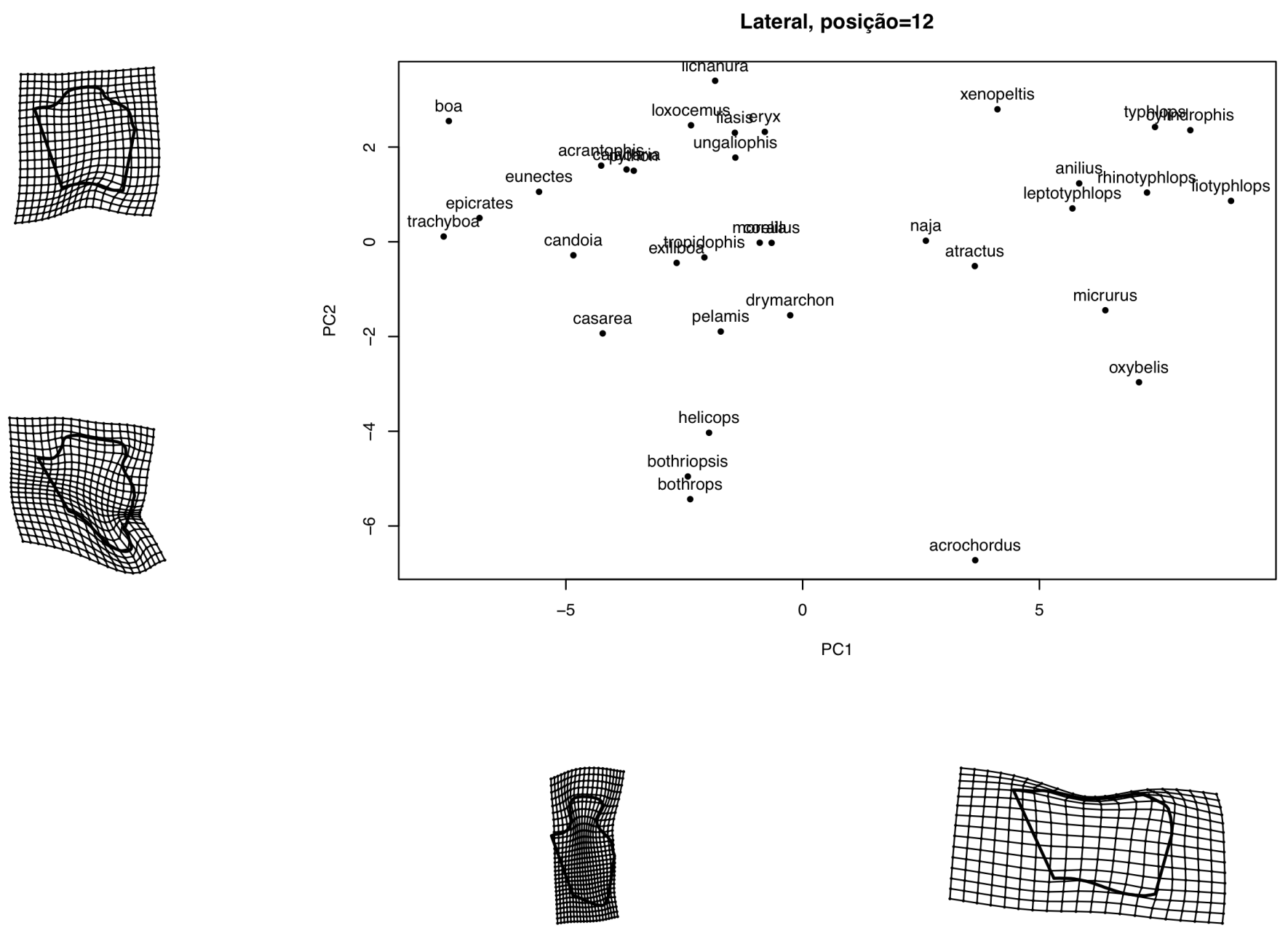

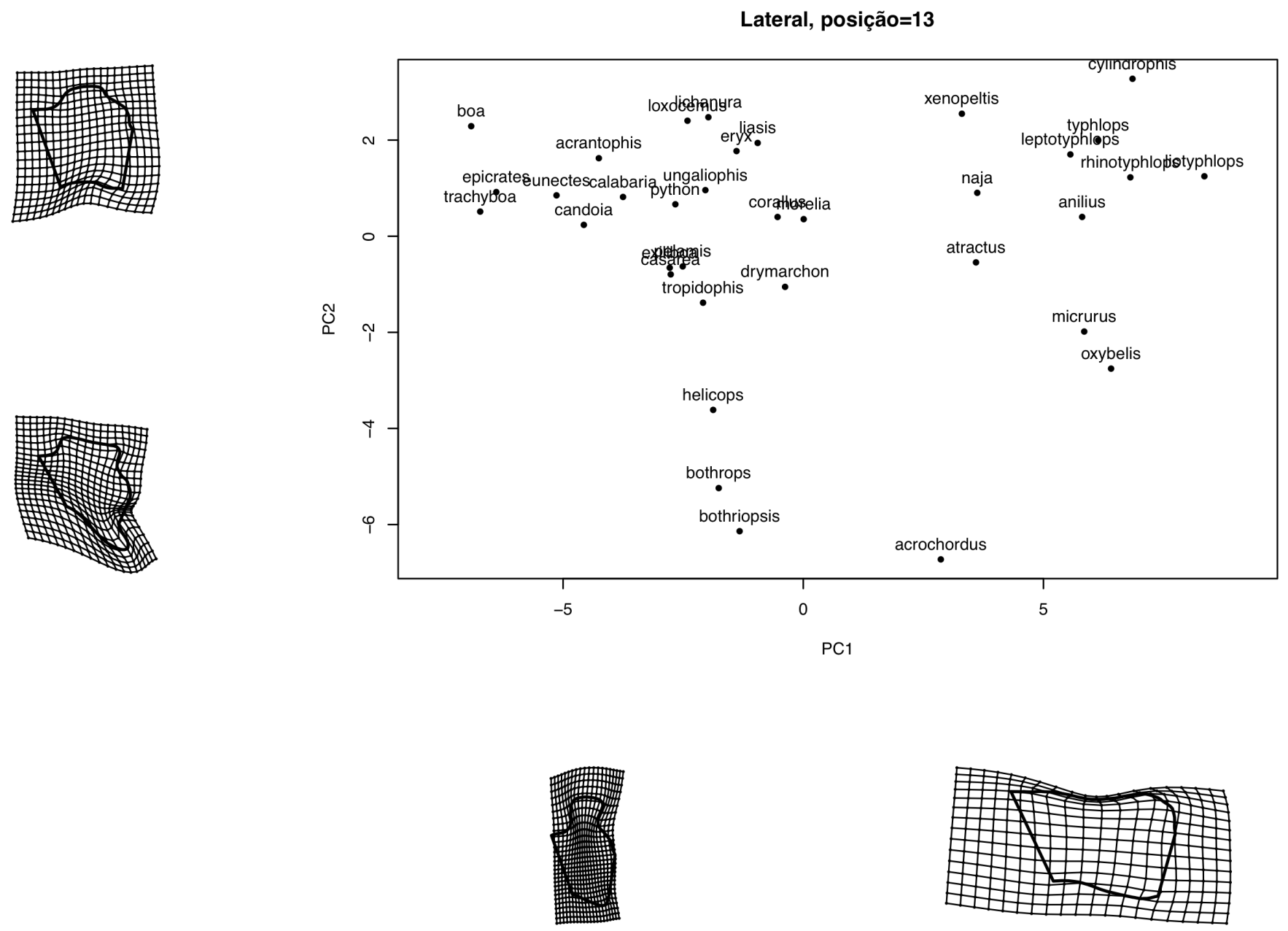

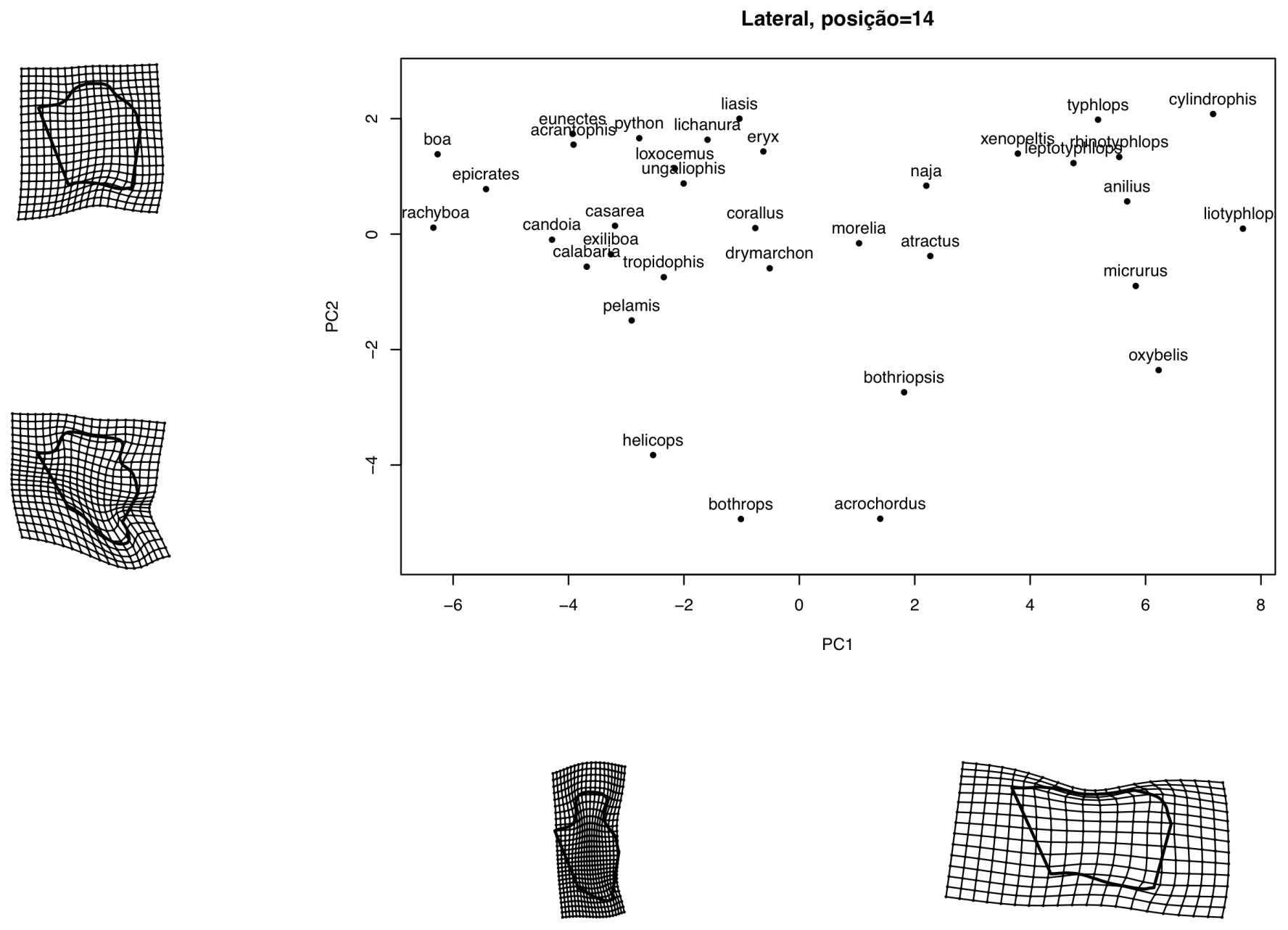

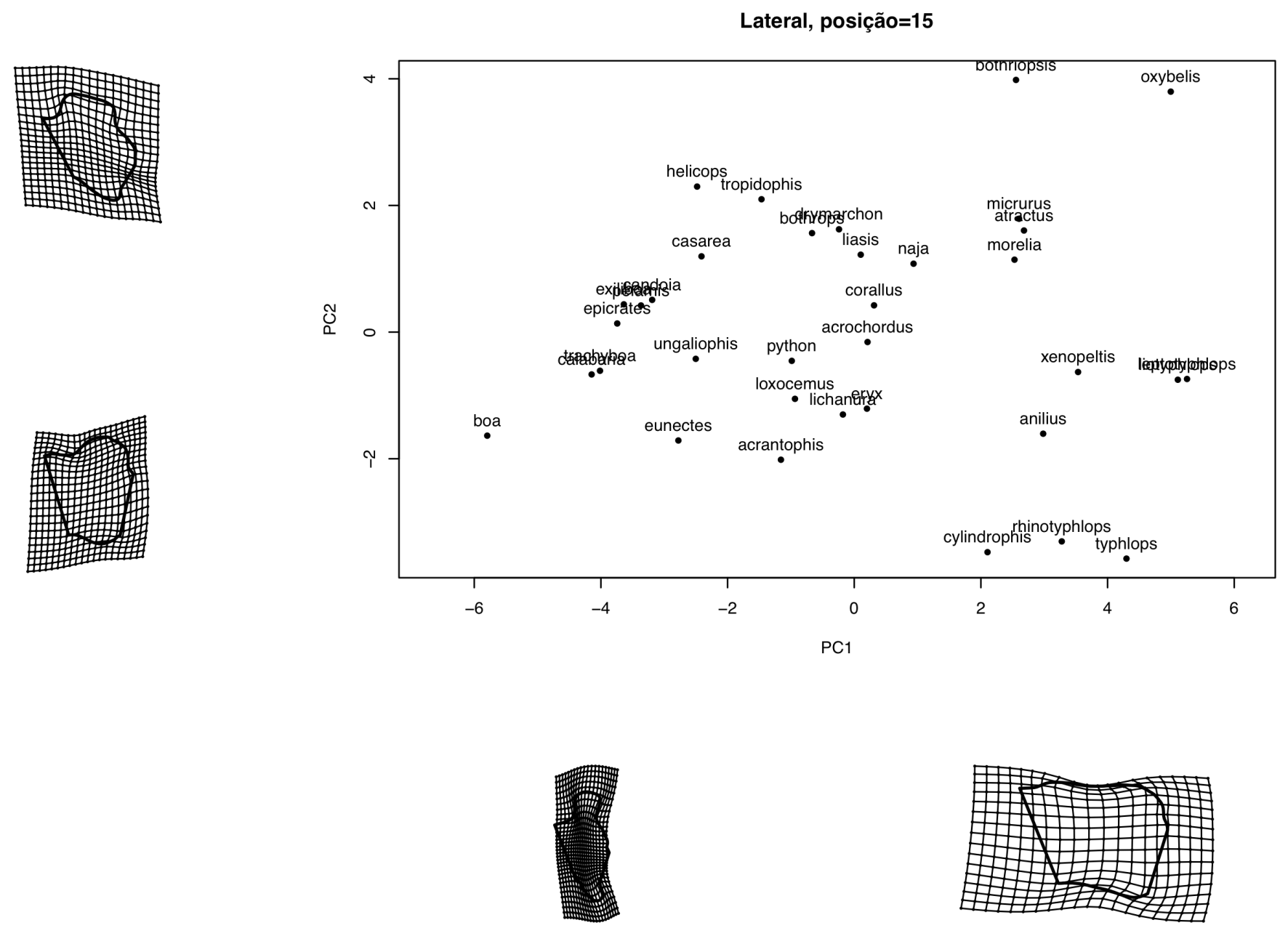
Posterior, posição=1
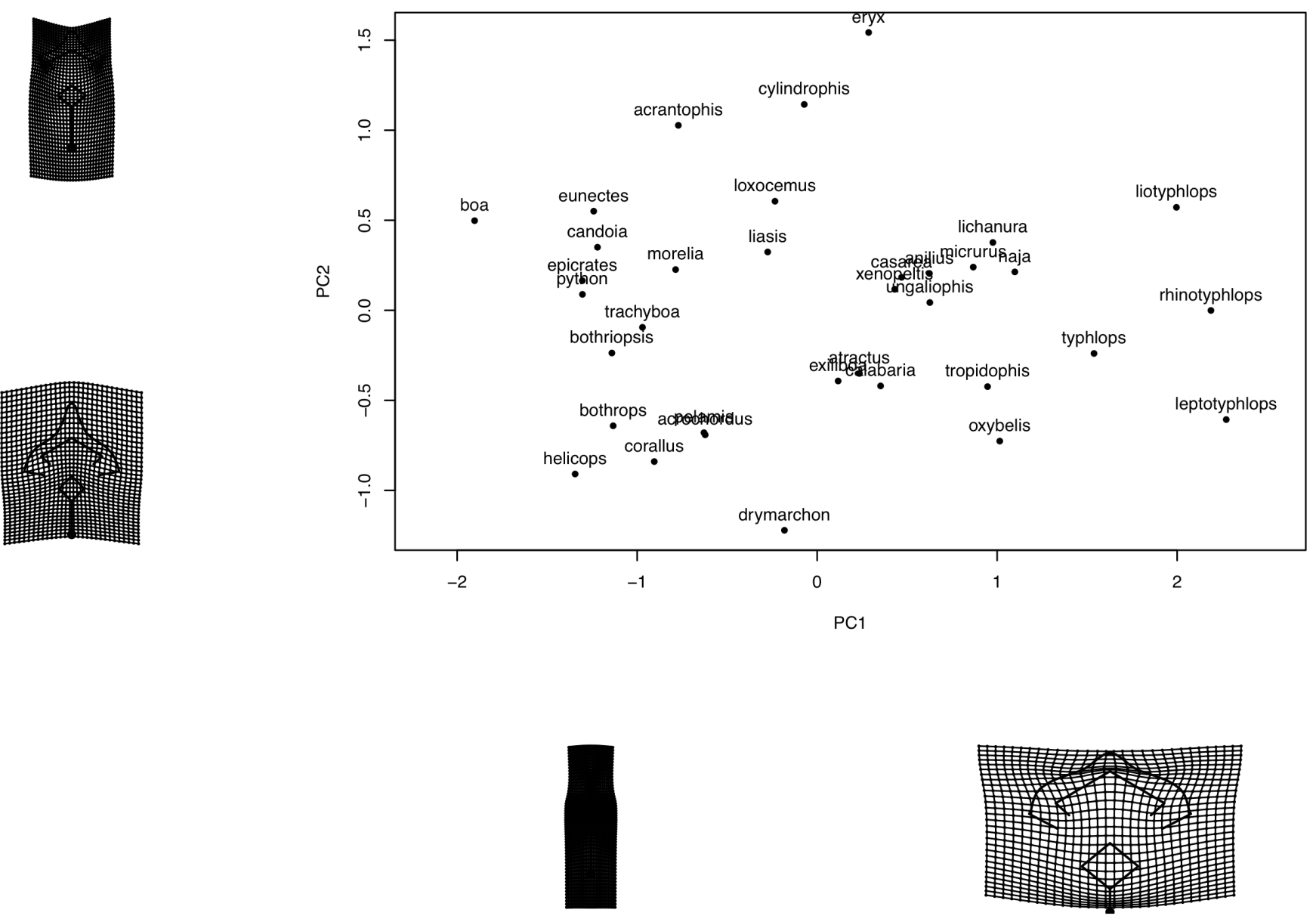
Posterior, posição=2
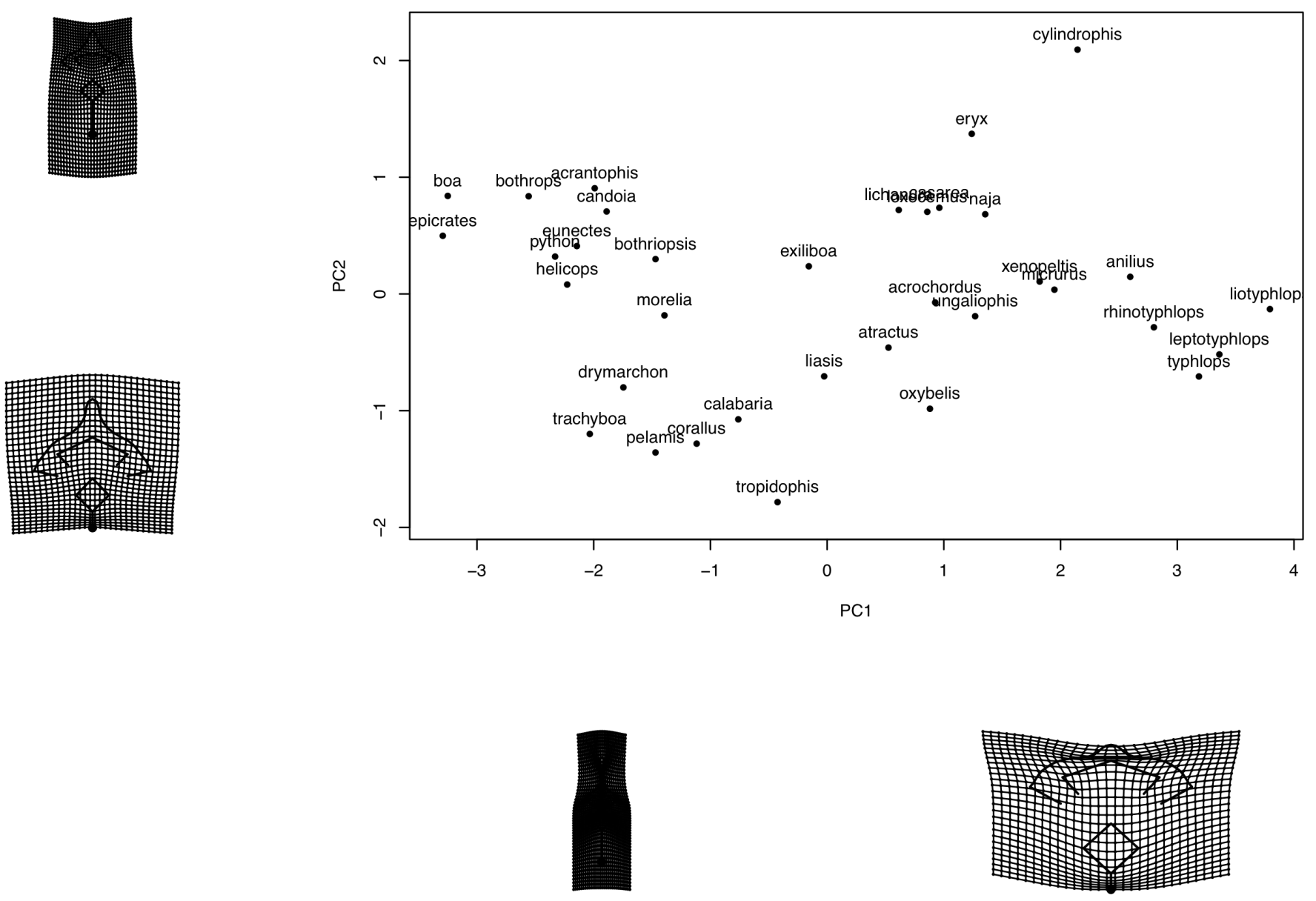
Posterior, posição=3
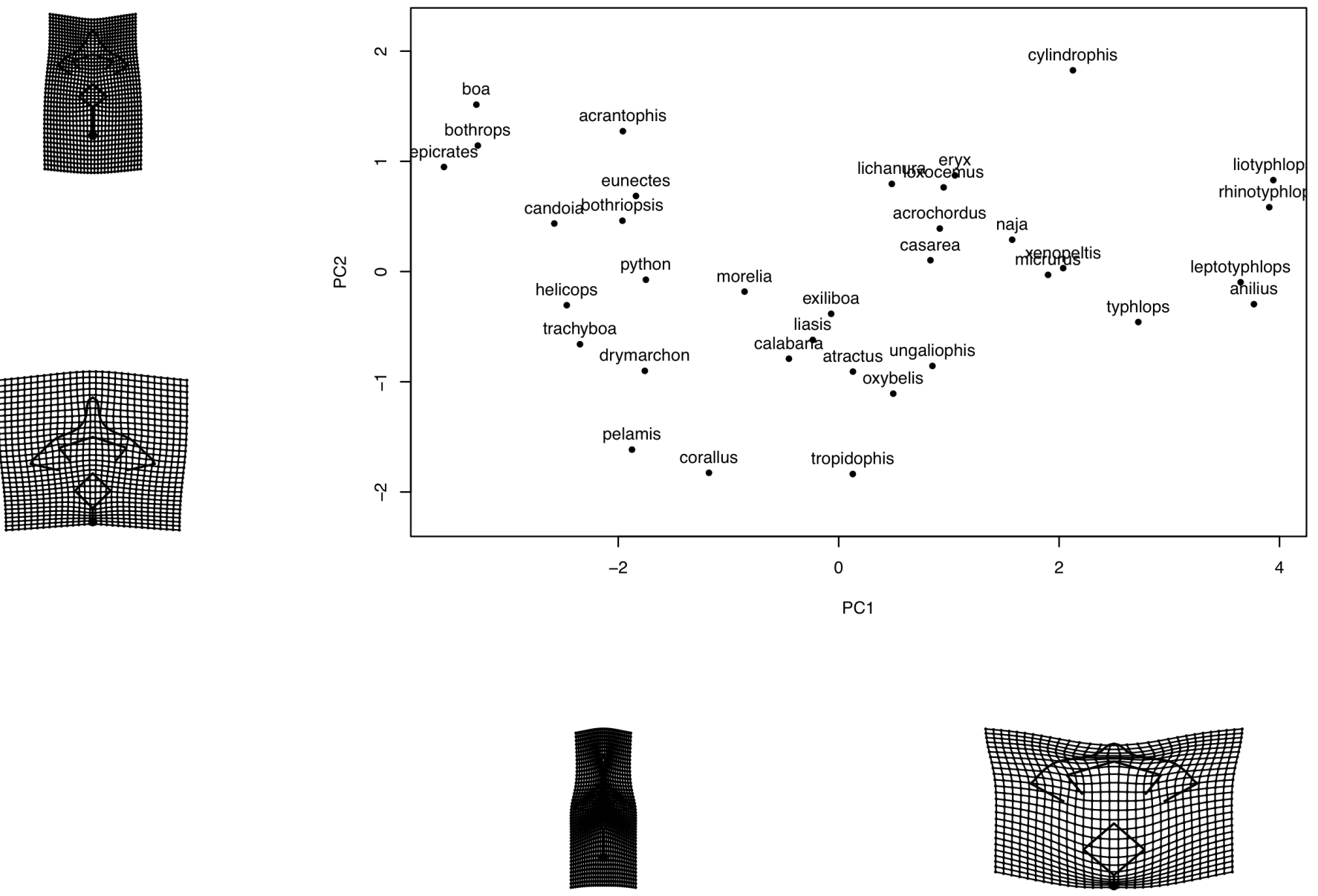
Posterior, posição=4
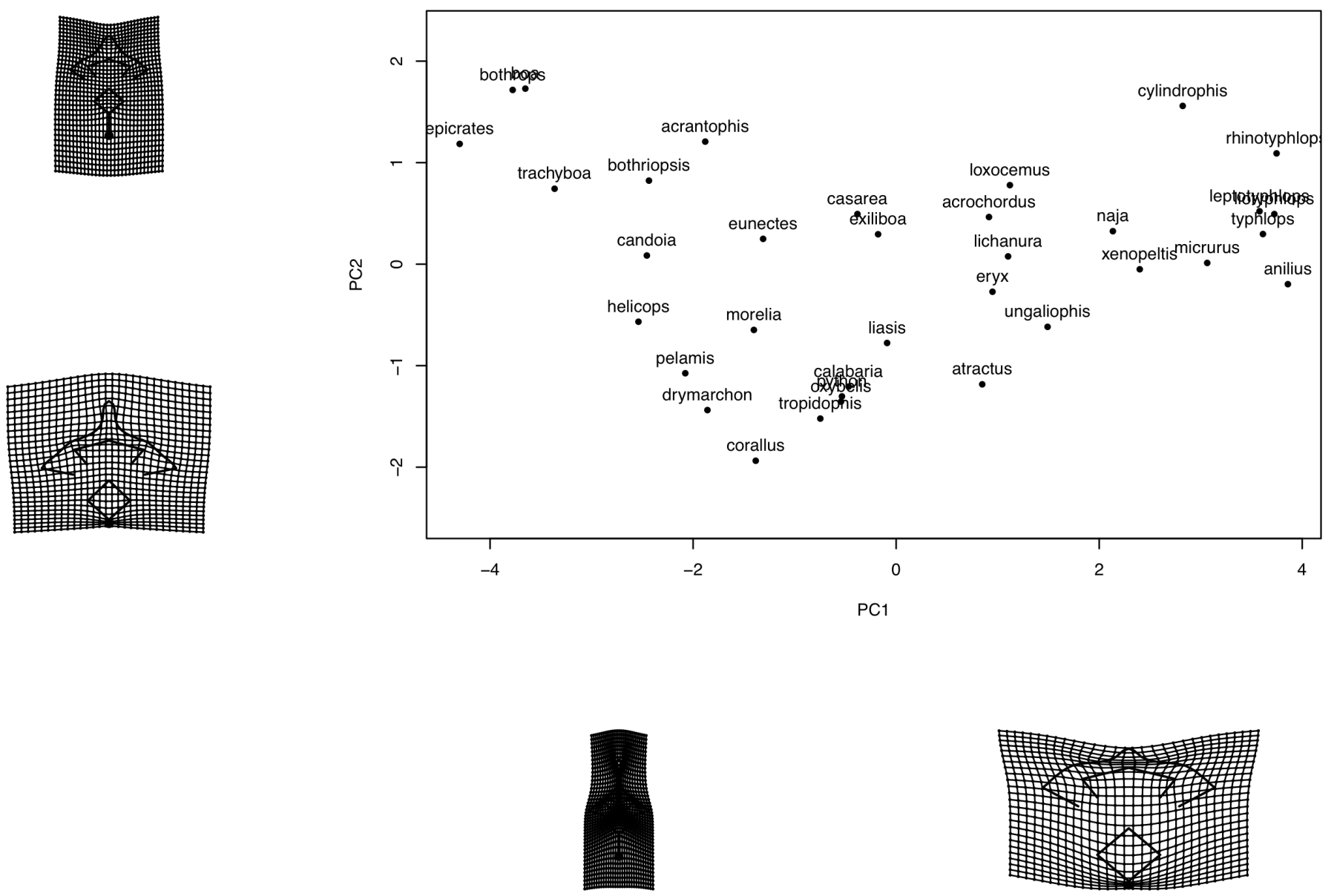
Posterior, posição=5
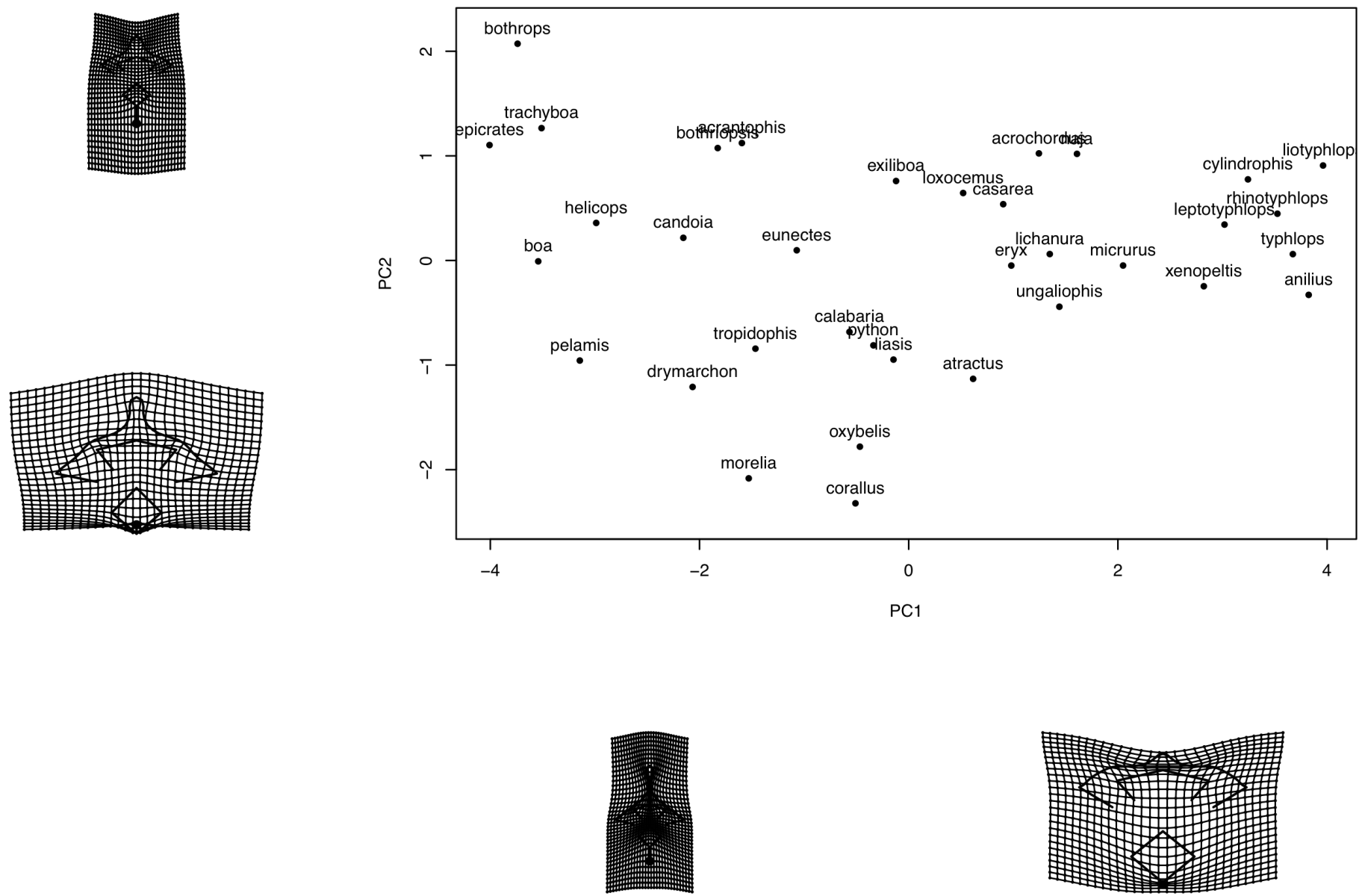
Posterior, posição=6
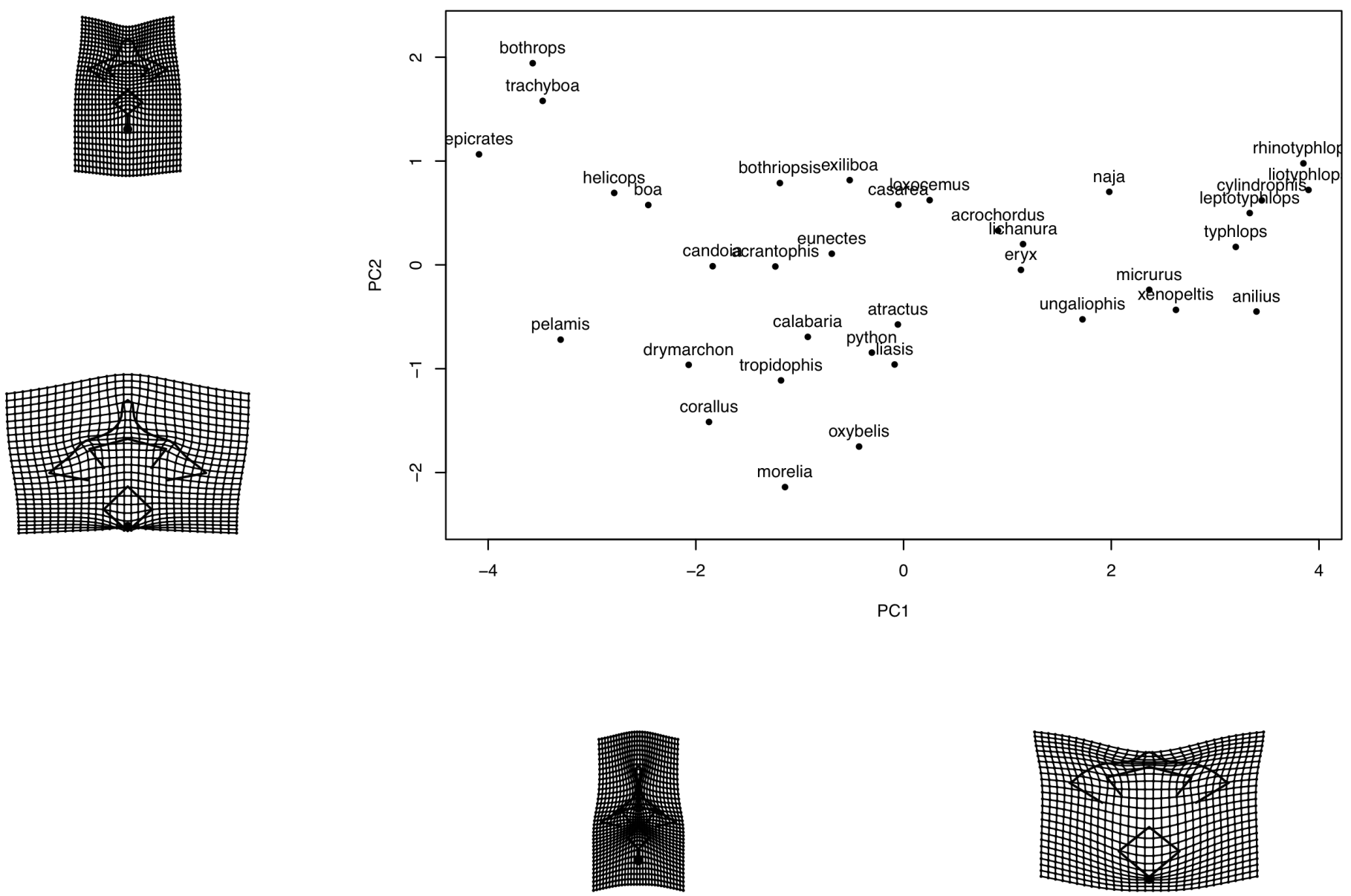
Posterior, posição=7
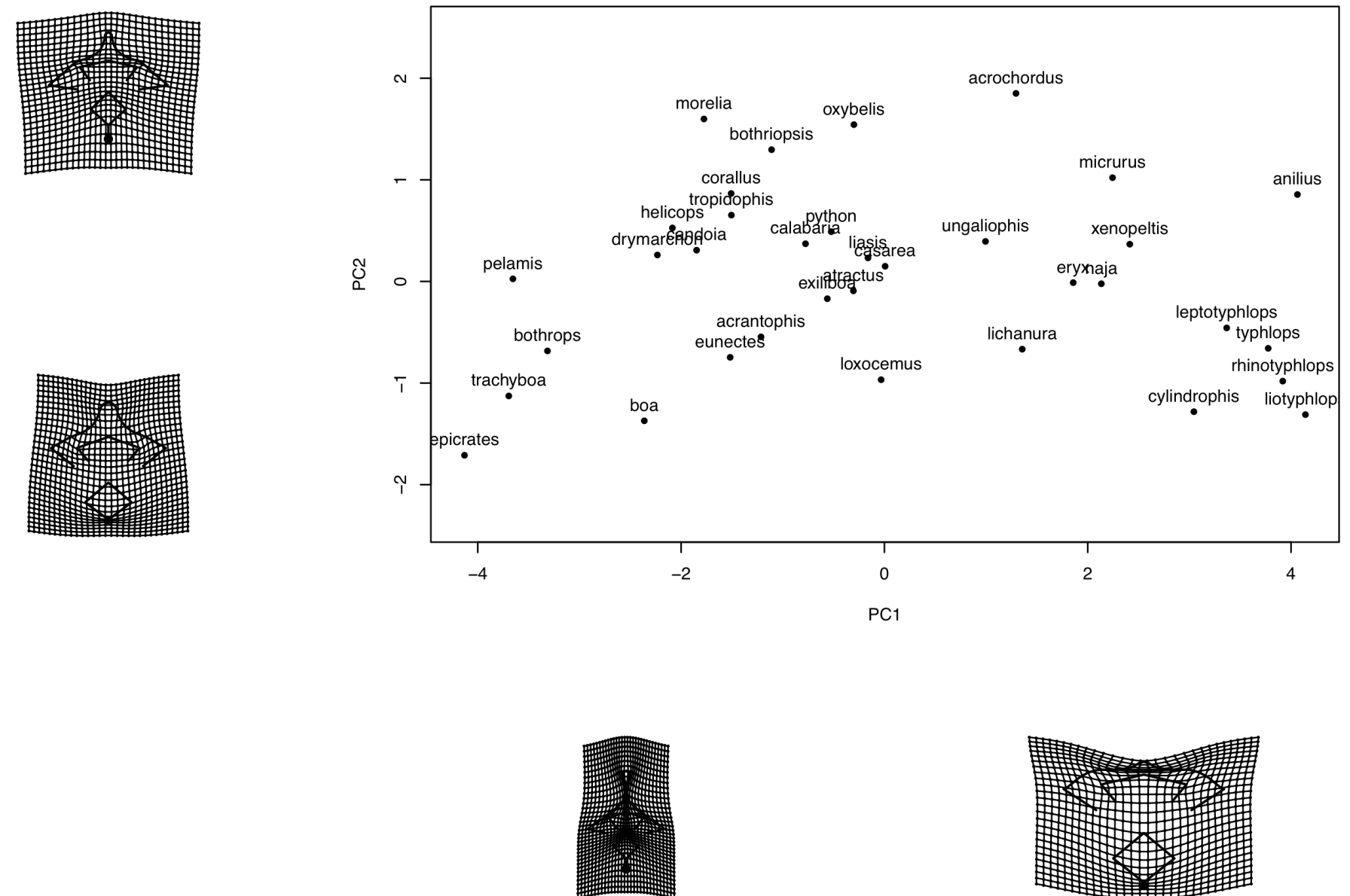
Posterior, posição=8
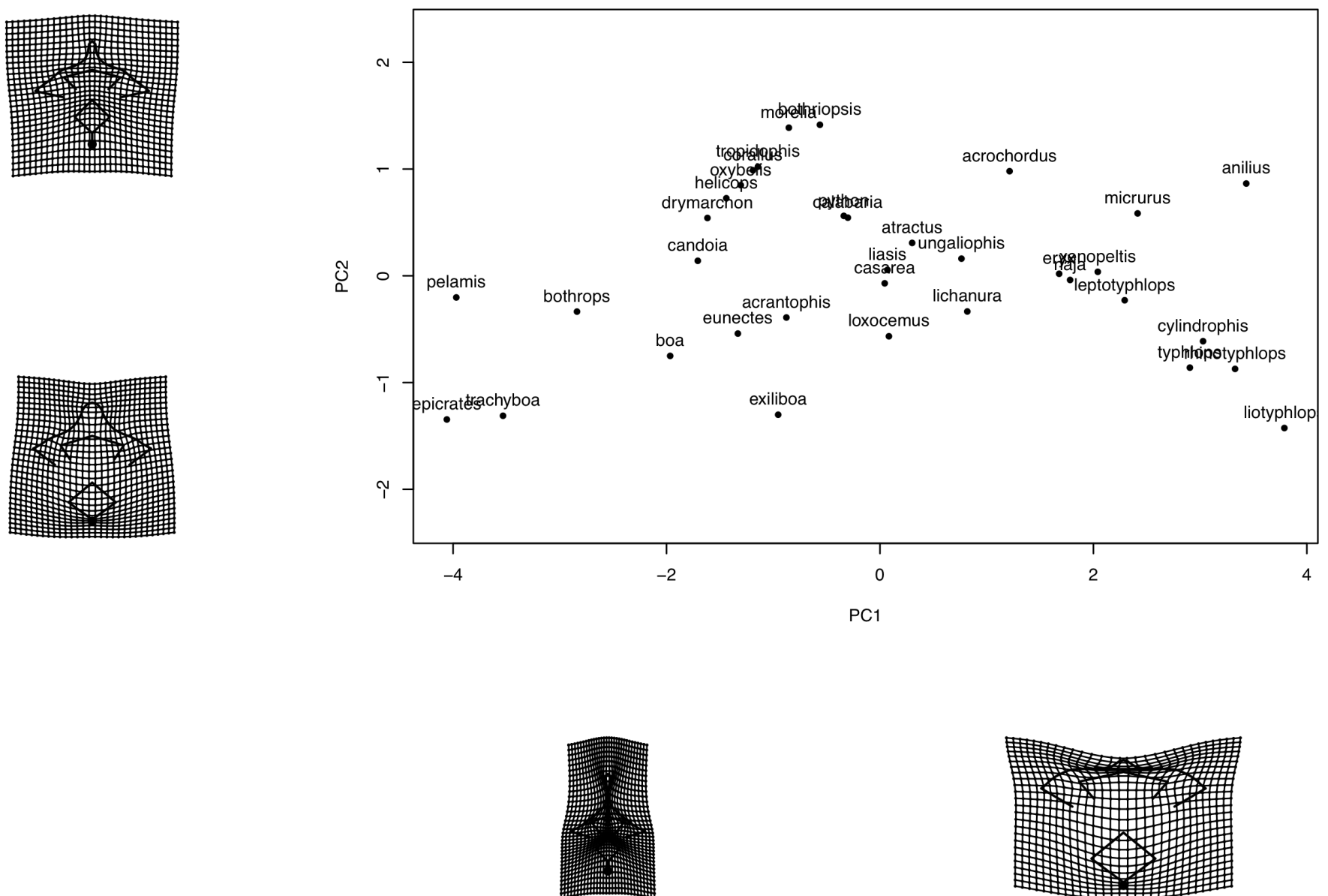
Posterior, posição=9
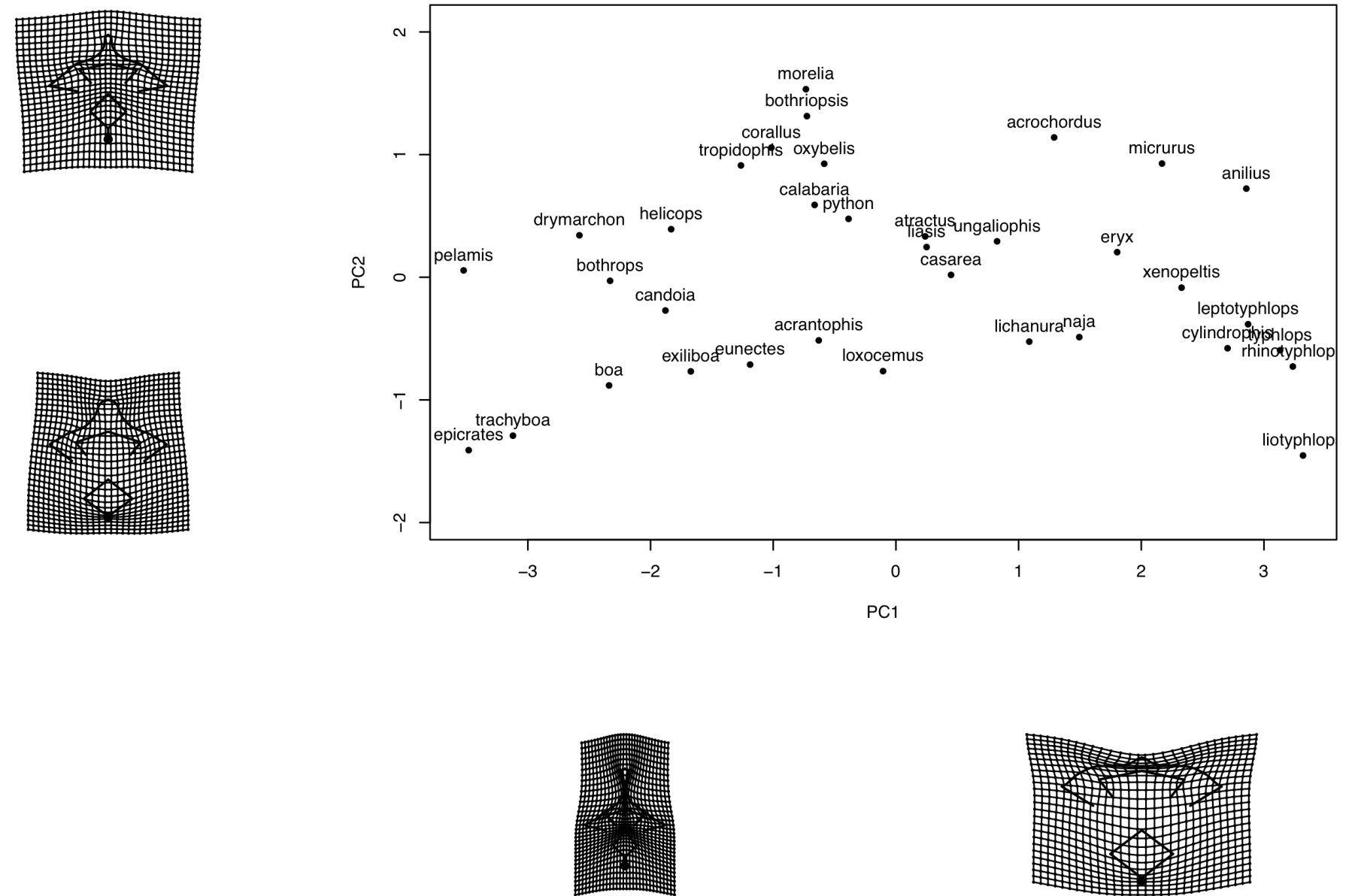
Posterior, posição=10
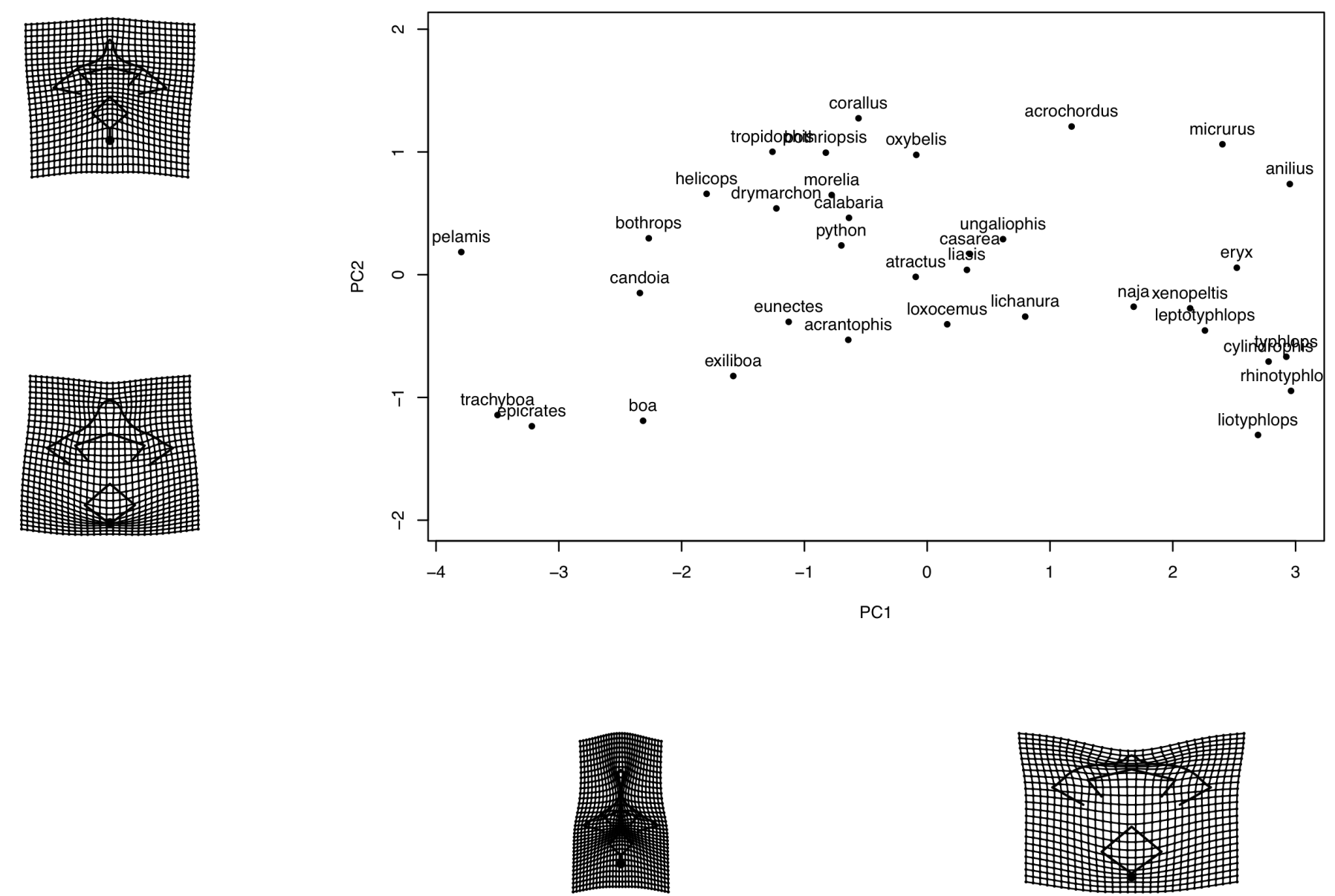
Posterior, posição=11
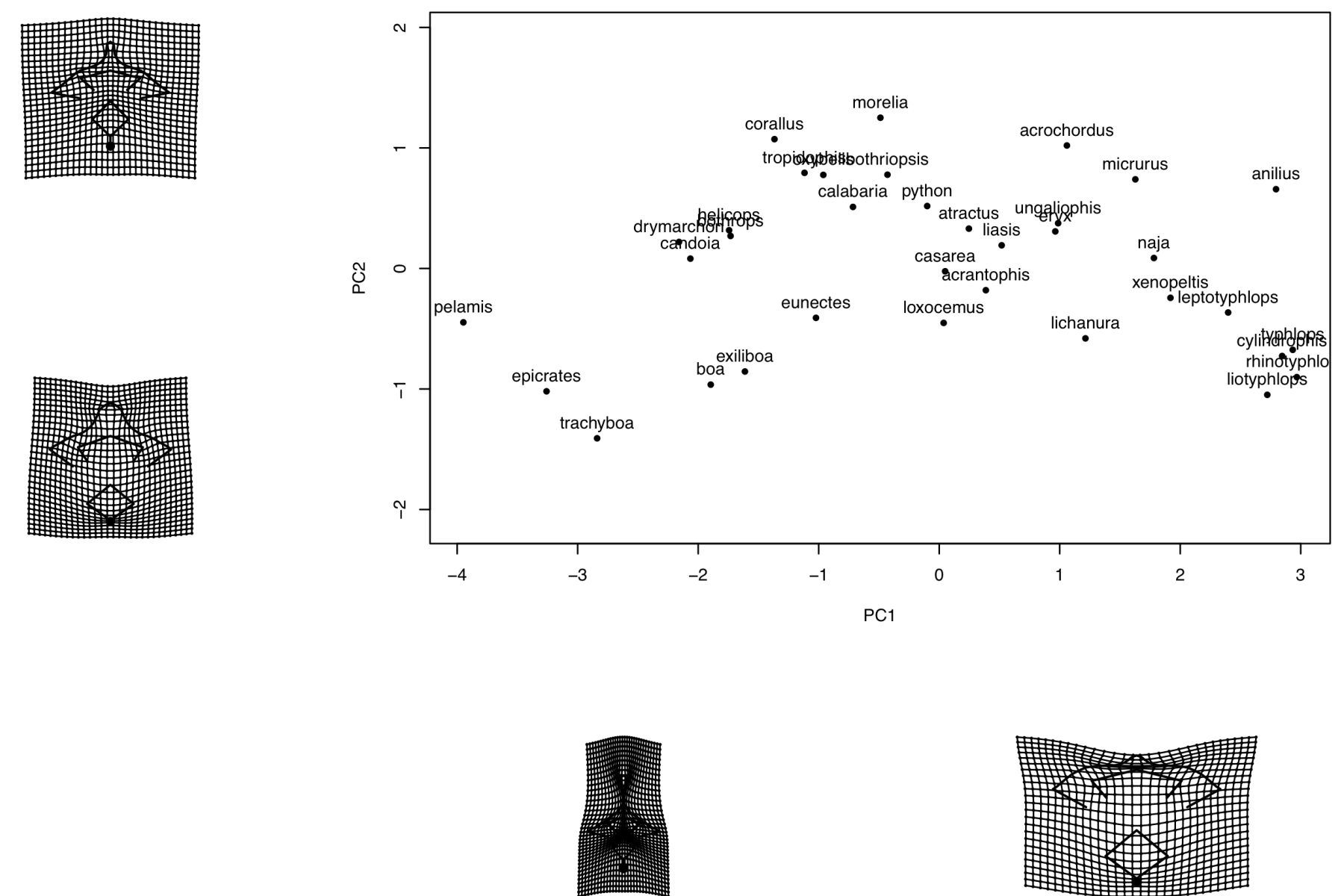
Posterior, posição=12
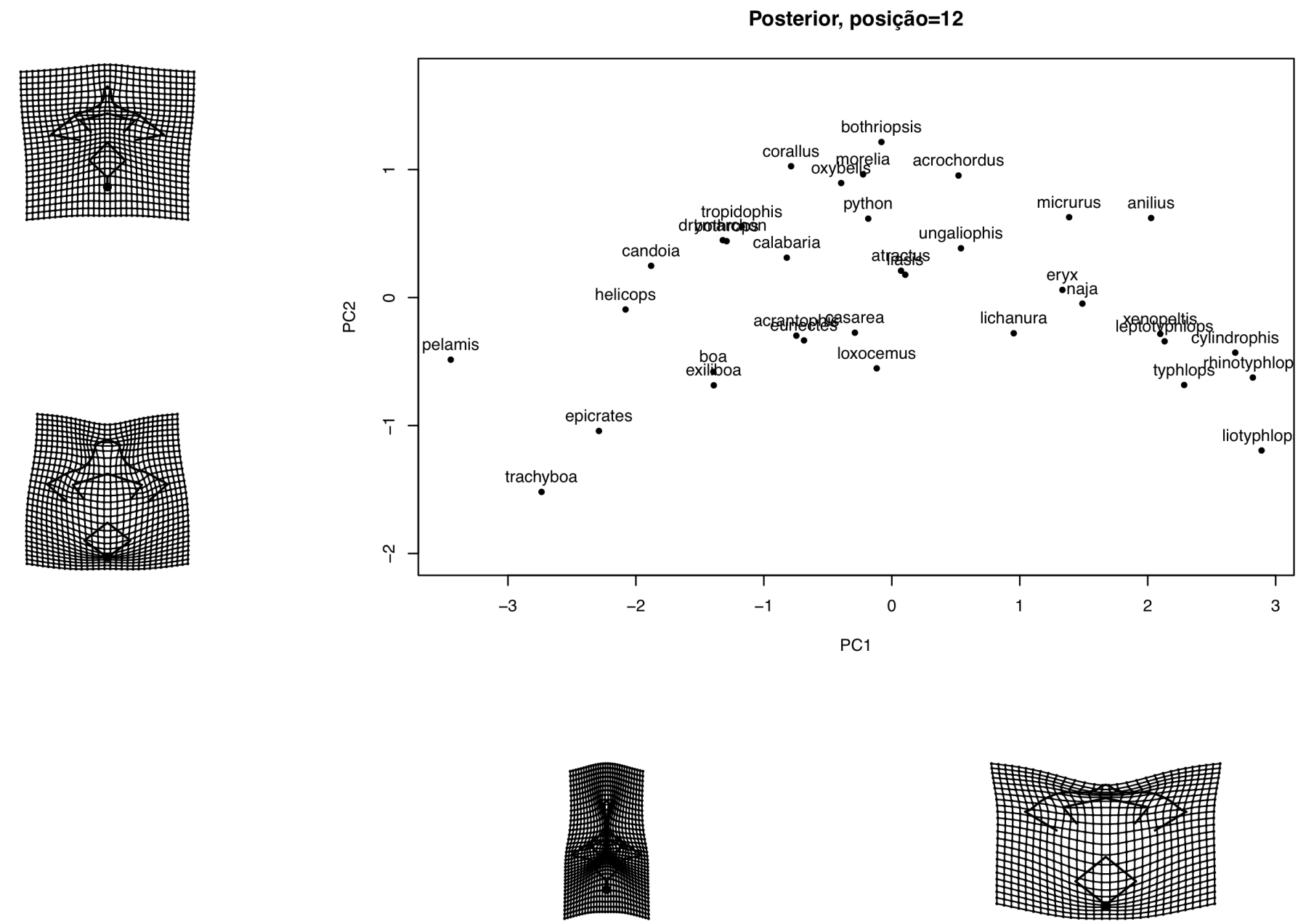
Posterior, posição=13
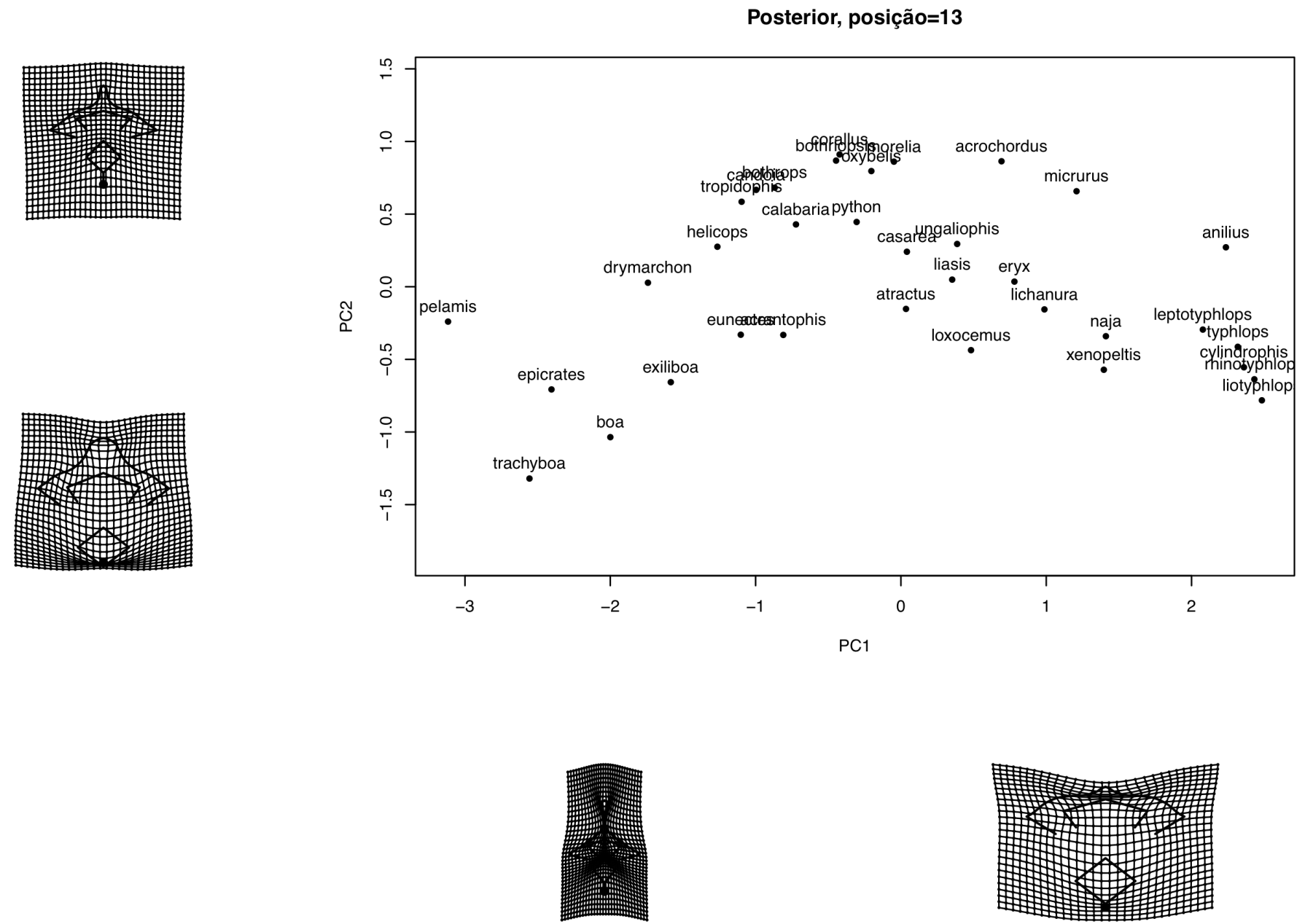
Posterior, posição=14
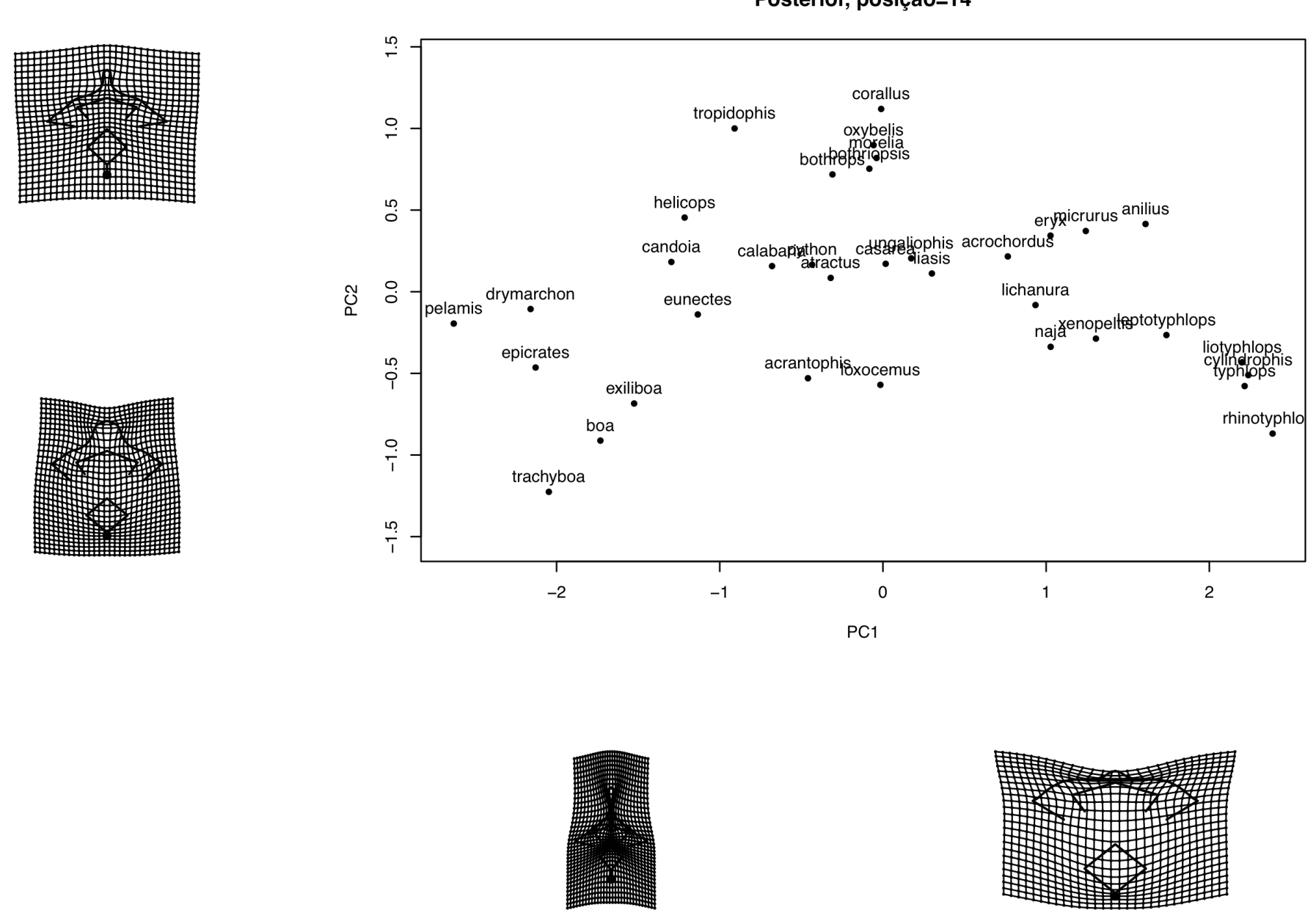
Posterior, posição=15
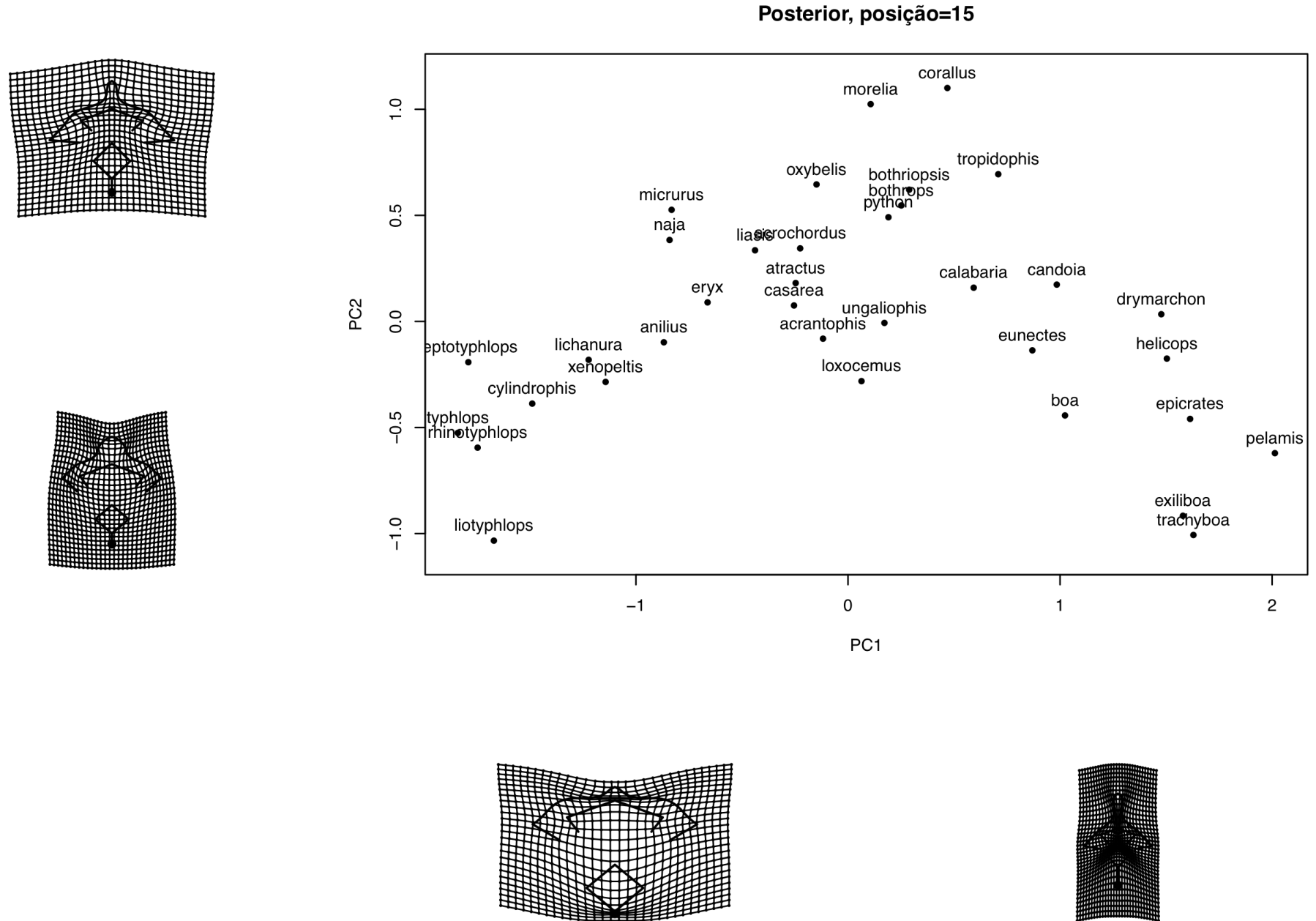
Ventral, posição=1
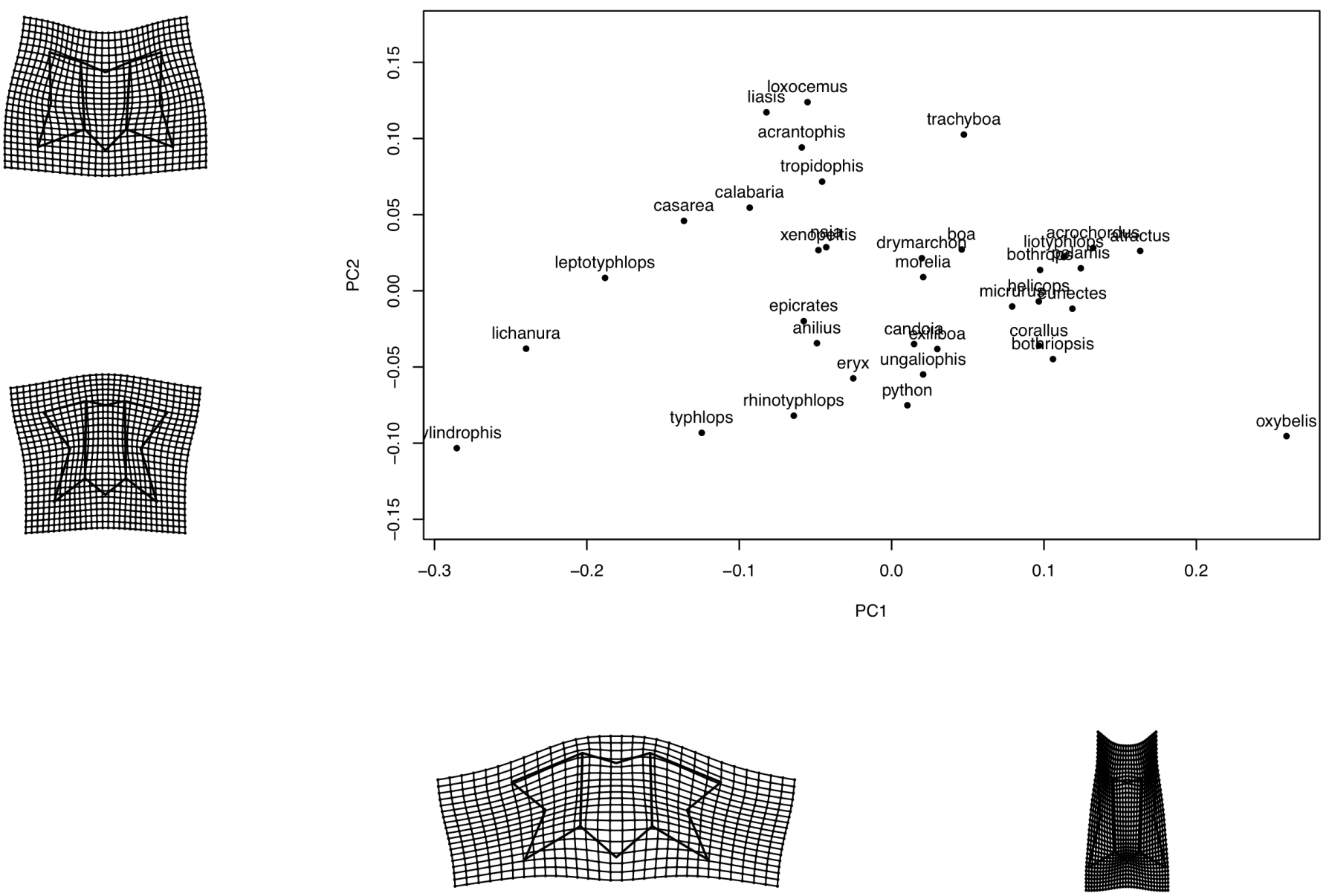
Ventral, posição=2
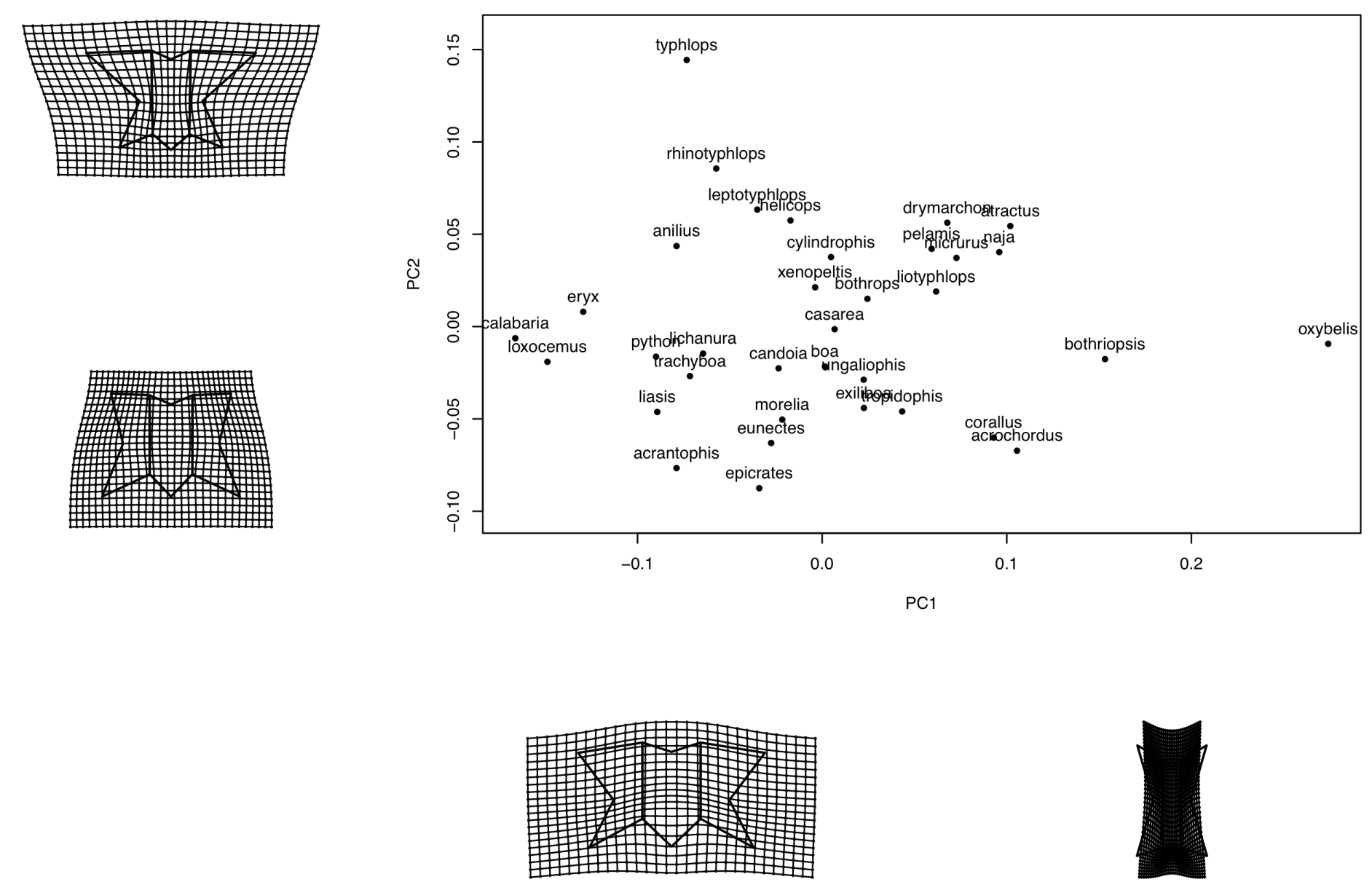
Ventral, posição=3
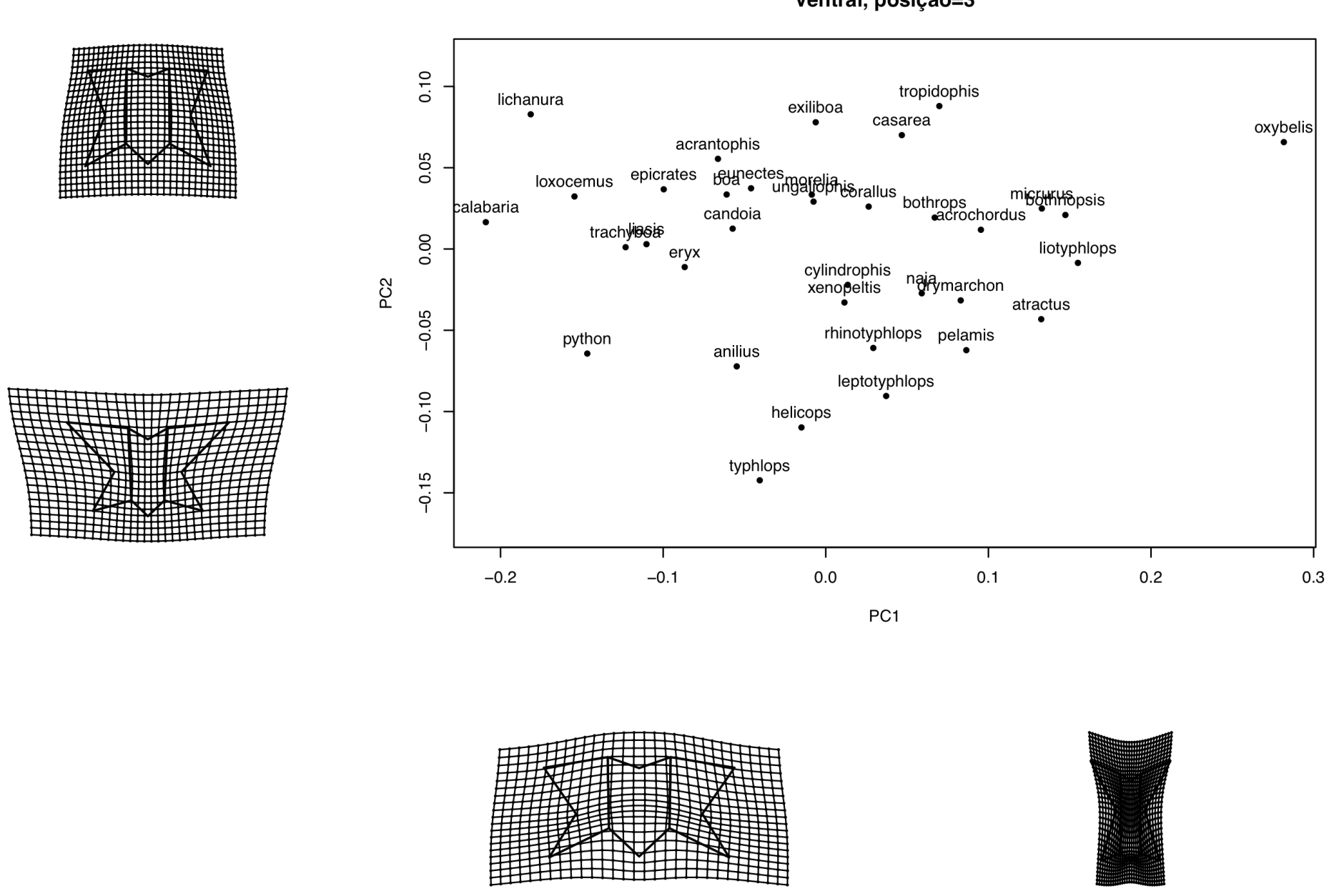
Ventral, posição=4
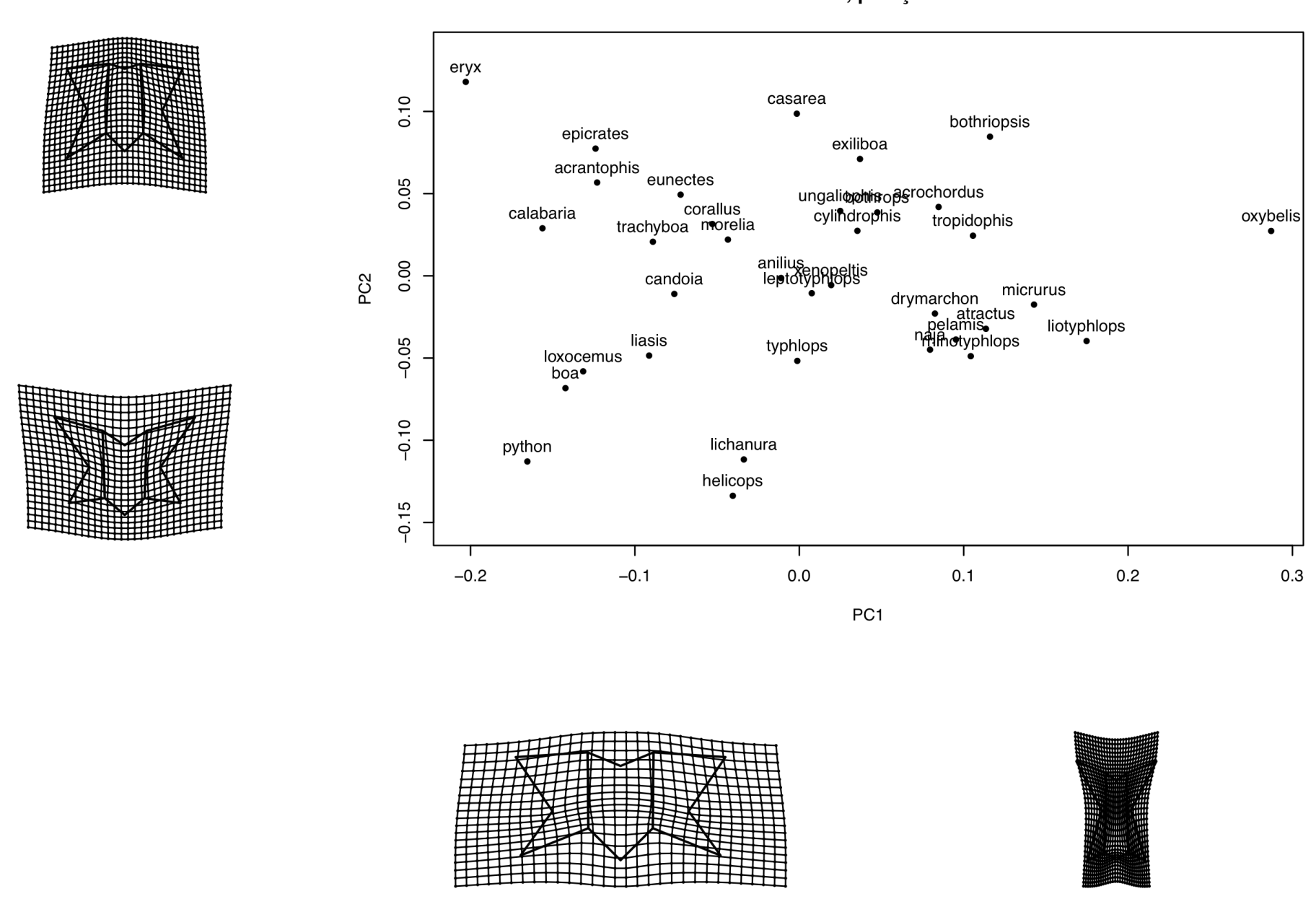
Ventral, posição=5
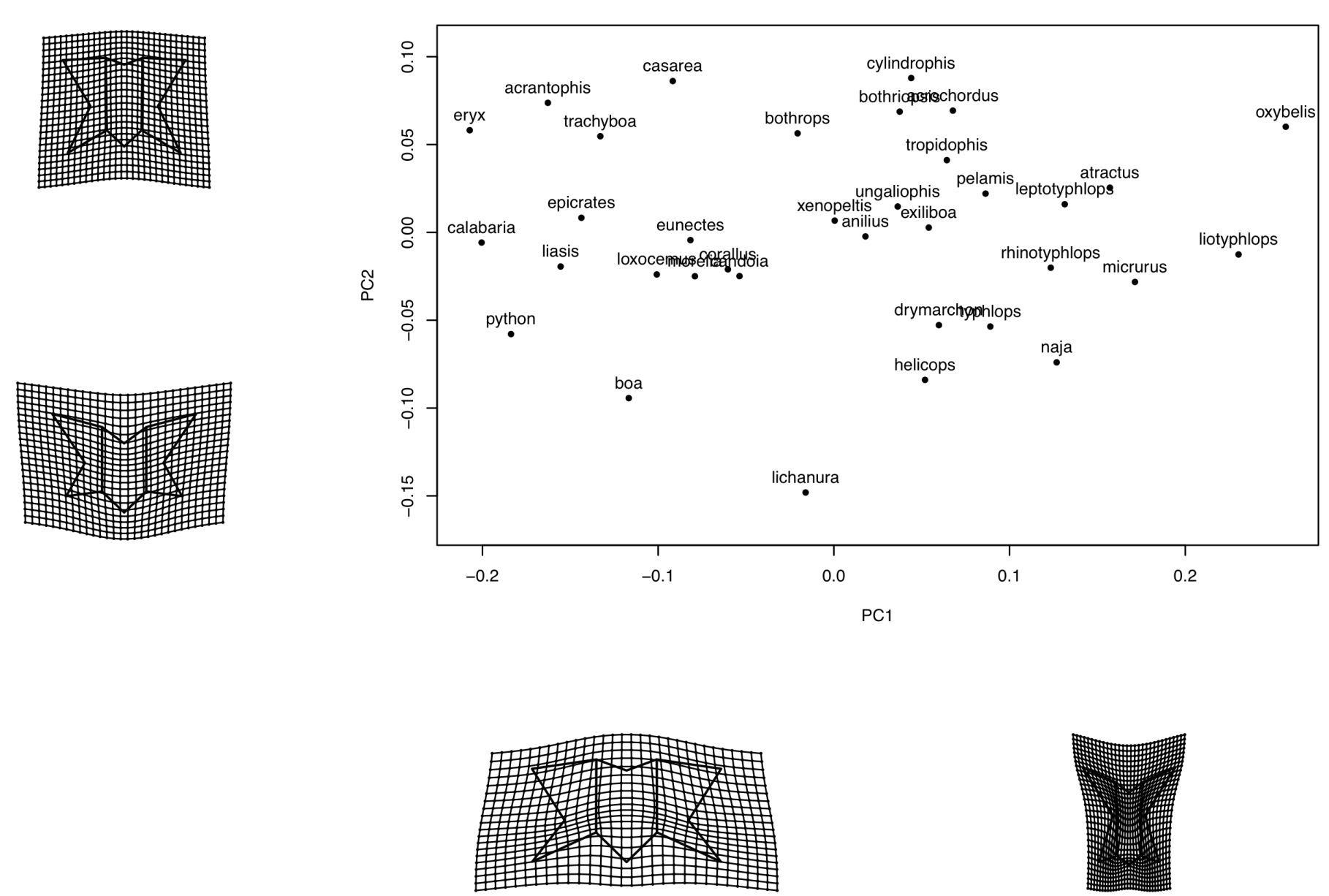
Ventral, posição=6
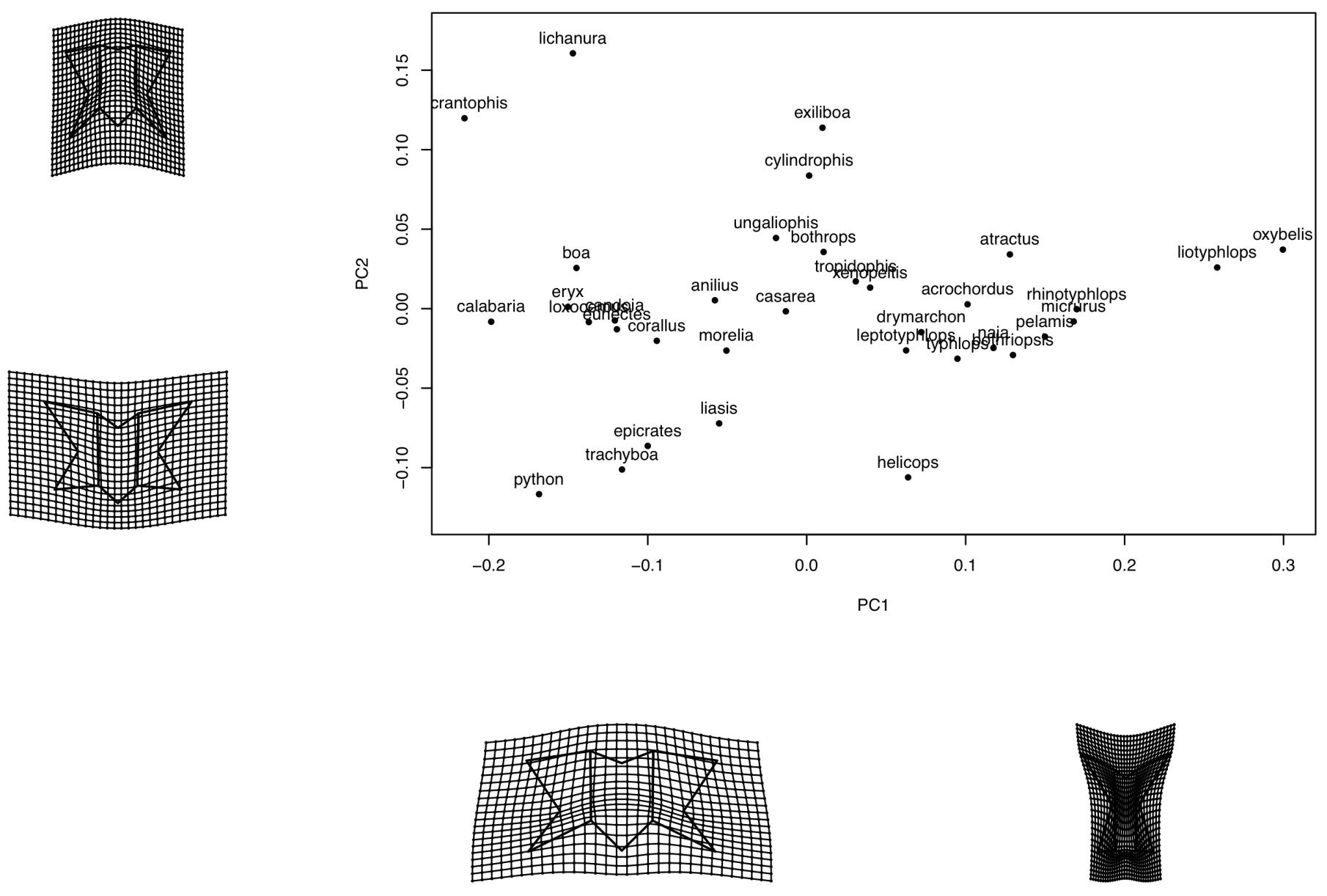
Ventral, posição=7
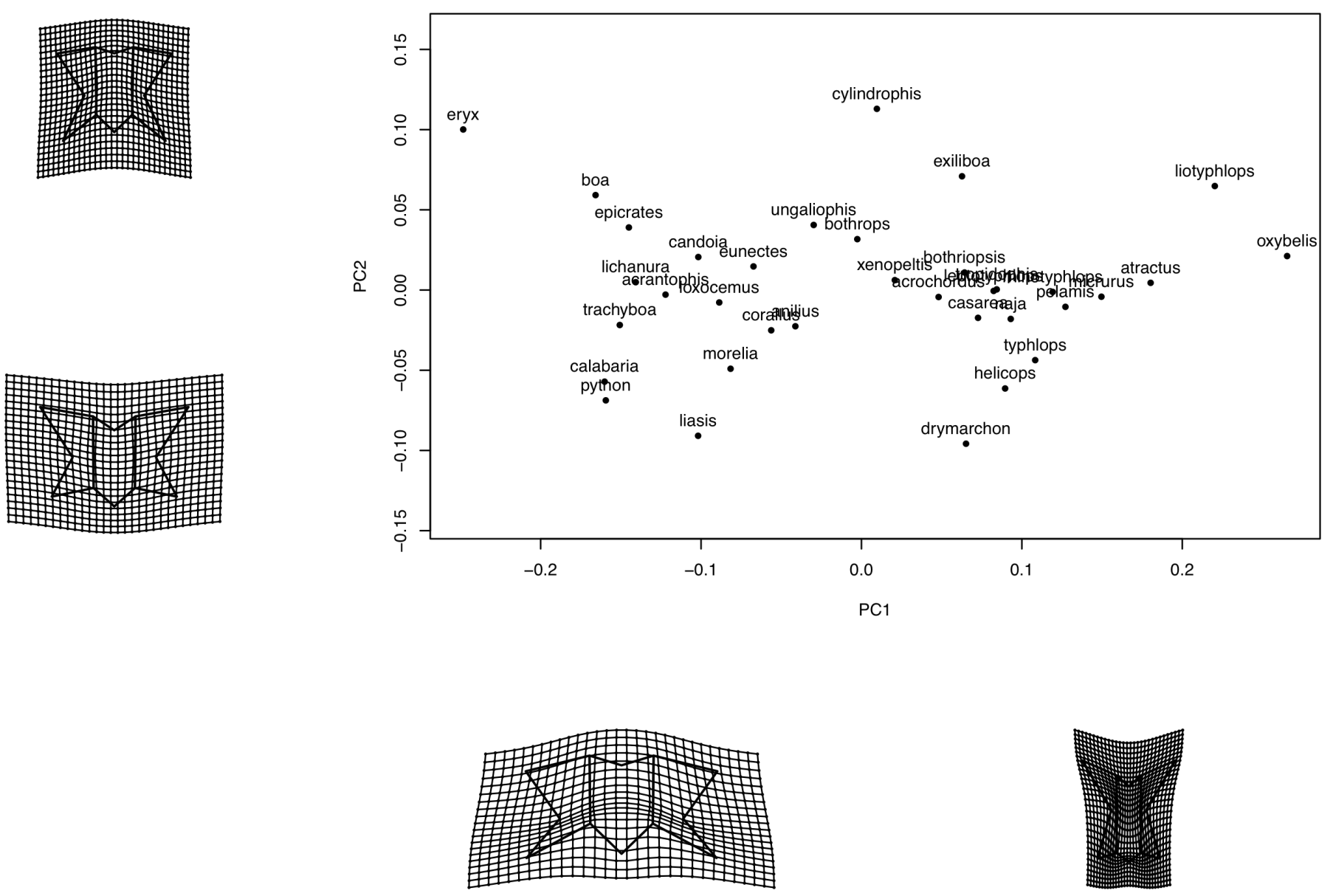
Ventral, posição=9
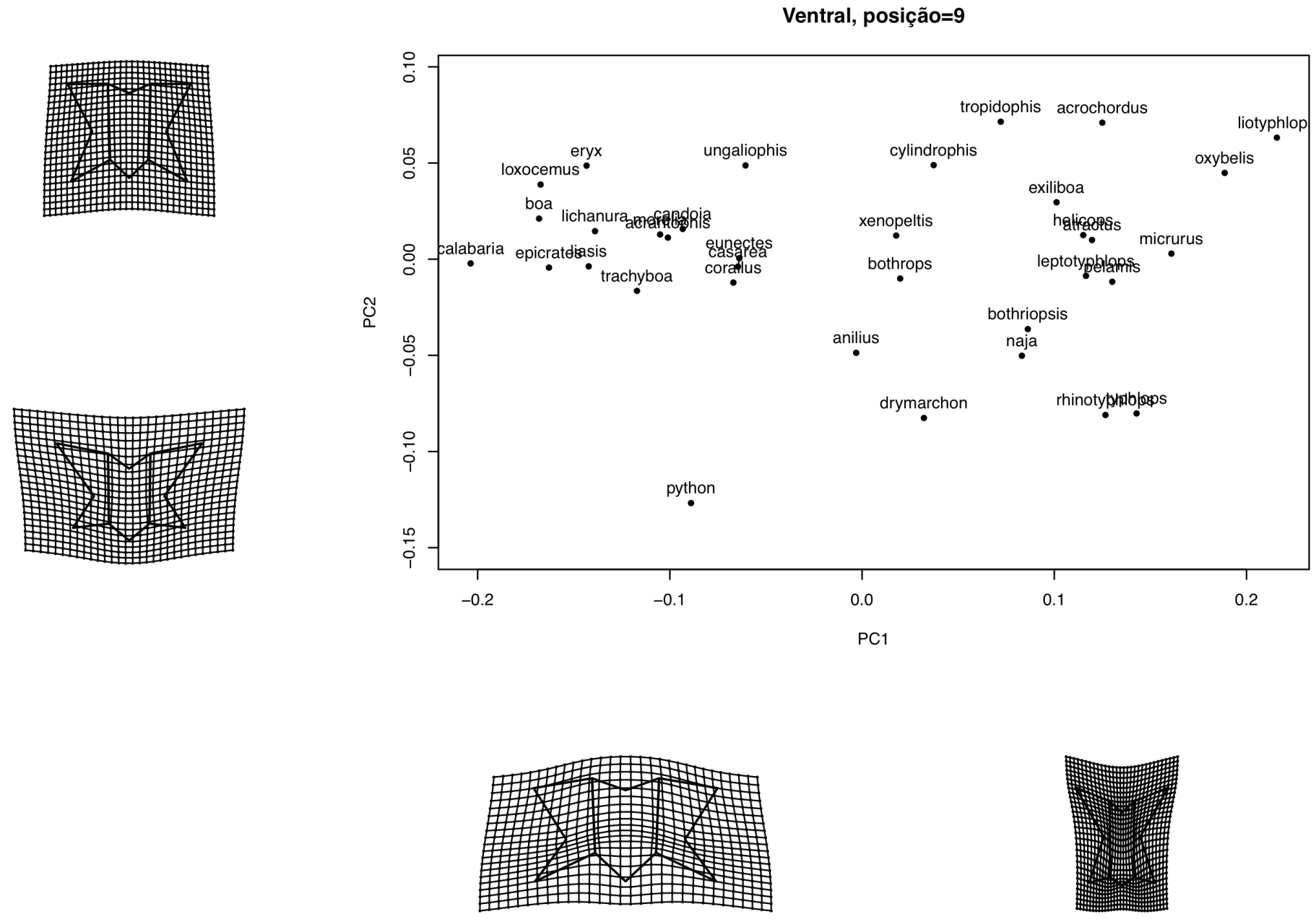
Ventral, posição=8
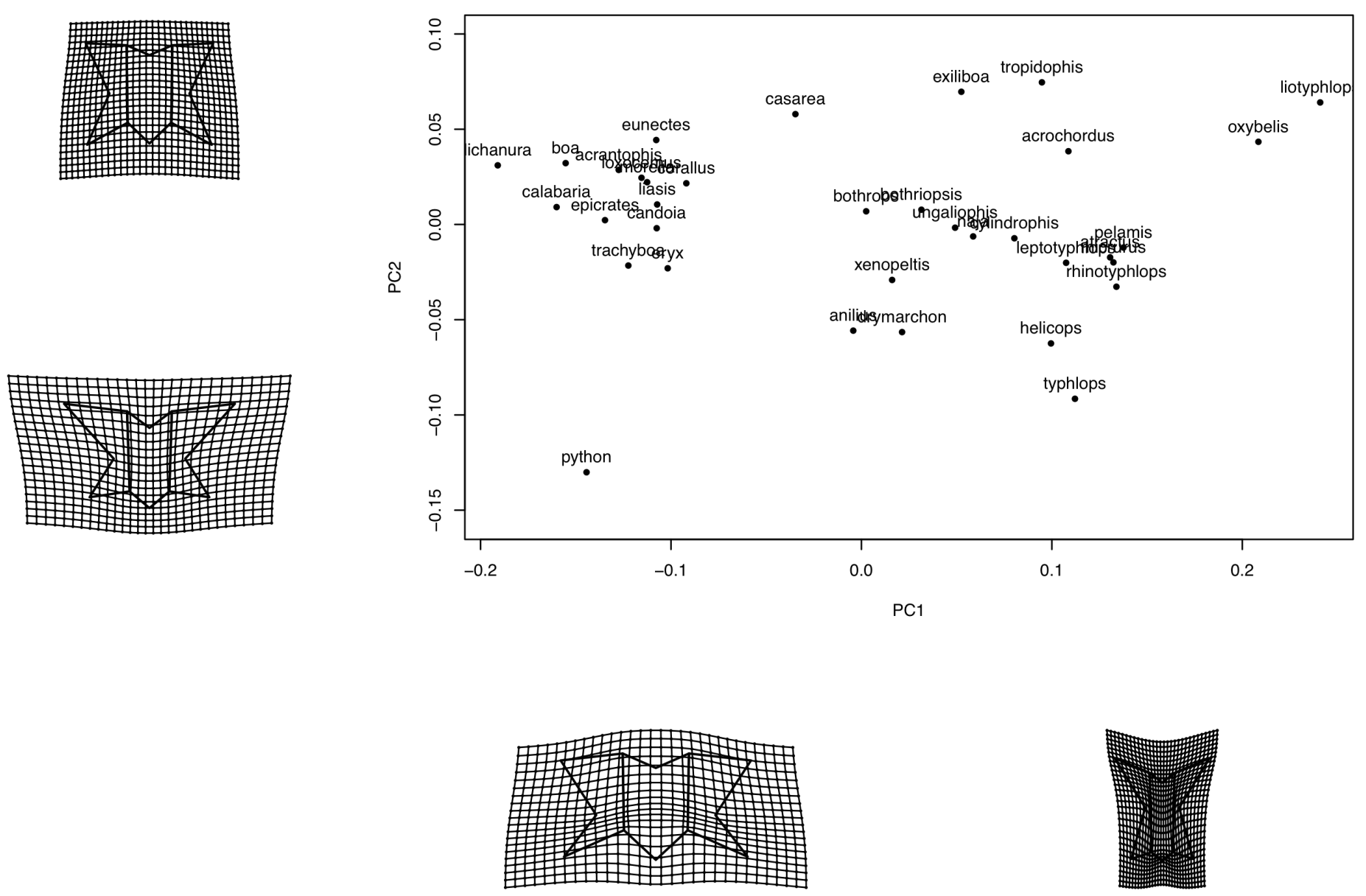
Ventral, posição=10
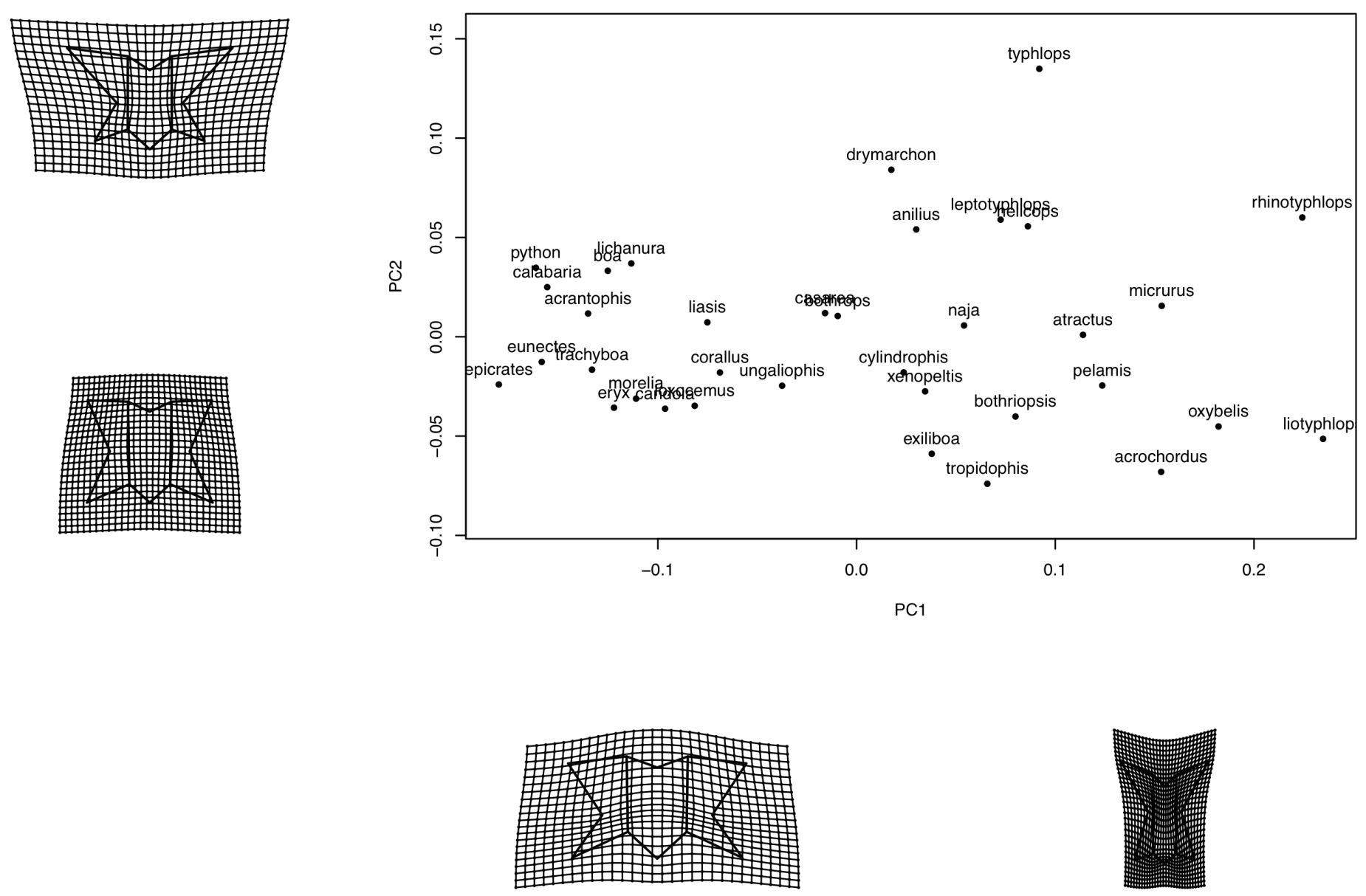

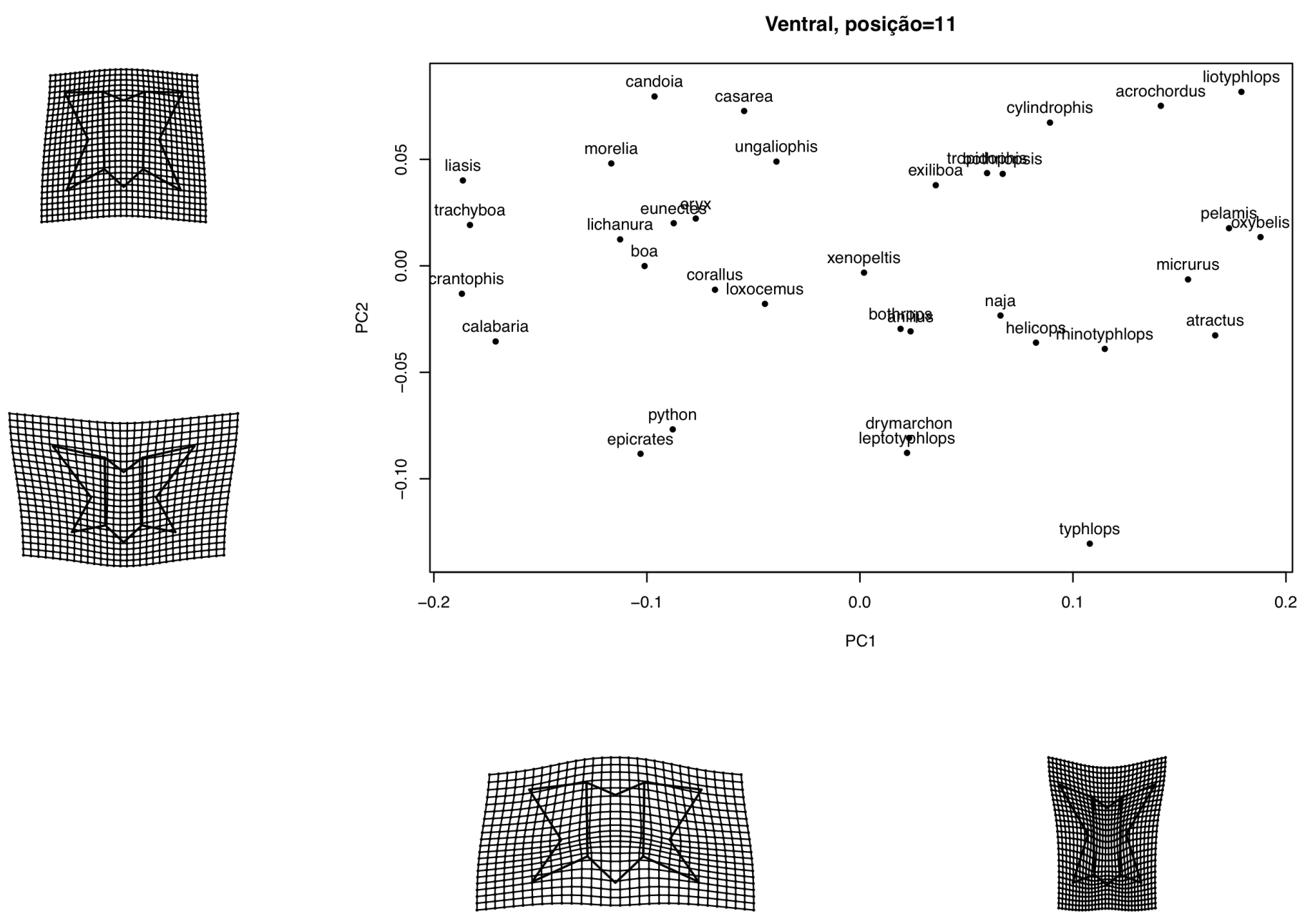
Ventral, posição=12
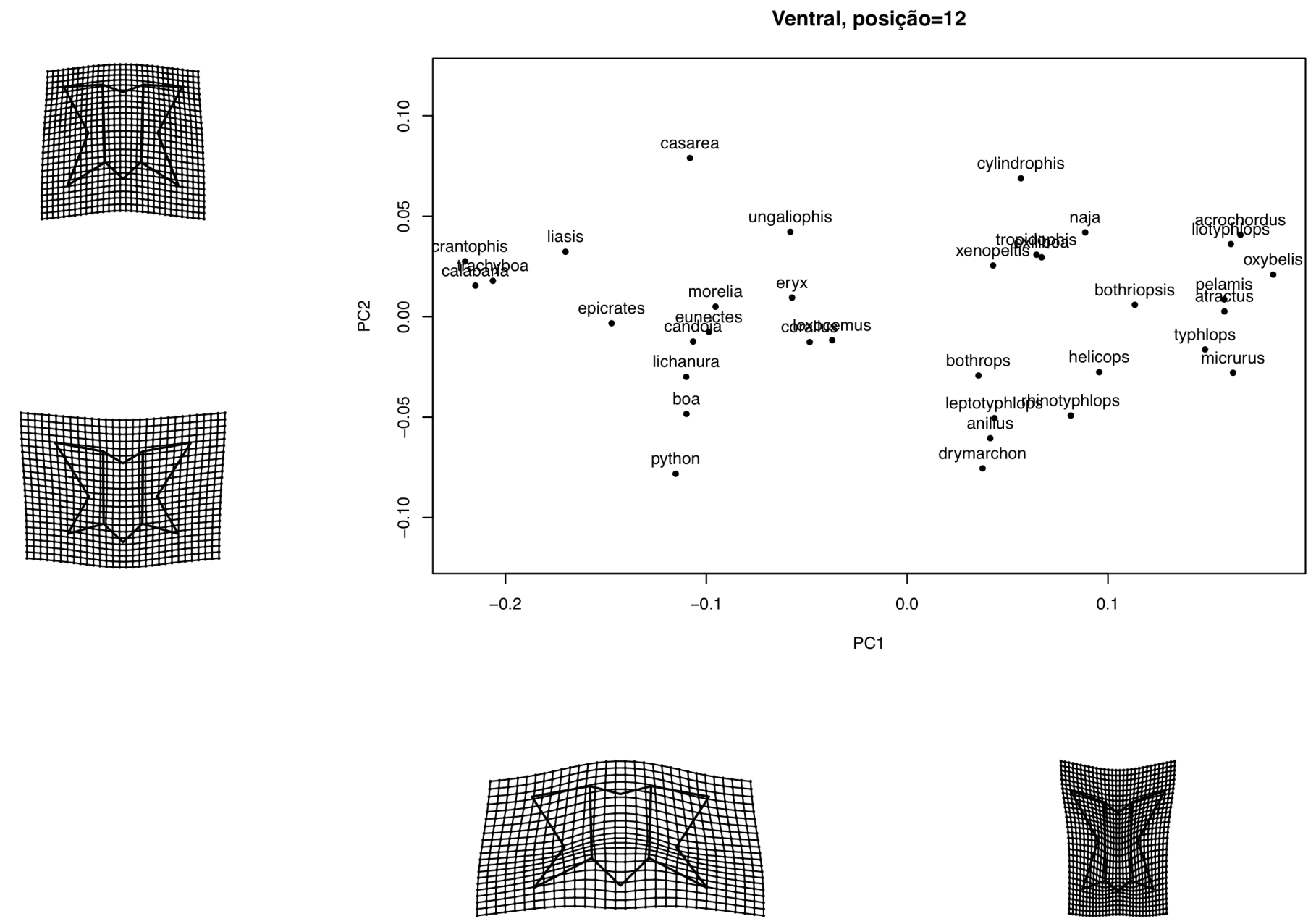
Ventral, posição=13
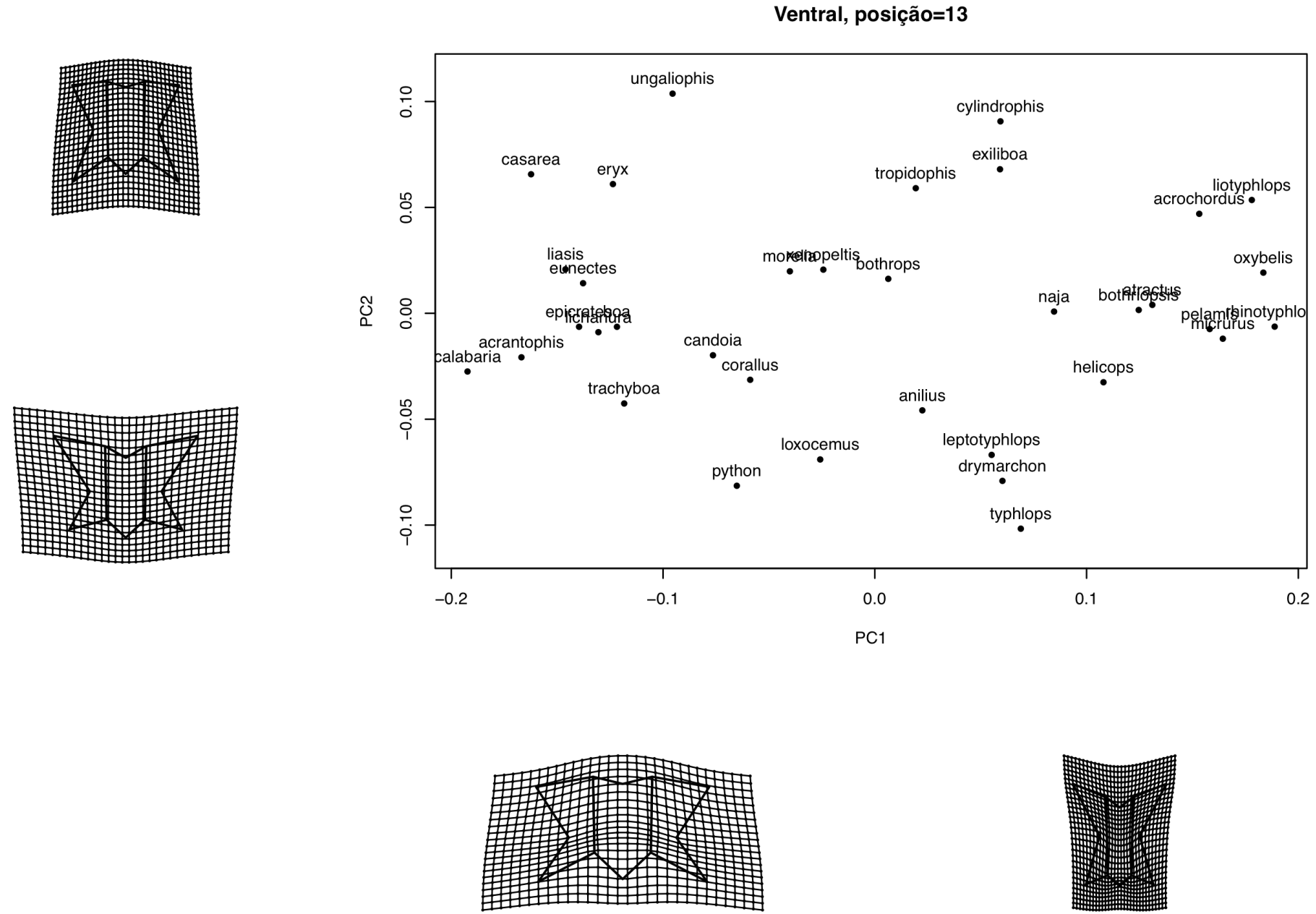
Ventral, posição=14
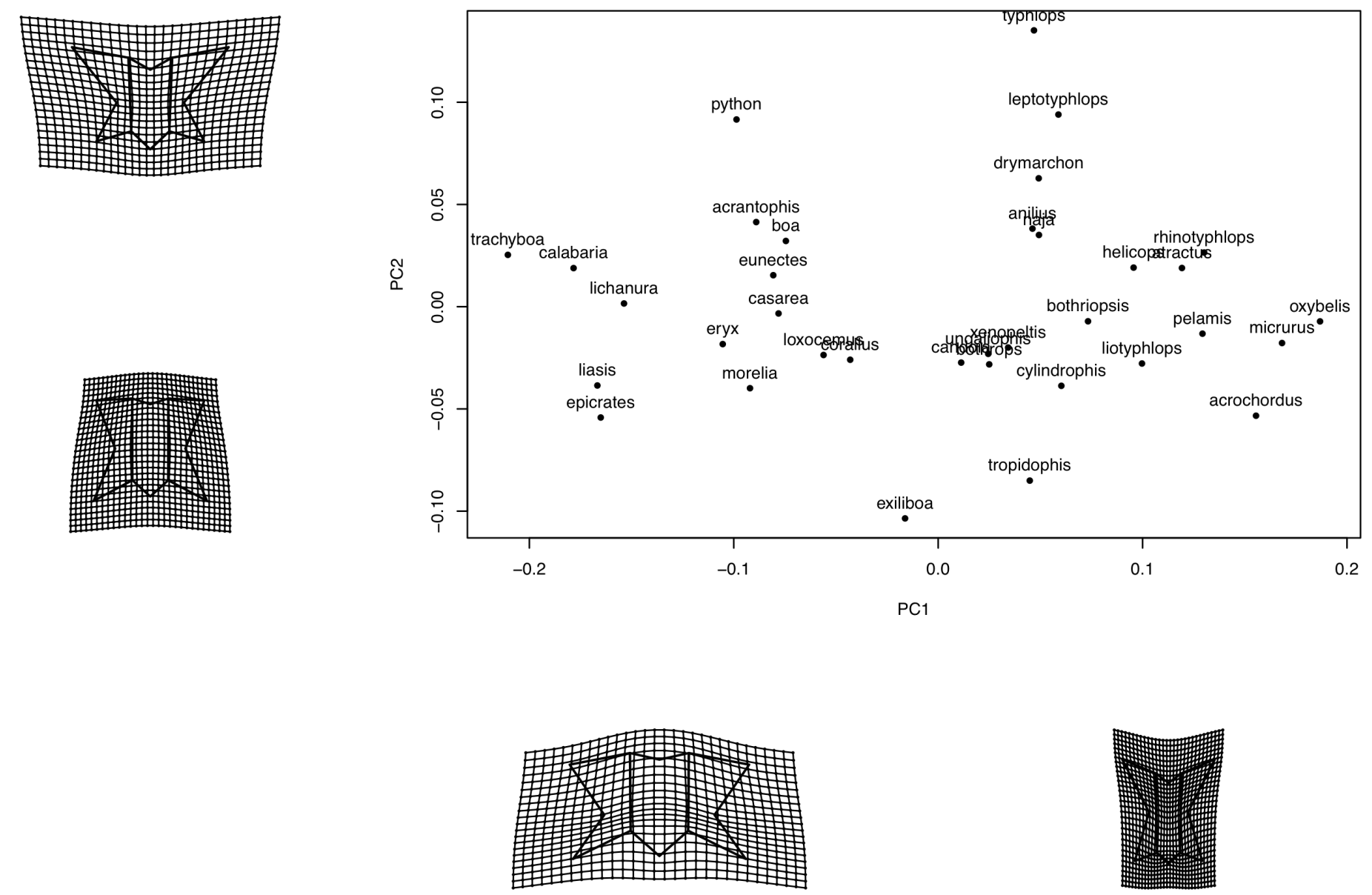
Ventral, posição=15
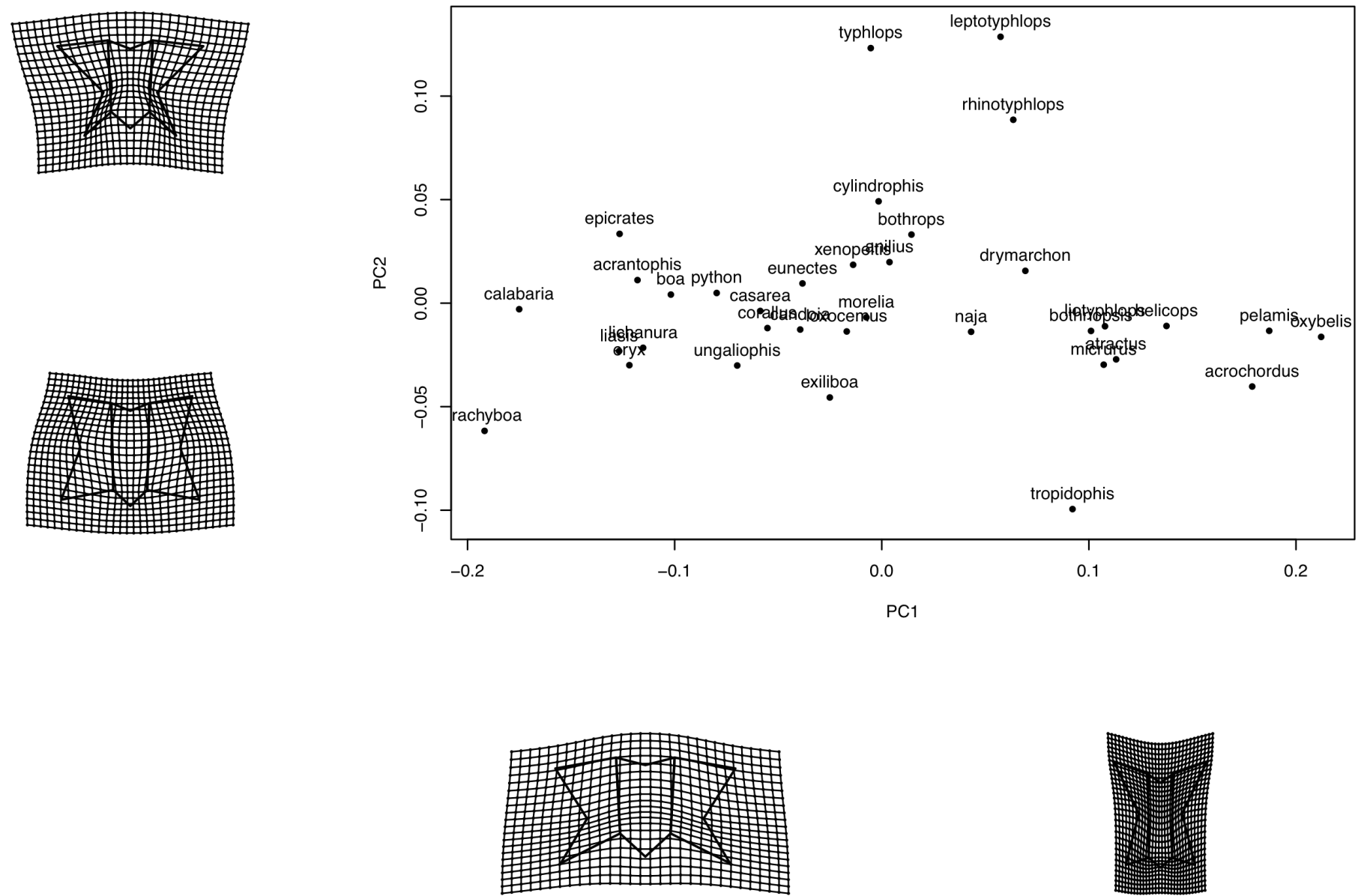